JOSÉ FERNANDO FERREIRA BREGA

GOVERNO ELETRÔNICO E DIREITO ADMINISTRATIVO

TESE DE DOUTORADO

ORIENTADORA: PROFESSORA TITULAR

ODETE MEDAUAR

FACULDADE DE DIREITO DA UNIVERSIDADE DE SÃO PAULO

São Paulo

2012 
JOSÉ FERNANDO FERREIRA BREGA

GOVERNO ELETRÔNICO E DIREITO ADMINISTRATIVO

TESE DE DOUTORADO

FACULDADE DE DIREITO DA UNIVERSIDADE DE SÃO PAULO

São Paulo

2012 
JOSÉ FERNANDO FERREIRA BREGA

\section{GOVERNO ELETRÔNICO E DIREITO ADMINISTRATIVO}

Tese apresentada à banca examinadora da Faculdade de Direito da Universidade de São Paulo, como exigência parcial para obtenção do título de Doutor em Direito, sob orientação da Professora Titular Odete Medauar.

\section{São Paulo}


BANCA EXAMINADORA 
À vó Carlota, minha torcedora fanática, por seus 100 anos de vida. 


\section{AGRADECIMENTOS}

À Professora Odete Medauar, acadêmica exemplar, pelo estímulo, pelo respeito e pelas críticas construtivas.

Ao Professor Julián Valero Torrijos e a todos os amigos da Universidade de Murcia, pela receptividade e pelas impecáveis condições de trabalho.

A todos que ajudaram com suas leituras e sugestões: meu irmão Remo e os amigos Dimitri Brandi de Abreu, Fernando Henrique Minchillo Conde, Guilherme Almeida de Almeida, Gustavo Almeida de Almeida e José Antonio Apparecido Júnior.

À minha esposa, Camila, companheira, colaboradora e revisora, ouvidos, descanso e ombro, sem quem a vida seria muito mais difícil. 


\section{RESUMO}

As últimas décadas têm sido caracterizadas por um intenso desenvolvimento da informática e da telemática. Na Administração Pública, a utilização dessas novas tecnologias provocou o aparecimento de um novo modo de atuação, designado pela expressão governo eletrônico. O governo eletrônico constitui uma realidade a ser explorada também sob uma perspectiva jurídica. As bases constitucionais e legais pertinentes permitem verificar que ele está sujeito a um enquadramento sistemático, sendo regido por princípios como a equivalência de suportes, a eficiência administrativa, a equivalência de garantias e a interoperabilidade entre os sistemas informáticos. $\mathrm{O}$ uso das novas tecnologias traz importantes reflexos sobre institutos clássicos do direito administrativo, tais como o ato e o processo administrativo, que precisam ser reavaliados de acordo com o novo contexto. $\mathrm{O}$ ato administrativo, antes formalizado somente em papel e com a intervenção direta do homem, é passível de ser expedido em forma eletrônica ou pela atuação automatizada de um sistema informático. O processo administrativo, visto como um mecanismo de troca e produção da informação, pode valer-se do suporte digital, abrindo a oportunidade para o relacionamento telemático e para a automatização de tarefas, com relevantes consequências sobre a estrutura do procedimento e sobre os atos processuais.

Palavras-chave: governo eletrônico; administração eletrônica; ato administrativo eletrônico; processo administrativo eletrônico. 


\begin{abstract}
The last decades have been characterized by an intense development of information technology and telematics. In public administration, the use of these new technologies produced a new way of operating, designated e-government. E-government must be explored also under a legal perspective. The applicable constitutional and legal bases allow one to verify that electronic government is submitted to a systematic framework, governed by principles such as media neutrality, administrative efficiency, equivalence of guarantees and interoperability between computer systems. The use of new technologies has important effects on traditional elements of administrative law, such as administrative act and administrative procedure, which must be revisited according to this new context. The administrative act, which previously was only paper-based and had a direct involvement of an individual, may now be issued in electronic form or by an automated computer system. The administrative procedure, seen as a mechanism of information exchange and production, can make use of digital media, creating the opportunity for telematic interaction and automation of tasks, with important consequences for the structure of the procedure and procedural acts.
\end{abstract}

Keywords: electronic government; e-government; electronic administrative act; electronic administrative procedure. 


\section{SUMÁRIO}

\section{CAPÍTULO 1 - O CONTEXTO DA SOCIEDADE DA INFORMAÇÃO E O DIREITO ADMINISTRATIVO}

16

1.1. O ADVENTO DA SOCIEDADE DE INFORMAÇÃO __ 16

1.2. NOVOS INSTRUMENTOS PARA A ATIVIDADE ADMINISTRATIVA__ 24

1.3. A EVOLUÇÃO DA INFORMÁTICA NA ADMINISTRAÇÃo PÚBLICA___ 39

1.4. O ALCANCE DO GOVERNO ELETRÔNICO __ 45

1.4.1. A terminologia: governo eletrônico, administração eletrônica e democracia eletrônica __ 45

1.4.2. As dimensões interna e externa _ 51

1.4.3. Atividades realizadas com apoio da tecnologia __ 53

1.5. A RELEVÂNCIA DAS NOVAS TECNOLOGIAS PARA O DIREITO ADMINISTRATIVO _ _ 59

1.6. UMA POSIÇÃO ADEQUADA FRENTE À REALIDADE INFORMÁTICA __ 66

\section{CAPÍTULO 2 - BASES JURÍDICAS DO GOVERNO ELETRÔNICO__ 72}

2.1. A BUSCA DOS FUNDAMENTOS DA MATÉRIA __ 72

2.2. A DOCUMENTAÇÃO DAS ATIVIDADES ADMINISTRATIVAS 76

2.2.1. O documento administrativo eletrônico __ 78

2.2.2. O valor jurídico do documento eletrônico na Administração Pública ___ 82

2.2.3. A assinatura eletrônica ___ 89

2.3. NOVAS TECNOLOGIAS E EFICIÊNCIA ADMINISTRATIVA __ 99

2.3.1. A eficiência administrativa como fundamento do governo eletrônico__ 100

2.3.2. As exigências relativas à eficiência administrativa em meios digitais___ 106

2.3.3. A convivência entre eficiência administrativa e legalidade ___ 109

2.4. A EQUIVALÊNCIA DE GARANTIAS___ 112

2.4.1. A submissão à legalidade e a reserva de lei ___ 117

2.4.2. A igualdade na utilização das tecnologias _ـ 124

2.4.2.1. Desafios à isonomia na criação de serviços digitais ___ 131

2.4.2.2. A neutralidade tecnológica _ 136

2.4.3. A necessidade de segurança jurídica __ 138

2.4.4. A transparência administrativa e o direito à informação por meios informáticos 143

2.4.4.1. O aumento da necessidade de informação___ 143 
2.4.4.2. Os meios informáticos e telemáticos e a realização do direito à informação 145

2.4.4.3. A transparência por meios digitais no ordenamento brasileiro _ 150

2.4.4.4. Os diferentes níveis de acesso à informação 155

2.4.5. As novas tecnologias e o respeito à intimidade e à vida privada 158

2.4.5.1. A proteção da intimidade e da vida privada em relação ao Estado 162

2.4.5.2. A proteção da intimidade em relação a terceiros 171

2.4.6. Responsabilidade patrimonial pela atuação por meios eletrônicos 177

2.5. A INTEROPERABILIDADE ENTRE OS SISTEMAS INFORMÁTICOS 180

CAPÍTULO 3 - ATO ADMINISTRATIVO ELETRÔNICO 192

3.1. ANTECEDENTES 192

3.2. CONCEITO E TIPOLOGIA DO ATO ADMINISTRATIVO ELETRÔNICO 195

3.3. OS ATOS ADMINISTRATIVOS ELETRÔNICOS EM SENTIDO ESTRITO 197

3.4. ATOS ADMINISTRATIVOS AUTOMATIZADOS 201

3.4.1. A viabilidade da automatização 204

3.4.2. A vinculação entre a atuação automatizada e o ordenamento jurídico 207

3.4.2.1. A definição dos critérios a serem aplicados pela máquina 210

3.4.2.2. A aprovação do software 213

3.4.3. O conteúdo da programação 217

3.4.3.1. A fixação de critérios segundo o quadro normativo 218

3.4.3.2. A antecipação do exercício da discricionariedade administrativa

3.4.3.3. A definição de regras para verificação dos elementos de fato 227

3.4.4. Uma nova estrutura para a decisão 229

3.4.5. A admissibilidade do ato administrativo automatizado 234

3.4.6. Vícios do ato automatizado 239

CAPÍTULO 4 - PROCESSO ADMINISTRATIVO ELETRÔNICO 244

4.1. ANTECEDENTES 244

4.2. O PROCESSO ADMINISTRATIVO NA SOCIEDADE DA INFORMAÇÃO 247

4.3. CONCEITO E TIPOLOGIA 249

4.4. O APROVEITAMENTO DAS OPORTUNIDADES PROPORCIONADAS PELA TECNOLOGIA 254

4.5. O CONTROLE DO IMPULSO E DOS ATOS PROCESSUAIS___ 257

4.6. GARANTIAS APLICÁVEIS AO PROCESSO ELETRÔNICO___ 261

4.7. A LEGISLAÇÃO EXISTENTE E SUA ADAPTAÇÃO _ 266

4.8. O EXPEDIENTE ADMINISTRATIVO ELETRÔNICO 267 
4.9. A DINÂMICA DO PROCESSO ADMINISTRATIVO ELETRÔNICO 272

4.9.1. O requerimento e os demais atos dos interessados 273

4.9.2. A instrução processual 276

4.9.2.1. A transposição de documentos para o suporte digital 277

4.9.2.2. O uso de equipamentos eletrônicos para a produção de informações

4.9.2.3. A transformação da instrução processual 281

4.9.2.4. A vedação às provas ilícitas 285

4.9.2.5. A padronização da instrução processual 286

4.9.3. Finalização do processo eletrônico 289

4.9.4. Os portais e o protocolo eletrônico 291

4.9.5. Tempo dos atos processuais e prazos 293

4.9.6. A intimação dos interessados 295

4.9.7. Recursos no processo eletrônico 300 


\section{INTRODUÇÃO}

As últimas décadas têm sido caracterizadas por um intenso desenvolvimento das tecnologias da informação e da comunicação. Os equipamentos e sistemas informáticos são usados em grande parte das atividades humanas e estão incorporados ao cotidiano de muitos. A internet é a principal plataforma de relacionamento utilizada por pessoas físicas e jurídicas, propiciando a realização de negócios e o oferecimento de inúmeros serviços e utilidades. É o contexto da sociedade da informação, consequência da revolução tecnológica.

A Administração Pública não pode estar alheia a essa revolução, porque o Estado já não tem condições de atuar somente com os meios outrora empregados. Exigese dos órgãos governamentais o aproveitamento dos benefícios trazidos pela tecnologia, em todos os seus aspectos. A Administração deve estar atualizada em relação às melhores práticas existentes, tanto em sua atuação interna quanto no relacionamento com cidadãos e fornecedores.

Embora a utilização de sistemas de informação pelo Poder Público não seja algo tão recente, o desenvolvimento tecnológico dos últimos anos propiciou transformações nas diversas modalidades de atuação administrativa, particularmente no relacionamento com o público. Nos dias de hoje, as novas ferramentas tecnológicas constituem um insumo indispensável para a atuação administrativa. Isso já é algo visível: em paralelo às formas tradicionais, a grande maioria dos entes governamentais, por meio de um endereço na internet, oferece informações de variadas espécies e, muitas vezes, serviços que antes só eram prestados presencialmente nas repartições públicas. Fala-se, cada vez mais, em governo eletrônico.

De fato, o governo eletrônico tornou-se um modo de atuação do Poder Público. As novas tecnologias dão respaldo a atividades externas e internas (v.g., os sistemas informáticos de execução orçamentária e de controle de pessoal). As atividades externas incluem tanto o simples fornecimento e recebimento de informações quanto a efetiva prestação de serviços. O rol de serviços disponíveis por meios eletrônicos aumenta a cada 
dia. O uso das novas tecnologias na Administração Pública tem propiciado, por exemplo, o fornecimento de certidões, o recebimento de declarações (v.g., imposto de renda e notas fiscais), a expedição de licenças (v.g., para automóveis e estabelecimentos comerciais) e a realização de compras públicas.

O uso das ferramentas eletrônicas normalmente decorre da ação de administradores públicos e profissionais da informática, que vislumbram as vantagens e possibilidades da atualização tecnológica. Na maior parte das vezes, os juristas têm ficado à parte de tais transformações, especialmente porque a matéria, em geral, não é objeto de uma legislação sistematizada e não chega ao contencioso dos tribunais. No entanto, tendo em vista que os meios informáticos são utilizados na atividade administrativa, soa inaceitável que se entenda tratar-se de uma realidade apenas informática, que não mereça reflexões jurídicas.

Caso se entenda essa realidade como algo jurídico, é também inquietante imaginar que toda a incorporação da tecnologia na atuação administrativa deixe de ter seus próprios fundamentos sistemáticos, de acordo com o ordenamento constitucional vigente e seus princípios, estando assim limitada a debates isolados e soluções improvisadas à luz de problemas concretos. Nesse sentido, parece impossível situar o governo eletrônico à margem dos princípios constitucionais relativos à atuação administrativa, impedindo que os fundamentos a ele referentes sejam objeto de um enquadramento sistemático.

Por outro lado, as soluções computacionais desafiam alguns tradicionais institutos do direito administrativo, estruturados sobre a atuação administrativa pautada pelo documento em papel, pela atuação humana e pela interação presencial entre os sujeitos envolvidos. Com o advento das novas tecnologias, o registro da informação passa a ser feito em meios digitais, sob os cuidados de equipamentos informáticos. Por outro lado, uma série de tarefas passa a ser realizada de modo automatizado, o que dispensa a participação direta do servidor público. Além disso, o relacionamento entre sujeitos passa a darse a distância, fora das repartições públicas, em espaços virtuais tais como os portais da Administração Pública na internet. 
Em vista de todas essas provocações, a presente tese tem por objeto os reflexos jurídicos do governo eletrônico. Seu propósito é investigar os aspectos jurídicos envolvidos na utilização das novas tecnologias na atividade administrativa, para mostrar as diversas questões que elas proporcionam, encontrando soluções apropriadas, sob o ângulo do direito administrativo, a fim de propor as linhas gerais de um regime jurídico pertinente ao desempenho da função administrativa com o uso da informática e da telemática.

Por certo, em razão da extensão dos efeitos das novas tecnologias sobre a atividade administrativa, não seria possível pensar em um trabalho exaustivo a esse respeito. A realidade do governo eletrônico é extremamente rica e complexa, podendo oferecer questões de variadas espécies, referentes às particularidades dos diversos temas do direito administrativo. Assim, cabe esclarecer que o objetivo deste estudo é oferecer um tratamento sistemático da matéria, o que já se mostra bastante desafiador. Cabe, pois, ressalvar que este estudo não trata de temas específicos, nem mesmo aqueles em que o governo eletrônico parece ter chegado a um estado mais avançado de desenvolvimento, como é o caso da utilização de meios digitais na administração tributária, na execução orçamentária, na gestão de pessoal e nos pregões eletrônicos.

É importante ressaltar, também, que este não é um estudo sobre tecnologia da informação ou sobre organização administrativa, mas uma tese jurídica. Nesse sentido, os propósitos almejados estão relacionados com os impactos das novas tecnologias sobre o direito administrativo, procurando, tanto quanto possível, uma posição neutra a respeito dos temas relacionados às demais ciências. Os conceitos próprios dos demais ramos do conhecimento são trazidos ao texto não para discussão, mas para propiciar a compreensão e o enfrentamento dos temas relacionados ao direito administrativo. Nesse sentido, devem ser considerados referências, passíveis de aprofundamento e melhor avaliação em trabalhos próprios, no âmbito do respectivo setor do conhecimento.

Os objetivos da tese devem ser alcançados por meio da avaliação de três hipóteses: 1) o governo eletrônico é uma realidade jurídica, que pode ser compreendida também sob a perspectiva do direito administrativo; 2) na condição de realidade jurídica, o governo eletrônico está sujeito a um conjunto de fundamentos, decorrentes do ordenamento vigente, em especial de seus preceitos constitucionais; 3) a utilização de meios eletrôni- 
cos provoca consequências substanciais em relação a institutos clássicos do direito administrativo, tornando necessário que estes e suas respectivas bases sejam reavaliados pela ciência do direito a partir da realidade tecnológica atual e dos fundamentos jurídicos sistemáticos referidos na hipótese anterior.

O tema mostra-se relevante. Os estudos sobre o governo eletrônico são dotados de atualidade e importância prática, em vista da difusão de tal fenômeno na realidade contemporânea. Tais estudos não têm sido efetuados a partir de uma perspectiva jurídica, mas em outros campos do conhecimento, especialmente a ciência da administração e a tecnologia da informação. Há necessidade, contudo, de avaliar se o governo eletrônico também pode ser objeto de estudos no âmbito do direito, trazendo importantes questões que precisam ser identificadas e respondidas sob tal perspectiva.

Tal enfrentamento da matéria, sob a perspectiva jurídica, de modo sistemático, ainda não foi objeto de trabalhos científicos em âmbito nacional. Nesse sentido, a presente tese, ao investigar as hipóteses referidas, cuida de um tema novo e interdisciplinar, com o propósito de trazer uma contribuição original à ciência jurídica brasileira.

O caráter original do estudo tornou necessária a pesquisa bibliográfica de textos estrangeiros. Essas obras foram utilizadas como referências na elaboração desta tese, tendo em vista, sobretudo, o caráter praticamente universal da incorporação das novas tecnologias no âmbito da Administração Pública, o que tem produzido tendências comuns de caráter mundial. Os elementos doutrinários colhidos em países de tradição jurídica próxima da brasileira puderam ser usados de modo mais intenso, sempre com a ressalva de que a transposição de qualquer entendimento adotado no exterior deve considerar a realidade nacional. Com essa cautela, é possível afirmar que os estudos estrangeiros constituíram elementos fundamentais para a elaboração desta tese.

Embora o texto faça referência a situações reais decorrentes do uso das novas tecnologias na Administração Pública, em especial para ilustrar explicações ou sustentar argumentos, é preciso ressalvar que este estudo não decorre de uma pesquisa empírica. Ele é baseado em fontes bibliográficas, das quais foram extraídos os elementos para a discussão das hipóteses aqui lançadas e para a obtenção das conclusões cabíveis. 
O trabalho é composto de quatro capítulos. No primeiro, é apresentado o contexto da sociedade da informação e o progressivo desenvolvimento do uso das tecnologias da informação e da comunicação na Administração Pública. Também neste capítulo, busca-se precisar a extensão conceitual do governo eletrônico, aspecto essencial para a definição dos limites temáticos deste estudo. Por fim, procura-se demonstrar a relevância das novas tecnologias para o direito administrativo e indicar qual deve ser sua posição em face da realidade informática.

No segundo capítulo, são investigadas as bases jurídicas do regime aplicável ao governo eletrônico, a partir de uma avaliação dos postulados que norteiam a atividade administrativa. Nesse sentido, serão apresentados, de maneira sistemática, os princípios jurídicos que devem reger o governo eletrônico, por meio de uma confrontação entre as diversas situações verificadas na realidade contemporânea, próprias da utilização das novas tecnologias na Administração Pública, e os preceitos basilares do direito administrativo, sobretudo aqueles resultantes do sistema constitucional vigente.

O propósito do terceiro capítulo é avaliar os efeitos das novas tecnologias sobre a temática do ato administrativo. Nesse capítulo são considerados os aspectos referentes à expedição de atos administrativos em suporte digital e as diversas complexidades inerentes à prática de atos de modo automatizado, assunto essencial no âmbito do governo eletrônico.

Por fim, no último capítulo, vem apresentada uma reflexão abrangente a respeito de como tais instrumentos tecnológicos vêm transformando o processo administrativo, identificando e explorando os eixos dessa transformação, a fim de oferecer elementos para o enquadramento das inovações e seu adequado tratamento jurídico.

Com o exame de tais temas, será possível desenvolver as hipóteses supra mencionadas, de forma a lançar respostas a respeito de como é possível admitir, sob o aspecto jurídico, a atuação administrativa por meio digital, o que permitirá identificar as relações existentes entre o governo eletrônico e o direito administrativo. 


\section{CAPÍTULO 1 - O CONTEXTO DA SOCIEDADE DA INFORMAÇÃO E O DIREITO ADMINISTRATIVO}

\subsection{O advento da sociedade de informação}

A sociedade humana sempre esteve baseada na informação, no conhecimento e na comunicação ${ }^{1}$. O ser humano, dotado de habilidades racionais, detém a capacidade de identificar diferenças observáveis na realidade ${ }^{2}$. Essas diferenças são os dados, que podem representar objetos reais ${ }^{3}$, tais como fatos ou ideias, de um modo formalizado ${ }^{4}$. Para essa formalização, os dados devem apresentar-se ou codificar-se de certa maneira, para que assim possam ser utilizados como figuras, linguagem, sons, textos ou imagens.

\footnotetext{
${ }^{1}$ Cf. GÓMEZ PUENTE, Marcos, La administración electrónica, in VVAA, La autorización administrativa. La administración electrónica. La enseñanza del derecho administrativo hoy. Actas del I Congreso de la Asociación Española de Profesores de Derecho Administrativo, Pamplona, Aranzadi, 2007, p. 93.

${ }^{2}$ Cf. KLUTH, Winfried, NuCKET, Jana, La legislación de procedimiento administrativo y la generación de conocimiento en el ámbito de la administración pública, in VVAA, La Transformación del Procedimiento Administrativo, Sevilla, Global Law Press - Editorial Derecho Global, 2006, p. 481.

${ }^{3}$ Cf. STAIR, Ralph M., REYNOLDS, George W., Principles of information systems: a managerial approach, $6^{\mathrm{a}}$ ed., trad. port. de Flávio Soares Corrêa da Silva (coord.), Giuliano Mega, Igor Ribeiro Sucupira, Princípios de sistemas de informação: uma abordagem gerencial, São Paulo, Pioneira Thomson Learning, 2006, p. 5.

${ }^{4}$ Cf. DENTE, Bruno, Informatica e pubblica amministrazione, in Amministrare, n. 38, Milano, Giuffrè, 1972, p. 90. De forma mais minuciosa, pode-se considerar os dados como "fatos ou observações crus, normalmente sobre fenômenos físicos ou transações de negócios, correspondendo a medidas objetivas dos atributos (as características) de entidades (como pessoas, lugares, coisas e eventos)" (O’BRIEN, James A., Introduction to information systems, $11 .^{\text {a }}$ ed., 2003, trad. port. de Célio Knipel Moreira e Cid Kneipel Moreira, Sistemas de informação e as decisões gerenciais na era da internet, 2. ${ }^{a}$ ed., São Paulo, Saraiva, 2004, p. 12).
} 
A partir dos dados, o ser humano é capaz de produzir informação ${ }^{5}$. Isso ocorre quando aqueles são submetidos a certas atividades de processamento, tais como cálculo, seleção, organização, comparação, separação, classificação e resumo ${ }^{6}$. Assim, enquanto os dados referem-se a observações em estado bruto sobre determinados eventos, a informação pode ser entendida como o dado organizado de modo a ter valor adicional, ou seja, apresentado de maneira compreensível e útil para o ser humano ${ }^{7}$. Já o conhecimento corresponde à consciência e ao entendimento de um conjunto de informações, a fim de torná-las úteis para a realização de uma tarefa específica ou para a tomada de uma decisão ${ }^{8}$.

A comunicação desempenha um papel essencial na produção e refinamento das informações e dos conhecimentos produzidos, tornando possíveis as relações humanas e, com isso, a vida em sociedade. Como instrumento viabilizador da comunicação, a linguagem sempre serviu como veículo para as informações e para o conhecimento: primeiro, o emprego da palavra oral propiciou a evolução dos relacionamentos humanos, possibilitando transmitir de modo claro, preciso e rápido as experiências adquiridas, que devem servir de base para novas experiências; depois, a utilização da forma escrita repre-

\footnotetext{
${ }^{5}$ Em geral, os textos normativos utilizam como equivalentes os vocábulos "dado" e "informação" (cf. GUERRA, Maria Paola, Circolazione dell'informazione e sistema informativo pubblico. Profili giuridici dell'accesso interamministrativo telematico, in Diritto Pubblico, n. 2, 2005, p. 539). Na verdade, não se trata de algo restrito à realidade normativa: "As pessoas, muitas vezes, empregam os termos dados e informações de modo intercambiável. Entretanto, é melhor encarar os dados como recursos de matéria-prima que são processados em produtos acabados de informação. Logo, podemos definir informação como dados que foram convertidos em um contexto significativo e útil para usuários finais específicos. Dessa forma, os dados normalmente são submetidos a um processo de valor adicionado (que chamamos de processamento de dados ou processamento de informação) em que (1) sua forma é agregada, manipulada e organizada, (2) seu conteúdo é analisado e avaliado e (3) é colocado em um contexto adequado a um usuário humano. Portanto, você deve encarar a informação como dados processados colocados em um contexto que confere valor para usuários finais específicos" (O'BRIEN, James A., op. cit., p. 13, grifos nossos). Neste estudo, os vocábulos também são utilizados por vezes como sinônimos, ressaltada a preferência por utilizar dado para fazer referência à informação constante dos chamados bancos ou bases de dados, entendidos como coleções organizadas de fatos e informações (cf. STAIR, Ralph M., REYNOLDS, George W., op. cit., p. 15), em que os registros e arquivos restam logicamente relacionados entre si (cf. O'BrIEN, James A., op. cit., pp. 16 e G-3). Com isso, o texto pretende alinhase com a terminologia empregada pela Constituição brasileira, que ora utiliza o vocábulo dessa forma, sobretudo ao referir-se à comunicação de dados (art. $5^{\circ}$, XII), ou como sinônimo de informação, o que ocorre no dispositivo atinente ao habeas data (art. $5^{\circ}$, LXXII).

${ }^{6}$ Cf. O’BRIEN, James A., op. cit., p. 14 e STAIR, Ralph M., REYNOLDS, George W., op. cit., p. 6.

${ }^{7}$ Cf. Laudon, Kenneth C., Laudon, Jane P., Essentials of management information systems, 5. ${ }^{a}$ ed., 2004, trad. port. de Arlete Simille Marques, revisão técnica de Érico Veras Marques e Belmiro João, Sistemas de informação gerenciais: administrando a empresa digital, 3. ${ }^{a}$ reimpressão, São Paulo, Pearson Prentice Hall, 2006, p. 7 e STAIR, Ralph M., REYNOLDS, George W., op. cit., p. 4.

${ }^{8}$ Cf. STAIR, Ralph M., REYNOLDS, George W., op. cit., p. 5.
} 
sentou um instrumento ainda mais formidável, permitindo memorizar e levar para o futuro experiências cuja transmissão era apenas confiada às simples tradições orais ${ }^{9}$.

O desenvolvimento tecnológico das últimas décadas revolucionou as modalidades de produção, transmissão e conservação do conhecimento ${ }^{10}$. Surgiram as tecnologias da informação e da comunicação, entendidas como as ferramentas tecnológicas, soluções e estruturas que servem para o recolhimento, armazenamento, conservação, tratamento, difusão e transmissão de informações, sejam elas textuais, visuais ou sonoras ${ }^{11}$.

Vocábulo criado em 1962 pelo francês Philippe Dreyfus, por meio da contração entre informação e automática, a informática designa um procedimento de memorização artificial dos dados, por meio de impulsos eletromagnéticos, sobre um suporte físico (v.g., fita, disco, silício), que permite o confronto, a análise e a agregação dos dados assim registrados, bem como a decifração e a comunicação visual impressa ou sobre uma tela ${ }^{12}$. Os meios informáticos têm como referência o tratamento automático da informa-

\footnotetext{
${ }^{9}$ Cf. DunI, Giovanni, L'amministrazione digitale - il diritto amministrativo nella evoluzione telematica, Milano, Giuffrè, 2007, pp. 1-2.

${ }^{10}$ Cf. MASUCCI, Alfonso, Il documento amministrativo informatico, Rimini, Maggioli, 2000, p. 12.

${ }^{11}$ Cf. Martínez Gutiérrez, Rubén, Administración Pública Electrónica, Cizur Menor (Navarra), Civitas Thomson Reuters, 2009, p. 213 e MERLONI, Francesco, Sviluppo dell'e-government e riforma delle amministrazioni, in MERLONI, Francesco, Introduzione all'e-government, Torino, G. Giappichelli, 2005, p. 5.

${ }_{12}$ Cf. FROSINI, Vittorio, Telematica e informatica giuridica, in Enciclopedia del Diritto, XLIV, Milano, Giuffrè, 1992, p. 61. O suporte é a base física na qual são registrados dados ou informações. Sobre o suporte informático, cf. infra, item 2.2 .
} 
ção ${ }^{13}$, de acordo com operações lógicas, lineares e em forma simbólica, realizado mediante a utilização de equipamentos conhecidos comercialmente como computadores ${ }^{14}$.

A contração das palavras telecomunicação e informática, por sua vez, deu origem ao vocábulo telemática ${ }^{15}$, que se refere ao diálogo entre computadores, por meio da transmissão de dados entre eles ${ }^{16}$. Com a telemática, passa-se de uma realidade composta por arquiteturas estáticas e parceladas, no interior das quais o elemento central era representado por equipamentos isolados, a um mundo caracterizado por sistemas dinâmicos e interconectados, no qual predomina a figura da rede ${ }^{17}$, onde a informação circula de forma multidirecional e não hierárquica ${ }^{18}$. A ligação física entre os equipamentos é feita mediante conexões de cabos ou pela transmissão de impulsos eletromagnéticos, enquanto a

\footnotetext{
${ }^{13}$ Cf. OCHOA MonZÓ, Josep, MARTínEZ GuTIÉRREZ, Rubén, La permeabilidad de la actividad administrativa al uso de tecnologías de la información y de la comunicación: hacia la administración electrónica y el procedimiento administrativo electrónico, in FABRA VAlls, Modesto, Blasco DíaZ, José Luis (org.), La administración electrónica en España: experiencias y perspectivas de futuro, Castelló de la Plana, Universitat Jaume I, 2007, p. 75. Os autores distinguem os meios informáticos dos meios eletrônicos, sendo estes os que utilizem qualquer técnica eletrônica como base ou ajuda para o desempenho de uma atividade (v.g., microfilmagem, fotocópia, transmissão de fax). De modo mais rigoroso, pode-se afirmar que a informática depende da eletrônica, ou seja, dos diferentes mecanismos baseados no movimento de elétrons em circuitos. Distinção conceitual análoga pode ser feita em relação aos meios digitais, entendidos como aqueles que registram e processam a informação em formato numérico. Tais conceitos levam ao uso dos adjetivos eletrônico, informático e digital para qualificar diversas realidades que se utilizam das novas tecnologias. Sobre o uso indistinto de tais adjetivos, inclusive neste estudo, cf. infra, nota 195.

${ }^{14}$ Cf. DAVARA RODRÍGUEZ, Miguel Ángel, El documento electrónico en la vigente ley de régimen jurídico de las administraciones públicas y del procedimiento administrativo común, in Revista de Administración Pública, n. 131, Madrid, Centro de Estudios Políticos y Constitucionales, mai.-ago. 1993, p. 483. Para executar esas operações, o computador deve ser instruído segundo um conjunto de instruções denominado programa ou software. Sobre o conceito de software, cf. infra, nota 941.

${ }^{15}$ Cf. Frosint,Vittorio, Telematica e informatica giuridica, cit., p. 60. A palavra telemática é geralmente atribuída a NORA e MINC, em trabalho clássico sobre a revolução tecnológica (cf. NORA, Simon, MiNC, Alain, L'informatisation de la societé, 1978, trad. port. de Luísa Ribeiro, A informatização da sociedade, Rio de Janeiro, FGV, 1980, p. 3). No entanto, segundo VILLAR PALASí, o vocábulo teria surgido num estudo de LUIS ARROYO GALÁN, denominado Telemática: Una nueva actitud ante el fenómeno informático (Revista Novatica, n. 15, mai-jun. 1977, p. 39). Oito meses mais tarde, o informe NORA-MINC usou o mesmo termo (cf. VILLAR Palasí, José Luis, Aspectos jurídicos y políticos de la Telemática, in Revista Española de Derecho Administrativo, n. 19, Madrid, Civitas, out.-dez. 1978, p. 501).

${ }^{16}$ Cf. DAVARA RodRíGUEZ, Miguel Ángel, op. cit., p. 484. O presente estudo emprega a expressão novas tecnologias para fazer referência ao conjunto de técnicas que compreende tanto a informática quanto a telemática.

${ }^{17}$ Cf. MASUCCI, Alfonso, Erogazione on line dei servizi pubblici e teleprocedure amministrative - disciplina giuridica e riflessi sull'azione amministrativa, in Diritto Pubblico, n. 3, Bologna, Il Mulino, 2003, p. 991.

${ }^{18} \mathrm{Cf}$. TRUDEL, Pierre, Améliorer la protection de la vie privée dans l'administration électronique : pistes afin d'ajuster le droit aux réalités de l'État en réseau, Montréal, Ministère des Relations avec les citoyens et de l'Immigration, Montréal, mar. 2003, disponível em: http://www.institutions-democratiques.gouv.qc.ca/accesinformation/documents/Rapport_Me_Pierre Trudel.pdf, acesso em 30.12.2010, p. 3.
} 
ligação lógica é feita por meio de protocolos, ou seja, conjuntos de normas que regulam as comunicações entre computadores ${ }^{19}$.

De todos os instrumentos telemáticos desenvolvidos, o mais importante, sem dúvida, é a internet. ${ }^{20}$. Ela foi criada inicialmente pela agência estadunidense DARPA (US Defense Advanced Research Projects) como um programa para desenvolver técnicas que iriam permitir aos computadores comunicar-se por meio de redes múltiplas, possibilitando aos cientistas executar programas em computadores remotos ${ }^{21}$. A partir dos anos setenta, durante cerca de vinte anos, a internet esteve circunscrita aos ambientes universitários e militares, pois o acesso e a simples consulta de dados exigiam conhecimentos técnicos avançados. A partir do início dos anos noventa do século passado, com o oferecimento de serviços na forma de texto ${ }^{22}$, o acesso à internet deixou de ser prerrogativa dos informáticos e desde então foi progressivamente estendido aos usuários comuns ${ }^{23}$. Atualmente, a

\footnotetext{
${ }^{19}$ Cf. OCHOA MONZÓ, Josep, MARTíNEZ GUTIÉRREZ, Rubén, La permeabilidad de la actividad administrativa al uso de tecnologías de la información y de la comunicación, cit., p. 75.

${ }^{20} \mathrm{~A}$ internet não constitui propriamente uma rede, mas um conjunto de protocolos de comunicação que possibilita o fluxo de informação entre diferentes redes (cf. BARNÉS VÁZQUEZ, Javier, Una reflexión introductoria sobre el Derecho Administrativo y la Administración Pública de la Sociedad de la Información y del Conocimiento, in Revista Andaluza de Administración Pública, n. 40, Sevilla, Instituto Andaluz de Administración Pública, out.-dez. 2000, p. 31). No Brasil, a internet é definida por norma oficial como "nome genérico que designa o conjunto de redes, os meios de transmissão e comutação, roteadores, equipamentos e protocolos necessários à comunicação entre computadores, bem como o 'software' e os dados contidos nestes computadores" (Item 3, "a”, da Norma n. 4/1995, aprovada pela Portaria n. 148, de 31.05.1995, do Ministério das Comunicações). O presente texto refere-se à internet nessa forma genérica, ou seja, como rede em sentido amplo, que propicia a integração entre equipamentos informáticos.

${ }^{21}$ Cf. HOLMES, Douglas, E-gov, an E-business plan for government, London, Nicholas Brealey, 2001, pp. 3-4 e FountaIN, Jane E., Building the virtual state: information technology and institutional change, Washington, Brookings, 2001, p. 21.

${ }^{22}$ A World Wide Web trouxe uma determinada metodologia de gestão das redes telemáticas, caracterizada pelas modalidades intuitivas e imediatas de aproximação ao sistema, especialmente pelo uso do chamado hipertexto, por meio do qual, na leitura de um sítio telemático presente na rede, é possível acessar diretamente outros sítios a que o primeiro faz referência (cf. MARONGIU, Daniele, Il governo dell'informatica pubblica - Tra Stato, regioni ed enti locali, Napoli, Edizioni Scientifiche Italiane, 2007, p. 14). O mais relevante, neste caso, é a universalização dos padrões, que permite a integração por meio da rede: "A World Wide Web é um sistema de armazenagem, recuperação, formatação e exibição de informações em ambiente rede com padrões universalmente aceitos. A informação é armazenada e apresentada como 'páginas eletrônicas' que podem conter texto, elementos gráficos, animações, som e vídeo. Essas páginas Web podem ser interligadas eletronicamente a outras, independentemente de onde estiverem localizadas, e podem ser vistas em qualquer tipo de computador" (LAUDON, Kenneth C., LAUDON, Jane P., op. cit., p. 17).

${ }^{23}$ Cf. MARONGIU, Daniele, Il governo dell'informatica pubblica, cit., p. 15. CASTELLS ressalta o ambiente da região do Vale do Silício estadunidense, ao afirmar que a criação e o desenvolvimento da internet provieram de uma combinação entre estratégia militar, cooperação de grandes projetos científicos, espírito empresarial tecnológico e inovação contracultural (cf. The Rise of the Network Society, The Information Age: Economy, Society and Culture Vol. I., 2000, trad. esp. de Carmen Martínez Gimeno e Jesús Alborés, La sociedad red, 2. ${ }^{\mathrm{a}}$ ed., Madrid, Alianza, 2001, p. 77).
} 
internet é a maior rede de computadores do mundo, composta por inúmeras redes públicas e privadas interconectadas e livres para a troca de uma imensa quantidade de informações, de variadas espécies ${ }^{24}$, desempenhando um papel essencial na vida de milhões de pessoas e empresas. Trata-se de uma plataforma tecnológica universal: simples, veloz e econômica ${ }^{25}$.

A combinação de meios informáticos e telemáticos traz efeitos notáveis. De fato, nos períodos anteriores da história humana, a transmissão da informação era feita sem que pudesse haver alteração do conteúdo da mensagem entre emissor e destinatário. Já a informação elaborada de maneira automatizada pode ser transformada por um sistema computadorizado programado para tanto, de sorte que as informações recebidas podem gerar novas informações por meio de um procedimento lógico ${ }^{26}$. Dessa maneira, a revolução tecnológica contemporânea é marcada pela aplicação da informação e do conhecimento em um contínuo processo de retroalimentação ${ }^{27}$.

A informática e a telemática, cada vez mais evoluídas ${ }^{28}$, permitem realizar um relacionamento entre dados a distância, valendo-se de uma rede de transmissão eletrônica, possibilitando ao pensamento mover-se de modo abstrato e em tempo real, a uma velocidade mais rápida que aquela passível de ser atingida pelos corpos físicos ${ }^{29}$, sem estar limitada a um suporte material, como sucedia com o documento escrito em papel ${ }^{30}$. O uso das tecnologias da informação e da comunicação permite acumular, relacionar, processar e transmitir a informação em volumes e velocidades nunca antes imaginados ${ }^{31}$, com

\footnotetext{
${ }^{24}$ Cf. CAMmarota, Giuseppe, L'erogazione on line di servizi pubblici burocratici, in Informatica e diritto, n. 2, Napoli, Edizioni Scientifiche Italiane, 2002, pp. 49-50; LAUdON, Kenneth C., LAUdON, Jane P., op. cit., p. 16 e STAIR, Ralph M., REYNOLDS, George W., op. cit., p. 15.

${ }^{25}$ Cf. CAMMAROTA, Giuseppe, L'erogazione on line di servizi pubblici burocratici, cit., pp. 49-50 e LAUDON, Kenneth C., LaUdon, Jane P., op. cit., p. 17.

${ }^{26}$ Cf. Frosini,Vittorio, Telematica e informatica giuridica, cit., p. 61.

27 Assim, “[o] que caracteriza a revolução tecnológica atual não é o caráter central do conhecimento e da informação, mas a aplicação desse conhecimento e informação a aparatos de geração de conhecimento e processamento da informação/comunicação, em um círculo de retroalimentação acumulativo entre a inovação e seus usos" (CASTELLS, Manuel, op. cit., p.62, tradução livre).

${ }^{28}$ Sobre a evolução tecnológica em si, cf. o minucioso relato de CASTELLS, Manuel, op. cit., pp. 70-110, com a importante ressalva de que qualquer relato sobre tecnologias se torna imediatamente obsoleto (p. 70). A mesma observação cabe em relação ao presente trabalho, o qual, muito embora não seja um estudo sobre tecnologia, reflete um determinado contexto tecnológico.

${ }^{29}$ Cf. MASUCCI, Alfonso, Erogazione on line dei servizi pubblici e teleprocedure amministrative, cit., p. 992.

${ }^{30}$ Cf. Frosini, Vittorio, Telematica e informatica giuridica, cit., p. 61.

${ }^{31}$ Cf. Gómez PUENTE, Marcos, op. cit., p. 94.
} 
custos cada vez menores ${ }^{32}$. Os sistemas de informação computadorizados, como conjuntos de componentes inter-relacionados responsáveis por essas tarefas ${ }^{33}$, assumem uma posição central em grande parte das atividades humanas ${ }^{34}$, pois todas elas estão relacionadas, de algum modo, com a informação ${ }^{35}$.

Esse crescimento exponencial das novas formas de comunicação e a necessidade de troca de informação entre os cidadãos, os operadores econômicos e o Estado caracterizam a denominada sociedade da informação ${ }^{36}$. A sociedade da informação implica a substituição de uma cultura material por uma economia da informação ${ }^{37}$, caracterizando-se como uma sociedade pós-industrial produtora de serviços, na qual a informação constitui a fonte vital de atuação em qualquer âmbito da vida social, econômica e políti$\mathrm{ca}^{38}$. A informação já não é considerada apenas no seu valor de conteúdo, mas na sua nova

${ }^{32}$ Cf. Guillén Caramés, Javier, La administración electrónica, in García MeXía, Pablo, Principios de derecho de internet, $2^{\mathrm{a}}$. ed., Valencia, Tirant lo Blanch, 2005, p. 248.

${ }^{33}$ Cf. STAIR, Ralph M., REYNOLDS, George W., op. cit., p. 14.

${ }^{34} \mathrm{Na}$ verdade, as pessoas têm recorrido a sistemas de informação há muitos séculos, utilizando dispositivos físicos para armazenagem da informação (normalmente documentos escritos), sendo esta processada por seres humanos de acordo com certas regras e transmitida por determinados canais (cf. O'BRIEN, James A., op. cit., p. 6). Os sistemas de informação podem ser formais, quando operam em conformidade com regras pré-definidas relativamente fixas ou dificilmente alteráveis, ou informais, quando dependem de regras de comportamento não declaradas ou previamente definidas (cf. LAUDON, Kenneth C., LAUDON, Jane P., $o p$. cit., p. 9). Até meados do século XX, com o desenvolvimento das organizações burocráticas, aprofundou-se a formalização de muitos sistemas de informação. Com o advento da informática, surgiram os sistemas de informação formais baseados em computadores, de forma que muitos sistemas inicialmente manuais tornaram-se computadorizados (cf. STAIR, Ralph M., REYNOLDS, George W., op. cit., p. 13). Os sistemas computadorizados são formados por dispositivos físicos e equipamentos de processamento da informação (hardwa$r e$ ), instruções para o processamento da informação e controle dos dispositivos físicos (software), redes de comunicação, mecanismos de armazenagem de informação (bases de dados) e recursos humanos (especialistas em sistemas e usuários).

${ }^{35}$ Assim já se observou: "Como a informação é uma parte integral de toda atividade humana, todos os processos de nossa existência individual e coletiva estão diretamente moldados (ainda que sem dúvida não determinados) pelo novo meio tecnológico" (CASTELLS, Manuel, op. cit., p. 103).

${ }^{36}$ Cf. PITSCHAS, Raines, El derecho administrativo de la información. La regulación de la autodeterminación informativa y el gobierno electrónico, in VVAA, Innovación y reforma en el Derecho Administrativo, Sevilla, Derecho Global, 2006, p. 217.

${ }^{37}$ Cf. CASTELLS, Manuel, op. cit., pp. 59-60.

${ }^{38}$ Cf. GARCÍA MACHO, Ricardo, Procedimiento Administrativo y sociedad de la información y del conocimiento, in VVAA, La Transformación del Procedimiento Administrativo, Sevilla, Global Law Press - Editorial Derecho Global, 2006, p. 189 e LAUdON, Kenneth C., LAUdON, Jane P., op. cit., p. 4. De forma semelhante, BARNÉS VÁZQUEZ afirma que "[a] sociedade da informação excede em muito a tecnologia: representa uma forma de economia e um tipo de sociedade pós-industrial na qual o protagonismo da produção e distribuição de bens parece deslocar-se para uma sociedade de serviços, em cujo centro se situa a obtenção, processamento e distribuição de informação" (Sobre el procedimiento administrativo: evolución y perspectivas, in VVAA, Innovación y reforma en el Derecho Administrativo, Global Law Press - Editorial Derecho Global, Sevilla, 2006, p. 301). 
característica específica de bem econômico, social e jurídico, ou seja, de produto industrial feito à máquina, com valor agregado de modo artificial ${ }^{39}$. O computador, como um novo personagem social coletivo, constitui o símbolo mais representativo dessa sociedade ${ }^{40}$.

Não há dúvida de que as discussões sobre a revolução tecnológica pecam muitas vezes pelo exagero profético e pela manipulação ideológica, mas não é possível deixar de considerar suas repercussões ${ }^{41}$. Os efeitos da sociedade da informação são extremamente relevantes ${ }^{42}$, induzindo e acelerando mudanças profundas no sistema social ${ }^{43}$, transformações talvez paulatinas, mas seguramente globais ${ }^{44}$. No contexto da sociedade da informação, a tecnologia constitui eixo da atividade econômica ${ }^{45}$ e um componente de nossa vida cotidiana ${ }^{46}$. Assim, a revolução tecnológica ou digital é um acontecimento histórico pelo menos tão importante quanto foi a Revolução Industrial do século XVIII ${ }^{47}$, de importância equiparável à que um dia trouxeram consigo a agricultura, a roda ou a máquina a vapor $^{48}$. $\mathrm{O}$ aprofundamento dessa revolução é uma tendência para os próximos anos, mas não há dúvida alguma a respeito das consequências que dela já advieram. Várias delas são de especial interesse para o presente estudo.

\footnotetext{
${ }^{39}$ Cf. Frosini,Vittorio, Telematica e informatica giuridica, cit., pp. 61-62.

${ }^{40}$ Cf. Frosini, Vittorio, Informática y Administración Pública, in Revista de Administración Pública, n. 105, Madrid, Centro de Estudios Políticos y Constitucionales, set.-dez. 1984, p. 447.

${ }^{41}$ Cf. CASTELls, Manuel, op. cit., p. 60.

${ }^{42}$ Cf. BARNÉS VÁZQUEZ, Javier, Una reflexión introductoria sobre el Derecho Administrativo y la Administración Pública de la Sociedad de la Información y del Conocimiento, cit., p. 50.

${ }^{43}$ Cf. FAnTIGRossi, Umberto, Automazione e pubblica amministrazione: profili giuridici, Bologna, Il Mulino, 1993, p. 11.

${ }^{44}$ Cf. MARTín DELGADO, Isaac, La administración electrónica como reto del derecho administrativo en el siglo XXI, in García Costa, Francisco Manuel, PARdo LóPEZ, María Magnolia, Retos del Derecho en el Siglo XXI, Valencia, Tirant lo Blanch, 2009, p. 310.

${ }^{45}$ Cf. GOMEZ PuENTE, Marcos, op. cit., p. 95.

${ }^{46}$ Cf. COMEAU, Paul. A., Les enjeux socio-politiques de la mise en place de l'autoroute de l'information, in Revue française d'administration publique, n. 81, Paris, ENA, jan.-mar. 1997, p. 73.

${ }^{47} \mathrm{Cf}$. GAMERO CASADO, Eduardo, El derecho administrativo ante la era de la información, in GAMERO CASADO, Eduardo, VALERO TORRIJOS, Julián (coord.), Comentarios a la Ley de Administración electrónica Ley 11/2007, de 22 de junio, de acceso electrónico de los ciudadanos a los servicios públicos, 1. ${ }^{\mathrm{a}}$ ed., 2. ${ }^{\mathrm{a}}$ imp., Cizur Menor (Navarra), Thomson-Civitas, 2009, p. 29 e ZugMAN, Fábio, Governo eletrônico, São Paulo, Livro Pronto, 2006, p. 16.

${ }^{48}$ Cf. Gómez Puente, Marcos, op. cit., p. 98.
} 


\subsection{Novos instrumentos para a atividade administrativa}

A passagem da sociedade industrial para a emergente sociedade da informação inclui também a utilização das tecnologias da informação e da comunicação no setor público $^{49}$, ainda que isso não ocorra com a mesma intensidade ou com a mesma velocidade que no setor privado ${ }^{50}$. Assim, do mesmo modo que veio a transformar o funcionamento das organizações privadas ${ }^{51}$, a revolução tecnológica atinge a Administração Públi$\mathrm{ca}^{52}$, a qual deve acompanhar o ritmo dinâmico e veloz das mudanças verificadas na sociedade ${ }^{53}$.

Não é de hoje que a informação desempenha uma função primordial nas atividades estatais. Com efeito, o pensamento weberiano, que constituiu a base para a estrutura lógica do Estado burocrático no século $\mathrm{XX}^{54}$, dá relevância à aplicação de regras de maneira racional e impessoal por um corpo técnico especializado, o que depende essencialmente da informação e do conhecimento. A administração burocrática constitui a forma de dominação pelo conhecimento, adquirido na execução de tarefas ou obtido por meio da documentação ${ }^{55}$, tornando necessário que as considerações preliminares, requisitos e decisões sejam fixados por escrito ${ }^{56}$. A racionalidade da Administração Pública está na aplicação de regras segundo a documentação ${ }^{57}$, ou seja, segundo o conhecimento e as informações disponíveis.

\footnotetext{
${ }^{49}$ Cf. Holmes, Douglas, op. cit., p. 3.

${ }^{50}$ Cf. Frosini, Vittorio, Informática y Administración Pública, cit., p. 448.

${ }^{51}$ Cf. GarcíA MEXÍA, Pablo, El Derecho de Internet y sus implicaciones para la Administración, in Documentación Administrativa, n. 265-266, Madrid, Escuela Nacional de Administración Pública, jan-ago. 2003, p. 112 .

${ }^{52}$ Cf. Mestre Delgado, Juan Francisco, Nuevas tecnologías y Administración Pública, in Documentación Administrativa, n. 265-266, Madrid, Escuela Nacional de Administración Pública, jan.-ago. 2003, p. 122. No mesmo sentido, PINHEIRO, Patrícia Peck, Direito digital, 4ª . ed., São Paulo, Saraiva, 2010 , p. 281.

${ }^{53}$ Cf. Medaudr, Odete, Direito administrativo moderno, 12a . ed., São Paulo, RT, 2008, p. 102.

${ }^{54}$ Cf. FOUNTAIN, Jane E., op. cit., p. 48.

${ }^{55}$ Cf. WEBER, Max, Wirtschaft und Gesellschaft: Grundriss der verstehenden Soziologie, 1972, trad. port. de Regis Barbosa e Elsabe Barbosa, Economia e sociedade: fundamentos da sociologia compreensiva, 4. ed., Brasília, UnB, São Paulo, Imprensa Oficial, 2004, p. 147.

${ }^{56}$ Cf. ibidem, p. 143.

${ }^{57}$ Cf. ibidem, p. 142.
} 
Funcionando com base na criação e aplicação de regras, o Estado constitui o mais complexo procedimento de formação, transmissão e difusão dos dados simbólicos relativos à conduta humana ${ }^{58}$, sendo a Administração Pública um centro de geração e gestão de informação de magnitude dificilmente equiparável com a de qualquer sujeito, ou seja, um gigantesco sistema de informações e comunicações ${ }^{59}$ ou uma imensa máquina informacional $^{60}$. Com efeito, para cumprir suas funções, o Poder Público produz, coleta, trata, armazena, distribui e difunde grandes quantidades de informação ${ }^{61}$.

Nessa condição, a Administração Pública não é somente influenciada pela revolução tecnológica; é, na verdade, protagonista da sociedade da informação ${ }^{62}$, tendo um especial interesse em aproveitar as oportunidades de rapidez de manejo, magnitude e confiabilidade que oferecem os atuais sistemas de tratamento da informação, cuja definitiva incorporação às atividades do Poder Público representa um ponto-chave do seu processo de modernização administrativa ${ }^{63}$. A Administração deve aproveitar os progressos do tratamento da informação simbólica e da comunicação trazidos pelos progressos da tecnologia da informação ${ }^{64}$ para alcançar pelo menos quatro objetivos principais em relação às

\footnotetext{
${ }^{58}$ Cf. Frosini, Vittorio, Cibernetica diritto e società, $3^{\mathrm{a}}$. ed., Milano, Edizioni di Comunità, 1977, p. 41.

${ }^{59}$ Cf. GARDINI, Gianluca, Le regole dell'informazione: principi giuridici, strumenti, casi, Milano, Bruno Mondadori, 2005, p. 260.

${ }^{60}$ Cf. MAISL, Herbert, Le citoyen «internaute», entre liberté d'accès aux documents administratifs et protection des données personnelles, in Revue française d'administration publique, n. 81, Paris, ENA, jan.-mar. 1997, p. 77.

${ }^{61}$ Cf. Asís RoIG, Agustín de, Documento electrónico en la Administración Pública, in GALlaRdo ORTIZ, Miguel Ángel (org.), Ámbito Jurídico de las tecnologías de la información, Madrid, Consejo General del Poder Judicial, 1996, pp. 140-141. A Administração seria, assim, a principal produtora de informação (cf. CERRILlO I MARTíNEZ, Agustí, La información del sector público: del acceso a la reutilización, in CERRILLO I MARTíneZ, Agustí, GALÁn GALÁn, Alfredo (org.), La reutilización de la información del sector público, Granada, Comares, 2006, p. 2; DomínguEZ LuIS, José Antonio, El derecho de información administrativa: información documentada y transparencia administrativa, in Revista Española de Derecho Administrativo, n. 88, Madrid, Civitas, out.-dez. 1995, p. 537 e TORRES LÓPEZ, Maria Asunción, El documento electrónico en las relaciones jurídico-administrativas: especial referencia a los actos de comunicación, in Revista Vasca de Administración Pública, Oñati, Instituto Vasco de Administración Pública, n. 55, set.-dez. 1999, p. 254).

${ }^{62} \mathrm{Cf}$. Merloni, Francesco, Sviluppo dell'e-government e riforma delle amministrazioni, cit., p. 3.

${ }^{63}$ Cf. Asís RoIG, Agustín de, op. cit., pp. 140-141.

${ }^{64}$ Cf. BAQUIAST, Jean-Paul, Internet et les administrations: la grande mutation, Paris, Berger-Levrault, 1999, p. 31. Há cerca de cinquenta anos, FORSTHOFF já percebia essas oportunidades: "De momento seria irreal ocupar-se seriamente da imagem futura de uma Administração organizada de um modo inteiramente automático, regida pelas leis da cibernética; mas seria igualmente irreal passar por alto aquelas mudanças estruturais da Administração que - falando cautelosamente - são, pelo menos, propícias às exigências técnicas da automatização" (Rechtsfragen der leistenden Verwaltung, 1959, Der Staat als Auftraggeber, 1963, trad. esp. de Celestino Fernández de la Vega, Sociedad industrial y Administración Pública, Madrid, Escuela Nacional de Administración Pública, 1967, p.100).
} 
informações: recolhê-las em maior número, em um espaço físico cada vez menor; tratá-las e transmiti-las a uma velocidade cada vez alta; permitir a sua troca, mesmo quando recolhidas com técnicas e linguagens diversas; garantir sua conservação e segurança ${ }^{65}$.

A simples eliminação do suporte papel não constitui o objetivo principal da incorporação das tecnologias da informação e da comunicação às atividades da Administração Pública ${ }^{66}$. Por mais que a limpeza estética de cada repartição pública e a concentração de armários inteiros de arquivos em um pequeno disco sejam um resultado útil e interessante $^{67}$, a aplicação das referidas tecnologias tem mais relevância nos sucessivos mecanismos de produção e circulação da informação ${ }^{68}$. De fato, a informação em meio digital oferece melhor funcionalidade que aquela em papel, pois é mais fácil de ser analisada, procurada, atualizada e compartilhada ${ }^{69}$. A sua circulação pode ser aperfeiçoada no âmbito interno de cada ente público e entre entes públicos, todos eles permanentemente conectados, bem como entre a Administração e os usuários. A própria tecnologia oferece meios para que seja possível processar essa grande quantidade de informações, o que pode ser usado para subsidiar a atuação humana ou para automatizar decisões.

O uso das tecnologias da informação e da comunicação pode contribuir para melhorar a produção e a circulação da informação, o que traz rapidez, qualidade, eficácia e eficiência, além de diminuir as margens para corrupção. No plano interno, as novas tecnologias são capazes de: a) acelerar a decisão e aumentar sua qualidade, ao evitar erros e permitir o aproveitamento de mais elementos informativos; b) possibilitar a cooperação em tempo real entre entidades, órgãos e servidores públicos; c) reduzir custos; d) viabilizar

\footnotetext{
${ }^{65}$ Cf. Merloni, Francesco, Sviluppo dell'e-government e riforma delle amministrazioni, cit., p. 6.

${ }^{66}$ Cf. MASUCCI, Alfonso, Erogazione on line dei servizi pubblici e teleprocedure amministrative, cit., pp. 992-993 e MARTínez GuTIÉRreZ, Rubén, Administración Pública Electrónica, cit., p. 213.

${ }^{67}$ Cf. Duni, Giovanni, L'amministrazione digitale, cit., p. 13 e Teleamministrazione, in Enciclopedia Giuridica Treccani, Roma, Istituto della Enciclopedia Italiana, 1993, disponível em http://spol.unica.it/teleamm/italiano/pubblicazioni/telea.htm, acesso em 07.12.2010, item 1.

${ }^{68}$ Também é possível combinar a descrição das mudanças de aparência e de essência: "Em vez de fábricas produtoras de decisão barulhentas e desorganizadas, cheias de inconstantes funcionários, várias dessas agências executivas estão se tornando silenciosas refinarias de informação, nas quais quase todas as decisões são pré-programadas por algoritmos e árvores digitais para decisão" (BOVENS, Mark, ZOURIDS, Stavros, From street-level bureaucracy to system-level bureaucracy: How ICT is transforming administrative discretion and constitutional control, in Public Administration Review, vol. 62, n. 2, mar. -abr. 2002, p. 175, tradução livre).

${ }^{69}$ Cf. Holmes, Douglas, op. cit., p. 8.
} 
uma interconexão permanente, sem limites territoriais; e) reduzir os recursos consumidos com atividades meramente formais, podendo redirecionar os servidores para tarefas que realmente exijam inteligência humana. No plano externo, os potenciais efeitos não são menos positivos, pois a informática e a telemática trazem oportunidades para: a) facilitar o recebimento de solicitações e a informação dos cidadãos; b) evitar a solicitação de elementos informativos já recebidos pelo Poder Público; c) oferecer informação personalizada a respeito de elementos constantes de arquivos públicos; d) orientar sobre o modo de efetuar solicitações, apresentando de maneira clara os requisitos técnicos e jurídicos pertinentes e evitando ônus desnecessários; e) permitir a atualização sobre andamento de cada solicitação, até mesmo de modo personalizado; f) aumentar a transparência, o controle democrático e a participação; g) proporcionar relacionamento instantâneo, em tempo real, sem intermediários, limitações de horário, barreiras territoriais ou deslocamentos ${ }^{70}$.

\footnotetext{
${ }^{70}$ São muitos os textos que tratam das vantagens e oportunidades decorrentes da utilização das tecnologias da informação e da comunicação na Administração Pública, cujas ideias são reproduzidas neste parágrafo. Mencione-se, apenas a título de exemplo, AIBAR PUENTES, Eduard, Gobernanza electrónica: innovación tecnológica y cambio organizativo en las burocracias públicas, in FABRA VALLS, Modesto, BLASCO DíAZ, José Luis (org.), La administración electrónica em España: experiencias y perspectivas de futuro, Castelló de la Plana, Universitat Jaume I, 2007, pp. 23-24; ALLi ARANGUREN, Juan-Cruz, Marco social y legal de referencia, in Alli ARANGuren, Juan-Cruz, ENÉRIZ Olaechea, Francisco Javier (org.), La administración eletrónica en la Administración de la Comunidad Foral de Navarra. Comentarios a la Lei Foral 11/2007, de 4 de abril, Pamplona, Gobierno de Navarra, 2008, p. 58; BomBARDELLI, Marco, Informatica pubblica, e-government e sviluppo sostenible, in Rivista italiana di diritto pubblico comunitario, Milano, Giuffrè, 2002, p. 1013; CANTERO, Anne, Des actes unilatéraux des comune dans le contexte électronique -Vers la dématérialisation des actes administratifs?, Aix-en-Provence, PUAM, 2002, p. 406; CHAHIN, Ali et al., e-gov.br: a próxima revolução brasileira: eficiência, qualidade e democracia: o governo eletrônico no Brasil e no mundo, São Paulo, Prentice Hall, 2004, p. 65; FABRa VAlls, Modesto, Blasco Díaz, José Luis, Introducción, in Fabra Valls, Modesto, BLASCo DíAZ, José Luis (org.), La administración electrónica en España: experiencias y perspectivas de futuro, Castelló de la Plana, Universitat Jaume I, 2007, p. 13; GAMERO CASADO, Eduardo, El derecho administrativo ante la era de la información, cit., pp. 31-32; GARCÍA MARCO, Francisco Javier, Administración electrónica: el acceso electrónico de los ciudadanos a los servicios públicos, in GALINDO AYUDA, Fernando, Rover, Aires José (coord.), Derecho, gobernanza y tecnologías de la información en la sociedad del conocimiento, Zaragoza, Prensas Universitarias de Zaragoza, 2009, p. 188; GómEZ PUENTE, Marcos, op. cit., pp. 111 e 131; GRISTI, Éric, La réforme de l'État, Paris, Vuibert, 2007, p. 507; MASUCCI, Alfonso, Erogazione on line dei servizi pubblici e teleprocedure amministrative, cit., pp. 993-994; MESTRE DELGADO, Juan Francisco, op. cit., p. 123; NATALINI, Alessandro, La semplificazione e l'amministrazione digitale, in Giornale di diritto amministrativo, n.1, Milano, Ipsoa, 2008, p. 105; PINHEIRO, Patrícia Peck, op. cit., pp. 276-281; PIÑAR MAÑAS, José Luis, Revolução tecnológica, derecho administrativo y administración pública. Notas provisionales para una reflexión, in VVAA, La autorización administrativa. La administración electrónica. La enseñanza del derecho administrativo hoy. Actas del I Congreso de la Asociación Española de Profesores de Derecho Administrativo, Pamplona, Aranzadi, 2007, p. 6; RondEAU, Jean-Claude, Vers une redéfinition des relations entre l'administration, les citoyens et les entreprises, in Revue française d'administration publique, n. 81, Paris, ENA, jan.-mar. 1997, p. 12; RUSSO, Vincenzo, Introduzione agli atti amministrativi elettronici: tra discrezionalità e vincolatività, in CARBONI, Sandro, Russo, Vincenzo (org.), Diritto e Nuove Tecnologie - saggi di informatica giuridica avanzata, Sgurgola, D-lex, 2008, pp. 85-99, disponível
} 
Se as vantagens são consideráveis, os possíveis problemas relativos ao emprego das novas tecnologias também são muitos ${ }^{71}$. A incorporação dos meios informáticos e telemáticos exige elevados investimentos, muito maiores que os tradicionais, tanto em equipamentos e aplicativos informáticos quanto na contratação, readaptação e treinamento de servidores públicos, despesa que não necessariamente é acompanhada de uma diminuição de custos nos trabalhos desempenhados à moda antiga. Por outro lado, as várias vantagens decorrentes da telemática dependem do diálogo entre equipamentos informáticos, envolvendo uma complexa definição e observância de padrões comuns pelos vários sujeitos implicados, o que nem sempre é realizado com êxito. Há ainda a questão das diferenças de adaptação das pessoas às tecnologias da informação e da comunicação, podendo ocorrer discriminação entre usuários e atribuição de atividades a um grupo restrito de servidores de boa vontade ${ }^{72}$. Isso tende a levar à concentração do poder nas mãos de $\operatorname{poucos}^{73}$ ou ao risco de que a Administração confie a pessoas privadas o desempenho de suas tarefas institucionais ${ }^{74}$. Por fim, há as incertezas jurídicas relativas à utilização dessas tecnologias, podendo ocorrer um ceticismo que leve à alegação de impedimentos legais nem sempre existentes, situação que seria capaz de conduzir à inutilização de todos os investimentos e trabalhos realizados ${ }^{75}$.

em http://www.nuovetecnologie.itisavogadro.org/sito/materiale_informativo/diritto_nuove_tecnologie.pdf, acesso em 08.12.2010, p. 96; SÁNCHEZ RODRÍGUEZ, Francisco, Las nuevas tecnologías de la información y la comunicación en la Administración Pública como paradigmas de un servicio público eficaz y eficiente prestado a los ciudadanos, in PUNZÓN MORALEDA, Jesús (coord.), Administraciones Públicas y nuevas tecnologías, Valladolid, Lex Nova, 2005, p. 28; VALERO TORRIJOS, Julián, El régimen jurídico de la eAdministración, $2^{\mathrm{a}}$ ed., Granada, Comares, 2007, p. 10.

${ }^{71}$ Sobre tais problemas, em geral, cf. GAMERO CASADO, Eduardo, El derecho administrativo ante la era de la información, cit., pp. 32-35. Mencionando um longo rol de desafios para o governo eletrônico, cf. CHAHIN, Ali et al., op. cit., p. 53-55.

${ }^{72}$ Cf. FINOCCHIARO, Giusella, Informatica e pubblica amministrazione, Bologna, CLUEB, 1991, p. 11.

${ }^{73} \mathrm{Cf}$. DE LuCA, Flavio, Informatica e pubblica amministrazione (sputi di indagine), in Il diritto delle radiodiffusioni e delle telecomunicazioni, n. 2, Roma, RAI, mai.-ago. 1980, pp. 295-316, disponível em http://www.flaviodeluca.net/dettarticolo.php?idx=15\&dt=1827\&stqry=0\&an=1980, acesso em 15.12.2010, p. 299.

${ }^{74}$ Cf. MARONE, Umberto, L'informatica nella pubblica amministrazione, Napoli, Esselibri-Simone, 1998, pp. $17-18$.

${ }^{75}$ Segundo VALERO TORRIJOS, os problemas para a modernização tecnológica não são somente jurídicos, sendo os demais problemas até mesmo mais difíceis de serem resolvidos (cf. La nueva regulación legal del uso de las tecnologías de la información y las comunicaciones en el ámbito administrativo: ¿el viaje hacia un nuevo modelo de Administración, electrónica?, in Revista Catalana de Drét Públic, n. 35, Barcelona, Escola de Administració Pública de Catalunya, nov. 2007, p. 209). Esses outros problemas são mais organizacionais e políticos do que técnicos (cf. HolmES, Douglas, op. cit., p. 10). 
Na verdade, não cabe avaliar a utilização de meios informáticos e telemáticos de forma simplista: não pode ser vista como a solução de todos os problemas da Administração Pública ${ }^{76}$, porém tampouco deve ser objeto de um cinismo fácil ${ }^{77}$. De acordo com uma postura equilibrada, deve-se ver as novas tecnologias não como um fim a ser perseguido, mas como um meio, ou seja, na condição de ferramentas indispensáveis para organizações que, como a Administração Pública, lidam com grandes volumes de informações para o atingimento de seus fins institucionais ${ }^{78}$. Todavia, a chegada das novas tecnologias não resolve por si problemas como a falta de legitimação dos governos ou o excesso de necessidades dos cidadãos a serem atendidas pelo sistema administrativo ${ }^{79}$. Além disso, é preciso ter em mente que a simples introdução material de equipamentos e sistemas não traz, isoladamente, benefícios consideráveis ${ }^{80}$. É evidente que a disponibilidade dos meios de qualidade é essencial para o governo eletrônico; entretanto, a realização efetiva de suas potencialidades só pode ocorrer se estiver acompanhada de mudanças de outras nature$\operatorname{zas}^{81}$, sendo indesejável a simples adaptação das velhas metodologias às novas tecnologias $^{82}$ e a mera reprodução de antigos processos burocráticos ${ }^{83}$, pois a informática, por si só,

\footnotetext{
${ }^{76}$ Cf. Gross, Thomas, E-Government: Influences on Procedure and Organisation of Public Administration, in Flogaitis, S., KarPen, U., Masucci, A. (eds.), E-Government and E-Democracy, London, Esperia, 2006, p. 79 e QuADros, Jaqueline Maria, Governo eletrônico e direito administrativo, in ROVER, Aires José, Direito e Informática, Barueri, Manole, 2004, p. 243. Colocar o Estado em rede "não pode constituir por si a panaceia pela qual o Estado pós-moderno poderá renovar seu próprio modelo, suas abordagens, seu discurso e sua racionalidade jurídica" (BENYEKHLEF, Karim, L'administration publique en ligne au Canada: précisions terminologiques et état de la réflexion, in Revue française d'administration publique, n. 110, Paris, ENA, 2004, p. 277, tradução livre).

${ }_{78}^{77}$ Cf. HoLMeS, Douglas, op. cit., p. 2.

${ }^{78}$ Cf. Alli Aranguren, Juan-Cruz, op. cit., p. 42; Davara RodríGuez, Miguel Ángel, op. cit., p. 479; FILGUEIRAS JÚNIOR, Marcus Vinícius, L'atto amministrativo elettronico in Brasile, in Quaderni del DAE Rivista di Diritto Amministrativo Elettronico, jul. 2004, disponível em http://www.cesda.it/quadernidae/index.php, acesso em 15.12.2010, p. 1.

${ }^{79}$ Cf. VILLORIA MENDIETA, Manuel, La modernización de la administración como instrumento al servicio de la democracia, Madrid, INAP, 1996, p. 303. Segundo o autor, "A tecnologia é um meio, não um fim em si mesmo, um meio, mais ainda, perigoso caso utilizado de forma inadequada, ainda quando se faça com boas intenções" (ibidem, p. 303, tradução livre). Para CHATILLON, haveria praticamente uma confusão entre serviço público e máquina (cf. Administration électronique et services publics, in Actualité juridique - Droit administratif, n. 20, jul.-ago 2001, p. 618). A afirmação não parece sustentar-se, uma vez que a Administração não se esgota nos meios que usa. Se, por mais que se pretendesse fazer referência aos excessos burocráticos, o serviço nunca pôde confudir-se com o papel, tampouco pode confundir-se com as ferramentas informáticas e telemáticas.

${ }^{80}$ Cf. ARENA, Gregorio, E-government y nuevos modelos de administración, in Revista de Administración Pública, n. 163, Madrid, Centro de Estudios Políticos y Constitucionales, jan.-abr. 2004, p. 413 e BomBARDELLI, Marco, op. cit., p. 994.

${ }^{81}$ Cf. Chatillon, Georges, Préface, in Chatillon, Georges, MARais, Bertrand du (org.), L'administration électronique au service des citoyens, Bruxelles, Bruylant, 2003, p. 9.

${ }^{82}$ Cf. MARONE, Umberto, op. cit., p. 12.

${ }^{83}$ Cf. BOMBARDELLI, Marco, op. cit., p. 995.
} 
não constitui garantia de melhoria alguma ${ }^{84}$. De fato, um dos maiores erros que podem ser cometidos na utilização das novas tecnologias é fazê-lo sobre estruturas e práticas existentes, desenvolvidas segundo a lógica da forma de atuação tradicional ${ }^{85}$, o que importaria em gerar uma versão eletrônica dos antigos problemas ${ }^{86}$, desperdiçando o potencial para mu$\operatorname{dança}^{87}$.

Deve-se ressalvar, também, que a introdução das novas tecnologias no setor público não pode ser feita da mesma forma pela qual ocorre no setor privado, dadas as notáveis diferenças entre ambos ${ }^{88}$. Em regra, a Administração Pública é mais lenta que a organização privada $^{89}$, sendo essa defasagem ainda mais pronunciada no caso da revolução tecnológica, pois a Administração tem menor liberdade para correr riscos - não podendo, por exemplo, admitir a mesma possibilidade de fracasso geralmente aceita pelas empresas que atuam na internet ${ }^{90}$. Além disso, o governo tem dificuldade para estabelecer mecanismos de premiação para o êxito de complexos projetos de informatização, estratégia normalmente usada nas empresas ${ }^{91}$. Por fim, a Administração Pública atua de modo intensamente normatizado, de forma que a utilização de meios informáticos e telemáticos, sem maiores cuidados, pode levar a atos inválidos, afastando muitos dos benefícios inicialmente buscados.

\footnotetext{
${ }^{84}$ Cf. STAIR, Ralph M., REYNOLDS, George W., op. cit., pp. 13-14.

${ }^{85}$ Cf. CULbERTSON, Stuart, Building E-government: Organisational and Cultural Change in Public Administration, in OLIVER, E. Lynn, SANDERS, Larry (ed.), E-Government Reconsidered: Renewal of Governance for the Knowledge Age, Regina, Canadian Plains Research Center, 2004, p. 59.

${ }^{86} \mathrm{Cf}$. VALERO TORRIJOS, Julián, La nueva regulación legal del uso de las tecnologías de la información y las comunicaciones en el ámbito administrativo, cit., p. 209.

${ }^{87}$ Cf. Laudon, Kenneth C., Laudon, Jane P., op. cit., p. 26.

${ }^{88}$ Cf. Holmes, Douglas, op. cit., p. 5.

${ }^{89}$ Cf. IASELLI, Michele, La pubblica amministrazione digitale, Napoli, Simone, 2009, p. 5.

${ }^{90}$ Cf. Holmes, Douglas, op. cit., p. 5. Há quem defenda, em função disso, a construção de uma cultura que adote a inovação e tolera o risco dentro da accountability pública (cf. CULBERTSON, Stuart, op. cit., p. 69). No entanto, essa perspectiva privilegiaria a eficiênca em detrimento da segurança jurídica. A A observância conjunta desses dois princípios é essencial para o governo eletrônico e será analisada no capítulo 2.

${ }^{91}$ Como já foi observado: "Enquanto ganhos dramáticos de eficiência e diminuição de custos são recompensados, na economia, mediante lucros, promoções, aumento do valor do estoque e participação no mercado, ganhos similares no governo são recompensados com cortes de orçamento, diminuição de equipes, diminuição de recursos e fusão de programas" (FounTAIN, Jane E., op. cit., p. 13).
} 
O êxito da utilização de meios informáticos e telemáticos na Administração Pública depende, antes de tudo, de mudanças culturais ${ }^{92}$. As maiores resistências ao uso das novas tecnologias são dessa natureza ${ }^{93}$, tendo origem em inércias e vícios próprios dos excessos burocráticos ${ }^{94}$, bem como em uma diferença significativa entre a cultura administrativa tradicional e a cultura informática ${ }^{95}$ - ou e entre a cultura do papel e a cultura da internet ${ }^{96}-$, que se manifesta principalmente no comportamento dos servidores e se projeta no próprio relacionamento entre a Administração e o usuário ${ }^{97}$. O êxito do governo eletrônico demanda novos valores e atitudes ${ }^{98}$, para considerar as alternativas oferecidas ou exigidas pelas novas tecnologias, especialmente em relação à abertura, ao compartilhamento, à cooperação e à transparência ${ }^{99}$, repensando a lógica das relações entre os organismos públicos e entre estes e os particulares ${ }^{100}$. Isso envolve não somente um processo natural de mudança de hábitos, mas exige um esforço ativo de treinamento e capacitação dos servidores públicos para o manejo de equipamentos e sistemas ${ }^{101}$. Trata-se certamente de uma transformação de grande complexidade, relacionada a formas e métodos de atuação crista-

\footnotetext{
92 De forma geral, a cultura organizacional é capaz de influenciar de forma significativa o desenvolvimento e a operação dos sistemas de informação de qualquer organização (cf STAIR, Ralph M., REYNOLDS, George W., op. cit., p. 45).

${ }^{93}$ Cf. Holmes, Douglas, op. cit., p. 70.

${ }^{94}$ Cf. VALERO TORRIJOS, Julián, Las garantías jurídicas en la Administración electrónica ¿avance o retroceso?, in Cuenta con IGAE, Madrid, IGAE, n. 22, 2009, p. 19.

95 Cf. Bombardelli, Marco, op. cit., p. 995. De forma mais específica, pode-se falar em cultura computacional e cultura dos sistemas de informação. A primeira corresponderia ao "conhecimento dos sistemas e equipamentos computacionais e de como eles funcionam", enquanto a outra iria além, incluindo o "conhecimento de como os dados e informações são usados por indivíduos, grupos e organizações”, incluindo, especialmente, o conhecimento sobre como implantar os sistemas (cf. STAIR, Ralph M., REYNOLDS, George W., op. cit., p. 27-28).

${ }^{96}$ Cf. Beloulou, Véronique, Les téléprocédures: un enjeu essentiel pour les citoyens et pour l'Etat, in Actualité Juridique - Droit Administratif, n. 7, 2001, p. 624.

${ }^{97}$ Cf. SÁNCHEZ RODRÍGUEZ, Francisco, op. cit., p. 45.

${ }^{98}$ Cf. BARNÉS VÁZQUEZ, Javier, El procedimiento administrativo y el gobierno electrónico, in Cuadernos de Derecho Local, n. 22, Madrid, Fundación Democracia y Gobierno Local, fev. 2010, p. 84. Afirmando a necessidade de mudança no modo de agir e pensar dos servidores públicos, cf. ZUGMAN, Fábio, op. cit., p. 36.

${ }^{99}$ Cf. PIRAS, Paola, Organizzazione, tecnologie e nuovi diritti, in Informatica e diritto, n. 1/2, Napoli, Edizioni Scientifiche Italiane, 2005, p. 92.

${ }^{100}$ Cf. MASUCCI, Alfonso, Erogazione on line dei servizi pubblici e teleprocedure amministrative, cit., pp. 992-993.

${ }^{101}$ Cf. VAlero ToRriJos, Julián, Administración pública, ciudadanos y nuevas tecnologías, in SoSA WAGNER, Francisco, El derecho administrativo en el umbral del siglo XXI - Homenaje al Profesor Dr. D. Ramón Martín Mateo, Valencia, Tirant lo Blanch, 2000, p. 2949 e FrosinI, Vittorio, Informática y Administración Pública, cit., p. 453.
} 
lizados, que não pode ocorrer de maneira brusca e imediata ${ }^{102}$, porém é essencial para a realização efetiva das potencialidades do governo eletrônico.

Dentro do desafio de mudança cultural está a necessidade de superar as visões fragmentadas da atuação administrativa, em que as várias atividades especializadas são desempenhadas em paralelo. Mais que uma consequência do progresso tecnológico, o governo eletrônico deve ser produto de um trabalho interdisciplinar, que possibilite o diálogo entre os conhecimentos das áreas de direito, ciência da administração e tecnologia da informação ${ }^{103}$. Assim, os projetos de informatização, além de considerar os aspectos relativos aos sistemas computadorizados, devem estar baseados em um conhecimento consistente das normas, estruturas e funcionamento da Administração Pública ${ }^{104}$. Se as relações entre o direito administrativo e ciência da administração já podiam ser consideradas como vínculos de coexistência, de inter-relação e de auxílio científico mútuo ${ }^{105}$, tal relaciona-

\footnotetext{
${ }^{102}$ Cf. Davara RodríGUez, Miguel Ángel, op. cit., p. 488 e Palomar OlmedA, Alberto, La utilización de las nuevas tecnologías en la actuación administrativa, in Revista Española de Derecho Administrativo, n. 87, Madrid, Civitas, jul.-set. 1995, p. 365.

${ }^{103}$ Cf. MARTín DELGADO, Isaac, La administración electrónica como reto del derecho administrativo en el siglo XXI, cit., p. 315. Embora seja corrente o uso da expressão tecnologia da informação para fazer referência aos mecanismos tecnológicos em si, este estudo, apenas para tentar obter alguma padronização terminológica, reserva tal expressão para designar a área do conhecimento voltada ao estudo da informática e da telemática, utilizado estes últimos vocábulos para fazer referência às operações de processamento e transmissão da informação.

${ }^{104}$ Cf. CARIDI, Gianfranco, Informatica giuridica e procedimenti amministrativi, Milano, Franco Angeli, 1983 , p. 27.

${ }^{105}$ Cf. Medauar, Odete, O direito administrativo em evolução, 2. a ed., São Paulo, RT, 1992, p. 180.
} 
mento passa a incluir também o diálogo com a informática ${ }^{106}$. Somente uma estreita e continuada colaboração entre juristas, administradores e técnicos informáticos pode trazer avaliações realistas, soluções eficazes ${ }^{107}$ e resultados verdadeiramente úteis ${ }^{108}$, fazendo uso pleno das possibilidades oferecidas pela tecnologia ${ }^{109}$. Integrar as diversas áreas do conhecimento parece ser um dos principais desafios para a introdução das tecnologias da informação e da comunicação no âmbito da Administração Pública ${ }^{110}$.

${ }^{106}$ Sobre tal interdisciplinaridade, cf. HOESCHL, Hugo César, $O$ que é governo eletrônico?, in KAMINSKI, Omar (org.), Internet legal: O direito na tecnologia da informação, Curitiba, Juruá, 2003, p. 199. Segundo BARNÉS VÁZQUEZ, a tecnologia permite opções diferentes, porém a decisão sobre o modelo a ser adotado não cabe ao técnico. Assim, o diálogo entre o técnico e o jurista nunca foi tão necessário (El procedimiento administrativo y el gobierno electrónico, cit., p. 85). Na verdade, todas as áreas oferecem diversas opções: assim como há alternativas tecnológicas, costuma haver alternativas jurídicas e funcionais. Cada perspectiva pode trazer limites, como é o caso das ferramentas informáticas dispendiosas em excesso, das soluções tecnicamente inviáveis ou das propostas contrastantes com o sistema jurídico; mas a adequada tomada de decisões, dentro das margens permitidas pela área do conhecimento, deve ser objeto de um diálogo que possa revelar, dentre as diversas combinações viáveis, qual delas oferece a melhor solução, com possibilidade de trazer melhores resultados. Vale mencionar, pois, a precisa descrição a seguir, que poderia alcançar também a ciência da administração: "A relação entre técnica e direito é simbiótica e tem uma dúplice conotação: de um lado este último é constrangido a seguir o desenvolvimento científico, oferecendo uma disciplina que seja útil à tutela dos bens ameaçados pelo progresso ou à regulamentação das novas situações que o progresso cria; de outro lado, porém, é a técnica que se põe em posição de serva do direito, oferecendo uma série de meios idôneos para a satisfação de exigências que desde sempre caracterizam o mundo jurídico e que encontram, com a solução dos sistemas informáticos, nova forma de serem satisfeitas" (OROFINO, Angelo Giuseppe, Forme elettroniche e procedimenti amministrativi, Bari, Cacucci, 2008, p. 9, tradução livre). De forma semelhante, MARTín DELGADo indica dois desafios para a utilização das novas tecnologias na Administração Pública: um desafio tecnológico, que seria criar programas e sistemas adequados às exigências do direito administrativo, e um desafio jurídico, que seria estabelecer essas exigências, por meio de inovações ou adaptações, determinando o regime jurídico da aplicação dessas novas tecnologias (cf. La administración electrónica como problema actual para la investigación y la docencia en el derecho administrativo, in Revista Aragonesa de Administración Pública, Monográfico XI, Zaragoza, Instituto Aragonés de Administración Pública, 2009, p. 358). No âmbito das relações entre a tecnologia da informação e a ciência da administração, segundo uma perspectiva dirigida às organizações privadas, é clara a percepção sobre a crescente interdependência entre estratégia empresarial, regras e processos, de um lado, e programas, equipamentos, bancos de dados e telecomunicações, de outro. Fala-se, pois, em capacitação em sistemas de informação, como uma compreensão mais ampla de sistemas de informação, que abrange um entendimento das dimensões organizacionais e administrativas dos sistemas, bem como de suas dimensões técnicas (cf. LAUDON, Kenneth C., LAUDON, Jane P., op. cit., pp. 9 e 15). A visão aqui proposta depende de uma integração mais abrangente, em que as regras aplicáveis à atuação administrativa referidas têm caráter jurídico, trazendo a necessidade de diálogo com a ciência do direito.

${ }^{107}$ Cf. VALERO TORRIJOS, Julián, Administración pública, ciudadanos y nuevas tecnologías, cit., p. 2945.

108 Cf. DunI, Giovanni, Verso un'amministrazione integrata dei procedimenti amministrativi, in Informatica e diritto, n. 1/2, Napoli, Edizioni Scientifiche Italiane, 2005, p. 44.

${ }^{109}$ Cf. MARONE, Umberto, op. cit., p. 14.

${ }^{110}$ Cf. De Roy, David, De Terwangne, Cécile, Poullet, Yves, La Convention européenne des droits de l'homme en filigrane de l'administration électronique, in Entre ombres et lumières: cinquante ans d'application de la Convention Européenne des Droits de l'Homme en Belgique, Bruyllant, Bruxelles, 2008, p. 357. 
Tais mudanças culturais devem estar associadas, também, a transformações estruturais. Não se trata, por certo, de procurar um modelo de organização administrativa universal, pois cada Administração deve encontrar a estrutura adequada que atenda às exigências específicas de sua realidade ${ }^{111}$. Mesmo assim, é possível encontrar alguns aspectos naturalmente presentes nessas novas estruturas, como é o caso da necessidade de um esforço de racionalização da atividade e da gestão administrativa ${ }^{112}$, a fim de compatibilizá-la com os requisitos próprios dos sistemas informatizados, dotados de uma estrutura lógica definida com antecedência, que oferece menos espaço para a improvisação.

Além dessa necessidade de racionalização, até mesmo óbvia, deve-se notar que a utilização de meios informáticos e telemáticos envolve uma espécie de mudança de paradigma, consistente na passagem de uma Administração fortemente verticalizada, ou setorial, para uma Administração de funcionamento mais horizontal, ou transversal ${ }^{113}$. $\mathrm{Na}$ administração tradicional, predomina uma organização piramidal ${ }^{114}$, própria da era industrial $^{115}$ e por vezes semelhante ao modelo hierárquico-militar ${ }^{116}$, com procedimentos estruturados como séries de atos praticados por órgãos estanques ${ }^{117}$, pouco incentivo para a cooperação $^{118}$ e sem compartilhamento de informações ${ }^{119}$, o que leva a uma fragmentação da atuação administrativa, vista atualmente como antítese da eficácia administrativa ${ }^{120}$. Já o governo eletrônico exige uma organização em rede, com intensa troca de informações e

\footnotetext{
${ }^{111}$ Cf. Bombardelli, Marco, op. cit., p. 1028 e Brousseau, Eric, Les trois défis de l'administration électronique, in CHATILLON, Georges, MARAIS, Bertrand du (org.), L'administration électronique au service des citoyens, Bruxelles, Bruylant, 2003, p. 251.

${ }_{112}$ Cf. SÁnChEZ RodríGUEZ, Francisco, op. cit., p. 34 e IASELli, Michele, op. cit., p. 5.

${ }^{113}$ Cf. GRISTI, Éric, op. cit., p. 509 e RABBITO, Chiara, Il percorso di attuazione dell'e-government nella pubblica amministrazione italiana, in PALMIRANI, Monica, MARTONI, Michele, Il cittadino elettronico e l'identità digitale nell'e-governance, Bologna, Gedit, 2006, p. 22.

${ }^{114}$ Cf. BOMBARDELLI, Marco, op. cit., p. 995.

${ }^{115}$ Cf. Holmes, Douglas, op. cit., p. 58.

${ }^{116}$ Cf. CARIDI, Gianfranco, op. cit., p. 33.

${ }^{117} \mathrm{O}$ isolamento ocorre tanto em relação a outros órgãos e entidades públicas, como no relacionamento com os cidadãos e o setor privado, em relação aos quais a Administração é tradicionalmente pouco aberta (cf. BAQUIAST, Jean-Paul, Internet et les administrations, cit., p. 46), sendo marcada pelo segredo e pelo distanciamento em relação aos cidadãos (cf. CERRILlo I MARTíNEZ, Agustí, La información del sector público, cit., p. 6).

${ }_{118}$ A falta de incentivo para a cooperação é provocada pela própria estrutura verticalizada segundo a qual a Administração está estruturada do ponto de vista legal, do orçamento e da orientação política (cf. CULBERTSON, Stuart, op. cit., p. 61).

${ }_{119}$ Cf. BOMBARDELLI, Marco, op. cit., p. 995.

${ }^{120}$ Cf. De Terwangne, Cécile, Lobet-MARIs, Claire, Poullet, Yves, L'e-gouvernement: aux armes, citoyens?, in Revue Louvain, n. 166, dez. 2006 - jan. 2007, p. 23 e HoLMES, Douglas, op. cit., p. 3.
} 
integração entre sistemas ${ }^{121}$, que possibilita a cooperação entre diversos órgãos administrativos $^{122}$, estruturados para atender as necessidades reais dos cidadãos e do setor privado ${ }^{123}$, os quais passam a estar integrados às atividades administrativas, na condição de colaboradores $^{124}$.

Exigindo grandes mudanças culturais e estruturais para seu êxito ${ }^{125}$, o governo eletrônico aproxima-se, de certa maneira, da temática da reforma da Administra-

${ }^{121}$ Cf. BOMBARDELLI, Marco, op. cit., p. 995.

${ }_{122}$ Cf. Culbertson, Stuart, op. cit., p. 67 e Holmes, Douglas, op. cit., p. 3.

${ }^{123}$ A Administração não deve estar presa às estruturas herdadas do passado, de forma fixa e imodificável, devendo centrar-se nas necessidades dos cidadãos, a serem consideradas em função das prioridades do momento. Cabe à Administração reconhecer sua própria complexidade, ao invés de exigir que os usuários a suportem (cf. CARCENAC, Thierry, Pour une administration électronique citoyenne: contributions au débat, Paris, La Documentation française, 2001, disponível em: http://lesrapports.ladocumentationfrancaise.fr/cgibin/brp/telestats.cgi?brp ref=014000291\&brp file $=0000$.pdf, acesso em 31.12.2010, pp. 24-25). Vale ressaltar que os problemas sociais são complexos e transversais, de forma que as necessidades das pessoas não cabem exatamente nos compartimentos departamentais (cf. HOLMES, Douglas, op. cit., p. 58).

${ }^{124}$ Ao contrário do que ocorre no modelo burocrático, em que os recursos da sociedade são ignorados, "[a] administração em rede descreve um modelo de administração pública próprio das sociedades pluralistas, complexas e interdependentes, que se baseia na colaboração entre administração e cidadãos, e não somente na reivindicação: supõe a passagem de um conceito de administração do tipo hierárquico a um de administração em forma de rede" (CERRILLO I MARTíNEZ, Agustí, E-información: hacia una nueva regulación del acceso a la información, in IDP - Revista de Internet, Derecho y Política, n. 1, 2005, disponível em http://www.ouc.edu/idp/1/dt/esp/cerrillo.pdf, acesso em 27.08.10, p. 6, tradução livre). Permitindo um amplo compartilhamento de informações entre sujeitos públicos e privados, as novas tecnologias tornam possível superar os modelos organizativos fundados na separação entre o público e o privado e na setorialização dos fluxos informativos (cf. ARENA, Gregorio, op. cit., pp. 413 e 428 e DELgado GarCía, Ana María, Oliver CuEllo, Rafael, La actuación administrativa automatizada. Algunas experiencias en el ámbito tributario, in Revista Catalana de Drét Públic, n. 35, Barcelona, Escola de Administració Pública de Catalunya, nov. 2007, p. 2, disponível em http://www10.gencat.net/eapc revistadret/recursos interes/Notes/NOTA 35 DelgadoOliver.pdf, acesso em 12.10.2010). Verifica-se, assim, uma transformação radical das relações dos usuários com a Administração (cf. Chatillon, Georges, Préface, cit., p. 9).

${ }^{125}$ Cf. Chissick, Michael, Harrington, Justin, E-Government: a Practical Guide to the Legal Issues, London, Sweet \& Maxwell, 2004, p. 11. 
ção ${ }^{126}$, ainda que com ela não se confunda ${ }^{127}$. A tecnologia em si não é um fator capaz de superar práticas tradicionais fortemente arraigadas; isso só pode ocorrer por meio de uma decisão do mais alto nível diretivo e político ${ }^{128}$ que impulsione o uso das novas tecnologias $^{129}$, combinada com uma postura generalizada, no âmbito interno e externo, em favor das vantagens dessa utilização e de todo o esforço que isso exige ${ }^{130}$. O governo eletrônico não pode surgir de modo espontâneo, tendo em vista a necessidade de pesados investimentos que só podem ocorrer com respaldo político, mas tampouco pode sustentar-se como algo

\footnotetext{
${ }^{126}$ Frequentemente há uma relação estreita entre a introdução das novas tecnologias na Administração Pública e estratégias de reforma administrativa, principalmente no contexto do chamado new public management (cf. GROSS, Thomas, op. cit., p. 66). Não é o propósito deste estudo, entretanto, adotar uma visão que faça aproximar ambas as perspectivas, especialmente porque a utilização meios informáticos e telemáticos pelo Poder Público não parece estar vinculada, de forma exclusiva, a uma determinada corrente de pensamento adotada por estudiosos da ciência da administração, por mais contemporâneos que sejam um tema e outro (nesse sentido, MARTínez DíEZ, Roberto, El proceso de informatización de la Administración Pública Española, in Documentación Administrativa, n. 200, Madrid, Escuela Nacional de Administración Pública, jan.-mar. 1984, pp. 133-134). Fazendo referência à reforma administrativa decorrente da implantação de técnicas de informação e de comunicação, cf. MEDAUAR, Odete, $O$ direito administrativo em evolução, cit., p. 134. Aproximando a administração eletrônica do new public management, cf. SANZ LARRUGA, Francisco Javier, Las bases jurídicas de la 'administración electrónica' en España: el uso de las técnicas informáticas, electrónicas y telemáticas en las Administraciones públicas, in Anuario da Facultade de Dereito da Universidade da Coruña, A Coruña, Universidade da Coruña, n. 6, 2002, p. 715 e Cotino HuEso, Lorenzo, Derechos del ciudadano, in GAMERO CASADO, Eduardo, VALERO TORRIJOS, Julián (coord.), Comentarios a la Ley de Administración electrónica - Ley 11/2007, de 22 de junio, de acceso electrónico de los ciudadanos a los servicios públicos, 1.a ed., 2. ${ }^{a}$ imp., Cizur Menor (Navarra), Thomson-Civitas, 2009, p. 124. Mencionando a necessidade de reestruturação da Administração no âmbito do governo eletrônico, cf. BAL, Aminata, Quelques réflexions sur l'administration électronique, in Lex Electronica, vol. 10, n. 1, 2005, disponível em http://www.lex-electronica.org/articles/v10-1/bal.htm, acesso em 19.10.2010, p. 2; CARCENAC, Thierry, op. cit., pp. 24-25; Chahin, Ali et al., op. cit., p. 64; Chatillon, Georges, Préface, cit., p. 9; Fernandes, Ciro Campos Christo, Governo eletrônico e transformação da administração pública, in CHAHIN, Ali et al., op. cit., pp. 102-107; FounTAIN, Jane E., op. cit., p. 6.

${ }^{127}$ A reforma do Estado é algo muito mais vasto, pesado, longo e custoso, em que as questões técnicas se misturam às questões administrativas e questões eminentemente políticas (cf. BROUSSEAU, Eric, op. cit., p. 251). Na verdade, a reforma administrativa não pressupõe necessariamente a informatização, porém é possível que ela encontre, a posteriori, um meio natural de implementação (cf. MARONGIU, Daniele, Il governo dell'informatica pubblica, cit., pp. 20-21).

${ }^{128}$ Cf. VAlero TorRiJos, Julián, La nueva regulación legal del uso de las tecnologías de la información y las comunicaciones en el ámbito administrativo, cit., p. 211.

${ }_{129}$ Cf. CERrillo I MARTínez, Agustí, E-información, cit., p. 8. A vontade política constitui um primeiro passo, sem o qual não é possível dar o segundo, que consistiria na elaboração de um quadro legal apropriado (cf. PRINS, J.E.J. (ed.) et al., E-Government and its Implications for Administrative Law: Regulatory Initiatives in France, Germany, Norway and the United States, The Hague, TMC Asser, 2002, p. 104).

${ }^{130}$ Cf. BOMBARDELLI, Marco, op. cit., p. 998.
} 
imposto, que não decorra de um desejo compartilhado com servidores públicos e usuá$\operatorname{rios}^{131}$.

Embora desafiadoras, essas exigências tendem a ser atendidas. No setor privado, o estímulo à inovação tecnológica é a necessidade de expansão e sobrevivência das organizações ${ }^{132}$. No setor público, o impulso tem sido político, ocorrendo por meio da crescente pressão dos usuários, que exigem mais e melhores serviços por parte da Administração ${ }^{133}$, de forma a acompanhar o incremento de qualidade verificado em grande parte do setor privado ${ }^{134}$. De fato, na sociedade da informação, cidadãos e empresas estão habituados ao uso cotidiano das tecnologias no desempenho de muitas atividades. Isso provoca uma necessidade de que a Administração adapte às novas tecnologias suas formas habituais de atuação, de maneira que os cidadãos não tenham de alterar suas fórmulas habituais de comunicação e interação quando a outra parte da relação é um ente público ${ }^{135}$. Os servidores públicos também tendem a ser mais receptivos com as iniciativas de modernização,

\footnotetext{
${ }^{131}$ Dependendo apenas de uma liderança pessoal e episódica, sem respaldo na sociedade e no corpo de servidores, a implantação das novas tecnologias acaba por não se sustentar no tempo. Conforme a doutrina já observou, "[à]s vezes é surpreendente que organizações que realizam notáveis esforços na simplificação administrativa e documental percam toda sua virtualidade quando os impulsores dessas campanhas desaparecem e de maneira inexplicável em poucos meses se volta à situação prévia à simplificação sem que praticamente ninguém se desse conta de como se produz esse passo para trás" (PALOMAR OLMEDA, Alberto, Gestión Electrónica de los procedimientos, in GAMERO CASADO, Eduardo, VALERO TORRIJOS, Julián (coord.), Comentarios a la Ley de Administración electrónica - Ley 11/2007, de 22 de junio, de acceso electrónico de los ciudadanos a los servicios públicos, 1. ${ }^{a}$ ed., 2. ${ }^{\mathrm{a}}$ imp., Cizur Menor (Navarra), Thomson-Civitas, 2009, p. 417).

${ }^{132}$ Cf. LaUdon, Kenneth C., LaUdon, Jane P., op. cit., p. 4.

${ }^{133}$ Cf. Curtin, Gregory G., SOMmER, Michael H., VIS-SOMmER, Veronika, The world of e-government, New York, Haworth Press, 2003, p. 5 e RoNDEAU, Jean-Claude, op. cit., p. 11.

${ }^{134}$ Percebendo o poder da internet e experimentando o bom serviço no setor privado, as pessoas se tornarão menos tolerantes com o pobre e impessoal serviço do setor público (cf. HolmEs, Douglas, op. cit., p. 3). As pressões dos usuários podem ocorrer sobre o Executivo, para que passe a usar de forma intensa as novas tecnologias, ou mesmo sobre o Legislativo, para que isso seja determinado por lei.

${ }^{135}$ Cf. MARTínez GutiérRez, Rubén, Nuevos derechos y nuevos retos del modelo de Administración electrónica, in Actualidad Jurídica Aranzadi, Navarra, Aranzadi, n. 786, 19.11.2009, p. 2. PALOMAR OLMEDA afirma de forma expressiva: "A Administração de nossos dias não pode manter-se em um processo prestador de serviços que, por sua inadequação com os tempos e, portanto, por sua desconexão com o âmbito social em que se insere, obrigue os cidadãos a relacionar-se com ela de forma diferente de como o fazem com o resto dos operadores sociais" (Un paso más en la aplicación de la tecnología en el procedimiento administrativo: hacia un procedimiento administrativo común de base tecnológica, in Revista Aranzadi de Derecho y Nuevas Tecnologías, n. 3, Cizur Menor (Navarra), Aranzadi, set.-dez. 2003, p. 91).
} 
especialmente porque sentem as insatisfações do público e percebem o quanto a utilização de meios anacrônicos pode pôr em risco sua própria dignidade profissional ${ }^{136}$.

O setor público não pode ficar preso ao passado, indiferente à revolução tecnológica ${ }^{137}$ : para continuar a cumprir seu papel, a serviço de todos os cidadãos, o Estado deve reconhecer esse novo contexto econômico, tecnológico e cultural, muitas vezes incompatível com os meios tradicionais ${ }^{138}$. Os governos que se mantiverem presos às antigas formas de atuação serão levados ao distanciamento, à deslegitimação e à marginalização frente à sociedade ${ }^{139}$, expondo-se ao ridículo e a acusações de incompetência e corrupção ${ }^{140}$. O processo de adaptação às mudanças produzidas pelo desenvolvimento tecnológico no campo da informação e da comunicação constitui um dever das Administrações Públicas no novo contexto da sociedade da informação do século XXI ${ }^{141}$.

\footnotetext{
${ }^{136}$ Cf. HOLMES, Douglas, op. cit., p. 58.

${ }^{137}$ Cf. GuILlÉN CARAMÉS, Javier, op. cit., p. 247 e LenK, Klaus, TRAUnMÜLler, Roland, Broadening the Concept of Electronic Government, in PRINS, J.E.J. (ed.), Designing e-Government: On the Crossroads of Technological Innovation and Institutional Change, The Hague, Kluwer Law International, 2001, p. 72. São as palavras de PÉREZ LUÑO: "A informática, ao possibilitar a racionalização, simplificação, celeridade e segurança das práticas administrativas, apresenta-se como uma exigência inadiável para qualquer Estado que não deseje viver de costas para o progresso" (Manual de informática y derecho, $1^{\mathrm{a}}$ ed., Barcelona, Ariel, 1996, p. 84, tradução livre).

${ }^{138}$ Cf. La Coste, Pierre de, BenARD, Vincent, L'Hyper-République: bâtir l'administration en réseau autour du citoyen, Paris, Ministère de la fonction publique, de la réforme de l'Etat et de l'aménagement du territoire, 2003, disponível em: http://lesrapports.ladocumentationfrancaise.fr/cgi-

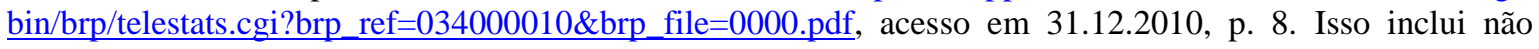
somente a informatização e a conexão em rede, mas a adoção de métodos de gestão e de medição de resultados desenvolvidos no setor privado (cf. BENYEKHLEF, Karim, op. cit., p. 267).

${ }^{139}$ Cf. PALOMAR OlMEDA, Alberto, La utilización de las nuevas tecnologías en la actuación administrativa, cit., pp. 362-363.

${ }^{140}$ Cf. Holmes, Douglas, op. cit., p. 11.

${ }^{141}$ Cf. TinTó GIMBERnAT, Montserrat, Administración electrónica y ciberprocedimiento, Barcelona, Observatorio de la Evolución de las Instituciones, Universitat Pompeu Fabra, 2006, p. 9. Segundo BARNÉS VÁzQUEZ, a Administração não pode atuar, no plano executivo, com estruturas pesadas e hierárquicas: "Deve ser uma Administração da informação e do conhecimento, cooperativa, que faça a ponte entre a política e outras organizações autônomas da sociedade moderna" (Una reflexión introductoria sobre el Derecho Administrativo y la Administración Pública de la Sociedad de la Información y del Conocimiento, cit., p. 38, tradução livre).
} 


\subsection{A evolução da informática na Administração Pública}

Em vista da generalizada convicção a respeito das possibilidades oferecidas pelas tecnologias da informação e comunicação ${ }^{142}$, bem como da demanda social por modernização das estruturas e atividades administrativas ${ }^{143}$, a utilização de meios eletrônicos no setor público já é uma realidade plena em muitos países ${ }^{144}$. Considerando as redes telemáticas como elemento-chave para seu futuro e eixo estrutural de sua modernização, a grande maioria das administrações do planeta, de todos os níveis, iniciou nos últimos anos grandes projetos de governo eletrônico, com consideráveis investimentos e grandes expectativas de êxito, muitas vezes associadas a um impacto midiático e propagandístico ${ }^{145}$. Fala-se, pois, dos primeiros anos deste século, como aqueles da administração eletrônica ${ }^{146}$.

Não se trata, por certo, de um processo simples e instantâneo, nem que esteja restrito ao século atual. $\mathrm{O}$ uso da informática na atividade administrativa vem ocorrendo há algumas décadas ${ }^{147}$. Na verdade, desde os fins dos anos 1950 , com o início da utilização de computadores, já era possível começar a falar em informatização da Administração Pública $^{148}$. Na década de 1960, eles passaram a ser bastante usados em setores caracterizados por um elevado nível de padronização, tais como gestão da contabilidade, gestão do pessoal e manutenção de arquivos, registros e estatísticas ${ }^{149}$. Buscava-se substituir o

\footnotetext{
${ }^{142}$ Cf. FABra VAlls, Modesto, Blasco Díaz, José Luis, Introducción, cit., p. 13.

${ }^{143}$ Cf. VALERO TORRIJOS, Julián, El régimen jurídico de la e-Administración, cit., p. XXI.

${ }^{144}$ Cf. Fernández SAlmerón, Manuel, VAlero TorriJos, Julián, Protección de datos personales y Administración electrónica, in Revista Española de Protección de Datos, n. 1, Madrid, Agencia de Protección de Datos de la Comunidad de Madrid - Civitas, jul.-dez./2006, p. 117.

${ }^{145}$ Cf. AIBAR PUENTES, Eduard, op. cit., pp. 22-23.

${ }^{146}$ Cf. CHATILlON, Georges, Administration électronique et services publics, cit., p. 617.

${ }^{147}$ Cf. VAlero Torrijos, Julián, LóPEZ PelliCER, José Antonio, Algunas consideraciones sobre el derecho a la protección de los datos personales en la actividad administrativa, in Revista Vasca de Administración Pública, Oñati, Instituto Vasco de Administración Pública, n. 59, jan.- abr. 2001, p. 263.

${ }^{148}$ Cf. PONTI, Benedetto, L'informatica nelle pubbliche amministrazioni, in MERLONI, Francesco, Introduzione all'e-government, Torino, G. Giappichelli, 2005, p. 59.

${ }^{149}$ Cf. Gómez PuENTE, Marcos, op. cit., p. 138 e PONTI, Benedetto, op. cit., p. 60. É interessante mencionar que a palavra holerite, de uso frequente entre os servidores públicos brasileiros como sinônimo de contracheque, tem origem em hollerith, a máquina de cartões perfurados usada no processamento dos vencimentos. $\mathrm{O}$ equipamento recebeu essa denominação por ter diso inventado por Herman Hollerith, empresário estadunidense e um dos fundadores da IBM, uma das principais companhias do ramo da tecnologia da informação.
} 
trabalho humano, automatizando tarefas repetitivas, com os fins de simplificação e redução de custos ${ }^{150}$.

Assim, os sistemas informáticos eram utilizados essencialmente para atos internos de recompilação de dados informativos massificados, para seu processamento e arquivo magnético ${ }^{151}$. É a época dos grandes arquivos ${ }^{152}$ e do início da automatização da Administração Pública ${ }^{153}$, assim chamada por analogia à automatização industrial ${ }^{154}$. No correr dos anos, houve um aprofundamento da utilização da tecnologia, por meio de sistemas cada vez mais flexíveis, adaptados à realidade administrativa existente ${ }^{155}$, e com atividades mais complexas de processamento de dados. O computador passou a substituir, ainda que parcialmente, o elemento humano ${ }^{156}$, ao efetuar diretamente os cálculos e as comparações exigidos por um ato administrativo ${ }^{157}$, o qual assim se tornou passível de ser produzido por via informática ${ }^{158}$.

No entanto, nas primeiras décadas, os sistemas informáticos eram fecha$\operatorname{dos}^{159}$, sem qualquer forma de coordenação institucional ${ }^{160}$. Nesse contexto, pois, era incomum a ideia de usar computadores para comunicação ${ }^{161}$, sendo o documento em papel essencial para realizar a integração entre órgãos administrativos e entre o usuário e a Ad-

\footnotetext{
${ }^{150}$ Cf. PONTI, Benedetto, op. cit., p. 60.

${ }^{151}$ Cf. FROSINI, Vittorio, Informática y Administración Pública, cit., p. 456, BEAUVAIS, François, SCHNÄBELE, Philippe, Réforme de l'Etat et téléprocédures, in Actualité juridique - Droit administratif, v. 57, n. 7-8, 2001, p. 608 e OCHOA MONZÓ, Josep, Hacia la ciberadministración y el ciberprocedimiento?, in SOSA WAGNER, Francisco, El derecho administrativo en el umbral del siglo XXI-Homenaje al Profesor Dr. D. Ramón Martín Mateo, Valencia, Tirant lo Blanch, 2000, p. 159.

${ }^{152}$ Cf. TRuChe Pierre, FAugere, Jean-Paul, FliChY, Patrice, Administration électronique et protection des données personnelles - Livre blanc, Paris, La Documentation française, 2002, disponível em: http://lesrapports.ladocumentationfrancaise.fr/cgi-

bin/brp/telestats.cgi?brp_ref=024000100\&brp_file=0000.pdf, acesso em 30.12.2010, p. 19.

${ }^{153}$ Cf. OCHOA MONZÓ, Josep, MARTínez GuTIÉRREZ, Rubén, La permeabilidad de la actividad administrativa al uso de tecnologías de la información y de la comunicación, cit., p. 116.

${ }^{154}$ Cf. FrosinI, Vittorio, Informática y Administración Pública, cit., p. 449.

${ }^{155}$ Cf. GUILlEN CARAMES, Javier, op. cit., p. 256.

${ }^{156}$ Cf. Trata-se de "passar da fase do computador-arquivo para a fase do computador-funcionário" (cf. MASUCCI, Alfonso, L'atto amministrativo informatico, Napoli, Jovene, 1993, p. 13).

${ }^{157}$ Cf. FrosinI, Vittorio, Informática y Administración Pública, cit., p. 453.

${ }^{158}$ Cf. OCHOA MonZó, Josep, Hacia la ciberadministración y el ciberprocedimiento?, cit., p. 159. Sobre a automatização dos atos administrativos, cf. infra, item 3.4.

${ }^{159}$ Cf. MERLONI, Francesco, Sviluppo dell'e-government e riforma delle amministrazioni, cit., pp. 9-10.

${ }^{160}$ Cf. PONTI, Benedetto, op. cit., p. 60.

${ }^{161}$ Cf. Fountain, Jane E., op. cit., p. 21.
} 
ministração. Acabava por haver sempre uma duplicação: os atos eram formalizados em papel e depois inseridos em um computador, a fim de que pudessem ser matéria-prima para a informação automática, ou o ato era elaborado no computador, mas, para ter validade, devia ser impresso em papel e depois assinado ${ }^{162}$. Com uma comunicação restrita entre os sistemas, a introdução das tecnologias na Administração teve efeito limitado ${ }^{163}$ : em regra, o uso dos computadores era previsto como um instrumento operativo adicional para acelerar tarefas pontuais ${ }^{164}$, ou seja, um simples auxílio aos processos administrativos tradicionais $^{165}$.

Um novo ciclo de mudanças, mais amplo, verificou-se com o desenvolvimento dos sistemas de comunicação, que permitem aos meios eletrônicos substituir o papel não apenas na documentação (momento estático), mas na atividade telemática (momento dinâmico) ${ }^{166}$. Assim, a conexão interna entre computadores possibilitou a criação de redes que permitiram o acesso instantâneo a informações conservadas em arquivos separados por território ${ }^{167}$, levando os meios informáticos a serem usados diretamente para a realização de atividades, e não apenas para seu controle e monitoramento ${ }^{168}$. Posteriormente, em pouco tempo e com maior repercussão, a interatividade com a internet passou a constituir uma peça essencial da Administração. A internet foi muito além da divulgação de informações por meio de páginas acessíveis por meio de endereços eletrônicos ${ }^{169}$ : tornou-se,

\footnotetext{
${ }^{162}$ Cf. Duni, Giovanni, Teleamministrazione, cit., item 2.1. Segundo o mesmo autor, é teoricamente possível um ato administrativo eletrônico, com pleno valor formal, fechado em um computador não conectado a uma rede de telecomunicações. Mas, assim que surge a necessidade de tornar disponível esse ato a outro órgão, surge a necessidade do papel que se pretendia eliminar (op. cit., item 1).

163 Segundo OROFINO, certamente não são desprezíveis as vantagens derivadas da eliminação dos arquivos em papel e da consequente simplificação da localização e catalogação de atos e documentos memorizados em suporte magnético. Entretanto, sem que os computadores sejam conectados em rede, a utilidade decorrente da digitalização da atuação da Administração Pública seria de pequena importância (cf. Forme elettroniche $e$ procedimenti amministrativi, cit., p. 141).

${ }^{164}$ Cf. PONTI, Benedetto, op. cit., p. 59.

${ }^{165}$ Cf. Duni, Giovanni, L'amministrazione digitale, cit., pp. 13-14.

${ }^{166}$ Cf. ibidem, p. 18, tradução livre.

${ }^{167}$ Cf. Frosini, Vittorio, Informática y Administración Pública, cit., p. 456.

${ }^{168}$ Essa foi uma evolução verificada na utilização de sistemas de informação em todas as organizações. Na visão mais antiga, o sistema de informação é externo à atividade, servindo para monitorá-la e controlá-la. Na visão atual, os sistemas de informação estão tão entrelaçados à atividade subjacente que podem ser considerados parte dele (cf. STAIR, Ralph M., REYNOLDS, George W., op. cit., p. 40).

${ }^{169}$ Cf. BARNÉS VÁZQUEZ, Javier, Una reflexión introductoria sobre el Derecho Administrativo y la Administración Pública de la Sociedad de la Información y del Conocimiento, cit., pp. 42-43.
} 
de fato, um novo paradigma de administração ${ }^{170}$, viabilizando um aprofundamento e ampliação da comunicação entre órgãos administrativos, de forma que hoje as informações circulam cada vez menos em bancos de dados localizados e cada vez mais em rede ${ }^{171}$.

Também a incorporação das tecnologias às atividades com projeção externa tem uma linha de evolução. O primeiro impulso refere-se à difusão unilateral de informações aos usuários na internet ${ }^{172}$, para que estes encontrem mais facilidade em suas relações com a Administração, pelas formas tradicionais (v.g., sabendo quais os documentos em papel são necessários para efetuar um pedido corretamente). Em uma segunda fase, é possível falar não somente no oferecimento unilateral de informações, mas na troca de informações, especialmente para a prática de transações. Isso permite prestar serviços eletrônicos remotos ao usuário, os telesserviços ou teleprocessos ${ }^{173}$. É o momento atual, em que surge uma nova concepção de Administração, com o progressivo desaparecimento do suporte papel e da necessidade de deslocamento físico do usuário até as repartições públicas $^{174}$. Os meios tradicionais ainda existem e convivem com os sistemas informatizados, que têm trazido uma contribuição considerável para a qualidade dos serviços ${ }^{175}$.

O aprofundamento dessa evolução levará a uma fase de integração entre todos os órgãos administrativos, passando-se da administração estanque para a teleadministração ${ }^{176}$ ou administração em rede ${ }^{177}$, em que todos os atos e processos administrativos

\footnotetext{
${ }^{170}$ Cf. Fernández SAlMerón, Manuel, VALERo TORRIJOS, Julián, Protección de datos personales y Administración electrónica, cit., p. 123.

${ }^{171}$ Cf. TRUDEL, Pierre, op. cit., acesso em 30.12.2010, p. 6.

${ }^{172}$ Cf. VALERo TORRIJOS, Julián, Administración pública, ciudadanos y nuevas tecnologías, cit., p. 2960.

${ }^{173}$ Cf. GRISTI, Éric, op. cit., pp. 497 e 502.

${ }^{174}$ VALERo TORRIJOS, Julián, La e-Administración Pública, in FERNÁNDEZ SALMERÓN, M., SIERRA RodríGUEZ, J., y VAlERO TORRIJOS, J. (coord.), Nuevos retos en el horizonte de las Administraciones Públicas, Murcia, Universidad de Murcia - Facultad de Derecho, 2003, p. 104.

${ }^{175}$ Segundo VALERo TORRIJOS, a utilização de meios informáticos e telemáticos se desenvolveu mais no campo tributário e da seguridade social, o que decorre principalmente das funções arrecadatórias e do elevado número de pessoas afetadas em tais casos (cf. El régimen jurídico de la e-Administración, cit., p. 10). A tais explicações merecem ser acrescidos o caráter mensurável dos resultados de tais atividades e a padronização dos objetivos em torno de números.

${ }^{176}$ É o termo criado por DUNI, usado em várias de suas obras. Cf., especialmente, Teleamministrazione, cit.

${ }^{177}$ Cf. CARCENAC, Thierry, op. cit., p. 16.
} 
não serão mais realizados em papel, mas diretamente na memória dos computadores ${ }^{178}$, sendo acessíveis por meio da comunicação entre os entes públicos e dispensando deslocamentos físicos. Isso exigirá a completude dos equipamentos e da rede, bem como a digitalização dos documentos em papel ainda não disponíveis em meio eletrônico ${ }^{179}$, o que, embora já seja possível do ponto de vista tecnológico, tende a encontrar dificuldades decorrentes da falta de recursos financeiros ${ }^{180}$.

O emprego das novas tecnologias da informação e da comunicação certamente modifica as relações tradicionais entre cidadão e Administração ${ }^{181}$. Essa modificação alcança a forma da prestação dos serviços, os meios materiais utilizados ${ }^{182}$ e a atuação dos servidores públicos ${ }^{183}$. Além disso, atinge referências básicas que sempre estruturaram a atuação administrativa, como é o caso dos parâmetros de espaço e de tempo ${ }^{184}$. O Poder Público, ao prestar serviços por meios digitais, já não está limitado a fronteiras geográficas, podendo alcançar destinatários dispersos por todo o planeta ${ }^{185}$. A comunicação com os

\footnotetext{
${ }^{178}$ Cf. DUNI, Giovanni, L'amministrazione digitale, cit., pp. 13-14 e, do mesmo autor, La teleamministrazione come terza fase dell'informatica amministrativa, in DUNI, Giovanni (org.), Dall'informatica amministrativa alla teleamministrazione, Roma, Istituto Poligrafico dello Stato, 1992, disponível em http://spol.unica.it/teleamm/italiano/pubblicazioni/dallin-sezione1.htm\#duni, acesso em 08.12.2010, item 1.

${ }^{179}$ Cf. DunI, Giovanni, L'utilizzabilità delle tecniche elettroniche nell'emanazione degli atti e nei procedimenti amministrativi. Spunto per una teoria dell'atto amministrativo emanato nella forma elettronica, in Rivista Amministrativa della Repubblica Italiana, Vol. CXXIX, fasc. 6, jun. 1978, Di Castello, Tappini, 1978, disponível em http://spol.unica.it/teleamm/italiano/1978/luti.htm, acesso em 25.10.2010.

${ }^{180}$ Cf. PIRAS, Paola, op. cit., p. 95.

${ }^{181}$ Cf. BARNÉS VÁZQUEZ, Javier, Sobre el procedimiento administrativo, cit., p. 305.

${ }^{182}$ Cf. PÉreZ GálvEZ, Juan Francisco, Incidencia de las nuevas tecnologías en el procedimiento administrativo español, in AlenZa García, José Francisco, RAZQuin LiZARRaga, José Antonio, Organización y Procedimientos Administrativos, Navarra, Arazandi - Instituto Navarro de Administración Pública, 2007, p. 572. Dando evidência aos meios de atuação administrativa, FounTAIN define o Virtual State como um governo organizado cada vez mais em termos de órgãos administrativos virtuais, redes entre órgãos e redes públicoprivadas cujas estruturas e capacidade dependem da internet e da web (cf. op. cit., p. 4).

${ }^{183}$ Para FROSINI, por exemplo, a profunda transformação verificada na Administração Pública traz o computador como um novo tipo de funcionário público, evidentemente em sentido metafórico (cf. Informática y Administración Pública, cit., p. 448).

${ }^{184}$ Cf. PUNZÓn MORALEDA, Jesús, Introducción, in PUNZÓn MORALEDA, Jesús (coord.), Administraciones Públicas y nuevas tecnologías, Valladolid, Lex Nova, 2005, p. 9.

${ }^{185}$ Cf. Bernadí GIL, Xavier, Derecho Público y Administración Electrónica: una visión panorámica, in Nuevas Políticas Públicas - Anuario multidisciplinar para la modernización de las Administraciones Públicas, Sevilla, Instituto Andaluz de Administración Pública, n. 1, 2005, p. 217.
} 
usuários mais distantes, assim como com as unidades administrativas mais remotas, pode ser feita instantaneamente ${ }^{186}$, vinte e quatro horas por dia, todos os dias do ano ${ }^{187}$.

Nos ainda recentes estudos sobre governo eletrônico ${ }^{188}$, passa-se a discutir a existência de uma reinvenção do governo ou de um redescobrimento da Administração, indagando-se sobre a possibilidade de que esta continue a ser a mesma ${ }^{189}$. Há quem aponte a necessidade de um novo Estado e, especialmente, de uma nova Administração ${ }^{190}$, com uma nova lógica da ação administrativa ${ }^{191}$. Entretanto, a mera adjetivação, de caráter classificatório, não traz uma discussão tão proveitosa. Mesmo que não se reconheça a existência de uma nova categoria de Administração Pública, é indiscutível a necessidade de aperfeiçoar de modo profundo seu funcionamento por meio do emprego das novas tecnologias da informação e da comunicação ${ }^{192}$.

${ }^{186}$ Cf. RondeAU, Jean-Claude, op. cit., p. 12.

${ }^{187}$ Ultrapassando os limites impostos pelos suportes tradicionais, especialmente o papel, as tecnologias da informação afetam os fluxos de informação, a coordenação e o trabalho da burocracia, alterando o relacionamento entre a informação e os fatores de distância, tempo e memória (cf. FounTAIN, Jane E., op. cit., p. 33).

${ }^{188}$ É certo que o governo eletrônico já existe há anos, porém em vários aspectos ele ainda está em sua infância, sendo seu estudo ainda muito recente (cf. CURTIN, Gregory G., SOMMER, Michael H., VIS-SOMMER, Veronika, op. cit., p. 7).

${ }^{189}$ Cf. BARNÉS VÁZQUEZ, Javier, Una reflexión introductoria sobre el Derecho Administrativo y la Administración Pública de la Sociedad de la Información y del Conocimiento, cit., p. 50.

${ }^{190}$ Cf. Cotino Hueso, Lorenzo, Derechos del ciudadano administrado e igualdad ante la implantación de la Administración electrónica, in Revista Vasca de Administración Pública, Oñati, Instituto Vasco de Administración Pública, n. 68, jan-abr. 2004, p. 153.

${ }^{191}$ Cf. MASUCCI, Alfonso, Erogazione on line dei servizi pubblici e teleprocedure amministrative, cit., pp. 992. Essa nova lógica poderia ser assim descrita: “A visão que está por trás do conceito de governo eletrônico é um horizonte caracterizado por uma rede de grandes sistemas de informação distribuídos, interconectados e profundamente integrados capazes de trocar informação administrativa e política dentro de si e entre si de maneira em grande parte automatizada, realizado de forma eficiente os processos administrativos comuns e oferecendo uma experiência de uso simples, integrada e centrada no usuário. Vislumbra-se, assim, uma grande rede de sistemas de informação pública interoperáveis - capazes de trocar informação - que apresentem ao usuário toda a informação que necessita nesse momento, que recuperem do resto da rede os dados necessários para o procedimento que será realizado e que se usem como o mínimo de esforço" (GARCíA MARCO, Francisco Javier, Ontologías y documentación electrónica en las actividades públicas, in GALINDO AYUDA, Fernando (org.), Gobierno, derecho y tecnología: las actividades de los poderes públicos, Cizur Menor (Navarra), Thomson-Civitas, 2006, p. 180, tradução livre).

${ }^{192}$ Cf. GuILlen CARAMES, Javier, op. cit., p. 253. 


\subsection{O alcance do governo eletrônico}

A utilização das tecnologias da informação e da comunicação no âmbito estatal constitui uma realidade bastante ampla. Há, por isso, um risco de que o estudo da matéria incorra em uma vagueza inaceitável para os propósitos científicos. Dessa maneira, é necessário trazer uma visão analítica a respeito do que constitui essa realidade denominada governo eletrônico. Essa análise deve trazer confrontações importantes no âmbito da terminologia utilizada na matéria, das dimensões em que atua o governo eletrônico e das atividades administrativas às quais podem ser incorporadas as novas tecnologias.

\subsubsection{A terminologia: governo eletrônico, administração eletrônica e democracia ele- trônica}

A utilização das tecnologias da informação e da comunicação no âmbito do Estado, como fenômeno novo, tem trazido uma considerável confusão terminológica ${ }^{193}$. O prefixo "e" está cada vez mais ligado a aspectos do governo ${ }^{194}$, levando ao emprego de vocábulos estrangeiros como e-government, e-governance e e-democracy, bem como de formas aportuguesadas, tais como e-administração, e-governo, e-governança e edemocracia, ou, como adotado neste estudo, governo eletrônico, administração eletrônica e

\footnotetext{
${ }^{193}$ Cf. BeNYEKHLEF, Karim, op. cit., pp. 268-269.

${ }^{194}$ Cf. Oliver, E. Lynn, SANDERS, Larry, Introduction, in Oliver, E. Lynn, SANDERS, Larry (ed.), EGovernment Reconsidered: Renewal of Governance for the Knowledge Age, Regina, Canadian Plains Research Center, 2004, p. xii.
} 
democracia eletrônica ${ }^{195}$. Dada a profusão desses novos vocábulos e expressões, é necessário realizar algum esforço dogmático para encontrar certo rigor conceitual em sua utilização ${ }^{196}$, até com o propósito de definir com a precisão devida os limites do presente estudo.

Não parece haver dúvida de que, na maioria das vezes, tais vocábulos procuram referir-se, em linhas gerais, a duas grandes realidades: a utilização de meios eletrônicos nas atividades próprias da Administração Pública e o emprego de meios eletrônicos em relação ao processo democrático. No entanto, a distinção entre tais atividades não tem sido suficiente para a adoção de uma terminologia unívoca, especialmente em razão da ampla difusão mundial da expressão e-government e sua delicada tradução para o sistema político-administrativo europeu.

Na Europa, tem-se entendido que a expressão inglesa e-government não poderia ser traduzida como governo eletrônico, e sim como administração eletrônica, uma vez que se refere, de forma mais estrita, ao uso das tecnologias da informação e da comunicação pelas Administrações Públicas quando desempenham suas atividades burocráticas. Governo eletrônico seria um conceito mais amplo que o de administração eletrônica, alcançando a utilização das tecnologias da informação e da comunicação nas tarefas de go-

\footnotetext{
195 Analisando o sistema italiano, DUNI usa indistintamente os vocábulos eletrônico, digital, informático ou desmaterializado, porque a linguagem comum e legislativa não adota uma relação precisa entre terminolgia e conceitos (L'amministrazione digitale, cit., p. 11). MARCUS VINICIUS FILGUEIRAS JÚNIOR evita o vocábulo virtual, por considerar que os dados digitais são concretos (cf. Ato administrativo eletrônico e teleadministração. Perspectivas de investigação, in Revista de Direito Administrativo, n. 237, jul. /set. 2004, Rio de Janeiro, Renovar, p. 248. FouILLEUL apresenta a origem do conceito de desmaterialização na França, relacionada à supressão dos suportes fisicamente palpáveis no caso dos valores mobiliários, esclarecendo que não se pode falar em desmaterialização quando o registro e a circulação da informação se utilizam da matéria. Nesse sentido, o emprego da eletrônica não seria imaterial, mas incorpóreo (cf. Le contrat administratif electronique - L'exemple des marchés publics, Aix-en-Provence, PUAM, 2007, pp. 37-38). O conjunto dessas observações leva este estudo a usar de modo equivalente os vocábulos eletrônico, digital e informático, evitando-se a terminologia desmaterializado e virtual. Sobre a distinção conceitual entre meios eletrônicos, informáticos e digitais, cf. supra, nota 13. Sobre a diferença entre os adjetivos eletrônico e digital para qualificar as assinaturas, cf. infra, nota 434.

${ }^{196}$ Cf. VALERO TORRIJOS, Julián, La nueva regulación legal del uso de las tecnologías de la información y las comunicaciones en el ámbito administrativo, cit., p. 223 e CURTIN, Gregory G., SOMMER, Michael H., VIS-SOMMER, Veronika, op. cit., pp. 1-2.
} 
verno em toda sua extensão ${ }^{197}$. Como grande parte da doutrina jurídica anglo-saxã faz referência ao e-government apenas como equivalente a administração eletrônica ${ }^{198}$, foi necessário criar uma expressão, e-governance, para referir-se à aplicação das tecnologias da informação e da comunicação em quaisquer tarefas de governo ${ }^{199}$. Assim, no sistema institucional político-administrativo europeu, seriam equivalentes as expressões e-government, administração eletrônica e e-administração, todas elas referentes à aplicação das tecnologias pela Administração Pública, sendo o governo eletrônico equivalente ao anglo-saxão $e$ governance $^{200}$. A expressão administração eletrônica é a preferida das instituições comunitárias europeias, ainda que internacionalmente se encontre mais difundida a expressão $e$ government ${ }^{201}$.

Contudo, a identificação da principal causa para a confusão terminológica não é capaz de solucionar a questão terminológica e conceitual, havendo uma vasta variação de conceitos, nem sempre tão precisos. Há quem entenda como sinônimos adminis-

\footnotetext{
${ }^{197}$ Cf. MARTínEZ GutIÉRREZ, Rubén, Instrumentos para el acceso de los ciudadanos a la administración electrónica, in Galindo AyUdA, Fernando, Rover, Aires José (coord.), Derecho, gobernanza y tecnologías de la información en la sociedad del conocimiento, Zaragoza, Prensas Universitarias de Zaragoza, 2009, pp. 193-194. Adotando a mesma conceituação, cf. DELPIAZZO, Carlos E., Las nuevas telecomunicaciones y el tránsito de la administración prestacional a la administración electrónica, in Anuario da Facultade de Dereito da Universidade de A Coruña, n. 11, A Coruña, Universidade da Coruña, 2007, p. 190. Ainda sobre o tema, com uma análise parcialmente diversa, cf. BENYEKHLEF, Karim, op. cit., p. 272.

${ }^{198}$ Segundo observa BENYEKHLEF, na definição do E-government Act estadunidense não se inclui a democracia eletrônica (parágrafo 36) (cf. op. cit., p. 271). Segundo o referido texto normativo, “"electronic Government' means the use by the Government of web-based Internet applications and other information technologies, combined with processes that implement these technologies, to (A) enhance the access to and delivery of Government information and services to the public, other agencies, and other Government entities; or "(B) bring about improvements in Government operations that may include effectiveness, efficiency, service quality, or transformation" ( $\S 3601,3$, texto disponível em http://www.gpo.gov/fdsys/pkg/PLAW107publ347/pdf/PLAW-107publ347.pdf).

${ }^{199}$ Cf. MARTíneZ GuTIÉRREZ, Rubén, Instrumentos para el acceso de los ciudadanos a la administración electrónica, cit., p. 194.

${ }^{200}$ Cf. ibidem, pp. 195-196. O texto cita o Boletim terminológico 45, editado em 12.09.2002 pela União Europeia (http://www.europarl.europa.eu/transl_es/plataforma/pagina/celter/bol45.htm), segundo o qual as expressões inglesas eGovernment ou Government on line não se referem a governo, mas a administração, de forma que são errôneas as traduções e-Gobierno, Gobierno electrónico ou Gobierno en línea. De acordo com o texto, a expressão e-Government seria equivalente à expressão castelhana administración electrónica.

${ }^{201}$ Cf. GAMERO CASADO, Objeto y ámbito de aplicación de la Lei 11/07, in VVAA, La protección de datos en la Administración Electrónica, Pamplona, Aranzadi, 2009, p. 111 e GUILlÉn CARAMÉs, Javier, op. cit., p. 252.
} 
tração eletrônica e governo eletrônico ${ }^{202}$. Por outro lado, não faltam aqueles que compreendem e-government de maneira mais ampla, designando tanto a administração eletrônica quanto à democracia eletrônica ${ }^{203}$. Há também os que consideram o e-government como realidade ampla, incluindo a prestação de serviços eletrônicos, o e-service delivery e a $e$ governance, referente ao compartilhamento de informações e o engajamento dos cidadãos $^{204}$.

${ }^{202}$ Cf. GAMERO CASADO, Eduardo, Objeto, ámbito de aplicación y principios generales de la ley de administración electrónica; su posición en el sistema de fuentes, in GAMERO CASADO, Eduardo, VALERO TORRIJOS, Julián (coord.), Comentarios a la Ley de Administración electrónica - Ley 11/2007, de 22 de junio, de acceso electrónico de los ciudadanos a los servicios públicos, 1. ${ }^{\mathrm{a}}$ ed., 2. ${ }^{\mathrm{a}}$ imp., Cizur Menor (Navarra), ThomsonCivitas, 2009, p. 59. Entre nós, há quem entenda administração pública eletrônica como uma tradução adequada de electronic government, em função da terminologia própria do direito administrativo (cf. QUADROS, Jaqueline Maria, op. cit., pp. 242-243).

${ }^{203}$ Cf. MERLONI, Francesco, Sviluppo dell'e-government e riforma delle amministrazioni, cit., p. 4.

${ }^{204}$ Cf. Mitchinson, Tom, RATnER, Mark, Promoting Transparency Through the Electronic Dissemination of Information, in OLIVER, E. Lynn, SANDERS, Larry (ed.), E-Government Reconsidered: Renewal of Governance for the Knowledge Age, Regina, Canadian Plains Research Center, 2004, p. 89. Na verdade, a confusão terminológica aumenta em relação à e-governance, em relação à qual é muito mais difícil encontrar conceitos que possam ser considerados minimamente universais, tarefa que certamente foge aos propósitos do presente estudo. De fato, além dos sentidos mencionados no texto (e-governance como equivalente de governo eletrônico, em sentido amplo, ou parte deste), o conceito de e-governance poderia referir-se à governança (como conjunto de instituições e relacionamentos envolvidos no processo de governar, os processos e instituições, formais e informais, envolvidos na tomada de decisões coletivas) realizada em ambiente eletrônico, por meio de ferramentas eletrônicas (cf. SMITH, Peter Jay, New Information Technologies and Empowerment: The Implications for Politics and Governance, in OLIVER, E. Lynn, SANDERS, Larry (ed.), E-Government Reconsidered: Renewal of Governance for the Knowledge Age, Regina, Canadian Plains Research Center, 2004, p. 135), ou seja, "como utilização das tecnologias para a good governance de um certo território" (cf. PALMIRANI, Monica, Prefazione, in PALmiRAni, Monica, MARTONI, Michele, Il cittadino elettronico e l'identità digitale nell'e-governance, Bologna, Gedit, 2006, p. 8), bem como poderia ser aplicado às situações em que os serviços públicos e processos de decisão envolvem diferentes atores, alguns deles de fora da própria esfera governamental, de forma que o poder e os mecanismos do Governo estejam distribuídos em redes das quais participa não unicamente a Administração Pública e nas quais às vezes esta nem sequer é o ator mais importante (cf. AIBAR PUENTES, Eduard, Gobernanza electrónica: innovación tecnológica y cambio organizativo en las burocracias públicas, in FABRA VALLS, Modesto, Blasco DíaZ, José Luis (org.), La administración electrónica em España: experiencias y perspectivas de futuro, Castelló de la Plana, Universitat Jaume I, 2007, p. 22). Entre nós, entendendo a governança eletrônica como caracterizada pela interatividade entre governantes e cidadãos, relacionada à participação na tomada de decisões de interesse geral, cf. PEREIRA JÚNIOR, Jessé Torres, DOTTI, Marinês Restelatto, As licitações e contratações públicas no cenário da governança eletrônica, in Interesse Público, n. 50, Belo Horizonte, Fórum, 2008, p. 47. Adotando a expressão governo eletrônico, sob o argumento de que a governança eletrônica poderia não estar relacionada à Administração Pública, cf. SANTOLIM, Cesar, Aspectos jurídicos do governo eletrônico: as tecnologias da informação na Administração Pública, in Revista de Direito de Informática e Telecomunicações - RDIT, Belo Horizonte, Fórum, n. 2, jan.-jun. 2007, p. 89. 
No Brasil, a terminologia não parece alinhada com as diretrizes europeias, encontrando-se mais difundida a expressão governo eletrônico para referir-se à incorporação das tecnologias da informação e da comunicação nas atividades administrativas, sobretudo no tocante ao relacionamento com o usuário. Nesse sentido, o Decreto de 18 de outubro de 2000 prevê que o governo eletrônico está voltado para "a prestação de serviços e informações ao cidadão" (art. $1^{\circ}$ ). Da mesma maneira, governo eletrônico é a expressão mais frequente em portais eletrônicos oficiais ${ }^{205}$, bem como nas discussões relativas ao tema, em âmbito político ou científico ${ }^{206}$.

Nesse sentido, procurando alguma sistematização terminológica em língua portuguesa, sem desprezar a designação corrente no Brasil e as diversas contribuições doutrinárias para a devida precisão conceitual, este estudo considera a utilização das tecnologias da informação e da comunicação no âmbito do Poder Público sob o conceito de governo eletrônico em sentido amplo. Este incluiria tanto a democracia eletrônica quanto o governo eletrônico em sentido estrito ou administração eletrônica ${ }^{207-208}$.

A democracia eletrônica compreende todos os mecanismos que permitem ao cidadão, utilizando as tecnologias informáticas, participar ativamente da vida pública, tais como o voto eletrônico, o envio de propostas e a participação em procedimentos de decisão política e administrativa ${ }^{209}$. Dentro da democracia eletrônica está ainda incluído o relacionamento direto com as instituições públicas e representantes políticos (diálogo com

\footnotetext{
${ }^{205}$ Cf., por exemplo, o portal federal http://www.governoeletronico.gov.br, acesso em 01.02.2011.

206 Vale mencionar, por exemplo, a obra organizada por FlORENCIA FERRER e PAULA SANTOS, Egovernment: o governo eletrônico no Brasil (São Paulo, Saraiva, 2004), cujo título já ilustra a adoção da terminologia diante do quadro acima exposto, que faz um relato sobre a utilização da expressão governo eletrônico pelo governo federal brasileiro (cf. Introdução, de autoria das organizadoras, p. XIII).

${ }^{207}$ Ciberadministração, e-Administração, Administração on line, Administração virtual ou digital e teleadministração são outros vocábulos e expressões que podem ser usados como sinônimos de administração eletrônica (cf. SANZ LARRUGA, Francisco Javier, Las bases jurídicas de la 'administración electrónica' en España, cit., p. 714). Distinguindo a p-administração (a administração tradicional, que manipula o papel) e a e-administração, ou administração eletrônica, cf. CHATILlON, Georges, Préface, cit., p. 7.

${ }^{208}$ A concepção aqui adotada não considera integrante do governo eletrônico a utilização das novas tecnologias no âmbito do Poder Judiciário, que vem sendo, entre nós, tratada no âmbito do direito processual. Entendendo que o e-governo incluiria não somente o Poder Executivo, mas o Legislativo e o Judiciário, cf. GAROT, Marie José, De la administración electrónica a uma democracia digital, in Revista Direito GV, v. 2 , n. 1, São Paulo, FGV, jan-jun. 2006, p. 91.

${ }^{209}$ Cf. MERLONI, Francesco, Sviluppo dell'e-government e riforma delle amministrazioni, cit., p. 4.
} 
os partidos políticos, correio eletrônico de deputados, enquetes por meio da internet, foros de discussão, jornadas virtuais dos partidos, etc.), conhecido com e-politics ${ }^{210}$.

A administração eletrônica, ou governo eletrônico em sentido estrito, objeto do presente estudo, pode ser definida como o fenômeno, situado no contexto da chamada sociedade da informação, consistente no uso das tecnologias da informação e da comunicação, especialmente da internet, no âmbito da Administração Pública ${ }^{211}$, em substituição aos instrumentos tradicionais, baseados no documento em papel. Por meio da utilização dos meios eletrônicos, surge a oportunidade para melhorar a circulação da informação nas relações administrativas internas e externas, de forma a obter mais eficácia, eficiência, rapidez e transparência na atuação administrativa e na prestação de serviços ${ }^{212-213}$.

\footnotetext{
${ }^{210}$ Cf. PITSCHAS, Raines, op. cit., p. 258.

${ }^{211}$ Cf. TINTÓ GIMBERnAT, Montserrat, Administración electrónica y ciberprocedimiento, cit., p. 10.

${ }^{212}$ Cf. BOMBARDELli, Marco, op. cit., p. 992. São inúmeros os textos que trazem definições de administração eletrônica, entre eles: AIBAR PUENTES, Eduard, op. cit., p. 22; COMISSÃo EUROPEIA, Papel da Administração em linha (eGoverno) no futuro da Europa, COM (2003) 567, 26.09.2003, disponível em http://eurlex.europa.eu/LexUriServ/LexUriServ.do?uri=COM:2003:0567:FIN:PT:PDF, acesso em 12.02.2011; DELGAdo García, Ana María, Oliver Cuello, Rafael, op. cit., p. 3; GAMERo CASADO, Eduardo, Objeto, ámbito de aplicación y principios generales de la ley de administración electrónica, cit., p. 60 e Objeto y ámbito de aplicación de la Lei 11/07, cit., p. 109; Holmes, Douglas, op. cit., p. 2; JinESTA Lobo, Ernesto, Administraciones públicas electrónicas: retos y desafíos para su regulación, in Ivstitia, n. 261-262, São José, Vip Tax, set.-out. 2008, p. 6, disponível em www.ernestojinesta.com/ADMINISTRACIONES_PUBLICAS.pdf, acesso em 22.10.2010; MARTÍN DELGADO, Isaac, La administración electrónica como problema actual para la investigación y la docencia en el derecho administrativo, cit., p. 356; MERLONI, Francesco, Sviluppo dell'e-government e riforma delle amministrazioni, cit., p. 4; OLLER RUBERT, Marta, La administración electrónica en Europa, in FABRA VALLS, Modesto, BLASCO DÍAZ, José Luis (org.), La administración electrónica en España: experiencias y perspectivas de futuro, Castelló de la Plana, Universitat Jaume I, 2007, p. 50; SANZ LARRUGA, Francisco Javier, Las bases jurídicas de la 'administración electrónica' en España, cit., p. 714; VALERO TORRIJOS, Julián, Protecção de datos personales y administración electrónica, in CERRILLO I MARTínEZ, Agustí e oo., La administración y la información, Madrid, Marcial Pons, 2007, p. 44; WORLD BANK, Definition of e-government, disponível em http://go.worldbank.org/M1JHE0Z280, acesso em 10.02.2011.

${ }^{213}$ A alusão aos fins pode ser considerada algo não essencial na conceituação da administração eletrônica. De fato, como mostra GARCÍA MARCO, a administração poderia servir, em tese, até para aumentar o poder do Estado e das elites que o governam, não sendo desprezível, outrossim, a utilização de meios eletrônicos, por exemplo, para os fins estritos de aumento da arrecadação tributária (cf. Administración electrónica: el acceso electrónico de los ciudadanos a los servicios públicos, cit., p. 186). Segundo o autor, no mesmo trecho, "[p]romover o acesso e a comunicação entre o cidadão e a Administração é um bem instrumental, o importante é o que se consegue com esses meios". Sem dúvida, a incorporação de tecnologias da informação e comunicação em um Estado autoritário poderia também ser chamada de administração eletrônica. Entretanto, no caso da utilização de tais tecnologias em um Estado de Direito, não há como pretender alguma neutralidade em relação aos valores constitucionais adotados. Dessa maneira, qualquer novo instrumento deve ser visto em seu potencial para a realização dos preceitos constitucionais em vigor. Nesse sentido, é inevitável a alusão aos fins da administração eletrônica já em sua conceituação, embora a análise de seu relacionamento com o sistema constitucional brasileiro seja enfrentada somente mais adiante (cf. Capítulo 2).
} 
A distinção entre administração eletrônica e democracia eletrônica, porém, não pode ser considerada absolutamente precisa. Exige-se atualmente que a Administração - e não só o Parlamento - seja também democrática, prevendo-se inúmeros mecanismos participativos associados à atuação administrativa, não somente para fins de exercícios de direitos democráticos como para o próprio aperfeiçoamento da atividade administrativa. Alguns desses mecanismos podem ser realizados com o auxílio das tecnologias da informação e da comunicação (por exemplo, as consultas públicas eletrônicas e os fóruns de debate eletrônicos). Tais mecanismos podem ser validamente enquadrados tanto como integrantes da administração eletrônica quanto da democracia eletrônica.

\subsubsection{As dimensões interna e externa}

O governo eletrônico em sentido estrito, ou administração eletrônica, tem uma dimensão interna e uma dimensão externa ${ }^{214}$.

A dimensão interna, designada por meio das expressões Government to Government $(\mathrm{G} 2 \mathrm{G})$ e back office da administração eletrônica ${ }^{215}$, diz respeito à aplicação das novas tecnologias no trabalho administrativo interno e nas relações interadministrati$\operatorname{vas}^{216}$, tanto dentro de uma dada entidade pública quanto entre diversas esferas de governo $^{217}$, bem como no relacionamento com sujeitos privados que desempenham funções ou

\footnotetext{
${ }^{214}$ Cf. MARTínEZ GUTIÉRREZ, Rubén, Instrumentos para el acceso de los ciudadanos a la administración electrónica, cit., p. 198.

${ }^{215}$ Segundo MARTÍNEZ GUTIÉRREZ, back office seria a expressão corrente na doutrina anglo-saxônica (cf. Administración Pública Electrónica, cit., pp. 215-216).

${ }^{216}$ Cf. MARTíneZ GUTIÉRREZ, Rubén, Instrumentos para el acceso de los ciudadanos a la administración electrónica, cit., p. 198.

${ }^{217}$ Fazendo referência a duas dimensões internas, com os dois sentido indicados, cf. MERLONI, Francesco, Sviluppo dell'e-government e riforma delle amministrazioni, cit., p. 5. Entendendo o relacionamento com outras entidades como dimensão externa da administração eletrônica, cf. MAGÁN PERALES, José María Aristóteles, La nueva administración pública electrónica, las relaciones electrónicas entre la administración y el ciudadano. Especial referencia a la firma electrónica, in PUNZÓN MORALEDA, Jesús (coord.), Administraciones Públicas y nuevas tecnologías, Valladolid, Lex Nova, 2005, p. 81.
} 
prestam serviços públicos ${ }^{218}$. O back office compreende as atividades de gestão da organização e dos processos administrativos, sendo, na prática, tudo aquilo que o público não vê, mas permite a realização dos serviços a ele destinados ${ }^{219}$. Um dos temas mais relevantes da dimensão interna é a comunicação entre entes e órgãos públicos, responsável por facilitar o recebimento de solicitações, o compartilhamento de informações e os processos de trabalho comuns, o que pode acelerar a tomada de decisões ${ }^{220}$ e viabilizar projetos de reformulação interna da Administração ${ }^{221}$. Outro tema importante, integrante da dimensão interna, é o relacionamento eletrônico entre a Administração e seus servidores, que vem sendo denominado Government to Employees $(\mathrm{G} 2 \mathrm{E})^{222}$.

A dimensão externa, correspondente ao front office da administração eletrônica $^{223}$, refere-se à aplicação de meios informáticos e telemáticos para oferecer serviços públicos aos administrados ${ }^{224}$, sobretudo de modo automatizado e a distância ${ }^{225}$, transformando atividades realizadas pela Administração na parte de atendimento ao usuário ${ }^{226}$. A dimensão externa comporta dois aspectos ${ }^{227}$ : o das utilidades oferecidas ao setor privado, ou seja, às empresas, gerando a expressão Government to Business (G2B), pelo qual a Administração pode auxiliar os negócios, contratando com fornecedores e oferecendo informações e orientação por meios eletrônicos ${ }^{228}$; o dos serviços prestados aos cidadãos, ou seja, às pessoas físicas, referido pela expressão Government to Citizen (G2C), substituindo

\footnotetext{
${ }^{218}$ Cf. MERLONI, Francesco, Sviluppo dell'e-government e riforma delle amministrazioni, cit., p. 8.

${ }^{219}$ Cf. IASELLI, Michele, op. cit., p. 6.

${ }^{220}$ Cf. ChISSICK, Michael, HARRINGTON, Justin, op. cit., p. 6.

${ }^{221}$ Cf. BRousseaU, Eric, op. cit., p. 250.

${ }^{222}$ Considerando o tema relativo ao Government to Employees integrante da dimensão interna, cf. EzZ, Inas E., E-government Emerging Trends: Organization Challenges, in ANTTIROIKO, Ari-Veikko, Electronic government: concepts, methodologies, tools and applications, Hershey/New York, Information Science Reference, 2008, p. 3723. Além da gestão de recursos humanos e folhas de pagamento, o referido relacionamento permite os cursos por meios telemáticos, as várias formas de trabalho remoto e o acesso externo, por parte do servidor, às redes eletrônicas da Administração, inclusive correio eletrônico, alcançando também as várias situações em que o servidor, no seu próprio interesse, relaciona-se com o Poder Público (v.g., solicitações de férias e aposentadoria, que atualmente podem ser feitas por meio de sistemas computadorizados).

${ }^{223} \mathrm{O}$ front office, que poderia ser chamado, em português, linha de frente (cf. GIANESI, Irineu G. N., CORRÊA, Henrique Luiz, Administração estratégica de serviços, São Paulo, Atlas, 1994, p. 42), é o conjunto das estruturas de um ente que gere a interação com o público, ou seja, as funções de balcão da administração (cf. IASELLI, Michele, op. cit., p. 6).

${ }^{224}$ Cf. MARTínEZ GUTIÉRREZ, Rubén, Instrumentos para el acceso de los ciudadanos a la administración electrónica, cit., p. 198.

${ }^{225}$ Cf. BROUSSEAU, Eric, op. cit., p. 250.

${ }^{226}$ Cf. MARTíneZ GutiÉRrez, Rubén, Administración Pública Electrónica, cit., p. 223.

${ }^{227}$ Cf. MERLONI, Francesco, Sviluppo dell'e-government e riforma delle amministrazioni, cit., p. 5.

${ }^{228}$ Cf. Holmes, Douglas, op. cit., p. 6 e CHISSICK, Michael, HARRINGTON, Justin, op. cit., pp. 7-8.
} 
ou suplementando as atividades que tradicionalmente dependeram da troca de documentos físicos ou atendimento presencial dos cidadãos em repartições públicas ${ }^{229}$.

As duas dimensões são complementares, não podendo existir separadamente. Assim como na dimensão externa, a utilização das tecnologias pode trazer significativos benefícios nas atividades administrativas internas ${ }^{230}$. Entretanto, a Administração é mais visível quando presta serviços a cidadãos e empresas, havendo uma tendência a dar mais atenção à dimensão externa do governo eletrônico. Nesse sentido, é normal que haja mais discussões a respeito dos direitos dos usuários e da melhoria da qualidade das prestações oferecidas, esperando-se que a utilização de novas tecnologias traga resultados em tais aspectos. No entanto, o êxito na dimensão interna é indispensável para a obtenção desses resultados. Sem uma incorporação adequada de meios informáticos e telemáticos na atuação interna da Administração Pública, dificilmente poderão ser prestados serviços de qualidade. A adequada utilização das novas tecnologias deve ocorrer em paralelo em ambas as dimensões para que os resultados favoráveis desejados possam realmente surgir.

\subsubsection{Atividades realizadas com apoio da tecnologia}

As novas tecnologias têm um vasto campo de atuação na Administração Pública $^{231}$, pois todas as atividades públicas podem beneficiar-se de meios informáticos e telemáticos, tanto na atividade final como em seus estágios intermediários ${ }^{232}$. Além disso,

\footnotetext{
${ }^{229}$ Cf. ChISSICK, Michael, HARRINGTON, Justin, op. cit., p. 9. É importante notar que a administração eletrônica não está relacionada somente à possibilidade de conectar-se à Administração via internet, podendo haver também benefícios para o usuário quando um serviço é oferecido por meio de um agente, por guichê ou por telefone (cf. GRISTI, Éric, op. cit., p. 511).

${ }^{230}$ Cf. Fountain, Jane E., op. cit., p. 6.

${ }^{231}$ Cf. Truche Pierre, FAUGERE, Jean-Paul, Flichy, Patrice, op. cit., p. 15.

${ }^{232}$ Cf. BOMBARDELLI, Marco, op. cit., p. 1017.
} 
as ferramentas tecnológicas hoje disponíveis permitem realizar tarefas impensáveis no passado, em razão de limitações de meios pessoais e econômicos ${ }^{233}$.

Em princípio, as novas tecnologias podem ser empregadas em atividades formalizadas e não formalizadas da Administração. A atividade administrativa formalizada está relacionada basicamente à produção de atos jurídicos, de acordo com um esquema prévio destinado a assegurar sua legalidade, sendo suscetível de revisão jurisdicional. Já a atividade não formalizada tem uma vocação de serviço e ajuda ao cidadão, sendo suscetível de controle jurídico somente se sofre alguma espécie de formalização ou quando se discutem os efeitos, a validade e o acerto da informação dispensada ${ }^{234}$.

As atividades administrativas formalizadas, por seus efeitos, têm maior relação com o direito administrativo. Elas tendem a receber mais atenção nos estudos jurídicos, ressalvada a importância das atividades não formalizadas. $\mathrm{O}$ presente estudo não discrepa dessa tendência, inclusive no que concerne a ressalvar a relevância da incorporação das novas tecnologias às atividades administrativas informais. De fato, parece cada vez mais difícil deixar de reconhecer a importância das atividades administrativas informais ${ }^{235}$, pois o Estado social, cuja missão inclui o oferecimento de prestações materialmente fruíveis, já não se restringe à simples execução da lei, própria do Estado de polícia ${ }^{236}$.

Cabe ressaltar, contudo, as diferenças entre as questões e temas verificados no emprego das tecnologias da informação e da comunicação em um e outro tipo de atividade $^{237}$. Sistemas de informação facilitam atividades que ocorrem fora do âmbito de

\footnotetext{
${ }^{233}$ É a conclusão que FORSTHOFF chegava ao tratar de mecanização administrativa, o que parece ainda mais aplicável aos dias de hoje (cf. op. cit., p. 99).

${ }^{234}$ Cf. Palomar Olmeda, Alberto, Gestión Electrónica de los procedimientos, cit., p. 411 e Álamo GONZÁLEZ, Nayra, La utilización de las nuevas tecnologías en las relaciones entre las Administraciones Públicas y los ciudadanos, in Revista Española de Derecho Administrativo, n. 133, Madrid, Civitas, jan-mar. 2007 , p. 92.

${ }^{235}$ Segundo BARNÉS VÁZQUEZ, o procedimento administrativo tradicional alcança somente as atividades administrativas formais, devendo uma teoria moderna do procedimento reconhecer as atividades informais, garantindo-lhes, por exemplo, transparência, igualdade de oportunidades e acesso imparcial à informação (cf. Sobre el procedimiento administrativo, cit., p. 319).

${ }^{236}$ Cf. FORSTHOFF, Ernst, op. cit., pp. 87-88.

${ }^{237}$ Cf. Álamo GonzÁlez, Nayra, op. cit., p. 93 e OCHOA MONZÓ, Josep, Hacia la ciberadministración y el ciberprocedimiento?, cit., p. 158.
} 
processos administrativos - servindo, por exemplo, para agendar consultas, organizar a ordem de atendimento em repartições públicas ou para ajudar a definir o medicamento a ser prescrito ou a cirurgia a ser feita, conforme o processamento de dados do histórico do paciente. A diferença é que, nestes casos, muitas vezes não ocorre a produção de um efeito jurídico específico. Todavia, não se pode restringir o governo eletrônico à esfera de abrangência do direito administrativo, pois o Estado presta serviços de várias espécies, não somente aqueles de caráter burocrático e formal, que decorram de uma relação estrita entre fatos e normas $^{238}$.

Segundo outra perspectiva, é possível identificar a utilização das tecnologias da informação e da comunicação em atividades operacionais, gerenciais e estratégicas. Assim, elas são utilizadas em tarefas elementares e rotineiras, que antes tinham um uso intensivo de mão de obra ${ }^{239}$. Nesse sentido, os meios informáticos são usados como instrumento de processamento de dados, com o propósito de automatizar tarefas administrativas, tais como o fluxo de documentos, ou mesmo a prática de decisões de caráter operacional $^{240}$. Todavia, com sua evolução, a informática passou a ser empregada também em atividades gerenciais e estratégicas, com um nível ainda maior de sofisticação.

A tecnologia está transformando o processo de gerenciamento, com o fornecimento de novas e poderosas ferramentas para o cumprimento das funções clássicas

\footnotetext{
${ }^{238}$ O modelo de atuação da Administração Pública, embora normativo, não exige que todas as atividades públicas sejam formalizadas, mas apenas que alguns elementos essenciais sejam levados aos processos administrativos formais. Não é necessário, por exemplo, que o médico descreva os pormenores da cirurgia para que seja por ela remunerado; é necessário saber que ela foi feita. A atividade formalizada é responsável por processar adequadamente essas informações relevantes, dando-lhes as devidas consequências jurídicas. Com o advento das tecnologias da informação e das comunicações, que possibilitam lidar com um número cada vez maior de informações, tende a haver um aumento dos elementos a serem representados em mecanismos formais. Assim, pode não ser ainda necessário descrever a cirurgia, porém é bem possível obter dados de pacientes - índices de satisfação, sequelas, óbitos -, para compará-los entre si e, eventualmente, por exemplo, oferecer uma gratificação ao funcionário, por meio de uma atividade administrativa formalizada. Dessa maneira, ainda que o governo eletrônico não esteja limitado a atividades formais, ele pode ser responsável pela formalização de atividades, levando à existência de um número maior de comportamentos juridicamente regulados.

${ }^{239}$ Cf. STAIR, Ralph M., REYNOLDS, George W., op. cit., pp. 19-20.

${ }^{240}$ É o que a tecnologia da informação chama de decisões estruturadas, tidas como repetitivas e rotineiras, envolvendo um procedimento pré-definido, de modo que não é necessário tratá-las toda vez como se fossem novas (cf. LAUDON, Kenneth C., LAUDON, Jane P., op. cit., p. 87).
} 
de planejamento, organização, coordenação, decisão e controle ${ }^{241}$, bem como para a aferição global do desempenho de determinado órgão ou do conjunto de atividades da Administração ${ }^{242}$. Também a atividade estratégica, que envolve a definição dos grandes rumos da Administração segundo uma perspectiva de longo prazo, pode ser auxiliada pelas tecnologias da informação: neste caso, as autoridades têm à sua disposição elementos recebidos por meio das novas tecnologias, como é o caso das pesquisas e consultas efetuadas em bases de dados públicas, muitas vezes de modo automatizado ${ }^{243}$. Tanto nas atividades gerenciais como nas estratégicas, os sistemas de informação podem ser usados para subsidiar a tomada de decisões não usuais, relativas a problemas complexos que envolvem a avaliação de informações difíceis de obter ou de $u^{2} \mathrm{r}^{244}$.

É natural que a doutrina jurídica dê mais atenção à utilização das tecnologias da informação e da comunicação nas atividades que envolvam a aplicação mais estrita de normas jurídicas, por meio de processos administrativos que levam, ao fim, à prática de atos administrativos suscetíveis de controle judicial ${ }^{245}$. Em sentido contrário, as decisões gerenciais e estratégicas são tomadas com um nível elevado de discricionariedade, não sendo seu acerto ou desacerto, na maioria das vezes, suscetível de apreciação em termos propriamente jurídicos.

\footnotetext{
${ }^{241}$ Cf. ibidem, pp. 19 e 85.

${ }^{242}$ Atualmente as tecnologias não são usadas somente para registrar e guardar dados, como no início da automação, mas para controlar todo o processo de produção (cf. BovENS, Mark, ZoURIDS, Stavros, op. cit., p. 180). Existem, assim, os sistemas de informação gerencial, cuja função é "fornecer informações rotineiras a gerentes e tomadores de decisões", oferecendo "relatórios-padrão gerados com dados e informações do sistema de processamento de transações" (STAIR, Ralph M., REYNOLDS, George W., op. cit., p. 21). Os sistemas de nível gerencial servem para atender às atividades de monitoração, controle, tomada de decisões e procedimentos administrativos dos gerentes médios, auxiliando-os na resposta à questão: "as coisas estão indo bem?" (cf. LAUDON, Kenneth C., LAUDON, Jane P., op. cit., p. 40).

${ }^{243}$ No âmbito governamental, as atividades estratégicas são frequentemente realizadas por meio de lei. Nestes casos, é frequente que o Poder Executivo, normalmente gestor da informação estratégica e dotado de conhecimento específico para utilizá-la, apresente projetos de lei que contemplem estratégias definidas com o apoio da tecnologia de informação.

${ }^{244}$ Cf. LaUdon, Kenneth C., LAUdon, Jane P., op. cit., p. 45 e StaIR, Ralph M., ReYnolds, George W., op. cit., p. 22.

${ }^{245}$ Nesse sentido, fala-se na importância das tecnologias para "facilitação da atividade relacional, apoio nas tarefas administrativas e decisional", entendidas tais tarefas decisionais como decisões estruturadas de aplicação de normas jurídicas (cf. PAlOMAR OlMEDA, Alberto, Un paso más en la aplicación de la tecnología en el procedimiento administrativo, cit., pp. 92-93).
} 
É possível dividir as atividades de caráter operacional entre as que se situam no plano interno e as que estão no plano externo da Administração Pública. No plano interno, os meios informáticos e telemáticos podem ser usados no desempenho de dois tipos de atividades. As atividades informativas dizem respeito ao tráfego de informações entre os diversos sistemas informáticos e à produção de informação pelos diversos mecanismos admissíveis para tanto (recebimento de informação por parte de usuários, funcionários ou equipamentos). Já as atividades decisórias equivalem ao exercício de competências por meio de instrumentos informáticos, tema que traz questões jurídicas importantes para o governo eletrônico $^{246}$, pois as novas tecnologias podem levar a uma total automatização de várias tarefas, por meio da adoção de sistemas programados que dispensem a atuação humana em cada caso concreto.

Na dimensão externa da Administração, nem todos os serviços podem ser prestados mediante modalidades telemáticas ${ }^{247}$, pois há atividades que só se desenvolvem em caráter presencial ${ }^{248}$. Mesmo assim, elas podem ser beneficiadas pelos meios informáticos (por exemplo, compilando informações, agendando o atendimento, etc.). Em todos os casos, o denominador comum é a possibilidade de relacionar-se eletronicamente com a Administração Pública. Por meio da internet, as utilidades são oferecidas de maneira direta, sem intermediários ${ }^{249}$. O portal público na rede mundial de computadores pode ser

\footnotetext{
${ }^{246}$ Cf. Asís RoIG, Agustín de, op. cit., p. 142.

${ }^{247}$ Cf. CAMMAROTA, Giuseppe, Servizi pubblici in rete e applicabilità dei principi classici del servizio pubblico, in Informatica e diritto, n. 1/2, Napoli, Edizioni Scientifiche Italiane, 2005, p. 185.

248 "A possibilidade de utilizar meios eletrônicos na execução dos atos administrativos encontra-se certamente limitada pela singular natureza dos meios previstos para tanto, já que na maior parte dos casos a atividade a ser realizada é substancialmente material e deve ser realizada de forma presencial" (VALERO TORRIJOS, Julián, El régimen jurídico de la e-Administración, cit., p. 222).

${ }^{249}$ Cf. GARDINI, Gianluca, op. cit., p. 273 e DomíngueZ Luis, José Antonio, El derecho de información administrativa, cit., p. 548.
} 
compreendido como uma espécie de publicação oficial e como uma extensão da repartição pública, onde são prestados os serviços ${ }^{250}$.

É possível identificar, ainda, alguns tipos principais de serviços que podem ser prestados de maneira remota. Os mais simples seriam os informativos, pelos quais a Administração oferece informação, unilateralmente, ao cidadão ${ }^{251}$. De outra parte, no coração dos serviços prestados por meio da rede ${ }^{252}$ estão aqueles documentais ou burocrá$\operatorname{ticos}^{253}$, consistentes na entrega de um documento que permite ao usuário realizar uma atividade ou exigir da Administração uma determinada prestação (por exemplo, licenças e certidões) $)^{254}$. Há também os serviços transacionais, em que se estabelece uma relação complexa entre a Administração e o cidadão, com produção de efeitos jurídicos (por exemplo, reclamações e recursos eletrônicos, apresentação telemática de declarações tribu-

\footnotetext{
${ }^{250}$ Cf. QUADRos, Jaqueline Maria, Governo eletrônico e direito administrativo, in Rover, Aires José, Direito e Informática, Barueri, Manole, 2004, p. 245. CARLONI enfatiza a função do portal relativa à comunicação institucional (cf. I servizi in rete delle pubbliche amministrazioni, in MERLONI, Francesco, Introduzione all'egovernment, Torino, G. Giappichelli, 2005, pp. 202-203). O autor diferencia o oferecimento de informação sobre serviços, que seria um primeiro grau de evolução, da possibilidade de obter modelos para requerimentos e solicitações, que corresponderia a outro grau de evolução. Oferecer formulários eletrônicos constitui algo preparatório em relação à atividade principal, não podendo ser classificada inteiramente como mera informação nem como o próprio serviço (cf. op. cit., p. 205). Segundo o autor, o portal serve como ponto de acesso central para os diversos sítios (sites) da Administração, entendidos como as páginas da internet presentes em um servidor, acessíveis de modo unívoco por meio de um endereço associado ao ente público respectivo (ibidem, p. 197).

${ }^{251}$ Cf. MARTíNeZ GUTIÉRREZ, Rubén, Administración Pública Electrónica, cit., p. 229.

${ }^{252}$ Cf. CARLONI, Enrico, I servizi in rete delle pubbliche amministrazioni, cit., p. 192.

${ }^{253}$ Cf. CAMmaRota, Giuseppe, L'erogazione on line di servizi pubblici burocratici, cit., p. 47. Segundo o mesmo autor, a doutrina italiana majoritária anteriomente excluía da categoria "serviço público" as atividades jurídicas da Administração, enquadradas como "função administrativa". Mais recentemente, a noção de serviço público foi estendida também às atividades jurídicas da Administração Pública, incluindo nos serviços públicos os "serviços burocráticos" (cf. Servizi pubblici in rete e applicabilità dei principi classici del servizio pubblico, in Informatica e diritto, n. 1/2, Napoli, Edizioni Scientifiche Italiane, 2005, p. 186).

${ }^{254}$ Cf. MartíneZ GutiérRez, Rubén, Administración Pública Electrónica, cit., p. 230. O documento, no caso, não é necessariamente algo em papel, nem algo entregue fisicamente ao interessado. O conteúdo desses documentos tende a estar em bases de dados eletrônicas compartilhadas pelos órgãos públicos, não carecendo da intermediação por um documento em papel. Estes continuarão a ter grande importância enquanto não houver uma forma de a atividade estatal subsequente acessar a base de dados eletrônica correspondente ao resultado de uma atividade anterior. Sobre o tema, cf. infra, item 2.5.
} 
tárias, pagamento eletrônico de tributos e participação em processos de contratação pública) ${ }^{255}$.

\subsection{A relevância das novas tecnologias para o direito administrativo}

A ciência do direito não pode perder de vista temas atuais, muito menos deixar escapar à sua consideração a revolução decorrente das tecnologias do mundo contemporâneo $^{256}$. As mudanças radicais trazidas pela informática e pela telemática já não constituem um futurismo imaginativo, mas realidades - novos hábitos, novas formas de atuar, novas expectativas das pessoas - em relação às quais o jurista não pode ficar inerte, limitando-se a ignorá-las ${ }^{257}$. Elas se refletem de modo global sobre as relações humanas,

\footnotetext{
${ }^{255}$ Cf. BARNÉS VÁZQUEZ, Javier, Una reflexión introductoria sobre el Derecho Administrativo y la Administración Pública de la Sociedad de la Información y del Conocimiento, cit., pp. 42-43; CARLONI, Enrico, I servizi in rete delle pubbliche amministrazioni, cit., p. 204 e MARTíNEZ GUTIÉRREZ, Rubén, Administración Pública Electrónica, cit., p. 231. Neste caso, teria caráter transacional a realização de atividades que envolvem a produção de algum efeito jurídico. Pode-se falar, pois, em uma tipologia: (a) informação, como atividade unilateral; (b) comunicação, como atividade bilateral e (c) transação, como atividade bilateral dotada de efeitos jurídicos.

${ }^{256}$ Segundo BARNÉS VÁZQUEZ, os efeitos e consequências da internet afetam o Estado-nação e o conceito de soberania, a cultura administrativa, as garantias dos direitos fundamentais ou as relações entre o Estado e a sociedade, entre outras partes do direito público (cf. Una reflexión introductoria sobre el Derecho Administrativo y la Administración Pública de la Sociedad de la Información y del Conocimiento, cit., p. 28). Vale transcrever as fortes palavras do autor: "Sem embargo, e valha o exagero, enquanto nos ocupamos do passado, enchem-se bibliotecas inteiras nos Estados Unidos e na Europa sobre o futuro da Administração Pública e do Direito Administrativo. Enquanto debatemos se a Administração Pública é filha legítima da Revolução francesa ou sua filiação remonta muito além do Antigo Regime, constrói-se a Administração virtual, a Prefeitura virtual ou o non-stop-Government. No tempo em que nos detemos ao estudo das peças clássicas do processo administrativo, recobertas, no mais, por uma densa dogmática processualista e arraigadas em uma concepção um tanto reducionista das funções que cabe a ela cumprir, descobrem-se novas dimensões do processo administrativo como instrumento de informação, direção política e ponderação de interesses contrapostos, ou se instaura o governo eletrônico. E enquanto observamos o documento escrito, base de toda a filosofia que subjaz ao ato e ao procedimento administrativo ou à teoria da organização, aguarda-nos o documento eletrônico, com todos seus efeitos multiplicadores sobre tantas parcelas da vida administrativa (procedimento, organização, registros, etc.). Ou enquanto nos esforçamos por buscar um conceito geométrico de Administração Pública, forja-se uma Administração com uma nova face, na qual a transparência, a abertura e a participação da sociedade, a eficácia, a estrutura reticular e desconcentrada, não piramidal, ou as relações de cooperação, etc., emergem como renovadas marcas de identidade" (op. cit., p. 40, tradução livre).

${ }^{257}$ Cf. Villar Palasí, José Luis, op. cit., p. 501 e OCHOA Monzó, Josep, Hacia la ciberadministración y el ciberprocedimiento?, cit., p. 171.
} 
exigindo a adaptação do direito, para que possa garantir sua finalidade ${ }^{258}$. O direito tem a capacidade de disciplinar a vida social, mas certamente não pode imobilizá-la ${ }^{259}$, sobretudo quando a nova realidade pode trazer resultados que correspondem aos maiores anseios do respectivo sistema constitucional ${ }^{260}$. A realidade tecnológica, além de exigir uma normatização, abre novas possibilidades para a atuação do direito ${ }^{261}$. Nesse sentido, a tecnologia não é algo que se impõe ao jurista; ao contrário, é uma ferramenta flexível, objeto de opções de desenvolvimento e, portanto, de escolha ${ }^{262}$.

A informação sempre foi um elemento fundamental para o direito, na condição de meio de transmissão dos símbolos normativos do comportamento, refletidos e definidos nas palavras da lei ${ }^{263}$. Por isso, todo aperfeiçoamento no trato das informações tende a provocar efeitos significativos sobre o mundo jurídico. Nesse sentido, como veículo destinado ao suporte de informações juridicamente relevantes, o documento escrito representou uma revolução também para o mundo jurídico. Atualmente ocorre outra revolu-

${ }^{258}$ Cf. Gómez Puente, Marcos, op. cit., p. 149; Davara Rodríguez, Miguel Ángel, op. cit., p. 463; FERNÁNDEZ SALMERÓN, Manuel, VALERO TORRIJOS, Julián, La publicidad de la información administrativa en internet: implicaciones para el derecho a la protección de los datos personales, in Revista Aragonesa de Administración Pública, n. 26, Zaragoza, Instituto Aragonés de Administración Pública, jun. 2005, p. 79.

${ }^{259}$ Cf. PAlOMAR OlmEDA, Alberto, La utilización de las nuevas tecnologías en la actuación administrativa, cit., p. 366.

${ }^{260}$ Os problemas jurídicos ou organizativos decorrentes da novidade dos meios usados, neste caso, não podem impedir a continuidade da modernização administrativa, pois os objetivos e resultados atingíveis por meio do uso da telemática no desempenho da função administrativa são de segura importância e capazes de recompensar os esforços realizados (cf. OROFINO, Angelo Giuseppe, Telematica ed azione amministrativa, in Quaderni del DAE - Rivista di Diritto Amministrativo Elettronico, jul. 2004, disponível em http://www.cesda.it/quadernidae/index.php, acesso em 15.12.2010, p. 2). O tema é tratado, com grande expressividade, pela exposição de motivos da Lei espanhola n. 30/1992, de 26 de novembro: "El extraordinario avance experimentado en nuestras Administraciones Públicas en la tecnificación de sus medios operativos, a través de su cada vez mayor parque informático y telemático, se ha limitado al funcionamiento interno, sin correspondencia relevante con la producción jurídica de su actividad relacionada con los ciudadanos. Las técnicas burocráticas formalistas, supuestamente garantistas, han caducado, por más que a algunos les parezcan inamovibles, y la Ley se abre decididamente a la tecnificación y modernización de la actuación administrativa en su vertiente de producción jurídica y a la adaptación permanente al ritmo de las innovaciones tecnológicas" (texto disponível em http://www.boe.es/aeboe/consultas/bases datos/act.php?id=BOE-A-199226318 , acesso em 24.02.2011).

261 "Os avanços da ciência e da técnica têm sido, ao longo da história, determinantes na conformação das regras jurídicas e de sua transformação e desenvolvimento. É evidente a dependência do Direito em relação às inovações técnicas produzidas nos diversos ramos do saber humano, e em especial as geradas no mundo da ciência" (MestRe DELGADO, Juan Francisco, op. cit., p. 117). Essa influência das mudanças tecnológicas é particularmente significativa no caso da Administração Pública e do direito administrativo (cf. OCHOA MONZÓ, Josep, Hacia la ciberadministración y el ciberprocedimiento?, cit., p. 152).

${ }^{262}$ Cf. Poullet, Yves, La technologie et le droit: du défi à l'alliance, in VVAA, Mélanges G. Horsmans, Bruxelles, Bruylant, 2004, p. 966.

${ }^{263}$ Cf. FrosinI, Vittorio, Cibernetica diritto e società, cit., p. 46. 
ção, em razão do uso das novas tecnologias para a aplicação das normas jurídicas ${ }^{264}$, tornando-se a informação cada vez mais importante para o direito, considerada a possibilidade de seu processamento e transmissão automática para tal finalidade ${ }^{265}$.

Assim como o direito não pode deixar de levar em conta a sociedade da informação, o direito administrativo não tem como ignorar o governo eletrônico, com todas as inúmeras consequências por ele trazidas, inclusive em relação a institutos jurídicos fundamentais ${ }^{266}$. Com efeito, o direito administrativo é marcado pelo contato com a realida$\mathrm{de}^{267}$, sendo fortemente condicionado pelo contexto temporal, social e tecnológico ${ }^{268}$, transformando-se rápida e continuamente segundo a realidade existente ${ }^{269}$. Neste caso específico, cabe ao direito administrativo regular, de acordo com a realidade atual, o funcionamento da máquina informacional que é a Administração Pública. No modelo anterior de regulação, as atividades da Administração sempre tiveram como elemento básico e angular o documento escrito em papel ${ }^{270}$, reservando as tarefas de processamento da informação apenas aos seres humanos. A atualização desse modelo deve levar em conta utilização da tecnologia para suporte e processamento da informação, reconhecendo a sua importância para o direito.

\footnotetext{
${ }^{264}$ Cf. OCHOA MonZó, Josep, Hacia la ciberadministración y el ciberprocedimiento?, cit., p. 153.

${ }^{265}$ Com esas posibilidades, "[a] informação se converteu em objeto do direito" (GARCÍA MACHO, Ricardo, op. cit., p. 193).

${ }^{266}$ Cf. MARTíN DELGADO, Isaac, La administración electrónica como problema actual para la investigación y la docencia en el derecho administrativo, cit., p. 355. Segundo o mesmo autor, "A aparição de novas tecnologias acarretou uma revolução tecnológica de indubitáveis consequências no âmbito econômico e social, que está afetando a Administração e, com isto, a própria forma de entender o Direito administrativo" (cf. Naturaleza, Concepto y Régimen Jurídico de la Actuación Administrativa Automatizada, in Revista de Administración Pública, n. 180, Madrid, Centro de Estudios Políticos y Constitucionales, set.-dez. 2009, p. 354). Muito antes da chamada sociedade da informação, ZEIDLER já apontava que o uso de máquinas no exercício da função administrativa trazia problemas que forçavam a considerar as bases do direito administrativo (cf. Über die Technisierung der Verwaltung (Eine Einführung in die juristische Beurteilung der modernen verwaltung), 1959, trad. esp. de Manuel Heredero Higueras, Implicaciones jurídicas de la mecanización administrativa, Madrid, Centro de Formación y Perfeccionamiento de Funcionarios, 1963, p. 13).

${ }^{267}$ Assim já se reconheceu: "A atenção principal do jurista deve estar (ou deveria estar) dirigida sempre ao direito vigente. Mas ele também está obrigado a observar os fatos reais, para não perder nunca o contato com a realidade. $\mathrm{O}$ especial encanto do direito administrativo e, sobretudo, de sua parte não codificada, está em sua capacidade de adaptação a tal realidade" (ZEIDLER, Karl, op. cit., p. 71).

${ }^{268}$ Cf. MARTín DELGADO, Isaac, La administración electrónica como reto del derecho administrativo en el siglo XXI, cit., p. 326.

${ }^{269}$ Cf. ibidem, p. 309.

${ }^{270}$ Cf. MARTínez GutiérRez, Rubén, Administración Pública Electrónica, cit., p. 210.
} 
Da mesma maneira como a tecnologia tem chegado progressivamente à Administração Pública, as consequências sobre o direito administrativo seguem uma linha evolutiva. No momento em que os computadores eram usados apenas para o armazenamento de dados, de maneira isolada e estática, não havia efeitos significativos sobre o direito administrativo: de fato, toda a atividade administrativa era realizada pelos meios tradicionais e depois registrada em meio eletrônico, cabendo ao computador uma função auxiliar, sendo os efeitos jurídicos sempre intermediados por documentos em papel. O oferecimento dessa informação ao público trouxe a possibilidade de produção de consequências jurídicas, levando a discussões, em especial, quanto aos limites de acesso. Questões ainda mais relevantes surgem no plano das chamadas transações realizadas por meio da tecnologia, ou seja, operações com efeitos jurídicos processadas diretamente no computador sobretudo aquelas que substituem funcionalmente a atuação humana ${ }^{271}$. Por fim, o desenvolvimento da telemática traz um maior potencial para discussões jurídicas, especialmente no tocante a problemas relacionados à interação entre o usuário e o aparato administrativo, por meio da internet, fazendo surgir questões relevantes a respeito de portais institucionais, assinaturas eletrônicas e notificações por meio de sistemas informatizados ${ }^{272}$.

No momento atual da evolução da incorporação das novas tecnologias na Administração Pública, essas consequências sobre o direito administrativo chegaram a um elevado nível de importância. Tal como ocorreu em relação às revoluções constitucionalistas ocidentais do final do século XVIII, que transformaram o mundo e deram origem ao direito administrativo, a transformação hoje em curso deve levar a mudanças relevantes nesse ramo do direito, que por certo não equivalem a simples retoques superficiais ${ }^{273}$. É claro que as novas tecnologias não mudarão a essência da Administração Pública e do di-

\footnotetext{
${ }^{271}$ Desde os anos 60 as possibilidades de tratamento automático de informações passaram a ser aceitas por juristas "práticos" e pelos operadores do direito (cf. CARIDI, Gianfranco, op. cit., p. 15). Realmente, desde então, muitas operações juridicamente relevantes, especialmente em matéria contábil e de recursos humanos, têm sido desempenhadas por meio de sistemas informatizados, com efeitos jurídicos plenos, sem que isso gere perplexidades ou questionamentos relevantes. O baixo nível de contenciosidade talvez explique o fato de esses milhões de operações juridicamente relevantes serem pouco levadas em conta sob a ótica do direito.

${ }^{272}$ Há quem considere o direito do governo eletrônico uma consequência da internet (cf. GARCía MEXía, Pablo, op. cit., p. 88). Essa perspectiva, contudo, equivale a restringir um âmbito temático maior, que inclui não somente a rede mundial de computadores, mas a aplicação de regras jurídicas no plano interno da Administração, por meio de sistemas informatizados. A internet atualmente é um elemento essencial para o governo eletrônico, porém ambos não se confundem.

${ }^{273}$ Cf. GAMERO CASADO, Eduardo, El derecho administrativo ante la era de la información, cit., p. 35.
} 
reito administrativo, ou seja, a sua natureza, objetivos e limites ${ }^{274}$, bem como seus princípios fundamentais ${ }^{275}$. Todavia, em vista da necessidade de repensar o direito administrativo com a mesma intensidade com que se transforma a realidade, não é despropositado falar em um novo direito administrativo, decorrente da incorporação das novas tecnologias na Administração Pública ${ }^{276}$.

Esse novo direito administrativo pode ser considerado sob duas perspectivas diversas: a do direito positivo e a da ciência do direito. Sob a primeira perspectiva, a nova realidade social gerada pelas tecnologias da informação e da comunicação exige uma resposta eficaz por meio de regras que a disciplinem e, assim, garantam a validade jurídica das operações realizadas com seu auxílio, de forma a alcançar os objetivos constitucionais de prestação de melhores serviços ${ }^{277}$. Com aplicação das novas tecnologias à atividade

${ }^{274}$ Cf. Gómez Puente, Marcos, op. cit., pp. 117-118). Segundo o autor, por mais novos que sejam, estes problemas e questões não se afastam do objeto clássico do direito administrativo: a dialética entre poder estatal e liberdade individual, a eficácia da ação administrativa, o controle da legalidade e o conflito entre o interesse geral e os interesses particulares. Por isso, o desenvolvimento da administração eletrônica não vai necessitar refundação ou reinvenção da Administração e do direito administrativo, ainda que sem dúvida tenhamos que revisar seus procedimentos e métodos (pp. 118-119). Em sentido contrário, falando em reconsiderar o conceito mesmo de Direito Administrativo e Administração, cf. PIÑAR MAÑAS, José Luis, op. cit., p. 51.

${ }^{275}$ Cf. MARTín DELGADO, Isaac, La administración electrónica como problema actual para la investigación y la docencia en el derecho administrativo, cit., pp. 359-360. Segundo GROSS, a estruturação constitucional da organização administrativa é responsável pelo fato de o governo eletrônico não levar, na prática, a uma transformação generalizada da Administração Pública, tendo apenas como efeito facilitar a colaboração e a coordenação entre os órgãos públicos, mas não causando o desaparecimento dos atores individuais ou a transferência de responsabilidades (cf. op. cit., p. 72).

${ }^{276}$ Cf. BARNÉS VÁZQUEZ, Javier, Sobre el procedimiento administrativo, cit., p. 302. Segundo o autor, esse novo direito administrativo teria como pontos centrais a a informação e a comunicação, e nele a internet e as novas tecnologias não constituiriam um setor especial, uma política pública ou um simples método de trabalho da Administração, mas teriam um papel central (cf. Sobre el procedimiento administrativo: evolución y perspectivas, in VVAA, Innovación y reforma en el Derecho Administrativo, Global Law Press - Editorial Derecho Global, Sevilla, 2006, p. 303). Para DUNI, o uso da telemática na ação administrativa constitui um princípio geral do novo direito administrativo (cf. L'amministrazione digitale, cit., p. 12). Segundo LUIS CARLOS CANCELLIER DE OLIVO, “[u]ma nova sociedade exige a constituição de um novo Estado que se orienta por normas jurídicas de um novo Direito. No presente caso, de um novo Direito Administrativo, sintonizado com as demandas e os desafios contemporâneos" Segundo o autor, "este é o desafio do novo milênio: construir um Direito Administrativo da Era Digital, da sociedade do conhecimento, do Estado em rede" (Desafios do direito administrativo diante do Estado em rede, Florianópolis, UFSC, 2000, p. 27).

${ }^{277}$ Cf. MARTín DELGADO, Isaac, La administración electrónica como problema actual para la investigación y la docencia en el derecho administrativo, cit., p. 375 e La administración electrónica como reto del derecho administrativo en el siglo XXI, cit., p. 332). Segundo o autor, variam as formas, pois a organização administrativa e o exercício da função administrativa são marcadas pelo emprego de novas tecnologias, porém o procedimento administrativo eletrônico não é diferente do procedimento administrativo comum (cf. MARTíN Delgado, Isaac, Naturaleza, Concepto y Régimen Jurídico de la Actuación Administrativa Automatizada, in Revista de Administración Pública, n. 180, Madrid, Centro de Estudios Políticos y Constitucionales, set.-dez. 2009, p. 355). 
administrativa, deve-se reconsiderar a regulação em função da existência dos suportes informáticos, adaptação que normalmente ocorre com mais antecedência em outros ramos do direito, como é o caso do direito privado ${ }^{278}$.

Já a ciência do direito não pode deixar de reconhecer a existência de uma realidade a ser estudada e compreendida, de acordo com uma base conceitual ${ }^{279}$ que permita encontrar as grandes diretrizes de transformação e as consequências produzidas pelas referidas tecnologias em relação aos institutos jurídicos fundamentais ${ }^{280}$. De fato, a dogmática tradicional do direito público tende a não ser suficiente para explicar as novas estruturas internas, as formas de cooperação interadministrativa e o novo paradigma de relacionamento com o usuário que caracterizam o governo eletrônico ${ }^{281}$. Os princípios constitucionais da Administração Pública encontram, nessa realidade, novas formas de serem aplicados, para dar conta das várias situações novas emergentes. É necessário rever vários aspectos da doutrina do direito administrativo segundo o contexto tecnológico atual ${ }^{282}$, sendo necessário conceber categorias dogmáticas ainda não tratadas pela doutrina ou até mesmo reavaliar algumas das existentes ${ }^{283}$.

Os meios para a realização de atividades administrativas, sobretudo as atividades burocráticas, nunca foram considerados um tema de estudo relevante. A ciência do direito administrativo sempre teve pouco interesse pelos temas relacionados à atuação material realizada pela Administração, que normalmente obedece a determinações técnicas

\footnotetext{
${ }^{278}$ Cf. MARTínez GutiÉRrez, Rubén, Administración Pública Electrónica, cit., p. 210.

${ }^{279}$ Ressaltando a necessidade de uma base conceitual que analise com profundidade os efeitos do desenvolvimento da era digital sobre o direito, cf. PIÑAR MAÑAS, José Luis, op. cit., p. 61.

${ }^{280}$ Cf. FANTIGROSSI, Umberto, op. cit., p. 9.

${ }^{281}$ Dessa forma, "[a] dogmática tradicional do direito público, afirma-se, resulta insuficiente, pelo menos nos âmbitos da informação e do conhecimento. A ideia de subsunção da hipótese de fato de uma norma estável deve ser complementada ou substituída por sistemas operativos e procedimentos adequados, por instrumentos de direção capazes de adaptar-se ao ritmo vertiginoso dos tempos, quando as normas atemporais se mostrem ineficazes" (BARNÉS VÁZQUEZ, Javier, Una reflexión introductoria sobre el Derecho Administrativo y la Administración Pública de la Sociedad de la Información y del Conocimiento, cit., p. 38, tradução livre). Muito antes da chamada sociedade da informação, ZEIDLER já apontava que o uso de máquinas no exercício da função administrativa trazia problemas que forçavam a considerar as bases do direito administrativo (cf. op. cit., p. 13).

${ }^{282}$ Falando em reelaborar a teoria do direito administrativo com vistas à implantação da teleadministração na Administração Pública brasileira, com foco no ato administrativo praticado por meio da informática, cf. FILGUEIRAS JÚNIOR, Marcus Vinicius, Ato administrativo eletrônico e teleadministração, cit., p. 244.

${ }^{283}$ Cf. JINESTA LOBO, Ernesto, op. cit., p. 4.
} 
e não a postulados jurídicos. No passado, essa abstenção por parte do direito administrativo não tinha efeitos significativos, pois o poder político fixava de modo taxativo os fins próprios da ação administrativa e reconhecia à Administração alguma liberdade para definir como atingi-los. A partir do desenvolvimento tecnológico, é imprescindível rever a liberdade relativa aos meios de atuação, pois estes passaram a ter a possibilidade de influir diretamente nas finalidades perseguidas, havendo o risco de a Administração manipulá-los conforme seus interesses ${ }^{284}$.

De fato, na tradição do direito administrativo, dificilmente se cogitaria elaborar uma tese de doutorado em direito sobre a técnica de juntada de papéis, o uso de colchetes e clipes, as dimensões e densidades dos papéis, as cores de impressão e escrita ou o posicionamento, em cada folha, de elementos gráficos como timbres, carimbos e assinaturas. Cada um desses temas pode comportar regras técnicas de trabalho destinadas a trazer ganhos de eficiência, mas os meios tradicionais realmente não trazem complexas questões jurídicas. Para realizar atividades administrativas pelos meios tradicionais, basta adotar como aplicáveis alguns postulados universais, de fácil compreensão e aplicação, geralmente regulados de modo expresso pelo direito privado, como é o caso do documento em papel e da assinatura manuscrita. Rompendo com tais ideias de simplicidade, neutralidade e estabilidade, os complexos mecanismos informáticos e telemáticos podem proporcionar novas questões jurídicas, pois dependem da intermediação por um equipamento, podem ser usados de modo muito mais direcionado ${ }^{285}$ e estão em contínua transformação, trazendo novos problemas a cada momento. Assim, as novas tecnologias acentuam a importância jurídica

\footnotetext{
${ }^{284}$ Cf. CASTElls ARTeChe, José Manuel, La limitación informática, in MARTín RetORTILlO, Sebastián (org.), Estudios sobre la Constitución Española - Homenaje al Profesor Eduardo García de Enterría, Tomo II: De los Derechos y Deberes Fundamentales, Madrid, Civitas, 1991, p. 939.

${ }^{285}$ Nesse sentido, "[a] tecnologia não é neutra e parece razoável, para não dizer essencial, proceder, além das adaptações imediatas do quadro jurídico, a uma análise aprofundada das arquiteturas informacionais estabelecidas a fim de assegurar sua licitude e, sobretudo, garantir o respeito dos direitos fundamentais dos cidadãos" (BENYEKHLEF, Karim, op. cit., p. 268).
} 
dos meios necessários para a atividade administrativa, sobretudo aqueles usados como suporte de informações e decisões ${ }^{286}$.

\subsection{Uma posição adequada frente à realidade informática}

A premente adaptação do direito administrativo às novas tecnologias normalmente não ocorre no tempo devido ${ }^{287}$. Em geral, há uma proverbial defasagem entre normas e as transformações sociais a serem reguladas ${ }^{288}$, ou, mais especificamente, uma assincronia nas relações entre direito e tecnologia, de maneira que a absorção jurídica dos avanços da ciência e da técnica costuma ser lenta ${ }^{289}$. No caso do governo eletrônico, esse caráter conservador do direito é acompanhado pelo apego à sacralidade das formas - que sempre representou uma causa de atraso na aceitação do novo ${ }^{290}$-, bem como pela alienação, muito comum entre os juristas, em relação às tecnologias da informação e da comuni-

\footnotetext{
${ }^{286}$ As particularidades dos meios informáticos provocaram, há alguns anos, uma tendência à defesa de um novo ramo do direito, que seria o direito da informática. Entretanto, a posterior e maciça utilização das tecnologias da informação nos vários ramos jurídicos tradicionais acabou por revelar que o direito da informática poderia ser apenas uma linha de pesquisa ou de especialização, mas não um ramo do direito. De fato, assim como nunca houve um "direito do papel", não há necessidade de reconhecer a existência de um direito da informática, como ramo autônomo. A tendência é a incorporação profunda dos temas relativos às tecnologias da informação e da comunicação nos ramos do direito já conhecidos, levando o chamado direito da informática a confundir-se com o direito comum dos processos administrativos e das relações comerciais (cf., a respeito desse último ponto, BRAIBANT, Guy, Données personnelles et société de l'information: rapport au Premier ministre sur la transposition en droit français de la directive numéro 95-46, Paris, La Documentation française, 1998, disponível em: http://lesrapports.ladocumentationfrancaise.fr/cgibin/brp/telestats.cgi?brp_ref=984000836\&brp_file=0000.pdf, acesso em 30.12.2010, p. 13).

287 Entendendo que o direito administrativo não tem acompanhado a evolução tecnológica, cf. FILGUEIRAS JÚNIOR, Marcus Vinicius, Ato administrativo eletrônico e teleadministração, cit., p. 244.

${ }^{288}$ Cf. FernándeZ SAlMERÓn, Manuel, VAlERo TORRIJOS, Julián, La difusión de información administrativa en Internet y la protección de los datos personales: análisis de un proceso de armonización jurídica, in Nuevas Politicas Públicas: Anuario multidisciplinar para la modernización de las Administraciones Públicas, n. 1, Sevilla, Instituto Andaluz de Administración Pública, 2005, p. 309, disponível em http://www.juntadeandalucia.es/institutodeadministracionpublica/servlet/descarga?up=16514, acesso em 24.10.2010.

${ }^{289}$ Cf. PÉrez GálVEZ, Juan Francisco, op. cit., p. 570 e OChOA Monzó, Josep, Martínez GutiérRez, Rubén, La permeabilidad de la actividad administrativa al uso de tecnologías de la información y de la comunicación, cit., p. 78.

${ }^{290}$ Cf. DunI, Giovanni, L'amministrazione digitale, cit., p. 1.
} 
cação ${ }^{291}$. Com isso, os reflexos jurídicos da difusão da tecnologia ainda não foram adequadamente avaliados, sendo a disciplina jurídica da matéria quase inexistente entre nós, sendo também poucos os estudos a respeito do tema ${ }^{292}$.

A omissão do direito em regular de modo amplo e consistente a utilização das novas tecnologias no âmbito da Administração Pública traz sérias consequências negativas. De maneira apenas ilustrativa, pode-se identificar três atitudes diversas em relação ao tema, em vista da falta de uma regulação adequada da utilização das novas tecnologias: a) não reconhecer a possibilidade de utilizar as novas tecnologias, sob o argumento de elas se encontrarem previstas normativamente; b) aceitar somente a utilização dos meios que puderem ser compatibilizados com os limites do ordenamento vigente, após uma criteriosa avaliação; c) admitir sempre a utilização das novas tecnologias sem restrições substanciais, por se tratar apenas de meios para a atividade administrativa, que não trazem, em si, questões jurídicas significativas.

A primeira atitude parte do pressuposto de que leis e regulamentos, ao exigir assinaturas, timbres e registros, devem ser considerados dados imodificáveis e incontornáveis do problema ${ }^{293}$, pois leis formais não poderiam ser simplesmente derrogadas em vista de um melhor funcionamento da Administração ${ }^{294}$. Nessa linha, seria admissível

\footnotetext{
${ }^{291}$ Cf. Cotino HuESo, Lorenzo, Derechos del ciudadano administrado e igualdad ante la implantación de la Administración electrónica, cit., p. 125, com a ressalva de que esse problema vem sendo superado. A questão já foi objeto de críticas mais contundentes em tempos passados: "É precisamente ao jurista que se costuma imputar e não sem certa parte de razão um atraso de atitude mental dada sua tradicional formação, quando contempla a utilização destas técnicas do computador. Todos os demais ramos [do conhecimento] participam deste desejo pela utilização do computador e da telemática e são escassos os juristas que se sentem com autêntica inquietude esta preocupação" (VILlar PALASí, José Luis, op. cit., p. 503). Para MARÇAL JUSTEN FILHO, haveria uma espécie de impermeabilidade do direito às novas tecnologias, provocada pela dissociação entre conhecimento técnico e conhecimento jurídico. $\mathrm{O}$ autor observa que grande parte dos atuais juristas desenvolveu sua formação no contexto da primeira metade do século XX, tendo assim domínio dos aspectos jurídicos, mas não das questões tecnológicas, ao passo que as novas gerações estão produzindo a revolução tecnológica (cf. Pregão: comentários à legislação do pregão comum e eletrônico, 5. ${ }^{a}$ ed., São Paulo, Dialética, 2009, pp. 277-278). O problema, contudo, não foi exclusivo dos juristas: estudos de tecnologia e organização durante muito tempo foram considerados exclusivos para especialistas em sistemas de informação, tendo sido ignorados pelos cientistas sociais e políticos, exceto aqueles com um interesse explícito em tecnologia (cf. FounTAIN, Jane E., op. cit., p. 9 e GROSS, Thomas, op. cit., p. 65).

${ }^{292}$ Cf. Justen Filho, Marçal, Pregão, cit., p. 277. Segundo o autor, "verifica-se uma significativa dissociação entre a realidade econômica e a disciplina jurídica, eis que esta última ainda não formulou os princípios e as regras pertinentes à utilização da nova tecnologia" (op. e loc. cit.).

${ }^{293}$ Cf. DUNI, Giovanni, Teleamministrazione, cit., item 2.2.

${ }^{294}$ Cf. IASELLI, Michele, op. cit., p. 5.
} 
somente um modo de atuação em que os processos administrativos não fossem substancialmente alterados, podendo o computador apenas memorizar os dados provenientes de atos produzidos no modo tradicional, em papel $^{295}$. Essa atitude enfrenta hoje um difícil confronto com a realidade: com efeito, grande parte da atividade administrativa formal já é desempenhada diretamente por meios informatizados, os quais não servem apenas como meio de armazenamento de atos praticados em papel. Nesse sentido, o uso das tecnologias não é mais apenas uma realidade social; é uma realidade administrativa e jurídica, presente na atividade administrativa formalizada. Não admitir a possibilidade jurídica de utilizar as tecnologias da informação e da comunicação implicaria reconhecer a invalidade de milhões de atos administrativos já praticados. Isso traria não somente problemas de ordem prática, mas um rompimento da própria segurança jurídica, decorrente da invalidade maciça de tantos atos administrativos hoje plenamente eficazes.

A segunda atitude é uma variação da primeira, pois valoriza apenas alguns obstáculos normativos, tidos como incontornáveis. Admitidos esses impedimentos, a única saída é selecionar, entre as atividades a serem informatizadas, aquelas que são facilmente enquadráveis no esquema tradicional da atividade burocrática, procurando assim evitar vícios formais ${ }^{296}$. Embora pareça equilibrada, e muitas vezes seja a melhor solução possível, essa alternativa não traz somente aspectos positivos. Na verdade, ela tende a gerar formas de atuação excessivamente semelhantes às que existiam antes da era dos computadores e da informática ${ }^{297}$, ao aceitar uma limitação na utilização de meios que poderiam, caso bem regulados, trazer melhorias concretas para a atividade administrativa. Em outras palavras, a subserviência a determinados impedimentos normativos pode significar um desperdício para o aperfeiçoamento da atividade administrativa, objetivo que não pode ser ignorado pelo operador do direito.

A terceira atitude tampouco merece encômios. Com efeito, procurar reconhecer a validade da atividade administrativa formal realizada por meios informatizados,

\footnotetext{
${ }^{295}$ Segundo DUNI, este sempre foi um problema prático verificado pelos profissionais da informática em suas atividades no âmbito da Administração Pública (cf. La teleamministrazione come terza fase dell'informatica amministrativa, cit., item 2).

${ }^{296}$ Cf. BOMBARDELLI, Marco, op. cit., pp. 996-997.

${ }^{297}$ Cf. DunI, Giovanni, Teleamministrazione, cit., item 2.2.
} 
rejeitando a importância jurídica dos meios e suportes, pode até ser a posição mais atraente do ponto de vista pragmático, mas enfrenta dois problemas fundamentais: primeiro, essa solução despreza o fato de que os meios para as atividades administrativas tornaram-se complexos e suscetíveis de questões jurídicas substanciais; segundo, menospreza o papel fundamental do direito na regulação da Administração Pública. O governo eletrônico passa a ser uma iniciativa dos profissionais da informática e da ciência da administração, parecendo ser mais bem compreendido por essas outras ciências ${ }^{298}$. Ao direito é reservada uma função passiva e marginal, a reboque da realidade e dos estudos dessas outras disciplinas $^{299}$. Essa situação é bastante frequente na prática, pois vários documentos sobre governo eletrônico simplesmente não fazem referência ao direito administrativo ${ }^{300}$.

Nenhuma dessas atitudes, assim, parece apropriada. O direito não pode ser simplesmente contrário às novas tecnologias, não deve desperdiçar sua utilidade e não comporta a simples adesão às linhas traçadas pelas demais áreas do conhecimento. Na verdade, ele precisa estar devidamente adaptado para dar conta, de maneira ampla, da introdução das tecnologias da informação no setor público, com uma postura ativa, de liderança $\mathrm{a}^{301}$, que garanta a supremacia das exigências normativas em vista da submissão constitucional da Administração Pública ao ordenamento jurídico ${ }^{302}$. As novas tecnologias não

\footnotetext{
${ }^{298}$ Segundo tal entendimento, essas outras perspectivas (ciência política, ciência da administração, econômicas, etc.) seriam mais adequadas à investigação do governo eletrônico, por suas menores dificuldades de trabalhar sobre a realidade atual e sua maior flexibilidade metodológica para atuar sobre ela (cf. COTINO HUESO, Lorenzo, Derechos del ciudadano administrado e igualdad ante la implantación de la Administración electrónica, cit., p. 127).

${ }^{299}$ Cf. Cotino HuESo, Lorenzo, Derechos del ciudadano administrado e igualdad ante la implantación de la Administración electrónica, cit., p. 126.

${ }^{300}$ Cf. VAlERO TORRIJOS, Julián, Administrative Law and eGovernment, in EUROPEAN COMMISSION, DG INFORMATION SOCIETY, EGOVERNMENT UNIT, Breaking Barriers to eGovernment - Overcoming obstacles to improving European sublic services, 2006, disponível em http://www.egovbarriers.org/downloads/deliverables/Deliverable_1b_Aug_16_2006.pdf, acesso em 30.01.2011, p. 42.

${ }^{301}$ Em sentido contrário, entendendo que o direito "aguardará os movimentos políticos e sociais para a eles se adequar", cf. AlmEIDA, André de, Aspectos jurídicos do e-government no Brasil, in FERRER, Florencia, SANTOS, Paula, E-government: o governo eletrônico no Brasil, São Paulo, Saraiva, 2004, p. 54.

${ }^{302}$ Cf. VALERO TORRIJOS, Julián, Administración pública, ciudadanos y nuevas tecnologías, cit., p. 2944 e Las garantías jurídicas en la Administración electrónica ¿avance o retroceso?, in Cuenta con IGAE, Madrid, IGAE, n. 22, 2009, p. 28. Assim, a questão principal já não diz respeito a se é ou não possível a aplicação das novas tecnologias no âmbito da Administração Pública, devendo ser discutido como tornar possível a compatibilidade entre as novas tecnologias e os princípios garantistas da atividade administrativa (cf. PALOMAR OLMEDA, Alberto, La utilización de las nuevas tecnologías en la actuación administrativa, cit., p. 384).
} 
constituem um fim em si mesmas, mas um meio real para atingir muitos dos fins a serem buscados pela Administração, por força da Constituição ${ }^{303}$.

Para tanto, é preciso ter em mente que, mesmo no governo eletrônico, a estrutura normativa deve provir de mecanismos alinhados ao ordenamento constitucional. Como os sistemas de informação funcionam com base em regras, apesar de invisíveis ${ }^{304}$, é indispensável reconhecer que várias dessas regras também fazem parte do ordenamento jurídico. Somente desse modo é possível trazer também para o governo eletrônico a noção de Estado de Direito, somando as conquistas da tecnologia aos avanços consolidados no curso de vários séculos, sobretudo no tocante à garantia e efetivação dos direitos fundamentais. As regras contidas em sistemas informatizados não devem ser mais importantes que o ordenamento jurídico, muito menos alheias a este: devem, na verdade, integrar-se ao sistema normativo estatal ${ }^{305}$.

Assumindo sua missão, o direito pode ter três diferentes funções em relação à incorporação das tecnologias da informação na Administração Pública. Uma é limitar o emprego indevido de meios informáticos e telemáticos, preservando o ordenamento jurídico $^{306}$ e observando as fronteiras legais ${ }^{307}$, pois nem todas as possibilidades oferecidas pela tecnologia são admissíveis juridicamente, em vista das finalidades peculiares buscadas pela atividade administrativa ${ }^{308}$. Outra é conformar o uso das novas tecnologias, servindo

\footnotetext{
${ }^{303}$ Cf. MARTín DELGADO, Isaac, La administración electrónica como reto del derecho administrativo en el siglo XXI, cit., p. 327 e FILGUEIRAS JÚNIOR, Marcus Vinicius, Ato administrativo eletrônico e teleadministração, cit., p. 247.

${ }_{304}$ Cf. FounTAin, Jane E., op. cit., p. 61.

${ }^{305}$ Assim, os debates e as análises destinadas à elaboração e implantação de sistemas eletrônicos devem estar abertos à participação da sociedade. Os efeitos normativos e sociais são fruto das decisões e das escolhas da arquitetura dos sistemas, que não são neutras. Ao contrário, elas pressupõem valores e representações que devem ser objeto de uma discussão pública prévia (cf. BENYEKHLEF, Karim, op. cit., p. 277).

${ }^{306}$ Ainda tratando da mecanização, na década de 1960, ZEIDLER questionava: "Quanto antes assimile o jurista este novo estilo de administração, e quanto antes tente influir sobre sua evolução, tanto menores serão os perigos que possam derivar-se para nosso ordenamento jurídico. Quem senão o jurista está chamado a preservar o direito de uma degradação pela lei da máquina?" (op. cit., p. 72).

${ }^{307}$ Cf. GARCía MARCO, Francisco Javier, Ontologías y documentación electrónica en las actividades públicas, cit., p. 180.

${ }^{308}$ Cf. VALERO TORRIJOS, Julián, Protecção de datos personales y administración electrónica, cit., p. 45.
} 
para dar melhor rumo a tais iniciativas ${ }^{309}$, definindo critérios de acordo com o sistema legal e enquadrando os avanços tecnológicos para preservar a dignidade e as liberdades individuais $^{310}$. A última função é impulsionar os projetos de modernização tecnológica ${ }^{311}$, participando de modo ativo do desenvolvimento da administração eletrônica ${ }^{312}$, por meio de reformas legais ${ }^{313}$ que criem condições normativas para que a Administração possa extrair o máximo das tecnologias informáticas e telemáticas, mantido o respeito às exigências e garantias jurídicas pertinentes ${ }^{314}$.

\footnotetext{
${ }^{309}$ Cf. CASTELls ARTECHE, José Manuel, Aproximación a la problemática de la informática y administración pública, in Jornadas Internacionales sobre Informática y Administración Pública, Oñati, Instituto Vasco de Administración Pública, 1986, p. 28.

${ }^{310}$ Cf. De Roy, David, De Terwangne, Cécile, Poullet, Yves, op. cit., p. 356.

${ }^{311}$ Cf. VALERO TORRIJOS, Julián, El régimen jurídico de la e-Administración, cit., p. XVIII.

${ }^{312}$ Cf. SÁNCHEZ RODRÍGUEZ, Francisco, op. cit., p. 46.

${ }^{313}$ Cf. PETRAUSKAS, Rimantas, KISKIS, Mindaugas, Teaching on E-government: aspects of legal environment, in Galindo, Fernando, TRAUNMÜLLER, Roland (ed.), E-Government: Legal, Technical and Pedagogical Aspects, Zaragoza, Seminario de Informatica y Derecho, 2003, p. 339.

${ }^{314}$ Cf. VALERO TORRIJOS, Julián, Las garantías jurídicas en la Administración electrónica, cit., p. 21. Esse marco normativo deve observar as peculiaridades e fins próprios do setor público, de forma que não pode ser simplesmente inspirado em formas correntes no setor privado, como é o caso do comércio eletrônico (cf. GUILLÉN CARAMÉS, Javier, op. cit., p. 253; MARTÍN DELGADO, Isaac, La administración electrónica como reto del derecho administrativo en el siglo XXI, cit., p. 330; VALERO TORRIJOS, Julián, Administrative Law and eGovernment, cit., p. 42).
} 


\section{CAPÍTULO 2 - BASES JURÍDICAS DO GOVERNO ELETRÔNICO}

\subsection{A busca dos fundamentos da matéria}

A devida compreensão do relacionamento entre o governo eletrônico e o direito administrativo, que constitui o objeto deste estudo, pressupõe a identificação sistemática das grandes linhas mestras concernentes à disciplina jurídica relativa à introdução das novas tecnologias na Administração Pública brasileira, a fim de identificar como o direito positivo pátrio pode fundamentar, limitar ou conformar a utilização de tais tecnologias. Cuida-se, aqui, de encontrar as bases jurídicas do governo eletrônico no Brasil.

A busca dessas bases jurídicas será feita no próprio ordenamento brasileiro, sobretudo no texto constitucional vigente e em algumas normas esparsas relacionadas à matéria. Trata-se de uma tarefa prospectiva que envolve dificuldades substanciais, por duas razões diferentes: não há uma disciplina da matéria em nível legislativo nacional e as normas constitucionais não fazem referência tão expressa à utilização de meios eletrônicos pela Administração Pública, muito menos trazem referências claras a respeito de uma disciplina jurídica referente ao suporte material da atividade administrativa.

De fato, a Constituição brasileira reflete o contexto tecnológico da época de sua promulgação. $\mathrm{Na}$ ocasião, os equipamentos e sistemas informáticos já eram uma realidade e vários deles eram utilizados largamente na atividade administrativa. Por tal razão, o texto constitucional faz referência à informática (art. 22, IV), à comunicação de dados (art. $5^{\circ}$, XII) e mesmo à eletrônica (art. 222, § $\left.3^{\circ}\right)^{315}$. No entanto, o constituinte desconhecia, por exemplo, as imensas possibilidades da telemática, que só depois vieram a revelar-se. Assim, o texto constitucional não dedica uma só palavra à disciplina da integra-

\footnotetext{
${ }^{315}$ A palabra sistema é utilizada pela Constituição com alguma frequência, porém a primeira referência a sistema eletrônico só veio a ser feita com a Emenda Constitucional n. 62/09, que dispôs sobre a criação de leilões para o pagamento de créditos referentes a precatório judicial ( $\$ 9^{\circ}$ do art. 97 do Ato das Disposições Constitucionais Transitórias).
} 
ção telemática entre órgãos públicos e à utilização da internet para o relacionamento com o administrado.

No entanto, a ausência de previsão expressa não deve ser compreendida como uma vedação à utilização das novas tecnologias, mas como uma simples omissão, provocada pelo fato de a Constituição ter sido elaborada em um contexto tecnológico bastante diverso do atual. Nem seria possível condicionar o uso de uma tecnologia à sua previsão expressa na Lei Maior, porquanto a constante atualização do conhecimento tecnológico parece incompatível com a permanência própria do ordenamento constitucional. Assim, mais importante que encontrar, no texto constitucional, normas expressas a respeito de tecnologias cuja expansão ocorreu em momento sucessivo é apurar se as normas constitucionais são substancialmente compatíveis com elas. Sob este aspecto, não há incompatibilidade alguma entre o disposto pela Constituição brasileira e a utilização de meios informá$\operatorname{ticos}^{316}$, não sendo possível identificar impedimento jurídico que a tecnologia disponível não possa resolver ${ }^{317}$.

$\mathrm{Na}$ verdade, a compatibilidade das novas tecnologias com o ordenamento jurídico pátrio só depende de uma visão que atualize as normas constitucionais em face da sociedade da informação ${ }^{318}$. Nesse sentido, temas jurídicos fundamentais - tais como legalidade, igualdade, transparência e segurança jurídica - devem ser revisitados à luz das possibilidades oferecidas pelas novas tecnologias, oferecendo a devida tutela para as situações jurídico-subjetivas existentes $^{319}$. Cuida-se, pois, de - mantendo os princípios da vida na

\footnotetext{
${ }^{316}$ É o que tem sido entendido, por exemplo, a respeito da Constituição espanhola: "Nossa Constituição, como tantas outras, não estava pensada para o novo mundo digital e globalizado, não obstante, suas regras e princípios relativos à Administração se adequam com prática perfeição às novas exigências que devem redefinir a organização e a atuação administrativas" (COTINO HUESO, Lorenzo, Derechos del ciudadano administrado e igualdad ante la implantación de la Administración electrónica, cit., p. 153, tradução livre).

${ }^{317}$ Nesse sentido, todo problema pretensamente jurídico é de fato um problema sociológico, decorrente do antagonismo entre a tradição administrativa e a nova cultura internet (cf. LA COSTE, Pierre de, BÉNARD, Vincent, op. cit., p. 6).

${ }^{318}$ Sobre essa visão, cf. BERNADÍ GIL, Xavier, op. cit., p. 229. Analisando os efeitos da informática sobre o direito, já há algum tempo, LUIZ OLAVO BAPTISTA considerava necessário "procurar uma nova maneira de abordar o problema, levando em conta as características próprias do sistema informático e, de outro lado, aquelas premissas sobre as quais se funda o sistema normativo ou jurídico" (Direito e informática: reflexões sobre novas fronteiras, in Revista de Direito Publico, n. 86, São Paulo, RT, abr.-jun. 1988, p.161).

319 Cf. Donati, Daniele, Digital divide e promozione della diffusione delle ICT, in MERLONI, Francesco, Introduzione all'e-government, Torino, G. Giappichelli, 2005, p. 217.
} 
sociedade democrática e a natureza da relação entre administrado e Administração - considerar a adaptação do direito público e da prática administrativa às implicações concretas da introdução das tecnologias da informação ${ }^{320}$. Essa readaptação de esquemas dogmáticojurídicos próprios da administração em papel $^{321}$ exige que a mente dos juristas também esteja apta a raciocinar no novo mundo do governo eletrônico, evitando transportar para este, sem maiores cuidados, as limitações dos raciocínios próprios da administração tradicional $^{322}$.

Para encontrar as bases jurídicas do governo eletrônico no Brasil, é importante fazer uso de elementos doutrinários estrangeiros, advindos de países com modelos constitucionais semelhantes, em que o desenvolvimento de estudos jurídicos sobre o tema se encontra em estágio mais avançado. Mostra-se oportuno esclarecer, a propósito, que a referência à doutrina comparada não deve ocorrer simplesmente de molde a aplicar à realidade brasileira, às cegas, conclusões alcançadas com base em ordenamentos estrangeiros. O importante, neste estudo, é aproveitar a experiência da doutrina jurídica na avaliação de questões relativas a temas jurídicos muitas vezes universais, provocadas por tecnologias hoje globalizadas.

A composição dessas duas linhas - a busca das referências normativas e o aproveitamento da doutrina especializada - permitem a identificação de princípios do governo eletrônico. Tais princípios, que dão consistência a este capítulo, incluem tanto a aplicação, à realidade das novas tecnologias, dos tradicionais princípios referentes à atividade administrativa, quanto novos princípios relevantes para a compreensão e para o adequado funcionamento jurídico do governo eletrônico.

\footnotetext{
${ }^{320}$ Cf. Comeau, Paul. A., op. cit., pp. 73-74.

${ }^{321}$ Cf. OCHOA MONZÓ, Josep, Hacia la ciberadministración y el ciberprocedimiento?, cit., p. 170.

${ }^{322}$ Cf. DUNI, Giovanni, Ancora sul procedimento amministrativo telematico: le ultime ricerche, in Quaderni del DAE - Rivista di Diritto Amministrativo Elettronico, jul. 2004, disponível em http://www.cesda.it/quadernidae/pdf/Duni_DAE2004.pdf, acesso em 08.12.2010, pp. 1-2.
} 
O propósito deste capítulo não é apenas relacionar um grande número de novos princípios, independentemente de sua base normativa, apenas na tentativa de dar estatura doutrinária a este campo de estudo. Na verdade, a identificação de princípios jurídicos para o governo eletrônico tem encontrado alcance na doutrina ${ }^{323}$, em ordenamentos estrangeiros e em documentos internacionais relativos ao governo eletrônico ${ }^{324}$. Isso mostra a importância de procurar linhas mestras que possam estruturar um campo de estudos desafiador e ainda incipiente.

Em geral, este estudo procura alguma parcimônia em relação aos princípios metalegais, que sempre oferecem problemas, mesmo em relação ao governo eletrôni$\mathrm{co}^{325}$. Por isso, apontam-se como princípios próprios do governo eletrônico aqueles referentes à equivalência de suportes, à equivalência de garantias e à interoperabilidade, todos eles com indicação de alguma referência normativa, embora não sejam explicitamente contemplados pelo ordenamento jurídico. Também o princípio da eficiência pode ser considerado uma das bases do governo eletrônico, embora a ele não esteja restrito. Além disso, outros princípios referentes à atuação administrativa, que não surgiram em razão das novas tecnologias, serão analisados no transcorrer deste capítulo, sobretudo para apurar como eles podem atuar para limitar, conformar ou impulsionar o governo eletrônico brasileiro.

Os princípios aqui descritos poderão ser usados para a compreensão dos inúmeros aspectos jurídicos mais concretos relativos à incorporação das novas tecnologias nas atividades administrativas ${ }^{326}$, inclusive os que serão analisados, de maneira detida, nos capítulos seguintes. Também poderão servir para facilitar a aplicação, ao governo eletrônico, do regime jurídico pertinente à Administração Pública, o que ocorrerá por meio da ado-

\footnotetext{
${ }^{323}$ Cf. PETRAUSKAS, Rimantas, KISKIS, Mindaugas, op. cit., p. 340.

${ }^{324}$ Cf. GÓMEZ PuENTE, Marcos, op. cit., p. 119. Em âmbito latinoamericano, por exemplo, JinESTA LOBO ressalta os princípios enunciados pela Carta Iberoamericana de Governo Eletrônico, aprovada em Pucón, Chile, em 31 de maio e $1^{\circ}$ de junho de 2007, por ocasião da IX Conferência Iberoamericana de Ministros da Administração Pública e Reforma do Estado, da qual participou também o Brasil (cf. op. cit., p. 9). Tal documento, disponível em http://www.clad.org/siare isis/innotend/gobelec/cartagovernoeletronico.pdf, acesso em 15.06.2011, ainda que não tenha valor normativo no Brasil, pode servir com uma importante referência na matéria.

${ }^{325}$ Cf. Não é de forma alguma pacífico admitir a formulação de princípios metalegais GAMERO CASADO, Eduardo, Objeto, ámbito de aplicación y principios generales de la ley de administración electrónica, cit., p. 100 .

${ }^{326}$ Cf. GÓMEZ PUENTE, Marcos, op. cit., pp. 116-117.
} 
ção de novos instrumentos normativos ou pela reinterpretação da legislação que tenha sido elaborada em um contexto distante do atual ${ }^{327}$.

\subsection{A documentação das atividades administrativas}

Como já exposto, a informação sempre desempenhou uma função essencial na Administração Pública. Em vista disso, é preciso dar atenção ao tema referente à documentação das atividades administrativas, que apresenta especial relevância para o tratamento jurídico do governo eletrônico.

Na estrutura burocrática adotada pela Administração, decorrente da evolução das formas orais, o conhecimento da informação e as decisões administrativas devem ser feitos de maneira formal. Em toda experiência burocrática as decisões devem constar por escrito para que seja possível saber quem, quando e como provocou a atuação administrativa $^{328}$. Isso evita os atos pessoais voluntaristas ${ }^{329}$ e assegura ao interessado e a outras pessoas o acesso à decisão administrativa e aos elementos que a nortearam, o que serve como uma garantia para todos ${ }^{330}$. Nesse contexto, o registro da informação é a regra e a atuação oral, a exceção ${ }^{331}$.

\footnotetext{
${ }^{327}$ Cf. Fernández SAlMERón, Manuel, VALERo TorRIJOS, Julián, La difusión de información administrativa en Internet y la protección de los datos personales, cit., pp. 308-309, e, dos mesmos autores, La publicidad de la información administrativa en internet, cit., p. 78.

${ }^{328}$ Cf. RIVERO ORTEGA, Ricardo, El expediente administrativo - de los legajos a los soportes electrónicos, Navarra, Arazandi, 2007, p. 190.

${ }^{329}$ Cf. Fountain, Jane E., op. cit., p. 48 e Rivero ORTEGA, Ricardo, El expediente administrativo, cit., p. 194.

${ }^{330}$ Cf. Domínguez Luis, José Antonio, El derecho de información administrativa, cit., p. 538.

${ }^{331}$ A necessidade de registro das informações pode ser considerada uma exigência implícita no ordenamento brasileiro, sendo essencial para a garantia de direitos, como é o caso daquele assegurado pela alínea $b$ do inciso XXXIV do art. $5^{\circ}$ da Constituição da República, referente à obtenção gratuita de certidões em repartições públicas, para defesa de direitos e esclarecimento de situações de interesse pessoal. Nesse sentido, defendendo a necessidade de documentação escrita, por força do $\S 35$ do art. 153 da Constituição anterior, cf. Mello, Celso Antonio Bandeira de, Ato administrativo e direitos dos administrados, São Paulo, RT, 1981, p. 43.
} 
O documento, do latim docere, tem a função de fazer conhecer ${ }^{332}$. Isso ocorre de forma indireta, por meio da representação duradoura de atos ou fatos ${ }^{333}$. Assim, na visão tradicional, o documento é o objeto corpóreo capaz de representar tais eventos de maneira perene, por meio da percepção de signos gráficos nele incorporados ${ }^{334}$. O ato e o fato encerram-se após sua ocorrência; já o documento permanece no tempo ${ }^{335}$, podendo ser usado ou exibido no futuro ${ }^{336}$. Por sua capacidade de representar atos ou fatos juridicamente relevantes, que servem de base para a atividade administrativa, o documento pode ser considerado sede da atividade formal da Administração Pública ${ }^{337}$.

O documento é composto de um suporte, elemento material, e da informação, elemento de caráter imaterial ${ }^{338}$. Tradicionalmente, o suporte documental é o papel. Como o mais usual é o documento escrito mecanicamente e depois assinado ${ }^{339}$, há quem o confunda com o próprio suporte papel, identificando documento e escrito ${ }^{340}$. Trata-se de um equívoco, pois o mais importante não é o papel em si, mas sua idoneidade para desem-

\footnotetext{
${ }^{332}$ Cf. MASUCCI, Alfonso, Il documento amministrativo informatico, cit., p. 9.

${ }^{333}$ Cf. Merloni, Francesco, La documentazione amministrativa digitalizzata. Aspetti giuridici, in MERLONI, Francesco, Introduzione all'e-government, Torino, G. Giappichelli, 2005, p. 86 e MASUCCI, Alfonso, Il documento amministrativo informatico, cit., p. 9. Grande parte da doutrina gira em torno do suporte de atos administrativos, porém a representação dos fatos que instruem o processo não é menos essencial, sendo uma das grandes utilidades do documento. Nesse sentido, já se reconheceu que toda atividade dos sujeitos públicos é representada em documentos, mas nem todos os documentos correspondem a atos (cf. RIVERO ORTEGA, Ricardo, El expediente administrativo, cit., p. 194). Assim, o objeto material do documento administrativo eletrônico deve referir-se a qualquer informação ou atuação administrativa (atos resolutórios ou de trâmite, informes, provas, informação pública, etc.) produzida pela Administração Pública (cf. SANZ LARRUGA, Francisco Javier, Documentos y archivos electrónicos, in GAMERO CASADO, Eduardo, VALERO TORRIJOS, Julián (coord.), Comentarios a la Ley de Administración electrónica - Ley 11/2007, de 22 de junio, de acceso elec-

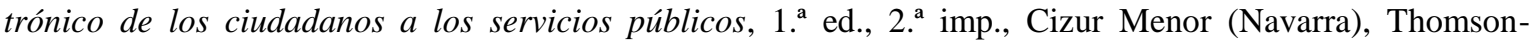
Civitas, 2009, p. 462). A conservação das atividades instrutórias é útil para compreender de que modo foi formada a vontade da Administração, sendo representadas em documentos públicos, porém não são decisões administrativas (cf. MERLONI, Francesco, La documentazione amministrativa digitalizzata, cit., p. 89).

${ }^{334}$ Cf. MASUCCI, Alfonso, Il documento amministrativo informatico, cit., pp. 10 e 12; CONTALDO, Alfonso, GoRGA, Michele, E-law - Le professioni legali, la digitalizzazione delle informazioni giuridiche e il processo telematico, Soveria Mannelli, Rubbettino, 2006, p. 57; MAGÁn PERALES, José María Aristóteles, op. cit., p. 95 e Heredero Higueras, Manuel, Problemas Jurídicos de la mecanización administrativa, in Documentación Administrativa, n. 124, Madrid, Escuela Nacional de Administración Pública, jul.-ago. 1968, pp. $72-73$.

${ }^{335}$ Cf. MASUCCI, Alfonso, Il documento amministrativo informatico, cit., p. 10.

${ }^{336}$ Cf. MERLONI, Francesco, La documentazione amministrativa digitalizzata, cit., p. 87.

${ }^{337}$ Cf. MARONE, Umberto, op. cit., p. 24.

${ }^{338}$ Cf. RABBito, Chiara, L'informatica al servizio della pubblica amministrazione e del citadino, Bologna, Gedit, 2007, p. 53, Domínguez LuIS, José Antonio, La explosión informática, el Derecho y la Administración, in Revista de la Facultad de Derecho de la Universidad Complutense, n. 86, Madrid, Universidad Complutense, 1996, p. 127 e, do mesmo autor, El derecho de información administrativa, cit., p. 543.

${ }^{339}$ Cf. Duni, Giovanni, L'amministrazione digitale, cit., p. 4.

${ }^{340}$ Cf. Domínguez LuIS, José Antonio, El derecho de información administrativa, cit., p. 539.
} 
penhar as funções próprias do documento ${ }^{341}$, tais como o registro de toda operação realizada ou decisão adotada ${ }^{342}$, o que pode ser obtido também por outros tipos de suporte.

\subsubsection{O documento administrativo eletrônico}

Na sociedade da informação, o conceito de documento tem abrangência maior que a tradicional ${ }^{343}$, incluindo, além do escrito em papel, o documento em suporte eletrônico $^{344}$. No primeiro caso, as informações são registradas graficamente sobre uma lâmina de origem vegetal, com o uso de uma linguagem acessível ao homem; no segundo caso, as informações - referentes a texto, gráfico, sons ou imagens - são registradas em um suporte utilizável por um computador. Esse suporte pode ser magnético (v.g., disquete e disco rígido), ótico (v.g., CD e DVD) ${ }^{345}$ ou qualquer outro reconhecido pela máquina (v.g., chips usados em cartões de memória e pendrives ${ }^{346}$ ). $\mathrm{O}$ registro de uma informação em

\footnotetext{
${ }^{341}$ Cf. DAVARA RodríGUEZ, Miguel Ángel, op. cit., p. 455.

${ }^{342}$ Cf. OROFINO, Angelo Giuseppe, Forme elettroniche e procedimenti amministrativi, cit., pp. 77-78. A lei norueguesa, por exemplo, define documento como uma quantidade de informações que é guardada em um suporte para posterior leitura, audição, mostra ou transmissão, não fazendo referência a papel (cf. PRINS, J.E.J. (ed.) et al., E-Government and its Implications for Administrative Law, cit., p. 76).

${ }^{343}$ Cf. MASUCCI, Alfonso, Il documento amministrativo informatico, cit., p. 15.

${ }^{344}$ Cf. OROFInO, Angelo Giuseppe, Forme elettroniche e procedimenti amministrativi, cit., pp. 77-78 e DOMínguez LuIS, José Antonio, La explosión informática, cit., p. 121; LINARES GIL, Maximino Ignacio, Identificación y autenticación de las administraciones públicas, in GAMERO CASADO, Eduardo, VALERO TORRIJOS, Julián (coord.), Comentarios a la Ley de Administración electrónica - Ley 11/2007, de 22 de junio, de acceso electrónico de los ciudadanos a los servicios públicos, 1. ${ }^{\mathrm{a}}$ ed., 2. ${ }^{\mathrm{a}}$ imp., Cizur Menor (Navarra), Thomson-Civitas, 2009, p. 286. Na verdade, mesmo antes dos suportes eletrônicos, já havia documentos em outros suportes que não o papel. É o caso, por exemplo, dos documentos de reprodução mecânica (v.g., fotográfica, cinematográfica ou fonográfica), expressamente referidos pelo art. 383 do Código de Processo Civil. A respeito dessas formas marginais, cf. CONTALDO, Alfonso, GORGA, Michele, op. cit., p. 57.

${ }^{345}$ Cf. SANZ LaRruga, Francisco Javier, Documentos y archivos electrónicos, cit., p. 463.

${ }^{346}$ É possível fazer referência a tais dispositivos como suporte eletrônico para o registro da informação, sendo os demais designados como suporte magnético ou ótico. Sob uma perspectiva jurídica, essa distinção não traz consequência alguma. Por isso, este estudo não adota uma distinção terminológica entre os diversos tipos de meios para o registro da informação próprios das novas tecnologias, designando-os genericamente como suporte eletrônico, digital ou informático.
} 
meio eletrônico ocorre por meio de sua codificação para uma linguagem binária ${ }^{347}$. Dessa maneira, documento eletrônico ${ }^{348}$ é aquele passível de ser gerado, alterado e lido por meio de um sistema informático ${ }^{349}$.

O documento eletrônico, assim, implica a modificação do suporte físico da informação e a maneira com que se faz acessível aos seres humanos ${ }^{350}$. A informação registrada em meio eletrônico não é inteligível diretamente ao homem ${ }^{351}$, sendo necessário um programa que converta em linguagem natural a expressão codificada e a represente em um suporte que possa ser visualizado ${ }^{352}$. Não se trata, portanto, de uma verdadeira forma

\footnotetext{
${ }^{347}$ Cf. LinARES GIL, Maximino Ignacio, Modificaciones del Régimen Jurídico Administrativo derivadas del empleo masivo de nuevas tecnologías. En particular el caso de la Agencia Estatal de Administración Tributaria, in MATEu De Ros, Rafael, LóPEZ-MONís GaLlEGo, Mónica, Derecho de Internet: La Ley de Servicios de la Sociedad de la Información y de Comercio Electrónico, Cizur Menor, Aranzadi, 2003, p. 729 e CoELHO, Fábio Ulhoa, op. cit., p. 42. Atribui-se um valor dúplice (zero ou um) à menor parte de material magnético ou ótico, dando-se a essa unidade mínima de informação o nome de bit. Um conjunto de bits a que é possível atribuir um significado é denominado byte (cf. CONTALDO, Alfonso, GorGA, Michele, op. cit., p. 66). Sobre a linguagem binária, cf. também JOLY-PASSANT, Elisabeth, L'écrit confronte aux nouvelles technologies, Paris, LGDJ, 2006, p. 59 e LOSANO, Mario G., Informática Jurídica, São Paulo, Saraiva-EDUSP, 1976, pp. 121-132.

${ }^{348}$ Há quem afirme que a terminología correta seria documento informático ou documento informatizado (cf. DOMINGUEZ LUIS, José Antonio, El derecho de información administrativa, cit., pp. 543-544). A rigor, como a informática é uma parte da eletrônica, há documentos eletrônicos que não têm relação com a informática, como é o caso das mensagens transmitidas por fax (cf. DAVARA RODRÍGUEZ, Miguel Ángel, op. cit., p. 457). Feita essa ressalva, vale esclarecer que a expressão documento eletrônico é utilizada neste estudo, em vista de seu uso corrente entre operadores e usuários, sendo também utilizadas, como sinônimos, as expressões documento digital e documento informático. Sobre as questões terminológicas, cf. também a nota 195.

${ }^{349}$ Cf. RABBITO, Chiara, L'informatica al servizio della pubblica amministrazione e del citadino, cit., p. 57.

${ }^{350}$ Cf. LinARES GIL, Maximino Ignacio, Modificaciones del Régimen Jurídico Administrativo derivadas del empleo masivo de nuevas tecnologías, cit., p. 729.

${ }^{351}$ Cf. COELHO, Fábio Ulhoa, op. cit., p. 42.

${ }^{352}$ Cf. Asís RoIG, Agustín de, op. cit., pp. 144-145 e Davara Rodríguez, Miguel Ángel, op. cit., p. 459. Fala-se, aqui, em documento eletrônico em sentido estrito, que não se confunde com o documento eletrônico em sentido amplo, ou seja, aquele preparado em um computador e depois impresso, o qual, sendo apreensível pelo ser humano e estando em suporte físico, em nada se diferencia do documento tradicional. Sobre a distinção, cf. CIAMPI, Isabella D'Elia, L'informatica e le banche dati, in CASSESE, Sabino (org.), Diritto amministrativo speciale, t. II, 2. ${ }^{a}$ ed., Milano, Giuffrè, 2003, pp. 1676-1677; CONTALDO, Alfonso, GorGA, Michele, op. cit., p. 67 e MASUCCI, Alfonso, Il documento amministrativo informatico, cit., p. 34.
} 
escrita $^{353}$, pois o documento digital não é diretamente legível pelo ser humano, exigindo, para sua inteligibilidade, a restituição por intermédio de um computador ${ }^{354}$.

A informática traz uma nova maneira de entender a materialidade dos documentos e, em especial, dos documentos administrativos ${ }^{355}$. Isso se dá principalmente porque, no caso do documento eletrônico, é possível separar a informação do suporte - por exemplo, transferindo o documento de um disco rígido para um disco ótico, mantido íntegro o seu conteúdo, ou mesmo efetuando cópias idênticas de um mesmo arquivo digital ${ }^{356}$. Assim, o suporte não é um elemento constitutivo do documento eletrônico, como o é no documento em papel: é um acidente em relação à substância imaterial da natureza do documento informático. Todavia, trata-se de um elemento acidental absolutamente necessário, pois o registro das informações deve estar em algum lugar para produzir efeitos ${ }^{357}$.

A convivência entre os tipos de documentos causa situações que devem ser adequadamente compreendidas, sobretudo nas passagens de um suporte para outro, que

\footnotetext{
${ }^{353}$ Cf. MASUCCI, Alfonso, Il documento amministrativo informatico, cit., pp. 14-15. Há quem afirme que o escrito agora poderia existir em suporte eletrônico (cf. BAUZÁ MARTORELL, Felio José, Procedimiento Administrativo Electrónico, cit., pp. 136-137). Segundo FANTIGROSSI, o documento digital constituiria realmente um escrito, por representar atos e fatos por meio de signos reconhecíveis e ter a capacidade de conservação e circulação (cf. op. cit., p. 58). Falando em escritos eletrônicos, cf. JOLY-PASSANT, Elisabeth, op. cit., p. 62. Também no sentido de que os escritos poderiam usar qualquer suporte, cf. FoullLeul, Nicolas, op. cit., pp. 83-84. De acordo com outra visão, o documento eletrônico supriria o requisito legal da forma escrita por meio de uma ficção jurídica (cf. GIURDANElla, Carmelo, GuARnACCIA, Elio, Elementi di diritto amministrativo elettronico, Matelica, Halley, 2005, p. 28). A equiparação parece uma solução apropriada, uma vez que não exige identificar, artificialmente, documento eletrônico e documento escrito, mas oferece as consequências jurídicas adequadas. O mais importante, como menciona MASUCCI, é evitar que a discussão sobre a forma escrita se desenvolva com métodos e técnicas hermenêuticas formalistas ou anacrônicos, devendo-se ter em conta, em respeito aos princípios que são o fundamento da forma escrita, a evolução e a transformação dos meios da atividade administrativa (cf. L'atto amministrativo informatico, cit., p. 90).

${ }^{354}$ Cf. CANTERO, Anne, op. cit., p. 333 e JOLY-PASSANT, Elisabeth, op. cit., p. 59.

${ }^{355}$ Cf. MAGÁn Perales, José María Aristóteles, op. cit., p. 95. Sobre a revitalização do documento administrativo como objeto de estudo, provocada pela modernização tecnológica da atidiade administrativa, cf. VALERO TORRIJOS, Julián, La gestión y conservación del documento administrativo electrónico, in El documento electrónico: aspectos jurídicos, tecnológicos y archivísticos, Castelló de la Plana, Universitat Jaume I, 2008 , p. 27.

${ }^{356}$ Cf. LiNARES GIL, Maximino Ignacio, Identificación y autenticación de las administraciones públicas, cit., p. 287 e DUNI, Giovanni, L'amministrazione digitale, cit., pp. 11-12.

${ }^{357}$ Cf. PONTI, Benedetto, op. cit., pp. 70-71. Muitos falam em documentos virtuais ou em desmaterialização, expressão de uso corrente na doutrina francesa (cf. CANTERO, Anne, op. cit., p. 21). Sobre a utilização de tais adjetivos, cf. supra, nota 195.
} 
normalmente geram cópias do documento original ${ }^{358}$. É assim, por exemplo, na digitalização de escritos em papel, atividade essencial para o desenvolvimento do governo eletrôni$\mathrm{co}^{359}$, que deve ser feita com mecanismos que assegurem a autenticidade do documento informático produzido ${ }^{360}$. É também o caso da reprodução impressa da informação que se encontra em suporte informático - o chamado printout $^{361}$. Nesta situação, embora seja frequente acrescentar ao impresso signos e símbolos tradicionais, como a assinatura, para ratificar seu conteúdo ${ }^{362}$, a impressão em papel nada acrescenta ao documento eletrônico, plenamente constituído no mesmo momento em que surge na memória do computador ${ }^{363}$. Importa, tão somente, garantir que a informação atribuída ao sistema realmente provenha dele $^{364}$. Assim, por exemplo, as cópias produzidas em papel, a partir de originais eletrônicos, devem incluir um código gerado eletronicamente que permita comparar a autenticidade mediante o acesso aos sistemas informáticos da Administração ${ }^{365}$. Entre documentos eletrônicos, contudo, em geral já não é possível falar em cópia, mas em duplicação, pois o

\footnotetext{
${ }^{358}$ A condição de cópia é adequadamente reconhecida, por exemplo, pelo Código de Processo Civil brasileiro (art. 365, V).

${ }^{359}$ Cf. VALERO TORRIJOS, Julián, El régimen jurídico de la e-Administración, cit., p. 183.

360 Cf. Merloni, Francesco, La documentazione amministrativa digitalizzata, cit., p. 99. O Código de Processo Civil admite, por exemplo, que o documento digitalizado seja apresentado "pelos órgãos da Justiça e seus auxiliares, pelo Ministério Público e seus auxiliares, pelas procuradorias, pelas repartições públicas em geral e por advogados públicos ou privados, ressalvada a alegação motivada e fundamentada de adulteração antes ou durante o processo de digitalização" (art. 365, VI), mas o responsável deve conservar o documento até o prazo para propositura da ação rescisória $\left(\S 1^{\circ}\right)$, podendo o juiz determinar o depósito do original em cartório $\left(\S 2^{\circ}\right)$.

${ }^{361}$ Cf. BAUZÁ MARTOREll, Felio José, Procedimiento Administrativo Electrónico, cit., p. 16 e DaVARA RODRÍGUEZ, Miguel Ángel, op. cit., p. 458.

${ }_{362}$ Cf. DAVARA RodríGUEZ, Miguel Ángel, op. cit., p. 458.

${ }^{363}$ Cf. DunI, Giovanni, L'utilizzabilità delle tecniche elettroniche nell'emanazione degli atti e nei procedimenti amministrativi, cit.

${ }^{364}$ Cf. DunI, Giovanni, Teleamministrazione, cit., item 2.3. O inciso V do Código de Processo Civil brasileiro, acrescido pela Lei n. 11.419/06, dispõe que os extratos digitais de bancos de dados públicos fazem a mesma prova que o original, desde que atestado pelo seu emitente que as informações conferem com as originais. Tal dispositivo, assim, não exige que a certidão seja expedida por meio informático, podendo constituir um documento manuscrito. Por outro lado, o $\S 2^{\circ}$ do artigo 399 do mesmo Código, também incluído pela Lei n. 11.419/06, admite que as repartições públicas forneçam documentos em meio eletrônico "conforme disposto em lei, certificando, pelo mesmo meio, que se trata de extrato fiel do que consta em seu banco de dados ou do documento digitalizado". A exigência de lei, bastante discutível por não limitar o uso da informação sem atender a propósito algum, parece ter sido atendida com a edição da Lei n. 12.527/11, que não faz distinção entre os suportes em relação a documentos e informações (art. $4^{\circ}$, I e II).

${ }^{365}$ Cf. VALERO TORRIJOS, Julián, La gestión y conservación del documento administrativo electrónico, cit., p. 54 e Cotino Hueso, Lorenzo, Derechos del ciudadano, cit., p. 205.
} 
arquivo obtido a partir da reprodução do original é exatamente idêntico a este ${ }^{366}$. Só faz sentido falar em cópia eletrônica quando o formato do segundo documento, apesar de eletrônico, não é idêntico ao primeiro ${ }^{367}$.

\subsubsection{O valor jurídico do documento eletrônico na Administração Pública}

Alguma desconfiança tem sido associada ao documento eletrônico ${ }^{368}$, por parte do usuário $^{369}$ ou mesmo entre vários juristas que já se ocuparam do assunto ${ }^{370}$, sobretudo em vista de sua volatilidade ${ }^{371}$, decorrente do fato de a informação não estar ligada de modo permanente a um suporte específico ${ }^{372}$ e em razão de não ser diretamente apreensível pelo ser humano. É comum questionar-se a excessiva facilidade de sua alteração, o risco de manipulação de suas informações e a possibilidade de problemas em sua transmissão ${ }^{373}$. É a falta de confiança na tecnologia que sustenta, por exemplo, a preferência, da parte de alguns, por exigir a duplicação do documento informático por meio de uma cópia em pa$\mathrm{pel}^{374}$. Por outro lado, por possibilitar o acesso telemático, o documento eletrônico faz sur-

\footnotetext{
${ }^{366}$ Cf. Cotino Hueso, Lorenzo, Derechos del ciudadano, cit., p. 205; DunI, Giovanni, Ancora sul procedimento amministrativo telematico, cit., pp. 2-3; GIURDANELLA, Carmelo, GUARNACCIA, Elio, op. cit., pp. 2021; MARTín Delgado, Isaac, La gestión electrónica del procedimiento administrativo, in Cuadernos de Derecho Local, n. 22, Madrid, Fundación Democracia y Gobierno Local, out. 2009, p. 93; MERLONI, Francesco, La documentazione amministrativa digitalizzata, cit., p. 99; OCHOA MONZÓ, Josep, MARTínez GuTIÉRREZ, Rubén, La permeabilidad de la actividad administrativa al uso de tecnologías de la información y de la comunicación, cit., p. 108; VALERO TORRIJOS, Julián, El régimen jurídico de la e-Administración, cit., p. 35.

${ }^{367}$ Cf. VALERO TORRIJOS, Julián, La gestión y conservación del documento administrativo electrónico, cit., p. 53.

${ }^{368}$ Cf. PUnZÓn MORALEDA, Jesús, Introducción, cit., p. 9 e VALERo TORRIJOS, Julián, La e-Administración Pública, cit., p. 98.

${ }^{369}$ Cf. Cotino Hueso, Lorenzo, Derechos del ciudadano, cit., p. 211.

${ }^{370}$ Cf. Así́ RoIG, Agustín de, op. cit., p. 145; DAVARA RodríGUEZ, Miguel Ángel, op. cit., p. 459 e Rivero ORTEGA, Ricardo, El expediente administrativo, cit., p. 181. Este último, por exemplo, no trecho referido, afirma que "a constância documental tem numerosas vantagens do ponto de vista do princípio da legalidade e da realização do Estado de Direito" (op. e loc. cit., tradução livre).

${ }^{371}$ Cf. DUNI, Giovanni, L'amministrazione digitale, cit., pp. 85-86 e LINARES GIL, Maximino Ignacio, Identificación y autenticación de las administraciones públicas, cit., p. 282.

${ }^{372}$ Cf. LinARES GIL, Maximino Ignacio, Identificación y autenticación de las administraciones públicas, cit., p. 287.

${ }_{373}$ Cf. SÁnCHEZ RodRíGUEZ, Francisco, op. cit., p. 33.

${ }^{374}$ Cf. MERLONI, Francesco, Sviluppo dell'e-government e riforma delle amministrazioni, cit., p. 12.
} 
gir novos riscos, tornando necessário proteger os canais de comunicação, para evitar a interceptação de informações ${ }^{375}$. No entanto, essa resistência psicológica, que pode ser atribuída ao desconhecimento ${ }^{376}$ ou ao simples preconceito ${ }^{377}$ em relação aos meios tecnológicos, precisa ser superada ${ }^{378}$.

É certo que o papel ofereceu historicamente alguns induvidosos mecanismos de segurança, dada sua consistência, maleabilidade e possibilidade de conservação, que permitiam garantir de maneira relativa a integridade da informação, assim como sua autenticidade $^{379}$, o que levou a uma supervalorização das vantagens técnicas do documento escrito $^{380}$. Entretanto, o papel jamais esteve isento de manipulações, falsificações, perdas ou destruições ${ }^{381}$. Na verdade, em vista do uso intensivo desse suporte ${ }^{382}$, os possíveis problemas a ele relacionados já estão incorporados à cultura burocrática, de sorte que parecem inexistentes ou menos preocupantes.

No entanto, tais problemas não se mostram mais graves no caso dos documentos eletrônicos, sendo uma ilusão acreditar que o papel constitui o meio mais seguro

\footnotetext{
${ }^{375}$ Cf. SÁNCHEZ RodríGUEZ, Francisco, op. cit., p. 39.

${ }^{376}$ Não é de hoje que se reconhece que os meios eletrônicos podem oferecer adequadas condições de segurança: "O problema surge da insegurança que proporcionam a dúvida, por um lado, e o desconhecimento, por outro. A dúvida, produto da possibilidade de manipulação dos conteúdos dos documentos que se encontram em suportes informáticos ou que tenham sido gerados por estes meios, com o que pode parecer inseguro em relação a sua originalidade ou autenticidade. Dúvida que provém, em muitas ocasiões, do desconhecimento da informática, porque da mesma maneira que ela oferece muitas possibilidades de manipulação, também oferece outras de asseguramento da autenticidade dos conteúdos” (DAVARA RoDRíGUEZ, Miguel Ángel, op. cit., p. 466).

377 Segundo VALERO TORRIJOS, “é imprescindível realizar um importante esforço por deixar de lado a mentalidade defasada que transforma em falsas barreiras as incapacidades pessoais para adaptar o direito à nova realidade" (Las relaciones con la Administración Pública mediante sistemas electrónicos, informáticos y telemáticos, in DAVARA RODRÍGUEZ, Miguel Ángel (coord.), JIS'2000, III Jornadas sobre informática y sociedad, Madrid, Universidad Pontificia Comillas, 2001, pp. 260-261, tradução livre). Na mesma linha, DUNI afirma que pode até parecer quase contra a natureza abandonar o papel e o sistema em documentos escritos usado há milhares de anos, substituindo algo tangível e material por uma alternativa que parece evanescente, fugaz, não controlável e perdível. Contudo, segundo o autor, "cabe à psicologia aplicada à ciência da administração resolver os problemas meramente mentais", porque, com as tecnologias de segurança informáticas atuais, o documento informático é mais seguro do que aquele em papel (cf. Teleamministrazione, cit., item 4.1, tradução livre).

${ }^{378}$ Cf. DunI, Giovanni, La teleamministrazione come terza fase dell'informatica amministrativa, cit., item 3.

${ }^{379}$ Cf. Asís RoIG, Agustín de, op. cit., p. 145.

${ }^{380}$ Já se apontou, assim, uma espécie de bênção do documento escrito (cf. DoMínGUEZ LUIS, José Antonio, El derecho de información administrativa, cit., p. 545 e La explosión informática, cit., p. 122).

${ }^{381}$ Cf. Duni, Giovanni, L'amministrazione digitale, cit., pp. 85-86.

${ }^{382}$ Cf. CoElHo, Fábio Ulhoa, op. cit., p. 43.
} 
para o registro da informação ${ }^{383}$. Com efeito, em vista dos avanços recentes, é possível afirmar que o documento eletrônico é capaz de oferecer níveis de desempenho funcional e de segurança mais elevados que os do escrito em papel $^{384}$. Esse fato é comprovado pela cada vez mais frequente utilização de meios informáticos em outros âmbitos da vida social, não havendo razão para afastá-los, em nome da segurança jurídica, apenas na Administração Pública ${ }^{385}$ - o que poderia causar até mesmo espanto no usuário ${ }^{386}$. Na verdade, a utilização do documento eletrônico não se coloca em prejuízo, mas em favor da realização da segurança exigida nas atividades administrativas.

O documento eletrônico não só é capaz de proporcionar mais garantias em relação às funções normalmente desempenhadas pelo papel, mas pode oferecer outras possibilidades. A informação constante do documento eletrônico pode ser obtida com muito mais facilidade ${ }^{387}$, sendo passível de tratamento automático, em larga escala, sem a necessidade de intermediação humana, a qual é indispensável no trabalho baseado no pa-

\footnotetext{
${ }^{383}$ Cf. PINHEIRO, Patrícia Peck, op. cit., p. 206.

${ }^{384}$ Nesse sentido, cf. BARNÉS VÁZQUEZ, Javier, Una reflexión introductoria sobre el Derecho Administrativo y la Administración Pública de la Sociedad de la Información y del Conocimiento, cit., p. 67; COELHO, Fábio Ulhoa, op. cit., p. 43, DAVARA RoDRíGUEZ, Miguel Ángel, op. cit., p. 473, 477 e 480; DUNI, Giovanni, Teleamministrazione, cit., item 2.1; PUNZÓN MORALEDA, Jesús, Introducción, cit., p. 10; VALERO TORRIJOS, Julián, Administración pública, ciudadanos y nuevas tecnologías, cit., p. 2955; VALERO TORRIJOS, Julián, Las garantías jurídicas en la Administración electrónica, cit., p. 23 e VALERO TORRIJOS, Julián, Las relaciones con la Administración Pública mediante sistemas electrónicos, informáticos y telemáticos, cit., pp. 260261. Segundo DUNI, por exemplo, a garantia de autenticidade informática, por ser absoluta e geral, oferece na prática mais garantia que a perícia no documento em papel, pois esta, por ser raríssima, meramente hipotética e relegada ao âmbito de possibilidades abstratas, deixa amplo espaço a falsidades que nunca são descobertas (cf. Teleamministrazione, cit., item 2.3).

${ }^{385}$ Cf. VALERO TORRIJOS, Julián, El uso de cookies por las administraciones públicas: ¿una vulneración de la normativa sobre protección de los datos personales, in Revista Aranzadi de Derecho y Nuevas Tecnologías, n. 3, Cizur Menor (Navarra), Aranzadi, set.-dez. 2003, p. 92. PALOMAR OLMEDA qualifica como rudimentar tal debate, acrescentando: "Nesse sentido não deixa de ser curioso que em uma sociedade que aceita processos mecanizados de formação e expressão da vontade em praticamente todos os âmbitos da vida social se questione esses processos por serem inseguros quando se trata de aplicá-los às Administrações Públicas. Esse debate, assim configurado, terá o alcance temporal que se queira, mas finalmente é insustentável e cairá por seu próprio peso precisamente porque a utilização de novas tecnologias acabará dotando os processos internos de muito mais segurança do que a que se pode conseguir pelos processos tradicionais. Isso para não dizer que eles serão mais rápidos e provavelmente mais baratos" (La utilización de las nuevas tecnologías en la actuación administrativa, cit., p. 366, tradução livre).

${ }^{386}$ Cf. DAVARA RodrígueZ, Miguel Ángel, op. cit., p. 490.

${ }^{387}$ Cf. VALERO TORRIJOS, Julián, Las garantías jurídicas en la Administración electrónica, cit., p. 23.
} 
$\operatorname{pel}^{388}$. Com o documento eletrônico, é possível desempenhar atividades impensáveis segundo os meios tradicionais ${ }^{389}$, permitindo, por exemplo, que pessoas trabalhem remotamente como se cada uma delas tivesse nas mãos o mesmo documento ou o mesmo expediente $^{390}$. Nesse sentido, o suporte eletrônico não deve ser visto apenas como um substituto para o papel, sujeito a todas as limitações deste; é preciso vencer os parâmetros e critérios tradicionais criados para o uso do papel ${ }^{391}$, de maneira a permitir a exploração das potencialidades das informações contidas em suporte digital. No governo eletrônico, isso é fundamental para que a informatização ultrapasse a mera digitalização de expedientes ${ }^{392}$, a qual seria capaz de produzir apenas uma versão digital das antigas deformações burocráti$\operatorname{cas}^{393}$.

O primeiro passo para o aproveitamento da tecnologia da informação é admitir o valor do documento eletrônico para o direito, como uma exigência da realidade social existente e das relações jurídicas que nela se desenvolvem ${ }^{394}$. O reconhecimento jurídico dessa nova forma de registro de informações constitui uma verdadeira pedra angular do governo eletrônico ${ }^{395}$, pois o uso da informática como instrumento legítimo da atividade administrativa exige o reconhecimento do valor jurídico das informações geradas em meio digital ${ }^{396}$, tanto no tocante ao documento informático (dimensão estática) quanto em relação à sua circulação em redes telemáticas (dimensão dinâmica) ${ }^{397}$. Para isso, o docu-

\footnotetext{
${ }^{388}$ Cf. DOMínGUEZ LuIS, José Antonio, El derecho de información administrativa, cit., p. 544. Não há dúvida sobre as vantagens funcionais propociadas por um documento em meio eletrônico: "É possível notar uma diferença entre um formulário de papel preenchido, contendo os dados pessoais dos usuários, e um formulário eletrônico, preenchido "on line", guardado numa base de dados? Naturalmente!" (ChATILLON, Georges, L'administration électronique, in Revue internationale de droit comparé, n. 2, abr.-jun. 2006, p. 698, tradução livre). Nesse sentido, toda vez que um documento eletrônico é decodificado para a linguagem natural e impresso em papel, há uma perda do valor por ele trazido, uma vez que o documento em papel não será suscetível de processamento automático e necessitará da intermediação pela leitura humana para que possa ter alguma utilidade.

${ }^{389}$ Cf. VALERO TORRIJOS, Julián, El régimen jurídico de la e-Administración, cit., pp. 14-15.

${ }^{390}$ Cf. Chatillon, Georges, L'administration électronique, cit., p. 709.

${ }^{391}$ Cf. VALERO TORRIJOS, Julián, La gestión y conservación del documento administrativo electrónico, cit., p. 66.

${ }_{392}$ Cf. Cotino Hueso, Lorenzo, Derechos del ciudadano, cit., p. 127.

${ }^{393}$ Cf. VALERO TORRIJOS, Julián, Las garantías jurídicas en la Administración electrónica, cit., p. 20.

${ }^{394}$ Cf. Domínguez LuIs, José Antonio, La explosión informática, cit., p. 124.

${ }^{395}$ Cf. TinTó GimBernAT, Montserrat, Administración electrónica y ciberprocedimiento, cit., p. 15 e DeLPIAZZO, Carlos E., op. cit., p. 192.

${ }^{396}$ Cf. MARONE, Umberto, op. cit., p. 22.

${ }^{397}$ Cf. PONTI, Benedetto, op. cit., p. 77.
} 
mento eletrônico deve ser definido de modo amplo, não restrito a uma concepção formalista, a qual poderia impedir um avanço jurídico num ritmo compatível com a tecnologia ${ }^{398}$.

O ponto de partida para o reconhecimento do valor jurídico do documento eletrônico é a verificação de que este, por si mesmo, em razão do mecanismo particular de registro de informações utilizado ${ }^{399}$, não apresenta nenhuma dificuldade diferente da que possa ter outro documento, sobretudo aquele em suporte pape $^{400}$. Com efeito, a premissa do ordenamento brasileiro é a admissibilidade de qualquer forma, processo ou veículo para o exercício do direito à informação (art. 220, caput, da Constituição da República), de modo que a nenhum suporte pode ser reconhecida, a priori, alguma espécie de preferência $^{401}$. Dessa maneira, a informática não justifica maiores exigências formais que o imposto ao escrito tradicional, exigindo apenas uma adaptação do formalismo clássico à sociedade da informação ${ }^{402}$.

Disso decorre o chamado princípio da equivalência de suportes, por meio do qual os documentos administrativos eletrônicos são equiparados, em valor e eficácia jurídica, aos escritos em suporte papel, sempre que reúnam certos requisitos e garanti-

\footnotetext{
398 Cf. Punzón MoraledA, Jesús, El documento tecnológico en el ámbito jurídico administrativo, in PunZÓn MoRAledA, Jesús (coord.), Administraciones Públicas y nuevas tecnologías, Valladolid, Lex Nova, 2005 , p. 57.

${ }^{399}$ Cf. FANTIGROSSI, Umberto, op. cit., p. 58.

${ }^{400}$ Cf. DAVARA RodríGUEZ, Miguel Ángel, op. cit., p. 463. Segundo o autor, "O suporte informático sobre o qual se encontram palavras e outros signos que identificam ideias é um documento com as mesmas características, em princípio e quanto a sua validade jurídica, que qualquer outro dos que tradicionalmente se aceitam em suporte papel" (op. cit., p. 489).

${ }^{401}$ Sobre este ponto, cf. BIGLIASSI, Renato, Governo eletrônico e teoria dos serviços públicos, in PEREIRA, Cláudia Fernanda de Oliveira, $O$ novo direito administrativo brasileiro: o Estado, as agências e o terceiro setor, Belo Horizonte, Fórum, 2003, p. 239. Vale considerar também a Convenção Americana de Direitos Humanos (Pacto de San José da Costa Rica), integrante do ordenamento brasileiro por força do Decreto $\mathrm{n}$. 678/92, que adota uma linguagem ainda mais contundente: "Toda pessoa tem o direito à liberdade de pensamento e de expressão. Esse direito inclui a liberdade de procurar, receber e difundir informações e ideias de qualquer natureza, sem considerações de fronteiras, verbalmente ou por escrito, ou em forma impressa ou artística, ou por qualquer meio de sua escolha" (art. 13, 1).

${ }^{402}$ Cf. CANTERo, Anne, op. cit., pp. 33 e 43 e FouILleul, Nicolas, op. cit., p. 154.
} 
as $^{403}$. Exige-se, assim, do documento eletrônico, para que tenha valor jurídico, o atendimento às mesmas funções desempenhadas pelo documento em papel ${ }^{404}$. O princípio implica a aceitação da idoneidade da forma eletrônica para satisfazer as exigências de comunicação e compreensão que estão na base do conceito jurídico de documento ${ }^{405}$, de sorte que a garantia da atividade formal não é questionada, mas apenas transformada ${ }^{406}$.

Para que possa desempenhar as mesmas funções do escrito em papel, o documento eletrônico precisa atender às seguintes exigências: a) integridade (garantia de prevenção contra alterações ou perdas de dados e informações); b) autenticidade (capacidade de vinculação entre a informação e a identidade de quem a produz, acessa ou recebe); c) disponibilidade (possibilidade de acesso às informações contidas no documento); d) confidencialidade ou acesso diferenciado (viabilidade de restringir o uso das informações a pessoas autorizadas); e) não repúdio (impossibilidade técnica de que o autor do docu-

\footnotetext{
${ }^{403}$ Cf. GAMERO CASADO, Eduardo, Objeto, ámbito de aplicación y principios generales de la ley de administración electrónica, cit., p. 100. A legislação de Québec reconhece como princípios diferentes a equivalência funcional e a equivalência de suportes, por ela denominada princípio da neutralidade tecnológica (cf. BENYEKHLEF, Karim, op. cit., p. 273). No presente texto, adota-se a terminologia equivalência de suportes, entendendo-se que a equivalência funcional é um pressuposto daquela, e não o princípio que norteia o reconhecimento de valor jurídico para os documentos eletrônicos, sendo a terminologia neutralidade tecnológica reservada para outro significado. Vale observar que grande parte da doutrina refere-se a um princípio de equivalência funcional, ao invés de equivalência de suportes (cf. Poullet, Yves, La technologie et le droit, cit. p. 957). Na verdade, como menciona o mesmo texto (p. 956), a teoria das equivalências funcionais foi desenvolvida no âmbito do comércio eletrônico, em relação à assinatura eletrônica e depois foi estendida à teoria jurídica do documento eletrônico. Conforme ressalta FÁBIO UlHOA COELHO, a Comissão das Nações Unidas para o Direito Mercantil Internacional (Uncitral) aprovou, em 1996, uma lei-modelo sobre comércio eletrônico, aperfeiçoada em 1998, tendo como princípio fundamental o que seria o princípio da equivalência funcional. Segundo o autor, o princípio estaria no art. $5^{\circ}$ dessa lei-modelo: "não se negarão efeitos jurídicos, validade ou executividade à informação tão-somente pelo fato de se encontrar na forma de mensagem de dados". Ainda de acordo com o autor, o pressuposto factual desse princípio seria a percepção de que o suporte eletrônico cumpre as mesmas funções do papel em relação ao registro de informações de relevância jurídica (cf. op. cit., pp. 42-43).

${ }^{404}$ Cf. CANTERO, Anne, op. cit., p. 173.

${ }^{405}$ Cf. FANTIGROSSI, Umberto, op. cit., p. 59.

${ }^{406}$ Cf. GuIllen CARAMES, Javier, op. cit., p. 269.
} 
mento negue tal autoria); f) conservação (aptidão para manter suas funções no curso do tempo, inclusive em caso de mudança de formatos e suportes) ${ }^{407}$.

Na verdade, o princípio da equivalência de suportes decorre de uma adequada compreensão das exigências documentais e suas justificativas, que permite identificar a razão de determinadas exigências formais, pois um documento nunca deve ser tido com um fim em si mesmo, mas como um meio de lograr uma finalidade - por exemplo, o adequado conhecimento de um fato. Nesse sentido, tal princípio oferece um instrumental hermenêutico, sob a perspectiva da interpretação teleológica, para afastar qualquer preconceito contra os documentos eletrônicos que leve a situações infundadas de discriminação, incompatíveis com o contexto da sociedade da informação. Nesse sentido, é preciso ter

\footnotetext{
${ }^{407}$ A respeito de tais atributos, para uma confrontação de todas as variações de nomenclaturas e conceitos, cf., entre muitos, AgirReaZkuenaga, Iñaki, Chinchilla, Carmen, El uso de medios electrónicos, informáticos y telemáticos en el ámbito de las Administraciones Públicas, in Revista Española de Derecho Administrativo, n. 109, Madrid, Civitas, jan.-mar. 2001, pp. 45; Asís RoIG, Agustín de, op. cit., p. 175; BARNÉS VÁZQUEZ, Javier, Una reflexión introductoria sobre el Derecho Administrativo y la Administración Pública de la Sociedad de la Información y del Conocimiento, cit., p. 67; DUNI, Giovanni, L'amministrazione digita$l e$, cit., p. 32; DunI, Giovanni, Teleamministrazione, cit., item 2.3; GAMERO CASADO, Eduardo, El derecho administrativo ante la era de la información, cit., pp. 33-35; GARCíA MARCO, Francisco Javier, Ontologías y documentación electrónica en las actividades públicas, cit., p. 183; HEREDERO HIGUERAS, Manuel, op. cit., p. 73; LINARES GIL, Maximino Ignacio, Identificación y autenticación de las administraciones públicas, cit., pp. 285 e 287; MACHADO, Robson, Certificado Digital ICP Brasil: os caminhos do documento eletrônico no Brasil, Niterói, Impetus, 2010, pp. 13-15; MAGÁn PERALES, José María Aristóteles, op. cit., p. 86; MERLONI, Francesco, La documentazione amministrativa digitalizzata, cit., p. 88; MARTín DELGADO, Isaac, Identificación y autenticación de los ciudadanos, in GAMERO CASADO, Eduardo, VALERO TORRIJOS, Julián (coord.), Comentarios a la Ley de Administración electrónica - Ley 11/2007, de 22 de junio, de acceso electrónico de los ciudadanos a los servicios públicos, 1. ${ }^{\mathrm{a}}$ ed., 2. ${ }^{\mathrm{a}}$ imp., Cizur Menor (Navarra), Thomson-Civitas, 2009, p. 354; ORTEGa ÁlvareZ, Luis, Nuevas Tecnologías y procedimiento administrativo, in Revista Jurídica de Castilla - La Mancha, n. 18, Toledo, Junta de Comunidades de Castilla-La Mancha, ago. 1993, p. 215; PUNZÓN MORALEDA, Jesús, Introducción, cit., p. 10; RIVERO ORTEGA, Ricardo, El expediente administrativo, cit., p. 181; VALERO TORRIJOS, Julián, Acceso a los servicios y difusión de la información por medios electrónicos, in GAMERO CASADO, Eduardo, VALERo TORRIJOS, Julián (coord.), Comentarios a la Ley de Administración electrónica - Ley 11/2007, de 22 de junio, de acceso electrónico de los ciudadanos a los servicios públicos, 1. ${ }^{a}$ ed., 2. ${ }^{a}$ imp., Cizur Menor (Navarra), Thomson-Civitas, 2009, pp. 274-275; VALERO TORRIJOS, Julián, Administración pública, ciudadanos y nuevas tecnologías, cit., pp. 2951-2952; VALERO TORRIJOS, Julián, La gestión y conservación del documento administrativo electrónico, cit., p. 55 e VALERO TORRIJOS, Julián, El régimen jurídico de la e-Administración, cit., pp. 38-41.
} 
olhos críticos em relação a eventuais preferências pelo papel em detrimento de suportes eletrônicos que apresentem as devidas condições funcionais ${ }^{408}$.

\subsubsection{A assinatura eletrônica}

Dentro do tema da equivalência de suportes, merece especial atenção a questão da assinatura dos documentos. Com efeito, a possibilidade de atribuir os atos a quem é seu autor constitui, em geral, um requisito da atividade jurídica ${ }^{409}$. Essa função de autenticação é tradicionalmente desempenhada pela assinatura manuscrita ou autógrafa, que proporciona alguma certeza sobre a participação de uma determinada pessoa no ato, vinculando-a ao conteúdo do documento ${ }^{410}$. Dessa maneira, por exemplo, a assinatura é capaz de transformar uma simples minuta, ainda sem valor para o direito, em um ato jurí$\operatorname{dico}^{411}$.

No contexto digital, o equivalente funcional da assinatura manuscrita, destinado a resolver problemas criados pela utilização de meios informáticos, desde que

\footnotetext{
${ }^{408}$ Para FÁBIO ULHOA COELHO, no ordenamento brasileiro "não existe nenhuma norma expressa preceituando que a validade, eficácia e executividade do documento eletrônico são idênticas à do papelizado". Há, assim, segundo o autor, uma lacuna que deve ser suprida pela aplicação do art. $4^{\circ}$ da Lei de Introdução ao Código Civil, invocando, como princípio geral de direito, o princípio da equivalência funcional. "O princípio da equivalência funcional pode e deve ser invocado pelos Juízes para a superação dessa lamentável lacuna" (cf. op. cit., p. 44). No entanto, assim dispõe o art. 225 do Código Civil: "As reproduções fotográficas, cinematográficas, os registros fonográficos e, em geral, quaisquer outras reproduções mecânicas ou eletrônicas de fatos ou de coisas fazem prova plena destes, se a parte, contra quem forem exibidos, não lhes impugnar a exatidão". Nesse sentido, a questão poderia ser mais de distribuição de ônus da prova do que de reconhecimento da validade jurídica do documento eletrônico. Mesmo assim, seria preciso considerar que a exatidão do documento, caso impugnada, deve ser analisada de acordo com as regras atuais da experiência, que, hoje, incluem a compreensão dos meios eletrônicos e seus requisitos.

${ }^{409}$ Cf. DunI, Giovanni, Teleamministrazione, cit., item 2.3.

${ }^{410}$ Cf. MAGÁn Perales, José María Aristóteles, op. cit., p. 95. O Código Civil brasileiro, por exemplo, assim prescreve: "As declarações constantes de documentos assinados presumem-se verdadeiras em relação aos signatários" (art. 219).

${ }^{411}$ Cf. DUNI, Giovanni, Teleamministrazione, cit., item 2.3.
} 
observados determinados requisitos, é a assinatura eletrônica ${ }^{412}$. Trata-se de um método informático capaz de realizar outras funções além daquelas atribuídas à firma tradicional $^{413}$, assegurando não só a autoria, mas a integridade do documento eletrônico ${ }^{414}$.

Assim como ocorre no uso dos meios tradicionais, há diferentes níveis de controle de autenticidade, devendo haver alguma proporcionalidade entre a atividade que se pretende realizar por meios eletrônicos e o nível de segurança exigido ${ }^{415}$. Sem dúvida, há uma diferença considerável entre comprar um jornal - o que nem exige identificação - e adquirir um bem imóvel - o que normalmente deve ser feito por escritura pública ${ }^{416}$. Isso se verifica também no caso do governo eletrônico, havendo várias hipóteses em que não é necessário garantir a autenticidade e integridade do documento digital, pois os efeitos jurídicos dele advindos são bastante restritos ${ }^{417}$. Por outro lado, deve ser respeitado o anonimato em todas as solicitações que não necessitem de identificação, sendo excessivo exigir que o usuário se identifique, por exemplo, para solicitar informações disponíveis para qualquer interessado ${ }^{418}$.

\footnotetext{
${ }^{412}$ Cf. Magán Perales, José María Aristóteles, op. cit., p. 95 e VAlero Torrios, Julián, SANZ Larruga, Francisco Javier, E-administración, identificación del ciudadano y protección de datos personales en la Unión Europea: ¿una ecuación posible?, disponível em http://www.apdcat.net/media/191.pdf, acesso em 27.08.10, p. 2 .

${ }^{413}$ Cf. LINARES GIL, Maximino Ignacio, Identificación y autenticación de las administraciones públicas, cit., p. 287; LINARES GIL, Maximino Ignacio, Modificaciones del Régimen Jurídico Administrativo derivadas del empleo masivo de nuevas tecnologías, cit., p. 731 e MAGÁn PERALES, José María Aristóteles, op. cit., p. 95.

${ }^{414}$ Cf. LinARES GIL, Maximino Ignacio, Modificaciones del Régimen Jurídico Administrativo derivadas del empleo masivo de nuevas tecnologías, cit., p. 737. No mesmo sentido, cf. PONTI, Benedetto, op. cit., pp. 6970. Ainda sobre as funções adicionais da assinatura eletrônica, cf. também CIAMPI, Isabella D'Elia, op. cit., p. 1681.

${ }^{415}$ Cf. VALERO TORRIJOS, Julián, La gestión y conservación del documento administrativo electrónico, cit., p. 43; JINESTA LOBO, Ernesto, op. cit., p. 9 e MARTín DELGADO, Isaac, Los derechos de los ciudadanos ante la administración electrónica, in VVAA, La protección de datos en la Administración Electrónica, Pamplona, Aranzadi, 2009, p. 166, e, de deste último autor, Identificación y autenticación de los ciudadanos, cit., p. 365 .

${ }^{416}$ Cf. LinARES GIL, Maximino Ignacio, Modificaciones del Régimen Jurídico Administrativo derivadas del empleo masivo de nuevas tecnologías, cit., p. 732.

${ }_{417}$ Cf. MARTín DELGADO, Isaac, Los derechos de los ciudadanos ante la administración electrónica, cit., pp. 166-167.

${ }^{418}$ Essa preferência pelo anonimato, sempre que possível, tem sido denominada princípio da segurança graduada pela doutrina francesa (cf. SAURET, Jacques, Efficacité de l'administration et service à l'administré: les enjeux de l'administration électronique, in Revue française d'administration publique, n. 110, Paris, ENA, 2004, pp. 291 e ss., fazendo referencia ao entendimento adotado pela Comission Nationale de l'Informatique e des Libertés, em seu 24e rapport d'activité 2003, p. 80, cujo texto está disponível em http://lesrapports.ladocumentationfrancaise.fr/cgi-bin/brp/telestats.cgi?brp_ref $=044000252 \& b r p \_f i l e=0000$.pdf, acesso em 18.06.2011).
} 
Todavia, embora haja operações que não exigem a identificação completa da pessoa ${ }^{419}$, o relacionamento com a Administração, muitas vezes, não pode ocorrer de forma anônima ${ }^{420}$. É possível distinguir, assim, entre os serviços, aqueles que são de livre acesso e os que estão condicionados à identificação do interessado ${ }^{421}$. No caso destes últimos, é importante garantir que a pessoa que se comunica com a Administração é quem diz $\operatorname{ser}^{422}$. Nesse sentido, o desenvolvimento do governo eletrônico depende de alguma segurança na identidade daqueles que se relacionam com o Poder Público ${ }^{423}$. Além disso, é preciso assegurar a autenticidade dos atos praticados pelos servidores públicos, de forma a garantir sua imputação ao respectivo órgão; caso contrário, resta inviabilizada a atividade administrativa $^{424}$. Por tais razões, a assinatura eletrônica constitui um importante instrumento para a difusão das novas tecnologias no âmbito da Administração ${ }^{425}$.

O efeito representativo da proveniência do documento, proporcionado pela assinatura eletrônica, não se realiza de modo direto, mas por meio da intermediação da máquina ${ }^{426}$. Assim, a assinatura autógrafa e eletrônica são realidades ontologicamente diversas, pois a primeira é resultado de um ato humano, ao passo que a segunda decorre de um procedimento informático ${ }^{427}$. Nesse sentido, os mecanismos destinados à garantia da

\footnotetext{
${ }^{419}$ Cf. TRUDEL, Pierre, op. cit., p. 46.

${ }^{420}$ Cf. VALERo Torrijos, Julián, SANZ LARruga, Francisco Javier, E-administración, identificación del ciudadano y protección de datos personales en la Unión Europea, cit., p. 1; JINESTA LOBO, Ernesto, op. cit., p. 13 e PIÑAR MAÑAS, José Luis, op. cit., p. 65.

${ }^{421}$ Cf. CAMMAROTA, Giuseppe, Servizi pubblici in rete e applicabilità dei principi classici del servizio pubblico, cit., p. 191.

${ }^{422}$ Cf. OCHOA MONZÓ, Josep, Hacia la ciberadministración y el ciberprocedimiento?, cit., p. 165.

${ }^{423}$ Cf. GUARNACCIA, Elio, Evoluzione del ruolo della firma digitale nel dialogo tra cittadino e P.A., in Quaderni del DAE - Rivista di Diritto Amministrativo Elettronico, jul. 2004, disponível em http://www.cesda.it/quadernidae/index.php, acesso em 15.12.2010, p. 1 e PIÑAR MAÑAS, José Luis, op. cit., p. 65.

${ }^{424}$ Cf. Martín Delgado, Isaac, Naturaleza, Concepto y Régimen Jurídico de la Actuación Administrativa Automatizada, cit., p. 362. Assim já foi apontado: "Desmaterialização e assinatura eletrônica são duas faces da mesma medalha, no sentido em que não pode haver desmaterialização da atividade jurídica se não houver técnicas que assegurem a possibilidade de atribuir o documento e, portanto, o ato, ao seu autor" (DUNI, Giovanni, L'amministrazione digitale, cit., p. 19, tradução livre).

${ }^{425}$ Cf. CRESPo RodríGUEZ, Miguel, Firma Electrónica y Administración Electrónica, in MATEU DE Ros, Rafael, López-Monís Gallego, Mónima, Derecho de Internet: La Ley de Servicios de la Sociedad de la Información y de Comercio Electrónico, Cizur Menor, Aranzadi, 2003, p. 714.

${ }^{426}$ Cf. MASUCCI, Alfonso, Il documento amministrativo informatico, cit., pp. 30-31. No mesmo sentido, CIAMPI, Isabella D’Elia, op. cit., p. 1681.

${ }^{427}$ Cf. MASUCCI, Alfonso, Procedimento amministrativo e nuove tecnologie, Torino, G. Giappichelli, 2011, pp. 74-75. Também apontando tal diferença, cf. MARCACINI, Augusto Tavares Rosa, Certificação eletrônica, sem mitos nem mistérios, in Revista do Advogado, n. 69, São Paulo, AASP, mai. 2003, p. 109.
} 
referida equivalência funcional são denominados assinatura eletrônica por mero costume terminológico $^{428}$.

A firma eletrônica não se confunde com a mera impressão do nome do autor do documento, nem com a assinatura digitalizada ${ }^{429}$. Esta última seria uma reprodução da imagem da assinatura de uma pessoa, que pode ser aposta em um documento eletrônico com finalidade apenas estética. A imagem digitalizada de uma assinatura manuscrita não é válida para fins de autenticação por não oferecer segurança a respeito de quem assinou o documento, pois qualquer pessoa pode escanear uma assinatura e reproduzi-la em um ato ou mensagem ${ }^{430}$.

Embora haja muitos métodos para autenticação de documentos informáticos, que podem ser denominados assinaturas eletrônicas, nem todos eles proporcionam adequadas condições de segurança ${ }^{431}$. Os mecanismos de autenticação simples - baseada em controles tradicionais de usuário e senha -, por exemplo, muitas vezes são insuficientes, na medida em que um terceiro pode efetuar adulterações e manipulações com relativa facilidade ${ }^{432}$. Tal insegurança é inadmissível nos casos em que há necessidade de controlar de modo rigoroso a vinculação de um documento ao seu autor.

Procurando alcançar níveis apropriados de segurança, um método específico alcançou maior difusão, em razão de suas qualidades técnicas ${ }^{433}$. Trata-se do sistema de assinaturas eletrônicas baseado na criptografia assimétrica, que passou a ser adotado por diversas legislações do mundo, inclusive a brasileira, como o meio mais adequado para dar

\footnotetext{
${ }^{428}$ Cf. DunI, Giovanni, L'amministrazione digitale, cit., p. 18.

${ }^{429}$ Cf. DunI, Giovanni, Teleamministrazione, cit., item 2.3.

${ }^{430}$ Cf. Magán Perales, José María Aristóteles, op. cit., p. 96 e Marcacini, Augusto Tavares Rosa, op. cit., p. 110 .

${ }^{431}$ Cf. MagÁn Perales, José María Aristóteles, op. cit., p. 104.

${ }^{432}$ Cf. BauzÁ Martorell, Felio José, Procedimiento Administrativo Electrónico, cit., pp. 55-56. No mesmo sentido, VALERO TORRIJOS, Julián, La gestión y conservación del documento administrativo electrónico, cit., pp. 44-45.

${ }^{43}$ Cf. LinARES GIL, Maximino Ignacio, Modificaciones del Régimen Jurídico Administrativo derivadas del empleo masivo de nuevas tecnologías, cit., p. 731.
} 
ao documento eletrônico as mesmas características funcionais oferecidas pelo papel ${ }^{434}$. Tendo em vista a importância de tal mecanismo, cabe explicar, de modo sintético, como ele funciona, até mesmo para permitir a compreensão dos conceitos adotados pelo direito positivo pátrio $^{435}$.

A criptografia constitui um processo reversível de codificação de mensagens $^{436}$. Como o documento eletrônico consiste em uma sequência numérica, compreensível pela máquina, ele pode ser codificado por meio do uso de um código secreto, denominado chave criptográfica ${ }^{437}$. A aplicação dessa chave por um software gera uma nova sequência numérica, que pode ser decodificada de modo semelhante. Quando a mesma chave é usada para codificar e decodificar o documento, fala-se em criptografia simétrica; quando são usadas chaves diferentes em tais operações, a criprografia é assimétrica $^{438}$.

Os métodos baseados na criptografia simétrica não oferecem segurança suficiente para garantia de autenticidade e integridade, pois aquele que deve ter acesso ao documento precisa dispor da mesma chave utilizada para codificá-lo, podendo alterá-lo como se fosse seu autor ${ }^{439}$. Além disso, é necessário que duas pessoas compartilhem o co-

\footnotetext{
${ }^{434} \mathrm{Na}$ Europa, a utilização de tal método de assinatura eletrônica foi prevista pela Diretiva 1999/93/CE do Parlamento Europeu e do Conselho, de 13 de dezembro de 1999, que pretendia uniformizar as regras legais dos países membros da União Europeia em matéria de assinatura eletrônica (texto disponível em http://eurlex.europa.eu/LexUriServ/LexUriServ.do?uri=OJ:L:2000:013:0012:0020:PT:PDF). Tal texto já trazia um conceito genérico de assinatura eletrônica $\left(\operatorname{art} .2^{\circ}, 1\right)$ e um conceito específico, de assinatura eletrônica avançada, entendida como aquela dotada de mecanismos específicos de segurança (art. $2^{\circ}, 2$ ). Sobre o tema, cf. PONTI, Benedetto, op. cit., pp. 74-75. Seguindo tal distinção, Itália e Espanha adotaram o conceito genérico de assinatura eletrônica, aplicável a qualquer mecanismo de autenticação, e a noção de assinatura digital, que seria aquela baseada em mecanismos de criptografia assimétrica, atribuindo efeitos jurídicos plenos somente a esta última. Tal distinção é adotada por este estudo para a definição da terminologia adotada em relação a cada método de assinatura. Tratando do assunto, cf. DunI, Giovanni, L'amministrazione digitale, cit., pp. 20 e 27; LINARES GIL, Maximino Ignacio, Identificación y autenticación de las administraciones públicas, cit., p. 288 e Modificaciones del Régimen Jurídico Administrativo derivadas del empleo masivo de nuevas tecnologías, cit., p. 732; MERLONI, Francesco, La documentazione amministrativa digitalizzata, cit., p. 98 e OROFINO, Angelo Giuseppe, Forme elettroniche e procedimenti amministrativi, cit., pp. 84-88.

${ }^{435}$ No Brasil, o tema é disciplinado pela Medida Provisória n. 2200/01, que instituiu a Infraestrutura de Chaves Públicas Brasileira - ICP Brasil, adotando expressamente a sistemática da criptografia assimétrica para assegurar a autenticidade e integridade dos documentos digitais. Para uma explicação mais detida, cf. MARCACINI, Augusto Tavares Rosa, op. cit., pp. 108-114.

${ }^{436}$ Cf. STAIR, Ralph M., REYNOLDS, George W., op. cit., p. 274.

${ }^{437}$ Cf. LAUdON, Kenneth C., LAUdON, Jane P., op. cit., p. 474.

${ }^{438}$ Cf. MACHADO, Robson, op. cit., pp. 29 e 36.

${ }^{439}$ Cf. BauzÁ Martorell, Felio José, Procedimiento Administrativo Electrónico, cit., p. 26.
} 
nhecimento dessa chave, o que nem sempre pode ser feito de modo seguro, sobretudo pela internet $^{440}$.

Já a criptografia assimétrica utiliza um par de chaves: a primeira, reservada ao autor do documento, é chamada chave privada. A outra, divulgável para conhecimento de todos, é denominada chave pública. É impossível deduzir uma a partir da outra, mas elas estão relacionadas matematicamente entre si, de maneira que a cada chave pública corresponde uma chave privada e vice-versa. A codificação feita com o uso de uma delas só pode ser desfeita pelo uso da outra. As técnicas de criptografia assimétrica foram inicialmente desenvolvidas para fins de sigilo: neste caso, a mensagem codificada com o uso de uma dada chave pública só pode ser lida pelo titular da respectiva chave privada, o que impede o acesso por terceiros ${ }^{441}$.

No entanto, a técnica passou a ser também usada de modo reverso, com o propósito de garantir a autenticidade e integridade dos documentos ${ }^{442}$. Isso ocorre com o auxílio de uma operação denominada hash, que produz um resumo da mensagem a ser assinada, também conhecido como impressão digital do documento ${ }^{443}$. Tal resumo é codificado com o uso da chave privada daquele que pretende assinar o documento, gerando um arquivo informático, que passa a acompanhar o documento eletrônico ${ }^{444}$. Esse arquivo é a assinatura digital. Qualquer mínima variação no conteúdo do documento acarreta uma mudança de sua impressão digital e da assinatura que seria obtida ao aplicar de novo sobre ele a chave privada ${ }^{445}$.

Qualquer pessoa pode verificar a autenticidade e integridade do documento, por meio de uma confrontação entre ele e a assinatura digital que o acompanha. São comparados, na verdade, dois resumos: o primeiro, obtido por meio do mesmo procedimento de hash, aplicado ao documento a ser conferido; o segundo, obtido pela decodifica-

\footnotetext{
${ }^{440}$ Cf. MACHADO, Robson, op. cit., p. 33-34.

${ }^{441}$ Cf. MARCACINI, Augusto Tavares Rosa, op. cit., p. 110.

${ }^{442}$ Cf. ibidem, p. 110.

${ }^{443}$ Cf. UnCITRAL, Model Law on Electronic Signatures with Guide to Enactment, New York, United Nations, 2002, disponível em http://www.uncitral.org/pdf/english/texts/electcom/ml-elecsig-e.pdf, acesso em 29.12.2010, p. 23.

${ }^{444}$ Cf. PONTI, Benedetto, L'informatica nelle pubbliche amministrazioni, cit., p. 72.

${ }^{445}$ Cf. MagÁn Perales, José María Aristóteles, op. cit., pp. 96-97.
} 
ção da assinatura eletrônica, usando a chave pública do assinante. Se há identidade entre ambos os resumos, isso significa que o documento foi gerado com o uso daquela chave privada. Se, depois da aposição da assinatura, ele foi modificado, tal procedimento de verificação não terá êxito ${ }^{446}$.

A chave privada constitui um arquivo eletrônico, gravado em um suporte físico que se encontra na posse do seu titular - v.g., um computador pessoal ou um dispositivo móvel de armazenamento de dados. O acesso a esse arquivo, intermediado por um software, pode ser controlado por uma senha, de conhecimento do titular, ou mesmo por um mecanismo biométrico ${ }^{447}$. Em vista da exclusividade da chave privada, garantida pela combinação dessas técnicas, presume-se que somente o seu titular é capaz de produzir o arquivo que possa ser decodificado com a chave pública correspondente ${ }^{448}$. Se a assinatura digital é conferida com a chave pública, é absolutamente certo que o documento foi produzido por alguém que tinha a posse da chave privada e que ele não foi alterado após isso ${ }^{449}$.

No mecanismo de assinatura eletrônica baseado na criptografia assimétrica, a autenticação depende da possibilidade de estabelecer um vínculo seguro entre uma pessoa e um determinado par de chaves criptográficas. Isso é necessário porque, se a assinatura manuscrita está vinculada intrinsecamente a um indivíduo, o mesmo não ocorre com as chaves criptográficas, sequências numéricas que podem estar relacionadas a qualquer pessoa $^{450}$. Por isso, é necessário que um terceiro seja responsável por registrar um determinado par de chaves em nome de uma pessoa. Também cabe a um terceiro dar publicidade à chave pública e informar, a pedido de quem interessar, em nome de quem ela está registrada.

\footnotetext{
${ }^{446}$ Cf. MASUCCI, Alfonso, Il documento amministrativo informatico, cit., p. 30.

447 Cf. Bauzá Martorell, Felio José, Procedimiento Administrativo Electrónico, cit., p. 69 e MARONE, Umberto, op. cit., pp. 83-84.

${ }^{448}$ Cf. MARCACINI, Augusto Tavares Rosa, op. cit., pp. 110-111.

${ }^{449}$ Cf. ibidem, pp. 111-112.

${ }^{450}$ Cf. MagÁn Perales, José María Aristóteles, op. cit., p. 107 e UnCITRAL, op. cit., p. 25.
} 
O atestado de que uma chave pública corresponde a uma pessoa é denominado certificado digital ${ }^{451}$. A principal função do certificado é, portanto, associar a identidade de uma pessoa determinada a uma chave pública e, indiretamente, a uma chave privada $^{452}$. Em vários países, incluindo o Brasil, as entidades responsáveis pela certificação são organizadas de modo hierárquico, de acordo com uma sistemática denominada infraestrutura de chaves públicas ${ }^{453}$. Nesse regime, a autenticidade do certificado digital é verificada por meio da atuação de um prestador de serviços de certificação de nível superior, repetindo-se a operação até chegar o certificador final, responsável pelo sistema. Assim, o sistema de assinaturas digitais exige uma infraestrutura ampla e complexa, no qual as autoridades certificantes operam sob normas estritas predeterminadas ${ }^{454}$.

A assinatura digital é baseada em uma lógica de presunções, porque não é possível saber quem estava utilizando o computador quando se deu a assinatura ${ }^{455}$. O fato de um documento estar acompanhado de uma firma digital só garante que a chave privada utilizada está registrada em nome daquela pessoa, mas não é capaz de assegurar que foi a própria pessoa que efetuou a assinatura. De fato, enquanto a firma manuscrita é intransferível, a chave privada é transferível a terceiros, de forma voluntária ou não ${ }^{456}$. Assim, há o risco de que ela seja usada por outra pessoa, sem consentimento de seu titular ${ }^{457}$ - por exemplo, é possível que uma pessoa falecida assine um documento ${ }^{458}$. Por isso, a chave privada deve ser zelosamente custodiada por seu titular, que responde pelas eventuais ope-

\footnotetext{
${ }^{451}$ Cf. MASUCCI, Alfonso, Il documento amministrativo informatico, cit., pp. 31-32. Assim também já se escreveu: "O certificado eletrônico é um documento eletrônico assinado digitalmente, que declara a identidade de alguém e lhe atribui a titularidade de uma chave pública" (MARCACINI, Augusto Tavares Rosa, op. cit., p. 112). O mesmo autor aponta que a certificação eletrônica deve ser entendida como um assunto subordinado ao estudo dos documentos eletrônicos e das assinaturas digitais, que são os verdadeiros temas principais da matéria (ibidem, p. 111). De fato, o tema da certificação digital tem assumido grande importância nos estudos contemporâneos, mas deve ser entendido sempre como um aspecto relevante situado no âmbito do estudo das assinaturas e documentos eletrônicos. No mesmo sentido, MACHADO, Robson, op. cit., p. 12.

${ }^{452}$ Cf. DelPIAZzo, Carlos E., op. cit., p. 196 e MASUCCI, Alfonso, Il documento amministrativo informatico, cit., p. 31. O certificado pode ser revogado, quando não for mais possível vincular a pessoa à chave privada (v.g., perda do dispositivo onde ela está gravada, comunicada à entidade responsável pela certificação).

${ }^{453}$ Cf. UnCITRAL, op. cit., p. 26. A Medida Provisória n. 2200/01, que disciplina o tema no Brasil, cria Infraestrutura de Chaves Pública brasileira, composta por uma autoridade gestora e uma cadeia de autoridades certificadoras, organizadas de modo hierárquico (art. $\left.2^{\circ}\right)$.

${ }^{454}$ Cf. MAGán Perales, José María Aristóteles, op. cit., p. 98.

${ }^{455}$ Cf. PONTI, Benedetto, op. cit., p. 73.

${ }^{456}$ Cf. BaUZÁ MARTORELL, Felio José, Procedimiento Administrativo Electrónico, cit., pp. 29-30.

${ }^{457}$ Cf. ibidem, p. 31.

${ }^{458}$ Cf. ibidem, p. 71.
} 
rações efetuadas com seu uso ${ }^{459}$. Em caso de roubo ou perda, ele deve solicitar de imediato sua revogação ou suspensão; do contrário, assume o risco de um eventual uso ilícito da chave $^{460}$.

Esses riscos são assumidos quando a lei atribui à firma digital os efeitos de autenticação, baseada na presunção de que o signatário de um documento é o titular da chave privada utilizada na assinatura ${ }^{461}$. A existência de tais riscos, contudo, não implica uma diminuição da segurança jurídica: na verdade, com o método baseado na criptografia assimétrica, a assinatura eletrônica proporciona segurança equivalente ou até superior à da firma tradicional ${ }^{462}$. A propósito, vale lembrar que esta também está fundada em alguma presunção, pois, embora seja absolutamente pessoal, não é única nem insuscetível de falsificação: ela evolui durante a vida do assinante e pode ser reproduzida por um terceiro ${ }^{463}$. Na verdade, a relação entre o assinante e a assinatura é mais direta no caso da eletrônica do que na manuscrita, pois qualquer pessoa pode tentar imitar uma assinatura autógrafa, porém o mesmo não ocorre com a eletrônica, mais ainda quando adotado o método da criptografia assimétrica $^{464}$. De fato, embora seja sempre a mesma, a chave privada, aplicada a documentos diferentes, gera assinaturas eletrônicas sempre diversas entre $\mathrm{si}^{465}$. Ademais, a assinatura digital pode ser conferida sempre, por meio de um procedimento automatizado $^{466}$, o que é impossível no caso da firma manuscrita.

A Administração Pública brasileira pode valer-se do sistema de assinaturas digitais criado pela Medida Provisória n. 2200/2001, pois os documentos públicos e particulares produzidos com a observância dos preceitos ali estabelecidos devem ser considerados verdadeiros em relação ao respectivo signatário (art. 10, caput e $\S 1^{\circ}$ ). Tendo em vista que a matéria, mesmo em âmbito administrativo, sempre sofreu a influência da disci-

\footnotetext{
${ }^{459}$ Cf. OROFINO, Angelo Giuseppe, Forme elettroniche e procedimenti amministrativi, cit., p. 110.

${ }^{460}$ Cf. MANDOLFO, Giovanni, L'atto amministrativo elettronico, in CASSANO, Giuseppe, Diritto delle nuove tecnologie informatiche e dell'internet, Milano, Ipsoa, 2002, p. 1308.

${ }^{461}$ Cf. Bauzá Martorell, Felio José, Procedimiento Administrativo Electrónico, cit., p. 31.

${ }^{462}$ Cf. MagÁn Perales, José María Aristóteles, op. cit., p. 98.

${ }^{463}$ Cf. MARTín DELGADO, Isaac, Identificación y autenticación de los ciudadanos, cit., p. 323.

${ }^{464}$ Cf. ibidem, pp. 324-325.

${ }^{465}$ Cf. MARONE, Umberto, op. cit., p. 83.

${ }^{466}$ Cf. MARCACINI, Augusto Tavares Rosa, op. cit., pp. 113.
} 
plina do direito civil ${ }^{467}$, nada impede que a atuação do Poder Público esteja lastreada em tal diploma normativo ${ }^{468}$. A sistemática das assinaturas digitais pode ser usada tanto na produção de documentos pela própria Administração quanto na conferência da autenticidade dos documentos recebidos de cidadãos e empresas.

Contudo, é preciso notar que a referida medida provisória não impede a utilização de outros meios que possam garantir a autoria e integridade de documentos eletrônicos, desde que "aceito pela pessoa a quem for oposto o documento" (art. 10, § $\left.2^{\circ}\right)^{469}$. Tal dispositivo parece extremamente apropriado e aplicável ao Poder Público, dando respaldo jurídico a situações reais, que não poderiam ser desprezadas. Nesse sentido, a utilização da assinatura digital deve ser vista como uma possibilidade, não afastando outros meios de autenticação adequados às peculiaridades da atividade desempenhada, de acordo com o que vier a ser estabelecido por cada ente público, no âmbito de sua capacidade de auto-organização $^{470}$.

De fato, é preciso reconhecer como válida a atuação eletrônica interna da Administração Pública, que há muito tempo - bem antes do referido diploma normativo -

\footnotetext{
${ }^{467}$ Cf. infra, notas 586 e 587.

${ }^{468}$ Na França, o artigo 1316-1 do Código Civil, que adota a equivalência de suportes, tem sido considerada aplicável à Administração Pública. É o texto da norma: "O escrito sob forma eletrônica é admitido em prova ao mesmo título que o escrito em suporte papel, sob a reserva que possa ser devidamente identificada a pessoa do qual emanou e que seja gerado e conservado nas condições adequadas para garantir sua integridade" (cf. CANTERO, Anne, op. cit., p. 173, tradução livre).

${ }^{469}$ Vale transcrever o dispositivo por completo: "O disposto nesta Medida Provisória não obsta a utilização de outro meio de comprovação da autoria e integridade de documentos em forma eletrônica, inclusive os que utilizem certificados não emitidos pela ICP-Brasil, desde que admitido pelas partes como válido ou aceito pela pessoa a quem for oposto o documento".

${ }_{470}$ Fazendo referência à necessidade de respeito ao princípio federativo, que impediria a União de impor aos demais entes federativos a sistemática por ela estabelecida, cf. MACHADO, Robson, op. cit., p. 128. Há, todavia, entendimento no sentido de que o sistema de assinaturas digitais estabelecido pela referida medida provisória seria indispensável em relação a documentos administrativos. É a opinião de MARCUS VINICIUS FILGUEIRAS JÚNIOR, para quem o parágrafo $2^{\circ}$ do art. 10 da Medida Provisória n. 2200/01 seria inaplicável aos atos administrativos eletrônicos, porque a terminologia "admitido pelas partes", também usada pelo dispositivo, seria típica de direito privado, não podendo a vontade das partes definir uma condição de existência de um ato administrativo (cf. Ato administrativo eletrônico e teleadministração, cit., pp. 259 e 262). No mesmo sentido, RAMOS JÚNIOR, Hélio Santiago, ROVER, Aires José, $O$ ato administrativo eletrônico sob a ótica do princípio da eficiência, in Anais da II Conferência Sul-Americana de Ciência e Tecnologia Aplicada ao Governo Eletrônico - CONEGOV 2005, Florianópolis, Ijuris, 2005, pp. 33-40, disponível em http://www.infojur.ufsc.br/aires/arquivos/ato\%20administrativo\%20eletronico\%20helioAires.pdf, acesso em 17.05.2011, p. 36. MARÇAL JUSTEN FILHO adota uma posição menos categórica, entendendo que todas as entidades administrativas devem recorrer ao sistema de assinaturas eletrônicas da referida medida provisória "para evitar riscos desnecessários" (Pregão, cit., p. 341).
} 
produz milhões de documentos em suporte digital, segundo regras próprias de segurança informática, que não podem ser simplesmente desprezados. É o caso, por exemplo, de diversas atividades incluídas no processamento de folhas de pagamento de servidores, da arrecadação tributária e da execução orçamentária. Por outro lado, não parece apropriado considerar inválidos os inúmeros atos praticados por cidadãos e empresas em seu relacionamento com a Administração, sem o uso dos mecanismos de assinatura digital previstos pela Medida Provisória n. 2200/01, nem sempre ajustados às condições dos usuários e às peculiaridades da atividade desempenhada. O princípio da proporcionalidade exige que o sistema de assinatura eletrônica adotado seja adequado à natureza e às circunstâncias do procedimento e ao grau de segurança exigido pela tramitação, de forma a evitar a criação de barreiras desnecessárias ao desenvolvimento do governo eletrônico ${ }^{471}$.

\subsection{Novas tecnologias e eficiência administrativa}

Com todas as possíveis vantagens trazidas pela utilização das tecnologias da informação e da comunicação paras as atividades administrativas, é óbvio associar o tema do governo eletrônico ao princípio da eficiência, contemplado na Constituição brasileira (art. 37, caput) a partir da Emenda Constitucional n. 19/98. No âmbito de uma preocupação quase universal com a modernização da Administração Pública, para que possa atuar com eficiência ${ }^{472}$, o governo eletrônico passou a ser reconhecido como uma ferra-

\footnotetext{
${ }^{471}$ Cf. MARTín DELGADO, Isaac, Los derechos de los ciudadanos ante la administración electrónica, cit., p. 171. É preciso ter atenção, em especial, para o fato de que o sistema de assinaturas digitais criado pela Medida Provisória n. 2200/01 não pode ser considerado acessível, sob o ponto de vista econômico, por grande parte da população brasileira, de maneira que sua obrigatoriedade tenderia a levar a indesejáveis efeitos discriminatórios (cf. item 2.4.2). Cabe à Administração, diante desse contexto e analisadas as peculiaridades do caso concreto, efetuar um juízo de ponderação a respeito de qual o mecanismo de autenticação mais adequado para o desempenho de uma dada atividade.

${ }^{472}$ Cf. MedauAR, Odete, Direito administrativo moderno, cit., p. 30.
} 
menta indispensável ${ }^{473}$, ou seja, uma parte crucial do caminho em direção a um melhor governo $^{474}$.

Mais do que uma associação intuitiva, é necessária uma exploração dogmática do relacionamento entre a realidade dos meios tecnológicos de vanguarda e os imperativos jurídicos de uma boa Administração Pública, de maneira a compreender devidamente a influência do princípio da eficiência sobre o governo eletrônico. Neste estudo, essa relação será explorada sob três perspectivas distintas: a eficiência administrativa como fundamento do governo eletrônico, as exigências para o atendimento da eficiência e a convivência entre a eficiência do governo eletrônico e a legalidade.

\subsubsection{A eficiência administrativa como fundamento do governo eletrônico}

Embora as diversas polêmicas em torno do princípio da eficiência constituam um campo fértil de debates que fogem ao escopo do presente estudo, é imprescindível, aqui, adotar uma referência conceitual a respeito.

Cabe observar, pois, que na física, na economia e na ciência da administração a eficiência é entendida em termos de rendimento ou produtividade das máquinas, mercados ou organizações, ao passo que a realização adequada de suas respectivas funções é designada pela palavra eficácia. Alguma diferenciação entre os vocábulos poderia decor-

\footnotetext{
${ }^{473}$ Cf. PINHeIRo, Patrícia Peck, op. cit., p. 279 e PORTA, Marcos de Lima, Direito Administrativo e influxos do Direito Eletrônico, in Consultor Jurídico, 03.06.2003, disponível em http://www.conjur.com.br/2003-jun03/direito administrativo_influxos direito_eletronico, acesso em 17.05.2011. É o mesmo que a doutrina espanhola vem reconhecendo em relação à eficácia: "Esta preocupação em introduzir o uso de novas tecnologias no seio das Administrações Públicas é totalmente lógica, já que, como é sabido, é uma exigência constitucional que a Administração atue com eficácia (...)" (AGIRREAZKUENAGA, Iñaki, ChINCHILLA, Carmen, op. cit., p. 36).

${ }^{474}$ Cf. OCDE, E-government for better government, 2005, trad. esp. de Teodoro Sacristián, E-gobierno para un major gobierno, Madrid, INAP, 2008, p. 23.
} 
rer do próprio texto constitucional brasileiro (art. 74), sugerindo uma distinção mais rigorosa entre eficiência e eficácia ${ }^{475}$.

No entanto, há algum tempo ${ }^{476}$ grande parte da doutrina jurídica brasileira vem dando um entendimento amplo à noção de eficiência, que passou a extrapolar, de certo modo, os conceitos das demais ciências. Tem-se adotado um significado mais vul$\operatorname{gar}^{477}$, relacionando-o tanto com as qualidades das atividades realizadas ${ }^{478}$ - o que poderia ser denominado eficácia - quanto com o rendimento do aparato administrativo ${ }^{479}$ - a efici-

${ }^{475}$ Fazendo essa diferenciação, JOSÉ DOS SANTOS CARVALHO FILHO apresenta uma conceituação mais rigorosa, incluindo também uma distinção em relação à efetividade (cf. Manual de Direito Administrativo, $22^{\mathrm{a}}$. ed., Rio de Janeiro, Lumen Juris, 2009, p. 30). Ainda sobre tal distinção, cf. SÁNCHEZ RoDRÍGUEZ, Francisco, op. cit., p. 38.

${ }^{476}$ Antes mesmo da Emenda Constitucional n. 19/98, Hely LOPES MEIRELLES já falava de um dever de eficiência, que imporia ao agente público realizar suas atribuições com presteza, perfeição e rendimento funcional. Seria o mais moderno princípio da função administrativa, que não se contenta apenas com a legalidade, exigindo resultados positivos para o serviço público e para o usuário (cf. Direito administrativo brasileiro,

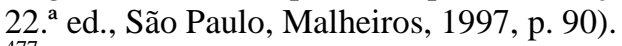

${ }^{477}$ EGON BOCKMANN MOREIRA propõe que a compreensão do princípio da eficiência não decorra das técnicas da economia ou da ciência da administração, mas de uma compreensão democrática da terminologia constitucional, fundada em linguagem vulgar, acessível ao povo (cf. Processo administrativo: princípios constitucionais e a Lei 9.784/1999, 2a . ed., São Paulo, Malheiros, 2003, p. 163). Assim, procura diferenciar eficácia e eficiência com base em conceitos jurídicos, afastando aqueles advindos da economia e da ciência da administração. A eficácia seria a potencialidade para gerar imediatamente os fins estabelecidos em lei ou a idoneidade do ato para produzir seus efeitos, ao passo que a eficiência corresponderia ao cumprimento da lei com o mínimo de ônus sociais, o melhor caminho social para atingir a eficácia, tendo relação não com a finalidade normativa, mas com o seu modo de execução (op cit., p. 181).

${ }^{478}$ Nessa linha, ODETE MEDAUAR entende que "(...) o princípio da eficiência determina que a Administração deve agir, de modo rápido e preciso, para produzir resultados que satisfaçam as necessidades da população" (Direito administrativo moderno, cit., p. 128). Para DióGENES GASPARINI, as atribuições devem ser executadas com perfeição, evitando sua repetição e reclamos por parte dos administrados (cf. Direito administrativo, 5. a ed., São Paulo, Saraiva, 2000, p. 20). A eficácia não está relacionada à rentabilidade financeira, mas ao grau de realização dos objetivos fixados pelos eleitos (cf. CHEVALLIER, Jacques, L'État post-moderne, 2008, trad. port. de Marçal Justen Filho, O Estado Pós-Moderno, Belo Horizonte, Fórum, 2009, p. 85).

479 Adotando o conceito da ciência da administração, segundo o qual a eficiência estaria ligada aos meios e a eficácia, com os resultados, cf. AMARAL, Antônio Carlos Cintra do, O princípio da eficiência no direito administrativo, in Licitações e contratos administrativos: uma visão atual à luz dos Tribunais de Contas, $1 .^{\mathrm{a}}$ ed., 5. ${ }^{a}$ reimpressão, Curitiba, Juruá, 2010, pp. 216-218. Segundo JosÉ DOS SANTOS CARVALHO FILHO, o núcleo do princípio é a procura de produtividade e economicidade, e, especialmente, a exigência de reduzir os desperdícios de dinheiro público (cf. op. cit., pp. 28-30). Em linha semelhante, embora com alguma referência aos resultados em si, JOSÉ AFONSO DA SILVA entende que o princípio da eficiência "orienta a atividade administrativa no sentido de conseguir os melhores resultados com os meios escassos de que se dispõe e a menor custo", tendo "como conteúdo a relação meios e resultados" (cf. Curso de direito constitucional positivo, 34ª ed., São Paulo, Malheiros, 2011, p. 672). Também na linha da eficiência como rendimento: "A Administração Pública, embora não tenha, em princípio, a função de produzir resultados econômicos, deve atuar em observância ao princípio do custo/benefício. O Administrador Público precisa ter em mente que ele é gestor de coisa pública, coisa da sociedade, e, por isso, deve planejar a atividade do órgão ou entidade que dirige de forma a gastar menos e obter o máximo de resultado social e econômico, quando for o caso" (FARIA, Edimur Ferreira de, Curso de Direito Administrativo Positivo, 6a ed., Belo Horizonte, Del Rey, 2007, p. 50). 
ência propriamente dita. Essa concepção mais ampla tem norteado o relacionamento, frequentemente observado pela doutrina, entre a eficiência administrativa e o direito fundamental à razoável duração do processo, previsto no art. $5^{\circ}$, LXXVIII, da Constituição da República $^{480}$, que se refere mais aos resultados do que ao rendimento da máquina pública. Assim, para os efeitos deste estudo, sem embargo da complexidade do tema, a eficiência administrativa será entendida de modo a alcançar tanto o atendimento das missões confiadas à Administração Pública quanto sua obtenção com o menor sacrifício possível para a coletividade ${ }^{481}$.

O princípio da eficiência constitui um ponto em que o ordenamento jurídico dá relevância aos meios necessários para a atividade administrativa ${ }^{482}$, o que constitui um ponto essencial para o governo eletrônico. Com efeito, a eficiência engloba não somente os fins - em sentido mais rigoroso, a eficácia -, mas os meios, expressamente referidos pelo texto constitucional no inciso LXXVIII de seu art. $5^{\circ}$, em relação à celeridade da ação administrativa. Dessa forma, estes não constituem um tema juridicamente irrelevante; ao contrário, revestem-se de especial significado, sobretudo em relação à realização dos objetivos confiados à Administração Pública. O princípio da eficiência implica o dever de escolher os melhores instrumentos para alcançar os objetivos da Administração ${ }^{483}$, de sorte que os meios passam a ser tão importantes quanto os fins a serem atingidos ${ }^{484}$.

\footnotetext{
${ }^{480}$ Processo com razoável duração não equivale a um processo veloz, mas a um processo que ofereça respostas em tempo hábil, devendo essa presteza ser considerada incluída na eficiência como princípio da Administração Pública (cf. Silva, José Afonso da, Curso de direito constitucional positivo, cit., p. 673 e Comentário contextual à Constituição, São Paulo, Malheiros, 2005, p. 176). Aproximando o princípio da eficiência e o direito à razoável duração do processo, cf. também CARVALHO FILHO, José dos Santos, op. cit., p. 29 e CoRRÊA, Davi Beltrão de Rossiter, Processo administrativo eletrônico, in Jus Navigandi, Teresina, ano 16, n.2850, 21.abr. 2011, disponível em http://jus.uol.com.br/revista/texto/18959, acesso em 03.05.2011, p. 2.

${ }^{481}$ Adota-se, pois, o entendimento de DIOGO DE FIGUEIREDO MOREIRA NETO, para quem a eficiência corresponde à "melhor realização possível da gestão dos interesses públicos, posta em termos de plena satisfação dos administrados com os menores custos para a sociedade" (Curso de Direito Administrativo, 15a. ed., Rio de Janeiro, Forense, 2009, p. 117).

${ }^{482}$ Assim, “(...) a eficiência administrativa se obtém pelo melhor emprego dos recursos e meios (humanos, materiais e institucionais) para satisfazer às necessidades coletivas num regime de igualdade dos usuários" (SILVA, José Afonso da, Curso de direito constitucional positivo, cit., pp. 672-673).

${ }^{483}$ Cf. FILGUEIRAS JÚNIOR, Marcus Vinícius, L'atto amministrativo elettronico in Brasile, cit., p. 1 e, do mesmo autor, A informática como opção jurídica vinculada da Administração Pública, in Boletim de Direito Administrativo, v. 21, n. 2, São Paulo, NDJ, fev. 2005, p. 193.

${ }^{484}$ Cf. FILGUEIRAS JúnIOR, Marcus Vinicius, A informática como opção jurídica vinculada da Administração Pública, cit., p. 194. Segundo o autor, o valor "informática" não se configura como fim do ordenamento jurídico, mas um instrumento, um meio para se atingir fins.
} 
No tocante aos serviços públicos, o dever de utilizar os melhores meios disponíveis resulta no princípio de atualidade ${ }^{485}$, corolário da eficiência surgido na legislação ordinária (Lei n. 8987/95, art. $6^{\circ}, \S 2^{\circ}$ ). Segundo esse princípio, é possível exigir da Administração a constante atualização e aperfeiçoamento das técnicas de prestação de serviços públicos, o que decorre da previsão constitucional relativa à qualidade dos serviços (art. 37, parágrafo $3^{\circ}$, I, in fine, da Carta Magna) ${ }^{486}$. Dessa maneira, a Administração tem o dever de utilizar as melhores técnicas disponíveis para o desempenho de suas atividades.

As melhores técnicas não são necessariamente as empregadas pelo setor privado; entretanto, se este utiliza determinadas técnicas com vantagens, é imperioso que a Administração esteja atenta para utilizá-las, pois, por força do princípio da eficiência, tem o dever de melhorar seu desempenho e baixar custos, realizando suas missões nas melhores condições $^{487}$. Por outro lado, a Administração deve ao menos equiparar-se à iniciativa privada no tocante à qualidade dos serviços prestados, pois não há sentido em que o usuário encontre melhores condições técnicas nos seus relacionamentos civis e comerciais do que nas suas interações com o Poder Público. Assim, para não ficar presa à idade da pedra tecnológica $^{488}$, a Administração deve utilizar os mesmos instrumentos empregados habitualmente pelos cidadãos em suas relações sociais ${ }^{489}$. Se, no setor privado, a melhoria do atendimento ocorre em virtude da pressão por reduzir custos e melhorar produtos em vista da sobrevivência da organização ${ }^{490}$, o mesmo deve ocorrer, no setor público, em virtude das

\footnotetext{
${ }^{485}$ Seria o "dever da Administração de atender, da melhor maneira e o mais prontamente possível, à extrema sensibilidade dos serviços de utilidade pública aos avanços científicos e tecnológicos, tratando-se de atividades de crescente expressão econômica e altamente demandantes de recursos, notadamente no que toca à qualidade das prestações aos usuários" (MOREIRA NETO, Diogo de Figueiredo, op. cit., p. 476). A atualidade, pela lei de concessões, está expressamente vinculada à prestação de serviços delegados, devendo ser imposta ao contratado e dele exigida. Não é este, contudo, seu único significado: é necessário exigir a atualidade das técnicas também da Administração, quando atua diretamente, sobretudo nos serviços públicos burocráticos.

${ }^{486}$ Cf. Moreira NeTO, Diogo de Figueiredo, op. cit., p. 477.

${ }^{487}$ Cf. Chevallier, Jacques, O Estado Pós-Moderno, cit., p. 84.

${ }^{488}$ Cf. VALERO TORRIJOS, Julián, El régimen jurídico de la e-Administración, cit., p. 9.

${ }^{489}$ Cf. VALero Torrios, Julián, Administración pública, ciudadanos y nuevas tecnologías, cit., p. 2965 e VALERO TORRIJOS, Julián, La e-Administración Pública, cit., p. 95. Em igual sentido, as expressivas palavras do autor: "A Administração de nossos dias não pode manter-se em um processo prestador de serviços que, por sua inadequação com os tempos e que, portanto, por sua desconexão com o âmbito social em que se insere, obrigue aos cidadãos a relacionar-se com ela de forma diferente de como o fazem com o resto dos operadores sociais" (VALERO TORRIJOS, Julián, El uso de cookies por las administraciones públicas, cit., p. 91).

${ }^{490} \mathrm{Cf}$. DunI, Giovanni, L'utilizzabilità delle tecniche elettroniche nell'emanazione degli atti e nei procedimenti amministrativi, cit.
} 
exigências dos usuários, canalizadas pelo ordenamento jurídico por meio do princípio da eficiência.

No contexto contemporâneo, exposto no primeiro capítulo deste estudo, não há dúvida de que as melhores técnicas - imprescindíveis para a realização da eficiência administrativa - incluem o uso de meios informáticos e telemáticos. Se as melhores técnicas envolvem a utilização de meios eletrônicos, é possível afirmar que estes decorrem do princípio da eficiência. Portanto, o emprego da informática, como instrumento de realização da eficiência, tem fundamento direto no texto da Constituição ${ }^{491}$.

Essa compreensão do princípio da eficiência não importa no reconhecimento abstrato de um dever de utilizar as novas tecnologias, que possa existir independentemente das condições concretas consideradas ${ }^{492}$. De fato, embora exista, de modo geral, um dever da Administração Pública no sentido de adaptar-se aos avanços da tecnologia ${ }^{493}$, há também situações de inviabilidade ou inconveniência de utilização de meios informáti-

${ }^{491}$ Cf. RAmos JúNIOR, Hélio Santiago, Democracia e direitos fundamentais na sociedade da informação: Desafios para o governo eletrônico, in Atuação - Revista Jurídica do Ministério Público Catarinense, vol. 5. n. 13, Florianópolis, PGJ/ACMP, set.-dez. 2007, pp. 63-74, disponível em http://www.mp.sc.gov.br/portal/site/conteudo/cao/ceaf/revista_juridica/revista13internet.pdf, acesso em 17.05.2011, p. 65 e PEREIRA JÚNIOR, Jessé Torres, DOTTI, Marinês Restelatto, A licitação no formato eletrônico e o compromisso com a eficiência: Projeto de Lei $n^{\circ} 7.709$, de 2007, in Revista do Tribunal de Contas da União, v.38, n.109, Brasília, TCU, mai.-ago. 2007, p. 54. É este também o entendimento adotado na Espanha, em torno do princípio da eficácia, tido como o fundamento da administração eletrônica (cf. TINTÓ GIMBERNAT, Montserrat, Administración electrónica y ciberprocedimiento, cit., p. 13; MARTíN DELGADO, Isaac, La administración electrónica como reto del derecho administrativo en el siglo XXI, cit., p. 317). Considerando a administração eletrônica como exigência do princípio da boa administração, cf. BLASCO DíAZ, José Luis, Los derechos de los ciudadanos en su relación electrónica con la Administración, in Revista Española de Derecho Administrativo, n. 136, Madrid, Civitas, out-dez. 2007, p. 795. Considerando-se que o princípio da eficiência, no Brasil, tem alcançado a noção de eficácia, conforme apontado acima, eventual legislação sobre governo eletrônico poderia invocar o mesmo fundamento. Comparando o princípio da eficiência brasileiro com o princípio da eficácia espanhol, cf. MOREIRA, Egon Bockmann, op. cit., p. 164.

${ }^{492}$ Considerando a existência de um dever constitucional da Administração Pública no sentido de utilizar as novas tecnologias, por força do princípio da eficiência, cf. os trabalhos de MARCUS VINícIUS FILGUEIRAS JÚNIOR, em especial: L'atto amministrativo elettronico in Brasile, cit., pp. 1-2; Ato administrativo eletrônico e teleadministração, cit., p. 247; A informática como opção jurídica vinculada da Administração Pública, cit., p. 196. Também reconhecendo a importância das modernas tecnologias na efetivação do princípio constitucional da eficiência, cf. Olivo, Luis Carlos Cancellier de, Desafios do direito administrativo diante do Estado em rede, cit., p. 19. No sentido de que tal dever estaria fundamentado na eficiência e na eficácia administrativa, considerando diversos ordenamentos jurídicos, cf. JINESTA LOBO, op. cit., p. 5.

${ }^{493}$ Cf. supra, item 1.2. 
cos e telemáticos avançados ${ }^{494}$ conforme a situação concreta do órgão público ou da atividade a ser atingida por tais tecnologias. Assim sendo, a efetiva utilização dos meios informáticos, embora seja impulsionada pelo ordenamento constitucional, por força do princípio da eficiência, deve resultar de prioridades definidas de acordo com o ordenamento constitucional, conforme juízo discricionário do administrador público ${ }^{495}$ ou por força de normas infraconstitucionais que venham a regular a matéria.

Contudo, a inexistência de um dever abstrato de utilizar as novas tecnologias não impede que o princípio da eficiência produza relevantes efeitos jurídicos em relação ao governo eletrônico. Assim, por força de tal princípio, aplicado ao atual contexto tecnológico, qualquer decisão da Administração a respeito dos meios a serem utilizados deve levar em consideração a possibilidade de utilização de meios eletrônicos, justificando a decisão pela utilização deste ou daquele meio. Nesse sentido, o princípio da eficiência impede que o Poder Público simplesmente renuncie ao avanço tecnológico, em prejuízo dos usuários e da própria Administração ${ }^{496}$. Por outro lado, tal princípio sempre poderá ser invocado para justificar os investimentos em tecnologia por parte da Administração, ainda que isso ocorra em virtude de uma decisão sujeita a juízo de oportunidade e conveniência. Por fim, o mesmo princípio constituiria o fundamento de uma regulação infraconstitucional que pretendesse - ponderando as condições fáticas existentes - impor à Administração o

\footnotetext{
494 “Note-se que nem sempre poderá a Administração Pública optar pela utilização de instrumentos informáticos por completa impossibilidade material, econômica ou mesmo jurídica. Mas a questão que ora se coloca é no sentido de que, em havendo tal possibilidade, a escolha revela-se vinculada em favor dos instrumentos informáticos" (FILGUEIRAS JúNIOR, Marcus Vinicius, A informática como opção jurídica vinculada da Administração Pública, cit., p. 196, grifos do original).

${ }^{495}$ Assim, a prioridade dos investimentos em tecnologia pode depender de várias circunstâncias, tais como o número de cidadãos a serem atendidos em cada caso, a proximidade entre as diversas repartições, o caráter centralizado ou descentralizado da estrutura organizativa, o volume de atividade a ser realizada e a eventual falta de pessoal (cf. VALERO TORRIJOS, Julián, El régimen jurídico de la e-Administración, cit., p. 25).

${ }^{496}$ Cf. DunI, Giovanni, La teleamministrazione come terza fase dell'informatica amministrativa, cit., item 3.
} 
dever de utilizar as novas tecnologias, garantindo ao administrado o direito correlato de se relacionar com o Poder Público por meios eletrônicos ${ }^{497}$.

Todavia, ainda que fosse previsto em lei, tal dever não seria necessariamente cumprido: de fato, a informatização não é matéria simples, que se solucione com um propósito voluntarista. Além das complexas questões já apresentadas no capítulo anterior, que dificultam a introdução das novas tecnologias na Administração Pública, deve-se considerar a necessidade de uma avaliação de mérito sobre a conveniência da aplicação de meios informáticos a uma dada atividade ${ }^{498}$. Dessa sorte, o reconhecimento do dever de levar a cabo o governo eletrônico precisa ser precedido da solução de tais problemas organizacionais, sem a qual não parece possível oferecer, por meio da tecnologia, vantagens efetivas para os administrados ${ }^{499}$.

\subsubsection{As exigências relativas à eficiência administrativa em meios digitais}

É preciso considerar, também, que a informatização não pode ser vista como a panaceia da eficiência administrativa ${ }^{500}$. Em primeiro lugar, porque as novas tecnologias tendem a ser mais úteis em relação à atividade administrativa formalizada - os trabalhos burocráticos -, não proporcionando necessariamente benefícios em relação a todas as atividades da Administração. Em segundo lugar, porque o avanço tecnológico é bastante exigente e não está isento de problemas.

\footnotetext{
${ }^{497}$ Cf. VAlERO TORRIJOS, Julián, Las relaciones con la Administración Pública mediante sistemas electrónicos, informáticos y telemáticos, cit., p. 269. Na Espanha, por exemplo, a Lei n. 11/2007, que trata do acesso eletrônico dos cidadãos aos serviços públicos, baseou-se declaradamente no princípio da eficácia. Assim é que consta de sua exposição de motivos que "A Administração está obrigada a transformar-se em uma administração eletrônica em função do princípio constitucional da eficácia administrativa" (in Boletín Oficial del Estado, 23.07.2007, pp. 27150-27166, disponível em http://www.boe.es/boe/dias/2007/06/23/pdfs/A2715027166.pdf, acesso em 20.05.2011, p. 27150).

${ }^{498}$ Cf. VALERO TORRIJOS, Julián, El régimen jurídico de la e-Administración, cit., p. 26.

${ }^{499}$ Para o administrado, a reorganização da Administração em vista do governo eletrônico é mais relevante que o reconhecimento de um direito a exigir e obter o uso de tecnologia informática no seu relacionamento com a burocracia (cf. NATALINI, Alessandro, op. cit., pp. 110-111).

${ }^{500} \mathrm{Cf}$. VALERO TORRIJOS, Julián, El régimen jurídico de la e-Administración, cit., p. 182.
} 
Entre as exigências próprias do governo eletrônico está a necessidade de que a introdução das novas tecnologias seja acompanhada do redesenho de processos administrativos e de uma profunda revisão das rotinas de trabalho ${ }^{501}$. A reengenharia de processos é uma tendência na administração contemporânea ${ }^{502}$, por forte influência da administração privada, sendo fundada, em grande parte, na introdução das novas tecnologias, mas não limitada a elas. Como as imperfeições na atuação administrativa nem sempre decorrem dos meios utilizados, é preciso que a informatização seja aproveitada como uma oportunidade para a revisão de métodos e formas de atuação ${ }^{503}$. Sem analisar devidamente as necessidades e exigências específicas acarretadas pelo uso de meios eletrônicos no processo, há um sério risco de reproduzir os hábitos e comportamentos próprios da administração baseada em papel e nas relações presenciais, de maneira que a modernização consista única e exclusivamente na mudança de suporte ${ }^{504}$, ou seja, em um revestimento tecnológico meramente cosmético ${ }^{505}$. Assim, mesmo com o uso intensivo de meios informáticos, é possível que persistam problemas ocasionados por fatores pouco relacionados à tecnologia $^{506}$. Isso sem esquecer a possibilidade de complicar, com a informática, aquilo que por papel é hoje simples, o que seria uma incongruência ${ }^{507}$.

Dentro do redesenho de processos está a questão da simplificação administrativa. Neste ponto, a utilização das novas tecnologias confronta-se com problemas ligados aos vícios dos excessos e deformações burocráticas ${ }^{508}$. De fato, o desenvolvimento de sistemas informatizados normalmente exige um esforço considerável em termos de padronização e simplificação, uma vez que a informática não é compatível com as complexas análises humanas, muito menos com as indefinições e armadilhas típicas das deformações

\footnotetext{
${ }^{501}$ Cf. GARCÍA MARCO, Francisco Javier, Ontologías y documentación electrónica en las actividades públicas, cit., p. 178. Sobre o redesenho de processos, cf. também o item 4.4, infra.

${ }^{502}$ Cf. PIPERATA, Giuseppe, Lo sportello unico, in Rivista trimestrale di diritto pubblico, vol. 52, n.1, 2002, p. 46. Ainda sobre o redesenho, cf. infra, nota 1185 .

${ }^{503}$ Cf. MARTín DELGADO, Isaac, La gestión electrónica del procedimiento administrativo, cit., p. 101.

${ }^{504} \mathrm{Cf}$. VALERO TORRIJOS, Julián, El régimen jurídico de la e-Administración, cit., p. 182.

505 Cf. Fernández SAlMerón, Manuel, VAlERo TORRIJOS, Julián, Protección de datos personales y Administración electrónica, cit., p. 117.

${ }^{506}$ Cf. VALERO TORRIJOS, Julián, El régimen jurídico de la e-Administración, cit., p. 182.

${ }^{507}$ Cf. DuNI, Giovanni, L'amministrazione digitale, cit., p. 80.

508 Cf. VALERo TORRIJOS, Julián, La nueva regulación legal del uso de las tecnologías de la información y las comunicaciones en el ámbito administrativo, cit., p. 209.
} 
burocráticas $^{509}$. Para não informatizar a burocracia, a introdução da tecnologia deve ser vista como uma ocasião importante para a simplificação administrativa ${ }^{510}$. Há quem afirme, pois, que o governo eletrônico estaria sujeito a um princípio de simplificação de trâmites, definido em torno da necessidade de eficiência ${ }^{511}$. A simplificação de processos deve ser feita de modo equilibrada, não apenas pela eliminação de partes do procedimento, sempre levando em consideração que as atividades públicas não têm somente repercussões do ponto de vista produtivo, mas servem para garantir direitos e expectativas fundadas no ordenamento jurídico ${ }^{512}$.

Convém observar, ainda, que a atuação em meio eletrônico é muito mais intensiva em planejamento e preparação do que aquela em meio tradicional, planejamento por vezes ausente das práticas administrativas mais difundidas ${ }^{513}$. O documento em papel pode funcionar, ainda que imperfeitamente, sem planejamento algum, sendo sempre possível desencadear uma ação administrativa por meio de um simples ofício, que provocará uma decisão. Já uma decisão em meio digital pode ser mais difícil de ser obtida, especialmente se ela depender da construção de um novo sistema informático. Por outro lado, uma decisão equivocada em papel encerra-se em si mesma, ao passo que os investimentos em sistemas mal informatizados podem transformar a busca de eficiência em prejuízo para os cofres públicos por um longo período de tempo ${ }^{514}$.

Por outro lado, assim como ocorre no setor privado, nem sempre a utilização de meios eletrônicos é realmente a solução mais econômica para a Administração Pública. Embora a introdução das novas tecnologias possa eliminar algumas despesas, tanto com o suporte material quanto com recursos humanos, elas trazem a necessidade de investimentos, geralmente elevados, em equipamentos, redes, aplicativos e programas infor-

\footnotetext{
${ }^{509}$ Tratando da simplificação verificada no caso do pregão eletrônico, em função da eliminação de variáveis incompatíveis com a lógica dos sistemas informatizados, cf. JUSTEN FILHO, Marçal, Pregão, cit., p. 279.

${ }^{510}$ Cf. PALOMAR OlMEDA, Alberto, Gestión Electrónica de los procedimientos, cit., p. 417.

${ }^{511}$ Cf. JinESTA LOBO, Ernesto, op. cit., p. 10. O princípio da simplificação de trâmites é expressamente referido pela legislação española (cf. GAMERO CASADO, Eduardo, Objeto, ámbito de aplicación y principios generales de la ley de administración electrónica, cit., p. 107).

512 Cf. PIPERATA, Giuseppe, op. cit., pp. 53-54.

513 Cf. VALERo TORRIJOS, Julián, La nueva regulación legal del uso de las tecnologías de la información y las comunicaciones en el ámbito administrativo, cit., p. 210.

${ }^{514}$ Cf. RAMOS JúNIOR, Hélio Santiago, Rover, Aires José, O ato administrativo eletrônico sob a ótica do princípio da eficiência, cit., p. 37.
} 
máticos $^{515}$. Assim, embora haja uma tendência a amortizar tais investimentos em médio prazo $^{516}$, pode haver um aumento de despesas nos estágios iniciais ${ }^{517}$. Por isso, a utilização de meios informáticos e telemáticos deve ser antecedida de uma ampla avaliação de custos e benefícios, levando em conta uma comparação com as ferramentas tradicionais ${ }^{518}$. É necessário, na comparação com os meios tradicionais, considerar não somente os custos diretos da Administração Pública, mas os custos gerados para os usuários do serviço, assim como deve ser avaliado o possível aperfeiçoamento dos resultados e os benefícios diretos e indiretos ocasionados pelas novas tecnologias ${ }^{519}$. Vale considerar, ainda, as vantagens futuras da introdução das tecnologias, sobretudo o reaproveitamento, para fins operacionais, gerenciais e estratégicos, de resultados de atividades realizadas e das informações produzidas.

\subsubsection{A convivência entre eficiência administrativa e legalidade}

A utilização das tecnologias da informação e da comunicação projeta-se também em um dos grandes temas de reflexão em torno dos princípios da Administração

\footnotetext{
${ }^{515}$ Cf. VALERo TORRIJOS, Julián, El régimen jurídico de la e-Administración, cit., p. 14. Assim, é correto afirmar que as novas tecnologias podem proporcionar economia de tempo, papel, tinta, grampos e trabalho (cf. CORRÊA, Davi Beltrão de Rossiter, op. cit., p. 11), mas essa economia não pode ser vista de forma unilateral, sem levar em conta os novos custos gerados. Considerar o governo eletrônico mais econômico, ignorando seus custos, seria o mesmo que afirmar que um veículo movido a álcool é mais econômico simplesmente porque consome menos gasolina.

${ }^{516}$ Cf. FERNÁNDEZ SALMERÓN, Manuel, El acceso a los registros y archivos administrativos: perspectiva telemática de un Derecho contemporáneo, in DAVARA RODRíGUEZ, Miguel Ángel (coord.), Quince años de encuentros sobre informática y derecho (1987-2002), tomo II, Madrid, Universidad Pontificia Comillas, 2002 , p. 615.

${ }_{517}$ Cf. FERNANDES, Ciro Campos Christo, Governo eletrônico e transformação da administração pública, in CHAHIN, Ali et al., op. cit., p. 107. Segundo o autor, poderia haver uma racionalização de tais despesas mediante o planejamento global dos investimentos e a revisão de iniciativas sobrepostas ou que não atendam a prioridades definidas em nível estratégico.

${ }^{518}$ Cf. VALERO TORRIJOS, Julián, Las relaciones con la Administración Pública mediante sistemas electrónicos, informáticos y telemáticos, cit., pp. 262-263.

${ }^{519}$ Por exemplo, a possibilidade de ter um maior número de participantes em um processo licitatório em meio eletrônico, de forma a aumentar a competitividade (cf. PEREIRA JÚNIOR, Jessé Torres, DOTTI, Marinês Restelatto, A licitação no formato eletrônico e o compromisso com a eficiência, cit., p. 52 e PIRES, Adriana Tavares Pereira, Leilão administrativo: eletrônico ou presencial, in Fórum de Contratação e Gestão Pública FCGP, n. 69, Belo Horizonte, Fórum, set. 2007, p. 40).
} 
Pública: a coexistência entre legalidade e eficiência. Neste caso, assim como há uma tendência a afirmar que o imperativo de eficiência não dispensa a legalidade ${ }^{520}$, as novas tecnologias não dispensam as garantias próprias do Estado de Direito, de modo que a eficiência não é fundamento para afastar a garantia de legalidade da ação administrativa também no governo eletrônico ${ }^{521}$.

Em alguns estudos jurídicos sobre o governo eletrônico, há uma tendência a descrever um antagonismo entre o garantismo, que exige segurança jurídica, e a busca de qualidade para obtenção de eficiência administrativa e à melhoria das condições de vi$\mathrm{da}^{522}$, ou a afirmar a necessidade de um equilíbrio entre eficiência e garantia ${ }^{523}$. Esses estudos são marcados pela desconfiança acerca da segurança proporcionada pelos sistemas informatizados e pela convicção de que cabe ao direito uma postura garantista para evitar prejuízos aos cidadãos, em detrimento de uma preocupação com o aperfeiçoamento da prestação de serviços e o aumento da eficiência ${ }^{524}$. No entanto, essa antítese já não se sustenta, pois é baseada na crença de que a utilização dos meios informáticos e telemáticos, embora trouxesse eficiência, poderia trazer algum prejuízo para as garantias jurídicas. Atualmente, é preciso que os juristas adotem outra mentalidade, que faça compatíveis os valores de rapidez e garantia, ao invés de confrontá- $\operatorname{los}^{525}$. Longe de se opor ao cumprimento da lei, o princípio da eficiência traz para o âmbito jurídico outros elementos relevantes, podendo ser considerada um ponto de diálogo interdisciplinar, ou seja, uma porta de entra-

\footnotetext{
${ }^{520}$ Cf. MedAUAR, Odete, Direito Administrativo Moderno, cit., p. 128 e GASPARINI, Diógenes, op. cit., p. 19.

${ }^{521}$ Sobre a submissão do governo eletrônico ao princípio da legalidade, cf. infra, item 2.4.1.

522 Cf. SÁNCHEZ RODRÍGUEZ, Francisco, op. cit., p. 37.

523 Cf. Gómez Puente, Marcos, op. cit., p. 118; OCHOA Monzó, Josep, Hacia la ciberadministración y el ciberprocedimiento?, cit., p. 157; OCHOA MONZÓ, Josep, MARTíNEZ GUTIÉRREZ, Rubén, La permeabilidad de la actividad administrativa al uso de tecnologías de la información y de la comunicación, cit., pp. 84-85.

${ }^{524}$ Cf. VALERO TORRIJOS, Julián, Administración pública, ciudadanos y nuevas tecnologías, cit., p. 2945. GARCÍA DE ENTERRÍA, por exemplo, descreve uma contradição entre o garantismo e o formalismo supostamente obsessivo dos juízes e a modernização e inovação administrativas, mostrando o que chama de exemplos chocantes dessa modernização não garantista. $\mathrm{O}$ autor critica uma tendência geral à fuga do direito administrativo em nome da flexibilidade da ação administrativa e à elevação do princípio da eficácia administrativa à mais elevada das categorias (Constitucionalización definitiva de las medidas cautelares contenciosoadministrativas y ampliación de su campo de aplicación (medidas positivas), y "jurisdicción plenaria" de los Tribunales contencioso-administrativos, no limitada al efecto revisor de actos previos. Dos sentencias constitucionales, in Revista Española de Derecho Administrativo, n. 109, Madrid, Civitas, jul.-set. 1993, p. 477).

${ }^{525}$ Cf. PALOMAR OlMEDA, Alberto, La utilización de las nuevas tecnologías en la actuación administrativa, cit., p. 366 e Un paso más en la aplicación de la tecnología en el procedimiento administrativo, cit., p. 92.
} 
da para aspectos que ultrapassam a simples legalidade e estão relacionados com uma Administração que, além de atuar de modo legal, funciona efetivamente bem.

Se a celeridade da conduta administrativa vier a contribuir para a prática de condutas incompatíveis com o ordenamento jurídico, não há uma verdadeira eficiência administrativa $^{526}$. Na verdade, medidas pretensamente adequadas ao bom andamento dos serviços que não atendam à legalidade tendem a produzir ineficiência no futuro ${ }^{527}$. Por outro lado, é preciso lembrar que o funcionamento eficiente da Administração constitui um meio indispensável para garantir o pleno respeito aos direitos dos cidadãos ${ }^{528}$. Além disso, os sistemas de informação, ao contrário do que muitos pensam, tendem a reforçar a formalização das atividades administrativas. Pode haver, como afirmado, uma simplificação dos processos, pela definição precisa de critérios e a eliminação de tarefas inúteis; entretanto, as informações úteis tendem a ser ainda mais registradas e conservadas, o processo pode ser mais minucioso e várias formalidades, antes impossíveis, passam a ser realizadas ${ }^{529}$.

Assim, a inconsistente antítese entre eficiência e garantias, especialmente a legalidade, deve ser superada ${ }^{530}$, pois a utilização de meios informáticos pode ser feita a fim de realizar os direitos antes existentes de modo ainda mais intenso, solucionando problemas anteriores, sobretudo caso se tenha em mente que o funcionamento da Administração pelos meios tradicionais sempre esteve longe de ser perfeito ${ }^{531}$. Hoje, já não se pode falar em opor eficiência e legalidade, mas em adaptar à nova realidade as necessárias e irrenunciáveis garantias tradicionalmente consagradas pelo direito administrativo, de sorte

\footnotetext{
${ }^{526}$ Cf. SÁNCHEZ RoDRÍGUEZ, Francisco, op. cit., p. 32.

527 É o que afirma MARÇAL JUSTEN FILHO: "O sacrifício dos controles formais acaba sendo sucedido pela destruição da eficiência" (Pregão, cit., p. 284).

${ }^{528}$ Cf. VAlERO TORRIJOS, Julián, Las relaciones con la Administración Pública mediante sistemas electrónicos, informáticos y telemáticos, cit., p. 260 e VALERO TORRIJOS, Julián, LóPEZ PELliCER, José Antonio, Algunas consideraciones sobre el derecho a la protección de los datos personales en la actividad administrativa, cit., p. 261.

${ }^{529}$ Sobre a manutenção do formalismo dos processos, cf. também o item 4.6, infra.

${ }^{530}$ Cf. VAlERO TORRIJOS, Julián, Las relaciones con la Administración Pública mediante sistemas electrónicos, informáticos y telemáticos, cit., pp. 261-262.

${ }^{531}$ Assim já se afirmou: "Nada mais longe de produzir faltas de garantias com a utilização da informática, quando é precisamente a excessiva burocratização, a escassez de meios e a inadequação dos existentes, assim como a lentidão dos procedimentos - problemas que poderiam ser superados com a utilização dos computadores - os que estão ocasionando, em grande parte, uma insegurança e desproteção que abre margem à falta de credibilidade dos administrados na própria Administração e, em certos casos, até na justiça" (DAVARA RODRÍGUEZ, Miguel Ángel, op. cit., p. 477).
} 
que a utilização das novas tecnologias da informação e comunicação também se torne um importante instrumento de garantia, podendo viabilizar o cumprimento das obrigações e o exercício de direitos por parte dos cidadãos ${ }^{532}$.

\subsection{A equivalência de garantias}

Elemento essencial para a compreensão jurídica do governo eletrônico é o princípio da equivalência de garantias. Segundo este princípio, a simples utilização de tecnologias informáticas e telemáticas na atividade administrativa não pode acarretar redução de garantias jurídicas consagradas no âmbito da administração em papel.

Não se trata, efetivamente, de um princípio expressamente previsto no ordenamento jurídico brasileiro ${ }^{533}$. No entanto, é justamente do silêncio do ordenamento que ele é extraído: com efeito, os direitos dos administrados não decorrem da tecnologia empregada na atividade administrativa, mas de normas jurídicas que a regulam. Assim

\footnotetext{
${ }^{532}$ Cf. VALERO TORRIJOS, Julián, Administración pública, ciudadanos y nuevas tecnologías, cit., pp. 2956 e 2958.

${ }^{533} \mathrm{O}$ princípio é adotado expressamente pela legislação espanhola, de sorte que são muitas as reflexões já efetuadas a respeito, que também falam em intangibilidade e conservação de garantias. Entre os vários trabalhos, vale mencionar: Asís RoIG, Agustín de, op. cit., p. 161; BAUZÁ MARTORELL, Felio José, Procedimiento Administrativo Electrónico, cit., p. 50; BAUZÁ MARTORELl, Felio José, Régimen jurídico de los registros telemáticos, in Revista Española de Derecho Administrativo, n. 118, Madrid, Civitas, abr-jun. 2003, pp. 188189; BLASCo Díaz, José Luis, Los derechos de los ciudadanos en su relación electrónica con la Administración, cit., p. 802; GAMERO CASADO, Eduardo, Objeto, ámbito de aplicación y principios generales de la ley de administración electrónica, cit., p. 92; MARTíNEZ GUTIÉRREZ, Rubén, Administración Pública Electrónica, cit., p. 214.
} 
sendo, a introdução das novas tecnologias não é capaz, por si só, de alterar posições jurídicas subjetivas, muito menos para restringir direitos devidamente assegurados ${ }^{534}$.

O princípio atua em dois planos diferentes. Por um lado, orienta a interpretação das normas jurídicas anteriores ao progresso tecnológico, caso não haja uma atuação legislativa para adaptação ao contexto eletrônico. Neste caso, os direitos preexistentes podem apenas ser reinterpretados à luz da realidade tecnológica e das possibilidades por ela oferecidas ${ }^{535}$, o que não deve levar a prejuízos sobre a esfera jurídica dos indivíduos. Por outro lado, caso haja necessidade de ajustes em nível legal, o referido princípio impõe que as adaptações do direito administrativo às novas tecnologias ofereçam um nível de garantias jurídicas equivalente ao proporcionado pelo suporte papel ${ }^{536}$, sobretudo no tocante à submissão aos princípios jurídicos da Administração Pública. Isso inclui a impossibilidade de criar, sem maiores razões, exigências mais rígidas para as atividades desempenhadas eletronicamente do que aquelas empregadas quando usados os meios tradicionais ${ }^{537}$.

A necessidade de equivalência de garantias tem origem em um contexto, generalizado até pouco tempo atrás, em que a informática procurava fundamentalmente satisfazer necessidades da organização administrativa, e não dos usuários ${ }^{538}$. Em vista disso, a tendência era opor os direitos dos indivíduos aos ganhos decorrentes da adoção das tecnologias - que atendiam à Administração -, procurando-se encontrar um ponto de equi-

\footnotetext{
${ }^{534}$ Nesse sentido, “(...) a tecnologia não põe nem retira direitos, não os suprime, não os cria. Só o Ordenamento Jurídico e os poderes da República o fazem" (MARTINI, Renato, Tecnologia e cidadania digital: ensaio sobre tecnologia, sociedade e segurança, Rio de Janeiro, Brasport, 2008, p. XII). É óbvio, pois, que a utilização de novas tecnologias não pode vulnerar nenhum direito fundamental reconhecido no ordenamento jurídico (cf. AgirReaZkuenaGa, Iñaki, Chinchilla, Carmen, op. cit., p. 44). Entendendo que a manutenção das garantias decorreria do princípio da legalidade, cf. MARTín DELGADO, Isaac, Naturaleza, Concepto y Régimen Jurídico de la Actuación Administrativa Automatizada, cit., p. 372 e JINESTA LOBO, Ernesto, op. cit., p. 9.

${ }^{535}$ Assim é que se fala em garantias equivalentes, embora não necessariamente iguais (cf. GAMERO CASADO, Eduardo, Objeto, ámbito de aplicación y principios generales de la ley de administración electrónica, cit., p. 92).

${ }^{536}$ Cf. GAMERO CASADO, Eduardo, Objeto, ámbito de aplicación y principios generales de la ley de administración electrónica, cit., p. 90. Entendendo que a inexistência ou inadequação dessa adaptação poderia implicar um nível mais baixo de garantia para os indivíduos e empresas, ameaçando o seu papel essencial de usuários dos serviços públicos eletrônicos, cf. VALERO TORRIJOS, Julián, Administrative Law and eGovernment, cit., p. 41.

${ }_{537}$ Cf. VALERo TORRIJOs, Julián, Administrative Law and eGovernment, cit., p. 45.

${ }^{538}$ Sobre essa preponderância da satisfação de necesidades internas, cf. VALERO TORRIJOs, Julián, La nueva regulación legal del uso de las tecnologías de la información y las comunicaciones en el ámbito administrativo, cit., p. 212.
} 
líbrio entre ambos ${ }^{539}$. A modernização tecnológica não poderia ocorrer em prejuízo dos direitos dos administrados ${ }^{540}$, entendendo-se possível o governo eletrônico somente quando satisfeitas, pelos meios telemáticos, as mesmas garantias existentes na atuação presenci$\mathrm{al}^{541}$.

No entanto, essa perspectiva hoje se revela insustentável, por duas razões distintas. A primeira é que a administração em papel não está isenta de críticas, podendo-se atribuir à excessiva burocratização e lentidão dos processos a insegurança e os prejuízos à defesa de direitos ${ }^{542}$, o que se intensifica em virtude da desatualização das técnicas de tutela de direitos ainda não adaptadas ao contexto tecnológico ${ }^{543}$. A segunda razão corresponde à crescente vocação das novas tecnologias também para a melhoria dos serviços praticados ao público, reconhecendo-se que a Administração somente atuará realmente bem caso seja capaz de aperfeiçoar a qualidade dos serviços prestados, o que inclui o devido respeito aos direitos dos usuários.

Adotando uma perspectiva mais positiva em relação ao desenvolvimento da tecnologia ${ }^{544}$, verifica-se que o emprego da informática pode efetivamente aumentar as liberdades dos indivíduos ${ }^{545}$, constituindo um elemento-chave para o aprofundamento dos

\footnotetext{
${ }^{539}$ Nesse sentido, haveria uma tensão dialética entre a incorporação de novas tecnologias, fundada na eficácia administrativa, e as garantias dos cidadãos (cf. SANZ LARRUGA, Francisco Javier, Las bases jurídicas de la 'administración electrónica' en España, cit., pp. 722-723). Contrapondo também a eficácia administrativa e as garantias contempladas pelo ordenamento, cf. GÓMEZ PUENTE, Marcos, op. cit., p. 131 e SÁNCHEZ RodRíGUEZ, Francisco, op. cit., p. 32.

${ }^{540}$ Cf. VALERO TORRIJOS, Julián, El acceso telemático a la información administrativa: un presuposto inexcusable para la e-Administración (Análisis desde la perspectiva del Derecho español), in Derecho y Tecnología, n. 6-7, San Cristóbal, Universidad Católica del Táchira, jan.-dez. 2005, p. 49 e, do mesmo autor, El régimen jurídico de la e-Administración, cit., p. 47.

${ }_{541}^{54}$ Cf. VALERO TORRIJOS, Julián, El régimen jurídico de la e-Administración, cit., p. 32.

${ }^{542}$ Cf. ibidem, p. 13.

${ }^{543}$ Sobre essa desatualização, cf. PITSCHAS, Raines, op. cit., p. 223.

${ }^{544}$ Cf. Poullet, Yves, La technologie et le droit, cit., p. 967. Segundo o mesmo autor, "A utilização de novas tecnologias da informação pela administração exige a passagem de uma reflexão 'negativa' para uma reflexão 'positiva'. Não se trata mais simplesmente de definir o direito do cidadão, defendendo seu jardim secreto em face da ação da administração, trata-se de traçar os princípios de uma melhor colaboração entre administração e cidadão, assegurando a transparência da ação da primeira e a salvaguarda dos interesses vitais dos segundo, ao serviço de uma sociedade mais democrática" (Informatisation et secteur public: de la protection des libertés à la transparence administrative, in Actes du colloque "Informatique et vie privée", Namur, 1 out. 1988, p. 42, tradução livre).

${ }_{545}$ Cf. Frosini, Vittorio, Informática y Administración Pública, cit., p. 457 e OlIVER, E. Lynn, SANDERS, Larry, The Regina Declaration - E-Government for the 21 st Century, in Optimum Online, v. 33, n. 2, jun.2003, disponível em http://www.optimumonline.ca/archives.phtml?volume=33\&, acesso em 27.01.2011.
} 
direitos reconhecidos aos cidadãos em suas relações com a Administração ${ }^{546}$. Desde que adotados os oportunos cuidados técnico-jurídicos ${ }^{547}$, a introdução das novas tecnologias pode trazer vantagens não só para o atendimento das necessidades internas do Poder Público, mas para as garantias dos administrados ${ }^{548}$, que passam a ter melhores condições de exercer diretamente vários de seus direitos, até mesmo sem intermediários humanos. Falase, então, em reciprocidade de vantagens, para restabelecer o equilíbrio tradicional entre as partes envolvidas: se a tecnologia aumenta a capacidade de atuação do Poder Público, é indispensável que seja configurada e utilizada de maneira que o administrado possa beneficiar-se na mesma proporção das vantagens por ela trazidas ${ }^{549}$.

Observada a equivalência de garantias, é possível identificar dois grupos de direitos: aqueles decorrentes da aplicação, ao entorno eletrônico, dos tradicionais direitos do cidadão em suas relações com a Administração, que devem ser aprofundados e potencializados à luz das novas tecnologias, e os que somente surgem a partir das peculiaridades destas ${ }^{550}$. A diferenciação entre as duas classes de direitos não é tão precisa, pois muitas vezes a posição jurídica favorável existente no âmbito do governo eletrônico apresenta um caráter instrumental em relação ao direito antes existente, a ser potencializado com o uso das novas tecnologias. Assim, por exemplo, o direito de informação pode receber uma nova conformação no contexto informático, pela facilidade e celeridade de localização dos elementos pertinentes, podendo ter como auxílio instrumental o direito de acesso por meio da internet.

Na inexistência, entre nós, de norma legal que imponha a utilização de meios informáticos pela Administração Pública em todas suas atividades, não é possível

\footnotetext{
${ }_{546}$ Cf. BERNADÍ GIL, Xavier, op. cit., p. 232.

${ }^{547}$ Cf. VALERO TORRIJOS, Julián, Las garantías jurídicas en la Administración electrónica, cit., p. 22.

548 Assim, "[a] revolução da informação é possível e desejável, não só do ponto de vista da eficácia, mas, sobretudo, da maior garantia para o cidadão" (VALERO TORRIJOS, Julián, Las garantías jurídicas en la Administración electrónica, cit., p. 22). No mesmo sentido, MARTín DELGADO, Isaac, La administración electrónica como problema actual para la investigación y la docencia en el derecho administrativo, cit., p. 356 . $\mathrm{O}$ Governo Federal brasileiro parece adotar essa visão positiva a respeito dos efeitos do governo eletrônico, enfatizando as vantagens por ele proporcionadas ao cidadão (cf. "Projetos do Programa de Governo Eletrônico Brasileiro", disponível em disponível em http://www.governoeletronico.gov.br/acoes-e-projetos, acesso em 10.05.2011).

${ }_{549}$ Cf. Poullet, Yves, La technologie et le droit, cit., p. 960.

${ }^{550}$ Cf. BLASCO DíAZ, José Luis, Los derechos de los ciudadanos en su relación electrónica con la Administración, cit., p. 802.
} 
reconhecer ao administrado o direito de se relacionar com ela de modo eletrônico ${ }^{551}$. Entretanto, há direitos instrumentais decorrentes das novas tecnologias que surgem a partir da prestação de utilidades em meio digital pelo Poder Público. Oferecido um serviço eletrônico, o usuário tem o direito à sua prestação, com todos os atributos de qualidade pertinentes $^{552}$, não cabendo entender-se que os novos meios constituiriam uma espécie de benevolência por parte da Administração Pública, que não lhe traria consequências jurídicas. Além disso, com a criação de serviços digitais, o usuário passa a ter direito: ao acesso ao próprio serviço, com qualidade e sem caráter discriminatório; à segurança e à conservação dos documentos eletrônicos; ao acesso a informações e orientações a respeito do funcionamento do sistema; à correta utilização das informações fornecidas e à correção de eventuais erros informáticos.

Tais direitos são apresentados em caráter apenas exemplificativo, não sendo possível esgotar as possibilidades de novas posições subjetivas concretas que possam surgir em razão da introdução das novas tecnologias. De todo modo, segundo o exposto, é possível identificar um critério para a identificação desses possíveis novos direitos. Com efeito, devem ser reconhecidos como direitos, no âmbito do governo eletrônico, todas as posições jurídicas que possam ser consideradas instrumentais em relação à necessidade de assegurar que o administrado tenha efetivamente garantias jurídicas equivalentes àquelas oferecidas pelas formas tradicionais de atuação administrativa.

O princípio da equivalência de garantias serve como uma referência para a avaliação das consequências específicas em relação a temas basilares do regime administrativo, tais como legalidade, igualdade, segurança jurídica, publicidade, privacidade do cidadão e responsabilidade da Administração Pública. Com efeito, cada um desses temas pode ser analisado no contexto das novas tecnologias, identificando como eles podem limi-

\footnotetext{
${ }^{551}$ No regime espanhol, o direito de relacionar-se por meio digital com a Administração constitui o eixo central da lei sobre administração eletrônica (cf. VALERO TORRIJOS, Julián, El régimen jurídico de la eAdministración, cit., p. 7).

${ }^{552}$ Cf. Blasco DíAZ, José Luis, Los derechos de los ciudadanos en su relación electrónica con la Administración, cit., p. 815. A respeito do pregão eletrônico, assim se posiciona MARÇAL JUSTEN FILHO: “Os poderes reconhecidos pelo Direito à Administração Pública para organizar e conduzir o pregão eletrônico são acompanhados de certos deveres inafastáveis, entre os quais o da eficiência das soluções adotadas. Ao escolher certas alternativas, a Administração assume a responsabilidade pelo seu funcionamento escorreito" (Pregão, cit., p. 296).
} 
tar, conformar e impulsionar o governo eletrônico, sempre sob a perspectiva da manutenção de direitos equivalentes para o administrado. É o que se fará nos itens seguintes.

\subsubsection{A submissão à legalidade e a reserva de lei}

Não há dúvida de que a utilização das novas tecnologias no setor público deve observar a plena sujeição à lei e ao direito ${ }^{553}$.

Assim, a utilização de suportes informáticos para o registro da informação e o desempenho de tarefas de modo automatizado não afasta a incidência das normas jurídicas. Como visto, o documento administrativo eletrônico é uma realidade para o direito, assim como todas as atividades administrativas desempenhadas por meio de sistemas informatizados. A atuação de tais sistemas, portanto, não constitui uma realidade paralela, restrita à tecnologia, mas deve ser desempenhada segundo regras compatíveis com o ordenamento jurídico.

Questão mais complexa, contudo, é a questão da reserva de lei, uma vez que o emprego da informática e da telemática no âmbito da Administração Pública raramente é objeto de normas legais expressas. Como já mencionado, trata-se de uma nova realidade a ser normatizada, um fenômeno de transformação social que gera uma intensa demanda por regulação jurídica ${ }^{554}$, devendo-se considerar os meios formais para a atuação administrativa como um tema a ser juridicamente regulado, tendo em vista o seu potencial para a geração de efeitos jurídicos relevantes, tanto no que se refere à realização quanto à violação de direitos. No entanto, tal demanda normalmente não é atendida pelas leis administrativas existentes, anteriores ao advento das novas tecnologias ${ }^{555}$. Apesar disso, é fre-

\footnotetext{
${ }_{553}^{5}$ Cf. GÓMEZ PUENTE, Marcos, op. cit., p. 127.

${ }^{554}$ Cf. FANTIGROSSI, Umberto, op. cit., p. 16.

${ }^{555}$ Cf. PIÑAR MAÑAS, José Luis, op. cit., p. 60.
} 
quente que as normas tradicionais sejam plenamente aplicáveis à atividade administrativa desenvolvida por meios informáticos e telemáticos ${ }^{556}$.

Nesse contexto, é preciso ter uma adequada compreensão a respeito do alcance do princípio da legalidade ${ }^{557}$, de maneira a concluir que nem sempre a utilização das novas tecnologias depende de uma previsão expressa em lei formal. Nesse sentido, apenas a atuação administrativa que possa ter efeitos desfavoráveis na esfera jurídica dos cidadãos deva fundar-se em uma base legal ${ }^{558}$, porque somente a norma legal poderia impor condutas (art. 5 , II da Constituição da República). Assim, não havendo uma vedação expressa ou contrariedade com uma lei formal ${ }^{559}$, é perfeitamente possível que a Administração atue de modo eletrônico sem um fundamento legal expresso no âmbito das atividades internas, ou mesmo quando não houver reflexos sobre a esfera do cidadão, o que ocorre, por exemplo, quando são mantidos, em paralelo, os meios tradicionais de atendimento ao usuário ${ }^{560}$.

No entanto, uma disciplina legal expressa é capaz de evitar dúvidas e obstáculos decorrentes de uma interpretação excessivamente restritiva do princípio da legalidade $^{561}$. A regulação da utilização das novas tecnologias na Administração é importante

${ }^{556}$ Cf. VALERO TORRIJOS, Julián, El régimen jurídico de la e-Administración, cit., p. 1.

${ }^{557}$ Sobre o tema, mostrando a impossibilidade de uma submissão total da Administração à lei, com menção à frequente omissão dos textos legais quanto ao modo de exercício do poder, cf. MEDAUAR, Odete, $O$ direito administrativo em evolução, cit., p. 145. Também a respeito do tema, cf., da mesma autora, Direito administrativo moderno, cit., pp. 123-124.

${ }_{558}$ Cf. MASUCCI, Alfonso, L'atto amministrativo informatico, cit., p. 61.

${ }^{559}$ A contradição com a lei formal justifica o questionamento da regulamentação do pregão eletrônico, em nível de decreto, por não ter observado as regras procedimentais da lei regulamentada, embora haja uma previsão legal genérica para a utilização da tecnologia (cf. JUSTEN FILHO, Marçal, Pregão, cit., p. 283).

${ }^{560}$ Cf. GAMERO CASADO, Eduardo, Objeto, ámbito de aplicación y principios generales de la ley de administración electrónica, cit., p. 93.

${ }^{561}$ Cf. VAlERo TORRIJOS, Julián, Administración pública, ciudadanos y nuevas tecnologías, cit., p. 2951. Segundo o autor, embora pudesse haver uma visão mais positiva da mudança tecnológica se o silêncio da lei pudesse ser interpretado como autorização implícita (cf. VALERO TORRIJOS, Julián, Administrative Law and eGovernment, cit., p. 46), há uma tendência a considerar a falta de tipificação não como mera alegalidade, mas como ilegalidade (cf. VALERO TORRIJOS, Julián, La nueva regulación legal del uso de las tecnologías de la información y las comunicaciones en el ámbito administrativo, cit., p. 212). Isso é provocado, na Espanha, por uma cultura administrativa que extrapola as exigências do princípio da legalidade próprias de um Estado de Direito e exige a regulação minuciosa e exaustiva das condições em que pode atuar a Administração Pública. O quadro não parece diferente do que ocorre no Brasil, onde a estrita legalidade pode ser facilmente invocado para a defesa de semelhante entendimento, malgrado sem a indicação de um propósito que não seja a simples veneração do próprio princípio. 
para afastar obstáculos formais que impedem a utilização de meios eletrônicos ${ }^{562}$ e para dar as garantias necessárias ao cidadão em relação aos serviços prestados em meio digital. Aumentando as condições de confiança nos cidadãos, dando segurança às atividades realizadas por meio da internet ${ }^{563}$, pode também haver benefícios para o próprio Poder Público. A adequada disciplina normativa do uso das novas tecnologias na Administração ${ }^{564}$ favorece o pleno aproveitamento das possibilidades que elas oferecem ${ }^{565}$.

O objeto da possível regulação sobre governo eletrônico alcança, por exemplo: a) uma declaração programática sobre objetivos a serem alcançados ou mesmo a possível imposição da informatização à própria Administração Pública ${ }^{566}$; b) aspectos da organização administrativa, especialmente a disciplina do relacionamento entre órgãos e entes públicos; c) a prescrição de deveres para a Administração; d) a garantia de direitos para os cidadãos, sobretudo no relacionamento com a Administração; e) a interferência, quando necessário, na esfera jurídica dos cidadãos, restringindo seus direitos; f) o regramento do documento eletrônico e da assinatura eletrônica; g) o regime da informação administrativa em meio digital; h) o regramento da proteção das informações de caráter pessoal; i) a disciplina da atividade administrativa automatizada ${ }^{567}$.

\footnotetext{
${ }^{562}$ Cf. DunI, Giovanni, L'utilizzabilità delle tecniche elettroniche nell'emanazione degli atti e nei procedimenti amministrativi, cit.

${ }^{563}$ Cf. MARTínez GutiÉRrez, Rubén, Administración Pública Electrónica, cit., p. 211.

${ }^{564}$ Cf. Beloulou, Véronique, op. cit., p. 626.

${ }^{565}$ Cf. VALERO TORRIJOS, Julián, El régimen jurídico de la e-Administración, cit., p. 1.

${ }^{566}$ Mencionando essa possibilidade como referente a um período anterior ao atual, cf. GONZÁLEZ NAVARRO, Francisco, Cincuenta años de procedimiento administrativo en un mundo cambiante, Madrid, Iustel, 2009, p. 681). Hoje, há alguma tendência à edição de normas legais que imponham o uso de meios eletrônicos: "Um dos pontos fundamentais em uma regulação legislativa futura das administrações públicas eletrônicas é que o uso e desenvolvimento das tecnologias da informação não pode reduzir-se a uma simples faculdade ou recomendação para os entes e órgãos públicos, à maneira de uma norma programática, mas deve impor-lhes seu uso no exercício das diversas facetas da função administrativa, a organização e das relações internas e externas com os administrados e outros sujeitos do direito público" (JINESTA LOBO, Ernesto, op. cit., p. 6, tradução livre).

${ }^{567}$ PALOMAR OLMEDA afirma que o regramento jurídico do governo eletrônico pode ser agrupado em três grandes capítulos: a) aspectos de documentação e acumulação informativa; b) tecnologia nas decisões informativas; c) aspectos relacionais (cf. Procedimientos administrativos y régimen documental en la actuación de la Agencia Española de Protección de Datos, in VVAA, La protección de datos en la Administración Electrónica. Pamplona, Aranzadi, 2009, p. 67).
} 
Esse conteúdo da regulação pode ser apresentado de várias formas. A estratégia pode ser: a) a elaboração de leis amplas, que procurem compreender todas as adaptações necessárias à atualização do regime administrativo às novas tecnologias; b) uma ou algumas leis genéricas, apenas para reconhecer, de modo simples, a admissibilidade de meios informáticos e a extensão a estes das regras da administração em $\operatorname{papel}^{568}$; c) um conjunto de leis, como intervenções normativas pontuais sobre cada tema de interesse da administração eletrônica; d) a mudança pontual das leis existentes para dar base à atuação por meios informáticos ${ }^{569}$. É também possível a elaboração de uma lei geral, que concentre os princípios da incorporação das novas tecnologias na Administração Pública, cabendo a outras leis a disciplina dos pontos mais específicos. Por fim, a regulação sobre o governo eletrônico deve considerar a existência de competências distribuídas segundo o regime federativo, o que pode levar à edição de vários diplomas legislativos sobre o tema.

Em qualquer das hipóteses, é preciso considerar a importância de combinar as necessidades mais restritas, pertinentes a cada temática ou a cada ente público, com a conveniência de que a regulação administração eletrônica não tenha um caráter fragmentário ou disperso, o que tende a provocar descoordenação e incompatibilidade entre sistemas, em prejuízo dos administrados ${ }^{570}$. A existência de padrões nacionais para o governo eletrônico parece indispensável em relação a temas como a integração entre sistemas de informação ${ }^{571}$. Além disso, parece conveniente para assegurar homogeneidade nos serviços

\footnotetext{
${ }^{568}$ Cf. PRINS, J.E.J. (ed.) et al., E-Government and its Implications for Administrative Law, cit., p. 56.

${ }^{569}$ Considerando a diferença entre uma adaptação extensa de todas as leis e normas ou um esforço mínimo para estabelecer algumas regras básicas a respeito da comunicação eletrônica na legislação sobre processo administrativo, cf. PRINS, J.E.J. (ed.) et al., E-Government and its Implications for Administrative Law, cit., p. 7.

${ }^{570}$ Cf. Blasco DíAz, José Luis, Los derechos de los ciudadanos en su relación electrónica con la Administración, cit., pp. 809-810. A questão é bastante relevante, tendo sido identificada há muitos anos no clássico trabalho de NORA e MiNC: "Se os poderes públicos deixarem a informática cair em desordem, congelarão o futuro. Inversamente, nenhum cenário global pode ser imposto a partir de um centro único, sem abafar a sociedade ou bloquear o Estado. É necessário conciliar um máximo de liberdade e um mínimo de co-ordenação, facilitando a mudança, ao invés de a impor" (cf. op. cit., p. 109).

${ }^{571} \mathrm{Cf}$. infra, item 2.5 .
} 
eletrônicos, oferecendo algum conforto ao usuário, que não merece arcar com o ônus de aprendizagem para viabilizar cada contato que tenha com um ente público diferente ${ }^{572}$.

Assim, é necessária uma regulação de conjunto $^{573}$, de modo que a administração eletrônica seja regida, ao menos, segundo uma sistemática geral, com um mínimo de integração, permitindo a compatibilização entre os vários sistemas e a solução das grandes questões jurídicas referentes à matéria ${ }^{574}$. Nesse sentido, é defensável a existência de uma lei que disponha sobre os fundamentos do desenvolvimento do governo eletrônico, cujo principal objetivo seria definir e especificar as bases necessárias ao desenvolvimento sucessivo da regulação legal do tema, assegurando estabilidade normativa e continuidade das políticas estatais ${ }^{575}$.

No entanto, a introdução das novas tecnologias é um fenômeno transversal, que atinge os diversos entes públicos e, portanto, setores diversos, que reagem ao advento das novas tecnologias com respostas diferenciadas, não necessariamente unívocas ${ }^{576}$. Assim, a evolução normativa de toda a matéria não pode ser confiada a uma fonte legislativa monocêntrica, mas a um policentrismo de fontes, dispostas em uma sequência coordenada de vários níveis ${ }^{577}$. A administração eletrônica traz também questões locais, que devem ser tratadas conforme as necessidades do ente público e seus órgãos, não cabendo, em Estados Federais, que toda a matéria seja esgotada na legislação editada pelo Poder central.

Outro ponto relevante a ser considerado é a necessidade de que as normas legais sejam suficientemente abertas e flexíveis, para que possam manter-se adaptadas às mudanças sociais, sobretudo para evitar a defasagem decorrente da velocidade das mu-

\footnotetext{
${ }^{572}$ VALERO TORRIJOS trata da necessidade de que os entes públicos utilizem programas informáticos compatíveis, de forma a reduzir ao mínimo os problemas decorrentes de uma excessiva heterogeneidade, principalmente no que concerne aos ônus econômicos e de aprendizagem do uso de diferentes ferramentas em função da pessoa pública (cf. Las relaciones con la Administración Pública mediante sistemas electrónicos, informáticos y telemáticos, cit., p. 266).

${ }^{573}$ Cf. MARTín DELGADO, Isaac, La administración electrónica como reto del derecho administrativo en el siglo XXI, cit., p. 323.

${ }^{574}$ Sobre o assunto, considerando a lei española, cf. GAMERO CASADO, Eduardo, Objeto, ámbito de aplicación y principios generales de la ley de administración electrónica, cit., p. 59.

${ }^{575}$ Cf. PeTRAUSKAS, Rimantas, KISKIS, Mindaugas, op. cit., p. 342.

${ }^{576}$ Cf. MERLONI, Francesco, Le difficoltà per una visione organica dell'e-government: la dispersione normativa, in MERLONI, Francesco, Introduzione all'e-government, Torino, G. Giappichelli, 2005, p. 17.

${ }^{577}$ Cf. CONTALDO, Alfonso, GoRGA, Michele, op. cit., p. 205.
} 
danças tecnológicas ${ }^{578}$. No âmbito do governo eletrônico, não é possível que a lei tenha a direção material de todos os temas ${ }^{579}$, nem que a estabilidade desejável para qualquer norma jurídica se torne um obstáculo para a adequação do regime jurídico em relação à realidade por ela regrada ${ }^{580}$. As leis relativas à utilização da informática e da telemática na Administração Pública devem estabelecer hipóteses de discricionariedade técnica e empregar conceitos jurídicos indeterminados, reservando para o âmbito da competência regulamentar os temas que exigem ajustes rápidos e constantes segundo o imprevisível progresso técni$\operatorname{co}^{581}$.

Em vista de tais necessidades, próprias da realidade da informática e da telemática, deve-se considerar a disciplina normativa no Brasil, de acordo com o ordenamento constitucional em vigor, sobretudo em relação ao regime de competências, identificando como poderia ser regulada a introdução da informática e da telemática na Administração Pública brasileira ${ }^{582}$.

Em nosso país, a autonomia dos entes políticos é bastante acentuada, de modo que a regra é que a competência para legislar sobre matérias do direito administrativo pertence a cada ente, havendo exceções previstas na própria Constituição, como é o caso da desapropriação e das normas gerais sobre licitações e contratos administrativos. Nesse sentido, temas relevantes para a administração eletrônica, como o processo administrativo, são elaborados de modo descentralizado.

\footnotetext{
${ }^{578}$ Cf. JINESTA LOBO, Ernesto, op. cit., p. 5; MASUCCI, Alfonso, L'atto amministrativo informatico, cit., p. 25 e CONTALDO, Alfonso, GORGA, Michele, op. cit., p. 204.

${ }^{579}$ Cf. BARNÉS VÁZQUEZ, Javier, Una reflexión introductoria sobre el Derecho Administrativo y la Administración Pública de la Sociedad de la Información y del Conocimiento, in Revista Andaluza de Administración Pública, cit., p. 39. O autor ressalta que, para a doutrina espanhola dominante, isso seria uma patologia, um desvio do sistema, pois o ideal consistiria na consecução do máximo grau de sujeição material da Administração à lei. Segundo COTINO HuESO, o processo de evolução das tecnologias e seu emprego extremamente dinâmico torna escassa a importância do direito como conformador dessa realidade (cf. Derechos del ciudadano administrado e igualdad ante la implantación de la Administración electrónica, cit., p. 127).

${ }_{580}$ Cf. VALERO TORRIJOS, Julián, Administración pública, ciudadanos y nuevas tecnologías, cit., p. 2951.

${ }^{581}$ Cf. Jinesta LOBO, Ernesto, op. cit., p. 5 e CONTALDO, Alfonso, GORGA, Michele, op. cit., p. 204.

${ }^{582}$ É claro que, como as novas tecnologias atingem a Administração Pública em suas várias atividades, vários regimes competenciais poderiam ser invocados (cf. BERNADí GIL, Xavier, op. cit., p. 224). Nesse sentido, o emprego das novas tecnologias em desapropriações deve ser regulada em lei federal, ao passo que sua utilização para o ordenamento territorial urbano deverá ser feita pelo Município. A questão, contudo, seria a competência para regular a administração eletrônica em si.
} 
Contudo, o surgimento de novos âmbitos de atuação normativa sempre traz importantes discussões sobre as questões de competência ${ }^{583}$. Em outros ordenamentos, havendo uma clareza sobre como se repartem as competências em relação aos diferentes aspectos das novas tecnologias, tem-se entendido como provável que o Estado central assuma a função regulatória global, inclusive dos aspectos aplicativos das normas ${ }^{584}$. No caso do ordenamento brasileiro, não chega a haver um silêncio da Constituição a respeito, pois a disciplina geral da administração eletrônica deve ser entendida como compreendida na competência da União para legislar sobre informática e telecomunicações (art. 22, IV da Constituição da República) ${ }^{585}$.

Além disso, há uma tradição de trazer do direito civil as normas básicas relativas aos atos jurídicos em geral ${ }^{586}$, o que se reflete em aspectos relevantes para a administração eletrônica, especialmente o documento eletrônico e a assinatura digital. Observando essa tradição, vem sendo entendido que a Medida Provisória n. 2200/01, ao reconhecer a validade de documentos públicos emitidos por meio eletrônico, ofereceu o respaldo necessário para o documento administrativo eletrônico ${ }^{587}$, inclusive em relação a Estados e Municípios.

Assim sendo, é viável a promulgação de uma lei federal sobre o assunto, que ofereça as linhas básicas do governo eletrônico e solucione suas grandes questões jurí-

\footnotetext{
${ }^{583}$ Cf. BERNADÍ GIL, Xavier, op. cit., p. 221.

${ }^{584}$ Cf. ibidem, p. 223.

${ }^{585}$ A disciplina das telecomunicações parece bastante compreensível como tema para distribuição de competência, podendo-se entender como poder para estabelecer regras sobre serviços de telecomunicações. O mesmo não ocorre com a informática, mencionada pela primeira vez pela Constituição de 1988, com muito mérito pela atenção à realidade emergente, mas com pouca precisão sobre aquilo em que consistiria esse título competencial. A competência parece decorrer de uma preocupação com a existência de padrões nacionais, o que tendem a ser importantes nessa área. Isso é bastante relevante na informática pública, que seria, por excelência, um campo próprio para o exercício dessa competência.

${ }^{586}$ Cf. MEDAUAR, Odete, Direito administrativo moderno, cit., p. 38. Segundo a realidade italiana, as normas sobre a forma dos atos jurídicos devem de qualquer modo ser uma prerrogativa do governo central, pois se trata de regras basilares do ordenamento jurídico geral, que prescindem da informática (cf. DuNI, Giovanni, L'amministrazione digitale, cit., p. 59).

${ }^{587}$ Nesse sentido, tratando do ato administrativo em meio eletrônico, cf. RAMOS JúNIOR, Hélio Santiago, Rover, Aires José, $O$ ato administrativo eletrônico sob a ótica do princípio da eficiência, cit., p. 36. Vale mencionar, também, a possibilidade de que sejam aplicados, por analogia, ao governo eletrônico, os dispositivos da Lei n. 11.419/06, que trata do processo judicial eletrônico. É evidente que essa não supre a ausência de regras legais sobre a atuação administrativa, uma vez que se trata de temas diversos. Entretanto, a aplicação analógica de dispositivos pode revelar-se uma solução necessária conforme o estágio da normatização acerca da utilização das novas tecnologias na Administração Pública.
} 
dicas. Essa lei poderia combinar-se a leis editadas no âmbito de cada pessoa política, com base na sua autonomia, com o fim de atender às particularidades locais ${ }^{588}$. Como a regulamentação legal da matéria não deve ter um caráter tão inflexível que possa prejudicar os avanços tecnológicos, nenhuma dessas leis deveria disciplinar questões técnicas, reservando para os regulamentos a contínua atualização normativa da administração eletrônica, na condição de realidade em frequente transformação.

\subsubsection{A igualdade na utilização das tecnologias}

A introdução das novas tecnologias na Administração Pública traz, ao mesmo tempo, grandes oportunidades e sérios riscos para a realização do princípio da igualdade, estabelecido pela Constituição brasileira (art. $3^{\circ}$, IV; $5^{\circ}$, caput e 19, III).

Por um lado, a utilização da informática tende a reduzir as situações de disparidade de tratamento entre diversos interessados ${ }^{589}$, justamente por padronizar as decisões, reduzindo a esfera da discricionariedade administrativa no caso concreto ${ }^{590}$ e garantindo a impessoalidade ${ }^{591}$. As decisões devem ser padronizadas segundo critérios que avaliem de modo correto as semelhanças e diferenças entre as situações consideradas, pois

\footnotetext{
${ }^{588}$ Seria possível, assim, adotar uma estrutura semelhante à do sistema italiano, no qual cabe ao Estado o papel de coordenação vertical, mas essa supremacia do poder central é circunscrita a uma área que, embora ampla, não abrange todos os fenômenos do governo eletrônico (cf. CARLONI, Enrico, Le difficoltà per una visione organica dell'e-government: il pluralismo amministrativo, in MERLONI, Francesco, Introduzione all'e-government, Torino, G. Giappichelli, 2005, p. 54).

${ }^{589}$ Cf. Alli Aranguren, Juan-Cruz, op. cit., p. 51.

${ }^{590}$ Cf. DunI, Giovanni, Teleamministrazione, cit., item 3.5.

591 "Os atos administrativos devem ser praticados de forma impessoal e nada melhor do que a vontade do administrador consubstanciada ou mediada por software inteligente. O software agiria como se fosse o próprio administrador, praticando de forma retilínea os atos em conformidade com a lei" (RAMOS JÚNIOR, Hélio Santiago, Rover, Aires José, $O$ ato administrativo eletrônico sob a ótica do princípio da eficiência, cit., p. 38). A atuação por meio do sistema, nesse sentido, equivaleria a levar ao extremo a perspectiva objetiva a ser adotada, em vista do princípio da impessoalidade, em relação à vontade subjacente ao ato administrativo. Sobre a vontade em sentido objetivo como forma de realização da impessoalidade, cf. MEDAUAR, Odete, Direito administrativo moderno, cit., p. 134.
} 
tratar igualmente, por meio do sistema, situações diferentes entre si, poderia acarretar uma violação do próprio princípio da igualdade ${ }^{592}$.

É também importante considerar a possibilidade de substituir o serviço de massa por um tratamento personalizado ao usuário ${ }^{593}$. Trata-se de uma tendência advinda do comércio eletrônico, decorrente da adaptabilidade proporcionada pela tecnologia ${ }^{594}$. Ao receber a solicitação, o sistema informatizado pode consultar o histórico do usuário, dando-lhe acolhida e tratamento conforme suas necessidades ${ }^{595}$, de maneira a oferecer-lhe serviços que possam ser de seu interesse. É possível realizar esse tipo de atendimento personalizado sem acarretar uma violação aos princípios da igualdade ${ }^{596}$ e da impessoalidade, uma vez que não se trata de adotar diferentes critérios de decisão, privilegiando uma pessoa em detrimento da outra, mas apenas de aperfeiçoar o atendimento e a prestação de informação relacionada a uma pessoa concreta ${ }^{597}$, de acordo com informações existentes e legitimamente obtidas ${ }^{598}$.

${ }_{592}$ Cf. MASUCCI, Alfonso, L'atto amministrativo informatico, cit., p. 37.

${ }^{593}$ Cf. MASUCCI, Alfonso, Erogazione on line dei servizi pubblici e teleprocedure amministrative, cit., p. 994 e CHAHIN, Ali et al., e-gov.br: a próxima revolução brasileira: eficiência, qualidade e democracia: o governo eletrônico no Brasil e no mundo, São Paulo, Prentice Hall, 2004, p. 62. Seria possível falar, também, em personalização em massa (cf. LAUDON, Kenneth C., LAUDON, Jane P., op. cit., p. 20).

${ }_{594}$ Cf. CHATILLON, Georges, L'administration électronique, cit., p. 684.

${ }^{595}$ Cf. GRISTI, Éric, op. cit., p. 503.

${ }_{596}^{596}$ Cf. RONDEAU, Jean-Claude, op. cit., p. 13.

${ }^{597}$ Embora alguns autores enfatizem as vantagens desse tratamento personalizado, que guarda relação com os princípios da igualdade e da impessoalidade, outros demonstram preocupação com o que seria uma desumanização ou despersonalização da relação entre Administração e usuários (cf. OBERDORFF, Henri, L'administration électronique ou l'e-administration, in Recherches et Prévisions, n. 86, Paris, CNAF, dez. 2006, pp. 9-18, disponível em: http://www.caf.fr/web/WebCnaf.nsf/090ba6646193ccc8c125684f005898f3/6d586507f49dd316c12572a3003 64de9/\$FILE/RP86-HOberdorff.pdf, acesso em 31.12.2010, p. 14 e CHEVALLIER, Jacques, La mise en ouvre de l'administration électronique, in CHATILLON, Georges, MARAIS, Bertrand du (org.), L'administration électronique au service des citoyens, Bruxelles, Bruylant, 2003, pp. 389-390). Convém ressaltar, contudo, que a utilização das novas tecnologias pela Administração Pública não está necessariamente atrelada à eliminação do atendimento presencial em repartições públicas. A incorporação da tecnologia deve ser feita de acordo com as necessidades do usuário, com especial atenção para o contexto cultural do grupo social a ser atendido. Na condição de meio altamente maleável, a tecnologia deve ser usada de modo mais apropriado em vista do contexto. Se os usuários necessitam de atendimento presencial, a informática pode ser usada, por exemplo, para oferecer as melhores condições de trabalho ao atendente, levando ao aperfeiçoamento da qualidade do serviço.

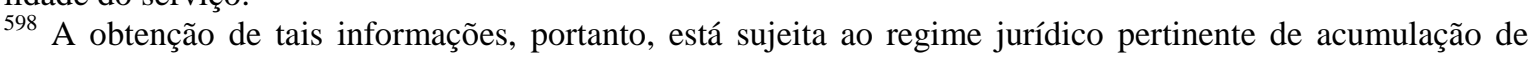
dados pela Administração, que é objeto do item 2.4.5.1, infra. 
A grande preocupação, em relação à preservação da igualdade, deve ser a garantia, diretamente decorrente da Constituição ${ }^{599}$, de que a utilização das tecnologias da informação e da comunicação não provoque consequências discriminadoras, acarretando restrições de qualquer natureza no acesso aos direitos inerentes ao processo administrativo e à prestação de serviços públicos ${ }^{600}$ para os cidadãos que se relacionem com as administrações públicas por meios não eletrônicos ${ }^{601}$. Fala-se, pois, em um princípio do acesso universal, relacionado à igualdade, segundo o qual nenhuma condição ou circunstância pessoal deve obstar ou impedir o acesso aos serviços oferecidos por meios eletrônicos ${ }^{602}$. Neste caso, verifica-se também uma projeção do princípio de equivalência de garantias, no sentido de que o uso de meios eletrônicos não pode acarretar a diminuição dos direitos do $\operatorname{administrado}^{603}$.

O principal fator a ser levado em conta é a eventual desigualdade no acesso à tecnologia ${ }^{604}$. Com efeito, atualmente há uma separação nítida ${ }^{605}$ entre os que podem e os que não podem ter tal acesso ${ }^{606}$. Esse fenômeno, com o emprego frequente do

\footnotetext{
${ }^{599}$ O art. 19, III da Constituição Brasileira veda aos entes da Federação "criar distinções entre brasileiros ou preferências entre si". A propósito dessa vedação e da aplicabilidade plena do preceito constitucional correspondente à administração eletrônica, em âmbito espanhol, cf. VALERO TORRIJOS, Julián, Las relaciones con la Administración Pública mediante sistemas electrónicos, informáticos y telemáticos, cit., p. 262.

${ }^{600}$ Cf. VALERO TORRIJOS, Julián, Administración pública, ciudadanos y nuevas tecnologías, cit., pp. 29552956 e AgirReaZKuEnaga, Iñaki, Chinchilla, Carmen, op. cit., p. 44. É uma preocupação dos documentos europeus evitar esse hipotético efeito perverso e inadimissível (cf. Mestre DELGADO, Juan Francisco, op. cit., p. 130).

${ }^{601}$ Cf. GAMERO CASADO, Eduardo, Objeto, ámbito de aplicación y principios generales de la ley de administración electrónica; su posición en el sistema de fuentes, cit., p. 95 e COTINO HuEso, Lorenzo, Derechos del ciudadano, cit., p. 158. Interessante observar, igualmente, no caso da prestação de serviços, que a igualdade de acesso está entre os postulados tradicionais da teoria do serviço público, que tem como princípios essenciais, além da regularidade e continuidade, a igualdade de acesso (cf. GÓMEZ PUENTE, Marcos, op. cit., pp. $119-120)$.

${ }^{602}$ Cf. GÓMEZ PuENTE, Marcos, op. cit., p. 119.

${ }^{603}$ Cf. MARTín DELGADO, Isaac, Los derechos de los ciudadanos ante la administración electrónica, in VVAA, La protección de datos en la Administración Electrónica, Pamplona, Aranzadi, 2009, pp. 159-160. ${ }^{604}$ Cf. DONATI, Daniele, op. cit., p. 209.

${ }^{605}$ Cf. VALERO TORRIJOS, Julián, Administración pública, ciudadanos y nuevas tecnologías, cit., p. 2944.

${ }^{606}$ Cf. IASELLI, Michele, op. cit., p. 17.
} 
idioma inglês, vem sendo denominado digital divide ${ }^{607}$. O efeito dessa separação, em relação àqueles que se encontram privados das novas tecnologias, recebe o nome de exclusão digital, expressão de uso mais corrente no Brasil ${ }^{608}$. As desigualdades entre indivíduos e grupos no acesso às tecnologias informáticas podem ter diversas origens, relacionadas às condições físicas do indivíduo, a aspectos cognitivos ou motivacionais e às características sócio-demográficas, tais como nível de instrução, renda, condição profissional, língua, etnia, idade, gênero e localização geográfica ${ }^{609}$.

A utilização das tecnologias da informação e da comunicação pela Administração Pública, caso feita sem as devidas cautelas, ao invés de contribuir para a difusão de uma cultura informática e dar acesso amplo aos recursos da sociedade da informação, pode aprofundar a exclusão digital, em prejuízo da igualdade exigida pela Constituição ${ }^{610}$. Seria um efeito perverso dividir a sociedade em cidadãos de primeira e segunda

\footnotetext{
${ }^{607}$ A doutrina tem aplicado a expressão digital divide para fazer referência às desigualdades existentes não somente entre pessoas e grupos da população, mas entre zonas geográficas (cf. ARENA, Gregorio, op. cit., p. 429, DUNI, Giovanni, L'amministrazione digitale, cit., p. 80 e GÓMEZ PUENTE, Marcos, op. cit., p. 120). Haveria, assim, o digital divide interno, ou social divide, relacionado às pessoas, e o digital divide externo, ou global divide, relacionado às diferenças existentes no acesso às novas tecnologias entre zonas geográficas (cf. DONATI, Daniele, op. cit., p. 224). Ainda sobre o digital divide externo, cf. GÓMEZ PUENTE, Marcos, op. cit., p. 96. No presente estudo, o enfoque é dado nas diferenças entre pessoas e sua repercussão em relação ao princípio da igualdade.

${ }^{608}$ Outros nomes para a exclusão digital seriam brecha digital, hiato digital, apartheid digital, fosso digital e divisão digital (cf. Olıvo, Luis Carlos Cancellier de, Controle social em rede da Administração Pública virtual, in Rover, Aires José, Direito e Informática, Barueri, Manole, 2004, p. 178).

${ }^{609}$ Cf. DONATI, Daniele, op. cit., pp. 228-229 e CAMMAROTA, Giuseppe, L'erogazione on line di servizi pubblici burocratici, cit., p. 53. Para o primeiro autor, o digital divide é efeito de desigualdades preexistentes à introdução das novas tecnologias, devendo todo efeito negativo ser atribuído à implantação dessas inovações em um determinado contexto (op. cit., pp. 221-222). O importante, assim, é que "[a]s novas tecnologias não devem gerar novas discriminações" (cf. GAROT, Marie José, op. cit., p. 95). Dessa maneira, não se deve imputar aos próprios novos meios de atuação a dificuldade em lidar com estes, sob pena de frustrar qualquer inovação. De fato, toda inovação sempre causará alguma defasagem de conhecimento em relação ao saber antes existente, relativo às práticas precedentes. No setor público, o propósito não deve ser o de obstar a inovação, com fundamento nessa inevitável defasagem, mas adotar medidas compensatórias para ajustar os efeitos negativos, muitas vezes inevitáveis. Num primeiro momento, certamente a tecnologia pode provocar uma divisão entre conectados e desconectados, assim como a invenção da escrita, de certo modo, acabou por gerar o analfabetismo, que predominou durante séculos. No momento atual, investir contra as novas tecnologias não constitui uma escolha proveitosa. Todavia, é indispensável enfrentar seus aspectos nocivos e procurar estender a todos seus efeitos benéficos.

${ }^{610}$ Cf. BOMBARDELl, Marco, op. cit., p. 1023; CHEVALLIER, Jacques, La mise en ouvre de l'administration électronique, cit., p. 390; OROFINO, Angelo Giuseppe, Forme elettroniche e procedimenti amministrativi, cit., p. 159; PIRAS, Paola, op. cit., p. 96; SCORZA, Guido, Il cittadino digitale tra vecchi e nuovi diritti e libertà, in Quaderni del DAE - Rivista di Diritto Amministrativo Elettronico, jul. 2004, disponível em http://www.cesda.it/quadernidae/index.php, acesso em 15.12.2010, p. 2. Entre os autores brasileiros, cf. PINHEIRO, Patrícia Peck, op. cit., p. 278.
} 
classe, conforme a velocidade que tivessem na relação com a Administração Pública ${ }^{611}$. Em um país como o Brasil, marcado pelos contrastes sociais e culturais, tal aspecto é ainda mais relevante e merece ser levado em conta por qualquer política de governo eletrôni$\operatorname{co}^{612}$.

Portanto, ao utilizar as novas tecnologias da informação e da comunicação em seu relacionamento com o usuário, a Administração Pública deve levar em conta a questão da exclusão digital, adotando uma política ativa de fomento ${ }^{613}$ e estratégias para evitar situações discriminatórias, garantindo o acesso aos serviços telemáticos ${ }^{614}$. Seria um modo de transpor, do Estado social para o âmbito do governo eletrônico, o dever de promover a efetiva igualdade entre os indivíduos, por meio de uma plena integração de todas as pessoas na sociedade da informação e do conhecimento ${ }^{615}$. A linha divisória entre incluídos e excluídos não é estática, sofrendo rápidas mutações por parte do progresso tecnológico, sendo possível cruzar essa fronteira com relativa facilidade, em um ou outro sentido, em função de quais sejam os recursos investidos e os esforços pessoais e coletivos para combater a exclusão digital ${ }^{616}$.

Não existem soluções ou estratégias universais para tanto, de maneira que as situações de desigualdade devem ser enfrentadas conforme a especificidade do ambiente em que ocorrem ${ }^{617}$. Várias estratégias podem ser utilizadas para enfrentar a questão da exclusão digital, conforme sua origem, evitando a discriminação nos serviços oferecidos pela Administração Pública em meio eletrônico. Vale citar como exemplos de políticas inclusivas: a) no caso de dificuldades no acesso à internet, mecanismos para universalizá-

\footnotetext{
${ }^{611}$ Cf. PUNZÓN MORALEDA, Jesús, Introducción, cit., p. 11.

${ }^{612}$ Cf. SANTOS, Rogério Santana dos, Manifesto por um governo eletrônico democrático e socialmente includente, in FERRER, Florencia, SANTOS, Paula, E-government: o governo eletrônico no Brasil, São Paulo, Saraiva, 2004, p. 74.

${ }^{613}$ Cf. SANZ LARRUGA, Francisco Javier, Las bases jurídicas de la 'administración electrónica' en España, cit., p. 758.

${ }^{614}$ Cf. PIRAS, Paola, op. cit., p. 97.

${ }^{615}$ Cf. GAMERO CASADO, Eduardo, Objeto, ámbito de aplicación y principios generales de la ley de administración electrónica, cit., p. 102.

${ }^{616}$ Cf. BERNADí GIL, Xavier, op. cit., p. 230.

${ }^{617}$ Cf. DonATI, Daniele, op. cit., pp. 221-222.
} 
la, baixando seus custos ou oferecendo-a gratuitamente ${ }^{618}$; b) no caso de pessoas portadoras de deficiência, criação de serviços acessíveis, inclusive por meio de portais especialmente desenhados para essa finalidade; c) no caso de dificuldades cognitivas para integração na sociedade da informação, programas de alfabetização digital - inclusive em relação às consequências jurídicas da utilização de meios informáticos e telemáticos -, bem como a criação de portais e serviços simples e transparentes, que possam ser compreendidos e utilizados mesmo por aqueles que não gozam de profundos conhecimentos informáticos; d) no caso de resistência injustificada, desconfiança ou preconceitos contra a utilização de meios eletrônicos, campanhas informativas sobre as vantagens que eles podem proporcio-

\footnotetext{
${ }^{618} \mathrm{Na}$ sociedade da informação, o acesso à internet não é um luxo, mas uma necessidade (cf. HoLMES, Douglas, op. cit., p. 8). No âmbito do relacionamento com o Estado, a possibilidade de interconexão eletrônica deve ser vista como um direito de cidadania eletrônica (cf. CAMMAROTA, Giuseppe, L'erogazione on line di servizi pubblici burocratici, cit., p. 51), cabendo ao Poder Público garantir o acesso de todos às fontes de informação e às tecnologias que lhes servem de suporte. Nesse sentido, "[u]m acesso livre e igual à informação eletrônica ('E-Accesibility') constitui um elemento essencial do Estado de Direito que colabora com a sociedade, na era do governo eletrônico" (cf. PITSCHAS, Raines, op. cit., p. 258, tradução livre). Do ponto de vista da liberdade individual, o acesso às tecnologias informáticas e telemáticas constitui um pressuposto para o exercício de outros direitos fundamentais, entre eles a liberdade de expressão e a liberdade de acessar a informação e difundi-la (cf. PIETRANGELO, Marina, Il diritto all'uso delle tecnologie nei rapporti con la pubblica amministrazione: luci de ombre, in Informatica e diritto, n. 1/2, Napoli, Edizioni Scientifiche Italiane, 2005, p. 77), de modo que "[o] acesso, o uso e intercâmbio de informação devem ser concebidos como peças ou elementos das liberdades fundamentais e, em consequência, o Estado deverá criar as organizações e procedimentos que sejam necessários para sua efetividade” (cf. BARNÉS VÁZQUEZ, Javier, Una reflexión introductoria sobre el Derecho Administrativo y la Administración Pública de la Sociedad de la Información $y$ del Conocimiento, cit., p. 60, tradução livre). Por isso, a tendência é considerar o direito aos serviços de comunicação como direito fundamental, que precisa ser garantido pelo Estado (cf. SCORZA, Guido, op. cit., p. 2). Para realizar esse direito são necessários mecanismos de universalização do acesso à internet, tais como reduzir os custos de conexão, oferecer um sistema de acesso público nas escolas, nas bibliotecas, nos locais de trabalho (cf. DONATI, Daniele, op. cit., p. 227) ou mesmo em quiosques públicos, além de financiar a compra de computadores pessoais (cf. CAMMAROTA, Giuseppe, L'erogazione on line di servizi pubblici burocratici, cit., p. 52). Vale salientar, a propósito, a experiência dos Telecentros implantados no Município de São Paulo, em que é possível obter acesso gratuito à internet ou participar de cursos e oficinais, caracerizando-se como um caso bem sucedido de política de inclusão digital. Sobre o tema, cf. TIBIRIÇÁ, Beatriz, Telecentros de São Paulo: tecnlogia de informação no combate à pobreza, in FERRER, Florencia, SANTOS, Paula, E-government: o governo eletrônico no Brasil, São Paulo, Saraiva, 2004, pp. 132-136.
} 
nar, assim como a garantia da qualidade da prestação de serviços, sobretudo em relação à segurança e à correção das informações prestadas pela Administração ${ }^{619}$.

Há também a possibilidade de manter a prestação de serviços também pelas vias tradicionais, de forma que o acesso à tecnologia e o conhecimento a respeito não sejam pressupostos da prestação de serviços públicos ${ }^{620}$. Como a questão da possível discriminação em relação aos excluídos digitalmente aparece apenas no atendimento ao administrado (front office), essa utilização dos meios tradicionais pode ocorrer somente no relacionamento com o usuário, não se impondo em relação às atividades administrativas internas $^{621}$. Em relação às atividades externas, pode-se falar em uma estratégia de comuni-

\footnotetext{
${ }^{619}$ A necessidade de inclusão digital e seus vários mecanismos são temas recorrentes na doutrina jurídica da administração eletrônica. Sobre eles, cf. BARNÉS VÁZQUEZ, Javier, Una reflexión introductoria sobre el Derecho Administrativo y la Administración Pública de la Sociedad de la Información y del Conocimiento, cit., pp. 47 e 60; BLASCO DÍAZ, José Luis, Los derechos de los ciudadanos en su relación electrónica con la Administración, cit., pp. 805 e 808; CAMMAROTA, Giuseppe, L'erogazione on line di servizi pubblici burocratici, cit., p. 52; CerRILlo I MARTíneZ, Agustí, E-información, cit., p. 12; Cotino Hueso, Lorenzo, Derechos del ciudadano, cit., pp. 157 e 161; Cotino HuESo, Lorenzo, Derechos del ciudadano administrado e igualdad ante la implantación de la Administración electrónica, in Revista Vasca de Administración Pública, cit., p. 138; DonATI, Daniele, op. cit., pp. 228-229; DUNI, Giovanni, L'amministrazione digitale, cit., p. 81; GÓMEZ PueNTE, Marcos, op. cit., p. 123; JiNESTA LOBO, Ernesto, op. cit., p. 8; MARTOS GaRCía, Juan Jesús, DNI electrónico: obligaciones jurídicas para el titular y límites constitucionales en el derecho fundamental a la intimidad y a la protección de datos, in Revista Aranzadi de Derecho y Nuevas Tecnologías, n. 9, Cizur Menor (Navarra), Aranzadi, set.-dez. 2003, p. 83; SANZ LARRUGA, Francisco Javier, Las bases jurídicas de la 'administración electrónica' en España, cit., p. 758. Entre os autores brasileiros, cf. PINHEIRO, Patrícia Peck, op. cit., p. 278 e BIGLIASSI, Renato, op. cit., p. 245.

${ }^{620}$ Cf. Asís RoIG, Agustín de, op. cit., p. 172 e VALERo TorRiJos, Julián, Las relaciones con la Administración Pública mediante sistemas electrónicos, informáticos y telemáticos, cit., p. 263. Seria o caso, por exemplo, da exclusividade da edição eletrônica dos diários oficiais, cuja acessibilidade deve estar garantida pela possibilidade de consulta em repartições públicas ou bibliotecas públicas e obtenção de uma cópia em papel (cf. VALERO TORRIJOS, Julián, Acceso a los servicios y difusión de la información por medios electrónicos, cit., pp. 260-261).

${ }^{621}$ Cf. DUNI, Giovanni, L'amministrazione digitale, cit., p. 81. Em relação às atividades internas, poderia ser até mesmo recomendável que se impusesse aos funcionários a realização de determinadas atividades usando exclusivamente meios eletrônicos (cf. MARTíNEZ GUTIÉRREZ, Rubén, Administración Pública Electrónica, cit., pp. 217-218). Quando houver a necessidade de relacionamento com o usuário, é possível fazê-lo pelos meios tradicionais, adotando-se uma sistemática que proporcione a vinculação entre esse relacionamento e a atuação eletrônica - v.g., a Administração recebe uma solicitação em papel ou presencialmente e depois procede à sua digitalização. Isso implica algum ônus para o Poder Público, porém pode ser a solução mais adequada conforme o caso, pois permite manter as formas de atendimento tradicional e, ao mesmo tempo, efetuar as atividades internas por meios eletrônicos. É importante considerar, ainda, que há uma diferença entre a utilização das novas tecnologias para o desempenho da atividade administrativa e para o atendimento ao público. Neste último caso, muitas vezes é difícil que a tecnologia possa substituir o atendimento presencial, ainda que haja canais de comunicação variados e eficientes por meios eletrônicos, pois o usuário pode ter necessidade de discutir e esclarecer pontos específicos de sua situação, o que só pode ocorrer mediante um diálogo com um ser humano devidamente preparado. Sobre essa atenção personalizada, cf. PÉREZ GÁlVEZ, Juan Francisco, op. cit., p. 574.
} 
cação multicanal $^{622}$, que inclua o auxílio de funcionários para a realização de operações pelos interessados ${ }^{623}$ e a existência de terminais em que o usuário pode ter acesso aos serviços eletrônicos da Administração, localizados não somente em repartições públicas ou em centros destinados a oferecer uso gratuito à internet, mas em bibliotecas, oficinas postais, supermercados e similares ${ }^{624}$.

A adoção progressiva do relacionamento eletrônico, em paralelo com as formas tradicionais, tem a vantagem de possibilitar uma adesão facultativa às novas tecnologias nos primeiros períodos de funcionamento do sistema, o que pode servir para o aperfeiçoamento de sua qualidade e para avaliação por parte dos usuários; sendo bem sucedida essa fase, com uma considerável adesão dos usuários, pode ser estabelecida a exclusividade do atendimento digital, de modo não traumático ${ }^{625}$.

\subsubsection{Desafios à isonomia na criação de serviços digitais}

Do ponto de vista prático, devem ser citadas duas complexas questões, que constituem desafios em relação a possíveis discriminações decorrentes do relacionamento eletrônico entre a Administração Pública e usuários.

A primeira delas diz respeito à viabilidade jurídica da imposição do relacionamento com a Administração exclusivamente por meios eletrônicos. Mesmo conside-

\footnotetext{
${ }^{622}$ Cf. GRoss, Thomas, op. cit., p. 71. Sobre o tema, cf. também a nota 703, infra.

${ }^{623}$ Em tese, haveria também a possibilidade de que o funcionário realizasse as operações pelo interessado, por solicitação deste, mas isso pode levar a situações de discrepância entre a vontade do interessado e a que foi processada pelo funcionário (cf. VALERO TORRIJOS, Julián, Administración pública, ciudadanos y nuevas tecnologías, cit., pp. 2957-2958).

${ }_{624}$ Cf. ARENA, Gregorio, op. cit., pp. 429-430.

${ }^{625}$ Foi o que ocorreu, no Brasil, com as declarações de imposto de renda, em que os meios eletrônicos foram oferecidos de modo facultativo e depois vieram a ser tornados obrigatórios. Em 1991, a Receita Federal admitiu a elaboração da declaração em programa de computador e, em 1997, aceitou a transmissão pela internet, sempre de forma facultativa. Em 2011, foi abolido o formulário em papel, pela Instrução Normativa RFB n. 1095/2010. O histórico da utilização da tecnologia pela Receita Federal pode ser consultado em: http://www.receita.fazenda.gov.br/Memoria/irpf/declaracoes/programas/default.asp, acesso em 08.11.2011.
} 
rado o potencial discriminador das tecnologias da informação ${ }^{626}$, não é possível afirmar, desde logo, a existência de um indiscutível direito ao papel, ou seja, um direito de relacionamento com a Administração Pública por meios convencionais ou físicos ${ }^{627}$. De fato, em vista da natureza de sua interação com o usuário, a Administração não pode simplesmente fechar canais de relacionamento, como muitas vezes ocorreu no setor privado ${ }^{628}$. No âmbito da atividade administrativa, o atendimento exclusivo por meio digital constitui uma questão a ser analisada com bastante cuidado, de maneira a encontrar uma solução juridicamente equilibrada e aceitável.

A forma da prestação do serviço não tem, em si, tanta repercussão jurídica, devendo ser avaliado, concretamente, se ela oferece vantagens efetivas para a atividade administrativa e se causa algum prejuízo para os usuários ou parte deles, sobretudo no to-

\footnotetext{
${ }^{626}$ Cf. LEMAITRE, Marie-Françoise, Téléprocédure administrative: le pari de la confiance, in Actualité juridique - Droit administratif, n.20, jul.-ago. 2001, p. 630.

${ }^{627}$ Defendendo esse entendimento, GÓMEZ PUENTE indica um princípio da voluntariedade e uso alternativo, com o seguinte conteúdo: "Somente por causas justificadas e legalmente determinadas pode-se exigir o uso de serviços ou meios de administração eletrônica" (op. cit., p. 123). O ponto central, contudo, não é a voluntariedade, pois não é razoável atribuir ao cidadão o poder de definir a forma da prestação de serviços, mas a necessidade de evitar a discriminação, exigindo-se sempre que o serviço seja acessível. Reconhecendo um direito de opção entre o atendimento digital e o tradicional, porém sem caráter absoluto, em razão da possibilidade de ser imposto o atendimento eletrônico, cf. Cotino HuESo, Lorenzo, Derechos del ciudadano administrado e igualdad ante la implantación de la Administración electrónica, cit., p. 142. Considerando todos os procedimentos eletrônicos como facultativos e coexistentes com os de papel, cabendo aos usuários a liberdade de escolha, cf. Beloulou, Véronique, op. cit., p. 625; CANTERO, Anne, op. cit., p. 114 e JiNESTA LOBO, Ernesto, op. cit., p. 8. No sentido de que a utilização exclusiva de meios eletrônicos somente será possível quando reduzida a um mínimo o analfabetismo digital, cf. RIVERO ORTEGA, Ricardo, El expediente administrativo, cit., p. 201. Entendendo que se trata de uma questão política, relacionada à definição de políticas públicas, por não haver um direito fundamental à escolha da mídia, cf. GROSs, Thomas, op. cit., p. 71. Na verdade, o direito fundamental é ao acesso razoável e isonômico aos serviços da Administração Pública, que pode ser violado conforme a situação concreta, quando se restringem os meios para tanto. É importante ressalvar, também, que esse "direito ao papel", que pode ser considerado existente em determinadas situações, deve ter um âmbito de aplicação bem delimitado: o do relacionamento entre o usuário e o Poder Público, ou seja, o front office. A tramitação de expedientes em papel não poderia ser entendida como um direito do cidadão, porque ocorre dentro dos órgãos públicos, de acordo com a estrutura definida como a mais adequada pela Administração. Quando o cidadão tem o "direito ao papel", o expediente pode ser eletrônico, mas o cidadão deve ter acesso a uma cópia, em papel, do conteúdo desse expediente e dos elementos em meio digital que possam ser úteis à defesa de seus direitos. Sobre o expediente administrativo eletrônico, cf. infra, item 4.8.

${ }^{628}$ Cf. CulberTson, Stuart, op. cit., p. 70.
} 
cante à isonomia ${ }^{629}$. Assim, é necessário manter os dois meios de interação com o administrado quando a utilização exclusiva de meios eletrônicos puder criar discriminação ou injustiça, afastando os usuários da prestação do serviço, ao passo que, não havendo esse risco, tais meios poderão constituir o único canal de relacionamento ${ }^{630}$. A vedação à discriminação pode impor a manutenção do suporte papel em relação a pessoas ou grupos privados da cultura e dos recursos digitais, mas é aceitável eliminá-lo nas atividades cujos usuários tenham condições de utilizar os meios eletrônicos e estejam familiarizados com a informática ${ }^{631}$. Quando presentes razões de eficácia administrativa e de eficiência para a imposição do uso dos meios telemáticos ${ }^{632}$ deve haver uma justificativa concreta para a manutenção do relacionamento pela via tradicional.

Isso repercute em relação ao instrumento normativo adequado para a imposição do uso de meios informáticos. Quando ela não restringe as possibilidades de atuação dos usuários, deve ser entendida apenas como um condicionamento, que pode ser estabelecido por norma infralegal da própria Administração ${ }^{633}$. Havendo algum potencial restritivo ou discriminatório, a exclusividade do atendimento informático deve ser estabelecida por lei formal, por meio de uma ponderação que tenha em vista da realização de outro princípio constitucional - por exemplo, a eficiência administrativa. Todavia, caso não seja demonstrada a necessidade, a adequação e a proporcionalidade da restrição à isonomia, nem mesmo a lei poderá impor o uso exclusivo de meios eletrônicos, pois a tecnologia e as possíveis vantagens por ela trazidas não se sobrepõem, sem maiores cuidados, a outros bens e valores constitucionais.

\footnotetext{
${ }^{629}$ A exigência de apresentação de formulários preenchidos e carimbos, por exemplo, não é tida como uma questão juridicamente complexa, sendo aceitos, em geral, os requisitos formais estabelecidos pela Administração, como um mero condicionamento ao exercício de direitos, que não impede o acesso a eles. A utilização de formas complexas, como é o caso dos meios informáticos, é que traz possíveis repercussões negativas sobre o exercício de direitos, sobretudo em razão de possíveis discriminações. Sobre o uso de formulários, cf. infra, item 4.9.1.

${ }^{630}$ Cf. PRINS, J.E.J. (ed.) et al., E-Government and its Implications for Administrative Law, cit., p. 32.

631 Cf. Bernadí GIL, Xavier, op. cit., p. 230 e VALERo TorriJos, Julián, El régimen jurídico de la eAdministración, cit., p. 52.

${ }^{632}$ Cf. Gómez PUENTE, Marcos, op. cit., p. 124.

${ }^{633}$ Entendendo que a imposição dos meios informáticos somente poderia ocorrer mediante lei, cf. MARCOU, Gérard, Le régime de l'acte administratif face à l'électronique, in CHATILLON, Georges, MARAIS, Bertrand du (org.), L'administration électronique au service des citoyens, Bruxelles, Bruylant, 2003, p. 87.
} 
Uma imensa casuística ${ }^{634}$ está associada a um contexto cultural heterogêneo e em constante mutação, no qual as situações concretas precisam ser cuidadosamente analisadas. Todavia, é possível indicar alguns critérios passíveis de serem utilizados para avaliação da questão ${ }^{635}$. Quanto mais geral é o grupo de destinatários de um serviço, mais difícil é justificar o emprego exclusivo das novas tecnologias, de sorte que as relações gerais da Administração com os cidadãos comportam menos a obrigatoriedade do uso dos meios informáticos e telemáticos que as relações com servidores públicos e empresas ${ }^{636}$. Mesmo assim, o uso das tecnologias pode ser inadequado conforme as particularidades do grupo de pessoas a ser atendido, sendo difícil fundamentar, no contexto atual, por exemplo, que a inscrição em programas de assistência social seja feita exclusivamente por meio da internet $^{637}$.

A segunda questão, relativa aos casos em que há a prestação de serviços por meios informáticos e pelos meios tradicionais, diz respeito à admissibilidade de diferenças de tratamento entre os usuários, ou seja, à eventual necessidade de observância de uma paridade de tratamento em relação aos processos que se utilizam da via eletrônica e os que se valem da via tradicional. Em princípio, não há razão para um tratamento diferenciado entre eles ${ }^{638}$, de maneira que, não havendo uma justificativa material para a desigualdade, resta caracterizado seu caráter discriminatório ${ }^{639}$. Certamente não seria admissível que existissem duas administrações, com velocidades distintas: uma, moderna, eficaz e rápida, destinada aos usuários dotados de melhores conhecimentos tecnológicos, e outra, lenta, trabalhosa e tradicional para os excluídos do uso das novas tecnologias ${ }^{640}$, tampouco seria

\footnotetext{
${ }^{634}$ Cf. COTINo HuESo, Lorenzo, Derechos del ciudadano administrado e igualdad ante la implantación de la Administración electrónica, cit., p. 147.

${ }^{635}$ Entendendo haver na realidade da sociedade brasileira uma desconfiança quanto ao uso das novas tecnologias e certa resistência quanto ao uso da tecnologia de forma impositiva, mais nítida entre a parcela da população atingida pela exclusão digital, cf. RAMOS JÚNIOR, Hélio Santiago, Democracia e direitos fundamentais na sociedade da informação, cit., p. 67.

${ }^{636}$ Cf. COTINO HuESo, Lorenzo, Derechos del ciudadano administrado e igualdad ante la implantación de la Administración electrónica, cit., p. 146. Segundo o autor, conviria criar um procedimento para estabelecer as diferenciações, de forma a evitar as decisões impetuosas e precipitadas por parte de administrações ansiosas por eliminar custos ou diminuir os demandantes por serviços (ibidem, p. 145).

${ }^{637}$ Seria difícil adotar a obrigatoriedade também em serviços como educação, saúde e seguridade social (cf. ibidem, p. 147).

${ }^{638}$ Cf. BLASCO DíAZ, José Luis, Los derechos de los ciudadanos en su relación electrónica con la Administración, cit., p. 811.

${ }^{639}$ Cf. VALERO TORRIJOS, Julián, El régimen jurídico de la e-Administración, cit., p. 56.

${ }^{640}$ Cf. OBerdorfF, Henri, op. cit., p. 13.
} 
juridicamente aceitável adotar medidas punitivas contra aqueles que não utilizassem os meios eletrônicos ${ }^{641}$.

Todavia, devem ser entendidas como admissíveis as diferenças de tratamento fundadas em outros valores constitucionais, que atendam à proporcionalidade, levando em conta fatores sociológicos e valorativos para alcançar uma interpretação ajustada ao contexto social ${ }^{642}$. A maior agilidade na atuação administrativa decorre dos instrumentos técnicos empregados, o que pode constituir uma circunstância objetiva para justificar um tratamento diferenciado ${ }^{643}$. Assim, algumas decorrências práticas do emprego dos meios informáticos devem ser entendidas como inevitáveis. O pedido enviado pelo correio convencional será apreciado depois do pedido enviado por via telemática, pois este será recebido antes pela Administração. Também será analisado de modo mais ágil o requerimento acompanhado de documentação e informações em meio digital, que facilite sua inclusão nas bases de dados públicas, não exigindo uma anterior digitalização por parte da Administração ${ }^{644}$. De fato, estando informatizados os dados remetidos pelo usuário, já não é preciso realizar manualmente as tarefas necessárias para sua obtenção, armazenamento e sistematização, possibilitando ao órgão competente atuar de imediato a partir da informação disponível ${ }^{645}$. Segundo o mesmo critério, é aceitável que sejam cobradas taxas e preços públicos diferenciados entre serviços prestados em papel ou por meios informáticos, desde que justificada a diferença ${ }^{646}$.

\footnotetext{
${ }^{641}$ Cf. VALERO TORRIJOS, Julián, Administración pública, ciudadanos y nuevas tecnologías, cit., p. 2956.

${ }^{642} \mathrm{Cf}$. Cotino Hueso, Lorenzo, Derechos del ciudadano administrado e igualdad ante la implantación de la Administración electrónica, cit., pp. 143-145.

${ }^{643}$ Cf. VALERO TORRIJOS, Julián, El régimen jurídico de la e-Administración, cit., p. 186.

${ }^{644}$ Nesse sentido, "se a demora na tramitação é determinada pela opção do cidadão pela utilização do suporte papel, ele deve suportar as consequências derivadas dessa escolha, já que poderia tê-las evitado se tivesse usado os meios de comunicação telemáticos" (ibidem, p. 56, tradução livre).

${ }^{645} \mathrm{Cf}$. ibidem, p. 185. É importante notar que as atividades desempenhadas não são as mesmas: em um caso, a Administração apenas decide a respeito do pedido; no outro, prepara a informação e depois pratica a decisão. Sendo diferentes as atividades, não seria exigível que elas fossem realizadas em tempos iguais.

${ }^{646}$ Em sentido contrário, entendendo razoável a ideia de não existirem diferenças entre os meios tradicionais e eletrônicos no tocante aos custos a serem cobrados, cf. GÓMEZ PUENTE, Marcos, op. cit., p. 122.
} 


\subsubsection{A neutralidade tecnológica}

O princípio da igualdade também deve aplicar-se à escolha das tecnologias a serem utilizadas pela Administração, decisão que não deve acarretar consequências discriminatórias. Em tese, a escolha de uma determinada tecnologia está situada na esfera discricionária do Poder Público, mas tem evidentes efeitos regulatórios ${ }^{647}$. A preferência da Administração por um determinado meio ou produto pode distorcer a competição entre os fornecedores, favorecendo um ou alguns deles e tolhendo a iniciativa de outros ${ }^{648}$, de maneira a interferir com a liberdade para desenvolver avanços tecnológicos em um âmbito de livre mercado ${ }^{649}$. Caso seja imposto ao cidadão o uso de um determinado software, por exemplo, afeta-se seu direito de escolha à alternativa tecnológica que lhe interesse, o que tampouco parece aceitável.

Por isso, a melhor solução é definir, sempre que possível, especificações técnicas que possam ser atendidas por qualquer fabricante ${ }^{650}$, garantindo a universalidade do acesso independentemente dos meios empregados pelos usuários ${ }^{651}$. Fala-se, pois, em neutralidade tecnológica ${ }^{652}$. A neutralidade tecnológica não deve ser vista como uma finalidade em si, mas como uma projeção do princípio da igualdade cuja finalidade é evitar abusos e favorecimentos.

A inexistência de uma disciplina específica da matéria, no ordenamento brasileiro, impede a adoção de um entendimento mais concreto a respeito da neutralida-

\footnotetext{
${ }^{647}$ Cf., fazendo referência à escolha do software, BARNÉS VÁZQUEZ, Javier, Sobre el procedimiento administrativo, cit., p. 305.

${ }^{648}$ Cf. GÓMEZ PUENTE, Marcos, op. cit., p. 125.

${ }^{649}$ Cf. GAMERO CASADO, Eduardo, Objeto, ámbito de aplicación y principios generales de la ley de administración electrónica, cit., p. 96.

${ }^{650}$ Cf. Gómez PuENTE, Marcos, op. cit., p. 126.

${ }^{651}$ Cf. VALERO TORRIJOS, Julián, El régimen jurídico de la e-Administración, cit., p. 69 e BLASCO DíAZ, José Luis, Los derechos de los ciudadanos en su relación electrónica con la Administración, cit., p. 809.

${ }^{652}$ Além deste significado, relacionado à referência a uma tecnologia particular, PoULLET também aponta como conteúdo do princípio da neutralidade tecnológica a exigência de não reservar uma sorte diferente às operações realizadas por meio dos processos eletrônicos em relação àqueles consagrados pelas operações conduzidas pelos processos tradicionais (cf. La technologie et le droit, cit., pp. 958-959). Já a legislação de Québec emprega a expressão neutralidade tecnológica com significado próximo ao de equivalencia funcional entre suportes (cf. nota 404).
} 
de $^{653}$. Embora a adoção de uma tecnologia restritiva deva ser considerada suspeita, em razão de seu possível caráter discriminatório, ela pode constituir uma providência adequada, baseada em critérios técnicos que apontem a necessidade de tal opção. Constitui um ônus do órgão responsável pelo sistema a ser construído, contudo, justificar a escolha com fundamentos técnicos que mostrem a inexistência de discriminação em favor da tecnologia escolhida.

Dentre as questões relacionadas à neutralidade tecnológica, a mais importante diz respeito à possibilidade de que a Administração adote preferência pelo chamado software livre, o qual permite, sem ônus financeiros, o conhecimento, alteração e redistribuição de seu conteúdo em linguagem de programação - o chamado código fonte. Embora haja alguma tendência prática nesse sentido ${ }^{654}$, convém ressaltar que, do ponto de vista estritamente jurídico, a opção pelo software livre também deve ser justificada de modo consistente, levando em conta as vantagens para o usuário e para a Administração ${ }^{655}$,

\footnotetext{
${ }^{653} \mathrm{Na}$ Espanha, por exemplo, o principio da neutralidade tecnológica foi adotado de modo expresso, para impedir que a Administração Pública estabeleça obstáculos de caráter técnico baseados na incompatibilidade dos programas e aplicativos que não respondam ao uso de padrões abertos (cf. VALERO TORRIJOS, Julián, $E l$ régimen jurídico de la e-Administración, cit., pp. 66-68).

${ }^{654} \mathrm{O}$ Governo Federal brasileiro, por exemplo, tem adotado expressamente uma política em favor do software livre, a partir do Decreto de 29 de outubro de 2003, havendo até mesmo um portal temático a respeito: http://www.softwarelivre.gov.br/. Sobre o mesmo tema, cf. também BRASIL, Guia Livre. Referência de Migração para Software Livre do Governo Federal, Brasília, 2005, disponível em www.governoeletronico.gov.br/anexos/E15_469GuiaLivre_v099.pdf, acesso em 17.01.2011.

${ }^{655} \mathrm{Na}$ verdade, há muitos fatores que podem interferir na decisão de utilizar esta ou aquela tecnologia, de modo que não é possível pretender esgotar a questão, a qual foge aos limites deste estudo. É possível, por exemplo, que as tecnologias abertas sejam mais onerosas para a Administração. Neste caso, embora lhe incumbisse oferecer alguma flexibilidade tecnológica para viabilizar o relacionamento com o maior número de usuários, o Poder Público não tem o dever de arcar com esse ônus (cf. Cotino Hueso, Lorenzo, Derechos del ciudadano, cit., p. 217). Excepcionando também a situação de ônus econômicos desproporcionais, cf. VALERO TORRIJOS, Julián, El régimen jurídico de la e-Administración, cit., p. 69. Embora mais onerosa, a opção pelo chamado software livre pode justificar-se pela disponibilidade dos códigos fonte, que dá à Administração controle absoluto da atuação do software, evitando a introdução de códigos espiões e outras práticas indevidas. Por outro lado, a opção por uma tecnologia comercial pode decorrer de sua maior penetração entre os usuários (cf. GAMERO CASADO, Eduardo, Objeto, ámbito de aplicación y principios generales de la ley de administración electrónica, cit., pp. 97-98). Por fim, é possível que o órgão público invista recursos no desenvolvimento de um software livre justamente com a finalidade de facultar seu uso a terceiros, o que não seria possível caso adquirida uma tecnologia de caráter comercial.
} 
sobretudo no tocante às possíveis utilidades do programa conforme os fins pretendidos ${ }^{656}$, o que nem sempre é viável apenas mediante o emprego de critérios gerais e abstratos ${ }^{657}$.

\subsubsection{A necessidade de segurança jurídica}

Em geral, a relação entre o direito administrativo e a segurança jurídica tem sido frequentemente limitada à vedação da aplicação retroativa da lei e a mudanças na interpretação dirigidas ao passado ${ }^{658}$. No entanto, o princípio da segurança jurídica traz outras interessantes repercussões em relação à atividade administrativa, as quais podem ser reveladas no estudo da introdução das novas tecnologias no âmbito da Administração Pública.

\footnotetext{
${ }^{656}$ O tema é analisado por TerCio SAMPaio Ferraz JÚnior e Juliano de SOUZA Albuquerque MaraNHÃO (Software livre: a Administração Pública e a comunhão do conhecimento informático, in Revista de Direito Público da Economia - RDPE, n. 11, Belo Horizonte, Fórum, jul. set./2005, pp. 173-208), com profundidade que não se pode aqui reproduzir. Vale mencionar, todavia, a valiosa observação oferecida pelos autores, no sentido de que os softwares comerciais - denominados proprietários - não constituem o mesmo produto que o software livre, porque ambos atendem a objetivos distintos: utilizar uma solução informática ou obter e promover conhecimento informático. Nesse sentido, em uma aquisição voltada para o atendimento de uma dessas necessidades, a opção pelo software aberto ou fechado define o objeto da licitação (op. cit., p. 203). Tal decisão compete ao Administrador Público e deve ser tomada em obediência às normas vigentes, $o$ que inclui o respeito à isonomia, que se projeta na neutralidade tecnológica.

${ }^{657}$ No Brasil, a questão da preferência pelo software livre é objeto da Ação Direta de Inconstitucionalidade n. 3059-RS, ainda não julgada no mérito, na qual se questiona a Lei n. 11.871/02, do Rio Grande do Sul, que estabeleceu a preferência por "programas abertos, livres de restrições proprietárias quanto a sua cessão, alteração e distribuição" (art. $1^{\circ}$ ). No julgamento da Medida Cautelar referente a tal ação, o Supremo Tribunal Federal, nos termos do voto do Ministro Ayres Britto, decidiu pela suspensão dos efeitos de tal diploma normativo, pelas seguintes razões: a) invasão de competência federal para fixar normas sobre licitações e contratos; b) invasão de competência do Poder Executivo, uma vez que somente diante das situações concretas seria possível optar por uma determinada tecnologia; c) restrição ao âmbito de competição dos interessados em contratar com a Administração Pública. O primeiro e o terceiro argumentos parecem discutíveis, tendo em vista que, como observado na nota anterior, a opção pelo software livre ou proprietário corresponde à fixação do objeto da licitação, o que deve ser considerado faculdade corriqueira no âmbito das licitações e não algo excepcional. $\mathrm{O}$ segundo argumento, contudo, parece sustentar-se, uma vez que a escolha de um dos tipos de software não deve dar-se por uma definição a priori, no âmbito legislativo, mas em função do exercício de competência discricionária pela Administração, no âmbito de sua política para informática.

${ }^{658}$ Adotando essa visão, cf., por exemplo, Di PIETRO, Maria Sylvia Zanella, Direito administrativo, 20. ${ }^{\mathrm{a}}$ ed., São Paulo, Atlas, 2007, p. 76.
} 
Por força da segurança jurídica, por exemplo, o Poder Público deve adotar uma postura mais cautelosa em projetos de informatização do que aquela usualmente empregada pelo setor privado. De fato, no âmbito do Poder Público, é recomendável que a incorporação dos novos meios seja orientada pela prudência e por critérios de prevenção e prudência $^{659}$, pois cabe à Administração evitar danos decorrentes de sua atuação e, sobretudo, os riscos jurídicos decorrentes da prática de atos ilícitos ${ }^{660}$.

A utilização de novos sistemas traz riscos tecnológicos, que precisam ser diminuídos tanto quanto possível, mas tolerados em benefício da possibilidade de inovação ${ }^{661}$. É preciso observar, a propósito, que a ocorrência de possíveis falhas não é exclusiva dos meios informáticos e ocorre com frequência na administração em papel e na atuação humana. As falhas dos meios informáticos podem ultrapassar o caso concreto, atingindo vários casos semelhantes, o que tende a trazer maiores problemas; todavia, a correção desses defeitos também oferece resultados mais efetivos, pois uma só intervenção nesse sentido pode prevenir uma série de erros futuros.

Por outro lado, a segurança jurídica também pode ser favorecida pelo emprego das novas tecnologias na Administração Pública. Com efeito, a informática pode trazer ganhos em relação à segurança jurídica, ao permitir serviços de acesso ao direito ${ }^{662}$, ou seja, a obtenção de dados normativos e jurisprudenciais devidamente organizados, inclusive com as informações necessárias a respeito de sua existência ou validade ${ }^{663}$.

Além desse aspecto informativo, o uso das novas tecnologias pode trazer vantagens em relação à garantia da norma a ser aplicada, sobretudo para evitar os equívocos pontuais decorrentes da atuação humana. Por mais regrados que sejam os comporta-

\footnotetext{
${ }^{659}$ Cf. GÓMEZ PUENTE, Marcos, op. cit., p. 131.

${ }^{660}$ Tratando da questão sob a perspectiva dos princípios que regem a atividade administrativa, sobretudo o da legalidade, cf. OCHOA MonZÓ, Josep, Hacia la ciberadministración y el ciberprocedimiento?, cit., p. 161.

${ }^{661}$ Cf. CUlbertson, Stuart, op. cit., p. 69.

${ }^{662}$ Cf. GRISTI, Éric, op. cit., p. 499.

${ }^{663}$ Cf. DomíngueZ LuIs, José Antonio, La explosión informática, cit., p. 118. Segundo o autor, isso teria uma função semelhante à da codificação. Entretanto, é possível notar as vantagens da informação oferecida em meios informáticos quanto à possibilidade de consulta por vários critérios diferentes, e não somente por aqueles que orientaram a codificação. A maior disponibilidade de critérios para consulta - sobretudo a pesquisa orientada por palavra - traz muito mais segurança quanto ao conteúdo das normas vigentes.
} 
mentos dos agentes públicos, a complexidade das situações normativas e fáticas exige, por vezes, que a identificação da norma a ser aplicada ocorra apenas diante do caso concreto, prejudicando a confiança legítima dos cidadãos. A administração eletrônica é ainda mais baseada em regras que a administração tradicional ${ }^{664}$, pois os sistemas informatizados exigem uma programação prévia, de acordo com critérios padronizados e objetivos fixados com antecedência a partir das normas aplicáveis. A clareza das regras e seu caráter prévio trazem evidentes ganhos em termos de segurança jurídica, que são reforçados caso os critérios empregados pela Administração sejam devidamente divulgados, atendendo também ao princípio da publicidade. Dessa maneira, o governo eletrônico cria condições para o aumento da confiança recíproca entre os cidadãos e a Administração ${ }^{665}$.

Entretanto, no caso do governo eletrônico, a questão das regras a serem aplicadas não oferece tanta relevância para a segurança jurídica quanto a confiabilidade dos próprios meios materiais que dão suporte à atividade administrativa. A garantia do registro da informação é essencial para tornar possível o respeito às situações jurídicas constituídas. De fato, seria impossível respeitar o ato jurídico perfeito e o direito adquirido se não houvesse maneira de conservar o instrumento material a partir do qual eles se originaram.

Por essa razão, a segurança jurídica norteia vários dos aspectos fundamentais relacionados ao documento eletrônico e à equivalência funcional que serve como referência para sua validade jurídica, temas já tratados neste estudo ${ }^{666}$. No entanto, a preocupação com a segurança não se encerra apenas no documento eletrônico, alcançando a utilização correta dos meios informáticos e telemáticos de acordo com aquilo que pode ser denominado segurança informática, ou seja, o conjunto de medidas lógicas, físicas, funcionais, administrativas e legais dirigidas a garantir a confidencialidade, integridade e acessibilidade da informação dentro de um sistema computadorizado ${ }^{667}$. Portanto, a necessidade de segurança informática decorre do princípio da segurança jurídica e fundamenta, do

\footnotetext{
${ }^{664}$ Cf. Fountain, Jane E., op. cit., p. 61.

${ }^{665}$ Cf. BOMBARDELLI, Marco, op. cit., p. 1015.

${ }^{666} \mathrm{Cf}$. supra, item 2.2 .

${ }^{667}$ Cf. Asís RoIG, Agustín de, op. cit., p. 173.
} 
ponto de vista legal, os investimentos em programas e equipamentos informáticos que tenham essa finalidade, assim como eventuais mudanças organizativas. Ao optar pela utilização dos meios informáticos, o Poder Público tem o dever de criar as estruturas que garantam as devidas condições de segurança ${ }^{668}$.

A segurança dos meios não se reflete somente na qualidade intrínseca dos trabalhos, ou seja, no fato de a atividade administrativa estar ocorrendo corretamente, mas tem sérias consequências em relação à confiança dos usuários nas novas tecnologias. Essa confiança, por favorecer a utilização dos serviços eletrônicos ${ }^{669}$, é indispensável para a generalização do governo eletrônico ${ }^{670}$. O fornecimento de serviços públicos eletrônicos deve ocorrer em um ambiente que inspire essa confiança nas novas tecnologias ${ }^{671}$, permitindo ao usuário estar seguro de que não terá problemas decorrentes de imperfeições no seu funcionamento. Caso contrário, a falta de segurança jurídica em relação ao uso das novas tecnologias em atividades administrativas poderia tornar-se um grande obstáculo para a modernização da Administração Pública ${ }^{672}$.

Por outro lado, é a segurança jurídica que serve de fundamento para referências legislativas à segurança em nível infraconstitucional, que tendem a orientar a utilização das novas tecnologias no setor público ${ }^{673}$. Entre eles, os possíveis mecanismos penais que podem ser empregados para a garantia do documento eletrônico, caso este seja considerado um bem jurídico-penal relevante. Nesta hipótese, a lei penal deve ser atualizada, para que os documentos eletrônicos tenham tanta proteção quanto os documentos em

\footnotetext{
${ }^{668}$ Cf. BARNÉS VÁZQUEZ, Javier, Una reflexión introductoria sobre el Derecho Administrativo y la Administración Pública de la Sociedad de la Información y del Conocimiento, cit., p. 60.

${ }^{669}$ Cf. GAROT, Marie José, op. cit., p. 95.

${ }^{670}$ Cf. EsPANHA, Lei 11/2007 - Exposición de motivos, in Boletin Oficial del Estado, 23.07.2007, cit., p. 27150.

${ }^{671}$ Cf. OCDE, op. cit., p. 25; BAL, Aminata, op. cit., p. 6; Trudel, Pierre, op. cit., p. 42 e BlASCO DÍAZ, José Luis, Los derechos de los ciudadanos en su relación electrónica con la Administración, cit., p. 820.

${ }^{672}$ Cf. VALERO TORRIJOS, Julián, Administrative Law and eGovernment, cit., p. 41.

${ }^{673}$ A Medida Provisória n. 2200/01, já analisada neste estudo (cf. item 2.2.3), faz referência à necessidade de garantir a realização de transações eletrônicas seguras (art. $1^{\circ}$ ). Já a Lei n. 14.141/06, do Município de São Paulo, condiciona a utilização dos meios eletrônicos à "segurança de dados e registros" (art. 49, II).
} 
papel $^{674}$. Isso já foi feito entre nós, mostrando também a importância do documento digital para o ordenamento brasileiro ${ }^{675}$.

A adoção de medidas em prol da segurança informática e, consequentemente, da segurança jurídica, deve levar em conta que, malgrado tragam novas oportunidades e vantagens, as novas tecnologias também trazem novos perigos ${ }^{676}$. Existem novas situações problemáticas, próprias dos meios informáticos, tais como a possível assunção de identidade eletrônica de uma pessoa por outra ${ }^{677}$, a interferência indevida de terceiros em relação à atividade administrativa ${ }^{678}$, os ataques direcionados e falhas que são capazes de causar sérios danos aos sistemas ${ }^{679}$, a invasão de sistemas e interceptação da comunicação de dados, a circulação indiscriminada de informações reservadas ou privativas ${ }^{680}$ e a sistematização ilícita de um volume imenso de informações dessa natureza ${ }^{681}$, tendo em vista os modernos motores de busca existentes na internet ${ }^{682}$. Em um contexto de constante mudança tecnológica, permanece sempre em aberto o grave problema da luta entre o aperfeiçoamento das defesas e a intensificação das falsificações e ataques aos sistemas informáticos, inclusive os da Administração Pública ${ }^{683}$. Por outro lado, a maior facilidade de gestão e armazenamento da informação permitida pelas tecnologias atuais pode ser uma ameaça ${ }^{684}$, exigindo a fixação de limites técnicos e jurídicos precisos, que impeçam ou dificultem a violação de direitos.

\footnotetext{
${ }^{674}$ Cf. DAVARA RodríGUEZ, Miguel Ángel, op. cit., p. 464.

${ }^{675}$ Há novos tipos penais que adaptam os delitos de falsidade à sociedade da informação, incluídos no Código Penal pela Lei n. 9983/00: art. 313-A ("Inserir ou facilitar, o funcionário autorizado, a inserção de dados falsos, alterar ou excluir indevidamente dados corretos nos sistemas informatizados ou bancos de dados da Administração Pública com o fim de obter vantagem indevida para si ou para outrem ou para causar dano") e Art. 313-B ("Modificar ou alterar, o funcionário, sistema de informações ou programa de informática sem autorização ou solicitação de autoridade competente", sendo as penas, nos termos do parágrafo único, "aumentadas de um terço até a metade se da modificação ou alteração resulta dano para a Administração Pública ou para o administrado").

${ }^{676}$ Cf. VALERO TORRIJOS, Julián, Administración pública, ciudadanos y nuevas tecnologías, cit., p. 2954.

${ }^{677}$ Cf. Martos García, Juan Jesús, op. cit., p. 83 e Gómez PuENTE, Marcos, op. cit., p. 115.

${ }^{678}$ Cf. Justen Filho, Marçal, Pregão, cit., p. 293.

${ }^{679}$ Cf. Zugman, Fábio, op. cit., p. 79.

${ }^{680}$ Cf. GÓMEZ PUENTE, Marcos, op. cit., p. 115.

${ }^{681}$ Cf. RIVERo ORTEGA, Ricardo, El expediente administrativo, cit., p. 174.

${ }^{682}$ Cf. VALERo TORRIJOS, Julián, Protecção de datos personales y administración electrónica, cit., p. 46.

${ }^{683}$ Cf. DuNI, Giovanni, L'amministrazione digitale, cit., p. 86.

${ }^{684}$ Cf. VALERO TORRIJOS, Julián, El régimen jurídico de la e-Administración, cit., p. 210.
} 


\subsubsection{A transparência administrativa e o direito à informação por meios informáticos}

Como ocorre em relação a outros temas tratados neste estudo, o princípio da transparência e o direito à informação não são matérias exclusivas do governo eletrônico, mas este os configura ou potencializa de modo diverso ${ }^{685}$. Na verdade, a utilização dos meios informáticos e telemáticos para a produção, processamento e transmissão da informação proporciona algo uma verdadeira revolução em relação a tais assuntos. Assim, já não se imagina que a transparência administrativa e o direito à informação possam ser realizados de modo pleno sem a utilização de meios informáticos e telemáticos, em especial a internet.

Entretanto, mais do que apenas celebrar a realização do direito de informação, parece necessário rediscutir seu alcance e modalidades em tal contexto tecnológico $^{686}$. De fato, por vezes a grande incidência da internet sobre a publicidade da atividade administrativa ocorre sem uma reflexão profunda sobre esses fenômenos ${ }^{687}$. Nos itens a seguir, em vista dessa realidade, serão analisados alguns aspectos fundamentais relativos ao direito de informação e à transparência administrativa no âmbito da sociedade da informação, à luz do contexto normativo brasileiro.

\subsubsection{O aumento da necessidade de informação}

Uma das maiores preocupações dos tempos atuais é ter rápido acesso à informação, com toda a liberdade e a todo momento ${ }^{688}$. Há necessidade de informação para

\footnotetext{
${ }^{685}$ Cf. DUNI, Giovanni, L'amministrazione digitale, cit., p. 82 e MERINO, Muriel, L'obligation d'informer dans l'action administrative, Aix-en-Provence, PUAM, 2006, p. 235.

${ }^{686}$ Cf. FERnÁNDEZ SALMERÓn, Manuel, El acceso a los registros y archivos administrativos, cit., p. 614.

${ }^{687}$ Cf. FERNÁNDEZ SALMERÓN, Manuel, VALERO TORRIJOS, Julián, La publicidad de la información administrativa en internet, cit., p. 78.

${ }^{688}$ Cf. MERINO, Muriel, L'obligation d'informer dans l'action administrative, cit., p. 236.
} 
todas as atividades humanas, sobretudo para o exercício de direitos ${ }^{689}$, até mesmo direitos fundamentais ${ }^{690}$. Nesse sentido, a efetividade dos princípios constitucionais em que se baseia o Estado Democrático de Direito é condicionada pelas possibilidades informativas reconhecidas aos administrados ${ }^{691}$. Em relação aos direitos relacionados à atividade burocrática do Estado, em especial, a informação administrativa mostra-se fundamental, pois o cidadão somente pode saber efetivamente como a Administração decide se tiver acesso às informações utilizadas como base para a decisão ${ }^{692}$.

Por isso, nos últimos anos, passou-se a reconhecer uma função informativa do Poder Público, tão importante quanto outras funções institucionais mais tradicionais ${ }^{693}$. O Estado deve proporcionar à sociedade informação em maior volume e com mais qualidade ${ }^{694}$, restando claro que o acesso à informação adequada é essencial para a tomada de decisões não só por parte da Administração, mas para o cidadão ${ }^{695}$.

Além disso, a utilização de meios eletrônicos traz novas necessidades de transparência, exigindo decisões reconhecíveis, produção aberta de decisão e informação acessível para legitimar novas formas de autoridade legal e racional ${ }^{696}$. Ao lado da legalidade, a transparência é um princípio fundamental do Estado Constitucional na sociedade

\footnotetext{
${ }^{689}$ Cf. RIVERO ORTEGA, Ricardo, El expediente administrativo, cit., p. 185.

${ }^{690}$ Cf. KLUTH, Winfried, NUCKET, Jana, op. cit., p. 495 e BARNÉS VÁZQUEZ, Javier, Una reflexión introductoria sobre el Derecho Administrativo y la Administración Pública de la Sociedad de la Información y del Conocimiento, cit., p. 58.

${ }^{691}$ Cf. VALERO TORRIJOS, Julián, El acceso telemático a la información administrativa, cit., p. 30.

${ }^{692}$ Considerando no âmbito da transparência administrativa o acesso à informação utilizada para as decisões, cf. Piñar MAÑas, José Luis, op. cit., p. 66.

${ }^{693}$ Cf. GARDINI, Gianluca, op. cit., p. 260. Há quem fale até mesmo em protagonismo da atividade informativa desempenhada pela Administração Pública (cf. Mestre Delgado, Juan Francisco, op. cit., p. 127). Entendendo que as atividades informativas e de comunicação devem ser incluídas na noção de serviço público em rede, cf. CAMMAROTA, Giuseppe, Servizi pubblici in rete e applicabilità dei principi classici del servizio pubblico, cit., p. 194.

${ }_{694}^{69}$ Cf. PITSCHAS, Raines, op. cit., p. 255.

${ }^{695}$ Cf. GARCÍA MACHO, Ricardo, op. cit., p. 211.

${ }^{696}$ Cf. Bovens, Mark, ZouRIDS, Stavros, op. cit., p. 183.
} 
da informação ${ }^{697}$, servindo para garantir a confiança do administrado na atuação estatal por meios informáticos e telemáticos ${ }^{698}$.

Esse imperativo de transparência se reflete, em particular, na necessidade de explicitar, em linguagem humana e compreensível ao usuário, os critérios adotados e as operações realizadas por sistemas informatizados. A atividade administrativa em meio digital não deve estar escondida sob equipamentos informáticos, sendo imprescindível a divulgação dos atributos essenciais dos sistemas informáticos que possam interferir com os direitos dos usuários, para que o uso da tecnologia não importe em uma diminuição das possibilidades informativas existentes no modo de atuação tradicional.

\subsubsection{Os meios informáticos e telemáticos e a realização do direito à informação}

Esse aumento das necessidades informativas ocorre em paralelo com a evolução verificada em relação à publicidade administrativa e ao direito de informação. Como tem sido notado, após a Segunda Guerra, sobretudo a partir dos anos setenta, vem ocorrendo a superação da tradição do secreto e do invisível, contrário ao caráter democrático do Estado $^{699}$, de sorte que o direito de acesso à informação se tornou a regra e o segredo, a exceção, reservada à proteção justificada de determinados interesses públicos ou privados preponderantes ${ }^{700}$. Nesse contexto, em que se fala não somente em publicidade, mas em transparência administrativa, os novos meios tecnológicos desempenham uma função essencial. Com o desenvolvimento das tecnologias da informação e da comunicação, é possível aprofundar a evolução no sentido de superar a tradição de reserva e ocultismo na

\footnotetext{
${ }^{697}$ Cf. ibidem, p. 183. A confiança do usuário nos novos sistemas depende da transparência do uso dos seus dados pessoais por parte do Poder Público. Sem essa transparência, cria-se um paradoxo: o cidadão se encontrará em face de uma Administração que entende aproximar-se, mas ao mesmo tempo se torna cada vez mais opaca (cf. De Terwangne, Cécile, LOBET-MARIs, Claire, Poullet, Yves, op. cit., p. 22).

${ }^{698}$ Sobre a transparência como forma de garantir a confiança dos administrados no governo eletrônico, cf. DE Terwangne, Cécile, Lobet-Maris, Claire, Poullet, Yves, op. cit., p. 24.

${ }^{699}$ Cf. MedauAR, Odete, $O$ direito administrativo em evolução, cit., p. 237 e SALON, Serge, SAVIGNAC, JeanCharles, Le citoyen et l'administration, Paris, Berger-Levrault, 2006, p. 95.

${ }^{700}$ Cf. De Roy, David, De Terwangne, Cécile, Poullet, Yves, op. cit., p. 296.
} 
Administração, sendo agora ainda mais necessário eliminar seu distanciamento em relação ao administrado ${ }^{701}$.

Não há dúvida sobre a relevância das novas tecnologias na realização do princípio da transparência ${ }^{702} \mathrm{e}$ do direito à informação, em especial por meio da generalização da internet. Com efeito, trata-se de um novo paradigma, caracterizado por uma plataforma mais eficaz, instantânea, segura e acessível, que em apenas alguns anos adquiriu maior capilaridade e capacidade de penetração que os tradicionais sistemas de publicidade oficial ${ }^{703}$. A internet aumentou de modo substancial a informação em poder dos indivíduos por meio da acessibilidade à informação da Administração Pública ${ }^{704}$, sobretudo em razão da proliferação de potentes ferramentas de pesquisa ${ }^{705}$, sendo capaz de oferecer, de modo ágil, informações plenamente atualizadas ${ }^{706}$. Dessa forma, a utilização das novas tecnologias pode ter forte impacto na cultura administrativa, por reduzir a

\footnotetext{
${ }^{701}$ Cf. Domínguez LuIS, José Antonio, El derecho de información administrativa, cit., p. 555. A doutrina tem observado que "[o] acesso à informação evoluiu imensamente nas últimas décadas desde o reconhecimento formal do secreto como princípio próprio da atuação das Administrações Públicas até o reconhecimento de direitos subjetivos de acesso à informação em poder dos poderes públicos e a criação de serviços de informação administrativa que utilizam a internet como canal de difusão" (CERRILlo I MARTínEZ, Agustí, Einformación, cit., p. 1, tradução livre).

${ }^{702}$ Cf. Olivo, Luis Carlos Cancellier de, Desafios do direito administrativo diante do Estado em rede, cit., pp. 19 e 27; CERRILlo I MARTíNez, La difusión de información pública en internet, in CERRILlo i MARTíNEZ, Agustí e oo., La administración y la información, Madrid, Marcial Pons, 2007, p. 11 e GARCÍA-POGGIO, Paz, Hacia una nueva Administración pública en la sociedad de la información, in Actualidad Informática Aranzadi, n. 32, Navarra, Aranzadi, 1999, p. 10.

${ }^{703}$ Cf. Fernández SAlMERón, Manuel, VALERo TORRiJos, Julián, Protección de datos personales y Administración electrónica, cit., p. 123. No mesmo sentido, cf. CAMARGO, Guilherme Bueno de, Governança Republicana como vetor para a interpretação das normas de direito financeiro, São Paulo, USP, 2010, p. 130. Não se trata, é claro, de substituir completamente os demais meios de acesso à Administração (cf. GRISTI, Éric, op. cit., pp. 510-511). Além disso, nada obstante a relevância da internet, há uma tendência à administração multicanal, que difunde informação e presta serviços mediante diferentes mecanismos em função da pessoa interessada, tais como telefone, fax, telefone celular, computadores portáteis e televisão com acesso à rede (cf. CERRILLO I MARTíNEZ, La difusión de información pública en internet, cit., p. 15).

${ }^{704}$ Cf. CerRillo i MARTínez, Agustí, E-información, cit., pp. 2 e 9.

705 Cf. FernándeZ SAlmerón, Manuel, VAlero TORRIJOS, Julián, Protección de datos personales y Administración electrónica, cit., p. 122.

${ }^{706}$ Cf. VALERO TORRIJOS, Julián, Protecção de datos personales y administración electrónica, cit., p. 46.
} 
assimetria de informação entre o usuário e a Administração e, portanto, a desigualdade entre eles $^{707}$.

O acesso telemático propiciado pela internet é capaz de afastar problemas próprios dos mecanismos baseados na presença física do cidadão nas repartições públicas $^{708}$, tais como as dificuldades relacionadas à locomoção até elas ${ }^{709}$, as longas filas de espera, a limitação de horários ${ }^{710}$ e de consultas simultâneas ${ }^{711}$ e a possível interferência sobre o funcionamento normal da atividade administrativa ${ }^{712}$. Com as novas tecnologias, por exemplo, é possível ter conhecimento atualizado sobre o andamento de um expediente $^{713}$ ou mesmo a respeito do desempenho de programas governamentais ${ }^{714}$.

Por tais razões, a principal utilização que os cidadãos fazem da internet, quando se relacionam com a Administração Pública, é a busca de informação pública ${ }^{715}$. O acesso à informação é o primeiro passo do desenvolvimento do governo eletrônico, constituindo a base para estágios mais avançados, que envolvem a participação eletrônica e a aplicação da telemática aos processos administrativos ${ }^{716}$.

Ao contrário do que ocorre nos meios tradicionais de comunicação, nos quais alguns poucos decidem a informação a ser oferecida, a internet permite que o usuário acesse o que lhe interessa em um universo amplo de dados ${ }^{717}$. Assim, por meio da rede

\footnotetext{
${ }^{707}$ Cf. SAURET, Jacques, op. cit., p. 288. Há quem mencione, assim, uma democratização da informação, associada ao fato de esta estar disponível tanto para os servidores públicos quanto para os demais cidadãos (cf. LIMBERGER, Têmis, Transparência administrativa e novas tecnologias: o dever de publicidade, o direito a ser informado e o princípio democrático, in Revista de Direito Administrativo, Rio de Janeiro, FGV-Atlas, jan.-abr. 2007, pp. 260 e 262-263).

${ }^{708}$ Cf. VALERO TORRIJOS, Julián, Protecção de datos personales y administración electrónica, cit., p. 45 e VALERO TORRIJOS, Julián, El acceso telemático a la información administrativa, cit., p. 42.

${ }^{709} \mathrm{Cf}$. OROFINO, Angelo Giuseppe, Forme elettroniche e procedimenti amministrativi, cit., p. 211.

${ }^{710}$ Cf. FERnÁNDEZ SALMERón, Manuel, VALERO TORRIJOS, Julián, La publicidad de la información administrativa en internet, cit., p. 80.

${ }^{711}$ Cf. RIVERO ORTEGA, Ricardo, El expediente administrativo, cit., p. 167.

712 Cf. FERNÁNDEZ SALMERÓN, Manuel, VALERO TORRIJOS, Julián, La publicidad de la información administrativa en internet, cit., p. 79.

${ }^{713}$ Cf. GOMEZ PUENTE, Marcos, op. cit., p. 112.

${ }^{714}$ Cf. RONDEAU, Jean-Claude, op. cit., p. 12.

${ }^{715}$ Cf. CERRILlO I MARTínEZ, La difusión de información pública en internet, cit., p. 14.

${ }^{716}$ Cf. ibidem, p. 12.

${ }^{717}$ Cf. PÉreZ GÁlveZ, Juan Francisco, op. cit., p. 569.
} 
mundial de computadores, é possível passar da informação passiva à informação ativa ${ }^{718}$. No passado, o acesso à informação estava limitado a determinadas circunstâncias concretas, previstas nas normas pertinentes, e exigia prévia solicitação. Cabia à Administração atender de modo passivo as demandas advindas do público e dar acesso à informação solicitada, sendo pontuais as hipóteses em que o Poder Público se encarregava de tomar a iniciativa de oferecer informações $-v . g$., por meio da publicação de editais. Recentemente, a Administração passou a tomar essa iniciativa de modo mais amplo ${ }^{719}$, sem a necessidade de uma solicitação prévia ${ }^{720}$. As novas tecnologias permitem, além da difusão da informação, sua pesquisa, seleção e integração, assim como sua apresentação em um formato que possa ser útil e compreensível para os administrados ${ }^{721}$ - por exemplo, por meio dos portais oficiais e bases de dados passíveis de localização por meio dos chamados motores de busca $^{722}$.

É claro que as vantagens decorrentes da veiculação de informações pela rede mundial de computadores não importam na utilização exclusiva de meios eletrônicos na realização da publicidade, em vista dos possíveis riscos discriminatórios, a serem enfrentados de acordo com os critérios já apresentados neste estudo ${ }^{723}$. Nesse sentido, devese considerar que a publicação obrigatória de determinados atos só pode ocorrer exclusivamente por meio da internet caso seja apurado que isso não importaria em redução significativa dos efeitos da difusão de tal informação ${ }^{724}$, o que deve levar em conta o perfil do

\footnotetext{
${ }^{718}$ Cf. FernándeZ SALMERÓn, Manuel, VALERo ToRriJos, Julián, La difusión de información administrativa en Internet y la protección de los datos personales, cit., p. 317 e La publicidad de la información administrativa en internet, cit., pp. 96-97.

${ }^{719}$ Cf. De Roy, David, De Terwangne, Cécile, Poullet, Yves, op. cit., p. 296.

${ }^{720}$ Cf. CERRILlo I MARTíneZ, Agustí, E-información, cit., p. 13.

${ }^{721}$ Cf. CerRillo i MARTíNez, La difusión de información pública en internet, cit., p. 21.

${ }^{722}$ Cf. Mistichelli, Sara, L'informazione e la comunicazione pubblica, in MERLONI, Francesco, Introduzione all'e-government, Torino, G. Giappichelli, 2005, pp. 176-177. Há quem fale, neste caso, haver uma publicidade real, pelo alcance da divulgação das informações, em oposição à publicidade fictícia proporcionada pelos meios em papel, cujo número de leitores efetivos é restrito (cf. SANTOLIM, Cesar, op. cit., p. 95).

${ }^{723} \mathrm{Cf}$. item 2.4.2.1. A respeito das repercussões específicas da exclusão digital sobre a publicidade, cf. SANTOLIM, Cesar, op. cit., p. 95.

${ }^{724}$ Mencionando esse critério, de molde a não admitir a publicação exclusiva por meios eletrônicos, em vista da conjuntura da evolução tecnológica no Brasil, cf. BINENBOJM, Gustavo, O princípio da publicidade administrativa e a eficácia da divulgação de atos do poder público pela internet, in Revista Brasileira de Direito Público - RBDP, n. 13, Belo Horizonte, Fórum, abr.-jun. 2006, p. 97.
} 
público a ser atingido e sua familiaridade com as novas tecnologias ${ }^{725}$. Por outro lado, tendo em consideração que os meios telemáticos oferecem efetivamente condições plenas de publicidade, verifica-se, neste tema específico, mais uma razão para que o Poder Público garanta condições para o acesso à conexão com a internet ${ }^{726}$.

Não há dúvida de que as potencialidades das novas tecnologias, para trazerem resultados efetivos, precisam de uma atuação concreta por parte do Poder Público. Em tese, aliás, as novas tecnologias podem gerar tanto uma administração transparente quanto uma administração opaca ${ }^{727}$, pois os sistemas informáticos não atuam por si, mas de acordo com a programação efetuada pelo ser humano. Para que isso não ocorra, é preciso ter em conta que o adequado oferecimento de informações por meios telemáticos, sobretudo pela internet, não constitui uma benevolência por parte do Poder Público, mas uma exigência do princípio da transparência, própria do atual contexto tecnológico. Para a realização efetiva de tal princípio, é preciso interpretá-lo de modo atualizado, considerando como dever da Administração também a publicação e o acesso por meios telemáticos.

\footnotetext{
725 JESSÉ TORRES PEREIRA JÚNIOR e MARINÊS RESTELATTO DOTTI, por exemplo, entendem que a divulgação exclusiva de editais de licitação em mídia eletrônica, sem publicação na imprensa oficial, confrontaria com o princípio da publicidade, pois nem todas as empresas contam com acesso à rede mundial de computadores, problema semelhante ao verificado nos concursos públicos divulgados exclusivamente pela internet que admitem inscrições somente por este meio (cf. A licitação no formato eletrônico e o compromisso com a eficiência, cit., pp. 57-58). Todavia, em relação à realidade das empresas, esta crítica não parece sustentar-se, uma vez que elas devem prover-se dos meios necessários para suas atividades, sendo o acesso à internet, atualmente, um insumo indispensável - e até mais econômico que o próprio acesso à publicação oficial em papel. Quanto aos concursos públicos, a inexistência de questionamentos expressivos quanto a um possível caráter discriminatório decorrente da utilização de meios informáticos para publicações e inscrições parece dever-se à frequente compatibilidade entre o elevado nível de formação exigido nos certames - que, em geral, avaliam aptidões intelectuais - e a familiaridade do candidato com as novas tecnologias, o que, em regra, afasta o caráter discriminatório ou o torna inócuo.

${ }_{726}$ Assim, "[o] próprio conceito de direito à informação, nesse contexto, ganharia uma nova dimensão e qualidade, na medida em que não existirá o direito à informação desvinculado do direito de conexão" (OLIVO, Luis Carlos Cancellier de, Controle social em rede da Administração Pública virtual, cit., p. 185). Sobre as políticas públicas destinadas a essa finalidade, cf. supra, nota 618 .

${ }^{727}$ Cf. PIÑ̃R MAÑAS, José Luis, op. cit., p. 52.
} 


\subsubsection{A transparência por meios digitais no ordenamento brasileiro}

A Constituição brasileira traz um complexo de normas relativas ao direito de informação e à transparência administrativa, estabelecendo o princípio da publicidade (art. 37) e assegurando a todos o acesso à informação (art. 5, XIV), o direito à obtenção de certidões em repartições públicas, para defesa de direitos e esclarecimento de situações de interesse pessoal (art. $5^{\circ}, \mathrm{XXXIV,} b$ ) e o direito a receber dos órgãos públicos informações de seu interesse particular, ou de interesse coletivo ou geral, a serem prestadas no prazo da lei, sob pena de responsabilidade, ressalvadas aquelas cujo sigilo seja imprescindível à segurança da sociedade e do Estado (art. 5 XXXIII). Vale mencionar, ainda, a previsão, contida no art. $37, \S 3^{\circ}$, II, de que a lei deve regular o acesso dos usuários a registros administrativos e a informações sobre atos de governo, observadas as garantias à vida privada, a honra e a imagem das pessoas e a segurança da sociedade e do Estado.

Embora não haja referência explícita à utilização das novas tecnologias para viabilizar o acesso à informação, é garantido o direito de informação sob qualquer forma, processo ou veículo (art. 220, caput $)^{728}$. Entre eles certamente estão os meios eletrônicos, pois hoje é impossível realizar a transparência administrativa e do direito à informação sem aproveitar os benefícios decorrentes do uso das novas tecnologias.

Em nível infraconstitucional, não houve, entre nós, durante muito tempo, uma legislação de acesso à informação administrativa ${ }^{729}$, tendência verificada nas democracias mais desenvolvidas do mundo ${ }^{730}$. De fato, em vista de garantir um equilíbrio entre

\footnotetext{
${ }^{728}$ Tal dispositivo deve ser interpretado em conjunto com o art. 13, 1 da Convenção Americana de Direitos Humanos (Pacto de San José da Costa Rica), diploma normativo integrante do ordenamento brasileiro já transcrito neste estudo (cf. nota 401), que se refere de modo mais concreto ao direito de procurar, receber e difundir informações, verbalmente, por escrito ou por qualquer meio escolhido.

${ }^{729}$ Isso não significa que inexistissem disposições esparsas sobre alguns temas. Há algum tempo, por exemplo, certos diplomas legais exigem a divulgação de determinadas informações por meios eletrônicos, como é o caso da Lei de Responsabilidade Fiscal (art. 48, parágrafo único, II), da Lei de Licitações (art. $3^{\circ}$, § 13) e da legislação que regula o Programa Bolsa-Família (Lei n. 10.836/04, art. 13, parágrafo único).

${ }^{730}$ Cf. Rivero ORTEGA, Ricardo, Archivo y expediente electrónico: dos herramientas claves del derecho administrativo de la sociedad de la información y el conocimiento, in SÁNCHEZ SÁNCHEZ, Zulima (coord.), Nuevas Tecnologías, Administración y Participación Ciudadana, Granada, Comares, 2010, p. 40.
} 
publicidade, eficiência e privacidade, a melhor solução é adotar uma política institucional em relação à informação administrativa ${ }^{731}$, definida em lei, estabelecendo obrigações normativas claras e expressas tendentes a garantir o acesso à informação por meios informáti$\cos$ e telemáticos ${ }^{732}$. No contexto atual, um verdadeiro regime jurídico sobre o tema deve disciplinar, por exemplo: a) os mecanismos eletrônicos de acesso; b) as informações oferecidas aos usuários; c) as características e as condições de acesso; d) o uso da informação, inclusive no que concerne à sua circulação, dentro e fora da Administração; e) os mecanismos de garantia e de responsabilidade ${ }^{733}$. Sem uma referência legal clara, aumenta o risco de o Estado usar os sistemas para exercer uma vigilância sobre os cidadãos, cada vez mais transparentes ${ }^{734}$, havendo uma tendência a transformar uma opacidade generalizada em uma obsessão pela visibilidade do interior da Administração Pública, gerando excessos pouco recomendáveis, que podem colidir com direitos fundamentais ${ }^{735}$.

Embora ainda persistam algumas lacunas, tal vazio normativo foi preenchido com a recente edição da Lei n. 12.527/2011, que regula o acesso a informações em toda a Administração Pública brasileira (Lei de Acesso à Informação). Tal diploma legislativo tem como objetivo assegurar o direito fundamental de acesso à informação (art. $3^{\circ}$, caput), reconhecendo o correspondente dever do Estado (art. $5^{\circ}$ ). Adota a publicidade co-

\footnotetext{
${ }^{731}$ Cf. VALero ToRriJos, Julián, La e-Administración Pública, cit., p. 100.

${ }^{732}$ Cf. VALERO TORRIJOS, Julián, El acceso telemático a la información administrativa, cit., p. 31.

${ }^{733}$ Cf. CERRILlo i MARTínez, La difusión de información pública en internet, cit., p. 20; GARCÍA MACHO, Ricardo, op. cit., pp. 199 e 211; TRUDEL, Pierre, op. cit., p. 43. Nos Estados Unidos, o Freedom of Information Act, emendado em 1996, prevê expresamente a possibilidade de utilizar as tecnologias da informação e da comunicação para a difusão da informação administrativa (cf. CERRILLO I MARTínEZ, La difusión de información pública en internet, cit., p. 17). Há quem defenda a necessidade de elaborar um direito administrativo da informação, tendo como objeto a proteção de dados e sigilos oficiais, o uso e utilização da informação administrativa, a responsabilidade pelas informações, a igualdade de acesso, a eliminação da exclusão digital e a garantia dos direitos fundamentais do ciberespaço (cf. BARNÉS VÁZQUEZ, Javier, Una reflexión introductoria sobre el Derecho Administrativo y la Administración Pública de la Sociedad de la Información y del Conocimiento, cit., p. 40). Também mencionando o direito administrativo da informação, cf. SANZ LARRUGA, Francisco Javier, Documentos y archivos electrónicos, cit., p. 456. Já se apontou, a propósito, que, assim como Século XIX viu progressos em matéria de direitos políticos e a segunda metade do Século XX assistiu ao progresso dos direitos econômicos, é necessária, no século XXI, uma Carta dos Direitos de Informação e Responsabilidades (cf. OlIVER, E. Lynn, SANDERS, Larry, The Regina Declaration, cit., com referência ao possível conteúdo para tal carta).

${ }^{734}$ Cf. OBERDORFF, Henri, op. cit., p. 14.

${ }^{735}$ Cf. Fernández SAlmerón, Manuel, PARRa SÁez, Samuel, VAlero TorriJos, Julián, Crónica del año 2009, in Revista Española de Protección de Datos, n. 6, Madrid, Agencia de Protección de Datos de la Comunidad de Madrid - Civitas, jan.- jun. 2009, p. 151.
} 
mo regra e o sigilo, como exceção (art. $3^{\circ}$, I), cabendo salientar a menção à informação ativa (art. $3^{\circ}$, II e $8^{\circ}$ ) e ao uso da tecnologia da informação (art. $3^{\circ}$, III).

Não cabe a este estudo trazer um comentário minucioso dos preceitos da lei, sendo necessário apenas comentar algumas novidades por ela trazidas, sobretudo aquelas mais relacionadas ao governo eletrônico. Vale ressaltar, pois: a) a exigência de divulgação ativa de informações de interesse coletivo ou geral por meio de portais públicos na internet (art. $8^{\circ}, \S \S 1^{\circ}$ e $2^{\circ}$ ); b) a previsão de um regramento mínimo para tais portais (art. $8^{\circ}, \S 3^{\circ}$ ); c) a divulgação de dados, a pedido do interessado (acesso passivo), por meio dos referidos portais públicos (art. 10, $\S 2^{\circ}$ ); d) a possibilidade de fornecimento, em suporte eletrônico, da informação solicitada (art. $11, \S 5^{\circ}$ ).

Embora admita a publicação de informações de interesse coletivo por quaisquer meios e instrumentos legítimos, a nova lei exige sua publicação por meio do portal público na internet ( $\operatorname{art} .8^{\circ}, \S 2^{\circ}$ ), regra não aplicável somente aos municípios com até 10.000 habitantes ( $\operatorname{art} 8^{\circ}, \S 4^{\circ}$ ). O comando legal caracteriza uma inversão da lógica dos meios destinados à publicidade: as formas eletrônicas, antes um mero complemento em relação aos mecanismos tradicionais, passaram a protagonistas da transparência administrativa. Trata-se do reconhecimento expresso, por parte do ordenamento, das vantagens dos meios telemáticos, sobretudo da internet, para a realização do princípio da publicidade.

Merece ser salientado, também, o conteúdo mínimo exigido dos portais públicos. Os sítios oficiais na internet devem trazer informações de interesse coletivo referentes a: a) competências e estrutura organizacional, endereços e telefones das respectivas unidades e horários de atendimento ao público; b) repasses ou transferências de recursos financeiros; c) despesas; d) licitações e contratos; e) programas, ações, projetos e obras de órgãos e entidades; f) perguntas mais frequentes da sociedade. Outras informações podem ser acrescentadas, mas é sempre importante ter atenção para a necessidade de evitar a divulgação de informação inútil ${ }^{736}$, pois a própria capacidade intelectual do usuário pode ser

${ }^{736}$ Cf. CAMARGO, Guilherme Bueno de, op. cit., p. 130. 
vencida pela confusão e sobrecarga decorrente da vertiginosa proliferação das fontes e dos meios de comunicação ${ }^{737}$.

O regramento dos portais públicos, no tocante à publicação de informações de interesse coletivo, traz outros pontos a serem ressaltados, em especial pelo fato de disciplinar temas aparentemente técnicos, que no atual contexto trazem importantes repercussões em relação ao exercício de direitos. Na forma do regulamento (art. $\S 3^{\circ}$ ), os portais devem: a) oferecer ferramenta de pesquisa (inc. I) ${ }^{738}$; b) propiciar o acesso de forma objetiva, transparente, clara e em linguagem de fácil compreensão (inc. I) ${ }^{739}$; b) fornecer relatórios em formatos abertos e não proprietários, para facilitar a análise das informações (inc. II); c) permitir o acesso automatizado por sistemas externos (inc. III); d) divulgar os formatos empregados (inc. IV); e) garantir o acesso para pessoas portadoras de deficiência, atributo conhecido como usabilidade (inc. VIII). Com tais exigências, a legislação brasileira alinha-se às mais modernas políticas relativas ao tema ${ }^{740}$, que vêm sendo associadas à expressão dados abertos: trata-se da possibilidade de divulgar informações não apenas para conhecimento e acompanhamento, mas de tal maneira que possa permitir sua reutilização em outros projetos, sítios e aplicativos, bem como seu cruzamento com outros dados e sua apresentação em formas de visualização mais interessantes e esclarecedoras ${ }^{741}$.

\footnotetext{
${ }^{737}$ Cf. GóMEZ PUENTE, Marcos, op. cit., p. 97. O problema, aqui, muda de perspectiva: a imensa quantidade de informação pode exceder a capacidade de cada pessoa para processá-la e analisá-la (cf. SMITH, Peter Jay, op. cit., p. 144).

${ }^{738}$ A respeito do aperfeiçoamento do desenho dos portais eletrônicos da Administração Pública com a introdução de sistemas automatizados para facilitar a localização da informação, cf. FERNÁNDEZ SALMERóN, Manuel, VALERO TORRIJOS, Julián, La publicidad de la información administrativa en internet, cit., p. 81.

${ }^{739}$ Sobre a utilização de linguagem compreensível segundo o perfil do destinatário ou usuário, cf. JINESTA LOBO, Ernesto, op. cit., p. 9.

${ }^{740}$ Vale ressaltar, a propósito, o memorando expedido pela Presidência dos Estados Unidos da América, empregando a expressão open government, com grande repercussão nos debates a respeito. O documento pode ser encontrado em http://www.whitehouse.gov/the press_office/TransparencyandOpenGovernment/, acesso em 20.07.2011.

${ }^{741}$ Sobre o paradigma dos dados abertos, cf. DIETRICH, Daniel et al., The Open Data Manual, Cambridge, Open Knowledge Foundation, 2010, trad. e adapt. brasileira de Comunidade Transparência Hacker, Manual dos dados abertos: governo, São Paulo, W3C - Escritório Brasil, disponível em http://www.w3c.br/pub/Materiais/PublicacoesW3C/Manual_Dados_Abertos_WEB.pdf, acesso em 20.07.2011, p. 4. Segundo a linha adotada na obra, os dados abertos referem-se a informações de interesse coletivo, não alcançando dados pessoais e aqueles referentes à segurança nacional (ibidem, p. 16). Como se verá, o regime de acesso à informação brasileiro reconhece restrições à divulgação de informações pessoais e sigilosas, nos termos definidos em lei.
} 
A possibilidade de encaminhamento de pedidos de acesso por meio dos portais (art. 10, $\S 2^{\circ}$ ) também merece algumas considerações. Com esse dispositivo, a lei brasileira não apenas reconhece a possibilidade de utilização de meios telemáticos para o acesso passivo, mas os torna obrigatórios. Por se tratar de acesso a informações de interesse coletivo, essa forma de relacionamento pode ocorrer de maneira mais simplificada. É dispensável, por exemplo, um controle da identidade do solicitante, porquanto o acesso poderia ser feito por qualquer pessoa, já que é vedado exigir do interessado que declare os motivos determinantes da solicitação $\left(\operatorname{art.} 10, \S 3^{\circ}\right)^{742}$.

Por fim, merece encômios a previsão legal a respeito da possibilidade de fornecimento da informação em formato digital, caso assim armazenada, se houver anuência do requerente (art. $11, \S 5^{\circ}$ ), pois se trata de uma alternativa geralmente mais barata, capaz de oferecer maior utilidade e praticidade. Em vista da omissão do texto legal, parecem admissíveis tanto os mecanismos presenciais - por exemplo, a entrega de um disco ótico ao interessado - quanto os telemáticos - o envio por correio eletrônico. Em todo caso, é necessário que o documento digital oferecido apresente todos os atributos necessários à sua validade jurídica, sobretudo para que o interessado possa utilizá-lo em seu relacionamento com terceiros.

Os diversos deveres atribuídos ao Estado, por força da nova lei, fazem surgir direitos em favor dos administrados, que podem ser considerados instrumentais em relação ao direito fundamental de acesso à informação. Alguns desses direitos, aplicáveis a quaisquer mecanismos de divulgação, são declarados de modo expresso (art. $7^{\circ}$ ). Todavia, vale notar que os deveres do Estado relativos à temática das novas tecnologias, acima referidos, também geram direitos, de modo reflexo. Assim, deve-se reconhecer ao administrado o direito a obter, por meio do portal público na internet, informações de interesse cole-

\footnotetext{
${ }^{742}$ A questão do acesso às informações de interesse coletivo será analisada no próximo item (cf., em especial, a nota 755).
} 
tivo, na extensão temática prescrita, em formato eletrônico, observados os requisitos técnicos estabelecidos e as exigências mínimas de qualidade da informação ${ }^{743}$.

As exigências impostas pela nova lei quanto à qualidade da informação (art. $7^{\circ}$ ) também valem para qualquer forma de acesso, não somente aquele efetuado por meios eletrônicos ${ }^{744}$. Todavia, é necessário reconhecer as maiores repercussões da utilização da divulgação das informações na internet. Quando a informação difundida na internet não tem a qualidade necessária, ela pode não alcançar as finalidades previstas, limitar os usos esperados ou até mesmo causar danos para as pessoas destinatárias ${ }^{745}$. Assim sendo, a informação administrativa eletrônica deve ser completa, objetiva, exata, fidedigna, relevante, atualizada, idônea para satisfazer as necessidades dos usuários e fácil de encontrar, de entender e de usar ${ }^{746}$.

\subsubsection{Os diferentes níveis de acesso à informação}

A tecnologia não só é capaz de trazer avanços, mas ao mesmo tempo pode oferecer novos perigos e inconvenientes, além de incrementar a potencialidade nociva daqueles já existentes ${ }^{747}$. Mais do que viabilizar a publicidade, as novas tecnologias dão uma nova dimensão aos critérios mais tradicionais que definem o que deve ou não ser pu-

\footnotetext{
${ }^{743}$ Mencionando direitos do administrado no acesso à informação eletrônica, cf. AGIRREAZKUENAGA, Iñaki, Chinchilla, Carmen, op. cit., p. 45; Bernadí GIL, Xavier, op. cit., p. 235; MARTín DelGADO, Isaac, La gestión electrónica del procedimiento administrativo, cit., p. 97; PALOMAR OLMEDA, Alberto, La utilización de las nuevas tecnologías en la actuación administrativa, cit., p. 375; SANZ LARRUGA, Francisco Javier, Documentos y archivos electrónicos, cit., p. 489.

${ }^{744}$ Além disso, as exigências de qualidade não estão limitadas à operação de acesso aos dados, como parece sugerir a lei. A qualidade não se refere apenas à informação em si ou a sua divulgação, mas a todos os processos com ela relacionados, tais como sua criação, recolhida e armazenamento (cf. CERRILLO I MARTínEZ, La difusión de información pública en internet, cit., p. 23). Nos Estados Unidos da América, foi adotado o Information Quality Act, para estabelecer parâmetros de qualidade ante a crescente difusão de informação administrativa feita pelas agências federais (cf. ibidem, p. 27).

${ }^{745}$ Cf. CERRILlO I MARTínEZ, La difusión de información pública en internet, cit., p. 22.

${ }^{746}$ Falando em atribuitos das informação, cf. VALERO TORRIJOS, Julián, La nueva regulación legal del uso de las tecnologías de la información y las comunicaciones en el ámbito administrativo, cit., pp. 229-230.

${ }^{747}$ Cf. Duni, Giovanni, L'amministrazione digitale, cit., p. 80 e FERnÁNDEZ SALMERÓN, Manuel, VALERO TORRIJOS, Julián, Protección de datos personales y Administración electrónica, cit., pp. 111 e 119.
} 
blicado pela Administração ${ }^{748}$. Em princípio, os dados que podem estar disponíveis em papel devem ser deixados disponíveis também no âmbito do governo eletrônico ${ }^{749}$. Assim, o acesso à informação contida em bases de dados públicas em regra deve ser acessível aos cidadãos, não podendo sofrer maiores limitações que as exigidas pela concorrência de outros bens jurídicos constitucionalmente protegidos ${ }^{750}$.

De outra parte, a eventual necessidade de respeito aos demais bens constitucionais envolvidos torna imprescindível a fixação de níveis de acesso, conforme a informação considerada ${ }^{751}$. No governo eletrônico, como já mencionado, a tendência é a prestação das informações de maneira ativa, sem que haja uma fase de avaliação sobre a pertinência de cada solicitação. Por essa razão, os níveis de acesso devem ser estabelecidos antes de tornar disponível o serviço, ocasião em que deverão ser adotados os cuidados pertinentes, tais como a definição dos critérios para a verificação da legitimidade do acesso e da forma pela qual a informação poderá ser oferecida. A nova legislação brasileira segue essa tendência, ao prescrever a classificação para efeito de sigilo (art. 23 e 24 da Lei n. $12.527 / 11)^{752}$.

\footnotetext{
${ }^{748}$ As questões aqui apresentadas acompanham a evolução tecnológica. De fato, enquanto não utilizados os meios telemáticos, os problemas relacionados à preservação da intimidade não eram tão sensíveis. A primeira onda de informatização das Administrações Pública, nas décadas de 1960 e 1970, orientada principalmente para a busca de produtividade, manifestava pouca consideração pelas questões da vida privada (cf. TRUCHE Pierre, FAUGERE, Jean-Paul, Flichy, Patrice, Administration électronique et protection des données personnelles - Livre blanc, Paris, La Documentation française, 2002, op. cit., p. 19). No entanto, desde então, a questão vem sendo objeto de debate (cf. GRISTI, Éric, op. cit., p. 512). A informatização da Administração foi descrita com frequência, por cerca de trinta anos, como fonte de ameaças para o administrado, possivelmente sujeito a um insuportável controle social simbolizado pela figura do Big Brother (cf. MAISL, Herbert, De l'administration cloisonnée a l'administration en réseau: fin de la vie privée et/ou satisfaction de l'usager, in ChATILlON, Georges, MARAIs, Bertrand du (org.), L'administration électronique au service des citoyens, Bruxelles, Bruylant, 2003, p. 349). Hoje tais temas se referem a uma realidade concreta, que permite identificar as respectivas questões jurídicas e procurar solucioná-las.

${ }_{749}$ Cf. DUNI, Giovanni, L'amministrazione digitale, cit., p. 65.

${ }^{750}$ Cf. GonZÁLEZ Bustos, María de los Ángeles, Derecho a la información del ciudadano y las nuevas tecnologías, in SÁNCHEZ SÁNCHEZ, Zulima (coord.), Nuevas Tecnologías, Administración y Participación Ciudadana, Granada, Comares, 2010, p. 25 e VALERO TORRIJOS, Julián, El acceso telemático a la información administrativa, cit., p. 33.

${ }^{751}$ Propondo níveis de acesso, cf. DuNI, Giovanni, I "viaggi telematici" dell'atto informatico. Note sul procedimento informatico, in Quaderni del DAE - Rivista di Diritto Amministrativo Elettronico, jul. 2003, disponível em http://www.cesda.it/quadernidae/index.php, acesso em 08.12.2010, p. 1.

${ }^{752}$ A Lei n. 14.141/06, do Município de São Paulo, condiciona a utilização das novas tecnologias à garantia de "níveis de acesso às informações" (art. 49, I).
} 
Há situações mais extremas, que não comportam grandes questionamentos quanto à introdução das novas tecnologias. De um lado, as informações básicas, imprescindíveis para o funcionamento democrático e de interesse para o público em geral tais como legislação, jurisprudência e informação sobre a atuação parlamentar -, estão sujeitas a um regime de liberdade de circulação ${ }^{753}$ e devem ser oferecidas indiscriminadamente a todos os cidadãos, em igualdade de condições ${ }^{754}$, do modo mais amplo possível e sem nenhuma forma de controle de identidade do solicitante ${ }^{755}$, cabendo apenas garantir ao administrado a autenticidade de tal informação ${ }^{756}$. São as informações de interesse coletivo referidas pela Lei de Acesso à Informação $\left(\operatorname{art.~} 8^{\circ}\right.$ ). De outro lado, as informações sujeitas ao sigilo, por necessidades relacionadas à segurança da sociedade ou do Estado, não devem ser objeto de publicidade alguma (art. 23). Tendo em vista o dever de controlar o acesso a estas informações (art. 25) é imprescindível, caso empregados meios informáticos, a utilização das técnicas apropriadas para evitar que tais dados sejam levados ao conhecimento do público, conforme o disposto em regulamento (art. $25, \S 3^{\circ}$ ), sem prejuízo das providências em relação à observância do sigilo pelos profissionais envolvidos (art. 26, caput).

Outra situação é a das informações pessoais, entendidas como aquelas que fazem referência a pessoas determinadas, o que pode ser verificado de modo direto ou por meio de uma operação lógica ${ }^{757}$. Neste caso, a realização da transparência administrativa passa a confrontar-se com o direito à proteção dos dados pessoais, aspecto integrante do direito à intimidade e à vida privada ${ }^{758}$. Tal tema será tratado nos itens seguintes.

\footnotetext{
${ }^{753}$ Cf. TRUDEL, Pierre, op. cit., p. 47.

${ }^{754}$ Assim já se afirmou: "A igualdade de todos no acesso à informação administrativa constitui um ponto de singular relevância. Relaciona-se com o princípio democrático, a cláusula do Estado de Direito e o princípio da divisão de poderes. A tal propósito, a Administração deve exercer um papel ativo, de caráter prestacional, que assegure a qualidade da oferta pública da informação" (cf. BARNÉS VÁZQUEZ, Javier, Una reflexión introductoria sobre el Derecho Administrativo y la Administración Pública de la Sociedad de la Información y del Conocimiento, cit., p. 76, tradução livre).

${ }^{755}$ Cf. GARCÍA-PogGiO, Paz, op. cit., pp. 8-9. Aplica-se, aqui, o princípio da segurança graduada, ou seja, o respeito ao anonimato em todas as solicitações que não exijam identificação (cf. nota 418).

${ }^{756}$ Cf. FERNÁNDEZ SALMERÓN, Manuel, El acceso a los registros y archivos administrativos, cit., p. 617. É o caso, também, dos editais em geral, que podem encontrar maior difusão e capilaridade por meio da internet, inclusive pela possibilidade de localização de informação por meio de motores de busca (cf., comentando a legislação española, que prevê expresamente os editais em meio digital, VALERO TORRIJOS, Julián, Acceso a los servicios y difusión de la información por medios electrónicos, cit., p. 265).

${ }^{757}$ Cf. VALERO TORRIJOS, Julián, El acceso telemático a la información administrativa, cit., p. 34.

${ }^{758}$ Cf. TRUDEL, Pierre, op. cit., p. 15.
} 


\subsubsection{As novas tecnologias e o respeito à intimidade e à vida privada}

A conformação tradicional da transparência administrativa foi construída em torno de um determinado contexto tecnológico, marcado por uma fragmentação da visão do governo a respeito do cidadão: a informação concernente a cada indivíduo era armazenada em diferentes arquivos físicos ou, em período mais recente, espalhada em centenas de bases de dados informatizadas, mas em geral não conectadas e tecnicamente incompatíveis. De modo perverso, essa situação caótica acabou por assegurar que as informações não fossem usadas para propósitos alheios à razão pela qual elas foram obtidas ${ }^{759}$. O recebimento de dados pelo Estado ficava circunscrito a um espaço delimitado e a difusão da informação, em relação a terceiros, restava submetida aos limites da capacidade humana. Tais dificuldades práticas serviram, durante muitos anos, como uma forma de preservação de direitos.

As novas tecnologias, por sua vez, pulverizam as limitações tradicionais à recompilação de dados que afetam a vida das pessoas ${ }^{760}$, trazendo problemas relacionados à violação do direito fundamental à privacidade e à intimidade, em especial no que se refere aos chamados dados de caráter pessoal ${ }^{761}$.

Entretanto, o governo eletrônico não pode ser oferecido à custa de expectativas consagradas relativas à proteção da privacidade ${ }^{762}$. Por isso, a autonomia ou autodeterminação individual - que permite às pessoas proteger uma zona de sua vida privada, reservada frente às interferências alheias, do Poderes Público e de terceiros - deve ser compreendida no âmbito da realidade tecnológica atual ${ }^{763}$. Adotada essa perspectiva, o direito à privacidade assume uma característica diferente, configurando-se como um direito

\footnotetext{
${ }^{759}$ Cf. HoLMES, Douglas, op. cit., p. 31.

${ }^{760}$ Cf. Mestre Delgado, Juan Francisco, op. cit., p. 120.

761 Cf. Fernández SAlmerón, Manuel, PARra SÁEZ, Samuel, VAlero TorriJos, Julián, Crónica del año 2009, cit., p. 151.

762 Cf. Culbertson, Stuart, op. cit., p. 72.

763 Cf. VAlERo TORRIJOS, Julián, LÓPEZ PELliCER, José Antonio, Algunas consideraciones sobre el derecho a la protección de los datos personales en la actividad administrativa, cit., p. 274.
} 
de autotutela e de autodeterminação sobre os próprios dados pessoais no confronto com sua memorização e gestão nos bancos de dados privados ou públicos ${ }^{764}$.

É certo que o direito à vida privada varia em função do contexto, das épocas, dos costumes e, sobretudo, da posição ocupada pelas pessoas na sociedade ${ }^{765}$. Nesse sentido, não há dúvida de que atualmente as pessoas sofrem um altíssimo nível de exposição pessoal, especialmente por meio da internet, o que traz progressivas mudanças no entendimento sobre o que deve ser considerado informação pessoal suscetível de proteção pelo ordenamento jurídico. No entanto, a situação é bastante peculiar se consideradas as informações pessoais contidas em bancos de dados públicos, muitas vezes recolhidas de modo compulsório.

O tema é tão sensível que, em outros países, vem sendo objeto de um regime jurídico específico ${ }^{766}$. Entre nós, durante muito tempo, a legislação não trouxe disposições sobre o direito à proteção de dados de caráter pessoal, embora este pudesse ser considerado integrante do ordenamento brasileiro, como uma decorrência do respeito à intimidade e à vida privada na divulgação de registros públicos e atos de governo (art. 37, §3º, III da Constituição da República). Recentemente, a Lei de Acesso à Informação trouxe uma seção sobre o tema (art. 31), dispondo sobre a necessidade do respeito à intimidade, à vida privada, à honra e à imagem das pessoas no tratamento de dados pessoais (art. 31, caput).

Não obstante, é preciso apontar a timidez das disposições da lei, que não se mostra tão minuciosa quanto necessário. São regulados apenas alguns temas relativos à proteção de dados pessoais, sobretudo aqueles referentes à sua divulgação, havendo pouca

\footnotetext{
${ }^{764}$ Cf. Frosini,Vittorio, Telematica e informatica giuridica, cit., p. 66 e MENICHETTI, Enrico, op. cit., p. 138. ${ }^{765}$ Cf. TRUDEL, Pierre, op. cit., p. 14.

${ }^{766} \mathrm{Na}$ Espanha, por exemplo, não somente a Constituição contém um dispositivo expresso a respeito da proteção de dados de caráter pessoal (art. 18), como existe uma lei que define um regime jurídico para a matéria (Lei Orgânica de Proteção de Dados), que tem grandes repercussões em relação à disciplina do governo eletrônico, pois as autoridades de controle em matéria de proteção de dados acabaram por assumir uma função de avaliação sobre o modo pelo qual devem ser apreciadas as solicitações feitas pelos cidadãos no exercício do direito de acesso a expedientes e documentos administrativos (cf. FERNÁNDEZ SALMERÓn, Manuel, PARRA SÁEZ, Samuel, VALERO TORRIJOS, Julián, Crónica del año 2009, cit., p. 154).
} 
clareza quanto às demais operações que caracterizam o tratamento da informação ${ }^{767}$. Tampouco há uma autoridade incumbida de efetuar o controle do respeito, pelo Poder Público, às informações de caráter pessoal, estrutura presente em outros países, capaz de oferecer mais garantias ao administrado.

Outra falha diz respeito à falta de uma estratificação conceitual das informações de caráter pessoal, entendidas apenas como aquelas relacionadas à pessoa natural identificada ou identificável (art. $\left.4^{\circ}, \mathrm{IV}\right)$. Na verdade, os riscos de violação à intimidade e à vida privada variam conforme a informação considerada ${ }^{768}$. Por tal razão, em outros ordenamentos, tem sido notada a diferença entre os dados pessoais em geral (informação relativa a pessoa física, pessoa jurídica, ente ou associação, identificada ou identificável, mesmo de modo indireto, mediante referência a qualquer outra informação, inclusive um número de identificação pessoal) e dados sensíveis (informação idônea a revelar a origem racial ou étnica, as convicções religiosas, filosóficas ou de outro gênero, as opiniões políticas, a adesão a partidos, sindicatos, associações ou organizações de caráter religioso, filosófico, político ou sindical, bem como os dados pessoais capazes de revelar o estado de saúde e a vida sexual), estando estes últimos relacionados a perigos muito mais relevantes $^{769}$. A possível utilização indevida de dados desta última categoria poderia pôr em perigo outros direitos fundamentais, como a liberdade de opinião, a liberdade de consciência e proibição de discriminação em função desses caracteres ${ }^{770}$.

Isso traz repercussões em relação ao direito de acesso, que não foram alcançadas pela legislação pátria. De fato, dentre as informações pessoais, há aquelas que poderiam ser denominadas qualificadas ${ }^{771}$, por estarem à disposição somente de pessoas determinadas, ocupantes de uma dada posição jurídica ${ }^{772}$. Assim, por exemplo, só o próprio contribuinte pode ter conhecimento, perante a autoridade tributária, do andamento da

\footnotetext{
${ }^{767}$ Segundo a Lei n. 12.527/11, o tratamento da informação corresponde a um "conjunto de ações referentes à produção, recepção, classificação, utilização, acesso, reprodução, transporte, transmissão, distribuição, arquivamento, armazenamento, eliminação, avaliação, destinação ou controle da informação" (art. $4^{\circ}$, V).

${ }^{768}$ Cf. TRUDEL, Pierre, op. cit., p. 45.

${ }^{769}$ Cf. MENICHETTI, Enrico, Accesso alle informazioni pubbliche e trasparenza amministrativa, in MERLONI, Francesco, Introduzione all'e-government, Torino, G. Giappichelli, 2005, p. 138.

${ }^{770} \mathrm{Cf}$. BRAIBAnt, Guy, Données personnelles et société de l'information, cit., p. 7.

${ }_{771}$ Cf. FERnÁNDEZ SALMERÓn, Manuel, El acceso a los registros y archivos administrativos, cit., p. 618.

${ }^{772}$ Cf. VAlero TorriJos, Julián, Protecção de datos personales y administración electrónica, cit., p. 45.
} 
análise de sua declaração de renda. Neste caso, não há mudança substancial no direito de acesso eletrônico em relação ao acesso pelas vias tradicionais. A questão, neste caso, é a adaptação da tecnologia para atender a esse oferecimento restrito de informações ${ }^{773}$. Para tanto, deve-se estabelecer um mecanismo de comunicação sigiloso que garanta a confidencialidade $^{774}$, impedindo o acesso de terceiros não autorizados ${ }^{775}$, e permita o reconhecimento da referida posição jurídica, função geralmente desempenhada pela assinatura eletrônica ${ }^{776}$. Todavia, há informações que, embora referentes a pessoas determinadas, não oferecem, em si, razão alguma para ter sua publicidade restringida - por exemplo, a publicação de um ato administrativo com menção ao nome do interessado.

Sem levar em conta essa diferença, a legislação brasileira simplesmente impôs o sigilo dos dados pessoais pelo prazo máximo de 100 anos, permitindo sua divulgação com base em lei ou com o consentimento expresso daquele que é referido pela informação, dispensada essa concordância em certas hipóteses (art. 31, §§ $3^{\circ}$ e $4^{\circ}$ ).

As omissões da lei e a inexistência de disposições distintas conforme o nível de risco da informação pessoal considerada tende a gerar problemas. Algumas dessas dificuldades serão analisadas nos itens seguintes, sob duas perspectivas: a proteção de dados pessoais em relação ao próprio Estado e em relação a terceiros.

\footnotetext{
${ }^{773}$ Cf. VALERo TORRIJOS, Julián, El acceso telemático a la información administrativa, cit., p. 45.

${ }^{774}$ Cf. FERNÁNDEZ SALMERÓN, Manuel, VALERO TORRIJOS, Julián, La publicidad de la información administrativa en internet, cit., p. 98.

${ }^{775}$ Cf. VALERO TORRIJOS, Julián, El acceso telemático a la información administrativa, cit., p. 43.

${ }^{776}$ Cf. FernándeZ SALMERÓN, Manuel, VAlero TORRIJOS, Julián, La publicidad de la información administrativa en internet, cit., p. 97. Muitas vezes a legitimidade para atuar em um procedimento não está perfeitamente identificada desde logo, o que obriga os possíveis interessados a pleitear ao órgão competente o reconhecimento dessa condição (cf. FERNÁNDEZ SALMERÓN, Manuel, El acceso a los registros y archivos administrativos, cit., p. 620).
} 


\subsubsection{A proteção da intimidade e da vida privada em relação ao Estado}

É necessário tutelar a esfera de privacidade e intimidade em face dos riscos próprios da sociedade da informação ${ }^{777}$, de maneira equilibrada com as exigências de publicidade e de eficiência ${ }^{778}$ na Administração Pública. Isso exige uma ponderação entre esses bens constitucionais ${ }^{779}$, o que não constitui uma tarefa simples ${ }^{780}$.

O primeiro problema diz respeito à possibilidade técnica de obtenção, processamento e utilização indiscriminada de dados pelo Estado ${ }^{781}$, potencializada pela comunicação telemática entre os órgãos públicos ${ }^{782}$, o que cria reais condições para controlar a vida dos indivíduos ${ }^{783}$. As novas tecnologias devem trazer uma transparência da Administração para o cidadão e não do cidadão para a Administração ${ }^{784}$, de tal modo que o

\footnotetext{
777 Cf. MeNichetTI, Enrico, op. cit., p. 137; BARNÉS VÁZQUEZ, Javier, Una reflexión introductoria sobre el Derecho Administrativo y la Administración Pública de la Sociedad de la Información y del Conocimiento, cit., p. 70 e PALOMAR OLMEDA, Alberto, La utilización de las nuevas tecnologías en la actuación administrativa, cit., p. 369.

${ }^{778}$ Cf. VALERO TORRIJOS, Julián, El acceso telemático a la información administrativa, cit., p. 46.

${ }^{779}$ A doutrina tem identificado a necessidade de um novo equilíbrio entre a livre circulação de dados, a legislação estatal de proteção de dados e a sua autoproteção, assim como uma paralela intensificação da comunicação entre o Estado e os cidadãos no marco do Estado de Direito, marcado pela colaboração ou cooperação com a sociedade. Nesse sentido, é necessário um novo marco legal, que decorra de um complexo processo de ponderação (cf. PITSCHAS, Raines, op. cit., p. 221).

${ }^{780}$ Cf. VALERO TORRIJOS, Julián, El acceso telemático a la información administrativa, cit., p. 38.

${ }^{781}$ Em vista do arsenal de dados que passa a ter em mãos, "[a] Administração Pública aparece como um organismo de poderes muito mais sutis e implacáveis que os imaginados por Hobbes em seu Leviathan" (PÉREZ LUÑO, Antonio-Enrique, op. cit., p. 85).

782 Cf. Chevallier, Jacques, La mise en ouvre de l'administration électronique, cit., p. 390. Segundo GROSS, a existência de serviços integrados exige a conexão entre bases de dados, de forma que o conflito com a separação informacional de poderes é inevitável. Para o autor, não há solução perfeita para esse conflito (op. cit., p. 75).

${ }^{783}$ Cf. BOMBARDELLI, Marco, op. cit., pp. 1024-1025.

${ }^{784}$ Cf. CANTERO, Anne, op. cit., p. 406.
} 
desenvolvimento tecnológico não crie uma indevida vigilância do Estado sobre o cidadão ${ }^{785}$.

O tema não é referido de modo expresso pelo art. 31 da Lei n. 12.527/11, que dispõe sobre o tratamento de informações pessoais. É essencial, contudo, reconhecer ao administrado alguma proteção jurídica em relação à construção de bases de dados que façam referência a informações atribuíveis a pessoas determinadas. A tais pessoas devem ser reconhecidos, por exemplo, os direitos a: a) ter conhecimento a respeito da existência de tais bases de dados oficiais e de quais são as informações pessoais ali registradas; b) obter acesso a essas informações; c) pleitear a retificação, esclarecimento, atualização ou eliminação de qualquer informação que lhe diga respeito; d) ter recolhidas tais informações de modo regular, sem a utilização de meios fraudulentos ou desleais; e) opor-se, por motivos legítimos, a que as informações sejam objeto de tratamento ou transferência a terceiros; f) ser informado sobre a destinação das informações recolhidas, inclusive sobre os terceiros a quem a informação tenha sido transferida, caso isso seja legalmente admissível; g) não ter as informações deformadas, danificadas ou comunicadas a terceiros não autorizados; h) ter o conhecimento e a oportunidade de contestar as informações utilizadas nos tratamentos automatizados cujos resultados lhe sejam opostos; i) ver canceladas as infor-

\footnotetext{
${ }^{785}$ Cf. TRUDEL, Pierre, op. cit., p. 39. Deve-se considerar que a nossa sociedade atual está baseada, em grande medida, no manejo de informação referente a pessoas físicas concretas ou que, no mínimo, podem ser identificadas (cf. VALERO TORRIJOS, Julián, El acceso telemático a la información administrativa, cit., p. 46). Assim, a própria abrangência da vida privada pode ser posta em discussão em vista de uma publicização dos indivíduos, própria do processo de informatização da sociedade, na qual, independentemente da atuação do Estado, há uma intensa proliferação de dados pessoais (cf. PITSCHAS, Raines, op. cit., p. 218), sendo impossível a manutenção de monopólios estatais de informação totalitários (ibidem, p. 220). Nesse contexto, o Estado não tem condições de garantir uma completa e segura proteção do indivíduo em todos os cenários e formas de comunicação imagináveis, nem se pode entender que se trate de uma função estatal exclusiva (ibidem, p. 241).
} 
mações que, por sua natureza ou pela atividade institucional no âmbito da qual foram geradas, possam ser conservadas somente por um período limitado de tempo ${ }^{786}$.

Outro ponto importante, também omitido pela legislação brasileira, diz respeito à identificação de limites para a construção de bases de dados pelo Poder Público. É certo que a disponibilidade de informações é imprescindível para o cumprimento das funções da Administração, mas essa necessidade não pode impor-se simplesmente com o sacrifício da esfera jurídica do administrado ${ }^{787}$. Nos dias de hoje, a informação constitui um ativo poderoso e, mais do que isso, um mecanismo de acúmulo de poder, o que aumenta o potencial para violação de direitos. Além disso, o fato de se exigir do cidadão a apresentação de muita informação pode provocar uma perda de confiança de sua parte, na medida em que possa sentir-se perseguido pela Administração ${ }^{788}$.

O governo eletrônico não deve ter por objetivo recolher novas informações sobre os usuários ${ }^{789}$, mas maximizar a utilidade das bases de dados existentes, observadas as garantias constitucionais pertinentes. Por essa razão, a acumulação informativa não pode ser realizada pelo Estado sem limites ou sem estar vinculada a uma finalidade legítima, devendo a Administração Pública somente ter acesso aos dados a respeito dos

\footnotetext{
${ }^{786}$ Não parece possível indicar somente um fundamento para esse rol de direitos, uma vez que eles parecem decorrer de um conjunto de normas que regram a atuação estatal para coibir desvios e abusos, em detrimento dos indivíduos. De qualquer forma, além dos postulados básicos do sistema jurídico que sustentam tais direitos, como a legalidade da atuação administrativa, a publicidade e a preservação da publicidade e da intimidade, convém mencionar a garantia conferida pelo habeas data (art. $5^{\circ}$, LXXII, da Constituição brasileira), que, reconhecendo a relevância jurídica das bases de dados estatais, acaba por definir direitos básicos a elas relacionados, tais como ter conhecimento de informações pessoais constantes de registros ou bancos de dados de entidades governamentais ou de caráter público, bem como a retificar tais dados. Vale dizer, ainda, que o rol de direitos aqui proposto levou em conta as observações de: BRAIBANT, Guy, Introduction, in VVAA, L'informatique dans l'administration, Paris, Cujas, 1969, p. 13 e Données personnelles et société de l'information, cit., p. 12; FANTIGROSSI, Umberto, op. cit., pp. 23-24; PALOMAR OLMEDA, Alberto, La utilización de las nuevas tecnologías en la actuación administrativa, cit., p. 371; TRUCHE Pierre, FAUGERE, Jean-Paul, FLICHY, Patrice, op. cit., pp. 23-26; VALERO TORRIJOS, Julián, LóPEZ PELliCER, José Antonio, Algunas consideraciones sobre el derecho a la protección de los datos personales en la actividad administrativa, cit., p. 256; e VILlar PAlasí, José Luis, op. cit., p. 510.

${ }^{787}$ Cf. VALERO TORRIJOS, Julián, LÓPEZ Pellicer, José Antonio, Algunas consideraciones sobre el derecho a la protección de los datos personales en la actividad administrativa, cit., p. 260.

${ }^{788}$ Cf. Alamillo DOMINGO, Ignacio, Urios APARISI, Xavier, HenaO HoYOS, Erika, La identidad y la firma electrónica en la participación electrónica, in SÁNCHEZ SÁNCHEZ, Zulima (coord.), Nuevas Tecnologías, Administración y Participación Ciudadana, Granada, Comares, 2010, p. 89. O mesmo texto propõe a minimização da informação, ou seja, a solicitação e armazenamento da mínima quantidade de informação para suportar as transações (cf. p. 90).

${ }^{789}$ Cf. TRUChe Pierre, FAUGERE, Jean-Paul, FLICHY, Patrice, op. cit., p. 65.
} 
quais ela tem realmente direito a receber comunicação ${ }^{790}$. A construção de bases de dados por parte do Estado está sujeita aos princípios da legalidade e da proporcionalidade, assim como às regras de competência constitucional. Os dados devem ser obtidos para uma finalidade legal devidamente declarada, que esteja na esfera de competência da pessoa considerada, na medida adequada e necessária para o atendimento de tais fins ${ }^{791}$. Não é admissível o recolhimento de dados em atendimento a interesses outros, sobretudo para aumentar a vigilância do Estado sobre os cidadãos ${ }^{792}$, nem sua conservação por tempo indeterminado, quando já não persistir a finalidade que justificou seu recolhimento ${ }^{793}$.

Os mesmos critérios devem ser aplicados ao processamento de dados e à sua cessão a outras entidades administrativas. Trata-se de um tema complexo que exige especial atenção do legislador, de maneira a fixar os requisitos, condições e limites segundo os quais tais operações poderiam ser realizadas sem violação dos direitos dos adminis$\operatorname{trados}^{794}$. Tais operações somente devem ocorrer para finalidades legalmente admissíveis, relacionadas à competência da Administração, na medida necessária e adequada para o atendimento de tais fins ${ }^{795}$.

\footnotetext{
${ }^{790}$ Cf. BRAIBANT, Guy, Introduction, cit., p. 13.

${ }^{791}$ PoULLET afirma que o direito de informação das autoridades públicas está sujeito aos princípios da legalidade, da proporcionalidade e da especialidade, entendendo-se este último como a exigência de que a Administração somente registre os dados referentes à missão que lhe foi confiada, devendo a finalidade de cada banco de dados ser claramente exposta (cf. Informatisation et secteur public: de la protection des libertés à la transparence administrative, in Actes du colloque "Informatique et vie privée", Namur, 1 out. 1988, pp. 41-42). Herbert MAISL enfatiza a importância do princípio da finalidade, segundo o qual os dados de caráter pessoal devem ser recolhidos para finalidades determinadas, explícitas e legítimas (cf. De l'administration cloisonnée a l'administration en réseau, cit., p. 352). Ainda sobre observância da finalidade para recolhimento de dados, cf. MARone, Umberto, op. cit., p. 43 e De Terwangne, Cécile, Lobet-MARIS, Claire, Poullet, Yves, op. cit., p. 24.

792 Cf. TRUDEL, Pierre, op. cit., p. 35). A preocupação com a exacerbação dos poderes do Estado em função da acumulação informativa é muito mais presente em países desenvolvidos do que no Brasil. Na Alemanha, por exemplo, a jurisprudência constitucional, a partir da década de 80 do século passado, deu grande ênfase à necesssidade de evitar que o Estado se tornasse um Leviatã faminto por dados pessoais (cf. PITSCHAS, Raines, op. cit., p. 212). Essa atenção em relação ao tema está relacionada à frequente existência de microssistemas jurídicos próprios para a proteção dos dados pessoais nos ordenamentos europeus.

${ }^{793}$ Existe, pois, um princípio da conservação limitada das informações em suporte informático, segundo o qual as informações só devem ser conservadas o tempo necessário para a realização das finalidades pelas quais foram coletadas (cf. TrUCHE Pierre, FAUGERE, Jean-Paul, FliCHY, Patrice, op. cit., p. 101).

${ }^{794}$ Cf. FERnÁndez SAlmerón, Manuel, VAlero TORRIJOS, Julián, Protección de datos personales y Administración electrónica, cit., p. 140.

${ }^{795}$ Cf. De Roy, David, De Terwangne, Cécile, Poullet, Yves, op. cit., p. 347. Mencionando também o princípio da finalidade, aplicado ao tratamento de dados, cf. CANTERO, Anne, op. cit., p. 121.
} 
Sob esse aspecto, a questão mais delicada diz respeito à possibilidade de utilização das informações pessoais em poder da Administração para finalidades diferentes daquelas que nortearam a criação da respectiva base de dados. Neste caso, verifica-se um conflito entre os direitos da pessoa referida por tais dados e o interesse da Administração em maximizar o uso de seu patrimônio informativo, no contexto da sociedade em rede, em que a circulação da informação deixou de ser uma exceção. Dessa forma, o acesso interadministrativo por via telemática coloca-se em uma linha de tensão entre exigências de eficiência e transparência da ação administrativa, de um lado, e de exigência de garantia, do outro ${ }^{796}$.

Como visto, a Lei n. 12.527/11 permite o acesso aos dados pessoais por terceiros - o que decerto inclui os demais órgãos da Administração - diante de previsão legal ${ }^{797}$ ou com a anuência expressa do sujeito referido pela informação. O consentimento é dispensado em casos de tratamento médico, realização de estatísticas, cumprimento de ordem judicial, defesa de direitos humanos e proteção do interesse público e geral preponderante (art. 31, $\S 3^{\circ}$ ), não se aplicando também o sigilo em casos de apurações de irregula-

${ }^{796}$ Cf. GUERRA, Maria Paola, Circolazione dell'informazione e sistema informativo pubblico, cit., p. 531 e VALERO TORRIJOS, Julián, La nueva regulación legal del uso de las tecnologías de la información y las comunicaciones en el ámbito administrativo, cit., pp. 220-222.

${ }_{797}$ A Constituição brasileira traz menção expressa ao compartilhamento de cadastros e informações fiscais das administrações tributárias (art. 37, XXII) na forma da lei ou convênio, previsão semelhante àquela encontrada no Código Tributário Nacional (art. 199). Dois pontos merecem ser observados: primeiro, não se exige lei formal para a disciplina do compartilhamento de dados, sendo admitido também o convênio; segundo, dessa previsão não se pode inferir, a contrario sensu, que seria vedado o compartilhamento de outros dados, sobretudo se este for feito de modo adequado, em vista de uma finalidade legítima ou em benefício do próprio administrado. 
ridades e fatos históricos de maior relevância (art. 31, § $\left.4^{\mathrm{o}}\right)^{798}$. Amplas em excesso, tais previsões podem servir como brecha para abusos, sobretudo quando adotadas visões distorcidas e voluntaristas a respeito do que seria um interesse público preponderante. Na tentativa de diminuir os riscos de tais deformações, é o caso de apresentar algumas considerações a respeito de a respeito de alguns condicionantes, que devem ser aplicados a todas essas hipóteses de acesso a dados pessoais.

O primeiro ponto diz respeito à necessidade da maior transparência possível em relação ao tratamento e cessão de dados pessoais. As pessoas devem conhecer os dados que estão em poder da Administração Pública e quais são objeto de cessão ou tratamento, de maneira a viabilizar o exercício dos direitos pertinentes ${ }^{799}$, inclusive o de oporse a tais operações. Sempre que possível, a pessoa referida por uma informação deve ter conhecimento, desde logo, de que esta poderá ser objeto de tratamento ou transferência a outra entidade pública, devendo-se explicitar a finalidade para a qual isso ocorrerá.

\footnotetext{
${ }^{798}$ Cabe ressaltar que a tendência no direito comparado, em relação à proteção de dados pessoais, é do princípio do consentimento (cf. TRUCHE Pierre, FAUGERE, Jean-Paul, Flichy, Patrice, op. cit., p. 27). Tal princípio é adotado, por exemplo, pelo art. 11 da Lei Orgânica de Proteção de Dados espanhola, segundo o qual a utilização dos dados não deve desviar-se da finalidade original, sendo necessário obter o consentimento da pessoa afetada para proceder a outras operações com esses dados. Sobre a aplicação do principio do consentimento, há vasta literatura naquele país: COTINO HUESO, Lorenzo, Derechos del ciudadano administrado $e$ igualdad ante la implantación de la Administración electrónica, cit., p. 149; FERNÁNDEZ SALMERÓN, Manuel, VALERO TORRIJOS, Julián, La difusión de información administrativa en Internet y la protección de los datos personales: análisis de un proceso de armonización jurídica, cit., p. 321; VALERO TORRIJOS, Julián, El régimen jurídico de la e-Administración, cit., p. 209; VALERO TORRIJOS, Julián, LÓPEZ PELLICER, José Antonio, Algunas consideraciones sobre el derecho a la protección de los datos personales en la actividad administrativa, cit., p. 275. O princípio do consentimento não é, contudo, uma solução universal. O legislador francês, por exemplo, adotou o princípio de ausência de consentimento prévio das pessoas relacionadas a esses tratamentos, sob o fundamento da natureza de serviço público dos tratamentos automatizados feitos pelo Poder Público (cf. CANTERO, Anne, op. cit., p. 123). TRUDEL faz uma contundente crítica ao princípio do consentimento, afirmando que ele, na verdade, decorre de uma extrapolação alarmista da preocupação em evitar a vigilância do cidadão pelo Estado. Segundo o autor, o impedimento à circulação das informações, independentemente de sua importância, acaba por levar à rigidez e à burocratização da atuação administrativa, atribuindo ao usuário o ônus de fornecer informações repetidas vezes ao Poder Público, o qual passa a conviver com a existência de informações redundantes. Assim, o paradigma da vigilância estatal, inspirado no livro 1984, de George Orwell, não se mostra tão pertinente quanto aquele contido em $O$ Processo, de Kafka. Para o autor, mais importante que exigir o consentimento, o que se tornou um fim em si mesmo, é voltar aos fundamentos do princípio da finalidade, assegurando a qualidade das informações utilizadas para servir aos fins almejados, evitando o uso inadequado, incompetente e cego dos dados pessoais (cf. op. cit., pp. 17-29). A lei brasileira adotou solução mais moderada, permitindo a cessão de dados mediante o consentimento do envolvido ou com base em previsão legal, que pode estar contida nas hipóteses da Lei n. 12.527 (art. $31, \S \S 3^{\circ}$ e $4^{\circ}$ ) ou em lei específica (art. $31, \S 1^{\circ}$, II da mesma lei).

${ }^{799}$ Cf. VALERO TORRIJOS, Julián, LÓPEZ PELLICER, José Antonio, Algunas consideraciones sobre el derecho a la protección de los datos personales en la actividad administrativa, cit., p. 278 e VALERO TORRIJOS, Julián, La nueva regulación legal del uso de las tecnologías de la información y las comunicaciones en el ámbito administrativo, cit., pp. 220-222.
} 
Caso a necessidade de tratamento ou transferência, por motivo de interesse público, não seja ainda conhecida no momento da geração da informação, deve ser dada publicidade a respeito de tais operações, evitando que a pessoa interessada seja surpreendida pela utilização de dados para finalidades diferentes daquelas que justificaram seu recolhimento $^{800}$. Essas exigências decorrem do princípio da confiança legítima e são importantes para que o usuário tenha segurança ao fornecer informações ao Poder Público, em razão da garantia de que elas serão objeto dos cuidados devidos ${ }^{801}$. Caso não sejam oferecidas condições que propiciem essa segurança, a própria Administração pode ver-se privada do recebimento de dados que lhe interessam, pois o administrado é desestimulado a oferecêlos, em vista dos possíveis usos a que estariam sujeitos.

O segundo ponto relativo à utilização das informações para finalidade diversa daquela que justificou seu recolhimento diz respeito aos critérios e limites a serem impostos ao tratamento e cessão indiscriminada de dados. Com efeito, as tecnologias atuais permitem que eles sejam trabalhados de maneira maciça, sem ter em vista uma finalidade concreta ou um caso determinado. Em geral, essas situações devem ser vistas como juridi-

\footnotetext{
${ }^{800}$ Há, de fato, uma dificuldade em determinar as finalidades de utilização dos dados em vista da evolução das tecnologias, pois a qualquer momento uma informação coletada para um propósito específico pode ser necessária para um propósito diferente. Isso justifica, no regime francês, a admissibilidade dos tratamentos ulteriores não previstos inicialmente, desde que haja compatibilidade do tratamento ulterior com aquele inicial (cf. De Roy, David, De Terwangne, Cécile, Poullet, Yves, op. cit., pp. 345-346). Nesse sentido, a utilização para um fim incompatível com o original tende a ser considerada como uma violação do princípio da finalidade da obtenção de tais dados (cf., afirmando a necessidade dessa compatibilidade, MAISL, Herbert, De l'administration cloisonnée a l'administration en réseau, cit., p. 352).

${ }^{801}$ Cf. Blasco Díaz, José Luis, Los derechos de los ciudadanos en su relación electrónica con la Administración, cit., p. 814.
} 
camente suspeitas, por extrapolarem os limites decorrentes do princípio da proporcionalidade $^{802}$.

Se há necessidade de obtenção de uma informação em outro órgão público, para a instrução de uma decisão, não é necessário consultar toda a base de dados do órgão, nem é preciso replicá-la por completo. A programação dos sistemas necessários ao tratamento e compartilhamento de dados deve obedecer ao princípio da proporcionalidade, procurando encontrar soluções técnicas que limitem a um mínimo indispensável o compartilhamento do patrimônio informativo público, de forma a evitar um aumento do poder estatal por motivos não vinculados às finalidades públicas ${ }^{803}$. É importante observar que a interconexão de bases de dados impede a verificação, caso a caso, da pertinência do acesso pretendido e da qualidade da informação trocada. Por essa razão, os sistemas informáticos

\footnotetext{
${ }^{802}$ Nesse sentido, “(...) as interconexões generalizadas de bases de dados devem considerar-se uma vulneração do direito fundamental à proteção dos dados de caráter pessoal na medida em que desaparece o controle da finalidade que justificaria o acesso (...)" (VALERO TORRIJOS, Julián, Acceso a los servicios y difusión de la información por medios electrónicos, cit., pp. 277-278 e, do mesmo autor, Implicaciones de la protección de datos de carácter personal para la Administración electrónica, in VVAA, La protección de datos en la Administración Electrónica. Pamplona, Aranzadi, 2009, p. 196.). Aplicando o princípio da proporcionalidade aos tratamentos de dados, cf. De Roy, David, De Terwangne, Cécile, Poullet, Yves, op. cit., p. 346. A Comission Nationale de l'Informatique et des Libertés francesa entendeu inviável proceder a uma interconexão generalizada das bases de dados, por violação ao princípio da finalidade, pois a interconexão levaria a permitir o uso de informações pessoais com qualquer outro propósito (cf. FERNÁNDEZ SALMERÓN, Manuel, VALERO TORRIJOS, Julián, Protección de datos personales y Administración electrónica, cit., p. 137). Sobre o assunto, vale consultar o $24^{\circ}$ Relatório de Atividades, de 2003, produzido pela referida comissão, que reconhece a interconexão como um mecanismo a ser usado em favor do usuário, observados os limites próprios da finalidade e da proporcionalidade (cf., especialmente, a p. 78 do referido relatório, disponível em: http://lesrapports.ladocumentationfrancaise.fr/cgi-bin/brp/telestats.cgi?brp_ref $=044000252 \& b r p \_f i l e=0000$.pdf, acesso em 18.06.2011).

${ }^{803}$ Haveria violação ao princípio da finalidade, por exemplo, se a informação pessoal, oferecida voluntariamente em um requerimento destinado a obter um resultado favorável, fosse depois usada para finalidades também públicas, mas dotadas de uma dimensão gravosa ou restritiva em relação à esfera jurídica do requerente (cf. Fernández SAlmerón, Manuel, VAlero TorRIJOS, Julián, Protección de datos personales y Administración electrónica, cit., p. 129). Observe-se que a necessidade de utilização da informação para várias finalidades públicas está relacionada ao aumento da eficiência administrativa e não pode ser entendida como um mal em si. De outra parte, o cruzamento de dados muitas vezes é necessário para prevenir e coibir fraudes e prejuízos ao erário. Se uma pessoa, por exemplo, declara a um órgão público não possuir renda alguma, para obter uma bolsa de estudos, mesmo tendo emprego e sendo contribuinte do regime de previdência estatal, parece inaceitável que o Estado não possa usar seu patrimônio informatico para detectar tal falsidade. O essencial, contudo, é dar ciência ao usuário a respeito de tais tratamentos de dados. No exemplo apresentado, ao solicitar seu ingresso no regime de previdência, o indivíduo deve saber, desde logo, que a informação a respeito desse fato será levada ao conhecimento das esferas públicas implicadas, sendo assim impeditiva da obtenção de benefícios incompatíveis. A inexistência de uma disciplina clara sobre a matéria certamente oferece insegurança aos usuários, muitas vezes preocupados com o eventual uso indevido de seus dados. É o caso, muito frequente na realidade dos paulistas, das pessoas que preferem não pedir o comprovante fiscal associado ao seu número de contribuinte, por imaginar uma atuação da Administração que possa vir em seu prejuízo.
} 
usados para o relacionamento entre os bancos de dados devem ser objeto de uma programação cuidadosa, que contemple a garantia da qualidade da informação transferida e mecanismos de controle para o acesso automatizado, de forma a impedir abusos ${ }^{804}$.

Por fim, vale considerar a venda, por parte da Administração, dos dados referentes a pessoas determinadas. Trata-se da reutilização da informação pública, tema sensível que tem sido muito discutido na Europa. Em tese, a Administração Pública poderia reaproveitar as informações de maneiras diferentes, comercializando-as de modo direto ou permitindo sua reutilização e exploração comercial por meio de terceiros ${ }^{805}$. De fato, tendo em vista o valor da informação como mercadoria ${ }^{806}$, sua comercialização é capaz de proporcionar receitas para o Poder Público e contribuir para o aumento da eficiência dos atores econômicos privados, em vista da disponibilidade de dados sobre seus possíveis clientes. Além disso, a definição de critérios transparentes para tal venda poderia assegurar que o acesso fosse feito de modo regular e isonômico, o que poderia contribuir para evitar a prática de acessos ilegais.

No entanto, a matéria é bastante polêmica, pois a comercialização de dados não parece exatamente compatível com a finalidade que justificou seu recolhimento, sendo questionável em que medida ela pode ser considerada um prolongamento da missão de serviço público da Administração Pública ${ }^{807}$. Assim, é impossível enquadrá-la até mesmo nas amplas hipóteses do art. $31, \S \S 3^{\circ}$ e $4^{\circ}$, da Lei n. $12.527 / 11$, não havendo fundamento legal que a autorize. De outra parte, para que a comercialização de dados pudesse ser admitida com base em outra lei, nos termos do inciso II do $\S 1^{\circ}$ do art. 31 do referido diploma normativo, seria necessário proceder a uma criteriosa avaliação de quais informações poderiam ser veiculadas, por meio de uma ponderação entre o direito de intimidade e as vantagens decorrentes da exploração do patrimônio informativo público, pois não se

\footnotetext{
${ }^{804}$ Cf. VALERO TORRIJOS, Julián, El régimen jurídico de la e-Administración, cit., pp. 208-209.

${ }^{805}$ Cf. CERRILlo i MARTínEZ, Agustí, La información del sector público, cit., p. 9. Neste caso, eventual conflito com a intimidade não se dá diretamente em relação a esses terceiros, que apenas obtiveram as informações, e sim em relação à Administração, que as forneceu. O tema é regulado, em âmbito europeu, pela Diretiva n. 2003/98/CE do Parlamento Europeu e do Conselho, relativa à reutilização de informações no setor público (cf. http://eur-lex.europa.eu/LexUriServ/LexUriServ.do?uri=OJ:L:2003:345:0090:0096:PT:PDF).

${ }^{806}$ Cf. VALERO TORRIJOS, Julián, El acceso telemático a la información administrativa, cit., p. 50.

${ }^{807}$ Cf. Poullet, Yves, Informatisation et secteur public, cit., p. 42.
} 
pode reconhecer ao legislador a competência para autorizar a cessão e divulgação indiscriminada das informações pessoais, à margem dos fundamentos constitucionais da matéria $^{808}$.

\subsubsection{A proteção da intimidade em relação a terceiros}

Outro problema são os chamados excessos de transparência ${ }^{809}$, verificados em razão do incremento da publicidade de dados pessoais e de seu tratamento por terceiros, inclusive de modo automatizado ${ }^{810}$, que podem levar, com alguma facilidade, à elaboração de um perfil completo a respeito de uma pessoa - a chamada radiografia do indi$v_{i ́ d u o}^{811}$-, sem seu conhecimento. Isso pode ocorrer tanto em razão da informação privada revelada de modo involuntário e inadvertido por ocasião da utilização da internet ${ }^{812}$, quanto a partir das informações constantes de bases de dados públicas, caso estas estejam indefesas no âmbito do sistema informático público ou sejam oferecidas pela própria Adminis$\operatorname{tração~}^{813}$.

Fosse aplicado de modo literal o disposto no art. 31 da Lei n. 12.527/11, caso não houvesse expressa previsão legal para tanto, a Administração não poderia publicar informação alguma que fizesse referência aos nomes daqueles que com ela se relacio-

\footnotetext{
${ }^{808}$ Nos Estados Unidos da América, o Freedom of Information Act permite a difusão comercial da informação pública (cf. CERRILlo I MARTINEZ, Agustí, La información del sector público, cit., p. 9).

${ }^{809}$ Cf. Fernández Salmerón, Manuel, PARra SÁez, Samuel, VAlero Torrijos, Julián, Crónica del año 2009 , cit., p. 151.

${ }^{810}$ Cf. FernándeZ SALMERón, Manuel, VAlero TorRiJos, Julián, Protección de datos personales y Administración electrónica, cit., p. 119.

${ }^{811}$ Cf. DUNI, Giovanni, L'amministrazione digitale, cit., p. 80. Ainda sobre o tema, cf. PALOMAR OLMEDA, Alberto, La utilización de las nuevas tecnologías en la actuación administrativa, cit., p. 369. Fala-se, neste caso, na chamada teoria do mosaico, pela qual os dados irrelevantes, a partir da interconexão de arquivos e da livre utilização dos dados, podem servir a uma finalidade diferente e, portanto, proporcionar referências completas sobre uma determinada pessoa (cf. CASTELLS ARTECHE, José Manuel, La limitación informática, cit., p. 924).

${ }^{812}$ Cf. VALERo ToRriJos, Julián, LóPEZ Pellicer, José Antonio, Algunas consideraciones sobre el derecho a la protección de los datos personales en la actividad administrativa, cit., p. 258.

${ }^{813}$ Cf. DUNI, Giovanni, L'amministrazione digitale, cit., p. 80.
} 
nam, apenas pelo fato de se tratar de um dado de caráter pessoal (art. $4^{\circ}$, IV), que estaria protegido pelo sigilo estabelecido (art. 31), pois não há, como visto, uma distinção legal entre os diversos tipos de informação pessoal e suas diferentes necessidades de tutela. Todavia, não constitui entendimento equilibrado vedar a publicidade de qualquer dado que possa ser relacionado a uma pessoa, pois há muitas hipóteses em que a divulgação de informações de interesse coletivo envolve alguma menção aos nomes dos envolvidos. Tampouco seria apropriado que uma lei estabelecesse a publicação indiscriminada de dados de caráter pessoal, sem atenção para os mecanismos necessários para diminuir o potencial lesivo à intimidade e à vida privada.

Na verdade, uma boa compreensão dessa problemática envolve a consideração de vários aspectos sutis relativos à publicidade das informações pessoais, sobretudo aquelas que não devem excluir, de modo absoluto, o conhecimento por terceiros. A chave é ter em mente, diante do contexto tecnológico contemporâneo, que a publicidade administrativa deve servir para finalidades de interesse público, e não para a divulgação indireta de informações que possam ser usadas para satisfazer meros interesses privados.

Com efeito, nos mecanismos de acesso tradicionais, as informações são fornecidas pontualmente aos interessados, quando estes se dirigem à Administração para consultar expedientes e obter certidões, ou são oferecidas de modo amplo, mediante publicações oficiais. Embora seja possível, em tese, a utilização de tais informações para finalidades ilegítimas, isso só pode ser feito com muito custo, pois há a necessidade de um trabalho humano para a extração das informações a partir de documentos em papel. O fornecimento de informações por meios eletrônicos elimina esses impedimentos e traz novos contornos para o assunto. De fato, a publicação de dados pessoais pela internet não se mostra tão inofensiva: estando em suporte eletrônico, eles podem ser objeto das referidas operações de processamento, colocando em perigo a intimidade e a esfera privada das pessoas envolvidas.

A problemática é perceptível, por exemplo, na publicação de atos administrativos. Sem dúvida, o direito ao conhecimento das decisões da Administração deve ser considerado fundamental em qualquer Estado democrático e não há dúvida de que esse 
direito pode ser satisfeito por meio do uso das novas tecnologias ${ }^{814}$. No entanto, na realidade atual, mesmo a difusão do conteúdo de atos administrativos por meio da internet pode trazer alguns inconvenientes sob a perspectiva da proteção de dados pessoais ${ }^{815}$, pois, com a ajuda de potentes e gratuitos motores de pesquisa hoje disponíveis, é fácil localizar informações associadas a pessoas determinadas $-v . g$., atos restritivos de direitos ou puniti$\operatorname{vos}^{816}$.

No contexto das novas tecnologias, não se pode presumir que o acesso à informação tenha sempre uma finalidade legítima, relacionada aos direitos inerentes à cidadania. Com a possibilidade de tratamento automático de dados por particulares, a baixo custo, é bastante provável que o acesso a uma informação pública não decorra de um interesse em exercer direitos de cidadania, mas do propósito de cometer verdadeiros atos ilícitos que afrontam a privacidade e a intimidade. Também não é possível deixar de considerar a situação, frequente nos dias atuais, de que o acesso seja feito por mera curiosidade, muitas vezes dirigida justamente sobre a esfera privada alheia, e não em razão de objetivos mais nobres. Em qualquer dos casos, os desvios associados à difusão de informação por meios informáticos têm repercussões muito mais amplas do que aqueles verificados quando usados os meios tradicionais.

Para evitar tais desvios, é necessário avaliar não somente se uma informação deve ser publicada, mas em que condições e em que suporte ${ }^{817}$. A publicidade de dados detidos pelo Poder Público oferece alguma complexidade, pois há diferentes mecanismos para tal, com características diversas. Com efeito, mesmo tendo em conta apenas a informação publicada com o uso da internet, há diversas situações, que não podem ser consideradas juridicamente equivalentes. De fato, existe uma grande diferença entre a informação divulgada de modo indiscriminado, sem limitação alguma de acesso, e a informação oferecida mediante solicitação pontual ou com algum mecanismo de controle. No primeiro caso, a informação está sujeita a captura mediante os motores de busca disponíveis na pró-

\footnotetext{
${ }^{814}$ Cf. CAMmarata, Manlio, E-content e accesso: le libertà fondamentali nel Codice dell'amministrazione digitale, in Informatica e diritto, n. 1/2, Napoli, Edizioni Scientifiche Italiane, 2005, p. 99.

${ }^{815} \mathrm{Cf}$. VALERO TORRIJOS, Julián, El régimen jurídico de la e-Administración, cit., p. 150.

${ }^{816}$ Cf. VALERO TORRIJOS, Julián, Las garantías jurídicas en la Administración electrónica, cit., p. 25.

${ }^{817}$ Cf. PIÑAR MAÑAS, José Luis, op. cit., p. 86.
} 
pria internet, sendo possível considerar a existência de uma publicidade de segundo grau, que torna a informação muito mais fácil de localizar e facilita, por outro lado, que ela seja utilizada para fins abusivos ${ }^{818}$.

É necessário garantir a difusão da informação e, ao mesmo tempo, impedir ou ao menos dificultar o recolhimento automatizado de dados pessoais ${ }^{819}$. Ainda que utilizados meios eletrônicos, o acesso pontual, referido a uma informação determinada, em especial quando dotado de mecanismos de segurança informática, não difere daquele efetuado sem o uso da tecnologia. Já o acesso automatizado, que proporciona a replicação completa de bases de dados públicas, deve ser visto com cuidado. Caso contrário, corre-se o risco de ter em mãos de particulares bases de dados pessoais copiadas daquelas construídas pelo Estado mediante o exercício dos poderes que lhe são inerentes ${ }^{820}$.

Nessa perspectiva, devem ser consideradas relevantes, sob o prisma jurídico, realidades aparentemente restritas à informática, como os mecanismos de controle de consultas automatizadas, a possibilidade de utilização de motores de busca dentro de portais eletrônicos da Administração Pública e o oferecimento de informações apenas mediante consulta pontual, e não por publicação ampla no portal. A correta utilização de tais mecanismos é fundamental para impedir que as informações detidas pelo Poder Público sejam utilizadas de modo indevido por particulares. Por outro lado, é preciso ver com cautela os

\footnotetext{
${ }^{818}$ É possível afirmar que a informação oferecida na internet, capturável por meio dos motores de pesquisa, oferece um nível de publicidade até agora desconhecido. Esse forma de divulgação facilita bastante a localização de informações relevantes e pode ser considerada até mesmo superior ao que seria necessário para a defesa de direitos. Ao mesmo tempo, traz riscos muito maiores. Em circunstâncias tecnológicas tão diferentes, simplesmente não é possível aproveitar as conclusões alcançadas no confronto entre publicidade administrativa e privacidade no âmbito da administração em papel. É preciso fazer uma nova avaliação, que leve em conta a realidade contemporânea, para identificar precisamente em que medida é possível veicular informações pela internet, sobretudo informações atribuíveis a pessoas determinadas que possam ser encontradas por meio de motores de pesquisa.

${ }^{819}$ Cf. FERNÁNDEZ SALMERÓN, Manuel, VALERo TORRIJos, Julián, La publicidad de la información administrativa en internet, cit., p. 82.

${ }^{820}$ Por essa razão, o paradigma dos dados abertos, que defende a difusão pública de informação apta ao tratamento automatizado, não alcança os dados pessoais, mas apenas as informações de acesso indiscriminado (cf. supra, nota 741). Nesse sentido, os formatos e exigências técnicas prescritas para os dados de interesse coletivo e geral (art. $8^{\circ}, \S 3^{\circ}$ da Lei n. 12.527/11) não se aplicam aos dados pessoais, que gozam de um nível diferente de proteção.
} 
pedidos que tenham por objeto não um acesso a uma informação específica, mas um conjunto de informações, tal como uma consulta ampla às bases de dados da Administração ${ }^{821}$.

A identificação de pessoas concretas nas informações administrativas objeto de publicidade não deve ser algo generalizado, cabendo restringi-la às situações em que o conhecimento dessa identidade seja necessário para o exercício de um direito ou interesse legítimo ${ }^{822}$. Se o conhecimento da informação não é determinante para a defesa dos direitos ou interesses legítimos de quem pretende conhecê-la, não é justificado sacrificar a privacidade $^{823}$. Ressalte-se, a propósito, que a veiculação de informações pessoais pela internet - ou mediante publicações oficiais acessíveis por ela - deve ser evitada tanto quanto possível, em especial se a informação for passível de pesquisa tendo como critério de busca o próprio nome da pessoa ${ }^{824}$. Caso possível tal pesquisa, a tendência natural é que a publicidade administrativa constitua um modo de proporcionar a indevida interferência sobre a esfera privada da pessoa referida pela informação publicada. Sempre que a divulgação dos nomes das pessoas envolvidas não for necessária para dar transparência à atuação da Administração e para o exercício de direitos ${ }^{825}$, sua divulgação por meio da internet

\footnotetext{
${ }^{821}$ Neste caso, é importante considerar qual seria o objetivo concreto da solicitação, de forma a identificar se o requerente ostenta de fato algum propósito relacionado à defesa do interesse público ou se pretende, simplesmente, apropriar-se do patrimônio informativo público. Cf., tratando de dados pessoais, FERNÁNDEZ SALMERÓN, Manuel, VALERO TORRIJOS, Julián, La publicidad de la información administrativa en internet: implicaciones para el derecho a la protección de los datos personales, cit., p. 89. Os mesmos autores trazem um exemplo enfrentado pela Justiça espanhola, em que foi denegado o acesso aos números das matrículas e cargas de todos os veículos que constavam dos registros da autoridade de tráfego em nome de uma determinada pessoa jurídica (cf. ibidem, p. 90).

${ }^{822}$ Cf. FernÁNDEZ SAlMERÓn, Manuel, VAlero ToRriJos, Julián, La publicidad de la información administrativa en internet, cit., p. 121 e, dos mesmos autores, La difusión de información administrativa en Internet y la protección de los datos personales, cit., p. 329.

${ }^{823}$ Cf. VALERO TORRIJOS, Julián, El acceso telemático a la información administrativa, cit., p. 40. No ordenamento brasileiro, em função do princípio da impessoalidade, a publicidade deve ser feita, tanto quanto possível, sem alusão a pessoas específicas. Do mesmo princípio deve decorrer uma espécie de presunção de que a informação referente a pessoas determinadas não é a mais relevante, quando se trata da difusão informativa. Pode surgir a necessidade de divulgação de nomes, conforme as características de cada caso, porém isso não deve ser visto como aspecto essencial do direito de informação.

${ }^{824}$ Trata-se de uma situação muito frequente, na prática, no caso de publicação de ato administrativo por meio da internet ou por publicação oficial disponível on line. A respeito da publicação de atos administrativos como meio para veiculação de dados de caráter pessoal, cf. FeRNÁNDEZ SALMERÓN, Manuel, VALERO TORRIJOS, Julián, La publicidad de la información administrativa en internet, cit., p. 115.

${ }^{825}$ Existem situações em que é indispensável oferecer informação específica ao cidadão a respeito de servidores, como é o caso de quando é preciso contatar uma pessoa específica (cf. FERNÁNDEZ SALMERÓN, Manuel, VALERO TORRIJOS, Julián, La publicidad de la información administrativa en internet: implicaciones para el derecho a la protección de los datos personales, cit., p. 122 e La difusión de información administrativa en Internet y la protección de los datos personales, cit., p. 329).
} 
não pode ser admitida ${ }^{826}$, porque o risco de prejuízos à intimidade não seria acompanhado de benefício significativo para a transparência, levando a uma violação do princípio da proporcionalidade $^{827}$. Observe-se que as tecnologias oferecem alternativas bastante interessantes em tais casos, como, por exemplo, a publicação das informações na internet com nomes fictícios e aleatórios, sem prejuízo de que a revelação das verdadeiras identidades ocorra mediante uma solicitação pontual de acesso por parte de eventual interessado.

O regime jurídico relativo à difusão de informações inclui também a definição de responsabilidades por eventuais abusos. Observe-se, a propósito, que a simples possibilidade de utilização indevida da informação não justifica um tratamento apenas preventivo da matéria, sendo necessário organizar mecanismos eficazes de sanção a tais abu$\operatorname{sos}^{828}$. A responsabilidade última pelas condições e pressupostos jurídicos que habilitam o acesso cabe exclusivamente a quem o permite ${ }^{829}$. No entanto, o simples fato de os dados terem sido publicados pela Administração Pública por meio de uma fonte acessível ao público não autoriza que eles possam ser empregados para qualquer finalidade, sem maiores

\footnotetext{
${ }^{826}$ No exercício de tal tarefa, as agências de proteção de dados europeias criaram uma doutrina que exige a aplicação de técnicas compatibilizadoras, entre as quais sobressai a "anonimização", muito frequente em países como Itália e França (cf. Fernández SAlmerón, Manuel, PARra SÁeZ, Samuel, VAlero TorRiJos, Julián, Crónica del año 2009, cit., p. 154).

${ }^{827}$ Uma situação interessante diz respeito à possibilidade de que informações relacionadas a uma pessoa sejam publicadas na internet, na condição de parte integrante de um ato administrativo - por exemplo, um ato sancionador referente a uma conduta que possa causar algum constrangimento moral à pessoa considerada. Caso a informação veiculada pela internet esteja sujeita a ser encontrada por um motor de pesquisa, em função do nome da pessoa, a publicidade acaba por extrapolar seus propósitos legítimos, relacionados ao controle da regularidade dos atos administrativos, servindo apenas para levar ao conhecimento de terceiros, a título de curiosidade, dados relacionados à vida privada de uma pessoa específica, o que motivaria um eventual pedido de reparação desses danos. Neste caso, três seriam, em tese, os possíveis responsáveis pelo dano: a Administração, a imprensa oficial e o titular do motor de pesquisa. Não seria propriamente absurdo considerar que o dano só ocorreu em função da existência do motor de pesquisa, que permitiu localizar a informação danosa em função do nome do envolvido. Todavia, esse entendimento não parece adequado em vista do contexto em que vivemos, no qual os motores de busca se tornaram uma realidade inafastável, ferramenta que é usada, de forma neutra, por quem está à procura de uma determinada informação. Nesse sentido, a publicação de qualquer informação deve ser feita com os cuidados próprios desse contexto tecnológico: sendo possível a pesquisa por nomes ou palavras, ela provavelmente ocorrerá. A publicação de atos vinculados a nomes pode ser entendida como necessária e lícita, mas é preciso que a entidade incumbida da publicação na internet utilize as práticas tecnológicas adequadas para evitar a utilização de motores de busca para localização de informações em função dos nomes das pessoas envolvidas. Sobre a questão, com entendimento semelhante, cf. VALERO TORRIJOS, Julián, Implicaciones de la protección de datos de carácter personal para la Administración electrónica, in VVAA, La protección de datos en la Administración Electrónica. Pamplona, Aranzadi, 2009, p. 183.

${ }_{828}$ Cf. TRUDEL, Pierre, op. cit., p. 49.

${ }^{829}$ Cf. VALERO TORRIJOS, Julián, Acceso a los servicios y difusión de la información por medios electrónicos, cit., p. 274.
} 
exigências e limitações ${ }^{830}$. Assim, a inclusão de dados pessoais em diários oficiais não permite, de modo generalizado, que essa informação possa ser tratada para qualquer finalidade, muito menos se esta se mostrar incompatível com o propósito que justificou sua inclusão em tal publicação ${ }^{831}$.

\subsubsection{Responsabilidade patrimonial pela atuação por meios eletrônicos}

Outra garantia essencial, a ser observada pelo governo eletrônico tanto quanto pela administração em papel, diz respeito à responsabilidade por danos causados a terceiros. Com efeito, a atuação da Administração Pública por meios eletrônicos, como qualquer atividade pública, está inteiramente sujeita à responsabilidade patrimonial. Embora o anonimato da máquina possa provocar no usuário a impressão de estar diante de um aparato impenetrável que foge a qualquer censura ${ }^{832}$, a atividade administrativa efetuada com o uso de meios eletrônicos é plenamente imputável à Administração Pública, que deve responder por eventuais danos causados ${ }^{833}$. Assim, por exemplo, deve ser reconhecida a responsabilidade patrimonial por danos causados por erros, inexatidões e falta de atualização da informação pública oferecida ao cidadão pela Administração ${ }^{834}$.

Tal garantia é ainda mais essencial em vista do contexto de mudança em que ocorre a introdução das novas tecnologias. Sem responsabilidade da Administração

\footnotetext{
${ }^{830}$ Cf. FERnÁNDEZ SALMERÓN, Manuel, VALERo TORRIJOS, Julián, La publicidad de la información administrativa en internet, cit., p. 103.

${ }^{831}$ Cf. FERNÁNDEZ SALMERÓN, Manuel, VALERO TORRIJOS, Julián, La difusión de información administrativa en Internet y la protección de los datos personales, p. 328 e La publicidad de la información administrativa en internet, cit., p. 119.

${ }^{832}$ Cf. MASUCCI, Alfonso, Il documento amministrativo informatico, cit., p. 37.

833 Cf. CASTELls ARTECHE, José Manuel, Aproximación a la problemática de la informática y administración pública, cit., p. 53.

${ }^{834}$ Cf. Cotino Hueso, Lorenzo, Derechos del ciudadano, cit., p. 215.
} 
não é possível confiança na utilização das novas tecnologias, o que poderia diminuir a adesão das pessoas aos serviços em meio digital ${ }^{835}$.

A responsabilidade administrativa deve ser entendida como uma responsabilidade tecnológica, relacionada ao funcionamento das máquinas utilizadas pela Administração Pública ${ }^{836}$. Isso é compatível com o regime de responsabilidade objetiva, adotado no Brasil, o qual impõe o dever de indenizar o dano apenas em razão da realização da atividade, não exigindo demonstração de culpa pelo dano ${ }^{837}$. Mesmo assim, sobretudo para efeito de direito de regresso, é preciso levar em conta que o computador é desprovido de capacidade de iniciativa e decisão, não podendo ter nenhuma responsabilidade ${ }^{838}$. Em caso de falha nos sistemas informáticos, deve ser avaliada sua imputabilidade a uma pessoa física $^{839}$, que deverá ressarcir a Administração por eventuais danos a terceiros nos casos de dolo ou culpa.

É bastante possível, contudo, que o caminho da responsabilidade não seja uma solução eficaz para situações de mau funcionamento de meios informáticos, pois o maior interesse do usuário é não ter problemas de espécie alguma, vendo simplesmente efetivado o seu direito. Além disso, na maioria das vezes, os danos tendem a ser de pequenas proporções, o que não justificaria o ajuizamento de uma ação judicial. É o caso, por exemplo, de um portal que fica indisponível por alguns minutos, de uma remissão que encaminha para a página errada da internet ou de um tempo de resposta ligeiramente maior que o esperado. São aspectos relacionados à qualidade do serviço, que, por suas características específicas, não são atendidos de modo adequado pela responsabilidade patrimonial da Administração. Isso não significa, contudo, que deixem de merecer atenção por parte do legislador, dos operadores do direito e dos estudiosos que se ocuparem da matéria, pois os pequenos erros, quando atingem um grande número de pessoas, precisam ser vistos como

\footnotetext{
${ }^{835}$ Cf. MARTín DELGADO, Isaac, La administración electrónica como reto del derecho administrativo en el siglo XXI, cit., p. 332.

${ }^{836}$ Cf. FrosinI, Vittorio, Informática y Administración Pública, cit., p. 454.

${ }^{837}$ Os danos causados pela atuação automatizada têm trazido maiores discussões nos ordenamentos que adotam a responsabilidade subjetiva. Analisando a questão, cf. CONTALDO, Alfonso, GORGA, Michele, op. cit., p. 196.

${ }^{838}$ Cf. ibidem, p. 454.

${ }^{839}$ Cf. Contaldo, Alfonso, Gorga, Michele, op. cit., p. 192 e VALERo Torrijos, Julián, Administrative Law and eGovernment, cit., p. 47.
} 
um problema de grande repercussão. A falta de litigiosidade judicial não deve disfarçar a existência de tal problema, muito menos as preocupações de caráter jurídico que o caracterizam.

Outro ponto importante a ser considerado, no âmbito da nova realidade informática, diz respeito à apuração do nexo causal, que tende a trazer diferenças em relação às posições mais consolidadas em matéria de responsabilidade patrimonial do Estado. $\mathrm{O}$ assunto tende a ser objeto de algum amadurecimento conforme a casuística que vier a ser submetida aos tribunais. Contudo, há situações que já começaram a ser identificadas pela doutrina, como, por exemplo, a limitação da responsabilidade patrimonial aos danos provocados por informações que têm origem na própria Administração, não alcançando situações em que esta tem apenas a condição de intermediária, apenas transferindo a informação oferecida por terceiros ${ }^{840}$.

Por fim, vale mencionar a total ineficácia das cláusulas de exclusão de responsabilidade, que se tornaram uma prática universal nos portais públicos ${ }^{841}$. Por meio dessas cláusulas, a Administração simplesmente se exonera de todas as consequências relacionadas à possível inexatidão da informação que se consulte ${ }^{842}$. A responsabilidade patrimonial do Poder Público não pode ser afastada por uma declaração unilateral, feita com o objetivo de transferir ao usuário o risco tecnológico decorrente da prestação do serviço por meios eletrônicos. Ademais, a veiculação de informações não pode ser tratada com tal falta de seriedade na Administração Pública contemporânea: se as informações foram oferecidas em um portal, mediante o emprego de recursos públicos, os usuários tendem a tomá-las por verdadeiras, não sendo possível admitir que tenham sido publicadas em caráter oficioso, experimental ou precário. Isso violaria não apenas o princípio da confiança legítima, mas o disposto no art. $7^{\circ}$ da Lei n. 12.527/11, segundo o qual o direito de acesso se refere a informação primária, íntegra, autêntica e atualizada (inc. IV).

\footnotetext{
${ }^{840}$ Cf. CERrillo i MARTÍNEZ, La difusión de información pública en internet, cit., pp. 32 e 35.

${ }^{841}$ Cf. MARTíneZ GutiérReZ, Rubén, Administración Pública Electrónica, cit., p. 230 e JinestA LOBO, Ernesto, op. cit., p. 10.

${ }^{842} \mathrm{Cf}$. VALERO TORRIJOS, Julián, Acceso a los servicios y difusión de la información por medios electróni$\cos$, cit., p. 256.
} 


\subsection{A interoperabilidade entre os sistemas informáticos}

$\mathrm{Na}$ linha do tradicional isolamento entre os diversos órgãos e entidades públicas $^{843}$, a introdução da informática na Administração Pública iniciou-se com a utilização da tecnologia em setores específicos, para o aperfeiçoamento de rotinas de trabalho relativamente circunscritas. Nesse modelo, os dados eram de acesso restrito, em diferentes sistemas departamentais, sem que houvesse uma visão global das informações detidas pelo Poder Público ${ }^{844}$.

Com o progressivo desenvolvimento da telemática, passou a ficar cada vez mais claro que a verdadeira utilidade de um sistema informático não reside em seu uso isolado, mas em sua capacidade de compartilhar a informação com outros aplicativos e sistemas, aumentando de modo exponencial seus resultados ${ }^{845}$. Nesse sentido, ganhos significativos de eficiência só podem ser alcançados mediante um maior compartilhamento de $\operatorname{dados}^{846}$, o que depende da superação do modelo de atuação fragmentado e da melhoria do relacionamento entre os diversos órgãos e entidades públicas ${ }^{847}$. Essa integração é uma das características mais inovadoras do governo eletrônico ${ }^{848}$.

$\mathrm{Na}$ atividade administrativa tradicional, a remessa de dados entre órgãos e entidades administrativas é necessária ${ }^{849}$ e frequente, porém resta limitada em razão da dependência de uma comunicação intermediada por seres humanos. Com efeito, cabe ao órgão interessado solicitar a outro a remessa de uma informação, devendo este analisar a

\footnotetext{
${ }^{843}$ Sobre tal isolamento, cf. MARTínEz GuTIÉRREZ, Rubén, Administración Pública Electrónica, cit., p. 219.

${ }^{844}$ Cf. Holmes, Douglas, op. cit., p. 59.

${ }^{845}$ Cf. GAMERO CASADO, Eduardo, Interoperabilidad y administración electrónica: conéctense, por favor, in Revista de Administración Pública, n. 179, Madrid, Centro de Estudios Políticos y Constitucionales, mai.ago. 2009, pp. 292-293.

${ }^{846}$ Cf. OCDE, op. cit., p. 24. Por essa razão, o impulso em favor do governo eletrônico vem geralmente das estruturas que dependem de maior integração horizontal das entidades públicas, as quais encontram dificuldades devido à falta de diálogo entre os diversos atores envolvidos (cf. BOMBARDELLI, Marco, op. cit., p. 1009).

${ }^{847}$ Cf. CERRILlO I MARTÍNEZ, La interoperabilidad y la protección de datos. La interconexión de los registros de protección de datos, in VVAA, La protección de datos en la Administración Electrónica, Pamplona, Aranzadi, 2009, p. 24 e CANTERO, Anne, op. cit., p. 405.

${ }^{848}$ Cf. ARENA, Gregorio, op. cit., p. 429.

${ }^{849}$ Cf. VALERO TORRIJOS, Julián, El régimen jurídico de la e-Administración, cit., p. 206.
} 
possibilidade de atendimento ao pedido; em caso positivo, envia-se a informação. Em vista dessas limitações práticas, e dada a divisão de responsabilidades entre os diversos órgãos administrativos, gera-se um considerável ônus para os administrados, por vezes obrigados a realizar uma série de solicitações sucessivas em diferentes repartições públicas, com o propósito de obter resultados materialmente únicos ${ }^{850}$, como é o caso de construir uma edificação ou abrir uma empresa.

No governo eletrônico, o compartilhamento de informação - que pode referir-se a uma informação específica ou a um amplo conjunto de dados - ocorre de modo automatizado, ou seja, por meio do relacionamento entre os sistemas informatizados, devidamente programados de acordo com critérios de compartilhamento das informações, pelos quais estas são tornadas disponíveis ${ }^{851}$. Com a melhoria na coordenação entre os sujeitos públicos envolvidos, a atuação administrativa torna-se mais eficiente ${ }^{852}$, o que se reflete na qualidade do atendimento ao administrado.

Nesse contexto é que surge como essencial, para a Administração Pública, o conceito de interoperabilidade. Tal conceito corresponde à capacidade dos sistemas informáticos de se relacionar mutuamente, o que lhes permite compartilhar e trocar infor-

\footnotetext{
${ }^{850}$ Cf. BERNADí GIL, Xavier, op. cit., p. 225.

${ }^{851}$ Cf. Duni, Giovanni, L'amministrazione digitale, cit., p. 66. Assim, deve ocorrer o acesso remoto, por um sistema, à informação residente em outro, sem efetuar uma cópia de tal informação, diferentemente do que ocorreria se houvesse uma troca de mensagens entre os órgãos. A cópia das informações contidas em sistemas públicos - especialmente por meio de correio eletrônico - pode ser feita facultativamente, até mesmo em papel, mas não deve fazer parte do expediente eletrônico, por não constituir uma boa prática de gestão (cf. DuNI, Giovanni, I "viaggi telematici" dell'atto informatico, cit., p. 3). A informação copiada é inútil e serve apenas para provocar confusão e dificuldade de gestão nos procedimentos (cf. ibidem, p. 1), podendo ocorrer até mesmo que a informação copiada seja inexata, pelo fato de não ser atualizada cotidianamente, como ocorre com a base de dados originária. A mesma razão recomenda evitar a duplicação de todo o banco de dados para entrega a outra entidade administrativa, mera usuária e não produtora de informações, solução adotada com frequência (cf. DUNI, Giovanni, L'amministrazione digitale, cit., p. 66). Além disso, deve-se considerar que, em regra, o acesso pontual à informação está menos sujeito a questionamento quanto à violação da proporcionalidade, ao passo que a cessão completa de uma base de dados muitas vezes extrapola os limites da possibilidade informativas do Estado, pela transferência de informação além do que seria necessário (cf. supra, item 2.4.5.1).

${ }^{852}$ Cf. BOMBARDELLI, Marco, op. cit., pp. 1015-1016.
} 
mações de forma útil ${ }^{853}$. A interoperabilidade é o desafio mais importante que se apresenta para a gestão administrativa na atualidade ${ }^{854}$, podendo ser considerada uma das pedras angulares do êxito do governo eletrônico ${ }^{855}$. Por meio dela, é possível economizar quantidades incalculáveis de tempo e dinheiro para a Administração Pública e para os cidadãos ${ }^{856}$, ao permitir a utilização da informação e de aplicativos para diferentes finalidades ${ }^{857}$, a tramitação de processos complexos e a integração de serviços em que intervenham vários órgãos ou entidades ${ }^{858}$. Com a interoperabilidade entre os sistemas, a tecnologia passa a ser vista como um instrumento que serve para unificar, e não para desconectar, as estruturas organizacionais do governo ${ }^{859}$.

Trata-se, contudo, de um grande desafio, que exige esforços em três diferentes níveis conhecidos como dimensões da interoperabilidade ${ }^{860}$, que se encontram inevitavelmente entrelaçadas e devem realizar-se de modo simultâneo para atingir a interoperabilidade plena ${ }^{861}$. A interoperabilidade organizativa está relacionada à coordenação e ao alinhamento dos processos administrativos ou empresariais e das estruturas de informação que ultrapassam os limites das organizações envolvidas, de forma a permitir a obtenção de resultados mutuamente acordados, tais como a fusão dos processos das diferentes organizações $^{862}$. A interoperabilidade técnica envolve os aspectos próprios da relação entre sistemas informáticos, que se articulam, por exemplo, por meio da fixação de tecnologias,

\footnotetext{
${ }^{853}$ Sobre o conceito de interoperabilidade, cf., entre muitos, CERRILLO I MARTÍNEZ, La interoperabilidad y la protección de datos, cit., pp. 30-31; GAMERO CASADO, Eduardo, Interoperabilidad y administración electrónica, cit., p. 292; IASELLI, Michele, op. cit., p. 60; MARTÍN DELGADO, Isaac, Identificación y autenticación de los ciudadanos, in GAMERO CASADO, Eduardo, VALERO TORRIJOS, Julián (coord.), Comentarios a la Ley de Administración electrónica - Ley 11/2007, de 22 de junio, de acceso electrónico de los ciudadanos a los servicios públicos, 1. ${ }^{a}$ ed., 2. a imp., Cizur Menor (Navarra), Thomson-Civitas, 2009, p. 356.

${ }^{854}$ Cf. GAMERO CASADO, Eduardo, Interoperabilidad y administración electrónica, cit., p. 294.

${ }^{855}$ Cf. CANTERo, Anne, op. cit., p. 404. No mesmo sentido, Oller Rubert, Marta, op .cit., p. 57. Falando em integração, cf. AIBAR PUENTES, Eduard, op. cit., p. 29. Vale observar que a interoperabilidade não é um atributo exclusivo dos sistemas informáticos da Administração Pública, sendo também um objetivo nas organizações privadas.

${ }^{856}$ Cf. GAMERO CASADO, Eduardo, Interoperabilidad y administración electrónica, cit., p. 293.

${ }^{857}$ Mencionando a economia de escala, cf. LA COSTE, Pierre de, BÉNARD, Vincent, op. cit., p. 24.

${ }^{858}$ Cf. Cerrillo i MARTíneZ, La interoperabilidad y la protección de datos, cit., pp. 30-31 e CHISSICK, Michael, HARRINGTON, Justin, op. cit., p. 10.

${ }^{859}$ Cf. HOLMES, Douglas, op. cit., p. 60.

${ }^{860}$ Cf. GAMERO CASADO, Eduardo, Interoperabilidad y administración electrónica, cit., p. 295.

${ }^{861}$ Cf. ibidem, p. 299. O autor observa que a interoperabilidade referente a sistemas e aplicativos já implantados é muito complexa, de maneira que o verdadeiro objetivo é observá-la no futuro (ibidem, pp. 299-300).

${ }^{862}$ Cf. CERRILlo I MARTínEZ, La interoperabilidad y la protección de datos, cit., p. 33 e GAMERO CASADO, Eduardo, Interoperabilidad y administración electrónica, cit., p. 296.
} 
interfaces, padrões e protocolos de comunicações ${ }^{863}$. Por meio da interoperabilidade semântica, a informação trocada pode ser interpretada de modo automatizado e reutilizada por outro aplicativo que não tenha sido desenvolvido inicialmente com esse objetivo, o que exige um acordo sobre o formato ou estrutura da informação trocada e sobre seu contexto ou conteúdo preciso ${ }^{864}$.

Em um estágio máximo de interoperabilidade, que ainda não existe, os sistemas dos diversos sujeitos públicos poderiam interagir entre si de modo pleno, permitindo não somente a troca de informações, mas a realização de atividades em caráter colaborativo $^{865}$. O governo poderia apresentar-se ao usuário por meio de um balcão único, um único interlocutor respaldado por sistemas informatizados inteiramente compatíveis, coerentes e integrados, proporcionando uma atuação administrativa unificada, ainda que a necessidade do usuário estivesse sujeita à competência de diferentes órgãos públicos ${ }^{866}$. Esse estágio constituiria um aperfeiçoamento considerável na qualidade da prestação de

${ }^{863}$ Cf. CERRILlo i MARTíneZ, La interoperabilidad y la protección de datos, cit., p. 33 e GAMERO CASADO, Eduardo, Interoperabilidad y administración electrónica, cit., p. 297.

${ }^{864}$ Cf. CERRILlO I MARTÍNEZ, La interoperabilidad y la protección de datos, cit., p. 34 e GAMERO CASADO, Eduardo, Interoperabilidad y administración electrónica, cit., p. 296. Segundo o último autor, a principal dificuldade que encontra a interoperabilidade semântica é a diversidade de linguagens de programação, que podem tornar ininteligíveis para um sistema informático os dados existentes no outro. Outro problema é a diversidade linguística no plano jurídico, pois os mesmos institutos jurídicos recebem denominações diferentes em cada idioma. Assim, caberia falar também em uma interoperabilidade jurídica, referente à compatbilização da legislação de um ente político para que os dados eletrônicos dele originados sejam reconhecíveis de acordo com o direito aplicável em outros âmbitos (pp. 296-297). Parece tratar-se, contudo, de um aspecto específico da interoperabilidade semântica, especialmente relevante para a estrututração jurídica do governo eletrônico.

${ }^{865}$ MARONGIU refere-se a graus sucessivos da interconexão (ligação física entre as máquinas), da interoperalibilidade (capacidade de trocar dados, pelo uso de formatos reciprocamente compatíveis) e da cooperação aplicativa (possibilidade de interagir à distância com um software que permita conduzir os trabalhos comuns). A cooperação aplicativa, grau mais avançado, representaria a solução para a realização do processo administrativo telemático, implicando mudança substancial do processo de implantação do governo eletrônico, que poderia ser sintetizado como a passagem da informatização por órgão a uma informatização por procedimento (cf. Il governo dell'informatica pubblica, cit., p. 37). No presente texto, a interoperabilidade é considerada em sentido amplo, de forma a alcançar os três graus referidos.

${ }^{866} \mathrm{Com}$ isso, seria possível o modelo do federalismo informático, que entende a Administração, mesmo na sua articulação de entes e competências, como um só complexo, formado por uma série de estruturas e aparatos estreitamente ligados e coordenados entre si, capazes de se apresentar ao cidadão de modo unitário. Nesse modelo, a Administração local é o front office de todo o sistema público e qualquer entidade pública do front line pode acessar serviços de back office fornecidos por todo o setor público, o que pressupõe uma forte direção central para a coordenação e a interação de partes potencialmente diversas, evitando a incomunicabilidade entre elas (cf. CARLONI, Enrico, Le difficoltà per una visione organica dell'e-government, cit., p. 40). Sobre a questão do governo inteiramente integrado, por meio da interoperabilidade, cf. CERRILLO I MARTÍNEZ, La interoperabilidad y la protección de datos, cit., p. 31; AlLI ARANGUREN, Juan-Cruz, op. cit., p. 61; Bernadí Gil, Xavier, op. cit., p. 225 e De Terwangne, Cécile, Lobet-Maris, Claire, Poullet, Yves, op. cit., p. 23. 
serviços públicos, pois os usuários tendem a não diferenciar os vários níveis de governo ${ }^{867}$, o que sempre constitui um problema para o atendimento das suas necessidades.

Embora pareça, à primeira vista, um tema eminentemente relacionado à informática, a interoperabilidade não constitui uma questão meramente técnica ${ }^{868}$. Trata-se de um tema que apresenta um considerável componente jurídico, não sendo poucos os pontos de contato que possui com importantes questões relacionadas ao direito.

O primeiro ponto a ser considerado é que a interoperabilidade tem base constitucional. Isso pode ser revelado por meio de uma releitura, no atual contexto tecnológico, do dispositivo que veda ao Poder Público recusar fé aos documentos públicos (art. 19, II). Com efeito, tal preceito sempre teve uma função essencial para a atuação da administração em papel, efetuando, por meio de um documento físico, a articulação entre as diversas atividades burocráticas da Administração. O dispositivo referido invoca, pois, a ideia do usuário que, interessado em uma determinada prestação da Administração, formula um requerimento instruído com um documento anterior, legitimamente obtido a partir de outra atividade administrativa, que não pode ser recusado pelo Poder Público nessa atuação sucessiva.

Com o advento das novas tecnologias, o preceito constitucional exige uma reinterpretação, porquanto o documento eletrônico - juridicamente equivalente ao documento em papel - não tem a mesma vocação para ser expedido em suporte tangível, devendo apenas estar disponível para consulta telemática e para constituir eventual elemento instrutório de outro processo ${ }^{869}$. Além disso, com a utilização de meios eletrônicos, tende a não haver mais a figura da pessoa responsável pelo recebimento do documento, a quem seria vedada sua recusa. No contexto do governo eletrônico, a vedação à recusa merece ser entendida como o dever de reconhecimento mútuo de documentos públicos eletrô$\operatorname{nicos}^{870}$, nos quais se incluem as informações constantes de bases de dados estatais a serem

\footnotetext{
${ }^{867}$ Cf. Holmes, Douglas, op. cit., p. 67.

${ }^{868}$ Cf. CERRILlo I MARTínEZ, La interoperabilidad y la protección de datos, cit., p. 32.

${ }^{869}$ Cf. DunI, Giovanni, I "viaggi telematici" dell'atto informatico, cit., p. 1.

${ }^{870}$ Sobre o reconhecimento recíproco de documentos públicos eletrônicos, cf. GAMERO CASADO, Eduardo, Objeto, ámbito de aplicación y principios generales de la ley de administración electrónica, cit., p. 106 e JiNESTA LOBO, Ernesto, op. cit., p. 10.
} 
compartilhadas. A interoperabilidade é, assim, o meio pelo qual cada órgão da Administração pode dar fé a tais documentos públicos eletrônicos produzidos por outros órgãos e entidades, cumprindo com o referido preceito constitucional.

Por outro lado, a interoperabilidade apresenta uma relevância jurídica especial em razão do fato de que grande parte dos direitos dos cidadãos, na atualidade, passa inevitavelmente pela interconexão entre os diversos órgãos públicos ${ }^{871}$. Essa integração informativa traz novos contornos a uma relevante questão, relativa à legitimidade da exigência, por parte da Administração, de documentos ou informações que já estejam em poder dos órgãos estatais. Com efeito, tal exigência sempre comportou algum questionamento à luz do princípio da proporcionalidade, por importar em um ônus para o administrado, questionável à luz da necessidade. No contexto da administração em papel, o tema nunca trouxe maiores discussões: de fato, em vista do volume absurdo de documentos arquivados, nem sempre com os devidos cuidados e métodos, bem como em razão das dificuldades operacionais relativas à remessa física dos papéis, seria razoável entender-se como necessária a exigência documental. Ademais, na prática, o próprio cidadão muitas vezes prefere trazer o documento que obteve em outra repartição pública, ao invés de insistir no desafio de exigir da Administração o cumprimento do dever de ela própria promover a instrução do expediente ${ }^{872}$. O interessado, assim, sempre assumiu a função de intermediário da informação, armazenando consigo uma quantidade considerável de documentos públicos que poderiam ser necessários para um requerimento administrativo.

A situação muda quando as informações exigidas passam a estar em uma base de dados informatizada pública. Quando isso ocorre, a exigência documental passa a ser juridicamente insustentável, pois já não é possível considerá-la necessária com base nas dificuldades atinentes à localização da informação no âmbito do próprio Poder Público. Tendo em conta a facilidade proporcionada pela remessa por meios eletrônicos, não parece justificado que o interessado deva continuar a realizar o trabalho de intermediação entre os órgãos públicos a fim de obter a informação de que um deles precisa para exercer suas

\footnotetext{
${ }^{871}$ Cf. VALERO TORRIJOS, Julián, El régimen jurídico de la e-Administración, cit., p. 204.

872 Sobre essa preferência do cidadão, cf. VALERO TORRIJOS, Julián, El régimen jurídico de la eAdministración, cit., p. 15.
} 
competências $^{873}$. Para suprimir as solicitações repetidas da mesma informação, é preciso um compartilhamento dessa informação entre as entidades públicas interessadas ${ }^{874}$. Cabe ao órgão solicitante, pois, providenciar o acesso à base de dados que contém a informação que se mostra necessária para a atuação administrativa, livrando o interessado de tal ônus. Para tanto, a solução que se impõe, pois, é tornar interoperáveis os sistemas dos órgãos públicos, compartilhando-se referida informação ${ }^{875}$.

Vale considerar, ainda, que a interoperabilidade tem um forte componente jurídico por ter uma expressão normativa ${ }^{876}$. A interoperabilidade é garantida mediante um marco institucional, correspondente à definição de padrões que permitam adotar os critérios comuns de atuação para a interação entre os diversos entes envolvidos, o que se conhece como a governança da interoperabilidade ${ }^{877}$.

\footnotetext{
${ }^{873}$ Cf. VALERO TORRIJOS, Julián, El régimen jurídico de la e-Administración, cit., p. 206. Entendendo que a Administração não deve oferecer tais informações em vista de razões de proteção à vida privada e outras liberdades, cf. BROUSSEAU, Eric, op. cit., p. 255 e MARCOU, Gérard, op. cit., p. 85.

${ }^{874}$ Cf. De Terwangne, Cécile, Lobet-Maris, Claire, Poullet, Yves, op. cit., p. 24.

${ }^{875} \mathrm{O}$ direito a não juntar documentos que estejam em poder da Administração Pública é previsto expressamente pela legislação espanhola e pode ser entendido como decorrente, por exemplo, do art. 37 da Lei Federal n. 9.784/99 e do art. 31 da Lei n. 14.141/06, do Município de São Paulo. Segundo o texto da lei federal, "[q]uando o interessado declarar que fatos e dados estão registrados em documentos existentes na própria Administração responsável pelo processo ou em outro órgão administrativo, o órgão competente para a instrução proverá, de ofício, à obtenção dos documentos ou das respectivas cópias". No mesmo sentido, com referência apenas ao Poder Executivo Federal, os artigos $2^{\circ}$ e $3^{\circ}$ do Decreto n. 6.932/09. Todavia, tal direito não é simples de ser posto em prática, especialmente em função da falta de coordenação interadministrativa (cf. BlASCO Díaz, José Luis, Los derechos de los ciudadanos en su relación electrónica con la Administración, cit., p. 816). Conforme tem sido entendido, ele necessita de uma administração mais aperfeiçoada, ágil e eficaz, que tenha meios para conhecer e transmitir os documentos que possui (cf. COTINO HUESO, Lorenzo, Derechos del ciudadano administrado e igualdad ante la implantación de la Administración electrónica, cit., p. 134). Sob este aspecto, vale ressaltar que "o processo de modernização tecnológica da gestão documental da Administração Pública passa em grande medida pela consolidação de uma nova forma de relações administrativas em que o cidadão já não faz a função de mero intermediário, isto é, de portador de documentos emitidos por uma delas com destino a outra; ao contrário, o pedido e a obtenção dos dados necessários ao exercício das competências administrativas acontecerão - e, de fato, já acontecem em muitos casos - mediante os acessos e as interconexões automatizadas de bases de dados, sem intervenção direta dos servidores públicos" (VALERO TORRIJOS, Julián, La gestión y conservación del documento administrativo electrónico, cit., p. 66, tradução livre).

${ }^{876}$ Tratando da necessidade de uma articulação jurídica da interoperabilidade, cf. CERRILlo I MARTínEZ, La interoperabilidad y la protección de datos, cit., p. 32.

${ }^{877}$ Cf. CERRILlo I MARTÍNEZ, La interoperabilidad y la protección de datos, cit., p. 26 e 41.
} 
Os instrumentos normativos variam conforme o modelo de interoperabilidade utilizado ${ }^{878}$. Caso seja adotado um modelo centralizado, as normas de interoperabilidade são editadas por uma autoridade superior, ao passo que a adoção de um modelo descentralizado ocorre mediante acordo entre as instituições que detêm os sistemas a serem relacionados ${ }^{879}$. Por outro lado, conforme se estabeleçam recomendações ou normas cogentes, pode-se falar em modelos voluntários ou vinculantes. Por fim, em função do grau de concreção das normas sobre interoperabilidade - mais precisas ou mais genéricas -, é possível falar em modelos rígidos ou flexíveis. Em qualquer caso, a escolha de um modelo e dos instrumentos para materializá-lo deverá ocorrer com fundamento no ordenamento jurídico $^{880}$.

$\mathrm{Na}$ condição de regras jurídicas, os padrões de interoperabilidade adotados pela Administração Pública sujeitam-se à compatibilização com outras normas integrantes do ordenamento ${ }^{881}$. Isso envolve, em primeiro lugar, o respeito às normas jurídicas referentes à própria atividade administrativa, tais como aquelas que se referem a atos e processos administrativos. Por outro lado, a definição da interoperabilidade deve fazer-se compatível com outros bens jurídicos protegidos pelo sistema. É o caso, por exemplo, dos limites à interoperabilidade decorrentes da necessidade de preservação da intimidade e da vida privada, que podem ser postas em risco pelo relacionamento irrestrito entre os sistemas informatizados ${ }^{882}$. Não havendo supervisão humana quanto à transferência de cada informação solicitada pelo outro órgão público, como ocorre na administração em papel, as

\footnotetext{
${ }^{878}$ Os modelos aqui considerados são os propostos por GAMERO CASADO (cf. Interoperabilidad y administración electrónica, cit., p. 300), com a ressalva de que as situações reais, verificadas na prática, correspondem a diferentes combinações dessas categorias (p. 301).

${ }^{879}$ Mencionando a celebração de convênios, cf. AgIRREAZKuEnaGa, Iñaki, Chinchilla, Carmen, op. cit., pp. 41-42; GUILlÉN CARAMÉS, Javier, op. cit., p. 256; MARTín DELGADO, Isaac, Identificación y autenticación de los ciudadanos, cit., p. 329; MARTíNEZ GuTIÉRREZ, Rubén, Administración Pública Electrónica, cit., p. 222.

${ }^{880}$ No Brasil, a Portaria Normativa n. 5, de 14 de julho de 2005, Secretaria de Logística e Tecnologia da Informação, com fundamento no art. 27 do Decreto n. 5.433/05 (com conteúdo smelhante ao do art. 28 do Decreto n. 7.063/2010), instituiu os Padrões de Interoperabilidade de Governo Eletrônico - e-PING, a serem utilizados obrigatoriamente pelos órgãos do Poder Executivo Federal e facultativamente por outras entidades públicas e privadas (cf. art. $1^{\circ}, \S 1^{\circ}$ e $2^{\circ}$ da referida portaria).

${ }^{881}$ Nesse sentido, o direito pode ser, de certa forma, um obstáculo para a interoperabilidade (cf. GAMERO CASADO, Eduardo, Interoperabilidad y administración electrónica, cit., p. 302). A existência ou ausência de interoperabilidade entre os aplicativos e sistemas de informação desenvolvidos por diferentes entidades públicas pode dever-se não somente a aspectos técnicos e organizativos, mas àqueles que derivam da regulação (cf. CERRILlO I MARTíNEZ, La interoperabilidad y la protección de datos, cit., p. 34).

${ }^{882}$ Cf. GUERRA, Maria Paola, Circolazione dell'informazione e sistema informativo pubblico, cit., p. 570.
} 
regras de compartilhamento apresentam uma relevância fundamental para que os sistemas operem de modo compatível com o ordenamento jurídico ${ }^{883}$.

Todavia, o ponto mais relevante diz respeito à compatibilização entre as regras de interoperabilidade e a adequada compreensão da autonomia organizativa dos entes públicos, adotada em nosso país, tema situado no âmbito de um antagonismo, tido como tradicional, entre uma concepção garantista da separação de competências e a busca da modernização e eficiência da Administração Pública ${ }^{884}$. Se a regulação de interoperabilidade entre os órgãos de um mesmo ente público não reserva tantos problemas ${ }^{885}$, é mais complexa a questão acerca da viabilidade jurídica de decisões centrais que imponham padrões informáticos a serem adotados pelos diversos entes políticos, com vistas à interoperabilidade, o que inclui não somente o reconhecimento dos documentos digitais produzidos por outros entes, mas a construção de sistemas de acordo com regras definidas e o compartilhamento compulsório de informações ${ }^{886}$. Neste caso, a regulação da interoperabilidade interfere na esfera de competência do ente destinatário de tais normas, não apenas em questões de organização institucional, mas em matéria de gestão administrativa interna ${ }^{887}$.

Com efeito, sendo os modelos consensuais insuficientes para dar consistência à interoperabilidade ${ }^{888}$, atualmente é cada vez mais necessário estabelecer marcos

\footnotetext{
${ }^{883}$ Assim sendo, na comunicação tradicional, há uma supervisão humana da informação a ser fornecida. No acesso automatizado, a obtenção da informação é feita diretamente na base de dados onde ela se encontra. Em um nível mais avançado e pressupondo o acesso automatizado, a interconexão permite cruzar as bases de dados de forma generalizada, viabilizando os tratamentos avançados da informação. A respeito da diferença de alcance material entre comunicação, acesso automatizado e interconexão, bem como sobre as repercussões jurídicas dessa distinção, especialmente em relação à existência de supervisão humana que possa garantir a qualidade dos dados, cf. VALERO TORRIJOS, Julián, Implicaciones de la protección de datos de carácter personal para la Administración electrónica, cit., pp. 195-196 e, do mesmo autor, Protecção de datos personales y administración electrónica, in CERRILLO I MARTÍNEZ, Agustí e oo., La administración y la información, Madrid, Marcial Pons, 2007, p. 52.

${ }^{884}$ Cf. GUERRA, Maria Paola, Circolazione dell'informazione e sistema informativo pubblico, cit., pp. 567568.

${ }^{885}$ Neste caso, segundo DUNI, seria até mesmo admissível que faltasse interoperabilidade entre órgãos da mesma entidade pública (cf. Ancora sul procedimento amministrativo telematico, cit., p. 10).

${ }^{886}$ Cf. VAlERo TORRIJOS, Julián, El acceso telemático a la información administrativa, cit., p. 50. Considerando a questão um problema constitucional nos modelos descentralizados europeus, cf. GROSS, Thomas, op. cit., p. 75.

${ }^{887}$ Cf. GAMERO CASADO, Eduardo, Interoperabilidad y administración electrónica, cit., pp. 322-323.

${ }^{888}$ Cf. NATALINI, Alessandro, op. cit., p. 107.
} 
institucionais vinculantes de governança, com alguma espécie de coordenação ${ }^{889}$, sobretudo em aspectos estratégicos, sem os quais é impossível avançar no desenvolvimento do governo eletrônico ${ }^{890}$.

Por outro lado, as normas de interoperabilidade estão situadas no âmbito da necessidade de um plano geral para o governo eletrônico, cada vez mais imprescindível. Se, no passado, cada departamento podia definir suas prioridades em tecnologia, hoje o plano de governo eletrônico deve ser uma estratégia corporativa abrangente ${ }^{891}$, que reflita uma visão de conjunto da Administração Pública ${ }^{892}$, de maneira a aproveitar devidamente as oportunidades por ele proporcionadas ${ }^{893}$.

A busca de um encaminhamento mais equilibrado para o problema vem sendo tratado com maior profundidade na Itália, onde a denominada coordenação informática tem previsão expressa na Constituição ${ }^{894}$ e tem sido entendida como a procura pela fórmula mais idônea para gerir a tecnologia, a fim de garantir que todos os entes públicos participem de um único sistema nacional, sem que isso possa acarretar desarmonia com a

\footnotetext{
${ }^{889}$ Seria necessária, assim, a existência de um "piloto no avião" (cf. LA COSTE, Pierre de, BÉNARD, Vincent, op. cit., p. 24).

${ }^{890}$ Cf. GAMERO CASADO, Eduardo, Interoperabilidad y administración electrónica, cit., p. 302. Segundo o autor, a lei que rege a administração eletrôncia espanhola prevê, em seu artigo 42.1, o Esquema Nacional de Interoperabilidade, adotando um modelo vinculante, rígido e centralizado, algo pioneiro que situa a Espanha na vanguarda das políticas de interoperabilidade (ibidem, p. 328). Entende o autor que esse modelo acarreta uma interferência no poder de auto-organização de todos os entes administrativos, mas com benefícios para os cidadãos, que têm simplificada sua relação com a Administração, podendo relacionar-se com um só interlocutor, por meio de uma porta de entrada pela qual terá acesso a todos os serviços e utilidades da administração eletrônica, em alguns casos sem sequer conhecer os cruzamentos de dados operados em rede (ibidem, p. 331).

${ }^{891}$ Cf. HOLMES, Douglas, op. cit., p. 62.

${ }^{892}$ Cf. Delgado GarCía, Ana María, Oliver Cuello, Rafael, op. cit., p. 2.

${ }^{893}$ Cf. FinOCCHIARO, Giusella, op. cit., p. 7. Tem sido identificada uma tendência centrípeta trazida pelas novas tecnologias (cf. MARONGIU, Daniele, Il governo dell'informatica pubblica, cit., p. 34), que favorecem a centralização e a concentração das informações, permitindo reforçar o poder da Administração central (cf. CASTELLS ARTECHE, José Manuel, Aproximación a la problemática de la informática y administración pública, cit., p. 37 e DENTE, Bruno, op. cit., p. 89). Além disso, embora não faça parte dos propósitos deste estudo, cabe faze referência aos impactos das novas tecnologias sobre o federalismo, conceito político baseado em um mundo territorial e segmentado, que, segundo já se observou, está desaparecendo rapidamente (cf. GIBBINS, Roger, Federalism and the Challenge of Electronic Portals, in OLIVER, E. Lynn, SANDERS, Larry (ed.), E-Government Reconsidered: Renewal of Governance for the Knowledge Age, Regina, Canadian Plains Research Center, 2004, p. 35). Segundo o autor, é difícil acreditar que revolução tecnológica deixará intocado o federalismo, pois as bases territoriais e preocupações competenciais dos Estados Federais são especialmente vulneráveis ao impacto transformador das novas tecnologias (ibidem, p. 41).

${ }^{894}$ Cf. art. 117, comma 2, r. Sobre essa previsão, cf. MARONGIU, Daniele, Il governo dell'informatica pubblica, cit., p. 35 .
} 
sua autonomia ${ }^{895}$. Por meio dessa fórmula, seria possível construir um sistema informático público em seu conjunto, ao mesmo tempo especializado e inspirado em critérios uniformes $^{896}$.

No ordenamento brasileiro, é preciso compreender de modo adequado a autonomia federativa, não sendo cabível uma interpretação que, vedando a possibilidade de estabelecer normas nacionais de interoperabilidade, frustre os relacionamentos entre os sistemas informatizados dos diversos entes públicos ${ }^{897}$. Por essa razão, deve-se entender que a autonomia política, que garante a auto-organização, não compreende a competência para a adoção de padrões que possam causar a incomunicabilidade com os sistemas informáticos de outros entes públicos e o não reconhecimento dos documentos públicos eletrônicos por eles emitidos.

Ademais, não haveria uma peculiaridade regional ou local que recomendasse a adoção de soluções diferenciadas conforme o ente político, de modo que o reconhecimento de uma autonomia dos entes políticos para dispor sobre padrões de interoperabilidade não lhes proporcionaria benefício algum. Por outro lado, para o Estado brasileiro, tal entendimento traria a necessidade da celebração de milhares de convênios ou de atos de adesão a um modelo federal que fosse definido em caráter facultativo. Assim, deve-se reconhecer que a matéria referente à interoperabilidade dos sistemas computacionais está compreendida na competência federal para legislar sobre informática (art. 22, IV), uma vez que estão presentes razões semelhantes àquelas que norteiam a competência para legislar sobre telecomunicações, sobretudo em relação à instituição de padrões nacionais.

Não caberia à lei, por certo, definir as normas de interoperabilidade, que têm um caráter técnico e devem estar sujeitas a uma frequente atualização. A lei federal poderia regular a interoperabilidade, constituindo uma sistemática institucional de produ-

${ }^{895}$ Cf. ibidem, p. 34. A Corte constitucional italiana entendeu que deve haver uma reserva de poderes ao Estado para assegurar alguma homogeneidade de linguagem, de procedimentos e de padrões, de modo a permitir a comunicação entre sistemas informáticos da Administração Pública (cf. CARLONI, Enrico, Le difficoltà per una visione organica dell'e-government, cit., p. 45).

${ }^{896}$ Cf. Guerra, Maria Paola, Circolazione dell'informazione e sistema informativo pubblico, cit., p. 527.

${ }^{897}$ A informatização pública integrada por meio de procedimentos administrativos unificados não deve ser paralisada em função de uma autonomia organizativa incompatível com o resultado global pretendido (cf. DUNI, Giovanni, Verso un'amministrazione integrata dei procedimenti amministrativi, cit., p. 47). 
ção das normas técnicas, contemplando a participação de entidades representativas e o recebimento de propostas por parte dos vários entes públicos envolvidos ${ }^{898}$. As normas que viessem a ser produzidas, nessa condição, poderiam ter caráter cogente e vinculariam as iniciativas de governo eletrônico de toda a Administração Pública brasileira.

\footnotetext{
${ }^{898} \mathrm{Na}$ administração em rede, deve-se passar de uma liderança autoritária para uma autoridade do tipo de maestro (cf. CARCENAC, Thierry, op. cit., p. 107). Assim, a existência de um organismo de coordenação não implica a imposição unilateral de soluções. A coordenação pode ser considerada como um guia, dotado de uma visão panorâmica do sistema de órgãos públicos, podendo apontar, dentre as soluções propostas nos vários âmbitos institucionais, aquelas que sejam mais eficazes e funcionais, para que sejam difundidas e generalizadas. Dessa forma, não se tolhem as iniciativas que nascem dos demais órgãos, mas fica afastado o perigo de uma proliferação descontrolada de projetos concebidos na ótica da auto-organização, pensados para procedimentos restritos a cada órgão e insuscetíveis de serem utilizados em relações interorgânicas e intersubjetivas (cf. MARONGIU, Daniele, Il governo dell'informatica pubblica, cit., p. 39).
} 


\section{CAPÍTULO 3 - ATO ADMINISTRATIVO ELETRÔNICO}

\subsection{Antecedentes}

A concepção tradicional do ato administrativo foi desenvolvida segundo um determinado contexto tecnológico. Durante anos, a expedição de atos administrativos esteve associada à utilização intensiva do papel e da força de trabalho humana, aspectos que trouxeram consequências em relação aos conceitos relativos à maneira de registrar a decisão e ao método de sua elaboração. Uma apresentação sucinta desses pontos é interessante para a análise das inovações trazidas pela informática em relação ao ato administrativo, a serem tratadas neste capítulo.

A forma do ato administrativo corresponde ao conjunto de providências relacionadas à sua exteriorização, que incluem as fases preparatórias, o registro da decisão em um suporte material, a expressão do ato em um instrumento e os mecanismos destinados à sua publicidade. Por meio da forma, a declaração estatal passa a ser socialmente reconhecível como ato administrativo ${ }^{899}$.

Em geral, o ato administrativo tradicional só passa a existir quando formalizado por escrito, de modo que essa forma escrita não tem apenas caráter ad probatio-

\footnotetext{
${ }^{899}$ Vale a transcrição: “A declaração estatal existe no momento em que é socialmente reconhecível. Essa recognoscibilidade social é possível porque a declaração tem, necessariamente, uma forma. O critério de recognoscibilidade da declaração não é jurídico. Como ato humano, ela é reconhecível de acordo com os padrões sociais vigentes. A recognoscibilidade social da declaração estatal pressupõe a redação de seu texto, a aposição da assinatura por um órgão estatal (mais exatamente: por alguém que é tido como órgão estatal) e a publicação. Em certos casos, o ato pode ser suscetível de notificação ou intimação ao destinatário. Há recognoscibilidade social quando há a publicação, ou, em certos casos, a notificação ou intimação ao destinatário" (AMARAL, Antonio Carlos Cintra do, Teoria do ato administrativo, Belo Horizonte, Fórum, 2008, p. 51).
} 
nem, mas ad substantiam ${ }^{900}$. Como a declaração consiste na própria formação do documento ${ }^{901}$, o ato escrito e sua prova documental surgem ao mesmo tempo. Antes de formalizado, o ato ainda não existe do ponto de vista jurídico.

$\mathrm{O}$ ato administrativo não escrito - v.g., ato verbal ou mímico ${ }^{902}$ - é admitido apenas em situações muito restritas, em que há necessidade de execução imediata, tais como ordens para assuntos rotineiros ou gestos de um guarda de trânsito ${ }^{903}$, bem como nas situações urgentes, transitórias ou irrelevantes ${ }^{904}$. Nas demais hipóteses, é indispensável o ato escrito, sob pena de invalidade da atuação administrativa ${ }^{905}$.

A importância da forma escrita nos atos administrativos tem sido associada a duas razões principais: a garantia da segurança jurídica e a viabilização do controle dos atos administrativos por parte do administrado, da própria Administração e dos demais poderes do Estado ${ }^{906}$.

\footnotetext{
${ }^{900}$ Cf. MeIRELLES, Hely Lopes, op. cit., pp. 135-136. Já se observou que, em seus diversos ramos, o direito seguiu, com algum atraso, o surgimento da escrita. Assim é que os escribas transcreviam os éditos dos príncipes e assim documentavam atos já existentes e em vigor. O escrito, em sua origem, servia como elemento de prova - forma escrita necessária ad probationem - e, com o tempo, transformou em parte do ato jurídico forma escrita ad substantiam (cf. DUNI, Giovanni, L'amministrazione digitale, cit., p. 3).

${ }^{901} \mathrm{Cf}$. MASUCCI, Alfonso, Il documento amministrativo informatico, cit., p. 11.

${ }^{902}$ Cf. Mello, Oswaldo Aranha Bandeira de, Princípios gerais de direito administrativo, Vol. I: Introdução, $3^{\text {a }}$. ed., São Paulo, Malheiros, 2007, p. 509. Há quem afirme também que a forma usual é a escrita, além da qual existem, excepcionalmente, atos orais (ordens dadas a um servidor), atos pictóricos (placas de sinalização de trânsito), atos eletromecânicos (semáforos) e atos mímicos (policiais dirigindo manualmente o trânsito e o tráfego - cf. GASPARINI, Diógenes, op. cit., pp. 57-58).

${ }^{903}$ Cf. Mello, Celso Antonio Bandeira de, Ato administrativo e direitos dos administrados, cit., p. 43 e CAVALCANTI, Themístocles Brandão, Teoria dos atos administrativos, São Paulo, RT, 1973, pp. 79-80.

${ }^{904}$ Cf. MeIRELLES, Hely Lopes, op. cit., p. 136.

905 Cf. ibidem, p. 136. Conforme ressalta MARCus Vinicius FilgueIRAS JúNIOR, a Lei Federal n. 9784/99 exige que o ato seja escrito e assinado pela autoridade competente (cf. Ato administrativo eletrônico e teleadministração, cit., p. 262).

${ }^{906}$ É a opinião corrente na doutrina: "Se na formação do ato jurídico de natureza privada a exteriorização da vontade é relevante, no ato administrativo a exteriorização reveste-se de grande importância, tendo em vista o fim de interesse público a que visa, daí decorrendo a necessidade de ser conhecido pelos cidadãos, por outros órgãos da Administração e pelos órgãos de controle" (MEDAUAR, Odete, Direito administrativo moderno, cit., p. 136). No mesmo sentido, cf. Di PIETRO, Maria Sylvia Zanella, op. cit., p. 193. Também fazendo referência ao controle, cf. MARTINS, Ricardo Marcondes, Efeitos dos vícios do ato administrativo, São Paulo, Malheiros, 2008, p. 254. Mencionando o controle, associado à necessidade de moralidade e publicidade, cf. FARIA, Edimur Ferreira de, op. cit., p. 263.
} 
No contexto tecnológico anterior, as várias operações envolvidas na formalização escrita do ato foram confiadas ao documento em papel ${ }^{907}$. Por força das características desse tipo de suporte, não havia distinção entre o registro da decisão e a formalização do ato em instrumento próprio, passível de acesso por parte de qualquer interessado. $\mathrm{O}$ papel também era usado de modo exclusivo na publicação do ato, normalmente por meio de uma cópia ou extrato publicado na imprensa oficial.

Por outro lado, na administração tradicional, o método de elaboração do ato envolve uma atuação humana direta na definição de seu conteúdo. Cabe à autoridade decidir, levando em consideração todos os elementos de direito e de fato pertinentes, por meio de um processo mental descrito na respectiva motivação. $\mathrm{O}$ ato administrativo é um ato humano, um meio pelo qual a autoridade administrativa se expressa no contato imediato com o caso concreto.

Esses conceitos tradicionais, que envolvem a utilização do papel na formalização do ato e a atuação humana em sua elaboração, são compatíveis com alguma utilização da tecnologia.

Não se afasta da concepção tradicional, por exemplo, a preparação do ato administrativo mediante o uso de equipamentos informáticos - v.g., com o emprego de um editor de texto - para posterior submissão à assinatura da autoridade, a quem a decisão é atribuída $^{908}$. Trata-se de um caso de pouca intensidade no uso da tecnologia ${ }^{909}$, pois ela constitui apenas um instrumento para auxiliar a elaboração de um ato tradicional, cuja validade decorre da atuação do agente público, incumbido de efetuar as avaliações e confe-

\footnotetext{
907 A doutrina francesa ressalta esse aspecto: "No coração dos grandes princípios colocados por Napoleão e no coração de nosso sistema de administração, o papel se impôs como suporte dos atos civis e administrativos e formaliza as relações entre a administração e o usuário" (cf. BELOUlOU, Véronique, op. cit., p. 624).

${ }^{908}$ Cf. GiURDANElla, Carmelo, GuARnACCIA, Elio, op. cit., p. 13.

${ }^{909}$ Cf. ZEIDLER, Karl, op. cit., p. 36.
} 
rências devidas ${ }^{910}$. Nestes casos, a utilização da informática, embora muitas vezes imprescindível, não traz grandes inovações do ponto de vista jurídico ${ }^{911}$.

A definição do conteúdo da decisão também pode beneficiar-se das novas tecnologias, de modo compatível com a concepção tradicional de ato administrativo. Isso ocorre, por exemplo, no caso da utilização de sistemas informáticos de apoio à decisão. Os meios eletrônicos são capazes de oferecer análises e verificações que instruem um determinado ato, podendo o ser humano valer-se desses elementos para decidir, o que tende a reduzir a subjetividade da atuação administrativa ${ }^{912}$. Todavia, quando o ato final continua a cargo do ser humano, o emprego de aparatos técnicos para gerar a decisão com maior rapidez, de maneira racional ou com menos perigo não constitui uma questão relevante para a teoria do ato administrativo ${ }^{913}$.

\subsection{Conceito e tipologia do ato administrativo eletrônico}

Em outras situações, o uso das novas tecnologias é capaz de romper os limites da concepção tradicional, viabilizando a formalização de atos administrativos em um suporte diverso do papel ou sem a intervenção humana direta na definição de seu conteúdo.

A aplicação de meios informáticos na exteriorização do ato faz surgir o conceito de ato administrativo em forma eletrônica. Trata-se do ato que surge diretamente na memória do computador ${ }^{914}$, não exigindo impressão em papel ou assinatura manuscri-

\footnotetext{
${ }^{910}$ Cf. MANDOLFO, Giovanni, op. cit., pp. 1305-1306 e DunI, Giovanni, L'amministrazione digitale, cit., p. 12.

${ }^{911}$ Seria mais adequado referir-se a tal situação como pertinente à informática administrativa paralela (cf. GiURDANELla, Carmelo, GUARNACCIA, Elio, op. cit., p. 13).

${ }^{912}$ Cf. Chevallier, Jacques, O Estado Pós-Moderno, cit., pp. 177-178.

${ }^{913}$ Cf. ZEIDLER, Karl, op. cit., p. 32.

${ }^{914}$ Cf. DuNI, Giovanni, L'amministrazione digitale, cit., p. 12.
} 
ta $^{915}$. Caso transposto para o papel, este impresso constitui uma cópia, permanecendo o original em suporte eletrônico ${ }^{916}$.

Outro conceito diz respeito ao ato administrativo elaborado eletronicamente $^{917}$ ou ato administrativo automatizado ${ }^{918}$. Neste caso, a máquina não se limita a auxiliar o homem em sua decisão ${ }^{919}$, pois o conteúdo do ato decorre da atuação de um sistema informático, que relaciona os dados inseridos no computador, por meio de um programa de computador (software), sem intervenção humana em cada caso concreto ${ }^{920}$.

Não há oposição entre os conceitos de ato em forma eletrônica e de ato automatizado, pois cada um deles se refere a um âmbito de utilização das novas tecnologias na produção do ato administrativo: o primeiro conceito refere-se ao suporte para o registro da decisão e o segundo, ao método de sua elaboração ${ }^{921}$. O conceito de ato administrativo em forma eletrônica é preliminar ao ato automatizado ${ }^{922}$, sendo possível a ocorrência

\footnotetext{
915 Cf. MANDOlfo, Giovanni, op. cit., p. 1305 e MinerVA, Massimiliano, L'atto amministrativo in forma elettronica e la sicurezza dei sistemi informativi pubblici, in Diritto dell'informazione e dell'informatica, $\mathrm{n}$. 4-5, Milano, Giuffrè, 1999, p. 940.

${ }^{916}$ Cf. GiuRDANELla, Carmelo, GuARnACCIA, Elio, op. cit., p. 14.

${ }^{917}$ Cf. USAI, Alessandro, Le elaborazioni possibili delle informazioni. I limiti alla decisioni amministrative automatiche, in DUNI, Giovanni (org.), Dall'informatica amministrativa alla teleamministrazione, Roma, Istituto Poligrafico dello Stato, 1992, disponível em http://spol.unica.it/teleamm/italiano/pubblicazioni/dallinsezione1.htm\#alessandrousai, acesso em 08.12.2010, item 1.2.

${ }^{918} \mathrm{O}$ ato automatizado difere do ato automático, entendido como caso extremo de ato vinculado, em que não há liberdade alguma para o órgão atuante (cf. LINARES GIL, Maximino Ignacio, Identificación y autenticación de las administraciones públicas, cit., p. 306 e Modificaciones del Régimen Jurídico Administrativo derivadas del empleo masivo de nuevas tecnologías. En particular el caso de la Agencia Estatal de Administración Tributaria, in MATEu de Ros, Rafael, LóPEZ-Monís GAlLeGo, Mónima, Derecho de Internet: La Ley de Servicios de la Sociedad de la Información y de Comercio Electrónico, Cizur Menor, Aranzadi, 2003, p. 741).

919 Cf. Martín Delgado, Isaac, Naturaleza, Concepto y Régimen Jurídico de la Actuación Administrativa Automatizada, cit., p. 361.

${ }^{920}$ Sobre o tema, apenas a título de exemplo, cf. CAMmarota, Giuseppe, L'erogazione on line di servizi pubblici burocratici, cit., p. 74; GIURDANELla, Carmelo, GUARNACCIA, Elio, op. cit., p. 14; MANDOLFO, Giovanni, op. cit., pp. 1300-1301; MARONGIU, Daniele, Gli atti amministrativi ad elaborazione elettronica: la compilazione di un "pre-software" in lingua italiana, in Quaderni del DAE - Rivista di Diritto Amministrativo Elettronico, jul. 2003, disponível em http://www.cesda.it/quadernidae/index.php, acesso em 08.12.2010, p. 1 e RUSSO, Vincenzo, op. cit., p. 88.

${ }^{921}$ Cf. UsAI, Alessandro, op. cit., item 1.2.

${ }^{922}$ Cf. ibidem, item 1.2.
} 
simultânea das duas perspectivas ${ }^{923}$. Essa coincidência, aliás, ocorre em todos os atos automatizados, que sempre adotam a forma eletrônica ${ }^{924}$.

Tais considerações permitem propor uma tipologia para os atos administrativos eletrônicos ${ }^{925}$. Devem ser considerados atos administrativos eletrônicos em sentido amplo todos aqueles atos administrativos expedidos em suporte eletrônico. Eles podem ser divididos entre atos administrativos automatizados e atos administrativos eletrônicos em sentido estrito. Os atos administrativos eletrônicos em sentido estrito incluem as várias situações em que ocorre uma atuação combinada entre a máquina e o homem, ao qual cabe a decisão final, formalizada em um suporte eletrônico ${ }^{926}$.

\subsection{Os atos administrativos eletrônicos em sentido estrito}

A formalização do ato administrativo está relacionada à sua dimensão documental. Antes de vincular-se a um suporte material específico - o papel -, a exigência da forma escrita deve ser entendida, na verdade, como uma necessidade de documentação, destinada a proporcionar adequadas condições de segurança e controle. Essas funções podem estar associadas, por tradição, ao suporte papel, mas o alargamento contemporâneo da

\footnotetext{
923 Cf. FeRnÁNDEZ SALMERÓN, Manuel, La protección de los datos personales en las administraciones públicas, Madrid, Thomson-Civitas, 2003, p. 384.

${ }_{924}$ Cf. UsAI, Alessandro, op. cit., item 1.2.

${ }^{925}$ Cf. Giurdanella, Carmelo, Guarnaccia, Elio, op. cit., p. 13.

${ }^{926}$ Cf. RUSSO, Vincenzo, op. cit., p. 86. MARCUS VINICIUS FILGUEIRAS JÚNIOR traz uma distinção entre ato administrativo eletrônico tradicional, ato administrativo eletrônico automático, ato administrativo eletrônico totalmente automático e ato administrativo parcialmente automático (cf. Ato administrativo eletrônico e teleadministração, cit., p. 252). Na classificação aqui apresentada, consideram-se como referências para a classificação apenas a forma do ato e a fase final de sua elaboração, sem embargo da possibilidade de automatização parcial da atividade administrativa. Essa combinação entre a atuação do homem e a máquina, contudo, pode ser explorada de forma mais apropriada no estudo do processo administrativo eletrônico, que será objeto do capítulo seguinte.
} 
noção de documento, já enfrentado neste estudo ${ }^{927}$, deve influenciar também a formalização dos atos administrativos.

Nesse sentido, o ato administrativo pode estar associado a um documento administrativo eletrônico. A forma eletrônica do ato deve ser entendida como uma aplicação particular do regime jurídico relativo ao documento eletrônico ${ }^{928}$, sobretudo do princípio da equivalência de suportes, exigindo a observância das condições técnicas para a garantia de integridade, autenticidade, disponibilidade, confidencialidade ou acesso diferenciado, não repúdio e conservação ${ }^{929}$. Atendidas tais exigências, é possível criar condições de segurança jurídica e de controle similares àquelas atribuídas ao documento em papel ${ }^{930}$, não havendo impedimento para aceitar os meios eletrônicos para a documentação de atos administrativos $^{931}$. Assim como ocorre com o registro das informações em geral, a representação da decisão, no mundo moderno, também é possível em formas diferentes do documento em papel $^{932}$. A questão, neste caso, envolve apenas uma variação de aspectos da forma como elemento essencial do ato administrativo ${ }^{933}$, cabendo avaliar as particularidades desse outro meio da exteriorização das decisões estatais.

A principal especificidade da utilização de meios eletrônicos para a formalização dos atos administrativos diz respeito à maneira de apresentar a informação, em vista da natureza da linguagem empregada pela máquina. Por estar representado em um documento digital, o ato administrativo eletrônico é registrado em linguagem binária, não

\footnotetext{
${ }^{927}$ Cf. infra, item 2.2.1.

${ }^{928}$ Cf. USAI, Alessandro, op. cit., item 1.2.

${ }^{929}$ É aqui feita remissão, pois, aos itens 2.2 .2 e 2.2 .3 deste estudo, particularmente no que concerne à aplicabilidade da Medida Provisória n. 2200/2001 e à viabilidade de utilização de outras técnicas, de acordo com a decisão de cada ente público. Tratando especificamente do tema, e considerando necessária a utilização da sistemática de tal diploma normativo para a expedição de atos administrativos eletrônicos, cf. FILGUEIRAS JúNIOR, Marcus Vinícius, L'atto amministrativo elettronico in Brasile, cit., p. 2 e Ato administrativo eletrônico e teleadministração, cit., p. 259.

930 O que importa, na verdade, é que o ato esteja devidamente registrado: "A legislação prevê casuisticamente a forma aplicável a cada atuação prescrita, embora, de modo geral, seja possível afirmar que o ato administrativo deve ser escrito ou de alguma forma registrado, o que inclui em tese os assegurados por meios eletrônicos, garantindo-se que seu teor não será alterado sem que se o detecte e que permaneça recuperável sempre que deva ser consultado" (MOREIRA NETO, Diogo de Figueiredo, op. cit., p. 156).

${ }_{931} \mathrm{Em}$ sentido contrário, entendendo que a expedição de atos eletrônicos estaria condicionada a norma legal expressa, por força do princípio da estrita legalidade, cf. SANTOLIM, Cesar, op. cit., pp. 93-94.

${ }_{932}$ Cf. DUNI, Giovanni, L'amministrazione digitale, cit., p. 5.

${ }^{933}$ Cf. MANDOLFO, Giovanni, op. cit., p. 1305.
} 
suscetível de leitura humana. $\mathrm{O}$ ato é acessível ao homem por meio de uma cópia, resultado de uma tradução, feita pela máquina, para um formato exibível na tela do computador ou passível de impressão. Trata-se, como visto, de uma peculiaridade da documentação eletrônica: o acesso indireto à informação registrada, em razão da intermediação feita pelo equipamento eletrônico ${ }^{934}$.

Surge, portanto, uma diferença entre o ato registrado em suporte digital e o ato tradicional: neste último, o documento em papel efetua, de modo simultâneo, o registro da decisão e a exteriorização do ato administrativo; no ato eletrônico, aquele é feito em linguagem binária e esta ocorre por meio de uma cópia, intermediada pela máquina. Utilizado o suporte eletrônico, passa a haver duas realidades: o documento original, em linguagem binária, destinado ao registro da informação, e sua cópia em linguagem natural, incumbida de proporcionar o acesso a qualquer interessado.

Essa distinção tem levado a doutrina a discutir se o ato administrativo contido em um documento digital poderia ser considerado propriamente escrito. $\mathrm{O}$ documento escrito seria caracterizado por um conjunto de sinais gráficos compreensíveis pelo ser humano, o que não se aplica à linguagem informática ${ }^{935}$. Dessa maneira, a forma escrita e a eletrônica poderiam ter efeitos jurídicos semelhantes, mas seriam distintas entre si. Nesse sentido, os meios digitais proporcionam uma nova maneira de formalizar o ato administrativo, sendo a forma eletrônica apenas equivalente à escrita, sob uma perspectiva funcional $^{936}$.

\footnotetext{
${ }^{934}$ Cf. supra, item 2.2.1, em especial a nota 354.

${ }^{935} \mathrm{Cf}$. supra, item 2.2.1, em especial a nota 353.

${ }^{936}$ Segundo MASUCCI, a forma eletrônica não constitui uma verdadeira forma escrita, podendo haver apenas uma equivalência entre elas, dada a diferença entre o escrever informático é o escrever em papel. Os impulsos magnéticos não são diretamente perceptíveis pelo homem, porém são legíveis por meio de um equipamento eletrônico. Assim, a exteriorização em suporte eletrônico representa uma nova forma para o ato administrativo: além da forma oral e da escrita, há a forma eletrônica. Segundo o autor, na legislação alemã, as três formas são mencionadas separadamente, nos termos do art. 37, 2, da Lei Federal de Processo Administrativo (cf. Procedimento amministrativo e nuove tecnologie, cit., p. 75).
} 
Por exigir o já mencionado atributo da disponibilidade da informação, a equivalência funcional só pode ser atingida mediante uma reprodução do ato administrativo em linguagem acessível ao ser humano, para oportuna impressão ou exibição na tela do computador. Como visto, a forma escrita deve proporcionar tanto a segurança jurídica quanto a oportunidade para o controle do ato. O registro da informação em linguagem informática, efetuado de acordo com as melhores técnicas, é capaz de atender à primeira função, porém o controle do ato administrativo depende de sua disponibilidade em linguagem acessível ao homem. Portanto, caso empregado o suporte digital, a tradução do ato para a linguagem natural deve estar disponível no mesmo instante em que se dá o registro da decisão em linguagem binária. Caso contrário, o ato não pode ser considerado vigente ${ }^{937}$.

Portanto, a discussão sobre a possibilidade de entender a forma eletrônica como uma espécie de forma escrita não apresenta um caráter apenas semântico. O tema é relevante, pois a característica principal do ato administrativo em forma eletrônica é o fato de o documento original respectivo estar em linguagem binária, sendo acessível ao ser humano por meio de uma cópia. Havendo alguma discrepância entre esses documentos, decorrente de algum problema na geração da cópia, deve prevalecer o original informático, corrigindo-se o erro. Além disso, o formato da apresentação do documento em linguagem natural pode ser livremente alterado, desde que preservado o conteúdo, sem caracterizar a expedição de um novo ato administrativo.

A identificação dessas duas realidades tem ainda importância prática, sobretudo porque a utilização do suporte eletrônico não se restringe à consulta na tela do computador. As maiores vantagens do uso do suporte eletrônico estão associadas à capacidade do original informático para produzir efeitos de modo independente de sua formalização em linguagem natural, em virtude da interconexão entre equipamentos. Como já afirmado, o documento digital não existe apenas para ser compreendido pelo homem; na ver-

\footnotetext{
937 O tema se aproxima, de certo modo, da discussão relatada por ODETE MEDAUAR a respeito de qual seria momento de início de vigência do ato administrativo, a data da assinatura ou a da publicação. Segundo a autora, o critério da publicidade seria mais adequado às características do ato administrativo, que só é introduzido na ordem jurídica quando publicado (cf. Direito administrativo moderno, cit., p. 139). No caso do ato registrado em suporte eletrônico, não é possível reconhecer a existência de publicidade antes de estar disponível a tradução da linguagem binária para um formato acessível ao ser humano.
} 
dade, ele acrescenta a vantagem da leitura automatizada, que pode oferecer ganhos de eficiência ${ }^{938}$. Essa leitura eletrônica independe da formalização do ato em linguagem natural ou da sua expedição em papel ${ }^{939}$.

Por fim, vale observar que a noção de ato administrativo em forma eletrônica aqui adotada tem por referência apenas o registro original da decisão. Não se ignora, contudo, a utilização do suporte eletrônico em outras fases da formalização do ato, como é o caso de sua publicação na internet, que constitui uma tendência da administração contemporânea ${ }^{940}$. Neste caso, embora haja a publicação de um documento digital, não é possível afirmar que exista sempre um ato administrativo eletrônico, pois a publicação on line pode ser feita a partir de um ato administrativo tradicional. Em tal hipótese, muito frequente nos dias de hoje, o texto publicado em meio eletrônico corresponde apenas a uma cópia ou extrato do documento original, produzido em papel e com assinatura manuscrita.

\subsection{Atos administrativos automatizados}

Como já apontado, o ato administrativo automatizado não decorre da intervenção humana no caso concreto, mas da atuação de um sistema informático, segundo um programa de computador ou software. O software constitui o conjunto de instruções

\footnotetext{
${ }^{938}$ Falando especificamente sobre as vantagens do ato administrativo em forma eletrônica, cf., entre muitos, DUNI, Giovanni, L'amministrazione digitale, cit., p. 12 e IASELLI, Michele, op. cit., p. 21.

${ }_{939}$ Assim, por exemplo, expedida uma licença por meio eletrônico, pode-se produzir um documento a ser entregue ao interessado. Todavia, o registro original de ato, integrante das bases de dados oficiais, pode ser empregado de modo automatizado na fiscalização, sem a necessidade de solicitar a apresentação do documento em papel. Quanto maior a interoperabilidade entre os sistemas informáticos públicos, menor a necessidade de impressão do documento em papel para exibição ao próprio agente de fiscalização.

${ }_{940} \mathrm{Cf}$. SAUNIER, Sébastien, Recherche sur la notion de formalisme en droit administratif français, Aix-enProvence, PUAM, 2007, p. 687.
} 
dadas aos equipamentos informáticos para o processamento de informações ${ }^{941}$. Trata-se de um complexo de regras precisas, analíticas, inequívocas, gerais e abstratas ${ }^{942}$, que definem um esquema de procedimento a ser seguido de modo absoluto em todos os seus elementos, levando a resultados predeterminados ${ }^{943}$.

Por meio do programa, o processo intelectivo humano destinado à aplicação de normas jurídicas é substituído pela atuação da máquina ${ }^{944}$, capaz de justapor elementos formalizados de fato e de direito ${ }^{945}$. Para tanto, as hipóteses normativas são traduzidas segundo a lógica informática, integrando-se num complexo de regras objetivas, ao passo que os elementos de fato são transformados em dados formalizados, permitindo ao computador aplicar ao fato a norma jurídica ${ }^{946}$.

A automatização dos atos administrativos envolve duas fases distintas. A primeira corresponde à preparação e construção de um sistema informático, que inclui a definição das regras a serem aplicadas e sua transposição para o respectivo software. A segunda diz respeito ao funcionamento efetivo do sistema, ao qual são submetidos os casos concretos. A justaposição dessas duas fases leva à produção dos atos administrativos au-

\footnotetext{
${ }^{941}$ A matéria, entre nós, é objeto de expressa e analítica disposição legal: "Programa de computador é a expressão de um conjunto organizado de instruções em linguagem natural ou codificada, contida em suporte físico de qualquer natureza, de emprego necessário em máquinas automáticas de tratamento da informação, dispositivos, instrumentos ou equipamentos periféricos, baseados em técnica digital ou análoga, para fazê-los funcionar de modo e para fins determinados" (art. $1^{\circ}$ da Lei Federal n. 9609/98). Sobre as definições doutrinárias de software, cf. CONTALDO, Alfonso, GoRGA, Michele, op. cit., pp. 179-180 e MASUCCI, Alfonso, L'atto amministrativo informatico, cit., p. 47. Segundo o último autor, o vocábulo programa tem um significado específico para a informática, que não se confunde com aquele geralmente presente em textos jurídicos - proposta ou projeto de ação para o futuro, lista de temas que se propõe a desenvolver, lista de princípios do que se pretende fazer, objetivos buscados e meios a serem usados. Esse aspecto parece bem resolvido no conceito adotado pela legislação brasileira, que se refere a programa de computador, o que permite diferenciá-lo do programa no outro sentido acima referido, empregado largamente pela Constituição brasileira e pelas normas de direito financeiro.

${ }_{942}$ Cf. Contaldo, Alfonso, GORGA, Michele, op. cit., pp. 179-180 e MASUCCI, Alfonso, L'atto amministrativo informatico, cit., p. 48.

${ }_{943}$ Cf. COnTALDO, Alfonso, Gorga, Michele, op. cit., p. 178 e MASUCCI, Alfonso, L'atto amministrativo informatico, cit., p. 48.

${ }^{944}$ Cf. Martín Delgado, Isaac, Naturaleza, Concepto y Régimen Jurídico de la Actuación Administrativa Automatizada, cit., p. 360 e RUSSO, Vincenzo, op. cit., p. 86.

${ }^{945}$ Cf. CONTALDO, Alfonso, GorGA, Michele, op. cit., p. 180.

${ }^{946}$ Cf. ibidem, p. 178.
} 
tomatizados $^{947}$, com o mesmo conteúdo do tradicional ato administrativo, praticado pelo ser humano ${ }^{948}$.

Por força dessa identidade de conteúdo, o ato administrativo automatizado pode desempenhar as mesmas funções do ato administrativo tradicional. Não se trata, contudo, de um tema simples do ponto de vista jurídico. Com efeito, na atuação realizada em suporte papel, o titular do órgão emite uma declaração baseada em fatos provados e na aplicação das normas jurídicas pertinentes, realizando um processo intelectivo pelo qual controla pessoalmente os elementos relevantes, de maneira que assume a responsabilidade direta pelo conteúdo do ato ${ }^{949}$. O mesmo não se verifica, contudo, quando a máquina passa a produzir diretamente o ato administrativo ${ }^{950}$.

Em vista da eliminação da atuação humana no caso concreto, a automatização de atos administrativos é um dos mais complexos e fascinantes temas do governo eletrônico $^{951}$, ensejando questões jurídicas relevantes, inclusive dificuldades dogmáticas e normativas que muitas vezes acabam por limitar a informática a servir apenas como mecanismo de apoio à decisão humana ${ }^{952}$. Sem um aprofundamento doutrinário em relação a essa problemática, tende a ser difícil realizar uma verdadeira automatização dos atos administrativos ${ }^{953}$. A adequada compreensão do tema é imprescindível para o atendimento das bases jurídicas do governo eletrônico, sobretudo no tocante ao princípio da equivalência de garantias. Esse aprofundamento será buscado nos itens seguintes.

\footnotetext{
${ }^{947}$ Cf. MARONE, Umberto, op. cit., pp. 88-89.

${ }^{948}$ Cf. MARTín DELGADO, Isaac, La administración electrónica como problema actual para la investigación y la docencia en el derecho administrativo, cit., p. 371. Assim, há uma clara correspondência entre a decisão administrativa tradicional e o resultado da aplicação do programa informático (cf. RUSSO, Vincenzo, op. cit., p. 88).

${ }_{949}$ Cf. VALERO TORRIJOS, Julián, El régimen jurídico de la e-Administración, cit., p. 72.

${ }^{950}$ Cf. FORSTHOFF, Ernst, op. cit., p. 102.

951 Cf. Russo, Vincenzo, op. cit., p. 89. Segundo já se observou, o uso de invenções eletrônicas para resolver problemas jurídicos, por meio de uma operação racional perfeitamente objetiva, despertou a perplexidade e a desconfiança dos juristas filiados à tradição humanista (cf. CASTELlS ARTECHE, José Manuel, Aproximación a la problemática de la informática y administración pública, cit., p. 46). Nesse contexto, a atuação administrativa automatizada constitui um dos paradigmas jurídicos mais inovadores originados pela administração eletrônica (cf. LINARES GIL, Maximino Ignacio, Identificación y autenticación de las administraciones públicas, cit., p. 283). Tratando da atividade administrativa automatizada como um dos desafios da administração eletrônica, cf. MARTín Delgado, Isaac, Naturaleza, Concepto y Régimen Jurídico de la Actuación Administrativa Automatizada, cit., p. 355.

${ }_{952}$ Cf. VALERO TORRIJOS, Julián, El régimen jurídico de la e-Administración, cit., p. 31.

${ }^{953}$ Cf. MASUCCI, Alfonso, L'atto amministrativo informatico, cit., p. 14.
} 


\subsubsection{A viabilidade da automatização}

Boa parte das vantagens decorrentes da utilização de meios eletrônicos na Administração Pública está relacionada à automatização de atos administrativos. Esta pode constituir um importante meio na busca da eficiência administrativa, pois permite atribuir à máquina as operações que ela é capaz de realizar melhor que o homem, de modo mais rápido e sem erros ${ }^{954}$, além de proporcionar uma racionalização e simplificação da ação administrativa. Por outro lado, a automatização das tarefas compatíveis com a lógica da informática permite liberar recursos humanos antes ocupados com atividades mecânicas e repetitivas, aproveitando-os de maneira mais adequada, em afazeres que exigem a capacidade humana, tais como investigações complexas ou avaliações pontuais de um caso determinado, segundo suas particularidades ${ }^{955}$.

A automatização também pode trazer vantagens em relação à observância de vários princípios jurídicos da atuação administrativa, tais como a igualdade, a legalidade e a eficiência. Como o elemento pessoal é substituído por uma atuação segundo regras previamente fixadas, sem referência a um caso concreto, há condições para a atuação norteada pela objetividade, imparcialidade e neutralidade ${ }^{956}$. A automatização é também capaz de afastar vários problemas decorrentes da atuação humana - v.g., a valoração errônea, a negligência, a arbitrariedade, a parcialidade ou falta de objetividade da decisão administrati-

\footnotetext{
${ }_{954}^{95}$ Cf. USAI, Alessandro, op. cit., item 3.1.

${ }^{955}$ Cf. MASUCCI, Alfonso, L'atto amministrativo informatico, cit., p. 36 e CORRÊA, Davi Beltrão de Rossiter, op. cit., p. 6.

${ }^{956}$ Cf. GÓMEZ PUEnTE, Marcos, op. cit., p. 128; MARTín Delgado, Isaac, Naturaleza, Concepto y Régimen Jurídico de la Actuación Administrativa Automatizada, cit., pp. 374-375; MASUCCI, Alfonso, L'atto amministrativo informatico, cit., p. 13; RUsso, Vincenzo, op. cit., p. 96. Na doutrina brasileira, assim já se considerou: "Os atos administrativos devem ser praticados de forma impessoal e nada melhor do que a vontade do administrador consubstanciada ou mediada por software inteligente. O software agiria como se fosse o próprio administrador, praticando de forma retilínea os atos em conformidade com a lei" (RAMOS JÚNIOR, Hélio Santiago, Rover, Aires José, $O$ ato administrativo eletrônico sob a ótica do princípio da eficiência, cit., p. 38).
} 
va $^{957}$. Com a utilização da tecnologia, pode-se atingir o máximo de autoridade legal racional, reduzindo a margem para o exercício arbitrário do poder ${ }^{958}$, o que pode propiciar até mesmo aumento das garantias jurídicas ${ }^{959}$. O incremento de eficiência reside na oportunidade para maximizar os resultados da atuação administrativa, pois o sistema informático, a partir de uma programação inicial, é capaz de dar resposta a um número inesgotável de problemas $^{960}$.

Entretanto, a diminuição do espaço para a arbitrariedade é acompanhada de um impedimento à flexibilidade própria das decisões humanas, nas quais é possível avaliar a melhor alternativa à luz do caso concreto ${ }^{961}$. Como os meios informáticos não admitem soluções abertas, exigindo sempre a opção entre duas alternativas excludentes entre si $^{962}$, a automatização dos atos administrativos impede a análise individual de cada caso ${ }^{963}$. Se a consideração dos elementos peculiares de cada situação concreta for necessária para a

957 Cf. Gómez PuENTE, Marcos, op. cit., p. 112. Por consequência, os órgãos que não informatizam suas atividades tendem a ter questionada sua atuação: "Se se considera que toda atividade humana racional a nível analítico é delegável ao computador, o qual lhe assegura o desempenho com mais rapidez, eficiência e imparcialidade, o fato de alguns órgãos não estarem informatizados deveria levar à conclusão de que em tais lugares o trabalho se realiza sem regras precisas, isto é, sem que seja assegurada a aplicação dos critérios de bom andamento e imparcialidade" (MARONE, Umberto, L'informatica nella pubblica amministrazione, cit., p. 23, tradução livre).

${ }_{958}$ Cf. BOVENS, Mark, ZouRIDS, Stavros, op. cit., p. 181.

959 Nesse sentido, "[a]s modernas ferramentas permitem assegurar, até com maior dose de certeza que os instrumentos tradicionais, o correto uso dos poderes administrativos e a salvaguarda da plena integridade de direitos e liberdades" (VALERO TORRIJOS, Julián, Administración pública, ciudadanos y nuevas tecnologías, cit., p. 2946, tradução livre).

${ }_{960}$ Nesse sentido, a automatização de atos administrativos seria coerente com a produção que hoje se espera da Administração. Conforme menciona MARÇAL JuSTEN FILHO, “o Estado pós-moderno é uma estrutura organizacional vocacionada a produzir atos em massa, não a promover atos isolados. Somente é possível compreender o Estado e a Administração Pública como um conjunto de instituições aptas a produzir atos em massa, para satisfazer grande quantidade de interesses e necessidades que parecem inexauríveis" (Curso de direito administrativo, $7^{\mathrm{a}}$. ed., Belo Horizonte, Fórum, 2011, p. 303).

${ }^{961}$ Cf. Borruso, Renato, Prefazione, in ConTAldo, Alfonso, Gorga, Michele, op. cit., pp. 6-7. Falando em riscos da informatização do direito, cf. DomínGUEZ LuIS, José Antonio, La explosión informática, cit., p. 118.

${ }_{962}$ Cf. Justen Filho, Marçal, Pregão, cit., p. 278.

963 Sobre a necessidade de exame individual dos expedientes e a impossibilidade de que uma diretriz reduza a nada toda faculdade de apreciação individual, cf. JACQUE, Jean Paul, Droit administratif et informatique, in VVAA, L'émergence du droit de l'informatique - Université de Paris X Nanterre, Paris, Ed. des Parques, 1983, pp. 108-109. 
prática de um ato administrativo, não sendo possível fixar regras abstratas que orientem tal decisão, a automatização tende a ser inviável ${ }^{964}$.

A automatização depende de uma padronização extrema ${ }^{965}$, correspondente à prévia conversão das providências tendentes ao ato em operações de dedução formal ou simbólica que possam compor o programa a ser executado pelo equipamento informático $^{966}$. Sob este aspecto, embora a Administração Pública seja um campo bastante fértil para a definição de padrões de atuação, a complexidade dos fatos da vida jamais poderá ser reproduzida em sistemas eletrônicos. O nível de padronização exigido pela automatização nem sempre é compatível com as situações mais complexas, nas quais é preciso deixar espaço para a intervenção do homem ${ }^{967}$. Isso provoca situações híbridas, tratadas adiante neste estudo, em que a atividade administrativa é objeto de automatização, mas a decisão final ainda precisa ser praticada pelo ser humano.

A expedição de atos automatizados também é inviável quando a fixação de tais regras oferece um alto grau de dificuldade, em prejuízo da relação custo-benefício. $\mathrm{Na}$ verdade, somente devem ser automatizados os atos cujas características justifiquem o investimento na construção do sistema, de maneira que este possa proporcionar um aumento da eficiência administrativa ${ }^{968}-v \cdot g$., os atos praticados em massa, repetidos com maior

\footnotetext{
${ }^{964}$ Analisando o tema da ameaça de desumanização por força da mecanização, FROSINI afirma que a questão da rigidez na aplicação de uma regra não é exclusiva do instrumento mecânico, mas decorrente também do formalismo jurídico excessivo. Segundo o autor, o verdadeiro problema é avaliar se o recurso à regra é sempre necessário ou se convém às vezes considerar a situação concreta. A verdadeira desumanização não viria da máquina, que executa sem sentir e entender, mas de magistrados muito íntegros e funcionários zelosos, que conhecem e praticam o respeito à lei, custe o que custar (cf. Cibernetica diritto e società, cit., p. 62). Havendo, portanto, o propósito de atuar segundo regras inflexíveis, a atividade humana pouco pode acrescentar, não havendo razão para temer a automatização; ao contrário, é o ser humano que, no exercício de uma atividade repetitiva, não-criativa e não-analítica, tende a errar mais que a máquina. De outra parte, reconhecida a existência de um espaço necessário de atuação humana, que leve em conta os atributos do caso concreto, a automatização torna-se inviável.

965 Cf. MARONE, Umberto, op. cit., p. 73.

${ }^{966}$ Cf. Heredero Higueras, Manuel, op. cit., p. 77.

${ }_{967}$ Cf. GiURDANElla, Carmelo, GUARnACCIA, Elio, op. cit., p. 33.

968 Cf. AlAmillo DOMIngO, Ignacio, URIOS APARISI, F. Xavier, La actuación administrativa automatizada en el ámbito de las administraciones públicas, Barcelona, Escola d'Aministració Pública de Catalunya, 2011, p. 18. A dificuldade de tal automatização consiste na elaboração de softwares idôneos e no carregamento de todos os dados necessários (cf. UsAI, Alessandro, op. cit., item 1.3). Uma receptividade para os modernos aparatos técnicos existirá onde os processos de trabalho se repitam em grande número e com características essencialmente idênticas (cf. ZEIDLER, Karl, op. cit., p. 49).
} 
frequência ${ }^{969}$. Também à luz do princípio da eficiência, justifica-se a automatização se houver aperfeiçoamento da qualidade da atuação, não sendo aceitável, por exemplo, que o uso de ferramentas informáticas para a prática de atos automatizados implique um aumento das dificuldades para o usuário no relacionamento com a Administração Pública.

Por outro lado, haverá dificuldade quando a lei impuser de modo expresso uma análise humana. Isso não pode ser tido com um óbice intransponível, pois a legislação, por vezes, foi elaborada em um contexto tecnológico diverso do atual, podendo ser objeto de uma interpretação destinada a atualizar seus comandos. Todavia, é possível presumir, diante de uma previsão legal expressa, que a habilidade peculiar ao ser humano era necessária e adequada a alcançar a melhor decisão na atividade administrativa por ela disciplinada. Nesse sentido, considerando possível a automatização, caberá à autoridade demonstrar a necessidade de uma interpretação que a sustente, levando em conta as vantagens para os administrados e a oportunidade para um incremento de eficiência.

\subsubsection{A vinculação entre a atuação automatizada e o ordenamento jurídico}

A existência de um sistema informático apresenta-se como uma realidade técnica, mas nem sempre uma realidade administrativa ou jurídica. Um determinado sistema pode produzir atos administrativos válidos caso seja reconhecido pela Administração como apto a esse fim, de modo que a ela possa ser imputado o resultado das atividades desempenhadas pela máquina, produzindo os respectivos efeitos jurídicos. É necessária, em síntese, uma vinculação entre a atuação do sistema informático e o ordenamento.

O reconhecimento da submissão da atividade automatizada ao ordenamento é essencial para dar cumprimento ao princípio da equivalência de garantias, de modo que a utilização das novas tecnologias não implique uma redução de direitos dos administrados. O sistema informático não pode aplicar critérios implícitos ou ocultos, sob pena

${ }^{969}$ Cf. MASUCCI, Alfonso, L'atto amministrativo informatico, cit., p. 13. 
de trazer menos garantias que aquelas presentes na atuação tradicional ${ }^{970}$. As regras adotadas devem ser públicas e transparentes, de maneira a permitir o controle da atividade administrativa, inclusive o questionamento dos critérios ali adotados ${ }^{971}$. Nenhuma passagem do processo decisório deve restar impenetrável, pois a utilização dos computadores precisa reforçar a posição jurídica dos administrados, e não enfraquecê-la ${ }^{972}$.

Por isso, a construção e operação de sistemas informáticos públicos deve ser acompanhada de atos administrativos destinados a sustentá-la. O principal desses atos é aquele pelo qual a Administração decide valer-se do sistema informático para a expedição de atos administrativos automatizados, reconhecendo como seus os atos produzidos dessa maneira ${ }^{973}$. Por meio desse ato, o resultado da atuação do sistema informático deixa de ser apenas uma realidade informática e passa a ter um sentido jurídico.

Não se trata, por certo, de uma prática generalizada. No contexto da revolução tecnológica que vivemos, nem todos os órgãos da Administração Pública têm adotado os devidos cuidados formais por ocasião do desenvolvimento de sistemas informáticos incumbidos da expedição de atos administrativos automatizados. A automatização de atos administrativos por vezes decorre de uma preocupação de ordem pragmática com a maxi-

\footnotetext{
${ }^{970}$ Já se afirmou que as regras embutidas nos sistemas de informação seriam normalmente menos visíveis e pareceriam menos repressoras que a discricionariedade burocrática (cf. FOUNTAIN, Jane E., op. cit., p. 61). A propósito, vale a pena comentar as palavras de MARÇAL JUSTEN FILHO, para quem "[o] programa indispensável à operação do sistema contém regras explícitas ou ocultas, que constrangem as escolhas e a conduta dos sujeitos" (Pregão, cit., p. 279). Na verdade, nenhuma regra oculta deve constranger a atuação dos usuários, e sim regras explícitas e compatíveis com o ordenamento jurídico.

${ }^{971}$ Cf. Bovens, Mark, ZouRIDS, Stavros, op. cit., p. 183; BRAIBANT, Guy, Données personnelles et société de l'information, cit., p. 11; MARTíN DELGADO, Isaac, Naturaleza, Concepto y Régimen Jurídico de la Actuación Administrativa Automatizada, cit., pp. 376-377 e VALERO TORRIJOS, Julián, El régimen jurídico de la eAdministración, cit., p. 81. Vale considerar, ainda, que o conhecimento público do processo intelectivo artificial é imprescindível para evitar, por exemplo, que juízes e tribunais tenham sempre de determinar provas periciais sobre o funcionamento do esquema informático para julgar uma demanda a respeito (cf. PALOMAR OLMEDA, Alberto, Un paso más en la aplicación de la tecnología en el procedimiento administrativo, cit., p. 94).

${ }^{972}$ Cf. MasucCI, Alfonso, L'atto amministrativo informatico, cit., p. 101 e Procedimento amministrativo e nuove tecnologie, cit., p. 102.

${ }^{973} \mathrm{Um}$ dos requisitos para a produção de um ato administrativo válido é que seja produzido pelo órgão competente, o que ocorre por meio de um mecanismo de imputação: a vontade e os atos da pessoa titular do órgão se tornam vontade e atos do ente público (cf. VALERO TORRIJOS, Julián, El régimen jurídico de la eAdministración, cit., pp. 70-71). Segundo o autor, estaria mantida a imputação ao órgão competente dos atos administrativos caso presente uma atividade de domínio e supervisão no funcionamento dos sistemas empregados (ibidem, p. 73). Sobre a adequada compreensão dessa vontade, cf. infra, item 3.4.4, em especial a nota 1095.
} 
mização do aproveitamento das novas tecnologias, não antecedida das devidas reflexões jurídicas. Nessa perspectiva, a decisão de automatizar tende a apresentar um caráter meramente tácito, decorrente do funcionamento do sistema informático, o que não oferece garantias suficientes para o administrado.

A exigência de que a opção pela automatização seja feita por meio de ato administrativo não constitui um formalismo inútil, mas algo fundamental para garantir a submissão da atividade automatizada ao ordenamento. Aliás, nem mesmo a simples decisão de automatizar é suficiente para tanto. Com efeito, não basta decidir atuar de modo automatizado, é preciso dizer por que e como isso ocorrerá.

A decisão de automatizar precisa decorrer de uma avaliação criteriosa a respeito da viabilidade da automatização da atividade administrativa considerada ${ }^{974}$. Essa decisão, embora apresente aspectos regrados, envolve também um forte componente discricionário $^{975}$. Por outro lado, tal opção não deve limitar-se a dar uma carta em branco ao sistema informático, imputando à Administração qualquer resultado dele advindo. A automatização de atos administrativos exige o pronunciamento a respeito de elementos logicamente antecedentes ao funcionamento do sistema.

Há vários aspectos relevantes na decisão de automatizar, tais como a fixação de regras para manutenção, supervisão, auditoria e controle de qualidade do sistema, a definição de qual será o órgão responsável por receber eventuais impugnações ${ }^{976}$ e a disciplina das hipóteses de suspensão das atividades - por exemplo, para manutenção de equipamentos. Todavia, há dois pontos principais, que constituem os mais importantes pressupostos da expedição automatizada de atos administrativos: a definição das regras a serem aplicadas pelo sistema e a aprovação do software por meio do qual isso ocorrerá. Tais temas serão tratados nos itens seguintes.

\footnotetext{
974 Cf. Martín Delgado, Isaac, Naturaleza, Concepto y Régimen Jurídico de la Actuación Administrativa Automatizada, cit., p. 373.

${ }^{975}$ Entendendo tratar-se de uma decisão claramente discricionária, cf. ALAMILLO DOMINGO, Ignacio, URIOS APARISI, F. Xavier, La actuación administrativa automatizada en el ámbito de las administraciones públicas, cit., p. 17.

${ }^{976}$ Cf. JinESTA LOBO, Ernesto, op. cit., p. 15.
} 


\subsubsection{A definição dos critérios a serem aplicados pela máquina}

Toda organização incumbida de resolver um grande número de casos tende a definir, com antecedência, as linhas e diretrizes a serem aplicadas na tomada de decisões ${ }^{977}$. Na Administração Pública, cabe à chefia da entidade ou órgão adotar preceitos para regular o exercício de seus próprios poderes ${ }^{978}$. Assim, aquilo que poderia ser decidido caso a caso é regrado por meio de prescrições gerais e abstratas, que constituem um imperativo dirigido pela autoridade a si mesma ou aos órgãos a ela subordinados ${ }^{979}$. Tudo isso decorre da capacidade de auto-organização do ente público, exercida por meio de atos administrativos gerais, tais como os regulamentos.

A utilização da informática para a produção de atos administrativos automatizados estende essa tendência a uma escala maior e mais rígida ${ }^{980}$, levando ao desaparecimento de um verdadeiro exame do caso concreto ${ }^{981}$. A automatização depende da prévia fixação, por parte da Administração, de todas as regras que poderiam ser aplicadas caso os atos fossem praticados pela via tradicional ${ }^{982}$. Tais regras devem orientar a atuação do computador, tornando-o capaz de executar operações objetivas diante do caso concreto, que levam à expedição do ato administrativo automatizado.

A definição de tais regras deve ser feita por meio de um ato administrativo, que pode ser a própria decisão de automatizar ou outro ato administrativo antecedente. Em qualquer dos casos, a identificação do conteúdo dessa decisão, relativa às regras a serem aplicadas pela máquina, é fundamental para a compreensão da automatização. Por isso, na linha da doutrina italiana, este estudo considerará, em separado, um ato administra-

\footnotetext{
${ }^{977}$ Cf. JACQUE, Jean Paul, op. cit., p. 108.

${ }^{978}$ Cf. MASUCCI, Alfonso, L'atto amministrativo informatico, cit., pp. 53-54.

${ }^{979}$ Cf. ibidem, pp. 54-55.

${ }_{980}$ Cf. JACQUE, Jean Paul, op. cit., p. 108.

${ }^{981}$ Cf. ibidem, pp. 107-108.

982 Assim, o ato-programa serve para desempenhar, na atuação automatizada, a função que vem sendo reconhecida ao ato administrativo tradicional, no sentido de sintetizar as normas a que estão submetidos os atos de exercício dos poderes administrativos. Sobre essa função do ato tradicional, cf. MEDAUAR, Odete, Administração Pública: do ato ao processo, in ARAGÃo, Alexandre Santos de, MARQUES NeTO, Floriano de Azevedo (coord.), Direito administrativo e seus novos paradigmas, Belo Horizonte, Fórum, p. 407.
} 
tivo com esse conteúdo específico, o chamado ato-programa. O ato-programa pode ser definido como o ato administrativo geral que disciplina a atuação de um sistema informático público, por meio de instruções genéricas e abstratas segundo as quais a Administração disciplina sua atuação automatizada, predeterminando as modalidades e conteúdos das informações a serem produzidas ${ }^{983}$.

Em vista do conteúdo mencionado, o ato-programa constitui uma espécie bastante particular de ato administrativo geral, que disciplina a própria atuação do sistema informático público. Seu fundamento jurídico é o poder de auto-organização da Administração Pública ${ }^{984}$ e a necessidade de uniformizar a aplicação do direito, atendendo à exigência de imparcialidade do agir administrativo ${ }^{985}$. Como ato administrativo geral, o atoprograma deve ser expedido sob os títulos normalmente atribuídos a tais atos, como decreto, portaria, resolução e circular ${ }^{986}$.

A maior peculiaridade desse ato administrativo geral reside no fato de os atos concretos nele fundamentados virem à luz de modo direto, sem a intervenção de ou-

\footnotetext{
983 Cf. MASUCCI, Alfonso, L'atto amministrativo informatico, cit., p. 57 e MARONE, Umberto, op. cit., p. 88. $\mathrm{O}$ último autor ressalva que, embora o ato-programa tenha natureza normativa, existem na Itália critérios muito precisos para qualificar um ato como normativo (cf. UsAI, Alessandro, op. cit., item 2.1). Em função desse motivo específico, FANTIGROSSI, apesar de reconhecer uma forte analogia entre as características do ato-programa e aquelas comumente atribuídas à atividade normativa da Administração Pública, considera o ato-programa um ato administrativo concreto, sob o argumento de que ele se referiria a todos os possíveis e imagináveis casos de exercício do poder e os correspondentes conteúdos das decisões (cf. op. cit., pp. 103 e 111). Na realidade brasileira, há alguma polêmica sobre a inclusão dos atos normativos entre os atos administrativos (cf. MEDAUAR, Odete, Ato administrativo: origem, concepções, abrangência, in MEDAUAR, Odete, SCHIRATO, Vitor Rhein, Os caminhos do ato administrativo, São Paulo, RT, 2011, p. 31). A exploração dessa discussão foge aos limites deste estudo, que adota como premissa a existência de atos administrativos normativos, dentro dos quais se inclui o ato-programa.

${ }^{984}$ Cf. MARONE, Umberto, op. cit., p. 88 e MASUCCI, Alfonso, Procedimento amministrativo e nuove tecnologie, cit., p. 86.

985 Cf. MASUCCI, Alfonso, L'atto amministrativo informatico, cit., p. 55. Tais fundamentos, na verdade, são comuns aos atos administrativos normativos em geral. Considerando o ato administrativo normativo um instrumento para a isonomia, cf. AlMEIDA, Fernando Dias Menezes de, Atos administrativos normativos: algumas questões, in MEDAUAR, Odete, SCHIRATO, Vitor Rhein, Os caminhos do ato administrativo, São Paulo, RT, 2011, p. 224.

${ }^{986}$ Apontando a semelhança com as circulares, cf. USAI, Alessandro, op. cit., item 2.1. Tratando do programa como uma verdadeira regulamentação, que deve ser expedida pela autoridade competente, cf. PLANTEY, Alain, Prospective de L'État, Paris, Centre National de la Recherche Scientifique, 1975, p. 98.
} 
tros sujeitos. Depois de traduzido em linguagem de programação ${ }^{987}$, o ato-programa produz efeitos externos, de modo direto e imediato, por meio do sistema informático ${ }^{988}$.

Não há dúvida da importância jurídica das atividades de programação dos sistemas informáticos destinados à expedição automatizada de atos administrativos ${ }^{989}$. A identificação do ato-programa permite reconhecer nessas atividades de programação uma fase de escolhas e de exercício do poder ${ }^{990}$, marcada por um ponderável componente jurídico. Produto das reflexões efetuadas para o desenvolvimento do sistema informático, o ato-programa deve ser visto como a decisão jurídica substancial antecedente aos atos automatizados concretos. Essa decisão deve obedecer ao regime jurídico dos atos administrativos, aspecto essencial para a observância do princípio da equivalência de garantias na atuação automatizada, sobretudo em relação aos princípios da legalidade e da segurança jurídica $^{991}$. Nesse sentido, uma programação adequada deve decorrer de critérios motiva$\operatorname{dos}^{992}$, compatíveis com as normas jurídicas superiores e definidos pelo órgão público competente.

Além disso, a identificação do ato-programa permite dar realce à já mencionada necessidade de divulgar as regras aplicadas pelo sistema informático, essencial para garantir a transparência da atividade automatizada. De tal maneira, qualquer definição substancial relativa aos critérios empregados pelo sistema deve ser publicada, como aspecto integrante de tal ato geral. Isso viabiliza a compreensão, por parte do administrado, a

\footnotetext{
${ }^{987}$ Cf. GiURdanella, Carmelo, GuARnaCcia, Elio, op. cit., p. 37.

988 Por isso, é impossível caracterizá-lo apenas como um ato interno (cf. MARONE, Umberto, op. cit., pp. 8889, Contaldo, Alfonso, Gorga, Michele, op. cit., p. 185). Entendendo que o programa é ato interno, porém não exclui uma relevância indireta em direção ao exterior e pode ser objeto de discussão na impugnação do ato conclusivo do processo, cf. MASUCCI, Alfonso, Procedimento amministrativo e nuove tecnologie, cit., p. 88.

${ }^{989}$ Cf. FANTIGROSSI, Umberto, op. cit., p. 77; GILLI, Jean-Paul, Informatique et administration, in VVAA, L'informatique dans l'administration, Paris, Cujas, 1969, p. 106 e PlANTEY, Alain, op. cit., p. 98. Dessa maneira, "[s]e em um procedimento administrativo ou na emanação de uma decisão administrativa atua um computador não somente na condição de fornecedor de dados, mas como executor de operações lógicas, é óbvio que a atenção do jurista deverá dirigir-se a examinar a fase da programação da máquina" (FANTIGROSSI, Umberto, op. cit., p. 51).

${ }^{990}$ Cf. FANTIGROSSI, Umberto, op. cit., p. 77.

${ }^{991}$ Cf. Martín Delgado, Isaac, Naturaleza, Concepto y Régimen Jurídico de la Actuación Administrativa Automatizada, cit., p. 373.

992 Tratando da motivação do ato-programa, cf. FANTIGROSSI, Umberto, op. cit., p. 98.
} 
respeito da atuação do sistema informático e o consequente controle de legalidade dos atos administrativos produzidos pela máquina.

\subsubsection{A aprovação do software}

O ato-programa não se confunde com o software empregado na expedição de atos automatizados. O primeiro é expresso em linguagem natural, de acordo com a forma própria dos atos administrativos ${ }^{993}$; já o segundo apresenta-se como uma versão do primeiro, mas em linguagem informática ${ }^{994}$. O programador, profissional da informática, deve transpor o texto normativo elaborado em língua natural para uma linguagem de programação $^{995}$. O desenvolvimento do sistema informático destinado à expedição de atos automatizados não depende apenas da definição dos critérios a serem aplicados, mas dessa conversão em linguagem de programação. Caso aprove o programa, a Administração assume que o sistema vai operar de acordo com as regras por ela fixadas, reconhecendo essa atuação como sua.

Em princípio, a conversão do ato-programa em um software poderia ser tida como uma operação técnica desprovida de efeitos jurídicos. Para tanto, seria preciso entender que todas as possíveis definições a respeito da construção do sistema informático estariam exauridas no ato-programa, de tal maneira que, depois dele, nada de substancial precisaria ser decidido. Todavia, a complexidade da realidade informática recomenda considerar a existência de dois âmbitos de decisão diversos: o primeiro refere-se aos critérios substanciais a serem aplicados na análise dos casos concretos; o segundo diz respeito aos

\footnotetext{
${ }^{993}$ Considerado o ato-programa como ato administrativo, é possível que ele seja publicado e levado ao conhecimento dos administrados, a quem seria possível questioná-lo. Sobre a questão, levantando a possibilidade de que a diretiva do programa seja considerada um ato regulamentar, cf. JACQUE, Jean Paul, op. cit., p. 109. A respeito da possibilidade de impugnar tal ato, cf. infra, item 4.9.7.

${ }^{994}$ Sobre essa diferença entre o programa e o ato administrativo que o fundamenta, cf. DuNI, Giovanni, L'amministrazione digitale, cit., p. 75 e SAITTA, Fabio, Le patologie dell'atto amministrativo elettronico e il sindacato del giudice amministrativo, in Quaderni del DAE - Rivista di Diritto Amministrativo Elettronico, jul. 2003, disponível em http://www.cesda.it/quadernidae/index.php, acesso em 15.12.2010, p. 26.

${ }_{995}$ Cf. MARONGIU, Daniele, Gli atti amministrativi ad elaborazione elettronica, cit., p. 2.
} 
aspectos técnicos envolvidos na construção do software, nos quais se inclui a tradução dos referidos critérios em linguagem informática.

De todo modo, a atividade de programação não se restringe à conversão do ato-programa em linguagem informática, envolvendo elementos importantes relativos a aspectos técnicos que podem interferir na atuação administrativa desempenhada por meio do sistema. Para aprovar o software, a Administração deve avaliar, por exemplo: os mecanismos destinados à segurança informática, em especial no tocante à preservação da disponibilidade, confidencialidade e integridade das informações tratadas pelo programa; as especificações sobre os meios, códigos e formas de acesso; a maneira de conservação dos suportes utilizados; a acessibilidade e usabilidade dos aplicativos desenvolvidos; critérios para auditoria do sistema; a tecnologia empregada e a observância da neutralidade tecnológica $^{996}$. Tais aspectos, embora possam trazer consequências jurídicas e ter efeitos externos à Administração ${ }^{997}$, são de caráter técnico e não se confundem com as próprias regras substanciais definidas no ato-programa.

Na verdade, o caminho metodológico para a automatização de atos administrativos começa com a compilação, em linguagem natural, das normas jurídicas aplicáveis, e termina com a conversão de tais regras em linguagem de programação ${ }^{998}$. Essas operações são sucedidas pela decisão da Administração no sentido de atuar de modo automatizado, reconhecendo como seus os atos praticados pelo sistema informático. Em princípio, poderia ser mais lógico se cada uma dessas atividades ocorresse segundo uma sequência temporal, por meio de atos administrativos específicos: assim, a Administração fixaria as regras que pretende ver aplicadas pela máquina (ato-programa), seguindo-se o desenvolvimento do sistema e a verificação, pelo próprio órgão público, sobre o atendimento dos propósitos almejados (aprovação do software). Depois disso, verificada a higi-

\footnotetext{
${ }^{996}$ Fazendo referência a alguns desses atributos, com base na legislação espanhola então vigente, cf. AGIRREAZKuenaga, Iñaki, Chinchilla, Carmen, op. cit., p. 45 e BAUZÁ MARTORELl, Felio José, Procedimiento Administrativo Electrónico, cit., p. 130.

997 Já se entendeu, a propósito, que a prévia aprovação dos programas e aplicativos não é uma questão que se coloque apenas sob a dimensão interna da administração eletrônica (cf. VALERO TORRIJOS, Julián, El régimen jurídico de la e-Administración, cit., p. 81).

${ }_{998}$ Sobre o caminho metodológico da informatização de atividades jurídicas, cf. CONTALDO, Alfonso, GoRGA, Michele, op. cit., pp. 14-15.
} 
dez da programação e do desenvolvimento do sistema, a Administração decidiria operar de modo automatizado, colocando o sistema em operação ${ }^{999}$.

Esse caminho lógico é aqui descrito com o propósito de identificar os diversos conteúdos materiais envolvidos na decisão de automatizar a expedição de atos administrativos, mas não para defender a necessidade jurídica da separação formal ou cronológica entre tais atos. Para assegurar a adesão da atuação automatizada em relação ao ordenamento jurídico, é preciso que a Administração decida a respeito de tais temas, porém não é imprescindível que o faça em atos administrativos distintos. Por meio de um só ato, a Administração pode decidir operar de modo automatizado, adotar os critérios materiais de decisão e aprovar o software incumbido de efetuar as operações pertinentes. Em razão da complexidade dos trabalhos envolvidos, em geral de caráter interdisciplinar, a tendência é o desenvolvimento conjunto de sistemas informáticos por técnicos do Poder Público e profissionais da informática, sendo comum que o próprio programador formalize as regras a serem adotadas, com a ajuda de um funcionário público ${ }^{1000}$.

O sistema pode ser desenvolvido inicialmente por técnicos da Administração, de acordo com os conhecimentos disponíveis, e depois submetido à autoridade competente, para aprovação e posterior avaliação sobre a conveniência e oportunidade de sua adoção como instrumento de expedição de atos administrativos automatizados ${ }^{1001}$. Neste caso, as regras empregadas no desenvolvimento do programa constituem um mero objeto de estudo até ganhar valor jurídico a partir da decisão que determina a efetiva operação do sistema. Também é admissível o aproveitamento de software já adotado por outro

\footnotetext{
999 MARONGIU propõe um procedimento formalizado para a fase da comunicação entre o funcionário e o programador, de forma a atingir a melhor correspondência possível entre o ato administrativo e o programa. Assim, o autor propõe que, numa fase preliminar à elaboração do programa, seja redigido um texto em língua natural, chamado ato-algoritmo ou pré-software, em que as instruções da Administração fossem expressas em forma de algoritmo, ou seja, com a rigidez lógica própria do programa. A versão final desse ato seria adotada pela autoridade competente, que assumiria a responsabilidade por ele, cabendo ao profissional informático basear-se nesse texto, simplesmente transpondo-o em linguagem de programação (cf. Gli atti amministrativi ad elaborazione elettronica, cit., p. 2).

${ }^{1000}$ Cf. ibidem, p. 3.

${ }^{1001}$ Há quem entenda, por exemplo, que a aprovação de programas e aplicativos é responsável por assegurar a plena sujeição dos aplicativos e serviços eletrônicos à lei e ao direito sob uma perspectiva material (cf. VALERO TORRIJOS, Julián, El régimen jurídico de la e-Administración, cit., pp. 79-80 e Administrative Law and eGovernment, cit., p. 47.).
} 
ente público ${ }^{1002}$, desde que o órgão interessado considere a programação compatível com sua realidade jurídico-administrativa ou caso possa efetuar as adaptações necessárias para tanto, hipótese a ser compreendida como elaboração de um novo programa. Não se pode tampouco descartar a utilização de um software que não tenha sido desenvolvido em sua origem para a Administração Pública, desde que compatível com as necessidades da atividade a ser automatizada, devendo sua utilização também ser definida por meio de ato administrativo, para todos os fins pertinentes ${ }^{1003}$.

A distinção entre os dois conteúdos materiais envolvidos na decisão de automatizar a expedição de atos administrativos - o ato-programa e a aprovação do softwa$r e-$ traz perspectivas significativas em alguns aspectos.

O primeiro aspecto diz respeito aos diferentes níveis de publicidade exigidos em cada um dos âmbitos de decisão. $\mathrm{O}$ ato-programa exige publicidade indiscriminada, dada sua qualidade de ato normativo responsável pela fixação de critérios cuja aplicação interfere nos direitos dos administrados ${ }^{1004}$. Já o ato de aprovação envolve atributos que não exigem publicação ou até mesmo se mostram incompatíveis com uma divulgação ampla. Assim, por exemplo, a aprovação do software deve importar na divulgação dos elementos que permitam a fiscalização da atuação automatizada ${ }^{1005}$ e possibilitem ao usuário saber quais os requisitos técnicos para relacionar-se de modo eficaz com a Administração Pública ${ }^{1006}$. De outra parte, há elementos técnicos integrantes da aprovação do programa desprovidos de consequências em relação à defesa de direitos, sendo dispensável sua publicação. Por fim, há aspectos que, por definição, não devem ser objeto de publicidade, como é o caso de determinadas regras referentes à segurança informática - a serem entendidas como informações sigilosas, de acesso restrito, na defesa do interesse público ${ }^{1007}$.

\footnotetext{
${ }^{1002}$ Cf. Martín Delgado, Isaac, Naturaleza, Concepto y Régimen Jurídico de la Actuación Administrativa Automatizada, cit., p. 378.

${ }_{1003}$ Cf. MASUCCI, Alfonso, Procedimento amministrativo e nuove tecnologie, cit., pp. 84-85.

${ }^{1004}$ Mencionando a aptidão do programa para criar obrigações para terceiros, cf. PLANTEY, Alain, op. cit., p. 98.

1005 Cf. Justen FILHO, Marçal, Pregão, cit., p. 280.

${ }^{1006}$ Cf. VALERO TORRIJOS, Julián, Administración pública, ciudadanos y nuevas tecnologías, cit., p. 2958.

1007 A revelação de tais informações poderia pôr em risco a sistemas de interesse estratégico, enquadrando-se no disposto no art. 23, VII, da Lei Federal n. 12.527/11.
} 
Outro aspecto relevante diz respeito ao alcance das decisões. O ato de aprovação do software tem efeitos apenas em relação à atuação automatizada, ao passo que o ato-programa, ao fixar as regras materiais de atuação do software, pode ter efeitos em relação à atividade desempenhada pelo ser humano, pois o uso da tecnologia não deve causar discriminações ou privilégios ${ }^{1008}$. Assim, caso ainda seja possível a prática de atos administrativos pela via tradicional, em paralelo à via automatizada - v.g., no caso de problemas técnicos no sistema -, o ser humano deverá aplicar, em sua atuação, os mesmos critérios substanciais adotados na programação do sistema.

\subsubsection{O conteúdo da programação}

Um problema pode ser solucionado pelo computador caso seja traduzível em um algoritmo ${ }^{1009}$. Algoritmo é uma sucessão ordenada de operações predeterminadas que formalizam um processo de raciocínio ${ }^{1010}$. Ele deve trazer um claro nexo de derivação entre a premissa e a consequência, sem contradições ou lacunas, decomponível em uma série de enunciados elementares ${ }^{1011}$. Por meio do software, a máquina aplica algoritmos, efetuando o processamento da informação de acordo com as instruções recebidas.

A aplicação automatizada de normas jurídicas depende, assim, da definição dos respectivos algoritmos ${ }^{1012}$. Isso pressupõe que a hipótese de fato relacionada a uma consequência jurídica esteja regulada e delimitada de modo exaustivo ${ }^{1013}$. Por isso, a elaboração dos algoritmos relativos à produção dos atos administrativos automatizados é feita por meio da formalização dos elementos de fato e de direito pertinentes ${ }^{1014}$. Para tanto, as

\footnotetext{
${ }^{1008}$ Cf. supra, item 2.4.2.

${ }^{1009}$ Cf. FANTIGROSSI, Umberto, op. cit., p. 51.

1010 Cf. ConTAldo, Alfonso, Gorga, Michele, op. cit., p. 180 e Russo, Vincenzo, op. cit., p. 86.

1011 Cf. ContAldo, Alfonso, Gorga, Michele, op. cit., p. 181.

1012 Tratando da possibilidade teórica da utilização de computadores para a solução de questões jurídicas, com uma crítica aos limites impostos pela lógica formal, cf. LOSANO, Mario G., op. cit., pp. 54-68.

${ }^{1013}$ Cf. JiNESTA LOBO, Ernesto, op. cit., p. 15

${ }^{1014}$ Cf. ConTaldo, Alfonso, Gorga, Michele, op. cit., pp. 179-180.
} 
regras jurídicas a serem aplicadas na produção dos atos administrativos e os acontecimentos da vida real são traduzidos em linguagem formal, para que o sistema informático possa considerar como realizada uma hipótese normativa quando recebida uma determinada informação. O sistema funciona, assim, de acordo com o esquema "se..., então...", em que o "se" corresponde aos elementos de fato a serem considerados e o "então" refere-se à consequência sempre devida caso presentes tais elementos ${ }^{1015}$. Assim, verificada a hipótese de fato concreta $\mathrm{A}$, segue-se a decisão $\mathrm{B}^{1016}$.

A definição dos algoritmos integrantes do software constitui uma tarefa complexa, relacionada a três diferentes dimensões: a) a fixação de regras segundo o quadro normativo em vigor; b) a antecipação do exercício da discricionariedade administrativa; c) a determinação de regras para verificação dos elementos de fato. Tais temas serão enfrentados nos itens a seguir.

\subsubsection{A fixação de critérios segundo o quadro normativo}

As regras a serem aplicadas pelo software devem espelhar o quadro normativo em vigor. Por essa razão, sua fixação deve decorrer de um completo estudo da realidade jurídica relacionada à atividade a ser informatizada. Isso inclui a identificação das normas relativas à matéria, a solução antecipada de possíveis lacunas e conflitos normativos, a verificação dos eventuais entendimentos jurisprudenciais e a adoção das soluções interpretativas adequadas ${ }^{1017}$.

O ato-programa, como ato administrativo, deve ser compatível com os princípios gerais da ação administrativa e com a específica disciplina legal de cada ato e-

\footnotetext{
${ }^{1015}$ Cf. ibidem, p. 177.

${ }^{1016}$ Cf. MASUCCI, Alfonso, L'atto amministrativo informatico, cit., pp. 48-49.

1017 Sobre a interpretação efetuada para a elaboração do ato-programa, cf. USAI, Alessandro, op. cit., itens 2.1 e 3.1 .
} 
manado ${ }^{1018}$. A tecnologia limita-se a substituir juízos intelectivos antes atribuídos a servidores públicos, mas sem fazer surgir um regramento tecnológico que se sobreponha à legalidade administrativa ${ }^{1019}$. Exige-se, portanto, uma perfeita correspondência entre os aplicativos informáticos e as normas a que se submete a Administração ${ }^{1020}$, ou seja, a programação do sistema deve respeitar todas as condições de legitimidade relativas aos atos a serem produzidos pela máquina ${ }^{1021}$. Assim, devem ser observadas as normas aplicáveis à atuação humana, preservando as garantias derivadas dos princípios incidentes sobre a atividade administrativa $^{1022}$ e as normas legais e regulamentares pertinentes ${ }^{1023}$.

A subordinação do ato-programa ao ordenamento inclui a obediência às normas existentes e àquelas que vierem a ser elaboradas. O programa deve conter, em cada momento, a realidade normativa aplicável ${ }^{1024}$. Por isso, alterada a disciplina legal de uma atividade automatizada, a autoridade competente deverá determinar a atualização da programação do sistema, para manter sua adesão ao ordenamento ${ }^{1025}$. Isso ocorre por meio de um novo ato-programa.

Além disso, normalmente as regras a serem aplicadas não constam de um só instrumento normativo, sendo necessário compilar todas as disposições pertinentes. Trata-se de uma tarefa tradicionalmente atribuída aos regulamentos, mas jamais levada a cabo

${ }^{1018}$ Cf. MASUCCI, Alfonso, L'atto amministrativo informatico, cit., p. 60; MARONE, Umberto, op. cit., p. 89 e RABBITO, Chiara, L'informatica al servizio della pubblica amministrazione e del citadino, cit., p. 36. Como ato administrativo normativo, o ato-programa constitui um ato de hierarquia inferior à lei, devendo nesta buscar seu fundamento de validade. Tratado dessa subordinação, em relação aos atos administrativos normativos em geral, cf. ALMEIDA, Fernando Dias Menezes de, op. cit., pp. 223-224.

${ }^{1019}$ Cf. PAlOMAR OlMEDA, Alberto, Procedimientos administrativos y régimen documental en la actuación de la Agencia Española de Protección de Datos, cit., p. 69.

${ }^{1020}$ Cf. GÓMEZ PUENTE, Marcos, op. cit., p. 127.

${ }^{1021}$ Cf. MASUCCI, Alfonso, L'atto amministrativo informatico, cit., p. 61 e PlANTEY, Alain, op. cit., p. 98.

${ }^{1022}$ Mencionando a legalidade e a segurança jurídica, cf. MARTín DELGADO, Isaac, La gestión electrónica del procedimiento administrativo, cit., pp. 100-101. Segundo MASUCCI, em função de do princípio da proporcionalidade, o programa não deve prever ao administrado ônus imprevisíveis e ocasionais, nem podem ser previstas instruções que acarretem restrições a direitos não justificadas pelos fins públicos a serem perseguidos (cf. L'atto amministrativo informatico, cit., pp. 62-63).

1023 Tratando da programação relativa ao pregão eletrônico, cf. JUSTEN FILHO, Marçal, Pregão, cit., p. 280.

${ }^{1024}$ Cf. PALOMAR OLMEDA, Alberto, Gestión Electrónica de los procedimientos, cit., p. 439.

1025 A impossibilidade técnica ou financeira de fazer ajustes nas regras de sistemas informáticos já foi um tema mais problemático tempos atrás, quando se considerava preocupante que se evitasse mudar regras ou entendimentos jurisprudenciais em vista de preservar a atuação informatizada (cf. BRAIBANT, Guy, Introduction, cit., p. 12). Com a evolução das técnicas informáticas, em regra é possível efetuar a atualização dos sistemas sempre que necessário, mantendo permanentemente sua correspondência com o ordenamento jurídico. 
com tanta exaustividade, pois em geral é permitido ao servidor público invocar preceitos normativos dispersos para desempenhar suas atividades de modo mais adequado. $\mathrm{O}$ sistema informático não oferece iguais possibilidades: caso seja verificada uma omissão na programação efetuada, ela deverá ser corrigida, não havendo como solucionar a questão apenas no caso concreto.

Não basta, contudo, compilar normas atualizadas; é preciso traduzi-las segundo as exigências próprias da informática. Com efeito, a primeira condição para a automatização é a possibilidade de reconstrução do preceito normativo segundo o esquema "se...então" "1026. A tradução das regras legais, por meio de uma formalização de seu conteúdo, constitui um ponto essencial da programação do sistema informático, que nem sempre pode ser atendido com facilidade.

Embora o esquema referido corresponda ao modelo clássico da norma jurídica $^{1027}$, nem todos os textos legais permitem identificá-lo de maneira tão simples. As normas jurídicas são elaboradas em linguagem natural e em geral retratam a expectativa de serem aplicadas pelo ser humano. Há textos normativos cujos enunciados elementares não permitem a identificação clara de uma relação entre antecedente e consequente, o que é incompatível com a atuação automatizada ${ }^{1028}$. É o caso, por exemplo, das leis orientadas por objetivos, que enumeram os interesses a serem levados em conta pela autoridade em sua decisão ${ }^{1029}$. Nesse sentido, é comum perceber que regras aparentemente muito precisas são, na verdade, insuficientes para a atuação informática ${ }^{1030}$. Não se tratando de uma avaliação realizável por meio de técnicas e ciências exatas, tende a ser impossível a aplicação automatizada da norma ${ }^{1031}$. Por isso, podem ser necessárias reformas legislativas para respaldar o desenvolvimento de sistemas destinados à automatização de atos administrati$\operatorname{vos}^{1032}$.

\footnotetext{
${ }^{1026}$ Cf. MASUCCI, Alfonso, L'atto amministrativo informatico, cit., p. 26.

${ }^{1027}$ Cf. CONTALDO, Alfonso, GoRGa, Michele, op. cit., p. 180.

${ }^{1028}$ Cf. MASUCCI, Alfonso, L'atto amministrativo informatico, cit., p. 30.

${ }^{1029}$ Cf. Bovens, Mark, ZouRIDS, Stavros, op. cit., p. 181.

${ }^{1030}$ Cf. GILLI, Jean-Paul, op. cit., p. 100.

${ }^{1031}$ Cf. MASUCCI, Alfonso, L'atto amministrativo informatico, cit., p. 41.

${ }^{1032}$ Cf. GÓMEZ PUENTE, Marcos, op. cit., p. 129.
} 


\subsubsection{A antecipação do exercício da discricionariedade administrativa}

Apesar dos avanços tecnológicos ocorridos nos últimos anos, nem todas as atividades podem ser desempenhadas por máquinas. Determinadas habilidades continuam a ser exclusivas do ser humano, sobretudo porque o computador não é capaz de atuar de modo criativo, faltando-lhe a capacidade de iniciativa para fazer algo que ultrapasse a simples comparação entre informações e regras objetivas.

Nesse sentido, grande parte da doutrina tem observado que são passíveis de automatização apenas os atos administrativos vinculados, plenamente compatíveis com as características dos sistemas informáticos, em razão da possibilidade de verificação objetiva de informações em face de pressupostos legais representados no programa, levando à adoção de uma decisão de conteúdo predeterminado ${ }^{1033}$. No caso dos atos discricionários, nos quais não há uma solução única a ser adotada, admitindo-se a escolha entre opções lícitas, os meios informáticos poderiam ser usados apenas como instrumento de apoio ${ }^{1034}$, coadjuvante da atuação humana ${ }^{1035}$. O mesmo ocorreria em relação aos atos decorrentes da aplicação de conceitos jurídicos indeterminados ${ }^{1036}$, tidos como incompatíveis com a for-

${ }^{1033}$ Cf. MARONE, Umberto, op. cit., p. 86. É a opinião da grande maioria da doutrina, podendo ser consultadas as observações constantes dos seguintes trabalhos: BRAIBANT, Guy, Introduction, cit., pp. 10-11; CASTELLS ARTECHE, José Manuel, Aproximación a la problemática de la informática y administración pública, cit., p. 46; CASTElls ARTECHE, José Manuel, La limitación informática, cit., p. 938; ConTALDO, Alfonso, GORGA, Michele, op. cit., pp. 182-183; FANTIGROSSI, Umberto, op. cit., pp. 63 e 81; FERNÁNDEZ SALMERÓN, Manuel, La protección de los datos personales en las administraciones públicas, cit., p. 385; GIURDANELLA, Carmelo, GuARnACCIA, Elio, op. cit., pp. 31-33; Gómez PuENTE, Marcos, op. cit., pp. 183-184; LINARES GIL, Maximino Ignacio, Identificación y autenticación de las administraciones públicas, cit., p. 311; LINARES GIL, Maximino Ignacio, Modificaciones del Régimen Jurídico Administrativo derivadas del empleo masivo de nuevas tecnologías, cit., p. 744; MINERVA, Massimiliano, op. cit., p. 941; PALOMAR OLMEDA, Alberto, Gestión Electrónica de los procedimientos, cit., p. 433; PALOMAR OLMEDA, Alberto, La utilización de las nuevas tecnologías en la actuación administrativa, cit., p. 383; PALOMAR OLMEDA, Alberto, Procedimientos administrativos y régimen documental en la actuación de la Agencia Española de Protección de Datos, cit., p. 88; RUSSO, Vincenzo, op. cit., pp. 94-95; USAI, Alessandro, op. cit., item 1.3; VALERO TORRIJOS, Julián, El régimen jurídico de la e-Administración, cit., 2007, p. 75.

${ }_{1034} \mathrm{Cf}$. VALERO TORRIJOS, Julián, El régimen jurídico de la e-Administración, cit., p. 75

1035 Cf. MANDOLFO, Giovanni, op. cit., p. 1315; BRAIBANT, Guy, Introduction, cit., pp. 10-11.

${ }^{1036} \mathrm{O}$ aprofundamento da análise da relação entre discricionariedade administrativa e conceitos jurídicos indeterminados foge aos limites do presente estudo. Apenas para efeito de discussão dos temas relacionados à automatização, adota-se como ponto de partida a ideia de que a discricionariedade pode decorrer da utilização, pela lei, de fórmulas amplas, quando estas gerarem a possibilidade de escolha entre diferentes soluções igualmente válidas. Nesse sentido, cf. MEDAUAR, Odete, Direito administrativo moderno, cit., p. 114. 
malização, a qual exige uma sintaxe regular e invariável ${ }^{1037}$, obtida por meio de preceitos que ofereçam uma interpretação unívoca ${ }^{1038}$.

Todavia, é melhor o entendimento segundo o qual a automatização é cabível se a discricionariedade for previamente disciplinada pela Administração, por meio da adoção de critérios precisos e compatíveis com a atuação do computador ${ }^{1039}$. Nesse sentido, para automatizar atos que, pela via tradicional, incluem uma avaliação de conveniência e oportunidade, é necessário antecipar essas tarefas para a fase de programação, momento no qual o ser humano interfere no conteúdo do ato automatizado, determinando os pressupostos na presença dos quais o ato deve ser expedido ${ }^{1040}$. Assim, ao invés de se pronunciar vez por vez, a Administração define de modo exaustivo comandos objetivos a serem transformados em algoritmos ${ }^{1041}$. Com isso, os critérios discricionários são convertidos em regras precisas, inequívocas, gerais e abstratas, que possam ser aplicadas pela máquina aos casos concretos ${ }^{1042}$. Neste caso, a fase de programação do sistema passa a constituir a sede de exercício do poder de determinação de um conteúdo comum a várias decisões singulares futuras ${ }^{1043}$.

A conversão dos critérios discricionários em algoritmos ocorre mediante a prévia identificação das situações a serem submetidas ao sistema incumbido da expedição dos atos automatizados ${ }^{1044}$. A autoridade relaciona a essas hipóteses imagináveis um

\footnotetext{
${ }^{1037}$ Cf. CONTALdo, Alfonso, Gorga, Michele, op. cit., p. 180.

${ }_{1038}$ Cf. MASUCCI, Alfonso, L'atto amministrativo informatico, cit., pp. 20-21.

1039 Cf. DuNI, Giovanni, L'amministrazione digitale, cit., p. 75.

${ }^{1040}$ Cf. DE LuCA, Flavio, op. cit., pp. 297-298. Assim, o poder discricionário é exercido "a montante" pela autoridade administrativa, mediante a predeterminação dos critérios e das modalidades adotados na definição do programa (cf. MASUCCI, Alfonso, Procedimento amministrativo e nuove tecnologie, cit., p. 94). Dessa maneira, não há problema em informatizar a atividade discricionária, depois de uma intervenção só inicial do homem (cf. SAITTA, Fabio, op. cit., p. 18). Ainda respeito da antecipação da discricionariedade, cf. MARTíN DELGADO, Isaac, La gestión electrónica del procedimiento administrativo, cit., p. 100 e, do mesmo autor, Naturaleza, Concepto y Régimen Jurídico de la Actuación Administrativa Automatizada, cit., p. 370. Sobre a possibilidade de automatização da atividade discricionária, cf. também, na doutrina brasileira, RAMOS JÚNIOR, Hélio Santiago, Rover, Aires José, $O$ ato administrativo eletrônico sob a ótica do princípio da eficiência, cit., pp. 38-39.

${ }^{1041}$ Cf. MARONGIU, Daniele, Gli atti amministrativi ad elaborazione elettronica, cit., p. 1 e MASUCCI, Alfonso, Procedimento amministrativo e nuove tecnologie, cit., p.93.

${ }^{1042}$ Fala-se, neste caso, em parametrização antecipada da discricionariedade, que deve ser suficientemente rígida e unívoca (cf. MARONGIU, Daniele, Gli atti amministrativi ad elaborazione elettronica, cit., p. 1).

${ }^{1043}$ Cf. FANTIGROSSI, Umberto, op. cit., pp. 94 e 139.

${ }^{1044}$ Cf. RABBITO, Chiara, L'informatica al servizio della pubblica amministrazione e del citadino, cit., p. 37 e FANTIGROSSI, Umberto, op. cit., p. 93.
} 
conjunto de conteúdos para as decisões futuras, por meio da seleção antecipada dos elementos de fato relevantes para o exercício do poder e a avaliação dos interesses envolvi$\operatorname{dos}^{1045}$, levando em conta eventuais diversidades das situações futuras ${ }^{1046}$. Em outras palavras, classificam-se as hipotéticas situações de fato tidas como significativas para os fins de emanação de atos individuais, de maneira a predeterminar tais decisões e seus conteúdos ${ }^{1047}$, reduzindo a avaliação das circunstâncias do caso às hipóteses programadas ${ }^{1048}$. Isso equivale a cumprir, nestes casos, aquele conjunto de apreciações que o legislador havia pretendido reservar à autoridade, quando lhe atribuiu o poder discricionário ${ }^{1049}$.

Isso depende de um notável incremento da atividade cognitiva da autoridade responsável pela decisão ${ }^{1050}$. Deve ser adquirido o maior número possível de informações não apenas sobre os dados de fato, mas sobre as opiniões e expectativas dos sujeitos, inclusive dos potenciais destinatários dos atos automatizados ${ }^{1051}$. Embora a contribuição dos interessados diretos possa ser mais efetiva, por trazer o conhecimento das situações concretas $^{1052}$, a discussão de critérios a serem adotados deve estar aberta não somente aos atuais interessados, mas a qualquer pessoa, pois todos poderão vir a ser atingidos pela atuação automatizada ${ }^{1053}$. De todo modo, deve-se deslocar para a fase de programação os diversos mecanismos próprios do exercício da discricionariedade, como é o caso dos parece-

\footnotetext{
${ }^{1045}$ Cf. FANTIGROSSI, Umberto, op. cit., p. 109.

${ }^{1046}$ Cf. MASUCCI, Alfonso, L'atto amministrativo informatico, cit., p. 62.

${ }^{1047}$ Cf. FANTIGROSSI, Umberto, op. cit., p. 94.

1048 Cf. DE LUCA, Flavio, op. cit., pp. 297-298.

1049 Cf. MASUCCI, Alfonso, L'atto amministrativo informatico, cit., p. 35-36.

${ }^{1050}$ Cf. FANTIGROSSI, Umberto, op. cit., p. 98.

${ }^{1051}$ Cf. ibidem, p. 116.

1052 Cf. ibidem, p. 119.

${ }^{1053}$ Sobre a legitimidade para participar do procedimento de elaboração do ato-programa, cf. ibidem, p. 118.
} 
res técnicos e jurídicos, bem como as deliberações dos órgãos colegiados ${ }^{1054}$ e os diversos mecanismos participativos, como as consultas públicas ${ }^{1055}$.

O exercício prévio da discricionariedade administrativa não implica mudança da natureza da atividade exercida ou das normas jurídicas aplicáveis. A própria lei que confere o poder discricionário impede sua eliminação ${ }^{1056}$. Apesar de exercida na construção de um sistema informático destinado à prática de atos automatizados, a discricionariedade administrativa continua a existir. Isso pode ser demonstrado pela contínua possibilidade de rever as regras do ato-programa, segundo outra avaliação humana - pela qual se exerceria, novamente, o poder discricionário. Assim, a expedição do ato-programa não implica a renúncia a avaliar, no futuro, situações de fato mudadas ou elementos que se tornem relevantes com o tempo ${ }^{1057}$. De outra parte, ao manter as regras incorporadas ao programa, a autoridade reitera a decisão já tomada a esse respeito.

A adequada compreensão desse mecanismo é importante para evitar que a automatização se torne uma causa de cristalização dos entendimentos administrativos, com prejuízo da renovação da ação administrativa. Com efeito, as definições adotadas por ocasião da elaboração do ato-programa, caso não decorram estritamente da lei, devem ser reavaliadas de modo contínuo à luz do contexto presente. As regras do ato-programa não devem apenas refletir as regras legais em vigor, devendo também estar atualizadas sob o aspecto da oportunidade e conveniência. Isso é ainda mais relevante em vista da falta do

\footnotetext{
${ }^{1054}$ A doutrina já apontou que as decisões praticadas por órgãos colegiados, decorrentes de um diálogo e da dialética entre os participantes, seriam incompatíveis com a atuação por sistema (cf. CONTALDO, Alfonso, GoRGA, Michele, op. cit., p. 184). Na verdade, a decisão colegiada é, por definição, humana. Sendo humana, não pode ser automatizada. Mas o órgão colegiado pode fixar, segundo uma decisão humana, parâmetros a serem aplicados por um sistema informático gerido por esse órgão. Também é possível que a decisão humana dos órgãos colegiados seja efetuada com auxílio da tecnologia (por exemplo, um sistema eletrônico para recebimento e contagem de votos), até mesmo de molde a tornar dispensável a reunião presencial (por exemplo, uma reunião por videoconferência ou segundo uma discussão orientada por correspondências eletrônicas). Todavia, nesses exemplos, não há decisão colegiada praticada por computador. As comissões, assim, devem intervir antes da máquina, no momento da definição de critérios, e não mais no momento de aplicação de tais regras (cf. BRAIBANT, Guy, Introduction, cit., p. 11).

${ }^{1055}$ Cf. PlanTEY, Alain, op. cit., p. 99.

1056 Cf. USAI, Alessandro, op. cit., item 3.1. Fosse possível considerar em separado a atuação da máquina, ela seria classificada como vinculada. Todavia, o ato administrativo automatizado, como se verá, deve ser entendido como uma decorrência da combinação das duas atuações: a do ser humano, na programação abstrata, e a do computador, na aplicação objetiva das regras do software ao caso concreto. Em sentido diverso, avaliando em separado a atuação do computador, RUSSO a considera uma atividade vinculada (cf. op. cit., pp. 93-94).

${ }^{1057}$ Cf. FANTIGROSSI, Umberto, op. cit., p. 94.
} 
confronto do homem com os casos concretos, que em geral contribuem para a evolução dos posicionamentos da Administração ${ }^{1058}$.

Por outro lado, é importante ressaltar que esse modo de exercício da discricionariedade não encontra, em si, impedimento jurídico algum. Trata-se de um mecanismo legítimo associado à atividade regulamentar, admitido no âmbito da administração em papel e dos atos administrativos tradicionais ${ }^{1059}$. A questão principal, na verdade, é se essa regulamentação em torno de parâmetros totalmente objetivos é possível ou adequada para uma determinada atividade. Se não for, a automatização é inviável, assim como seria uma atuação humana desempenhada segundo tais regras estritas.

Muitas vezes a discricionariedade administrativa existe em vista da impossibilidade prática de prever todas as situações concretas possíveis ou para atribuir à autoridade a flexibilidade necessária para a decisão à luz do caso concreto, sobretudo no caso de decisões complexas ${ }^{1060}$. Assim, estaria em contraste com a lei a eventual generalização de situações que necessitassem ser consideradas de acordo com suas particularidades ${ }^{1061}$. Sempre que os atributos imprevisíveis do caso concreto forem relevantes para a decisão, a atuação automatizada é prejudicada.

Quando a avaliação do caso concreto é necessária, ela deve ser feita pelo ser humano, o que pode ocorrer até mesmo em um processo administrativo eletrônico, mas com abertura para a atuação combinada do ser humano e da máquina ${ }^{1062}$. Também deve ser

\footnotetext{
${ }^{1058}$ MASUCCI aponta o perigo de uma tendência à rigidez da ação administrativa, com a perda da capacidade de adaptação a novas exigências sociais e aumento da contraposição entre cidadão e Administração, decorrente da automatização de atos que envolvam o exercício da discricionariedade, em razão da desindividualização da decisão (cf. L'atto amministrativo informatico, cit., p. 37-38). Por essa razão, não somente o órgão público responsável deve periodicamente reavaliar os critérios adotados no ato-programa, como os diversos canais de comunicação devem estar abertos ao questionamento de critérios e a Administração deve motivar a resposta a eventuais impugnações, explicando as razões pelas quais os critérios utilizados são os mais corretos. Sobre os recursos, com menção a outras formas de impugnação, cf. infra, item 4.9.7.

${ }^{1059} \mathrm{Na}$ administração tradicional, o regulamento é visto como um meio de disciplinar a discricionariedade administrativa, garantindo a igualdade na aplicação da lei. Vale mencionar, apenas a título de exemplo, as considerações de CELSO ANTONIO BANDEIRA DE MELLO, para quem o regulamento executivo, inteiramente subordinado à lei, constitui uma forma de garantir a segurança jurídica e garantir a aplicação isonômica da lei (cf. Curso de Direito Administrativo, $26^{a}$ ed., São Paulo, Malheiros, 2009, p. 359).

${ }_{1060}$ Cf. UsAI, Alessandro, op. cit., item 3.1.

${ }^{1061}$ Cf. MASUCCI, Alfonso, L'atto amministrativo informatico, cit., p. 37.

${ }^{1062}$ Cf. infra, item 4.3.
} 
considerada inviável a automatização de atos discricionários nos quais é difícil, se não impossível, encontrar com antecedência todas as hipóteses relevantes possíveis ${ }^{1063}$. A exigência de definir classes de decisões em um momento anterior à verificação concreta das várias situações limita a automatização aos setores em que haja a possibilidade concreta dessa antecipação, em razão da estabilidade das situações ou da previsibilidade das eventuais mudanças ${ }^{1064}$.

Sendo possível identificar classes de situações com características semelhantes, que possam ser objeto de uma regra comum, a disciplina da discricionariedade administrativa, por meio do ato-programa, deve ser entendida como legítima. A liberdade conferida pela norma jurídica não está sempre relacionada à avaliação caso a caso, podendo estar fixada por classes. Se a regra comportar aplicação por classes, é possível produzir decisões uniformes em relação a vários interessados, a quem cabe apenas comprovar pertencer àquela classe, sujeitando-se à consequência jurídica correspondente ${ }^{1065}$.

Neste caso, não há razão para entender que o computador não possa efetuar a verificação objetiva dos parâmetros adotados. Ao contrário, isso deve ser tido como desejável, pois a tecnologia permite o desempenho de tal tarefa com menos erros e muito mais agilidade. Quando a norma permite uma tipificação preventiva dos elementos de fato relevantes e dos conteúdos das decisões, o exercício antecipado da discricionariedade mostra-se até mesmo devido, pela possibilidade de realizar de modo mais adequado relevantes princípios da Administração Pública, tais como a igualdade e a segurança jurídica ${ }^{1066}$.

\footnotetext{
1063 Cf. RUSSO, Vincenzo, op. cit., p. 96.

${ }^{1064}$ Cf. FANTIGROSSI, Umberto, op. cit., p. 140.

1065 Cf. MASUCCI, Alfonso, L'atto amministrativo informatico, cit., p. 36.

1066 Sobre esses aspectos, cf. FANTIGROSSI, Umberto, op. cit., pp. 90 e 107; GóMEZ PUENTE, Marcos, op. cit., p. 128 e LINARES GIL, Maximino Ignacio, Identificación y autenticación de las administraciones públicas, cit., p. 312.
} 


\subsubsection{A definição de regras para verificação dos elementos de fato}

$\mathrm{Na}$ expedição automatizada de atos administrativos, a definição das regras a serem aplicadas precede o efetivo conhecimento a respeito dos casos concretos ${ }^{1067}$. A programação é obra do homem, mas o conhecimento das situações individuais é confiado diretamente ao sistema. Assim, cabe ao sistema informático efetuar a cognição, ou seja, tomar contato com os diversos elementos de fato que constituem o caso concreto, à luz dos quais o ato automatizado é expedido.

$\mathrm{Na}$ atuação tradicional, é o próprio ser humano quem avalia os elementos de fato, representados em documentos tidos como idôneos para a comprovação exigida pela hipótese normativa. Para tanto, pode fazer as verificações necessárias, inclusive a contraposição entre documentos diversos e até mesmo em relação a outros meios de prova. Muitas vezes, a solução de questões de fato constitui o mais relevante valor agregado trazido pela atuação administrativa, constituindo um aspecto fundamental do exercício do poder.

Para a prática do ato administrativo tradicional, o ser humano deve tomar conhecimento de uma dada situação de fato e, com base nesse conhecimento, aplicar a lei ao caso concreto. Assim, cabe ao agente público ler o documento, extrair dele o elemento de fato tido com relevante e proferir a decisão cabível. Não há separação entre conhecer e decidir: o ser humano realiza um processo intelectivo pelo qual toma conhecimento do fato e o confronta com a hipótese normativa pertinente, praticando o ato administrativo.

A mesma operação não pode ser efetuada pela máquina. Caso o ato administrativo dependa da avaliação de matéria probatória, essa tarefa não poderá ser confiada à atuação automatizada. Para viabilizar a automatização, não apenas os critérios normativos precisam ser convertidos em uma série de enunciados simples e lógicos, mas as próprias informações atinentes a elementos de fato necessitam ter seus requisitos fixados de

${ }^{1067}$ Cf. Heredero Higueras, Manuel, op. cit., p. 75. 
modo exaustivo. Em vista disso, é necessário definir, a priori, informações padronizadas que valham como comprovação da realização da hipótese normativa.

É o caso, por exemplo, das informações relativas a fatos já apurados em outras atuações da Administração, que estejam em bases de dados oficiais, ou mesmo das informações oferecidas unilateralmente pelo administrado, as quais, por critérios de conveniência e oportunidade, a Administração decide reputar verdadeiras, sem prejuízo de ulterior verificação. Com essa estrutura, a produção de atos automatizados não depende da solução de questões de fato, mas da fixação antecipada desses critérios e do acesso a informações a respeito.

O conhecimento dos fatos operativos deixa de depender de uma intervenção humana, podendo ocorrer por meio da definição dos atributos da informação, ou seja, pela descrição dos elementos objetivos e padronizados de uma informação que permitem considerá-la como meio de prova da realização de uma determinada hipótese normativa. A fixação da informação necessária para caracterizar a realização de uma hipótese normativa também constitui um exercício prévio do poder, realizado por meio da programação.

$\mathrm{Na}$ atividade administrativa tradicional, por exemplo, quando a idade do requerente é um elemento relevante para a tomada da decisão, por estar referida na respectiva hipótese normativa, cabe à autoridade analisar a documentação pertinente, extraindo dela o elemento de fato relevante, o que lhe possibilita verificar o atendimento a tal regra. $\mathrm{Na}$ atividade automatizada, a verificação da idade é feita pelo acesso a uma determinada base de dados - v.g., o registro de pessoas naturais -, que contém a data de nascimento do interessado, procedendo-se então ao cálculo da idade e à aplicação da regra, com a qual a máquina foi instruída.

Não é necessária, assim, a intermediação humana entre o documento, como elemento representativo de um fato jurídico, e a elaboração do ato concreto. O ser humano efetua uma avaliação hipotética por ocasião da programação, estabelecendo que uma informação, caso apresente certos atributos, sofrerá a incidência de uma dada norma jurídica. Todavia, a efetiva correlação entre a informação concreta e a norma é efetuada depois, por meio da máquina. É essa estrutura que permite ao homem atuar apenas na pro- 
gramação do sistema, deixando-o diretamente incumbido de dar as respostas necessárias aos casos concretos.

Tal estrutura permite, também, incrementar a utilização das informações possuídas pela Administração. Muitas dessas informações já foram processadas de modo rigoroso e, sobretudo quando contidas em bases de dados, tendem a estar formalizadas e aptas para a automatização ${ }^{1068}$. O uso desse patrimônio informativo tende a levar a um aumento de eficiência, pois uma informação pode ser utilizada várias vezes e para distintas finalidades ${ }^{1069}$.

\subsubsection{Uma nova estrutura para a decisão}

Como já mencionado, a expedição de atos administrativos automatizados envolve duas fases distintas: a) a decisão de atuar de modo automatizado, o que inclui a programação do sistema, efetuada pelo ser humano; e b) a aplicação das regras do atoprograma ao caso concreto, realizada pela máquina ${ }^{1070}$. As decisões relacionadas à construção e operação do sistema informático encaixam-se com maior facilidade nos conceitos jurídicos tradicionais, não havendo problemas, como visto, para identificá-las como atos

\footnotetext{
${ }^{1068}$ Cf. GARCÍA MARCO, Francisco Javier, Ontologías y documentación electrónica en las actividades públicas, cit., p. 174.

${ }^{1069}$ Observado, é claro, o regime jurídico pertinente ao acúmulo informativo por parte do Poder Público, já apresentado neste estudo (cf. item 2.4.5.1).

${ }^{1070}$ A distinção é inspirada FANTIGROSSI (op. cit., p. 114), que identifica como fases a elaboração do atoprograma e a aplicação de suas regras ao caso concreto. Falando em distinguir o ato-programa e a elaboração automática, cf. RABBITO, Chiara, L'informatica al servizio della pubblica amministrazione e del cittadino, cit., p. 35 e UsAI, Alessandro, op. cit., item 2.
} 
administrativos ${ }^{1071}$. Todavia, a natureza jurídica da operação desempenhada pela máquina constitui uma questão mais difícil ${ }^{1072}$.

De fato, considerada em separado essa fase - na qual o computador reconhece de modo objetivo determinadas informações para a comprovação da hipótese normativa e aplica, de modo automatizado, a consequência respectiva -, não é possível encontrar atributos típicos de um ato administrativo. O ser humano decide apenas no momento da elaboração e aprovação do programa, pois os atos singulares são meras consequências dessa programação, não decorrentes de uma conduta humana concreta ${ }^{1073}$. A atuação do computador diante do caso singular constitui uma nova realidade, para a qual a doutrina tem buscado explicações. Já se afirmou, por exemplo, tratar-se de um produto administrativo ${ }^{1074}$ ou de uma evidência informática ${ }^{1075}$.

Fosse possível avaliar em separado a fase referente à atuação do sistema, ela teria de ser enquadrada como um fato, próprio do contexto contemporâneo, correspondente ao simples funcionamento do sistema informático, pelo qual são geradas informações por meio de operações automatizadas. No entanto, tal entendimento parece pouco elucidativo, pois não explica como o ato automatizado produz resultados funcionalmente equivalentes aos atos administrativos editados pelo ser humano. Na verdade, a chave da questão não está em buscar um enquadramento teórico para essa segunda fase, mas em explorar a relação entre a programação, feita pelo homem, e a atuação da máquina.

Os recursos tecnológicos permitem e por vezes exigem separar as várias tarefas que compõem os atos administrativos tradicionais, em geral indiferenciadas entre

\footnotetext{
1071 Cf. ZEIDLER, Karl, op. cit., p. 43.

${ }^{1072}$ Essa seria uma crítica bastante provável por parte daqueles que se opõem ao que seria uma substituição do homem pela máquina. Segundo já se observou, o uso de invenções eletrônicas para resolver problemas jurídicos, por meio de uma operação racional perfeitamente objetiva, despertou a perplexidade e a desconfiança dos juristas filiados à tradição humanista (cf. CASTELLS ARTECHE, José Manuel, Aproximación a la problemática de la informática y administración pública, cit., p. 46).

${ }_{1073}$ Cf. DUNI, Giovanni, L'amministrazione digitale, cit., pp. 76-77.

${ }^{1074}$ Cf. ZEIDLER, Karl, op. cit., pp. 43-44. A palavra produto (fabrikat), segundo o autor, foi usada justamente para ressaltar a referência ao resultado da atuação da máquina.

${ }^{1075}$ Cf. DuNI, Giovanni, L'amministrazione digitale, cit., pp. 76-77 e Ancora sul procedimento amministrativo telematico, cit., p. 2.
} 
$\mathrm{si}^{1076}-v \cdot g$., a identificação e compilação das normas aplicáveis, o exercício da discricionariedade administrativa, o reconhecimento dos fatos e a aplicação da regra correspondente. Por força da atuação da máquina, o ato administrativo clássico é desdobrado em duas fases $\operatorname{distintas~}^{1077}$, passando a corresponder a um conjunto complexo de operações no qual se incluem a programação e o conhecimento do caso concreto ${ }^{1078}$. As duas fases manifestamse externamente como uma unidade, atribuída a um ente administrativo ${ }^{1079}$, a qual desempenha as mesmas funções do ato administrativo tradicional.

Os computadores e os mecanismos de comunicação são amplificadores e prolongamentos da mente humana ${ }^{1080}$. Por essa razão, o sistema informático empregado na automatização deve ser considerado uma longa manus da autoridade, um meio à sua disposição para perseguir e atingir o objetivo desejado ${ }^{1081}$, executando com precisão e fidelidade as operações que lhe são confiadas, por meio da programação, sem nenhuma possibilidade

\footnotetext{
${ }^{1076}$ Assim já se considerou: “A aplicação dos sistemas de elaboração automática de dados determina uma cisão entre a atividade cognitiva em função da respectiva possibilidade de realização mecânica. Deve-se distinguir atividades de comprovação de fatos, a mera busca de dados ou informação sobre disposições aplicáveis, decisões jurisdicionais sobre hipóteses de fato análogas e o que é especificamente atividade aplicativa de normas, raciocínio jurídico ou interpretação analógica de normas. Se na instrução não mecanizada de um procedimento todas essas atividades aparecem confundidas e indiferenciadas, sem que caiba estabelecer uma ordem ou sucessão temporal entre elas, a realização mecânica de tais atividades exigiria a mencionada cisão, porquanto a sucessão temporal viria imposta pelas exigências da máquina. Isto implicaria uma revisão das normas procedimentais, para estabelecer uma sucessão de fases ou etapas da instrução" (HEREDERO HIGUERAS, Manuel, op. cit., pp. 74-75, tradução livre).

${ }^{1077}$ Fazendo refência a um processo jurídico e um processo técnico distinto, cf. ZEIDLER, Karl, op. cit., pp. $42-43$.

${ }^{1078}$ Cf. FANTIGROSSI, Umberto, op. cit., p. 131.

${ }^{1079}$ Cf. ZeIDLER, Karl, op. cit., pp. 42-43.

${ }^{1080}$ Cf. CASTELLS, Manuel, op. cit., p. 62. As pessoas comuns e, infelizmente, alguns profissionais do direito, invocam o lugar comum de que o homem é insubstituível em tudo que diz respeito à aplicação do direito, sem que se tenha em mente que, por meio do software, o computador e o homem são o mesmo sujeito, pois o primeiro é o imago mentis do segundo, assim como um livro não é algo diverso da representação do pensamento e da vontade de seu autor (cf. Borruso, Renato, Prefazione, cit., p. 7).

${ }^{1081}$ Cf. MASUCCI, Alfonso, L'atto amministrativo informatico, cit., p. 87.
} 
de inovar ${ }^{1082}$. De modo indireto, a decisão humana produz efeitos, os quais são multiplicados pelo sistema ${ }^{1083}$, sendo possível afirmar, assim, que a atuação automatizada tem caráter apenas instrumental em relação ao surgimento do ato administrativo ${ }^{1084}$.

É importante ressaltar que a atividade administrativa automatizada não ocorre de modo alheio ao homem. Ocorre, é certo, uma quebra do elemento subjetivo do ato administrativo, na medida em que não existe uma intervenção imediata do titular do órgão na determinação de seu conteúdo ${ }^{1085}$. Assim, do ponto de vista material, o conteúdo do ato é definido pelo resultado de uma atividade automatizada sobre a qual não há uma supervisão direta e pessoal ${ }^{1086}$. Todavia, o desaparecimento da atuação humana é aparente ${ }^{1087}$. Por mais avançados que sejam os computadores, o homem é sempre o titular real do poder de decisão ${ }^{1088}$. Assim, não obstante provenha da máquina, o ato é sempre decorrente da decisão da Administração ${ }^{1089}$.

A decisão humana está presente nos diversos pressupostos da operação do sistema e deve ser considerada reiterada a cada momento, em razão do fato de o sistema informático estar em operação ${ }^{1090}$. A pessoa física está ausente na operação realizada frente

1082 Cf. ibidem, p. 86. FANTIGROSSI traz uma interessante comparação com as contratações eletrônicas. Naquele caso, as instruções contidas no programa formam parte integrante da manifestação de vontade contratual e consequentemente da relação jurídica gerada pelos contratos. A vontade, como elemento necessário para a existência, validade e relevância jurídica do contrato celebrado eletronicamente, está no ato de programação do sistema, condicionando a contratação à verificação de determinados eventos objetivamente predeterminados. Tal vontade existe desde o momento em que se programa o computador, porém a declaração só ocorre quando, pela verificação de todas as condições previstas pelo programa, o programa executa a operação programada. Somente nesse momento a vontade sai da esfera interna do sujeito e adquire eficácia externa, de modo que vontade e declaração advêm em momentos necessariamente diversos (op. cit., pp. 5354). Segundo o autor, haveria a mesma estrutura se o produto final não é o contrato, mas o ato administrativo. Neste caso, o que se antecipa é o exercício do poder, de modo a configurar o ato final como o resultado das determinações adotadas na preparação do programa (ibidem, p. 55).

${ }^{1083}$ Cf. JuSTEN FILHO, Marçal, Curso de Direito Administrativo, cit., p. 351.

${ }^{1084}$ Cf. MANDOLFO, Giovanni, op. cit., p. 1315.

${ }_{1085}$ Cf. VALERO TORRIJOS, Julián, El régimen jurídico de la e-Administración, cit., p. 73.

${ }^{1086}$ Cf. ibidem, p. 73.

${ }^{1087}$ Cf. AlAMILlO DOMINGO, Ignacio, URIOS APARISI, F. Xavier, La actuación administrativa automatizada en el ámbito de las administraciones públicas, cit., p. 16.

${ }^{1088}$ Cf. GILLI, Jean-Paul, op. cit., p. 106.

${ }^{1089}$ Nesse sentido, falando em manifestação de vontade, cf. MASUCCI, Alfonso, Procedimento amministrativo e nuove tecnologie, cit., p. 96.

${ }^{1090}$ Podem ser identificados três momentos em que o ser humano atua: primeiro, na decisão de automatizar; segundo, por ocasião do estabelecimento das condições informáticas de produção do ato; terceiro, na supervisão do funcionamento adequado dessas condições (cf. AlAMILlo DOMINGO, Ignacio, URIOS APARISI, F. Xavier, La actuación administrativa automatizada en el ámbito de las administraciones públicas, cit., p. 86). 
a cada caso singular ${ }^{1091}$, mas o ato administrativo automatizado deve ser sempre considerado como resultado da atuação da autoridade administrativa que programou o sistema, à qual devem ser imputados os atos automatizados ${ }^{1092}$. O ato é desejado, pois o sujeito por ele responsável assumiu o sistema como instrumento útil ou necessário para produzi-lo naquelas circunstâncias e na presença daqueles determinados pressupostos ${ }^{1093}$.

Tem sido apontado, por isso, que a vontade desempenha uma função importante também nos atos administrativos automatizados ${ }^{1094}$. É importante ressalvar, contudo, que a vontade relativa aos atos administrativos deve ser compreendida em sentido objetivo, que não decorre de preferências pessoais, mas dos preceitos legais e sua regulamentação ${ }^{1095}$. Essa perspectiva é bastante compatível com as características das decisões relativas à programação, que são tomadas sem o conhecimento concreto das inúmeras situações a serem submetidas ao sistema informático, ao qual apenas cabe aplicar, de modo objetivo, tais critérios fixados de maneira impessoal.

${ }^{1091}$ Cf. Martín Delgado, Isaac, Naturaleza, Concepto y Régimen Jurídico de la Actuación Administrativa
Automatizada, cit., p. 367.
${ }^{1092}$ Cf. MASUCC, Alfonso, L'atto amministrativo informatico, cit., pp. 85-86 e SAITTA, Fabio, op. cit., pp. 1213. Assim, se o observador externo tem a impressão de um poder de decisão dado à máquina, é sobretudo porque ele considera não a decisão, mas sua execução (cf. GILli, Jean-Paul, op. cit., p. 106). Devem ser mencionadas, ainda, as discussões existentes na doutrina, marcadas pelo ceticismo (Cf. DUNI, Giovanni, L'amministrazione digitale, cit., p. 75), a respeito da utilização, na atuação automatizada, de sistemas inteligentes (inteligência artificial) capazes de reproduzir o comportamento que o ser humano teria diante de certo problema, de modo que a resposta não seja oferecida por meio de uma rígida predeterminação dos casos possíveis e das consequências a eles associadas, mas por meio da capacidade do computador de aprender a adotar soluções, mediante a análise de situações concretas (cf. RUSSO, Vincenzo, op. cit., p. 99). Tais sistemas podem ser capazes de modificar os próprios programas com o acúmulo de novos dados que imponham variações do programa originário e por isso são capazes de transformar-se gradualmente para adequar-se às novas exigências (cf. USAI, Alessandro, op. cit., item 1.5). Assim, há quem fale, neste caso, em transferência de poderes a um sistema externo, para a qual não haveria previsão legal (cf. ibidem, item 3.2). Afora a questão da previsão legal, contudo, o problema da utilização de tais sistemas estaria relacionado à sua falta de transparência e à eventual impossibilidade de controle de legitimidade formal e substancial (cf. RUSSO, Vincenzo, op. cit., pp. 98-99). No momento, portanto, a tendência é a utilização de tais sistemas inteligentes apenas para o apoio à decisão humana (cf. PALOMAR OLMEDA, Alberto, La utilización de las nuevas tecnologías en la actuación administrativa, cit., p. 380).

${ }^{1093}$ Cf. MANDOLFO, Giovanni, op. cit., p. 1314. No mesmo sentido, Russo, Vincenzo, op. cit., pp. 90-91.

${ }^{1094}$ Cf. SAITTA, Fabio, op. cit., p. 13. Dessa forma, “[a] utilização de determinada tecnologia ou equipamento pressupõe a existência de uma manifestação de vontade. Portanto, sempre que se verifica, num caso concreto, a manifestação física da tecnologia ou do equipamento também se presume a vontade correspondente" (JUSTEN FILHO, Marçal, Pregão, cit., p. 303).

1095 Sobre a necessidade de compreender a vontade expressa no ato administrativo como momento objetivo, e não como fato psíquico, de caráter subjetivo, para o atendimento ao princípio constitucional da impessoalidade, cf. MedauAR, Odete, $O$ direito administrativo em evolução, cit., pp. 203-204 e Direito administrativo moderno, cit., p. 134. 


\subsubsection{A admissibilidade do ato administrativo automatizado}

Compreendida a estrutura dogmática pertinente e superados os preconceitos próprios do início da introdução das novas tecnologias na Administração, não há razão para ver inviabilidade jurídica alguma na automatização de atos administrativos.

Não existem motivos para exigir que o ser humano tome contato com todos os casos concretos. Para chegar a essa conclusão, basta raciocinar em um sentido inverso, procurando compreender o que ocorreria, no contexto atual, caso fosse exigido que todos os atos fossem praticados por um ser humano. Na realidade presente, seria inaceitável impedir que a Administração utilizasse meios tecnológicos para a verificação de dados e preparo de suas decisões. Conforme o caso, essas operações proporcionam todos os elementos e apurações necessárias para elaborar o ato. Nessas hipóteses, a atividade do funcionário, sendo posterior à da máquina, tende a constituir uma simples adesão à sugestão por ela apresentada, porque o ser humano não tem razão para refazer o trabalho já realizado. Assim, caso mantida a atuação humana em todos os casos, haveria uma atividade automatizada, idêntica àquela capaz de produzir diretamente o ato, mas ela não teria valor jurídico em si, devendo ser acrescida de uma fase de simples assinatura pela autoridade ${ }^{1096}$. Do ponto de vista formal, exigir uma intervenção do homem na sequência da atuação da máquina poderia atender as perspectivas mais conservadoras. Todavia, isso constituiria um despropósito, porque a intervenção humana ocorreria de modo apenas mecânico, nada acrescentando de substancial à decisão e só servindo para atrasar, sem razões sérias, a expedição do ato administrativo ${ }^{1097}$.

Como visto, a máquina tem condições para realizar com precisão as operações objetivas solicitadas pelo homem, afastando a necessidade de que este ocupe sempre o final da série de operações que leva à expedição do ato administrativo. O ser humano

\footnotetext{
1096 Cf., em relação a essa questão, verificada em relação à expedição de atos meramente declaratórios ou certificadores, VALERO TORRIJOS, Julián, El régimen jurídico de la e-Administración, cit., pp. 74-75.

${ }^{1097}$ Cf. LiNARes GIL, Maximino Ignacio, Modificaciones del Régimen Jurídico Administrativo derivadas del empleo masivo de nuevas tecnologías, cit., p. 744.
} 
pode programar a máquina para tomar contato com o caso concreto, executando com precisão as tarefas que lhe forem confiadas. O computador não é um sujeito pensante, dotado de liberdade de ação, mas apenas uma projeção da autoridade administrativa: os atos por ele produzidos decorrem de uma atuação humana, cujos efeitos são potencializados por meio da tecnologia, não havendo grande diferença entre tais atos e aqueles expedidos diretamente pelo ser humano ${ }^{1098}$. A diferença está nos meios empregados, que podem ensejar particularidades jurídicas, porém não mudam a natureza das atividades realizadas.

Entendidos os sistemas informáticos como uma extensão tecnológica da própria autoridade administrativa, exigir-se fundamento legal expresso para toda atividade automatizada constituiria um excesso injustificado ${ }^{1099}$. Em geral, a autoridade tem à sua disposição a discricionariedade para empregar os instrumentos mais adequados no exercício de sua competência, não sendo possível presumir uma preferência jurídica por este ou aquele meio. Do ponto de vista do direito, deve-se reconhecer a viabilidade - senão o dever - de utilizar os melhores meios na atuação administrativa, pro força do princípio da eficiência. As normas referentes a uma determinada atividade podem impor alguma espécie de avaliação humana, inviabilizando a atuação automatizada, o que não pode ser desprezado; todavia, no silêncio da lei, não há como presumir o impedimento à automatização, muito menos se observadas as garantias aplicáveis ao uso das novas tecnologias na Administração Pública.

A questão principal, na verdade, diz respeito à observância do princípio da equivalência de garantias. Nesse sentido, a expedição de atos automatizados não deve implicar uma redução de direitos, em prejuízo do administrado. Deve ser aplicado aos atos automatizados todo o regime de garantias já consolidado em relação ao ato tradicional,

\footnotetext{
${ }^{1098}$ Cf. Contaldo, Alfonso, Gorga, Michele, op. cit., p. 190 e Martín Delgado, Isaac, Naturaleza, Concepto y Régimen Jurídico de la Actuación Administrativa Automatizada, cit., p. 365.

${ }^{1099}$ Cogitando a existência de uma nova lei para conferir à Administração o poder de delegar ao software a competência para a prática de atos administrativos eletrônicos automáticos, cf. RAMOS JÚNIOR, Hélio Santiago, RoVER, Aires José, $O$ ato administrativo eletrônico sob a ótica do princípio da eficiência, cit., p. 38.
} 
com as devidas adaptações ${ }^{100}$. Assim, a Administração deve responder pela qualidade, adequação às tarefas desempenhadas e correta programação e funcionamento dos equipamentos e sistemas informáticos. Eventuais questionamentos em relação à atuação automatizada devem relacionar-se a tais aspectos, mas não ao emprego, em si, da tecnologia para a realização de operações sem a intervenção direta do homem, por maior que seja sua relevância na expedição de atos administrativos.

Sem pretender exaurir as possíveis garantias aplicáveis à expedição de atos administrativos automatizados, é possível afirmar que a atividade automatizada deve, no mínimo: a) ter por fundamento o ordenamento jurídico, sobretudo em relação aos critérios adotados pelo ato-programa, a fim de realizar em plenitude o princípio da legalidade; b) oferecer um adequado nível de segurança para os sistemas informáticos e documentos eletrônicos produzidos; c) proporcionar os devidos níveis de publicidade, de maneira a propiciar o controle dos atos produzidos de modo automatizado; d) fazer uso apropriado das informações, observando o regime jurídico mínimo a elas aplicável, em especial quanto ao respeito à intimidade e à privacidade; e) ensejar a responsabilidade da Administração pelos eventuais danos causados.

Por outro lado, os atos automatizados devem submeter-se às regras e respectivas exigências aplicáveis aos atos administrativos tradicionais, com as adaptações necessárias à realidade tecnológica ${ }^{1101}$. Os elementos são os mesmos do ato administrativo

\footnotetext{
${ }^{1100}$ Ressalve-se, contudo, que existem respeitáveis opiniões no sentido de que os meios eletrônicos não ofereceriam aos cidadãos as mesmas garantias da atuação humana. Assim, há quem entenda, por exemplo, que a automatização completa seria contrária aos princípios do direito administrativo e as liberdades fundamentais (cf. OBERDORFF, Henri, op. cit., p. 11). Na Itália, há quem considere que a necessidade de uma intervenção humana decorreria da responsabilidade pessoal do funcionário pelos atos da Administração, nos termos do art. 28 da Constituição (cf., refutando tal entendimento, GiURDANELla, Carmelo, GuARNACCIA, Elio, op. cit., p. 47). Já se apontou, contudo, que as interpretações mais rigorosas a respeito levam ao risco de paralisar em grande medida a atividade diária das modernas Administrações Públicas atuais (cf. VALERO TORRIJOS, Julián, El régimen jurídico de la e-Administración, cit., p. 73).

${ }^{1101}$ Entendendo que o regime do ato administrativo continua a impor-se, com adaptações, aos meios eletrônicos, cf. MARCOU, Gérard, op. cit., p. 80. No mesmo sentido, cf. MANDOLFO, Giovanni, op. cit., p. 1300.
} 
tradicional $^{1102}$ : agente competente, forma, objeto, motivo e fim ${ }^{1103}$. Cabe considerar, pois, como se apresentam tais elementos no ato automatizado, observado que as questões relativas à forma já foram analisadas na apresentação dos atos administrativos eletrônicos, dos quais os atos automatizados constituem uma categoria específica ${ }^{1104}$.

O agente competente é aquele que reconheceu como sua a atividade desempenhada de modo automatizado. Caso não haja um ato expresso nesse sentido, deve-se entender como competente o órgão incumbido da programação e supervisão do funcionamento dos sistemas de informação empregados ${ }^{1105}$. Observe-se, entretanto, que a automatização traz alguma tendência no sentido de minimizar a atuação do órgão, por meio da genérica imputação do ato à entidade pública ${ }^{1106}$. As relações tendem a produzir-se direta e globalmente com a Administração, sem intervenção de um órgão territorial ou funcional específico. Quando isso ocorre, pode ser conveniente que uma norma estabeleça de modo expresso, para efeito de eventuais recursos, a qual órgão administrativo a atuação automatizada deve ser imputada ${ }^{1107}$.

Os demais elementos - objeto, finalidade e motivo - são fixados de modo automatizado. Eles constituem, como o próprio ato, uma decorrência da programação do sistema informático, combinada com os elementos verificados no caso concreto. $\mathrm{O}$ ato automatizado deve identificar-se claramente como tal ${ }^{1108}$, permitindo ao administrado ter conhecimento de que tais elementos resultaram das decisões tomadas por ocasião da construção do sistema.

\footnotetext{
${ }^{1102}$ Cf. ConTaldo, Alfonso, Gorga, Michele, op. cit., p. 190. Para Martín Delgado, o ato automatizado deve ser conforme o ordenamento, praticado pelo órgão competente de acordo com o procedimento legalmente estabelecido, com conteúdo determinado e possível, adequado ao fim da competência envolvida, coerente com os fatos que lhe serviram de base e motivado (cf. Naturaleza, Concepto y Régimen Jurídico de la Actuación Administrativa Automatizada, cit., p. 365).

${ }^{1103}$ São os elementos do ato administrativo geralmente reconhecidos pela doutrina (cf. MEDAUAR, Odete, Direito Administrativo Moderno, cit., p. 135).

${ }^{1104}$ Cf. supra, item 3.3.

1105 Sobre a imputação dos atos automatizados ao agente incumbido da programação e manutenção do sistema informático, cf. Delgado García, Ana María, Oliver CuEllo, Rafael, op. cit., p. 8.

1106 Sobre essa tendência, no ordenamento espanhol, cf. VALERO TORRIJOS, Julián, El régimen jurídico de la $e$-Administración, cit., pp. 43 e 74.

${ }_{1107}$ Cf. CERVANTES SÁnCHEZ-RODRIGO, Carlos Javier et al., Guía de la Ley General Tributaria, Valencia, Cisspraxis, 2004, p. 229.

${ }^{1108}$ Cf. Delgado García, Ana María, Oliver Cuello, Rafael, op. cit., p. 11.
} 
Alguma ênfase merece o tema da exteriorização do motivo, ou seja, a motivação do ato administrativo. As regras tradicionais a esse respeito não são afetadas pelo uso da tecnologia ${ }^{109}$, em vista da necessidade de preservar as garantias relacionadas ao controle da atuação administrativa ${ }^{1110}$. Nesse sentido, os aspectos técnicos envolvidos na automatização não podem exonerar a Administração do dever de prestar contas a respeito de como se formou a decisão ${ }^{111}$. Ao contrário, a exigência de transparência é ainda maior neste caso, pois apenas a motivação pode aliviar a sensação de obscuridade e de anonimato do administrado em relação ao ato praticado pela máquina ${ }^{1112}$.

Também construída de modo automatizado ${ }^{113}$, a motivação deve propiciar o conhecimento do percurso lógico e jurídico que levou à decisão ${ }^{1114}$, inclusive no tocante à instrução realizada ${ }^{1115}$. Caso o ato automatizado tenha sido baseado em informações verificadas no caso concreto, elas devem ser indicadas na motivação, pois a informatização não se presta a autorizar o emprego de fundamentos genéricos, que poderiam ser usados indistintamente em qualquer outra situação ${ }^{1116}$. Além disso, o motivo deve ser exteriorizado de maneira compreensível para o ser humano, em linguagem natural, sendo inadmissível o uso de códigos misteriosos, conhecidos apenas por especialistas.

\footnotetext{
${ }^{1109}$ Cf. MARCOU, Gérard, op. cit., p. 91.

${ }^{1110}$ Apontando os riscos para o Estado de Direito, decorrentes de uma tecnicização progressiva, especialmente no tocante à motivação dos atos administrativos, cf. ZEIDLER, Karl, op. cit., p. 52.

${ }_{1111}$ Cf. MASUCCI, Alfonso, L'atto amministrativo informatico, cit., pp. 100-101.

1112 Cf. MASUCCI, Alfonso, Procedimento amministrativo e nuove tecnologie, cit., p. 101.

${ }^{1113}$ Cf. Giurdanella, Carmelo, GuARnACCIA, Elio, op. cit., p. 42 e UsAi, Alessandro, op. cit., item 2.4.

1114 Cf. ConTALDO, Alfonso, GoRGA, Michele, op. cit., pp. 191-192. Sobre a relação entre a motivação e a programação do sistema, cf. Cf. AlAMILlo DOMINGO, Ignacio, URIOS APARISI, F. Xavier, La actuación administrativa automatizada en el ámbito de las administraciones públicas, cit., pp. 21-22.

${ }^{1115}$ Cf. MASUCCI, Alfonso, L'atto amministrativo informatico, cit., pp. 100-101.

${ }^{1116}$ Assim, usando um exemplo singelo, se um requerimento é indeferido por intempestivo, não basta informar, de modo genérico: “indeferido por não atendimento do prazo". É preciso apresentar, no mínimo, qual seria o prazo correto naquele caso e quando o pedido foi formulado, demonstrando sua intempestividade.
} 


\subsubsection{Vícios do ato automatizado}

A introdução das novas tecnologias na Administração Pública costuma ser acompanhada da esperança de eliminar os erros da ação administrativa, imaginando-se que máquina poderia efetuar, de maneira impecável, a comparação entre dados padronizados e parâmetros fixados de modo objetivo. No entanto, essa expectativa constitui um mito ${ }^{1117}$, pois os atos automatizados também podem apresentar vícios ${ }^{1118}$.

A automatização elimina certas falhas humanas, porém abre margem para o surgimento de novos problemas ${ }^{1119}$. Algumas falhas surgem em razão da ausência do controle de plausibilidade feito pelo ser humano na via tradicional, com o qual são evitados erros manifestos ${ }^{1120}$. Outros vícios, relativos aos próprios atributos da atividade administrativa automatizada, serão examinados neste item.

Tais vícios apresentam características específicas, conforme as peculiaridades do ato administrativo automatizado ${ }^{1121}$. Por isso, o regime das invalidades dos atos tradicionais deve ser adaptado ao contexto eletrônico, investigando as causas dos vícios e as consequências de seu reconhecimento.

\footnotetext{
${ }^{1117}$ Cf. MASUCCI, Alfonso, L'atto amministrativo informatico, cit., p. 115 e Procedimento amministrativo e nuove tecnologie, cit., p.118.

${ }^{1118}$ É preciso substituir tal postura ingênua por uma visão crítica em relação à utilização dos sistemas informáticos, reconhecendo os possíveis vícios para que seja possível evitá-los. Vale ressaltar, a propósito, o entendimento de MARÇAL JUSTEN FILHO a respeito do funcionamento dos sistemas que sustentam os pregões eletrônicos, em relação aos quais “(...) não existe uma definição mais precisa quanto aos requisitos mínimos a serem observados no tocante à programação para o pregão eletrônico, nem há instrumentos de controle ou verificação dos programas propriamente ditos. Toma-se como inquestionável que todos os programas e todos os sistemas serão desenvolvidos de modo absolutamente seguro, imparcial e não suscetível a qualquer interferência individual" (Pregão, cit., p. 279). De fato, os sistemas podem ser objeto de várias formas de manipulação, o que justifica entender como cabíveis todos os mecanismos para prevenir e combater tais vícios, por meio do controle interno e externo da atividade administrativa.

${ }_{1119}$ Cf. MASUCCI, Alfonso, L'atto amministrativo informatico, cit., pp. 115-116.

${ }^{1120}$ Cf. ibidem, pp. 118-119. Todavia, é claro que não se pode pensar em submeter todo ato a verificação humana, o que contrastaria com o sentido da automatização e duplicaria o trabalho administrativo (ibidem, p. 119).

${ }^{1121}$ Em razão dessas peculiaridades, surgem questionamentos sobre se as categorias nascidas na administração em papel podem ser adaptadas por completo às atividades em forma eletrônica. Sobre tal questionamento, cf. DUNI, Giovanni, Ancora sul procedimento amministrativo telematico, cit., p. 2.
} 
Antes de tudo, o regime das invalidades dos atos administrativos automatizados deve trazer novos contornos para a questão da demonstração de prejuízos como um requisito para a invalidação ${ }^{1122}$. No contexto de rápidas inovações em que vivemos, nem todo projeto de introdução das novas tecnologias na Administração Pública tende a obedecer às melhores práticas sob o aspecto jurídico. Em muitos casos, determinadas questões ainda não foram exploradas com a profundidade devida, até porque ainda é escasso, entre nós, o tratamento legal, doutrinário e jurisprudencial da matéria. Por essa razão, os vícios da atividade automatizada nem sempre devem levar à invalidade do ato. É necessário demonstrar a existência de prejuízos, sobretudo na falta de norma legal expressa relativa à atuação automatizada ${ }^{123}$.

Os vícios dos atos administrativos automatizados podem estar relacionados aos seguintes aspectos: a) invalidade da decisão de automatizar uma determinada atividade; b) invalidade das regras a serem aplicadas pelo sistema (vício do ato-programa); c) irregularidade na conversão de regras do ato-programa em linguagem de programação (vício do software); d) problema no funcionamento do sistema (erro da máquina); e) inexatidão ou incompletude dos dados trazidos ao sistema (erro de input) ${ }^{124}$. Cada uma dessas situações está sujeita a um enquadramento jurídico próprio.

\footnotetext{
${ }^{1122}$ Sobre a questão das nulidades e dos efeitos sobre o interessado e sobre o processo, cf. PALOMAR OLMEDA, Alberto, Gestión Electrónica de los procedimientos, cit., p. 451 e, do mesmo autor, Administración electrónica y actuación jurisdiccional, in VVAA, La administración electrónica y el servicio a los ciudadanos: el Ministerio de Economía y Hacienda ante los retos de la Ley 11/2007, de Acceso Electrónico de los Ciudadanos a los Servicios Públicos, Madrid, Ministerio de Economía y Hacienda, 2009, p. 79.

${ }^{1123}$ É o caso, por exemplo, da falta de publicidade das regras do ato-programa. De fato, não se pode exigir da autoridade administrativa a plena consciência da existência de regras jurídicas que são aplicadas pelos sistemas informáticos da Administração Pública e das implicações que disso advêm. Isso não impede, contudo, que o sistema atue corretamente e produza atos administrativos automatizados compatíveis com o ordenamento jurídico. Nesse sentido, uma aplicação rigorosa do entendimento de que o ato-programa deve ser público poderia levar à nulidade de milhões de atos administrativos, sem a existência de um prejuízo efetivo que o justifique. Nessa situação específica, parece conveniente entender que a falta da divulgação das regras de programação implica a inversão do ônus da prova em relação à Administração, a qual passa a ser obrigada, em eventual demanda judicial, a apontar as regras aplicadas em seus sistemas e demonstrar que o sistema funciona de modo correto. Sobre o tema, cf. o item 4.9.7, infra, em especial a nota 1381.

${ }^{1124}$ Sobre as possíveis causas e a tipologia dos vícios dos atos administrativos automatizados, cf., entre muitos, CONTALDO, Alfonso, GORGA, Michele, op. cit., pp. 193-194; FORSTHOFF, Ernst, op. cit., p. 102; MARONE, Umberto, op. cit., pp. 89-90 e RABBITO, Chiara, L'informatica al servizio della pubblica amministrazione e del cittadino, cit., p. 38 .
} 
A invalidade relativa à decisão de automatizar uma atividade ocorre em caso de inadequação dos meios informáticos para tal finalidade, conforme as características da atividade desempenhada. Nem todo erro na opção pela automatização implica um vício de ordem legal, pois o equívoco pode residir nos aspectos discricionários dessa decisão. A automatização é inadmissível, sob o aspecto jurídico, quando houver uma norma impeditiva, levando à invalidade da opção pela automatização e dos atos expedidos pelo sistema informático.

Sendo o ato-programa o responsável pela fixação dos critérios substanciais a serem aplicados pela máquina, ele ocupa uma posição central em relação aos possíveis vícios dos atos administrativos. Se o ato automatizado não atende às regras legais pertinentes, por uma falha em algum de seus elementos, isso normalmente decorre de uma programação equivocada. Como a máquina atua sempre de modo objetivo, de acordo com as instruções recebidas, a elaboração do ato-programa é o único momento em que haveria margem para um eventual desvio de finalidade na atuação automatizada ${ }^{1125}$. Eventual vício também pode estar relacionado à omissão quanto a uma determinada situação, que exija a integração da programação ${ }^{1126}$.

As implicações da invalidação do ato-programa em relação aos atos administrativos concretos constituem algo relevante para a teoria dos vícios do ato administrativo $^{1127}$. Como os atos automatizados decorrem da aplicação dos critérios definidos pelo ato-programa, a invalidação do ato geral implica, em regra, a invalidação de todos os atos concretos dele decorrentes ${ }^{1128}$. Nesse sentido, caso retirado o ato-programa, devem ser tomadas providências para a declaração da invalidade de todos os atos automatizados que o

\footnotetext{
${ }^{1125}$ A respeito de eventuais desvios na definição das instruções para a máquina, cf. SAITTA, Fabio, op. cit., p. 19 e Martín Delgado, Isaac, Naturaleza, Concepto y Régimen Jurídico de la Actuación Administrativa Automatizada, cit., pp. 375 e 384 . Há entendimento no sentido de que o excesso de poder ocorreria somente no ato que contém as regras de programação do software e não no ato final, inválido só em via derivada (cf. GIURDANELlA, Carmelo, GUARNACCIA, Elio, op. cit., p. 91). É importante, contudo, reconhecer a possibilidade de um ato automatizado oriundo de um desvio de poder, a ser objeto de invalidação como qualquer ato viciado.

${ }^{1126}$ Cf. infra, item 4.9.7.

${ }^{1127}$ Cf. DunI, Giovanni, L'amministrazione digitale, cit., p. 84

${ }^{1128} \mathrm{O}$ ato-programa seria o ato-mãe da sequência procedimental que se conclui com o ato administrativo final, ao qual é transmitida a anormalidade do primeiro (cf. MASUCCI, Alfonso, Procedimento amministrativo e nuove tecnologie, cit., p. 111).
} 
adotaram como pressuposto ${ }^{1129}$. A casuística tende a ser mais complexa que esta simples assertiva, incluindo situações como a invalidade parcial do ato-programa, que não atinge todos os atos produzidos pelo sistema, e a possível convalidação do ato-programa, capaz de propiciar a manutenção dos atos automatizados concretos dele decorrentes.

Outra espécie de defeito é causada pela divergência entre a programação em linguagem informática e o ato-programa. O vício da programação informática decorre de um erro da autoridade administrativa, que autorizou a operação do sistema por desconhecer que a imperfeição poderia ocorrer. A invalidade reside, assim, no ato de aprovação do software. Caracterizada a falha, tende a não haver resistência alguma em reconhecê-la, pois o objetivo da Administração é sempre a atuação do sistema de acordo com as regras definidas no ato-programa ${ }^{1130}$.

Os erros da máquina correspondem a situações em que o sistema informático produz resultados incompatíveis com o ato-programa e com as instruções do software. Tais problemas tendem a ser pouco frequentes, em vista do atual estágio de desenvolvimento da tecnologia ${ }^{1131}$. Todavia, o assunto ainda merece atenção, sobretudo porque devem ser equiparados a tais erros os casos ainda comuns de violação de sistemas informáticos por parte de servidores públicos ou agentes externos. Os atos administrativos produzidos por força desse funcionamento irregular devem ser reconhecidos como inexistentes, porque não decorrem do exercício do poder pela autoridade administrativa ${ }^{1132}$. Os problemas da máquina podem ser considerados uma versão tecnológica dos erros materiais, categoria conhecida na administração em papel; já os atos gerados a partir da adulteração do

\footnotetext{
${ }^{1129}$ Cf. SAITTA, Fabio, op. cit., p. 27.

${ }^{1130} \mathrm{O}$ ato de aprovação torna a autoridade administrativa responsável pelo software. Todavia, é possível identificar, neste caso, uma responsabilidade diversa daquela que se revela na fixação das regras contidas no ato-programa. Com efeito, em geral não é a própria autoridade que prepara materialmente o programa, cabendo a ela obter os serviços de outrem e depois verificar, com as limitações que lhe são inerentes, o funcionamento do sistema - v.g., em uma fase de testes. Contudo, é possível que alguma falha do programador não seja detectada, de modo que o sistema venha a operar de forma incompatível com as regras definidas no atoprograma. Neste caso, o ato de aprovação incorreu em erro, o que faz necessária a correção do software e sua submissão a nova aprovação, cabendo ao programador deverá arcar com as consequências de sua falha.

${ }_{1131}$ Cf. GiURDANELla, Carmelo, GUARnACCIA, Elio, op. cit., p. 91.

${ }^{1132}$ Cf. USAI, Alessandro, op. cit., item 4.
} 
sistema informáticos devem ser tratados como produto de um ato ilícito, desprovido de efeitos jurídicos ${ }^{1133}$.

Por fim, devem ser considerados os vícios decorrentes dos dados empregados na atuação automatizada (vícios do input). Como visto, as informações constituem premissas da atividade automatizada. Assim, dados viciados - por exemplo, inverídicos geram atos automatizados inválidos ${ }^{1134}$. Neste caso, além da invalidação do ato, faz-se necessária a correção da respectiva base de dados, evitando o uso futuro da mesma informação inexata, o qual poderia levar à produção de novas invalidades.

\footnotetext{
${ }^{1133}$ Esse ato ilícito pode ser considerado crime, quando a alteração não autorizada de sistema informático ou programa de computador é efetuada por funcionário público (art. 313-B do Código Penal).

${ }^{1134}$ Cf. MASUCCI, Alfonso, L'atto amministrativo informatico, cit., pp. 116-117. Ainda sobre a invalidade decorrente dos dados inexatos ou incompletos, cf. SAITTA, Fabio, op. cit., p. 20 e GiURDANELla, Carmelo, GUARNACCIA, Elio, op. cit., p. 90 . O vício dos dados pode decorrer também de sua obtenção ilegítima - por exemplo, foram incorporados à base de dados oficial sem a existência de uma finalidade jurídica que o motivasse. Neste caso, a providência adequada é a correção da base de dados, por meio da supressão dos dados viciados. Fazendo referência à irregularidade no recolhimento dos dados, bem como à sua incompletude e inexatidão, cf. MASUCCI, Alfonso, Procedimento amministrativo e nuove tecnologie, cit., p.114. Existe, também, o problema da utilização ilegítima de informações corretas e regularmente obtidas - v.g., dados que deviam ser sigilosos e acabam por ser compartilhados entre os sistemas informáticos públicos (cf. SÁNCHEZ RODRÍGUEZ, Francisco, op. cit., p. 39). Neste caso, verifica-se também um vício, que não é propriamente do dado em si, mas da programação que previu sua utilização de forma indevida. Trata-se, pois, de uma hipótese específica de vício do ato-programa.
} 


\section{CAPÍTULO 4 - PROCESSO ADMINISTRATIVO ELETRÔNICO}

\subsection{Antecedentes}

A doutrina tem apontado a perda da centralidade do ato administrativo no âmbito dos estudos do direito administrativo, tendo em vista um progressivo deslocamento do foco das atenções para o processo administrativo ${ }^{1135}$. Mesmo assim, este ainda constitui um campo de investigação recente, no qual consideráveis divergências doutrinárias estão distantes de serem superadas ${ }^{1136}$.

Não cabe ao presente estudo enfrentar essas elevadas discussões. O tema desta tese não alcança os vários aspectos relativos ao processo administrativo em si, mas apenas a avaliação dos impactos decorrentes do uso de meios informáticos e telemáticos nas atividades formalizadas da Administração. Essa análise deve ser feita com base em alguns pontos de partida, adotados como referência conceitual para a confrontação com a realidade tecnológica. Tais conceitos por certo comportariam enfrentamento em investigações específicas, porém são trazidos a este estudo apenas como subsídio para a discussão dos temas nele tratados.

\footnotetext{
${ }^{1135}$ Cf. Medaudr, Odete, A Processualidade no Direito Administrativo, 2a . ed., São Paulo, RT, 2008, p. 147; Administração Pública: do ato ao processo, cit., p. 405 e $O$ direito administrativo em evolução, cit., p. 206.

${ }^{1136}$ Exemplo disso é a notória discussão doutrinária acerca de qual seria a expressão mais adequada, processo ou procedimento administrativo. Sobre os diversos aspectos da polêmica, cf. a análise minuciosa oferecida por Medauar, Odete, A Processualidade no Direito Administrativo, cit., pp. 33-46. A propósito do tema, vale citar, apenas a título de exemplo, as obras de Mello, Celso Antônio Bandeira de, Curso de Direito Administrativo, cit., p. 481, com preferência por processo administrativo, bem como de FIGUEIREDO, Lúcia Valle, Curso de Direito Administrativo, 9ª . ed., São Paulo, Malheiros, 2007, pp. 436-438, e de SUNDFELD, Carlos Ari, A importância do procedimento administrativo, in Revista de Direito Público, n. 84, São Paulo, RT, 1987, p. 65, empregando a expressão procedimento administrativo. Convém mencionar, ainda, a opinião de MARÇAL JUSTEN FILHO, adotando a expressão procedimento administrativo, mas com a ressalva de que uma opção terminológica não merece ser tida como correta ou incorreta (cf. Curso de direito administrativo, cit., p. 310.). Em meio a tal polêmica, o presente estudo adota a expressão processo administrativo, sobretudo em vista da necessidade de reforçar a aplicabilidade das garantias constitucionais, referidas ao processo, também no contexto do governo eletrônico e das novidades por ele trazidas. Vale observar, ainda, que vários textos estrangeiros citados empregam vocábulos que poderiam ser rigorosamente traduzidos como procedimento, porém as ideias contidas em tais trabalhos, aqui parafraseadas, foram trazidas com a utilização do vocábulo processo, apenas para efeito de uniformidade terminológica.
} 
O processo administrativo corresponde ao percurso jurídico entre as normas abstratas, tais como as leis e os regulamentos, e as decisões da Administração. Nesse sentido, o ato administrativo constitui, em regra, a decisão final produzida a partir de um processo ${ }^{1137}$, de sorte que ato e processo, embora correlacionados, não se confun$\mathrm{dem}^{1138}$. Como toda a atividade decisória é condicionada por princípios e regras de caráter processual $^{1139}$, o processo administrativo constitui uma exigência de caráter formalista destinada ao controle do exercício das competências estatais ${ }^{1140}$ e à garantia de melhor conteúdo para as decisões ${ }^{1141}$. Por força do processo, as decisões da Administração não decorrem da vontade psicológica do agente, mas da vontade impessoal do ordenamento, passível de um controle jurídico ${ }^{1142}$.

Entendido como uma série de atos encadeados lógica e juridicamente para ensejar uma decisão da Administração Pública ${ }^{1143}$, o processo apresenta o caráter de um vir a ser, de algo em realização ${ }^{1144}$, que tem o tempo como dimensão inseparável ${ }^{1145}$. Nessa estrutura, o exaurimento de uma fase é pressuposto de validade da instauração da seguinte, cada ato tem uma finalidade específica e todos eles têm um objetivo final comum, que deve guardar compatibilidade lógica com o conjunto dos atos praticados ${ }^{1146}$. A

${ }^{1137}$ São excepcionais as situações em que o ato administrativo é produzido de forma instantânea (cf. MEDAUAR, Odete, A Processualidade no Direito Administrativo, cit., p. 40). Assim tem sido notado: "É quase impossível configurar hipóteses em que determinado ato administrativo poderia ser produzido de modo desvinculado de um procedimento ou fora do desenvolvimento da atividade administrativa. (...) Salvo situações excepcionais, todo e qualquer ato administrativo deve ser produzidos no bojo de um procedimento" (JUSTEN FILHO, Marçal, Curso de direito administrativo, cit., p. 304).

${ }_{1138}$ Cf. MedauAr, Odete, A Processualidade no Direito Administrativo, cit., p. 29.

1139 Cf. SundFeld, Carlos Ari, Processo e procedimento administrativo no Brasil, in As leis de processo administrativo, São Paulo, Malheiros, 2000, pp. 17-36.

${ }^{1140}$ Fazendo referência à procedimentalização, cf. JUSTEN FILHO, Marçal, Curso de direito administrativo, cit., p. 305.

${ }_{1141}$ Cf. MEDAUAR, Odete, A Processualidade no Direito Administrativo, cit., p. 69.

${ }_{1142}$ Cf. SundFeld, Carlos Ari, A importância do procedimento administrativo, cit., pp. 67, 69 e 73.

1143 Cf. DAllari, Adilson Abreu, FERrAZ, Sérgio, Processo administrativo, 1. a ed., 3. a tir., São Paulo, Malheiros, 2003, p. 25. Há outras definições que também enfatizam a questão da sequência de atos, segundo as quais o processo administrativo é entendido como a "sucessão itinerária e encadeada de atos administrativos que tendem, todos, a um resultado final e conclusivo" (Mello, Celso Antônio Bandeira de, Curso de Direito Administrativo, cit., p. 480) ou como "a série de atos ou operações com que o administrador formula uma decisão e a executa, no sentido da realização prática de fins do Estado" (MENEGALE, J. Guimarães, Direito administrativo e ciência da administração, v. 2, Rio de Janeiro, Borsoi, 1950, p. 323).

${ }^{1144}$ Esses elementos são apontados por MEDAUAR, Odete, A processualidade no direito administrativo, cit., pp. 28-31.

${ }_{1145}$ Cf. DALlari, Adilson Abreu, FerRaz, Sérgio, op. cit., p. 39.

${ }^{1146}$ Cf. Justen FILHO, Marçal, Curso de direito administrativo, cit., p. 306. 
decisão administrativa deve ser logicamente compatível com os eventos que a antecederam e com os motivos por ela invocados ${ }^{1147}$.

Esses conceitos, expostos de maneira singela, refletem uma situação concreta da técnica $^{1148}$, materializada no expediente em papel. Isso gera várias repercussões na estrutura do processo, que serão discutidas no curso deste capítulo, por meio da confrontação com as possibilidades oferecidas pelas novas tecnologias, sobretudo quando os autos em papel são substituídos por um conjunto de documentos digitais.

Todavia, é preciso ressaltar, desde logo, que o expediente em papel não é incompatível com alguma utilização da informática. Várias funcionalidades eletrônicas podem ser direcionadas para o expediente administrativo em papel, na condição de mecanismo de apoio. Trata-se de uma situação bastante frequente nos dias de hoje, em que modernas tecnologias ainda convivem com formas tradicionais de atuação. Esses mecanismos de apoio tendem a ser introduzidos de maneira pontual, tendo por referência cada segmento do processo ${ }^{1149}$. Nesse sentido, podem ser apresentados como exemplos de usos da tecnologia em relação ao processo administrativo tradicional: a) o fornecimento de modelos e formulários digitais, utilizados para a criação de documentos a serem apresentados à Administração, para posterior juntada aos autos físicos ${ }^{150}$; b) o acompanhamento eletrônico

\footnotetext{
${ }^{1147}$ Cf. Justen FILHO, Marçal, Curso de direito administrativo, cit., pp. 305-306. ODETE MEDAUAR apresenta os elementos do núcleo da processualidade, aplicáveis ao processo administrativo: "a) os elementos in fieri e pertinência ao exercício do poder, pois o processo administrativo representa a transformação dos poderes administrativos em ato; b) o processo administrativo implica sucessão encadeada e necessária de atos; c) é figura jurídica diversa do ato; quer dizer, o estudo do processo administrativo não se confunde com o estudo do ato administrativo; d) o processo administrativo mantém correlação com o ato final em que desemboca; e) há um resultado unitário a que se direcionam as atuações interligadas dos sujeitos em simetria de poderes, faculdades, deveres e ônus, portanto em esquema de contraditório" (A Processualidade no Direito Administrativo, cit., p. 45).

${ }^{1148}$ Cf. Mestre Delgado, Juan Francisco, op. cit., p. 119.

${ }^{1149}$ Sobre a tendência a essa visão parcial, cf. NOTARMUZI, Carlo, Il Codice dell'amministrazione digitale, disponível em http://www.astrid-online.it/E-governme/Codice-del/NOTARMUZI-Codice-Amm-Digitale.pdf, acesso em 07.12.2010, p. 2.

${ }^{1150} \mathrm{Na}$ França, o Programa de ação governamental para a sociedade da informação (PAGSI), de janeiro de 1998, fazia referência às seguintes possibilidades: 1) obtenção de formulários on line, que depois seriam preenchidos e entregues pelos meios tradicionais; 2) preenchimento dos formulários na tela do computador, os quais seriam depois impressos e entregues pessoalmente; 3) preenchimento e transmissão on line dos formulários; d) aplicativo interativo entre a Administração e usuário (cf. BELOULOU, Véronique, op. cit., pp. 624-625). Embora seja possível que a remessa telemática de documentos e a troca interativa de informações estejam associadas a um processo administrativo eletrônico, tais funcionalidades também poderiam, em tese, servir a um processo administrativo em papel.
} 
dos autos em papel, por um sistema que registra e oferece informações sobre a tramitação, por vezes com cópias digitais de documentos juntados ao expediente; c) a informatização limitada aos serviços de atendimento ao público relacionados ao processo $^{1151}$; d) sistemas de protocolo dotados de chancelas eletrônicas aplicadas aos documentos em papel, para posterior remessa ao órgão competente e junção ao expediente. Em nenhum desses casos, a atuação deixa de depender de um suporte físico para as informações pertinentes, mantido o expediente em papel como o meio técnico para a realização da atividade processual.

\subsection{O processo administrativo na sociedade da informação}

O uso mais intenso das tecnologias da informação e da comunicação traz a possibilidade de exercício do poder por meio de novas formas e estruturas, que ultrapassam a lógica dos expedientes em papel, exigindo uma adequada compreensão por parte da ciência do direito.

Em princípio, por sua aparência, muitas delas poderiam até ser vistas como realidades meramente informáticas, alheias ao direito administrativo. Entretanto, este não seria o entendimento mais apropriado, pois o emprego das novas tecnologias não altera a premissa segundo a qual o exercício do poder, efetuado por meio da atividade administrativa formalizada, está sempre sujeito às regras do processo administrativo. Para evitar prejuízos aos direitos do administrado, realizando o princípio da equivalência de garantias, há necessidade de uma visão ampla do processo administrativo, na qual se incluam os diversos mecanismos de exercício de poder que se utilizam das novas tecnologias. ${ }^{1151}$ Cf. CAMmarota, Giuseppe, L'erogazione on line di servizi pubblici burocratici, cit., p. 75. Segundo o
autor, é possível prestar serviços on line independentemente da informatização do ato e do processo. 
A doutrina mais moderna centra sua atenção na dimensão informativa do processo $^{1152}$, compreendendo-o como um sistema de caráter interativo para estruturar os múltiplos contatos e relações entre o cidadão e a Administração ou entre órgãos públi$\cos ^{1153}$. Nessa perspectiva, o processo administrativo é baseado na informação e na comunicação ${ }^{1154}$, devendo ser compreendido como uma sequência organizada de obtenção e tratamento da informação ${ }^{1155}$, tendo por objetivo a produção de uma decisão racional baseada na comunicação ${ }^{1156}$. Assim, a decisão emanada do processo deve ser vista como o resultado final do processamento da informação ${ }^{1157}$. Nesse sentido, o processo administrativo, na medida em que se orienta para a resolução de uma situação concreta ou para tomada de uma decisão determinada, representa um instrumento para selecionar a informação tida como a mais relevante no caso considerado ${ }^{1158}$.

O processo administrativo clássico - entendido como a sucessão de trâmites procedimentais cujo produto final consiste na edição de uma decisão, e não na gera-

1152 Cf. BARNÉs VÁZQUEZ, Javier, Reforma e innovación del procedimiento administrativo, in VVAA, La Transformación del Procedimiento Administrativo, Sevilla, Global Law Press - Editorial Derecho Global, 2006, pp. 24-25.

${ }^{1153}$ Cf. BARNÉS VÁZQUEZ, Javier, Sobre el procedimiento administrativo, cit., p. 308 e Reforma e innovación del procedimiento administrativo, cit., pp. 24-25.

${ }^{1154}$ Cf. GARCÍA MACHO, Ricardo, op. cit., p. 214. Há anos, FROSINI afirmava que a atividade administrativa automatizada podia ser considerada sob o aspecto de uma rede de transmissão de mensagens, dotada de um centro de auto-regulação, segundo o princípio do moderno aparato de produção industrial, pela qual o processo administrativo poderia ser comparado ao percurso de uma linha de produção, existente entre o projeto e o produto da informação (Cibernetica diritto e società, cit., p. 58).

${ }_{1155}$ Cf. GARCÍA MACHO, Ricardo, op. cit., p. 200; KLUTH, Winfried, NUCKET, Jana, op. cit., p. 480 e SCHMIDT-ASSMANN, Eberhard, Pluralidad de estructuras y funciones de los procedimientos administrativos en el Derecho alemán, europeo e internacional, in VVAA, La Transformación del Procedimiento Administrativo, Sevilla, Global Law Press - Editorial Derecho Global, 2006, p. 75. Por isso, conceitos como informação, comunicação ou conhecimento devem gozar da mesma relevância para o processo administrativo assim como para todo o direito administrativo - que outrora tiveram noções como atividade da Administração ou ato administrativo (cf. GARCÍA MACHO, Ricardo, op. cit., p. 200). Há quem entenda que os processos da Administração são caracterizados por três fatores: lei, política e a informação como um recurso (cf. LENK, Klaus, TRAUNMÜLlER, Roland, op. cit., p. 67). Também a respeito da importância da informação administrativa, vinculada ao regime de expedientes e arquivos, cf. RIVERO ORTEGA, Ricardo, Archivo y expediente electrónico, cit., p. 33.

${ }^{1156}$ Cf. BARNÉS VÁZQUEZ, Javier, Sobre el procedimiento administrativo, cit., p. 309. Considerando o processo administrativo como meio para a tomada de decisões, compreendido como mecanismo informativo e comunicativo da Administração Pública, como o objetivo de otimizar as decisões administrativas, cf. RIVERO ORTEGA, Ricardo, El expediente administrativo, cit., p. 187.

1157 Cf. LENK, Klaus, TRAUNMÜLLER, Roland, op. cit., p. 67.

1158 Cf. BARNÉS VÁZQUEZ, Javier, Reforma e innovación del procedimiento administrativo, cit., pp. 24-25 e Procedimientos administrativos y nuevos modelos de gobierno. Algunas consecuencias sobre la transparencia, in GARCÍA MACHO, Ricardo (org.), Derecho administrativo de la información y administración transparente, Madrid, Marcial Pons, 2010, p. 57. 
ção de uma informação ${ }^{1159}$ - tende a ser insuficiente para sustentar as necessidades de troca de informação entre cidadão e Administração na sociedade da informação ${ }^{1160}$. Embora constitua o meio natural para a produção de atos administrativos tradicionais, o processo não se limita a tal finalidade, podendo alcançar outras situações que envolvam a obtenção e processamento da informação, independentemente de uma decisão final ${ }^{1161}$. No contexto atual, por exemplo, o administrado pode alterar seu endereço constante de uma base de dados da Administração Pública, com relevantes reflexos jurídicos, por meio de um contato feito pela internet; a declaração de imposto de renda enviada pela rede mundial de computadores desonera o contribuinte de seu dever tributário, muitas vezes sem que um funcionário receba ou analise a declaração.

É preciso reconhecer tais atividades como realidades jurídicas, compreendendo-as por meio do processo administrativo. Para isso, devem ser rompidos os limites impostos pelo suporte papel, tendo em consideração a documentação em meio digital, a possibilidade de relacionamento telemático e a automatização de atividades. Esses três mecanismos, que refletem o estágio tecnológico atual, podem ser considerados os eixos de transformação do processo administrativo na sociedade da informação. Os próximos itens procurarão mostrar aspectos dessa mudança, identificando algumas decorrências da utilização da tecnologia na atividade formalizada da Administração, com foco no processo administrativo eletrônico.

\subsection{Conceito e tipologia}

Assim como ocorre em relação aos atos administrativos, é grande a diversidade dos possíveis usos das novas tecnologias no âmbito dos processos administrativos. Vários fatores interferem na intensidade da utilização da tecnologia, tais como a dis-

\footnotetext{
${ }^{1159}$ Cf. GARCÍA MACHO, Ricardo, op. cit., p. 200.

${ }^{1160}$ Cf. ibidem, pp. 187 e 212.

${ }^{1161}$ Cf. BARNÉS VÁZQUEZ, Javier, El procedimiento administrativo y el gobierno electrónico, cit., p. 89.
} 
ponibilidade das ferramentas tecnológicas, a existência de recursos financeiros para utilizálas e sua compatibilidade com as regras jurídicas relativas ao processo.

Dentre as alternativas tecnológicas disponíveis, vale ressaltar o processo administrativo eletrônico. Trata-se de um estágio mais avançado da já mencionada utilização da informática para proporcionar melhorias pontuais no expediente tradicional. O processo administrativo eletrônico é totalmente baseado em meios digitais ${ }^{1162}$, sendo caracterizado pelo suporte eletrônico, em substituição ao papel ${ }^{1163}$. Pode ser definido como o processo administrativo em que as informações recebidas, processadas e produzidas estão representadas em documentos eletrônicos ${ }^{1164}$. Assim sendo, devem estar registrados em suporte digital o ato administrativo resultante do processo administrativo eletrônico e todas as atividades que lhe antecedem ${ }^{1165}$.

O processo administrativo eletrônico não constitui uma nova categoria jurídica, mas uma espécie de processo administrativo, definida de acordo com o suporte utilizado para o registro das informações. Não há, assim, nenhuma distinção conceitual

\footnotetext{
1162 Cf. TinTó Gimbernat, Montserrat, Actividad administrativa formalizada y medios telemáticos: requisitos legales y técnicos del procedimiento administrativo electrónico, in Revista de Estudios Locales. Cunal, $\mathrm{n}$. Extraordinário 1, Madrid, Cosital, 2004, pp. 60-61.

${ }^{1163}$ Cf. TINTÓ GIMBERnAT, Montserrat, Actividad administrativa formalizada y medios telemáticos, cit., p. 59.

${ }^{1164}$ Preferindo o vocábulo ciberprocedimiento, TINTÓ GIMBERNAT afirma que este poderia ser definido como o processo baseado no uso exclusivo de meios eletrônicos (cf. Administración electrónica y ciberprocedimiento, cit., p. 17). A doutrina francesa dá ênfase à utilização do suporte digital, ao tratar das chamadas téléprocédures. Elas seriam trocas desmaterializadas de formalidades administrativas entre os serviços públicos, seus parceiros e usuários, aliando o tratamento informatizado dos dados à sua transferência aos serviços destinatários via internet (cf. Beloulou, Véronique, op. cit., p. 624 e BAQUIAST, Jean-Paul, Internet et les administrations, cit., p. 99). Em sentido semelhante, fazendo referência ao respeito às disposições legais e regulamentares aplicáveis, cf. CANTERO, Anne, op. cit., p. 104. Tratando dos processos relativos a compras, com ênfase na mudança de suporte, cf. GuIllou, Yves-René, Le régime juridique de la dématérialisation, in LAJOIE, Thierry, HisLaIRE, Loïc, Les marches publics dématérialisés, Paris, Moniteur, 2004, p. 39. Sobre a noção de desmaterialização, cf. supra, nota 195. Há quem entenda o processo administrativo eletrônico como o meio de produção das disposições e resoluções administrativas em que uma ou diversas fases se produz mediante da utilização da telemática (cf. CERRILlo I MARTínEZ, Agustí, Administración electrónica, in PEGUERA POCH, Miquel (org.), Derecho y nuevas tecnologías, Barcelona, OUC, 2005, p. 269). Todavia, tal conceito não parece suficiente, pois permitiria classificar como processo administrativo eletrônico o conjunto de atividades iniciada por meio de um protocolo telemático, ainda que o documento fosse recebido, impresso, autuado em papel e depois decidido à maneira tradicional. $\mathrm{O}$ verdadeiro processo eletrônico deve ser plenamente digitalizado, sendo caracterizado pelo expediente eletrônico (cf. infra, item 4.8).

${ }^{1165}$ Segundo DUNI, todo o trabalho administrativo deve ser digitalizado antes dos atos administrativos, os quais são no fundo apenas a conclusão desse modo de operar (cf. Verso un'amministrazione integrata dei procedimenti amministrativi, cit., p. 46).
} 
fundamental quanto à sua natureza como instituto jurídico do direito administrativo, em relação ao processo em suporte papel ${ }^{1166}$. As novas questões provocadas pelas novas tecnologias devem ser compreendidas e avaliadas a partir das bases teóricas referentes ao processo administrativo, conforme se fará no decorrer deste capítulo ${ }^{1167}$.

Pode-se dividir o processo administrativo eletrônico em sentido amplo em duas categorias: o processo administrativo eletrônico em sentido estrito, no qual o ser humano atua com o auxílio da tecnologia, e o processo administrativo automatizado, em que todas as atividades, com exceção da provocação inicial, são desempenhadas pela máquina, sem necessidade de atuação humana ${ }^{1168}$.

O processo administrativo eletrônico em sentido estrito equivale a uma automatização parcial, em que se dá a combinação entre a atuação da máquina e a do homem $^{1169}$. Caso a tecnologia seja usada com pouca intensidade, apenas o registro da informação e alguns aspectos da gestão documental são confiados ao sistema informático, cabendo todas as demais tarefas ao ser humano. Em processos com um nível mais intenso de utilização da tecnologia, o sistema informático pode ser responsável pela gestão de um fluxo de trabalho automatizado, no qual estejam definidos de modo preciso os momentos e escopos da atuação humana. Tanto o homem quanto a máquina podem ser incumbido de atos instrutórios ou decisórios, sendo aceitável, por exemplo, que o sistema prepare os elementos necessários para uma decisão por parte da autoridade administrativa ou que uma

\footnotetext{
${ }^{1166}$ Cf. TinTó GimBernat, Montserrat, Actividad administrativa formalizada y medios telemáticos cit., pp. 60-61.

${ }^{1167}$ Por isso, os itens a seguir com frequência recorrem à doutrina tradicional para a caracterização de noções da doutrina do processo administrativo. Nesse sentido, nem todas as citações trazidas ao texto referem-se ao processo eletrônico, pois várias delas têm apenas o propósito de trazer conceitos tradicionais para o confronto com as novidades trazidas pelo uso das novas tecnologias.

${ }^{1168}$ Há processos em que até mesmo o início ocorre de forma automatizada, como é o caso das imposições de multa por infração de trânsito apurada por meio de equipamento eletrônico (cf. infra, item 4.9.2.2). Caso não seja apresentada defesa, o processo transcorre de forma totalmente automatizada, até que a sanção pecuniária é imposta e a pontuação respectiva é registrada no prontuário do condutor.

1169 Cf. CONTALDO, Alfonso, Gorga, Michele, op. cit., p. 183. Segundo o autor, isso poderia ocorrer por motivos de complexidade ou de custos (p. 15).
} 
decisão final automatizada seja antecedida de uma intervenção do homem na instrução do processo $^{1170}$.

Já o processo administrativo automatizado leva necessariamente à prática de um ato administrativo automatizado. Como antes exposto, o próprio ato automatizado pode ser questionada sua natureza jurídica de ato administrativo, em vista de não ser caracterizado por uma decisão humana diante do caso concreto ${ }^{1171}$. Da mesma maneira, a natureza jurídica do processo administrativo automatizado pode ter posta em dúvida, pelo fato de não apresentar elementos em geral associados à processualidade ${ }^{1172}$. Enquanto o processo tradicional apresenta como dimensão essencial o tempo, no qual são praticados os atos processuais, possibilitando a integração entre os sujeitos, o processo automatizado gera um ato administrativo de modo instantâneo, por ação do sistema informático, sem uma sucessão encadeada de atos e sem a atuação do ser humano diante do caso concreto.

Entretanto, assim como uma avaliação detida permite caracterizar o ato automatizado como modalidade de ato administrativo, o processo automatizado também se revela uma espécie de processo administrativo, quando examinado com os devidos cuidados. Com efeito, cabe ao processo intermediar o surgimento da manifestação jurídica no plano inferior (ato) a partir da manifestação jurídica no plano superior (lei ou regulamento ${ }^{1173}$. No caso das atividades realizadas pelo computador, essa função é desempenhada por um processo automatizado. De acordo com a sistemática exposta no capítulo anterior, o ato automatizado decorre de uma série de operações, executadas pela máquina como uma

\footnotetext{
${ }^{1170}$ Considere-se, por exemplo, a renovação de uma licença para conduzir veículo automotor, que exija somente um exame médico para seu deferimento. $\mathrm{O}$ ato final pode ser automatizado, caso a autoridade competente estabeleça, a priori, que os requerimentos sucedidos por uma avaliação clínica favorável serão deferidos pelo sistema informático. $\mathrm{O}$ ato automatizado certamente não será atribuível ao médico, mas à autoridade responsável pela expedição da licença, que decidiu fazê-lo de forma automatizada.

${ }_{1171}$ Cf. supra, item 3.4.4.

${ }^{1172}$ Assim já se entendeu: "Em nossa opinião não cabe falar com propriedade de procedimento administrativo quando não existe uma base que permita à administração emanar uma declaração de vontade, juízo, conhecimento e, inclusive, desejo, mediante a interação com o administrado. Se a decisão não se articula mediante a intermediação reflexiva dos agentes públicos, mas ela - neste caso a consistente em autorizar ou negar o acesso - não é mais que uma resposta automatizada de um sistema informático, esta já sim baseada em uma série de dados previamente recolhidos que permite a formulação de uma decisão instantânea, não cabe falar com propriedade de procedimento administrativo" (FERNÁNDEZ SALMERÓn, Manuel, El acceso a los registros y archivos administrativos, cit., p. 623, tradução livre).

${ }^{1173}$ A respeito dessa perspectiva, referida às teorias normativistas, cf. MEDAUAR, Odete, A Processualidade no Direito Administrativo, cit., p. 23.
} 
projeção do ser humano. Tais operações são efetuadas com velocidade extrema, mas constituem algo diverso do próprio ato e estão teleologicamente dispostas em vista de um resultado final. Portanto, do ponto de vista funcional, trata-se de um processo administrativo.

Além disso, o ato administrativo automatizado decorre do exercício do poder, efetuado com o auxílio da máquina ${ }^{1174}$. Isso torna indispensável o reconhecimento da existência de um processo administrativo ${ }^{1175}$, pois a processualidade está sempre vinculada à disciplina do exercício das competências estatais ${ }^{1176}$. Um entendimento abrangente a respeito permite aplicar às atuações automatizadas as garantias próprias da processualidade - v.g., o direito de recorrer contra o ato automatizado.

O reconhecimento das atividades totalmente automatizadas como verdadeiros processos administrativos permite compreender, do ponto de vista jurídico, várias das realidades contemporâneas supra referidas, que envolvem a produção e tratamento de informação. A simples troca de mensagens com o administrado, não sucedida por um ato administrativo em sua acepção tradicional, pode ser entendida como um processo administrativo pelo qual é efetuado o recebimento telemático de informações, seguido de uma decisão automatizada a respeito de sua inclusão nas bases de dados oficiais. Essa compreensão ampla cria condições para o cumprimento do princípio da equivalência de garantias, ao estender a tais operações automatizadas os ditames próprios do devido processo legal ${ }^{1177}$.

\footnotetext{
${ }^{1174}$ Algumas atividades, é certo, sofrem alterações que eliminam o próprio exercício do poder. É o fato, por exemplo, do fornecimento indiscriminado de informações por meio da internet, em tempo real, o que não ocorre pode meio de um acesso procedimentalizado (cf. FERNÁNDEZ SALMERÓn, Manuel, El acceso a los registros y archivos administrativos, cit., p. 623 e FERNÁNDEZ SALMERÓN, Manuel, VALERO TORRIJOS, Julián, La publicidad de la información administrativa en internet, cit., p. 106). Se o acesso à informação for restrito a determinadas pessoas, haverá processo, no qual será verificada a identidade do requerente e a sua legitimidade para o acesso, seguindo-se um ato a respeito, ainda que automatizado.

${ }^{1175}$ Sobre o processo como instrumento legítimo para o exercício do poder, cf. MEDAUAR, Odete, A Processualidade no Direito Administrativo, cit., p. 22.

${ }_{1176}$ Cf. ibidem, p. 32.

1177 Por esta razão, nada obstante a relevância das trocas de informação como possível resultado do processo administrativo (cf. supra, item 4.2, em especial a nota 1161), o presente estudo, nos itens seguintes, refere-se sempre à finalização do processo por meio de um ato administrativo, fazendo-se necessária a ressalva, portanto, quanto à possibilidade de que se trate de um ato automatizado, inclusive com o objeto específico de determinar a inclusão de certa informação à respectiva base de dados oficial.
} 


\subsection{O aproveitamento das oportunidades proporcionadas pela tecnologia}

Tem sido observado que o conceito estático de ato administrativo em forma eletrônica não produz consequências práticas revolucionárias, pois os verdadeiros benefícios são obtidos em virtude da utilização dinâmica da tecnologia, por meio do processo administrativo ${ }^{1178}$. Nesse sentido, ele constitui o âmbito de maximização das utilidades decorrentes da informática e da telemática ${ }^{1179}$. Parece oportuno, portanto, discutir como esse aproveitamento da tecnologia pode ocorrer, a fim de trazer os maiores benefícios possíveis para a eficiência administrativa.

De modo intuitivo, falar em processo administrativo eletrônico traz a ideia da transformação das folhas do expediente em imagens digitais, passíveis de exibição na tela de um computador. Entretanto, o processo administrativo eletrônico não deve estar limitado a essa concepção de autos digitalizados. O efetivo aproveitamento das oportunidades proporcionadas pela tecnologia exige uma visão mais aprofundada e crítica a esse respeito.

É evidente que apenas a digitalização da documentação processual já poderia trazer benefícios, propiciando ao administrado ter acesso ao expediente administrativo sem impedir a continuidade dos trabalhos da Administração e sem impossibilitar o exercício do mesmo direito por parte de outros interessados. Estes seriam, entretanto, benefícios ainda tímidos. Como antes exposto, o principal objetivo do governo eletrônico não é a simples eliminação do papel, mas o aproveitamento das funcionalidades proporcionadas pela capacidade de tratamento e circulação da informação em suporte digital, na busca da eficiência administrativa. Não há sentido em criar sistemas informáticos, por meio de um esforço orçamentário, organizativo e normativo, sem aproveitar de modo pleno as possibilidades da tecnologia, adaptando a um entorno tecnológico aquilo que foi concebido para o

\footnotetext{
1178 Cf. DUNI, Giovanni, L'amministrazione digitale, cit., p. 47.

1179 Cf. ibidem, p. 77. Defendendo a importância do processo administrativo para o governo eletrônico, cf. NotarmuZI, Carlo, op. cit., p. 2.
} 
expediente em papel e para as relações presenciais ${ }^{1180}$. Caso os processos administrativos fossem mantidos como no passado, apenas com a mudança no suporte documental, haveria um desperdício das potencialidades de modernização e eficácia propiciadas pelas tecnologias da informação e da comunicação, pois seria produzida apenas uma versão eletrônica dos antigos problemas ${ }^{1181}$.

As novas tecnologias são capazes de transformar o processo administrativo $^{1182}$. Para tanto, é preciso superar o modelo tradicional, repropondo sua estrutura, por meio de novas concepções ${ }^{1183}$, que levem em conta as alternativas tecnológicas atuais. As novas ferramentas informáticas exigem tal reflexão ${ }^{1184}$, pois a chave do êxito não está na tecnologia em si mesma, mas em aproveitar a iniciativa de modernização tecnológica para rediscutir os mecanismos de atuação administrativa ${ }^{1185}$. A tecnologia, por si, não provoca transformações; ao contrário, seu uso inadequado pode até mesmo impedir a mudança, reforçando velhos esquemas de pensamento ${ }^{1186}$. Por isso, o processo administrativo eletrônico somente pode trazer plenos resultados caso acompanhado de iniciativas de redesenho e simplificação, temas já tratados em outro capítulo deste estudo ${ }^{1187}$.

Na verdade, o uso do suporte digital permite outros avanços, ainda mais significativos, ao liberar a Administração das restrições próprias do documento em papel,

${ }^{1180}$ Cf. VALERO TORRIJOS, Julián, La gestión y conservación del documento administrativo electrónico, cit., p. 59.

${ }^{1181}$ Cf. VALERO TORRIJOS, Julián, La nueva regulación legal del uso de las tecnologías de la información y las comunicaciones en el ámbito administrativo, cit., pp. 209-210.

${ }^{1182}$ Cf. BARNÉS VÁZQUEZ, Javier, Sobre el procedimiento administrativo, cit., p. 305.

${ }^{1183}$ Cf. MARTÍN DELGADO, Isaac, La administración electrónica como problema actual para la investigación y la docencia en el derecho administrativo, cit., p. 359. Entendendo que o desenvolvimento dos processos administrativos eletrônicos deve ser acompanhado por uma transformação das relações entre a Administração e os usuários, além da lógica dos processos administrativos existentes, cf. LEMAîTRE, Marie-Françoise, op. cit., p. 628.

${ }_{1184}$ Cf. CARCENAC, Thierry, op. cit., p. 24.

1185 A propósito, a doutrina tem feito referência ao redesenho ou à reengenharia de processos (cf. IASELLI, Michele, op. cit., p. 25 e VALERO TORRIJOS, Julián, El régimen jurídico de la e-Administración, cit., p. 16). O redesenho de processos tem origem na readequação dos processos produtivos privados, com o forte influxo do instrumental oferecido pelas novas tecnologias. É preciso notar, contudo, que se trata de uma expressão advinda da ciência da administração, na qual o vocábulo processo não é utilizado em seu sentido jurídico. Ainda que a proximidade entre as noções mereça uma investigação científica, certamente esta ultrapassaria os objetivos deste estudo, que se restringirá a mencionar a necessidade de uma profunda reflexão em relação aos processos administrativos, em razão dos poderosos instrumentos oferecidos pelas novas tecnologias.

${ }_{1186}$ Cf. CARCENAC, Thierry, op. cit., p. 24.

${ }^{1187}$ Cf. supra, item 2.3.2. 
viabilizando o relacionamento telemático e a automatização de atividades. Longe de estar limitado a apresentar-se apenas como um conjunto de folhas digitalizadas, o processo eletrônico deve assumir a forma adequada para fazer uso dos modernos mecanismos relacionados à troca e ao processamento da informação, observadas as garantias jurídicas devidas.

O uso da telemática no processo administrativo constitui um dos aspectos fundamentais da inovação no governo eletrônico ${ }^{1188}$. O relacionamento remoto, por meio de redes como a internet, livre das restrições espaciais e temporais próprias da atuação presencial, possibilita um novo modo de interação com a Administração ${ }^{1189}$. De qualquer lugar do planeta e em qualquer horário, o interessado pode transmitir um documento ao Poder Público ou ter acesso ao expediente administrativo, sem a necessidade de intermediação por parte de um funcionário. Assim, com a telemática, há um relacionamento mais interativo entre Administração e administrado ${ }^{1190}$. A telemática viabiliza, outrossim, a participação de várias entidades públicas em um mesmo processo, o que sempre foi difícil na atuação baseada em atos presenciais ${ }^{1191}$.

Outras vantagens podem ser trazidas pela automatização de tarefas no âmbito do processo. Se a própria decisão final pode ser produzida por um sistema informático, como visto no capítulo anterior, também podem ser confiadas a ele atividades simples e repetitivas que não reclamam habilidades humanas. Os benefícios são semelhantes àqueles verificados na automatização dos atos administrativos, já expostas neste estudo ${ }^{1192}$. Mesmo sendo necessária uma atuação do homem em certas fases do processo, a realização automatizada de determinadas atividades pode trazer grandes vantagens para a Administração e para o interessado. Alguns desses mecanismos serão analisados nos itens seguintes.

\footnotetext{
${ }^{1188}$ Cf. DunI, Giovanni, Verso un'amministrazione integrata dei procedimenti amministrativi, cit., p. 46.

1189 Cf. MASUCCI, Alfonso, Procedimento amministrativo e nuove tecnologie, cit., p.14.

${ }^{1190}$ Cf. Mestre Delgado, Juan Francisco, op. cit., p. 123.

1191 A participação de vários entes públicos em um mesmo processo administrativo é um fenômeno crescente (cf. KLUTH, Winfried, NUCKET, Jana, op. cit., p. 493).

${ }^{1192}$ Cf. supra, item 3.4.1.
} 


\section{5. $O$ controle do impulso e dos atos processuais}

O processo administrativo constitui um modo de sistematizar as tarefas destinadas à expedição de atos administrativos. Isso permite ao administrado conhecer o funcionamento da Administração, o que lhe favorece a defesa dos direitos, bem como propicia a simplificação das rotinas por parte do Poder Público, evitando decidir, em cada caso, como se deve atuar ${ }^{193}$. Sistematizadas as tarefas integrantes do processo, é também mais fácil chegar a um resultado final, correspondente à decisão administrativa ${ }^{1194}$.

Um dos aspectos da sistematização diz respeito à tramitação e à disciplina dos atos processuais. $\mathrm{O}$ andamento do processo tradicional não depende de regras específicas a respeito, podendo ocorrer apenas por força das competências dos órgãos envolvidos: sendo apurada, diante do caso concreto, a necessidade de um elemento de fato, parecer ou decisão intermediária, o expediente é encaminhado ao órgão competente. No entanto, sobretudo nas atividades mais comuns, é habitual haver um ato normativo para disciplinar a sequência procedimental, prevendo onde o processo deve começar, tramitar e acabar, bem como quais atos precisam ser praticados. A disciplina normativa pode atingir cada um desses atos, determinando qual deve ser seu escopo preciso, cabendo a cada interveniente atuar de acordo com pautas juridicamente preordenadas ${ }^{195}$. Em casos mais simples, os

\footnotetext{
${ }^{1193}$ Cf. MedauAR, Odete, A Processualidade no Direito Administrativo, cit., p. 73. Os processos administrativos estão sujeitos a um permanente esforço de normalização, com três diferentes finalidades: a) restringir as possibilidades de arbítrio; b) oferecer as devidas garantias jurídicas; c) padronizar juridicamente a atividade da Administração Pública, de modo a evitar desvantajosas controvérsias, aumentando assim a eficiência (cf. MENEGALE, J. Guimarães, op. cit., pp. 325-326).

${ }^{1194}$ Essa não é somente uma consequência do próprio conceito de processo administrativo, mas uma decorrência do princípio da eficiência: "Aplicado ao processo administrativo, o princípio da eficiência exige que ele, no mínimo, chegue ao seu final, tenha uma decisão conclusiva, afirme ou negue um direito, solucione uma controvérsia. O que não pode ocorrer é a negativa ou a simples ausência de uma decisão final, para o quê é importante não admitir delongas, protelações, descumprimento de prazos, omissão de providências ou o puro e simples engavetamento, para não se falar em extravio nem em subtração delituosa" (DALLARI, Adilson Abreu, FERRAZ, Sérgio, op. cit., p. 78).

${ }^{1195}$ Cf. MedauAR, Odete, A Processualidade no Direito Administrativo, cit., p. 31.
} 
termos do processo são preparados com antecedência, de modo que a prática do ato processual consiste apenas no preenchimento de lacunas em formulários ${ }^{1196}$.

No processo em papel, grande parte das atividades não está regulamentada de maneira tão precisa, cabendo ao servidor público atuar de acordo com uma praxe não normatizada ou mesmo avaliar o caso concreto de acordo com suas particularidades, observadas regras mínimas aplicáveis aos processos administrativos ${ }^{1197}$. Ainda que haja alguma padronização, os atributos peculiares do caso concreto podem exigir adaptações, para atender de modo mais adequado as finalidades buscadas pelo ordenamento. De modo justificado, é possível criar variações do procedimento ou do conteúdo prescrito para os atos, sem acarretar vícios legais. Assim, mesmo quando sujeito a uma disciplina normativa precisa, o expediente em papel comporta considerável flexibilidade.

Esses pontos precisam ser vistos sob a perspectiva do processo administrativo eletrônico. Em tese, como visto, seria possível que o processo fosse informatizado de maneira superficial, restringindo-se à alteração do suporte documental ${ }^{1198}$. Nesta hipótese, não haveria novidades em relação à disciplina da tramitação dos processos e dos atos processuais, que estariam sujeitos a regras semelhantes àquelas aplicáveis ao processo em papel. Todavia, na busca pelo aproveitamento das oportunidades trazidas pela tecnologia, o processo administrativo eletrônico tende a dar novos contornos à questão do controle da tramitação do processo e do conteúdo dos atos processuais. Havendo necessidade de intervenção humana no processo, as novas tecnologias permitem prever com precisão em que momentos ela deve ocorrer e em qual extensão.

\footnotetext{
${ }^{1196}$ Cf. CavalcantI, Themístocles Brandão, Tratado de Direito Administrativo, vol. IV, São Paulo, Freitas Bastos, 1961, p. 537.

${ }^{1197}$ Tem sido apontado que os processos jurídicos, em geral, raramente correspondem a uma sequência determinística de operações, que prescreva comportamentos ou fatos em sequência, consistindo na maior parte das vezes em um esquema procedimental que atende a inumeráveis sequências de possibilidades (cf. CONTALDO, Alfonso, GoRGA, Michele, op. cit., p. 19).

${ }^{1198}$ Em atividades administrativas não padronizadas, que lidam com elementos de fato variáveis e situações imprevisíveis, é normal que o processo administrativo eletrônico tome a feição de um processo tradicional, sendo o sistema informático responsável apenas pela tramitação telemática de informações. Nessa hipótese, observadas as normas legais pertinentes, o funcionário poderia definir o conteúdo do ato e decidir de quem seria a próxima intervenção no processo, até que fossem obtidos os elementos necessários e o órgão competente praticasse um ato administrativo em forma eletrônica, lançado no sistema informático. Seria um nível pouco intenso de utilização da tecnologia, que não traria necessariamente ganhos de eficiência para a atuação administrativa em relação ao processo em papel.
} 
O sistema informático pode ser responsável pelo controle da própria sequência procedimental. Neste caso, em vez de cada funcionário encaminhar os autos ao próximo órgão, cabe ao sistema solicitar a providência subsequente. Realizada uma tarefa, ele recebe a informação a respeito e, de modo automatizado, solicita a outra pessoa que atue e assim por diante ${ }^{1199}$. Com isso, o sistema informático resta incumbido do próprio impulso processual ${ }^{1200}$, efetuando, de modo automatizado, a integração entre os órgãos envolvidos, de acordo com regras definidas com antecedência e incorporadas ao respectivo software $^{1201}$. O impulso automatizado permite o avanço ordenado do processo, eliminando obstáculos e anormalidades na tramitação ${ }^{1202}$. Para tanto, o software precisa ser concebido para uma contínua interação transversal dos órgãos, com uma definição antecipada de todas as possibilidades de tramitação, conforme as características próprias do caso, determinando a sucessão dos atos e responsáveis ${ }^{1203}$. Isso exige considerar de modo unitário todo o processo, confiando sua gestão à unidade administrativa à qual compete a emanação do ato final $^{1204}$.

No processo administrativo eletrônico, o impulso não ocorre necessariamente de acordo com uma sequência linear, porque esta é uma estrutura própria das limitações do expediente em papel, no qual cada tarefa depende da disponibilidade material dos autos, exigindo que o trabalho sucessivo só se inicie quando concluído o anterior ${ }^{1205}$. As novas tecnologias permitem que vários órgãos tenham acesso simultâneo à documentação do processo e trabalhem ao mesmo tempo ${ }^{1206}$, propiciando a transformação do esquema

\footnotetext{
${ }^{1199}$ Cf. DunI, Giovanni, Teleamministrazione, cit., item 3.4.

${ }^{1200}$ De acordo com o princípio da oficialidade - impulso oficial ou impulso de ofício -, cabe à Administração "tomar todas as providências necessárias ao trâmite contínuo para se chegar, sem delongas, à decisão final" (MedAuAR, Odete, A Processualidade no Direito Administrativo, cit., p. 130).

${ }^{1201}$ Fala-se, neste caso, em workflow (fluxo de trabalho), que corresponde à sequência de passos pela qual é executada uma atividade (cf. MARANHÃO, Mauriti, MACIEIRA, Maria Elisa Bastos, O processo nosso de cada dia: modelagem de processos de trabalho, Rio de Janeiro, Qualitymark, 2004, p. 66). Por meio do workflow documental, as informações trafegam entre pessoas e equipamentos informáticos de acordo com um conjunto de regras bem definidas, até a obtenção do resultado pretendido. Sobre o fluxo de trabalho documental, cf. IASELLI, Michele, op. cit., p. 25.

${ }^{1202}$ Cf. AlAmillo DOMINGO, Ignacio, URIOS APARISI, F. Xavier, La actuación administrativa automatizada en el ámbito de las administraciones públicas, cit., p. 151.

${ }^{1203}$ Cf. CONTALDO, Alfonso, Gorga, Michele, op. cit., p. 19.

${ }^{1204}$ Cf. DUNI, Giovanni, L'amministrazione digitale, cit., p. 48.

1205 Cf. Duni, Giovanni, Ancora sul procedimento amministrativo telematico, cit., pp. 3-4.

${ }^{1206}$ Cf. ibidem, p. 4.
} 
operativo linear em um sistema em raios ou em estrela ${ }^{1207}$. No processo eletrônico, pode ser necessário manter uma sequência linear de fases procedimentais, por força da norma ou por motivos de oportunidade e conveniência ${ }^{1208}$, mas isso já não constitui uma imposição dos limites do suporte, de modo que o desenho do processo deve levar em conta a possibilidade de atuação simultânea dos órgãos envolvidos ${ }^{1209}$. A execução simultânea de tarefas pode ser uma oportunidade para o aumento da celeridade do processo e para a concepção de novas estruturas de atuação, com maior cooperação entre os órgãos públicos.

Por outro lado, a padronização associada à utilização dos meios informáticos é capaz de alcançar, além da sequência procedimental, o próprio conteúdo dos atos processuais. Ao utilizar a tecnologia, a Administração pode impor a cada funcionário limites precisos em sua atuação, por meio da fixação do escopo e dos requisitos de cada ato, a serem controlados de modo eletrônico. Assim, por exemplo, a atuação do funcionário pode estar limitada ao preenchimento de um formulário digital, segundo as regras estabelecidas e incorporadas ao software responsável pela gestão do processo. Vale lembrar que os modelos em papel sempre existiram na administração tradicional, mas jamais foram tão inexoráveis. No processo eletrônico, a tendência é impedir a prática de atos fora dos formulários constantes do sistema informático.

Estando o sistema incumbido de efetuar o impulso processual ou de controlar o conteúdo dos atos administrativos, ele deverá estar programado com base em decisões semelhantes àquelas envolvidas na automatização dos atos administrativos, tratadas no capítulo anterior deste estudo. Cabe à Administração, por meio de atos administrativos fundados em sua capacidade de auto-organização, estabelecer uma programação destinada a esgotar as várias sequências possíveis, fixando critérios para padronizar as tarefas a serem efetuadas e os órgãos competentes para tanto, bem como a extensão das possíveis de-

\footnotetext{
${ }^{1207}$ Cf. ibidem, p. 5.

${ }^{1208}$ Cf. ibidem, p. 6.

${ }^{1209}$ Mesmo no processo em papel, o esquema em estrela já opera em todos os casos em que a Administração exige a duplicação da documentação justamente para permitir que vários órgãos trabalhem ao mesmo tempo (cf. ibidem, p. 6). Todavia, nestes casos, as cópias são encaminhadas internamente na condição de expedientes secundários, separados do principal, e somente são levados em conta quando as respectivas respostas retornam e são incorporadas ao expediente principal. No caso do expediente em estrela, as solicitações simultâneas fazem parte, desde logo, do expediente principal, podendo ser gerenciadas e consultadas como integrantes dele.
} 
cisões e seus efeitos em relação ao processo. As regras transpostas para o software têm natureza semelhante àquelas expressas por meio de atos normativos gerais, acima mencionados, que por vezes regulam o processo administrativo tradicional. Tais atos devem atender aos requisitos jurídicos pertinentes, assegurando sua compatibilidade com o ordenamento, sobretudo quanto à observância das garantias próprias do devido processo legal.

\subsection{Garantias aplicáveis ao processo eletrônico}

Aplica-se à digitalização dos expedientes o princípio da equivalência de garantias, de sorte que a utilização das novas tecnologias não deve acarretar diminuição dos direitos processuais dos administrados ${ }^{1210}$. O processo administrativo eletrônico deve observar os mesmos princípios que seu equivalente tradicional ${ }^{1211}$, assegurando o correto desempenho das funções administrativas na consecução do interesse público e possibilitando o controle jurisdicional ${ }^{1212}$. Para tanto, ele deve proporcionar níveis adequados de publicidade, transparência, participação e motivação, permitindo que o interessado exerça seus direitos no mínimo com a mesma intensidade que exerce quando adotados os meios tradicionais. Os direitos devem adaptar-se à nova estrutura da Administração Pública na sociedade da informação ${ }^{1213}$.

Alguns princípios podem ser até reforçados pela tecnologia, levando a uma ampliação das garantias processuais ${ }^{1214}$. Assim, por exemplo, a celeridade do processo pode tornar mais efetivo o princípio da eficiência e o direito à razoável duração do processo, ao passo que a maior transparência proporcionada pelos meios informáticos e a possibi-

\footnotetext{
${ }^{1210}$ Cf. Tintó Gimbernat, Montserrat, Actividad administrativa formalizada y medios telemáticos, cit., p. 61 e MARTíneZ GutiÉRreZ, Rubén, Administración Pública Electrónica, cit., pp. 232-233.

${ }^{1211}$ Cf. TinTó GIMBERnAT, Montserrat, Actividad administrativa formalizada y medios telemáticos, cit., p. 61.

1212 Cf. TINTÓ GIMBERNAT, Montserrat, Administración electrónica y ciberprocedimiento, cit., p. 17.

${ }^{1213}$ Cf. BARNÉS VÁZQUEZ, Javier, Una reflexión introductoria sobre el Derecho Administrativo y la Administración Pública de la Sociedad de la Información y del Conocimiento, cit., p. 48.

${ }^{1214}$ Cf. TinTó GimBERnAT, Montserrat, Actividad administrativa formalizada y medios telemáticos, cit., p. 61.
} 
lidade de relacionamento telemático podem viabilizar ainda mais o contraditório e a ampla defesa. Todavia, o foco principal de atenção deve ser a necessidade de evitar que a informatização dos processos importe em uma redução de direitos para o administrado.

A adaptação das garantias processuais clássicas aos processos administrativos eletrônicos pode ser avaliada de acordo com os desafios proporcionados pelos três eixos de transformação acima referidos: a digitalização das informações, o relacionamento telemático entre órgãos e administrados e a automatização das tarefas processuais.

Há quem entenda que a digitalização do suporte das informações poderia pôr em risco as garantias associadas ao formalismo ${ }^{1215}$. Todavia, tal posicionamento já não se sustenta no contexto atual, em que os documentos eletrônicos são capazes de desempenhar as mesmas funções do documento em papel. O princípio do formalismo moderado sempre teve relação com a previsão de ritos e formas simples, suficientes para propiciar certeza, segurança e respeito aos direitos dos sujeitos, sobretudo o contraditório e a ampla defesa $^{1216}$. Esses aspectos podem ser atendidos, sem problemas, pelo suporte eletrônico; aliás, eventual apego ao papel como único suporte possível é que seria contrário a tal princípio, o qual exige uma interpretação flexível e razoável quanto à forma, para evitar que esta seja tida como um fim em si mesmo, apartado das verdadeiras finalidades do processo $^{1217}$.

As tecnologias da informação e da comunicação oferecem uma oportunidade para superar o mau formalismo que por vezes aflige a Administração Pública ${ }^{1218}$. Não há dúvida da necessidade de preservar o respeito ao elemento formal no marco do processo

\footnotetext{
${ }^{1215}$ Cf. Chevallier, Jacques, La mise en ouvre de l'administration électronique, cit., p. 389.

${ }^{1216}$ Cf. MedauAr, Odete, Direito administrativo moderno, cit., p. 170 e A Processualidade no Direito Administrativo, cit., pp. 131-132. No mesmo sentido, DALLARI, Adilson Abreu, FERRAZ, Sérgio, op. cit., p. 80.

1217 Sobre essa outra perspectiva a respeito do princípio, cf. MEDAUAR, Odete, Direito administrativo moderno, cit., p. 170 e A Processualidade no Direito Administrativo, cit., pp. 65-67 e 133. Nas expressivas palavras de Marcos Juruena Villela Souto, esse apego ao processo em papel para o desempenho das atividades públicas remonta a um período anterior ao desenvolvimento tecnológico, "quando se tinham mais árvores e mais tempo" (Licitações e controle de eficiência: repensando o princípio do procedimento formal à luz do "placar eletrônico"!, in ARAGÃo, Alexandre Santos de, MARQUES NETO, Floriano de Azevedo (coord.), Direito administrativo e seus novos paradigmas, Belo Horizonte, Fórum, p. 554).

${ }^{1218}$ Cf. TinTó GIMBERnAT, Montserrat, Actividad administrativa formalizada y medios telemáticos, cit., p. 63.
} 
administrativo eletrônico ${ }^{1219}$, de modo que o bom formalismo não desaparecerá, mas será adaptado $^{1220}$, pois a forma constitui uma garantia tanto para os administrados quanto para o funcionamento da Administração ${ }^{1221}$. Como o formalismo é indispensável também para o êxito dos sistemas informáticos ${ }^{1222}$, tende a haver um aumento da importância da forma para o processo administrativo, manifestada na frequente necessidade de utilização de modelos padronizados ${ }^{1223}$ e na tendência a registrar um número maior de informações.

Quanto à utilização de mecanismos telemáticos, o princípio da equivalência de garantias incide tanto na troca de informações com o administrado quanto no tráfego de informações dentro da própria Administração Pública. Os direitos do usuário devem ser os mesmos que existiriam caso ele tivesse se deslocado pessoalmente às dependências administrativas ${ }^{1224}$. A transmissão telemática deve oferecer as adequadas garantias jurídicas ${ }^{1225}$, exigindo-se que o tráfego de informações seja objeto das adequadas medidas de segurança informática, de maneira a preservar os direitos fundamentais envolvidos no processo administrativo eletrônico, sobretudo a intimidade e a proteção dos dados de caráter pessoal ${ }^{1226}$.

Tanto a digitalização dos expedientes quanto a telematização de atividades trazem o problema da preservação da igualdade no processo administrativo eletrôni$\mathrm{co}^{1227}$. Com efeito, conforme antes exposto, a introdução das novas tecnologias na Administração Pública precisa levar em conta as frequentes diversidades entre os usuários no uso das ferramentas eletrônicas, para evitar indesejáveis discriminações. Em relação ao

\footnotetext{
${ }^{1219}$ Cf. ibidem, p. 62.

1220 Sobre tal adaptação, cf. OCHOA MONZÓ, Josep, MARTínEZ GuTIÉRREZ, Rubén, La permeabilidad de la actividad administrativa al uso de tecnologías de la información y de la comunicación, cit., p. 84 e FOUILLEUL, Nicolas, op. cit., p. 154.

${ }^{1221}$ Cf. CANTERO, Anne, op. cit., p. 687.

1222 Adotando esse entendimento e mencionando que a falta de formalização ou o desrespeito a ela têm sido a causa de várias falhas dos sistemas destinados a compras eletrônicas no setor privado, cf. HISLAIRE, Loïc, Le contexte de la dématérialisation, in LAJOIE, Thierry, HISLAIRE, Loïc, Les marches publics dématérialisés, Paris, Moniteur, 2004, p. 24.

${ }^{1223}$ Cf. MARTín DELGADO, Isaac, La gestión electrónica del procedimiento administrativo, cit., p. 91.

${ }^{1224} \mathrm{Cf}$. VALERO TORRIJOS, Julián, El régimen jurídico de la e-Administración, cit., pp. 2-3.

1225 Cf. MARTín DELGADO, Isaac, La administración electrónica como problema actual para la investigación y la docencia en el derecho administrativo, cit., pp. 358-359.

${ }_{1226}$ Cf. Mestre Delgado, Juan Francisco, op. cit., p. 130.

1227 Cf. TinTó GimBERnAT, Montserrat, Actividad administrativa formalizada y medios telemáticos, cit., p. 61.
} 
processo eletrônico, uma cautela é a possibilidade de oferecer ao interessado, quando solicitado, uma cópia em papel do conteúdo do expediente, possibilitando o exercício de suas garantias processuais. Não fosse assim, poderia haver diferentes níveis de acesso às informações processuais, conforme a familiaridade do interessado com as novas tecnologias, em prejuízo do princípio da isonomia.

Além disso, a automatização de tarefas, no âmbito do processo administrativo eletrônico, também está sujeita ao princípio da equivalência de garantias. As atividades desempenhadas com o auxílio da máquina decorrem de uma programação, a ser definida por meio de um ato administrativo compatível com as regras jurídicas vigentes. Aplicam-se, pois, às operações efetuadas pela máquina no curso do processo, as observações feitas no capítulo anterior a respeito da adesão entre a atividade automatizada e o ordenamento ${ }^{1228}$.

Outra questão relevante diz respeito ao exercício do contraditório e da ampla defesa nos processos administrativos automatizados. Com efeito, em vista do caráter instantâneo de tais processos, não seria possível o exercício de tais direitos durante o iter processual. Em vista disso, há quem entenda que a tomada de decisões com base exclusiva no tratamento automático de dados encontraria óbice na necessidade de participação dos interessados nos processos administrativos, pois sempre tende a haver outros elementos a serem considerados na decisão ${ }^{1229}$.

Não é o entendimento mais adequado, caso bem compreendida a estrutura da expedição de atos administrativos automatizados, descrita no capítulo anterior. A automatização não afasta o contraditório ou a participação, pois não impede que sejam levadas ao conhecimento do órgão competente as considerações destinadas a interferir no conteúdo da decisão. O exercício de tais direitos pode ocorrer até mesmo antes do requerimento - por exemplo, por meio do questionamento de informações constantes de bases de dados oficiais ou por meio da discussão dos critérios adotados na programação -

\footnotetext{
${ }^{1228}$ Cf. supra, item 3.4.2.

1229 A respeito desse ponto, fazendo referência aos dados de caráter pessoal, cf. FERNÁNDEZ SALMERÓN, Manuel, La protección de los datos personales en las administraciones públicas, cit., pp. 386-387.
} 
ou depois da atuação automatizada do sistema, por meio dos recursos administrativos cabíveis $^{1230}$. Dessa maneira, a automatização das decisões não implica a redução de direitos processuais, podendo apenas transferir o momento de seu exercício.

Esse rearranjo procedimental não pode ser feito em prejuízo do administrado, sendo necessária uma avaliação a respeito de quando é possível a automatização. Tal análise pode ser feita de acordo com as oportunidades para a participação e para o contraditório já consagradas no processo em papel, conforme o objeto do processo. Quando o rito processual permite a apresentação de elementos por parte do interessado no curso do processo, tornando necessário submetê-los a uma avaliação humana, a automatização tende a ser inviável. Isso se dá nos casos de imposição de sanções, que devem ser antecedidas da oportunidade para o exercício do contraditório ${ }^{1231}$. Não havendo apresentação de peça de defesa, o sistema pode finalizar o processo de modo automatizado. É o que ocorre, por exemplo, nos processos relativos à imposição de multas de trânsito ${ }^{1232}$.

O mesmo vale para os processos sujeitos a um fluxo de trabalho automatizado, que circunscreva os momentos específicos para o exercício do contraditório. A fixação precisa desses momentos deve ser considerada legítima quando decorrer de propósitos fundados, tais como a busca da eficiência administrativa. As regras contidas na programação do sistema responsável pelo impulso do processo eletrônico não podem acarretar restrições desproporcionais a direitos processuais dos administrados.

\footnotetext{
${ }^{1230}$ Cf. infra, item 4.9.7.

${ }^{1231}$ Sobre o caráter prévio da defesa em relação ao ato decisório, em especial nos processos sancionadores, cf. MedauAR, Odete, A Processualidade no Direito Administrativo, cit., pp. 122-123.

${ }^{1232}$ Nos casos de infrações de trânsito, a Súmula 312 do Superior Tribunal de Justiça reconheceu necessária a oportunidade para a defesa prévia, por força dos artigos 280, VI, 281 e 282, § $4^{\circ}$, da Lei n. 9503/97, de maneira que deve haver duas notificações, uma do auto de infração e outra, da imposição da penalidade (cf. MedauAr, Odete, A Processualidade no Direito Administrativo, cit., pp. 131-132). Assim, o sistema informático providencia a primeira notificação e aguarda o recebimento da informação sobre a apresentação da defesa ou o decurso do prazo. No primeiro caso, a defesa deverá ser analisada por seres humanos, de forma a avaliar todos os argumentos invocados. Caso não apresentada defesa, a atuação por meio do sistema poderá completar-se, podendo-se falar, pois, em processo administrativo automatizado.
} 


\subsection{A legislação existente e sua adaptação}

Tema interessante diz respeito à base normativa necessária para o processo administrativo eletrônico, tendo em vista as características da maioria das leis hoje existentes, elaboradas originalmente para dar respaldo às atividades desempenhadas em papel.

A ausência de lei expressa sobre processo administrativo eletrônico não constitui um impedimento. A viabilidade jurídica do processo digital é uma decorrência da admissibilidade do documento administrativo eletrônico: considerado o valor jurídico deste, há fundamento para a digitalização dos expedientes. Nesse sentido, a vasta atividade administrativa hoje desempenhada em suporte informático não padece de invalidade apenas por não haver, em todos os casos, norma legal expressa a respeito do processo eletrônico. Salvo disposição em contrário, ele está sujeito às regras do processo comum ${ }^{1233}$.

Certas regras processuais podem, contudo, causar problemas quando aplicadas no contexto eletrônico ${ }^{1234}$. Por vezes, há disposições legais expressas incompatíveis com o emprego do suporte eletrônico nos processos administrativos ou com a utilização das novas tecnologias em relação a determinados atos ou fases do processo. Em outras situações, essa incompatibilidade é aparente, pois a norma legal pode ser atualizada em sua interpretação, sobretudo se demonstrada a impossibilidade de prejuízos aos administrados. A casuística relativa a essa avaliação é tão numerosa e diversificada que não caberia nos limites deste estudo. Mesmo assim, é possível afirmar que a regra é a viabilidade do processo administrativo eletrônico, sendo ela só afastada por impedimentos legais específicos, conforme o ente público, a atividade administrativa ou a fase do processo considerada.

De todo modo, a edição de normas legais expressas a respeito do processo administrativo eletrônico pode ser conveniente para a disciplina de atos específicos e para dar mais segurança à atuação administrativa. Dessa sorte, vale retomar a observação

\footnotetext{
1233 Cf. PAlomar Olmeda, Alberto, Procedimientos administrativos y régimen documental en la actuación de la Agencia Española de Protección de Datos, cit., p. 74.

${ }^{1234}$ Cf. GIROT, Clarisse, op. cit., p. 19.
} 
feita em relação ao governo eletrônico em geral, no sentido de que uma disciplina legal expressa pode evitar dúvidas e obstáculos decorrentes das interpretações mais restritivas do princípio da legalidade, oferecendo melhores condições para inspirar confiança nos usuários $^{1235}$, o que pode maximizar o aproveitamento da tecnologia no processo eletrônico.

Resultados ainda mais positivos poderiam ser alcançados caso eventuais prescrições legais expressas não fossem incorporadas, de modo simplista, aos diplomas normativos relativos aos processos tradicionais. $\mathrm{O}$ acréscimo de prescrições a respeito das novas tecnologias em leis existentes tende a adotar uma visão limitada do processo administrativo eletrônico, restrita à digitalização dos antigos expedientes, servindo como um bloqueio às necessárias inovações. Por essa razão, embora não se trate de uma imposição estritamente jurídica, parece conveniente que a disciplina normativa dos processos eletrônicos seja feita por diplomas legais específicos, de acordo com uma sistemática concebida para o entorno informático, aumentando as possibilidades de obter a desejada eficiência decorrente do uso das novas tecnologias ${ }^{1236}$.

\subsection{O expediente administrativo eletrônico}

O expediente administrativo tradicional constitui um conjunto de documentos, juntados de modo sequencial, segundo uma ordem cronológica, destinado a receber os vários elementos instrutórios constantes de documentos em papel e a registrar os

\footnotetext{
1235 Cf. supra, item 2.4.1.

${ }^{1236}$ Também pode ser proveitosa a edição de uma norma aberta, que dê sustento à utilização dos meios informáticos e telemáticos no processo, mas sem o apego à sistemática do processo tradicional. Nesse sentido é o art. 49 da Lei n. 14.141/06, do Município de São Paulo, segundo o qual "[é] admitido o uso de meio eletrônico para formação, instrução e decisão de processos administrativos, bem como para publicação de atos e comunicações, geração de documentos públicos e registro das informações e de documentos de processos encerrados, desde que assegurados: I - níveis de acesso às informações; II - segurança de dados e registros; III - sigilo de dados pessoais; IV - identificação do usuário, seja na consulta, seja na alteração de dados; V armazenamento do histórico das transações eletrônicas; VI - utilização de sistema único para planejar e gerenciar os processos administrativos".
} 
diversos atos que compõem o processo administrativo ${ }^{1237}$. Todos os documentos relevantes sobre o assunto tratado devem incorporar-se ao expediente ${ }^{1238}$, propiciando a conservação dos vestígios do fluxo documental realizado ${ }^{1239}$.

Na lógica do processo em papel, o expediente administrativo desempenha importantes funções. Ele é responsável por dar segurança às informações constantes do processo, em especial quanto aos atos praticados e as datas em que isso ocorreu. Por tal razão, as folhas do processo devem ser numeradas e rubricadas, de maneira a evitar subtrações e substituições indevidas ${ }^{1240}$. Além disso, o expediente é o meio pelo qual o interessado pode ter acesso ao conteúdo do processo administrativo, sendo assim essencial para a realização dos princípios de participação e transparência, bem como para o exercício do contraditório frente à Administração ${ }^{1241}$. Por esse motivo, é vedado à autoridade administrativa decidir com base em elementos que não constam do expediente formal ${ }^{1242}$.

Os mesmos objetivos - segurança no registro das informações, acesso por parte dos interessados e delimitação do objeto da cognição - devem ser atingidos quando o suporte é digital. Assim, cada processo administrativo eletrônico deve corresponder a um expediente, incumbido de desempenhar as mesmas funções que os autos do processo tradicional. Entretanto, no atual contexto tecnológico, não se pode ter em mente algo que se assemelhe aos autos tradicionais em papel. O expediente administrativo eletrônico deve ser entendido como o conjunto determinado de informações registradas em su-

\footnotetext{
${ }^{1237} \mathrm{O}$ expediente assim já foi descrito pela doutrina nacional: "Em termos materiais, o processo administrativo consiste na reunião ordenada e cronológica das peças processuais que o compõem, a partir da inicial, envolvidas por uma capa, com indicações relativas ao assunto, ao interessado, e à data. Esse processo, assim formado, é numerado, e sua tramitação pelos órgãos e repartições da Administração Pública é anotada para que, a qualquer momento, se possa saber de seu paradeiro" (GASPARINI, Diógenes, op. cit., pp. 768-769).

${ }^{1238}$ Cf. Rivero ORTEGA, Ricardo, El expediente administrativo, cit., p. 168.

${ }^{1239}$ Cf. Truche, Pierre, FAugere, Jean-Paul, Flichy, Patrice, op. cit., p. 45.

1240 Cf. DALlari, Adilson Abreu, FERRAZ, Sérgio, op. cit., p. 124.

${ }^{1241}$ Cf. RIVERO ORTEGA, Ricardo, El expediente administrativo, cit., p. 190.

${ }^{1242}$ Cf. MedauAr, Odete, A Processualidade no Direito Administrativo, cit., p. 110.
} 
porte digital, que instruem as providências a serem efetuadas por meio do processo administrativo eletrônico ${ }^{1243}$.

Tal conceito não faz referência a uma centralização física dos documentos do processo, nem a elementos capazes de sugerir que as diversas informações devam estar dispostas em folhas sequenciais digitalizadas, à semelhança dos autos em papel. Na verdade, o processo administrativo eletrônico está associado a um novo modelo de gestão documental, fundado nas propriedades do suporte digital e caracterizado pela dispersão da informação ${ }^{1244}$. Nesse modelo, as informações podem encontrar-se em múltiplas bases de dados, não submetidas ao controle exclusivo do órgão administrativo competente para proferir a decisão final do processo e sujeitas a um regime de responsabilidades também disperso, cujas garantias dependem, em grande medida, da tecnologia ${ }^{1245}$. A segurança das informações não é assegurada pela localização física dos documentos integrantes do processo, mas pela possibilidade de garantir sua recuperação, integridade e autenticidade ${ }^{1246}$. O que importa é o registro das informações, efetuado segundo as exigências próprias dos documentos informáticos, de maneira a propiciar a equivalência entre o expediente eletrônico e o expediente físico. Assim, por exemplo, o protocolo de um documento gera o registro seguro de uma informação a respeito da data em que isso ocorreu, substituindo o controle físico proporcionado pela juntada sequencial de folhas ao expediente tradicional $^{1247}$.

\footnotetext{
${ }^{1243}$ Assim, o expediente eletrônico poderia ser compreendido como um recipiente dinâmico de informações onde se agrupam todos os elementos gerados pela tramitação eletrônica, ainda que não tomem a forma de um documento tradicional (cf. VELASCO RICO, Clara, Archivo y conservación de los documentos administrativos electrónicos. Especial referencia la Ley 11/2007, de acceso electrónico de los ciudadanos a las administraciones públicas, in COTINO HUESO, Lorenzo, VALERO TORRIJOS, Julián, Administración Electrónica - La Ley 11/2007, de 22 de junio, de acceso electrónico de los ciudadanos a los Servicios Públicos y los retos jurídicos del e-gobierno en España, Valencia, Tirant lo Blanc, 2010, p. 618).

${ }^{1244}$ A noção de documento eletrônico é consubstancial à de expediente eletrônico, pois todos os documentos que fazem parte de um expediente administrativo dessa espécie são eletrônicos (cf. VARCÁRCEL FERNÁNDEZ, Patricia, Documentos y archivos electrónicos, in PIÑAR MAÑAS, José Luis (dir.), Administración electrónica y ciudadanos, Cizur Menor (Navarra), Aranzadi, 2011, p. 621).

${ }_{1245}$ Cf. VALERO TORRIJOS, Julián, La gestión y conservación del documento administrativo electrónico, cit., p. 55. Assim, um mesmo documento pode fazer parte de vários expedientes (cf. RIVERO ORTEGA, Ricardo, Archivo y expediente electrónico, cit., p. 35).

${ }^{1246}$ Cf. VARCÁRCEL FERNÁNDEZ, Patricia, op. cit., p. 623.

${ }^{1247}$ Aqui pode ser notada uma diferença interessante: no processo tradicional, a junção aos autos é uma operação sucessiva ao protocolo. No processo eletrônico, o protocolo implica a imediata incorporação, ao expediente, das informações recebidas.
} 
A necessidade de delimitação do objeto da cognição torna necessário que o expediente eletrônico seja considerado um conjunto determinado de informações. No contexto eletrônico, por força da dispersão da gestão documental, surge o risco de violação ao contraditório, caso a autoridade decida com fundamento em informações não conhecidas pelos interessados, contidas em bases de dados remotas ${ }^{1248}$. Por essa razão, por mais dispersa que possa ser a gestão documental, permitindo o acesso a dados que não se encontram sob o domínio físico da autoridade, o expediente deve proporcionar uma delimitação dos elementos a serem considerados na decisão, servindo como uma garantia dos direitos processuais dos interessados.

Por outro lado, há peculiaridades no acesso ao expediente administrativo eletrônico por parte dos interessados. Conforme observado, o documento eletrônico não é passível de ser apreendido diretamente pelos sentidos humanos, necessitando da intermediação da máquina ${ }^{1249}$. Como o documento eletrônico original é inacessível, sua leitura humana ocorre sempre por meio de uma cópia, apresentada em um formato específico, impresso em papel ou projetado na tela de um computador. Assim, existem duas realidades distintas: os documentos originais, compreensíveis apenas pela máquina, e as cópias oferecidas em formatos acessíveis ao ser humano.

Para tornar possível o acesso humano ao expediente eletrônico, a máquina deve estar programada para oferecer um conjunto organizado de cópias de tais documentos, que não se confunde com os documentos originais. Este seria um extrato do expediente administrativo eletrônico, destinado ao acesso das informações por parte de qualquer ser humano. Fazendo uma comparação grosseira, seria como se, no processo tradicional, não fosse possível ter vista direta dos autos, sendo oferecido o acesso aos interessados sempre mediante cópia reprográfica.

\footnotetext{
${ }^{1248}$ MASUCCI entende o expediente (fascicolo) informático como um conjunto virtual de documentos, organizado segundo uma estrutura lógica (cf. Procedimento amministrativo e nuove tecnologie, cit., p. 26). Segundo a perspectiva adotada neste estudo, tal lógica deve alcançar não somente o relacionamento entre os elementos contidos no expediente, mas sobretudo os critérios que permitem identificar quais informações dele fazem parte, de modo a delimitá-las com a precisão necessária.

${ }^{1249}$ Cf. supra, item 2.2.1.
} 
O expediente eletrônico não pode ser visto de modo separado desse extrato, por meio do qual os sentidos humanos podem tomar contato com as informações referentes ao processo. A relação entre ambos é relevante, pois a cópia deve reproduzir de maneira fiel os documentos originais em linguagem binária, para que o interessado possa ter ciência exatamente do mesmo conjunto de informações constantes do expediente eletrônico. Houvesse alguma discrepância - v.g., na hipótese de um erro informático que gerasse cópias destoantes das informações originais -, o extrato irregular não poderia ter qualquer serventia, devendo ser corrigido o quanto antes, para ajustar-se aos elementos originais.

O extrato do expediente administrativo eletrônico deve ser organizado de modo a proporcionar adequadas condições de consulta, permitindo uma compreensão lógica, indispensável para a transparência e o exercício do contraditório ${ }^{1250}$. Isso pode efetivarse por meio da geração de imagens sequenciais, segundo uma ordem cronológica, para exibição na tela do computador ou impressão em papel, com a aparência dos autos administrativos tradicionais ${ }^{1251}$. Não é esta, contudo, a única forma que o extrato pode assumir, pois ele não está sujeito às mesmas limitações dos autos em papel, sendo admissíveis quaisquer formas que assegurem o acesso por parte dos interessados ${ }^{1252}$.

Uma possibilidade é a superação do modelo tradicional dos conjuntos documentais em papel por meio do uso de estruturas utilizadas na cultura da rede mundial de computadores. Nas páginas da internet, a regra é a utilização do hipertexto, tecnologia segundo a qual as palavras de um texto em forma eletrônica podem ser indexadas e conectadas de diversas maneiras por meio de um software, o que possibilita um modo de consul-

\footnotetext{
${ }^{1250}$ Embora essa venha sendo considerada uma propriedade do expediente em si, especialmente quanto à ordem cronológica dos documentos (cf. VARCÁRCEL FERNÁNDEZ, Patricia, op. cit., p. 624), tal não parece ser a melhor forma de compreender o tema. O expediente original corresponde a um conjunto de informações, interligados por meio de regras lógicas, mas não tem as características próprias dos autos em papel. Quando se afirma que o expediente eletrônico deve ser apresentado de forma acessível para o cidadão, pretende-se, na verdade, fazer referência à sua cópia, aqui denominada extrato do expediente.

${ }^{1251}$ Em vista do princípio da igualdade, pode ser necessário oferecer ao interessado uma cópia em papel do expediente, caso o acesso exclusivo por meio eletrônico possa ter algum caráter discriminatório (cf. supra, item 2.4.2).

${ }^{1252}$ É o caso, por exemplo, de grande parte das notificações relativas a infrações de trânsito, que constituem extratos das informações contidas em bases de dados estatais (v.g., medições e apurações feitas por aparelhos eletrônicos, associadas à placa do veículo). A correspondência enviada ao infrator, por correio, deve conter todos os elementos necessários ao exercício do contraditório.
} 
ta aleatória e interativa ${ }^{1253}$. No caso do extrato do expediente administrativo eletrônico, é possível criar ligações hipertextuais, permitindo acessar informações por meio de um clique sobre palavras contidas no texto, independentemente da ordem lógica ou cronológica em que elas estejam dispostas. A leitura é feita de acordo com as preferências do usuário, sendo possível, por exemplo, iniciar a consulta pelo ato final, do qual partem remissões para os diversos elementos do expediente ${ }^{1254}$.

\subsection{A dinâmica do processo administrativo eletrônico}

Nos itens a seguir, serão examinados alguns aspectos operacionais relativos ao processo administrativo eletrônico. Trata-se de um esforço meramente exemplificativo para identificar, problematizar e explicar temas que decorrem da utilização da tecnologia nas atividades processuais. A realidade é mais ampla do que os pontos a serem aqui tratados, os quais por certo merecerão estudos específicos no futuro. Mesmo assim, é indispensável problematizar algumas questões relativas à dinâmica do processo administrativo eletrônico, oferecendo respostas baseadas nas perspectivas já apresentadas neste estudo.

A exposição é feita segundo os conceitos e fases tradicionais do processo administrativo. Isso não importa, por óbvio, na defesa da preservação dos elementos advindos da concepção própria do expediente em papel, pois isso poderia limitar as inúmeras alternativas proporcionadas pelo uso das novas tecnologias. A estruturação proposta não decorre de um apego à tradição, mas da necessidade de facilitar a apresentação das ideias e sua compreensão pelo leitor.

\footnotetext{
${ }^{1253}$ Cf. O’BRIEN, James, op. cit., pp. 110 e G-13.

${ }^{1254}$ Mencionando a possibilidade de ligações hipertextuais no expediente eletrônico, cf. BUONOMO, Giovanni, Il nuovo processo telematico, Milano, Giuffrè, 2009, p. 215.
} 


\subsubsection{O requerimento e os demais atos dos interessados}

A prática de atos por parte dos interessados no âmbito do processo administrativo eletrônico pode beneficiar-se das novas tecnologias. O registro das informações em suporte digital traz vantagens por permitir o relacionamento telemático, que evita deslocamentos até a repartição administrativa e, assim, pode oferecer mais comodidade. Nesse sentido, até mesmo os encargos financeiros relativos ao processo podem ser pagos por meio da internet ${ }^{1255}$. Entretanto, o uso de meios informáticos e telemáticos não se limita a aspectos práticos relacionados à melhoria do atendimento e às facilidades proporcionadas ao usuário, podendo provocar algumas questões jurídicas.

Uma importante questão diz respeito à admissibilidade da utilização de sistemas informáticos, por parte do interessado, para a formulação automatizada de requerimentos à Administração. Sendo o sistema devidamente programado, pode não haver problemas quanto à autenticidade da manifestação de vontade, pois apenas serão feitos os pedidos desejados pelo requerente, com o auxílio da máquina. Todavia, o uso de tais mecanismos tende a ser inadmissível quando trouxer a possibilidade de discriminações ou favorecimentos, pois aquele que dispuser da tecnologia adequada poderá estar em situação vantajosa em relação aos demais usuários ${ }^{1256}$.

De outra parte, as novas tecnologias trazem uma tendência a intensificar o uso de modelos padronizados para a prática de atos. Não cabe transportar para o mundo eletrônico a experiência em papel, apenas substituindo os formulários em papel por equivalentes em meio digital; ao contrário, devem ser valorizadas as oportunidades abertas pelo uso da informática e da telemática ${ }^{1257}$. A utilização de modelos facilita as tarefas automatizadas sucessivas, ao passo que uma comunicação ordinária pode ser ilegível para o sistema

\footnotetext{
1255 Sobre tal hipótese, cf. MASUCCI, Alfonso, Procedimento amministrativo e nuove tecnologie, cit., p.19.

${ }^{1256}$ É o caso da utilização de sistemas automatizados para o oferecimento de lances em pregões eletrônicos, tema que já alcança alguma repercussão entre nós (cf. Robôs ganham licitações e preocupam empresários, in Folha de São Paulo, Negócios, edição de 20.03.2010).

${ }^{1257}$ Cf. MASUCCI, Alfonso, Erogazione on line dei servizi pubblici e teleprocedure amministrative, cit., p. 999.
} 
informático empregado pela Administração ${ }^{1258}$. Por isso, a utilização obrigatória dos modelos padronizados de solicitação constitui um instrumento decisivo para realizar as maiores possibilidades de eficiência oferecidas pelas novas tecnologias ${ }^{1259}$.

A utilização de formulários eletrônicos traz vantagens substanciais para o processo administrativo eletrônico, sobretudo em razão da automatização de tarefas. Tais benefícios compreendem a identificação de eventuais erros do usuário no uso do formulário ${ }^{1260}-v . g$., verificando se todos os campos foram preenchidos - ou a confrontação das informações oferecidas com aquelas presentes nos cadastros estatais ${ }^{1261}$. Além disso, o preenchimento de formulários eletrônicos permite à Administração instruir de imediato o processo $^{1262}$, por meio da consulta às bases de dados necessárias, bem como identificar, de maneira automatizada, qual deverá ser o tratamento dado ao documento recebido - por exemplo, é possível designar uma perícia, uma audiência ou dar uma solução final para o caso.

Assim como na administração tradicional, os formulários são em regra admissíveis para adoção de providências ou tomada de decisões rotineiras ${ }^{1263}$, desde que constituam um condicionamento e não uma restrição ao exercício de direitos. As informações exigidas devem obedecer ao regime de acumulação informativa por parte do Poder Público, já exposto neste estudo ${ }^{1264}$. Além disso, tais exigências não podem acarretar con-

\footnotetext{
1258 Cf. BauzÁ Martorell, Felio José, Procedimiento Administrativo Electrónico, cit., p. 79.

${ }^{1259}$ Cf. VALERO TORRIJOS, Julián, El régimen jurídico de la e-Administración, cit., p. 97.

${ }^{1260}$ Cf. VALERo Torrios, Julián, El régimen jurídico de la e-Administración, cit., p. 113, MASUCCI, Alfonso, Procedimento amministrativo e nuove tecnologie, cit., p.17 e, do mesmo autor, Erogazione on line dei servizi pubblici e teleprocedure amministrative, cit., p. 1000.

${ }^{1261}$ Cf. Truche, Pierre, FAugere, Jean-Paul, Flichy, Patrice, op. cit., p. 44. Se o usuário não sana os defeitos verificados, deve-se reconhecer que houve uma desistência prévia (cf. PALOMAR OLMEDA, Alberto, Gestión Electrónica de los procedimientos, cit., p. 423).

${ }^{1262}$ Cf. VALERo TORRIJOS, Julián, El régimen jurídico de la e-Administración, cit., p. 96 e VALERO TORRIJOS, Julián, Acceso a los servicios y difusión de la información por medios electrónicos, cit., p. 271.

${ }^{1263}$ Nesse sentido, por exemplo, o art. $7^{\mathrm{o}}$ da Lei Federal n. 9.874/99, comentado por DALLARI, Adilson Abreu, FERRAZ, Sérgio, op. cit., p. 121.

${ }^{1264}$ Cf. infra, item 2.4.5.1.
} 
sequências discriminatórias, o que deve ser avaliado em função das características dos usuários $^{1265}$.

A imposição de formulários pode ser avaliada à luz do princípio do formalismo moderado, do qual decorre uma liberdade formal na elaboração de documentos a serem apresentados à Administração ${ }^{1266}$. No contexto do governo eletrônico, essa questão toma uma proporção mais relevante, pois as comunicações dirigidas a um órgão administrativo muitas vezes devem ser elaboradas por meio de um software específico ${ }^{1267}$. É essencial que a obrigatoriedade do uso de meios eletrônicos na prática de atos não acarrete consequências discriminatórias ou imponha ônus desproporcionais ao administrado. Todavia, não se trata, a priori, de uma limitação questionável ao exercício de direitos, pois tais exigências não decorrem de mero capricho ou apego irracional à forma, mas de propósitos legítimos relacionados à eficiência da atuação administrativa.

A obrigatoriedade dos formulários eletrônicos não pode restringir o direito de petição. Por força desse direito, o Poder Público não pode deixar de aceitar, processar e avaliar um requerimento ${ }^{1268}$, não importa a forma utilizada em sua elaboração. Isso não impede, por se tratar de uma atividade padronizada, que a Administração recuse os efeitos próprios do ato disciplinado de modo mais estrito, caso ele não tenha sido praticado de acordo com as regras formais estabelecidas. Assim, por exemplo, qualquer documento pode ser apresentado à Receita Federal, no exercício do direito de petição, devendo receber a devida apreciação e resposta. Todavia, somente proporcionará o cumprimento dos deveres de natureza tributária a apresentação de declaração de imposto de renda no formato estabelecido (arquivo eletrônico elaborado pelo software oficial). Entendimento diverso poderia

\footnotetext{
1265 Aplicam-se, aqui, as observações feitas em relação à questão do acesso ao governo eletrônico e ao dever de evitar quaisquer discriminações, em especial no que concerne à chamada exclusão digital (cf. supra, item 2.4.2.

${ }_{1266}$ Cf. GÓMEZ PUENTE, Marcos, op. cit., p. 172.

1267 Cf. BauzÁ Martorell, Felio José, Procedimiento Administrativo Electrónico, cit., p. 79 e Régimen jurídico de los registros telemáticos, cit., p. 189.

${ }^{1268}$ Tratando da disciplina do direito de petição no âmbito da lei de processo administrativo, com fundamento no princípio da eficiência, cf. DALlARI, Adilson Abreu, FERRAZ, Sérgio, op. cit., p. 94. Vale considerar, contudo, a possibilidade de que os padrões sejam estabelecidos em ato infralegal, caso isso não tenha um caráter desproporcional, de forma a não impedir o exercício de direitos. Não há sentido em exigir lei formal para os condicionamentos que tenham em vista apenas disciplinar, de forma mais eficiente, a realização de atos processuais.
} 
pôr em risco a eficiência decorrente da utilização das novas tecnologias, sobretudo nas rotinas automatizadas relacionadas ao recebimento de documentos em processos administrativos eletrônicos, sem trazer benefício algum sob o aspecto do exercício do direito de petição.

\subsubsection{A instrução processual}

O contexto da sociedade da informação traz também novas perspectivas para a instrução processual. A decisão racional almejada pelo processo administrativo exige reunir e analisar uma série de informações, sobretudo aquelas referentes à situação de fato e às regras jurídicas aplicáveis ${ }^{1269}$. Sendo a informação um recurso imprescindível em toda tomada de decisão ${ }^{1270}$, a instrução deve ser vista como a fase em que a Administração obtém e prepara as informações necessárias para decidir ${ }^{1271}$. Tais providências podem ser efetuadas com o uso das novas tecnologias.

As atividades instrutórias somente podem ser realizadas com uso de meios eletrônicos quando oferecerem garantias equiparáveis àquelas oferecidas pelos meios tradicionais ${ }^{1272}$. Isso ocorre quando observadas determinadas condições técnicas e jurídicas, garantindo, além da eficiência, a validade da atuação administrativa ${ }^{1273}$. Sob essa premissa serão apresentadas as questões trazidas neste item, que dará ênfase à instrução processual realizada no âmbito do processo administrativo eletrônico.

\footnotetext{
${ }^{1269}$ Cf. Gómez PuENTE, Marcos, op. cit., p. 110.

${ }^{1270}$ Cf. Cerrillo i MarTíneZ, Agustí, E-información, cit., p. 7.

1271 Nesse sentido, o administrativista contemporâneo se refere à instrução em outros termos e fala de um processo de aquisição e tratamento da informação no qual a Administração e as partes interessadas participam com funções e papéis diferentes dos tradicionais (cf. KLUTH, Winfried, NuCKET, Jana, op. cit., p. 487). Isso pode ser acompanhado do uso da terminologia informática: afirma-se, assim, que o input é o conjunto de informações recolhidas pela Administração e inseridas no computador quando inicia um processo, no âmbito de sua fase instrutória (cf. CONTALDO, Alfonso, GoRGA, Michele, op. cit., p. 186).

1272 Cf. VALERO TORRIJOS, Julián, El régimen jurídico de la e-Administración, cit., p. 188.

${ }^{1273}$ Cf. ibidem, p. 188.
} 


\subsubsection{A transposição de documentos para o suporte digital}

A utilização de um determinado suporte para o registro de informações traz repercussões em relação ao formato dos documentos destinados à instrução processual. Em regra, no processo tradicional, as informações destinadas à instrução constam de documentos em papel; no processo eletrônico, elas são registradas em suporte digital.

No entanto, nem sempre as informações estão originalmente registradas no mesmo suporte adotado no processo. Há situações em que um documento digital precisa ser usado como prova em um processo em papel, assim como existem casos nos quais o documento tradicional precisa ser empregado em um processo eletrônico. Em tais hipóteses, a instrução processual é feita por meio de uma cópia do documento, produzida no suporte apropriado. Nesse sentido, o documento digital pode ser impresso e apresentado como prova em um processo tradicional, ao passo que o documento em papel pode ser convertido para o suporte informático, de modo a constituir um elemento instrutório no processo eletrônico.

A admissibilidade de documentos digitais como meio de prova em processos tradicionais é uma das mais frequentes discussões relacionadas às novas tecnologias. O debate foi marcado, no passado, pela desconfiança em relação ao suporte eletrônico. Nos dias de hoje, já não faz sentido discutir o documento digital em si, mas a observância dos requisitos que permitem atribuir-lhe funções equivalentes ao documento tradicional. Garantida a equivalência funcional, o documento eletrônico pode ser empregado, sem problemas, na instrução dos processos administrativos tradicionais ${ }^{1274}$.

Para este estudo, contudo, mais interessante é a necessidade de conversão dos documentos em papel para o suporte digital, de maneira a permitir que eles sejam usados no processo administrativo eletrônico. Isso pode ser feito por meio da geração de ima-

\footnotetext{
${ }^{1274}$ A respeito das condições para a garantia dessa equivalência, inclusive no tocante à observância dos requisitos de validade da cópia impressa em papel, cf. supra, item 2.2.1
} 
gens digitalizadas dos antigos documentos ${ }^{1275}$. Para tanto, o melhor mecanismo é aquele pelo qual o arquivo digital criado receba a assinatura eletrônica de seu autor, que assim deve responder pela compatibilidade entre a cópia em suporte digital e o respectivo original em papel $^{1276}$.

Muitos documentos expedidos no passado pelo Poder Público precisariam ser digitalizados e integrados aos sistemas informáticos públicos ${ }^{1277}$. Enquanto isso não ocorre de modo global, é possível reproduzi-los em suporte eletrônico conforme a necessidade de cada caso. Por se tratar de documentos públicos, seria desejável que essa tarefa coubesse à própria Administração. Isso exigiria, todavia, que o órgão público localizasse o escrito em papel, muitas vezes sob os cuidados de outra unidade administrativa, o que poderia ser problemático. Assim sendo, não parece aceitável impedir a digitalização e utilização do documento público que se encontre em poder do interessado. A Administração pode oferecer tal serviço, devolvendo de imediato o original ao usuário, assim que transposto para o suporte eletrônico. O serviço também pode ser oferecido por oficiais de registros públicos, aos quais caberia asseverar a autenticidade da copia com a fé pública que lhes é reconhecida.

Há, ainda, a possibilidade de digitalização pelo próprio interessado, sem a participação da Administração ou de terceiros. Em muitos casos, não há motivos para duvidar da idoneidade da cópia, podendo ser considerada suficiente, para tanto, a responsabilidade do autor pela regularidade da digitalização. Não havendo razão para uma conferência mais acurada, solução diversa poderia trazer excessivos ônus ao interessado, incompatíveis com as facilidades proporcionadas pelas novas tecnologias: de fato, ao invés de relacionar-se a distância com a Administração, ele teria de deslocar-se até a repartição ape-

\footnotetext{
1275 Cf. JinESTA LOBO, Ernesto, op. cit., p. 13.

1276 Esta é a solução adotada pela legislação espanhola (cf. art. 35, 2 da Lei n. 11/2007, acessível em http://www.boe.es/boe/dias/2007/06/23/pdfs/A27150-27166.pdf), a qual admite a juntada de documentos por meio de cópias digitalizadas, com o mesmo valor do original, devendo a fidelidade com este ser garantida pelo interessado mediante a utilização de assinatura eletrônica. Sobre o tema, cf. PALOMAR OLMEDA, Alberto, Gestión Electrónica de los procedimientos, cit., p. 424; PALOMAR OLMEDA, Alberto, Procedimientos administrativos y régimen documental en la actuación de la Agencia Española de Protección de Datos, cit., p. 75 e LiNARES GIL, Maximino Ignacio, Modificaciones del Régimen Jurídico Administrativo derivadas del empleo masivo de nuevas tecnologías, cit., p. 730).

${ }^{1277}$ Cf. Duni, Giovanni, Teleamministrazione, cit., item 4.2 e DuNI, Giovanni, L'amministrazione digitale, cit., p. 64.
} 
nas com o propósito de digitalizar documentos. Nesse sentido, a transposição para o suporte informático pelo próprio interessado é capaz de maximizar as utilidades do relacionamento telemático.

Outra questão diz respeito à viabilidade de impor ao interessado o ônus de apresentar os documentos em suporte digital, caso a Administração não ofereça o serviço de digitalização. Tal problema está relacionado à necessidade de garantir a igualdade no acesso aos serviços públicos. De acordo com as premissas já apresentadas neste estudo, referida imposição somente pode ser admitida se não houver consequências discriminatórias; caso contrário, a exigência da apresentação de documentos em suporte eletrônico dependerá do oferecimento de serviços de digitalização pela Administração.

\subsubsection{O uso de equipamentos eletrônicos para a produção de informações}

Outro impacto das novas tecnologias sobre a instrução processual diz respeito à possibilidade de uso de equipamentos eletrônicos para a produção de informações relevantes para a Administração, utilizadas como elementos de instrução do processo.

Há diferentes níveis de intensidade na utilização de tais equipamentos. Eles podem servir como mecanismos de apoio à instrução tradicional, sendo colocados à disposição do ser humano, responsável pela prática de atos processuais. Em geral, o uso de tais meios tecnológicos não traz problemas jurídicos substanciais. É o caso, por exemplo, das ferramentas informáticas destinadas a facilitar a busca de informação necessária para a decisão, no caso da pesquisa de normas ou precedentes. Em tais situações, as informações colhidas por meios eletrônicos são oferecidas pela máquina a um ser humano, que se responsabiliza pelo ato de instrução.

Também não parece trazer dificuldades a utilização de equipamentos eletrônicos pelo ser humano para a apuração e registro de dados da realidade, tais como câmeras fotográficas e aparelhos destinados a efetuar medições de variadas espécies. Nes- 
tes casos, como o ser humano é responsável pelo ato de instrução, o uso de tais meios tecnológicos não traz questões jurídicas mais complexas. Eventuais discussões a respeito devem estar circunscritas ao adequado funcionamento da máquina e à congruência entre os resultados por ela oferecidos e o ato de instrução praticado pelo ser humano.

Em outros casos, a tecnologia pode ser responsável por uma reformulação dos atos instrutórios. Nesse sentido, a prática de atos de instrução por meios telemáticos constitui uma questão cada vez mais importante. É o caso dos atos processuais realizados por videoconferência, que podem trazer a vantagem de dispensar os deslocamentos físicos ${ }^{1278}$. Não há razão, a priori, para negar validade jurídica a essas técnicas, desde que os atos sejam praticados com as devidas garantias ${ }^{1279}$.

Questões ainda mais interessantes surgem quando se verifica uma automatização do ato de instrução. Isso se verifica quando as informações produzidas por máquinas chegam ao processo sem a intermediação humana. Tal ocorre, por exemplo, na atuação dos radares fotográficos utilizados na identificação de infrações de trânsito, de acordo com a previsão do art. 280 da Lei n. 9503/97 (Código de Trânsito Brasileiro). A máquina é capaz de captar um dado da realidade, ensejando o início automatizado de um processo administrativo eletrônico, no qual este dado constitui um elemento instrutório fundamental. No exercício do contraditório, o interessado pode questionar o funcionamento da máquina, mas, em princípio, deve-se reconhecer-lhe a mesma fé pública atribuída ao agente de trânsito $^{1280}$.

\footnotetext{
${ }^{1278}$ Cf. VALERO TORRIJOS, Julián, El régimen jurídico de la e-Administración, cit., p. 201.

${ }^{1279}$ Cf. GómEZ PUENTE, Marcos, op. cit., p. 182. A respeito dos interrogatórios por via telemática em processos administrativos, defendendo a necessidade de que a percepção sensorial recebida pelo órgão instrutor seja equiparável à que obteria ao realizar a prova de forma presencial, cf. VALERO TORRIJOS, Julián, El régimen jurídico de la e-Administración, cit., p. 202.

${ }_{1280}$ Com o exemplo das contas telefônicas, em que não é possível discutir as chamadas realizadas, cf. ForsTHOFF, Ernst, op. cit., p. 99. Mencionando a discussão acerca do valor a ser cobrado pelo correio, que constituiria apenas uma controvérsia acerca do funcionamento de equipamentos, cf. ZEIDLER, Karl, op. cit., p. 54.
} 


\subsubsection{A transformação da instrução processual}

O uso mais amplo da informática e da telemática pode provocar uma transformação da instrução processual ${ }^{1281}$. O uso das novas tecnologias facilita a atividade instrutória $^{1282}$, pois permite recolher em tempo real, de diversas fontes, as informações relevantes para o processo, melhorando a qualidade da decisão e, portanto, a eficiência da ação administrativa ${ }^{1283}$. A relevância do tema recomenda uma exploração mais minuciosa.

A chave da transformação da instrução provocada pelas novas tecnologias é a obtenção de informações em suporte digital. Tais informações são passíveis de tratamento pela máquina, o que abre novas possibilidades, sobretudo quanto à produção de atos administrativos automatizados ${ }^{1284}$. Há uma diferença entre informações contidas em bases de dados, aptas a serem usadas em operações automatizadas, e os documentos compostos de cadeias de dados não estruturados, cuja identificação e utilização tende a ser mais difícil, reclamando a atuação humana ${ }^{1285}$. Grande parte dos dados mais interessantes para a Administração está contida em documentos dotados de informação não estrutura$\mathrm{da}^{1286}$, o que é característico dos escritos em papel e de suas cópias em suporte digital. Assim, os plenos efeitos da tecnologia em relação à instrução do processo administrativo ele-

\footnotetext{
${ }^{1281}$ Cf. VALERO TORRIJOS, Julián, El régimen jurídico de la e-Administración, cit., p. 201 e MASUCCI, Alfonso, L'atto amministrativo informatico, cit., pp. 70-71.

${ }_{1282}$ Cf. GÓMEZ PUENTE, Marcos, op. cit., p. 110.

${ }^{1283}$ Cf. MASUCCI, Alfonso, Erogazione on line dei servizi pubblici e teleprocedure amministrative, cit., p. 994. Segundo BARNÉS VÁZQUEZ, o acerto, a eficácia e a eficiência da decisão poderão ser maiores se a informação disponível for confiável, de qualidade, completa e atual, bem como se for gerida adequadamente e selecionada de acordo com sua relevância para o caso (cf. Procedimientos administrativos y nuevos modelos de gobierno, cit., p. 56).

${ }^{1284}$ Cf. supra, item 3.4.3.3.

${ }^{1285}$ Cf. GARCíA MARCO, Francisco Javier, Ontologías y documentación electrónica en las actividades públicas, cit., p. 188.

${ }^{1286}$ Cf. ibidem, p. 189.
} 
trônico dependem da disponibilidade de informações passíveis de leitura automatizada, não sendo suficientes os elementos apresentados nos moldes dos documentos tradicionais ${ }^{1287}$.

\section{É evidente que o processo administrativo eletrônico não pode prescindir} dos documentos tradicionais. Nesse sentido, como visto, os documentos expedidos em papel podem ser digitalizados para incorporar-se ao expediente eletrônico. Todavia, em vista das oportunidades referidas, a tendência é utilizar mecanismos de instrução que ofereçam informações já em suporte digital. Dois desses meios merecem ser salientados: a utilização de informações oferecidas pelos interessados e o compartilhamento de dados entre órgãos públicos.

Como já afirmado, os interessados podem praticar atos por meio de formulários eletrônicos, os quais oferecem informações devidamente estruturadas, aptas para a atividade automatizada. Em diversas situações, a Administração pode basear sua decisão em tais dados, caso não haja outras circunstâncias merecedoras de maior investigação ${ }^{1288}$. Tem sido apontado, aliás, que a desconfiança em relação aos administrados como um possível obstáculo para a digitalização dos expedientes ${ }^{1289}$, em vista da necessidade de conferir as informações apresentadas, muitas vezes mediante o confronto com documentos em papel. Para evitar isso, seria preciso adotar outras maneiras de controlar tais informações, sobretudo por mecanismos a posteriori ${ }^{1290}$.

Todavia, o aspecto mais notável da instrução do processo eletrônico diz respeito ao acesso remoto à informação relevante para a decisão. Com efeito, o documento

\footnotetext{
${ }^{1287}$ Em geral, o documento digitalizado demanda uma leitura humana, feita na tela do computador, não oferecendo informações passíveis de tratamento automatizado. Por isso, normalmente é aceitável que a Administração exija o envio do papel escaneado, para as devidas conferências, mas solicite o preenchimento de um formulário digital com as informações constantes do mesmo documento, para que essas possam ser processadas de modo eletrônico, trazendo ganhos de funcionalidade em relação à simples imagem digitalizada.

1288 Cf. KLUTH, Winfried, NuCKET, Jana, op. cit., p. 488.

${ }^{1289}$ Cf. Lemaitre, Marie-Françoise, op. cit., p. 631. Em tese, é aceitável que o pedido seja acompanhado por documentos digitalizados, assim como é possível a apresentação de um requerimento telemático sob a condição de um recebimento posterior da documentação em papel correspondente - por exemplo, por via postal -, o que limitaria muito os efeitos da utilização da tecnologia (sobre esta última hipótese, cf. CANTERO, Anne, op. cit., p. 110).

${ }^{1290}$ Cf. LEMAITRE, Marie-Françoise, op. cit., p. 631 . Há também situações em que o fornecimento de certas prestações administrativas repousa sobre um triângulo Estado-usuário-terceiro privado - v.g., notário, advogado, arquiteto -, a quem cabe asseverar determinadas informações (cf. TRUCHE, Pierre, FAUGERE, JeanPaul, FliCHY, Patrice, op. cit., cit., p. 46).
} 
informático não tem necessidade de ser expedido, mas deve estar disponível para consulta e para a instrução de outro processo ${ }^{1291}$. Ao contrário do que ocorre com o papel, o acesso a um documento eletrônico não pressupõe sua disponibilidade física, sendo suficiente a transferência e a colocação do documento em um espaço acessível pelo sujeito legitimado, em especial por meios telemáticos ${ }^{1292}$. Por essa razão, as bases de dados eletrônicas passam a constituir uma efetiva fonte de informações para a tomada de decisões ${ }^{1293}$.

As novas tecnologias podem oferecer celeridade aos processos administrativos quando há necessidade de envio e recepção de diversos documentos em poder de distintos órgãos da Administração Pública ${ }^{1294}$. A consulta remota a bases de dados permite reduzir os tempos necessários para a instrução, pois a Administração pode obter em tempo real a documentação necessária à sua decisão ${ }^{1295}$. É o caso, por exemplo, das informações relativas a atuações anteriores da Administração ou de elementos apurados em outros processos. As informações devem ser exatas e atualizadas, garantindo-se a segurança em sua modificação e custódia ${ }^{1296}$.

O processo eletrônico não pode excluir a aquisição dos dados por meio de uma atuação humana ${ }^{1297}$, o que ocorre, por exemplo, quando um funcionário solicita a outro o envio telemático de uma informação. Todavia, o acesso telemático é potencializado pela automatização. A interconexão constitui uma espécie de acesso automatizado à informação, que dispensa a intervenção direta dos órgãos ou pessoal administrativo no processo de comunicação ${ }^{1298}$. Observados os critérios devidos de qualidade e segurança, é possível

\footnotetext{
${ }^{1291}$ Cf. Duni, Giovanni, I "viaggi telematici" dell'atto informatico, cit., p. 1.

1292 Cf. MASUCCI, Alfonso, Procedimento amministrativo e nuove tecnologie, cit., p. 45.

1293 Cf. RIVERo ORTEGA, Ricardo, Archivo y expediente electrónico, cit., p. 31.

${ }^{1294}$ Cf. GuILLEN CARAMES, Javier, op. cit., pp. 254-255.

1295 Cf. MASUCCI, Alfonso, Procedimento amministrativo e nuove tecnologie, cit., p. 36. O art. $4^{\circ}$ do Decreto Federal n. 6932/2009 prevê o compartilhamento de informações entre órgãos públicos, nos seguintes termos: "No âmbito da administração pública federal, os órgãos e entidades gestores de base de dados oficial colocarão à disposição dos órgãos e entidades públicos interessados as orientações para acesso às informações constantes dessas bases de dados, observadas as disposições legais aplicáveis e as diretrizes, orientações e procedimentos estabelecidos pelo Comitê Executivo do Governo Eletrônico, criado pelo Decreto de 18 de outubro de 2000".

${ }^{1296}$ Cf. PALOMAR OLMEDA, Alberto, La utilización de las nuevas tecnologías en la actuación administrativa, cit., p. 368.

${ }_{1297}$ Cf. CONTALDO, Alfonso, GorGa, Michele, op. cit., p. 186.

1298 Cf. VALERo TORRIJOS, Julián, Acceso a los servicios y difusión de la información por medios electrónicos, cit., pp. 268-269.
} 
reconhecer à troca de informações por meio de sistemas computadorizados os mesmos efeitos jurídicos de um envio documental formal ${ }^{1299}$.

O compartilhamento de informações entre órgãos públicos desonera o cidadão, dispensando-o de apresentar a um órgão público o documento produzido pelo outro $^{1300}$. Ao mesmo tempo, permite ao Poder Público maximizar o uso de seu patrimônio informativo, em proveito da eficiência administrativa. No entanto, vale lembrar que esse compartilhamento depende da interoperabilidade dos sistemas informáticos, tema de tamanha importância que pode ser considerado, como já visto, uma das bases do regime jurídico do governo eletrônico ${ }^{1301}$.

É possível haver, ainda, uma composição entre as informações oferecidas pelo interessado e aquelas constantes de bases de dados públicas. Neste caso, a consulta remota a bases de dados pode alterar o fluxo informativo entre usuários e Administração. No processo tradicional, o usuário fornece a informação e depois a Administração efetua as verificações cabíveis, instruindo o expediente com as informações que se encontram em seu poder. No processo eletrônico, o interessado pode ser auxiliado no preenchimento de formulários, por meio de confrontações automáticas com os dados armazenados em sistemas próprios ou de outros entes públicos ${ }^{1302}$. A Administração podem também declarar as informações que já possui, cabendo ao usuário verificar sua pertinência, completá-las, atualizá-las ou corrigi-las ${ }^{1303}$.

\footnotetext{
${ }^{1299}$ Cf. NOTARMUZI, Carlo, op. cit., p. 20.

${ }^{1300}$ Cf. VALERO TORRIJOS, Julián, Acceso a los servicios y difusión de la información por medios electrónicos, cit., p. 271.

${ }_{1301}$ Cf. supra, item 2.5.

${ }^{1302}$ Cf. JiNESTA LOBO, Ernesto, op. cit., p. 14.

${ }^{1303}$ Cf. TRUChe Pierre, FAUGERE, Jean-Paul, Flichy, Patrice, op. cit., p. 44.
} 


\subsubsection{A vedação às provas ilícitas}

Valem em relação ao processo administrativo eletrônico as regras relativas à vedação de provas ilícitas (art. $5^{\circ}$, LVI, da Constituição da República) ${ }^{1304}$. Assim, as informações recebidas na instrução do processo eletrônico estão sujeitas à avaliação de sua licitude $^{1305}$, ou seja, não pode a autoridade obter elementos de maneira contrária ao ordenamento $^{1306}$.

Sob este aspecto, o ponto fundamental diz respeito à observância do regime jurídico relativo à acumulação informativa e do compartilhamento de dados, tratado em capítulo anterior deste estudo ${ }^{1307}$. Por força desse regime, nem sempre o compartilhamento de dados é admissível ${ }^{1308}$. O objetivo de maximizar o aproveitamento do patrimônio informativo público não justifica, sem maiores reflexões, o acesso ilimitado, por parte da Administração, a qualquer dado em posse de quaisquer órgãos públicos ${ }^{1309}$. Não se pode presumir, de modo simplista, que toda informação em poder da Administração possa ser usada como elemento instrutório em um processo administrativo.

O princípio do contraditório aplica-se a qualquer informação constante de bases de dados públicas a ser utilizada no processo eletrônico. De modo geral, deve-se reconhecer ao interessado a faculdade de questionar as informações trazidas ao processo pela Administração, em especial caso não tenha tido antes a oportunidade de fazê-lo - v.g., na atividade instrutória efetuada em outro processo $^{1310}$. A utilização automatizada de tais ele-

\footnotetext{
${ }^{1304}$ Sobre a aplicação da garantia ao processo administrativo, cf. MEDAUAR, Odete, A Processualidade no Direito Administrativo, cit., p. 128.

${ }^{1305}$ Cf. CONTALDO, Alfonso, Gorga, Michele, op. cit., p. 187.

${ }^{1306}$ Cf. MASUCCI, Alfonso, L'atto amministrativo informatico, cit., pp. 73-74.

${ }^{1307}$ Cf. supra, item 2.4.5.1.

${ }^{1308}$ Cf. MASUCCI, Alfonso, Procedimento amministrativo e nuove tecnologie, cit., p. 38.

${ }^{1309}$ Cf. ibidem, p. 39.

${ }^{1310}$ Há quem considere que os dados para as decisões automatizadas devem ser obtidos com o auxílio e a participação dos eventuais interessados na prática do ato (cf. USAI, Alessandro, op. cit., item 2.2). Isso, muitas vezes, poderia frustrar o propósito da automatização, criando uma complexa fase instrutória nos processos que poderiam ser concluídos sem intervenção humana, até mesmo em prejuízo do próprio interessado. Parece necessário, contudo, efetuar um acurado escrutínio das informações e dos interesses envolvidos, avaliando se o sujeito pode ter interesse em contraditar uma informação ou se ele já teve a oportunidade de fazê-lo.
} 
mentos não pode ser feita de maneira a causar surpresa ao administrado, devendo ser antecedida da oportunidade para que o interessado tome ciência de sua existência e, se quiser, apresente os questionamentos cabíveis.

\subsubsection{A padronização da instrução processual}

Tem sido observado, em relação ao processo tradicional, que a instrução deve ser a mais completa possível ${ }^{1311}$. Por isso, a Administração está obrigada a obter, de ofício, os elementos relevantes para esclarecimento dos fatos pertinentes, não estando limitada à versão apresentada pelos sujeitos ${ }^{1312}$. Por outro lado, o exercício do contraditório também contribui para que a Administração possa conseguir os elementos necessários para chegar a uma decisão correta ${ }^{1313}$. Por força do contraditório, os interessados têm o direito de apresentar os elementos que entenderem cabíveis para a defesa de seus pontos de vista.

Ao mesmo tempo, conforme a atividade considerada, há uma necessidade, fundada no princípio da eficiência, de que a Administração padronize a instrução processual, disciplinando com antecedência as formas específicas pelas quais admitirá a prova de um determinado fato. Nesse sentido, são muitos os atos normativos que estabelecem exigências documentais para a formulação de requerimentos. Em princípio, o interessado não está impedido de apresentar outros documentos, mas o órgão administrativo já se posiciona, desde logo, em relação a quais elementos poderão ser levados em conta na futura decisão. Em alguns casos, essa indicação é praticamente absoluta; em outros, a Administração não tem como limitar a apresentação de elementos adicionais, tendo em vista o direito ao contraditório e à ampla defesa.

\footnotetext{
${ }^{1311}$ Cf. Dallari, Adilson Abreu, FerraZ, Sérgio, op. cit., p. 124.

1312 Cf. MedauAr, Odete, A Processualidade no Direito Administrativo, cit., p. 131.

${ }^{1313}$ Cf. ibidem, p. 109.
} 
Essa tensão entre a demanda por informações e a padronização da instrução torna-se mais intensa no contexto da sociedade da informação. De um lado, a tendência hoje é operar com um nível de informações muito elevado, em vista da disponibilidade de fontes e da velocidade do tráfego de dados, elevando a expectativa do que seria uma boa instrução processual. De outra parte, a utilização de meios informáticos e a necessidade de maximizar sua utilidade levam a Administração a padronizar as modalidades de aquisição das informações, sem ter em conta as peculiaridades de cada hipótese concreta $^{1314}$. Uma visão apropriada a respeito da instrução do processo eletrônico deve decorrer de um equilíbrio entre o dever de uma instrução plena e o direito ao amplo contraditório, de um lado, e o imperativo de eficiência, de outro.

Tal equilíbrio por certo não se encontra na busca ilimitada de dados nas diversas fontes eletrônicas disponíveis. A disponibilidade de fontes de informação proporcionada pelas novas tecnologias não deve levar a um prejuízo à eficiência administrativa. O dever de obter elementos precisa ter limites, não sendo cabível a busca de informações até o infinito ${ }^{1315}$. É preciso usar com inteligência os meios informáticos e telemáticos, evitando cair em uma armadilha tecnológica. O que importa não é a quantidade de dados, mas sua idoneidade para representar de forma exata e completa as situações sobre as quais deve recair a decisão ${ }^{1316}$.

Por outro lado, embora o interessado tenha o direito de apresentar os elementos que julgar convenientes para a defesa de seus interesses no processo eletrônico $^{1317}$, essa posição jurídica pode ser restringida, atendidos os ditames da proporcionalidade, em vista da eficiência administrativa. A definição antecipada dos meios de prova idôneos para a comprovação de determinados fatos poderia implicar, em certos casos, uma

\footnotetext{
${ }^{1314}$ Cf. MASUCCI, Alfonso, Procedimento amministrativo e nuove tecnologie, cit., p.113.

1315 Cf. ConTAldo, Alfonso, Gorga, Michele, op. cit., p. 187.

${ }^{1316}$ Cf. MASUCCI, Alfonso, L'atto amministrativo informatico, cit., p. 72 e USAI, Alessandro, op. cit., item 2.2. Sobre as dificuldades práticas de efetuar uma instrução rigorosa e profunda, apontando questões como a existência de processos simplificados e a escassez de meios, cf. KLUTH, Winfried, NuCKET, Jana, op. cit., pp. 486-487.

${ }^{1317}$ Cf. VAlERo TORRIJOS, Julián, El régimen jurídico de la e-Administración, cit., p. 102. No mesmo sentido, entendendo que os meios eletrônicos devem garantir a possibilidade de o interessado formular alegações, apresentar provas ou realizar audiência de recebimento dos elementos de convicção, cf. JINESTA LOBO, Ernesto, op. cit., p. 14.
} 
inaceitável limitação ao exercício do contraditório. Isso ocorreria, por exemplo, nos processos de caráter sancionatório, nos quais se deve admitir como regra a defesa do interessado por quaisquer meios de prova. Todavia, sendo possível antever os fatos tidos como interessantes e os respectivos meios de prova, cabe fixar, desde logo, as informações que serão levadas em conta na decisão. Quando adotada nas situações apropriadas, essa padronização não traz prejuízos ao interessado; na verdade, tende a trazer-lhe vantagens, pois ele também é destinatário da eficiência. Definidos os elementos instrutórios necessários, o interessado tem condições de saber de modo exato o que deve apresentar à Administração e de fazê-lo uma só vez ${ }^{1318}$.

Caso seja padronizada da instrução, o desenho do processo administrativo eletrônico, incorporado no software incumbido de acompanhar as diversas fases da atuação administrativa, identifica os elementos necessários à instrução, exigindo determinadas informações como idôneas para a comprovação de fatos. Isso inclui definir com antecedência não apenas quais serão as informações necessárias para o processo, mas seus atributos específicos, tais como quem as apresentará ou qual a fonte a ser consultada. É possível estabelecer, também, se haverá algum controle, humano ou eletrônico, sobre as informações recebidas, ou se haverá preferência, desde logo, por uma entre duas informações conflitantes.

A padronização dos meios de prova no processo administrativo eletrônico não difere das diversas regras, frequentes na prática, pelas quais a Administração disciplina as exigências a serem satisfeitas para o deferimento de um pedido. Há uma diferença, muitas vezes, na estrutura da hipótese normativa, de acordo com os conceitos de cada época. Na tradição da atuação em papel, há uma tendência a fazer referência ao documento e não ao fato a ser comprovado - por exemplo, em vez de pedir ao interessado que comprove sua data de nascimento, pede-se diretamente a apresentação de algum documento em papel que contenha essa informação, embora a lei nem sequer faça referência a tal documento físico. Na instrução efetuada por meios eletrônicos, o foco volta-se para a informação e não para o documento que a contém. Outra diferença corresponde à flexibilidade de tais nor${ }^{1318}$ Defendendo a necessidade de que a informação seja apresentada uma só vez, cf. HoLMES, Douglas, op.
cit., p. 8. 
mas. No processo em papel, a previsão de um meio de prova não impede a Administração de reconhecer as peculiaridades do caso, aceitando outro documento entendido como equivalente; no processo eletrônico, uma adaptação nesse sentido teria de ser feita por meio da adequação das regras do próprio sistema informático, o que nem sempre é uma providência simples.

\subsubsection{Finalização do processo eletrônico}

Da mesma maneira que o processo em papel, o processo administrativo eletrônico deve levar a uma decisão a respeito de seu objeto. Tal decisão, neste caso, assume a forma de um ato administrativo eletrônico ${ }^{1319}$, expedido pela autoridade administrativa ou por um sistema informático. A formalização eletrônica dos atos administrativos e sua automatização já foram analisadas no capítulo anterior deste estudo. Neste ponto, cabe considerar alguns outros aspectos pontuais relacionados à fase de finalização do processo.

Um ponto relevante diz respeito às possíveis limitações impostas, por força da padronização, à própria autoridade responsável pela decisão final. É possível, por exemplo, que o desenho do sistema informático proponha à autoridade a escolha entre duas alternativas estritas, não lhe assistindo a faculdade de eleger outra opção. A exteriorização e a fundamentação do ato podem ter vários de seus aspectos definidos com antecedência, na construção do sistema, levando a uma diminuição da liberdade do agente na produção do ato. Tais limitações são admissíveis do ponto de vista jurídico, desde que tenham fundamento em atos administrativos legítimos, praticados pela autoridade competente por ocasião do desenvolvimento do sistema informático. Caso pretenda decidir fora dos limites estabelecidos, a autoridade deve providenciar a alteração do software responsável pela tramitação do processo.

${ }^{1319}$ Cf. MARTínez GutiÉRreZ, Rubén, Administración Pública Electrónica, cit., p. 235. 
Outro ponto a ser considerado diz respeito às situações em que o processo pode ser finalizado por decisão humana ou por um ato automatizado, de acordo com contingências próprias do caso concreto, passíveis de verificação objetiva. Assim, pode ser automatizado o reconhecimento da desistência do pedido ou da renúncia ao direito, caso o interessado assim se manifeste em um formulário eletrônico. O mesmo pode ocorrer nas situações em que, embora intimado, o sujeito não apresenta defesa em relação ao ato ilícito que lhe é imputado - v.g., uma infração de trânsito -, tornando desnecessária uma decisão humana na análise do mérito do caso.

Em outras situações, a decisão humana pode ser precedida de uma análise efetuada por um sistema informático, que propõe à autoridade a solução a ser adotada. Trata-se de uma situação cada vez mais frequente na realidade contemporânea, sobretudo em decisões complexas, que exigem a compilação de muitos elementos e uma reavaliação por parte do ser humano ${ }^{1320}$. Nesses casos, é evidente que a autoridade não está adstrita à proposta oferecida pela máquina, pois se trata de uma decisão atribuída ao ser humano. Todavia, a avaliação eletrônica prévia pode dar nova feição à necessidade de motivação do ato, porquanto a autoridade administrativa não está livre para atuar de modo arbitrário. Se a máquina ofereceu uma avaliação, adotando critérios aceitáveis, qualquer decisão contrária deverá demonstrar qual aspecto foi omitido ou mal avaliado pelo sistema informático.

Por fim, é de se observar que a decisão final não constitui o único possível resultado do processo administrativo eletrônico. Em sua atuação processual, a Administração recebe uma grande quantidade de informação, que pode ser armazenada de modo automatizado em bancos de dados públicos, para posterior utilização em outras atividades, observado o regime da acumulação informativa por parte do Estado. O administrado deve ter ciência das operações de armazenamento de tais informações, para que não seja surpreendido no futuro. Assim, por exemplo, se o usuário informa seu endereço em um requerimento, a Administração deverá informá-lo caso aquela declaração implique a atualização de dados cadastrais. A geração e o arquivamento de informação pública não podem ser vistos como algo de menor importância, que possa ser feito à revelia do administrado.

\footnotetext{
${ }^{1320}$ Fazendo referencia ao uso de sistemas inteligentes para o apoio à decisão humana, cf. PALOMAR OLMEDA, Alberto, La utilización de las nuevas tecnologías en la actuación administrativa, cit., p. 380.
} 


\subsubsection{Os portais e o protocolo eletrônico}

A administração tradicional é marcada por um forte elemento territorial, o que se projeta sobre o processo administrativo. Em regra, os autos em papel devem permanecer na sede do órgão responsável por sua instrução, onde também devem ser praticados os atos processuais e para o qual devem ser encaminhados os documentos produzidos em outros locais ${ }^{1321}$.

A importância do elemento territorial na administração convencional é enfraquecida pela revolução tecnológica ${ }^{1322}$, pois os autos em papel deixam de ser a referência para a atuação administrativa. O uso de mecanismos telemáticos permite uma distância física entre Administração e administrados, impossível na forma de atuação tradicional $^{1323}$. Nesse contexto, ganham importância os mecanismos técnicos responsáveis pelas diversas trocas de informações relativas ao processo administrativo.

Dessa sorte, os portais públicos na internet desempenham uma função essencial no processo administrativo eletrônico. Essa função vai além do oferecimento de informações a respeito do andamento de processos - utilidade associável também aos expedientes em papel. Tais portais constituem a referência para operações como a publicação de atos relativos ao processo, a prática de atos processuais e o recebimento de informações e solicitações.

As novas tecnologias são cada vez mais aplicadas às rotinas de protocolo de documentos. Na administração tradicional, o protocolo é uma operação pela qual é controlada a recepção e remessa de papéis, por meio da aposição, sobre o documento, de um número progressivo e da data correspondente, acompanhada do registro de tais dados e do conteúdo sumário do documento ${ }^{1324}$. O protocolo constitui um ato público que dá fé da

\footnotetext{
${ }^{1321}$ Cf. Dallari, Adilson Abreu, FerraZ, Sérgio, op. cit., p. 124.

1322 Cf. PIÑAR MAÑAS, José Luis, op. cit., p. 62.

${ }^{1323}$ Cf. VALERO TORRIJOS, Julián, El régimen jurídico de la e-Administración, cit., p. 2.

${ }^{1324}$ Cf. NotARMUZI, Carlo, op. cit., p. 18 e BAUZÁ MARTORELl, Felio José, Régimen jurídico de los registros telemáticos, cit., p. 192.
} 
tempestividade e do efetivo recebimento, por parte da Administração Pública, de um documento advindo do administrado ou de outra entidade ou órgão público ${ }^{1325}$, desempenhando, assim, uma função essencial na garantia da segurança jurídica dos atos praticados.

A recepção presencial de documentos em papel, por parte um ser humano, pode ser substituída pelo recebimento automatizado de documentos em suporte digital, enviados por meio do portal público na internet. Nesse sentido, o protocolo eletrônico é funcionalmente equivalente ao protocolo tradicional, permitindo enviar informações, por meio do preenchimento de formulários eletrônicos disponíveis on line e pela remessa de arquivos digitais, inclusive arquivos de imagem gerados a partir da digitalização de documentos em papel. Além disso, o protocolo eletrônico traz algumas vantagens, tais como a possibilidade de funcionar de modo ininterrupto e a aptidão para verificar os documentos enviados, de modo a apontar, desde logo, eventuais erros ${ }^{1326}$.

A adoção do protocolo eletrônico exige o cumprimento de alguns requisitos técnicos, sob pena de provocar uma inadmissível perda de direitos ${ }^{1327}$. Na condição de mecanismo automatizado, o protocolo eletrônico só pode assegurar as garantias jurídicas devidas caso adotado por meio de um ato formal que defina as regras básicas de seu funcionamento. Sendo possível o atendimento continuado, é necessário fixar um horário de referência e uma formulação de dias e horas úteis ${ }^{1328}$. Cabe regular, ainda, as consequências decorrentes de problemas técnicos - por exemplo, interrupção do funcionamento ou queda no sistema -, que podem acarretar a prorrogação de prazos ou a apresentação da documentação a outro protocolo eletrônico.

Em vista de sua dupla função de garantia, de segurança para o administrado e de controle para a Administração, o protocolo eletrônico deve oferecer a comprovação relativa à apresentação e recebimento do documento, bem como da data correspondente $^{1329}$. Para evitar os inconvenientes derivados do fato de a conexão ser efetuada por

\footnotetext{
1325 Cf. MASUCCI, Alfonso, Procedimento amministrativo e nuove tecnologie, cit., p.22.

${ }^{1326}$ Cf. VALERO TORRIJOS, Julián, Administrative Law and eGovernment, cit., p. 50.

${ }^{1327}$ Cf. VALERO TORRIJOS, Julián, El régimen jurídico de la e-Administración, cit., p. 90.

${ }^{1328}$ Cf. LinARES GIL, Maximino Ignacio, Modificaciones del Régimen Jurídico Administrativo derivadas del empleo masivo de nuevas tecnologías, cit., p. 735.

${ }^{1329}$ Cf. BauZÁ Martorell, Felio José, Procedimiento Administrativo Electrónico, cit., p. 157.
} 
meio de provedores privados de serviços de internet, é desejável que o protocolo ofereça recibo imediato e automático, de maneira que o usuário possa certificar-se de sua atuação ${ }^{1330}$. O recibo deve ser emitido em suporte eletrônico e transmitido ao remetente, que pode optar por manter consigo esse original ou efetuar uma cópia em papel ${ }^{1331}$. Devem estar registradas no recibo, de modo inalterável, as mesmas informações que seriam oferecidas caso a apresentação do documento tivesse sido feita de maneira presencial ${ }^{1332}$, em especial: a) o número de protocolo do documento, gerado pelo sistema informático; b) a data e o horário de registro do protocolo, aposta digitalmente pelo sistema; c) o emitente do documento recebido ou o destinatário do documento expedido; d) o código de identificação da transmissão; e) cópia do conteúdo transmitido, incluída no próprio recibo, adotados os mecanismos de segurança informática pertinentes ${ }^{1333}$.

\subsubsection{Tempo dos atos processuais e prazos}

Outras consequências da utilização da informática e da telemática no âmbito do processo administrativo dizem respeito ao tempo dos atos processuais e respectivos prazos. Nas formas tradicionais de atuação, as relações ocorrem de modo presencial, sendo referência apenas o tempo real, relativo ao horário do funcionamento das repartições

\footnotetext{
${ }^{1330}$ Cf. VAlERO TORRIJOS, Julián, Las relaciones con la Administración Pública mediante sistemas electrónicos, informáticos y telemáticos, cit., p. 267 e VALERO TORRIJOS, Julián, Administrative Law and eGovernment, cit., p. 50. Não haveria sentido a entrega presencial do recibo, pois esta eliminaria as vantagens da telemática, nem o envio por correio eletrônico, mecanismo geralmente desprovido da segurança necessária e que acarreta para o interessado o ônus de consultar sua caixa postal (cf. VALERO TORRIJOS, Julián, El régimen jurídico de la e-Administración, cit., p. 121).

1331 A Administração deve manter em sua base de dados o mesmo arquivo digital, o que permite criar um mecanismo para consulta, de modo a verificar, a todo tempo, a autenticidade da cópia impressa do recibo. Sobre essa possibilidade de conferência, cf. supra, item 2.2.1.

${ }_{1332}$ Cf. VALERO TORRIJOS, Julián, El régimen jurídico de la e-Administración, cit., p. 110.

${ }^{1333}$ Cf. OROFINO, Angelo Giuseppe, Forme elettroniche e procedimenti amministrativi, cit., p. 114; GUERRA, Maria Paola, Archivi delle pubbliche amministrazioni e gestione informatica dei documenti, in ARENA, Gregorio et al., La documentazione amministrativa: Certezze, semplificazione e informatizzazione nel d. P.R. 28 dicembre 2000, n. 445, Rimini, Maggioli, 2001, p. 238; JinESTA LOBO, Ernesto, op. cit., p. 12 e GUILLÉN CARAMÉS, Javier, op. cit., p. 277.
} 
públicas. Com a utilização das novas tecnologias, a realidade torna-se mais complexa, fazendo surgir novas questões, a serem aqui apresentadas ${ }^{1334}$.

Como o emprego das novas tecnologias provoca uma espécie de deslocalização da atividade administrativa, permitindo ao usuário acessar o portal eletrônico da Administração a partir de qualquer lugar do mundo, é necessário fixar critérios para determinar o horário oficial de funcionamento do protocolo, em vista da segurança jurídica ${ }^{1335}$. Em princípio, não havendo outra solução legal a respeito, deve-se adotar o horário oficial do local onde está localizado o órgão público responsável.

A possível disponibilidade ininterrupta dos protocolos eletrônicos permite contornar a tradicional limitação dos horários de abertura das repartições administrativas, pois passa a ser possível praticar atos em dias não úteis ou fora dos horários de funcionamento das repartições físicas, dificultando a determinação do momento em que se deve entender apresentado o documento ${ }^{1336}$. Por essa razão, é necessário um trabalho interpretativo para adaptar à realidade das novas tecnologias as normas relativas ao cômputo de prazos $^{1337}$. Salvo critério legal expresso, a solução mais adequada para o documento apresentado fora do horário de expediente é considerá-lo recebido no momento em que o protocolo convencional voltar a funcionar, no dia útil seguinte ${ }^{1338}$.

Entretanto, vale observar que embora essa seja a solução mais lógica, ela não é a única possível. Norma expressa poderia considerar protocolados no próprio dia os documentos enviados até a respectiva meia-noite, ou mesmo aqueles que fossem apresentados antes da abertura da repartição no dia seguinte ${ }^{1339}$. Essas soluções, contudo, seriam inaceitáveis caso mantido em paralelo o protocolo tradicional, pois a adoção de prazos diferenciados para o protocolo eletrônico importaria em oferecer uma posição mais vantajosa

\footnotetext{
${ }^{1334}$ Sobre a crise da noção de tempo e a possibilidade de diferir o processo de comunicação, cf. BERNADÍ GIL, Xavier, op. cit., p. 216.

${ }^{1335} \mathrm{Cf}$. VALERO TORRIJOS, Julián, El régimen jurídico de la e-Administración, cit., p. 125.

${ }^{1336}$ Cf. VALERO TORRIJOS, Julián, El régimen jurídico de la e-Administración, cit., p. 91.

${ }^{1337}$ Cf. ibidem, pp. 128-129.

1338 Cf. Jinesta LOBO, Ernesto, op. cit., p. 12 e VALERO TORRIJOS, Julián, El régimen jurídico de la eAdministración, cit., pp. 128-129.

${ }^{1339}$ Cf. AgIRreaZKUENAGA, Iñaki, Chinchilla, Carmen, op. cit., p. 49.
} 
para aqueles que dispusessem de condições de utilizar meios eletrônicos em seu relacionamento com a Administração, caracterizado uma violação ao princípio da igualdade.

Outro aspecto a ser considerado diz respeito a eventuais problemas técnicos de comunicação imputáveis à Administração, os quais, na falta de uma alternativa para a apresentação de documentos, tendem a acarretar um direito à prorrogação do prazo ${ }^{1340}$. Não se trata de uma questão nova, porquanto a prorrogação do prazo sempre foi devida nos casos em que a repartição pública precisa ser fechada antes do horário normal no dia do vencimento do prazo - v.g., em razão de um alerta de incêndio. No caso do protocolo eletrônico, a novidade corresponde ao fato de a dilação ocorrer por problemas informáticos, o que enseja outras questões, como a necessidade de uma justificação adequada, passível de auditoria, bem como a importância de dar ampla publicidade à prorrogação, tudo para evitar favorecimentos indevidos.

Por fim, vale considerar a utilidade das novas tecnologias para o controle do atendimento dos prazos legais. Esse controle pode ter um caráter preventivo, quando o sistema deixa de aceitar o protocolo do documento após o decurso do prazo para a prática do ato. Não havendo um mecanismo dessa espécie, o controle pode ser exercido depois da prática do ato. Neste caso, como não é necessária uma habilidade humana específica para efetuar a comparação objetiva entre o termo final e a data do protocolo, o sistema pode ser programado para rejeitar, de modo automatizado, os atos processuais intempestivos.

\subsubsection{A intimação dos interessados}

A exigência de celeridade na impulsão do processo administrativo tende a exigir que as comunicações ocorram em suporte eletrônico, caso se disponha de meios e

${ }^{1340}$ Cf. VALERO TORRIJOS, Julián, El régimen jurídico de la e-Administración, cit., p. 113. 
condições técnicas adequadas ${ }^{1341}$. Por isso, surge o importante tema do uso das novas tecnologias para a intimação dos interessados.

A intimação por meios eletrônicos é capaz de oferecer mais segurança de recebimento pelo destinatário do que os mecanismos de publicidade legalmente previs$\operatorname{tos}^{1342}$, podendo ser feita a qualquer momento, não importa o dia e o horário ${ }^{1343}$. Pode, ainda, eliminar possíveis nulidades decorrentes de problemas que ocorrem nos meios tradicionais, tais como aqueles referentes à ausência do interessado em seu domicílio e a recepção por pessoa distinta, inclusive no tocante à idade e à capacidade de quem recebe a comunicação $^{1344}$.

De maneira intuitiva, é normal pensar na utilização do correio eletrônico, ao invés do serviço postal comum, para efetivar tais intimações. Isso ocorre porque, nas relações sociais em geral, o correio eletrônico assumiu grande parte do espaço antes ocupado pelo correio tradicional. O e-mail está ao alcance de um número cada vez maior de pessoas, apresentando grandes vantagens em relação a outros meios de comunicação, por sua rapidez e economicidade ${ }^{1345}$. Assim, fala-se na possibilidade de o endereço eletrônico tornar-se a residência habitual da pessoa, para onde devem ser enviadas todas as notificações de atos jurídicos eletrônicos a ela pertinentes ${ }^{1346}$.

Entretanto, há dificuldades para considerar o endereço eletrônico de um sujeito equivalente à sua residência ou domicílio eleito ${ }^{1347}$. Na verdade, a intimação por correio eletrônico resolve alguns problemas, porém traz outros ${ }^{1348}$.

\footnotetext{
${ }^{1341}$ Cf. VAlERo TORRIJOS, Julián, Acceso a los servicios y difusión de la información por medios electrónicos, cit., p. 272.

${ }^{1342}$ Cf. VALERO TORRIJOS, Julián, El régimen jurídico de la e-Administración, cit., p. 147.

${ }^{1343}$ Cf. ibidem, p. 135.

${ }^{1344}$ Cf. JinESTA LOBO, Ernesto, op. cit., p. 12.

${ }^{1345}$ Cf. Gordillo, Agustín, Tratado de Derecho Administrativo, t. 4, 8a. ed., Buenos Aires, Fundación de Derecho Administrativo, 2004, p. III-34.

${ }^{1346}$ Cf. SÁNCHEZ RodRÍGUEZ, Francisco, op. cit., p. 30. Afirmando que o direito administrativo deveria apoiar utilização do correio eletrônico, cf. GoRDILlo, Agustín, op. cit., p. III-34.

${ }^{1347}$ Cf. MASUCCI, Alfonso, Il documento amministrativo informatico, cit., p. 42.

${ }^{1348}$ Cf. Álamo GonZÁlez, Nayra, op. cit., p. 116.
} 
Um deles é a necessidade de intermediação por parte de terceiros no tráfego de informações, pois a comunicação por meio de correio eletrônico exige a participação de ao menos dois provedores de serviços: o primeiro, encarregado de transmitir a mensagem a partir do equipamento do emissor, e o segundo, que deve recebê-la e colocá-la à disposição do destinatário ${ }^{1349}$. Assim, as informações relativas à intimação precisariam ser asseveradas por entidades privadas cuja fé pública pode ser posta em dúvida ${ }^{1350}$, exceto se houver previsão legal nesse sentido. Por outro lado, a autenticidade das declarações atinentes à transmissão e entrega de notificações precisaria estar garantida do ponto de vista técnico, o que também pode oferecer dificuldades, porquanto os serviços de correio eletrônico apresentam qualidade e características heterogêneas. Além disso, os provedores de correio muitas vezes estão situados fora do território nacional ${ }^{1351}$, sendo difícil disciplinar suas atividades, ainda que haja um regime legal a respeito.

Por outro lado, o correio eletrônico não está relacionado a um equipamento que esteja na posse do interessado, mas a uma caixa postal, gerida pelo provedor de serviços. Para acessá-la, é necessário conectar-se a esse provedor, utilizando a internet ${ }^{1352}$. Na notificação mediante correio eletrônico, o efetivo conhecimento da mensagem não depende apenas de sua entrega ao destinatário, pois é preciso que este acesse sua caixa pos$\operatorname{tal}^{1353}$. Por isso, o envio da mensagem eletrônica não garante seu recebimento ${ }^{1354}$, muito menos o tempo em que isso ocorrerá. Mesmo aqueles que têm bastante familiaridade com computadores e redes telemáticas não podem ser obrigados a estar sempre na internet, na busca de notícias de seu interesse ou na contínua consulta a todos os endereços de correio eletrônico ativados em seu nome ${ }^{1355}$.

Há dificuldades, ainda, para assegurar a identidade dos sujeitos que intervenham na comunicação e, em especial, a integridade da mensagem ${ }^{1356}$. Os provedores

\footnotetext{
${ }^{1349}$ Cf. VALERO TORRIJOS, Julián, El régimen jurídico de la e-Administración, cit., p. 135.

${ }^{1350}$ Cf. ibidem, pp. 152-153.

${ }^{1351}$ Cf. VALERO TORRIJOS, Julián, El régimen jurídico de la e-Administración, cit., pp. 152-153.

1352 Cf. NotarmuZI, Carlo, op. cit., p. 23.

${ }^{1353}$ Cf. GómeZ PuENTE, Marcos, op. cit., p. 179.

${ }_{1354}$ Cf. OROFINO, Angelo Giuseppe, Forme elettroniche e procedimenti amministrativi, cit., p. 184.

1355 Cf. ibidem, pp. 159-160.

${ }^{1356}$ Cf. VALERO TORRIJOS, Julián, El régimen jurídico de la e-Administración, cit., p. 136.
} 
de serviços de correio eletrônico nem sempre costumam utilizar os mecanismos mais seguros de assinatura eletrônica ${ }^{1357}$, de modo a garantir razoavelmente a exclusividade do acesso do destinatário. A senha necessária para receber as mensagens pendentes do servidor de correio pode ser conhecida pelo provedor ou por terceiros, havendo riscos consideráveis de interceptação da comunicação entre o usuário e o servidor no momento da leitura das mensagens pendentes ${ }^{1358}$.

Por tais razões, o correio eletrônico pode ser usado com as mesmas limitações que o telefone ou o fax, ou seja, sem a possibilidade de extrair dele um efeito jurídico preciso ${ }^{1359}$. Nesse sentido, o correio eletrônico pode constituir um meio alternativo para assegurar a ciência do interessado ${ }^{1360}$, não sendo cabível recusar, a priori, a eficácia desse mecanismo de comunicação, pois o destinatário pode aceitá-la e dar-se por intimado ${ }^{1361}$. Não se trata, por certo, de algo desprezível, sobretudo tendo em vista que o andamento do processo e o conhecimento da intimação muitas vezes convêm ao próprio interessado. Assim, a notificação por meio eletrônico pode ser um modo de usar o princípio do formalismo moderado em favor do administrado. No entanto, quando for necessária uma informação segura a respeito do recebimento da intimação por parte do interessado, para que isto lhe possa ser oposto, o correio eletrônico não constitui um meio apropriado de intimação.

Para tornar viável a intimação mediante correio eletrônico, a matéria precisaria, no mínimo, ser regulada em lei. Não, basta, contudo, uma simples alusão à possibilidade de intimação por $e$-mail. As particularidades dessa forma de comunicação justificam

\footnotetext{
${ }^{1357}$ Cf. ibidem, pp. 152-153.

${ }^{1358}$ Cf. ibidem, pp. 154 e 162 . Assim, o correio eletrônico não garante a autenticidade subjetiva das comunicações, na medida em que não elimina o risco de suplantação de identidade (cf. BAUZÁ MARTORELL, Felio José, Procedimiento Administrativo Electrónico, cit., p. 43).

${ }^{1359}$ Cf. Justen FILHo, Marçal, Curso de direito administrativo, cit., p. 331. Assim dispõe o art. $8^{\circ}$ do Decreto n. 6.932/09: "Para complementar informações ou solicitar esclarecimentos, a comunicação entre o órgão ou entidade e o interessado poderá ser feita por qualquer meio, inclusive comunicação verbal, direta ou telefônica, correspondência, telegrama, fax ou correio eletrônico, registrando-se a circunstância no processo, caso necessário".

${ }^{1360}$ Cf. DALlari, Adilson Abreu, Ferraz, Sérgio, op. cit., pp. 127 e 159.

${ }^{1361}$ Cf. VALERO TORRIJOS, Julián, El régimen jurídico de la e-Administración, cit., p. 169.
} 
a existência de um regime jurídico diferenciado ${ }^{1362}$, para estabelecer os requisitos de validade das intimações eletrônicas, equacionando algumas das questões acima apontadas.

A lei poderia estabelecer em que condições se presumiria a intimação do destinatário, em razão da inviabilidade prática de obrigá-lo a acessar sua caixa postal ou a ler a mensagem recebida. Caso não houvesse a confirmação de leitura da mensagem dentro de certo prazo, a lei consideraria a intimação como realizada, transferindo para o administrado o ônus de sempre verificar sua caixa postal. Há casos em que o ordenamento não pode contentar-se com a presunção derivada da entrega da mensagem na caixa postal ${ }^{1363}$, porém caberia à lei, por meio de um juízo político, sopesar as vantagens e problemas de tal regime de presunções, dando-lhe a extensão adequada em função do contexto cultural e das atividades que poderiam ensejar tal mecanismo de comunicação.

Tal legislação poderia estabelecer, ainda, os requisitos de autenticidade e a integridade da comunicação, indispensáveis para o atendimento do princípio da segurança jurídica ${ }^{1364}$. As normas legais deveriam proporcionar a garantia de confidencialidade da comunicação, tanto na remessa do ato por parte do órgão que o produziu quanto no acesso pelo interessado ${ }^{1365}$. A obrigatoriedade de utilização de mecanismos adequados de assinatura eletrônica poderia oferecer mais segurança às comunicações ${ }^{1366}$. Utilizado um mecanismo de certificação eletrônica, seria possível dar valor jurídico à transmissão de documentos produzidos e transmitidos mediantes instrumentos informáticos, que necessitam de um recibo de envio e um recibo de retorno ${ }^{1367}$. Neste caso, o provedor de correio eletrônico do remetente ofereceria um recibo como prova legal da expedição da mensagem, ao passo que o provedor do destinatário enviaria ao emitente o recibo da entrega, também com valor legal. Os recibos, assinados de modo digital, certificariam a expedição e recebimento da mensagem e sua integridade, bem como a data e hora de cada uma das operações ${ }^{1368}$.

\footnotetext{
1362 Cf. ibidem, p. 137.

${ }^{1363}$ Cf. PONTI, Benedetto, op. cit., p. 80.

${ }_{1364}$ Cf. BauZÁ Martorell, Felio José, Procedimiento Administrativo Electrónico, cit., pp. 60-61.

${ }^{1365}$ Cf. VALERO TORRIJOS, Julián, El régimen jurídico de la e-Administración, cit., p. 164.

${ }^{1366}$ Cf. ibidem, p. 165.

1367 Cf. NOTARMUZI, Carlo, op. cit., p. 25.

${ }^{1368}$ Cf. OrofinO, Angelo Giuseppe, Forme elettroniche e procedimenti amministrativi, cit., p. 190.
} 
De todo modo, o processo administrativo digital não admite apenas notificações por meio eletrônico. Com efeito, o sistema informático responsável por gerenciar o processo administrativo pode solicitar a realização de uma intimação presencial ou pelo serviço postal convencional. Efetuada a intimação, a informação pertinente pode ser registrada no sistema, para a continuidade do andamento processual. Como já afirmado, o processo administrativo eletrônico não impede a atuação humana combinada à informática, o que, por óbvio, aplica-se às intimações.

Por outro lado, a notificação eletrônica não necessariamente precisa ser efetuada mediante correio eletrônico. Embora a difusão social do correio eletrônico não possa ser desprezada, não se deve deixar de considerar os possíveis avanços da tecnologia e dos próprios hábitos da população. Outros mecanismos de conexão serão criados e novos equipamentos surgirão, assim como serão acrescidas novas funcionalidades aos meios existentes. Nesse sentido, é possível desenvolver mecanismos seguros que permitam o recebimento passivo de uma intimação, sem a necessidade de acessar uma caixa de correio eletrônico. De outra parte, é provável que o ser humano caminhe para a utilização de meios mais sofisticados de interação, como é o caso das redes sociais. Portanto, limitar ao correio eletrônico a comunicação da Administração com o interessado em processos administrativos eletrônicos constitui um equívoco a ser evitado.

\subsubsection{Recursos no processo eletrônico}

Não dependendo de previsão legal expressa ${ }^{1369}$, o direito de interpor recurso administrativo existe também no processo eletrônico. De modo geral, o direito de recorrer pode ser exercido por meio dos mecanismos aqui expostos, com aproveitamento

\footnotetext{
${ }^{1369}$ Segundo ODETE MEDAUAR, "O direito de interpor recurso administrativo independe de previsão expressa em lei ou demais normas, visto ter respaldo no direito de petição, que no ordenamento pátrio vem consignado pela Constituição Federal, art. $5^{\circ}$, XXXIV, $a$, integrante do rol dos direitos e garantias fundamentais" ( $A$ Processualidade no Direito Administrativo, cit., p. 124).
} 
dos benefícios proporcionados pelas novas tecnologias, em especial a interposição por via telemática.

Quando o recurso impugna ato praticado por um ser humano, não há grandes observações a serem feitas. A discussão pode até ter por objeto algum aspecto relacionado à tecnologia, mas isso não traz novas perspectivas em relação aos temas processuais. Questões mais significativas, relevantes para os propósitos deste estudo, são trazidas nos casos de recurso interposto contra ato administrativo automatizado.

Não há dúvida sobre o direito de recorrer em tal hipótese. Tendo sido expedido um ato administrativo, ainda que por via automatizada, com produção de efeitos jurídicos, o administrado deve ter a oportunidade de impugnar a atuação administrativa. Como já afirmado, a atuação automatizada está submetida à equivalência de garantias, devendo estar sujeita a controles jurídicos ${ }^{1370}$. Bem por isso, assiste ao administrado o direito de intervir na formação da decisão administrativa automatizada ${ }^{1371}$, o que pode ocorrer tanto na fase de programação do sistema informático quanto após sua atuação pontual no confronto com o caso concreto. Sendo possível a ocorrência de vícios nos atos administrativos praticados pela máquina, é necessário haver mecanismos para equacioná-los, sobretudo se acarretarem prejuízos à esfera jurídica do administrado ${ }^{1372}$.

O objetivo do questionamento dirigido contra o ato administrativo automatizado é forçar uma deliberação humana a respeito da matéria apresentada. Com efeito, se o problema fosse novamente submetido à máquina, o resultado seria o mesmo, pois o

\footnotetext{
${ }^{1370}$ A respeito da necessidade de tal controle, especialmente no que concerne à construção de sistemas informáticos mediante a tradução de regras legais, cf. Bovens, Mark, ZoURIDS, Stavros, op. cit., pp. 175 e 182. Considerando indiferente, para fins de controle, o mecanismo pelo qual foi gerado o ato, cf. MASUCCI, Alfonso, L'atto amministrativo informatico, cit., p. 102.

${ }^{1371}$ Cf. UsAI, Alessandro, op. cit., item 2.3.

${ }^{1372}$ Entender o contrário levaria a indisfarçável absurdo, que poderia pôr em perigo até mesmo em perigo as vantagens da automatização: "Outro risco que se deve ter presente é que a informática, em lugar de fazer mais transparente, flexível e acessível aos cidadãos o procedimento administrativo, contribua para aumentar seu formalismo e rigidez. Quando isto ocorre, faz-se mais difícil para os cidadãos obter esclarecimentos ou retificações da Administração, a partir do momento que o seu interlocutor passa a ser um computador que obedece somente à lógica infalível, inexorável e inapelável da informação informática" (PÉREZ LUÑO, Antonio-Enrique, op. cit., p. 85, tradução).
} 
percurso rígido por ela trilhado não se alteraria ${ }^{1373}$. Assim, o controle da atividade administrativa é direcionado para o momento em que se dá a atuação humana, da qual as operações efetuadas pela máquina são apenas consequências.

A alegação do recurso pode referir-se a qualquer dos vícios dos atos administrativos automatizados ${ }^{1374}$. Assim, em vista de reverter o ato automatizado com o qual não se satisfez, o interessado pode requerer: a) a prática de uma decisão por um ser humano, demonstrando que a automatização é inadequada naquele caso, implicando a invalidade do ato emanado do sistema informático; b) a alteração das regras que instruíram o sistema (ato-programa); c) a correção de um erro no software; d) a correção de um problema técnico no funcionamento do sistema; e) a correção de dados incorretos ou a integração de dados incompletos ${ }^{1375}$.

Quando são questionadas as regras de programação do sistema, o controle administrativo é estruturado em duas fases distintas, dirigidas ao ato-programa e ao ato informático final ${ }^{1376}$. Como antes mencionado, o reconhecimento do vício do ato final, nestes casos, tende a exigir o ajuste da programação. Caso contrário, haveria o risco de serem praticados outros atos inválidos semelhantes, embora a invalidade do programa já tivesse sido apurada ${ }^{1377}$, o que seria contrário aos princípios da isonomia e da segurança jurídica.

\footnotetext{
${ }^{1373}$ Cf. CONTALDO, Alfonso, GoRGa, Michele, op. cit., p. 178.

1374 Cf. supra, item 3.4.6.

1375 MASUCCI aponta algumas das possíveis consequências da procedência dos recursos. Para o autor, se a ilegitimidade decorre de uma programação incorreta, é necessário readequar o programa e depois corrigir todos os atos sucessivos, inclusive o próprio ato informático impugnado; caso a ilegitimidade decorra dos dados oferecidos ao sistema, é necessário eliminar os dados ilegítimos e depois inserir os legítimos, ao passo que se o problema é a falta de dados ou de atos procedimentais necessários, é necessário primeiro preencher essa lacuna e depois renovar o processo (cf. L'atto amministrativo informatico, cit., p. 128).

${ }^{1376}$ Cf. MARONE, Umberto, op. cit., p. 90. Por isso, a doutrina já apontou que a peculiaridade dos recursos contra atos automatizados diz respeito à relevância dos atos de programação (cf. MASUCCI, Alfonso, L'atto amministrativo informatico, cit., p. 103).

${ }^{1377}$ Cf. MASUCCI, Alfonso, L'atto amministrativo informatico, cit., pp. 104-105.
} 
A competência para apreciação do recurso deve ser apurada conforme o agente responsável pelo ato ${ }^{1378}$. Entretanto, a inexistência de uma deliberação humana prévia a respeito do caso concreto e a diversidade dos eventuais vícios provocam alguma heterogeneidade no encaminhamento do recurso. Se o recorrente questiona um critério adotado de modo intencional pela autoridade responsável pelo sistema informático, a decisão relativa ao recurso deverá ser apreciada pela autoridade superior. Se o reclamo tem em vista um erro de programação ou um problema técnico no funcionamento do sistema, a própria autoridade gestora poderá reconhecer o erro e dar provimento ao recurso. Por tal razão, é recomendável que as regras procedimentais estipulem a interposição perante a autoridade responsável pelo sistema informático, cabendo a ela apreciar o solicitado na condição de pedido de reconsideração, ou remetê-lo à autoridade superior, para que assim se garanta ao recorrente a apreciação da matéria por órgão diverso.

Em qualquer caso, não deve ser atribuído ao administrado o ônus de demonstrar eventuais problemas técnicos, pois ele em geral não está em condições de trazer provas concretas a respeito ${ }^{1379}$. Cabe ao recorrente apenas caracterizar o vício do ato e não ingressar nos meandros da atuação tecnológica. É a Administração que deve suportar os ônus da tecnologia, provando que seus equipamentos informáticos funcionam corretamente, de maneira a eliminar quaisquer dúvidas a respeito de aspectos técnicos ${ }^{1380}$. Isso é reforçado se não são divulgadas as regras de programação ou quando falta transparência às operações informáticas, levando à produção de atos com fundamentação ausente ou deficiente $^{1381}$.

\footnotetext{
${ }^{1378}$ Entendendo como solução mais lógica reconhecer tal competência ao mesmo órgão que praticaria o ato caso ele não fosse produzido de modo automatizado ou ao órgão responsável por estabelecer as especificações, cf. LINARES GIL, Maximino Ignacio, Identificación y autenticación de las administraciones públicas, cit., p. 311. A apreciação por autoridade distinta da responsável pela programação poderia trazer o problema, antes apontado, de rever decisão singular e manter a programação reconhecida como inválida.

${ }_{1379}$ Cf. ZeIDLER, Karl, op. cit., p. 56.

${ }^{1380}$ Cf. PALOMAR OLMEDA, Alberto, Administración electrónica y actuación jurisdiccional, cit., pp. 80-81.

${ }^{1381}$ Fazendo referência a tal presunção, caso descumpridas as exigências relativas à aprovação e publicidade do software, cf. PALOMAR OLMEDA, Alberto, El acto administrativo dictado sobre bases tecnológicas, in Revista de Derecho y Nuevas Tecnologias, n. 7, Cizur Menor (Navarra), Thomson-Aranzadi, p. 87.
} 
Uma importante função dos recursos contra atos automatizados diz respeito à possibilidade de obter uma avaliação do caso concreto ${ }^{1382}$, o que serve para atenuar a rigidez própria da atuação por meio do sistema informático ${ }^{1383}$. Com efeito, a atividade de programação pode não ter levado em conta uma hipótese que seria relevante para a lei, gerando um ato viciado. Quando isso ocorre, o interessado pode recorrer desse ato automatizado, pleiteando o reconhecimento da omissão e a integração da programação do sistema. Esta é a estrutura procedimental mais adequada para a garantia dos direitos do administrado, sem causar impedimento à automatização ${ }^{1384}$. Interposto o recurso, cabe à Administração justificar a razão pela qual as particularidades do caso concreto não foram levadas em conta na fixação das regras aplicadas pelo sistema informático. Caso o recurso seja procedente, é preciso corrigir a programação, sendo possível, conforme o caso, a prática de um ato pela via tradicional ${ }^{1385}$.

Os atos administrativos gerais que sustentam os sistemas incumbidos da expedição de atos automatizados podem ser impugnados mesmo na falta de um caso concreto $^{1386}$, pois é melhor admitir a impugnação direta da programação do que ter de remediar milhares de decisões ilegais, com o risco de produzir indesejáveis desigualdades ${ }^{1387}$. O questionamento dos atos gerais pode ser feito a todo tempo, por qualquer pessoa ${ }^{1388}$. Não

\footnotetext{
${ }^{1382}$ Alguns autores mencionam essa possibilidade como um direito do administrado. Reconhecendo a este a faculdade de pedir um exame de seu caso particular fora das rotinas automatizadas, em condições que lhe permitam fazer valer seu entendimento, cf. BRAIBANT, Guy, Données personnelles et société de l'information, cit., p. 11. Afirmando que os administrados devem ter a oportunidade de chamar a atenção para circunstâncias específicas que não cabem nos algoritmos existentes, cf. BovENS, Mark, ZOURIDS, Stavros, op. cit., p. 182.

${ }^{1383}$ Há quem aponte um risco de ordem constitucional decorrente do excesso de rigidez (cf. BovENS, Mark, ZOURIDS, Stavros, op. cit., p. 182). Nesse sentido, a redução do poder de apreciação dos casos concretos pela autoridade administrativa seria contrária a princípios relacionados a direitos fundamentais. Por isso, seria necessário que cada pessoa pudesse defender seus argumentos particulares e suscitar um exame especial de seu caso (cf. PlaNTEY, Alain, op. cit., p. 100).

${ }^{1384}$ Falando do direito a um exame particular de seu caso, sem se opor às iniciativas para melhoria da eficácia no serviço público, por meio da automatização de atos, cf. BRAIBANT, Guy, Données personnelles et société de l'information, cit., p. 11.

${ }^{1385}$ Cf. FANTIGROSSI, Umberto, op. cit., pp. 120-121. A expedição de um ato tradicional pode proporcionar uma solução imediata para o caso concreto, sendo a solução recomendável em casos urgentes. Todavia, caso se trata de uma invalidade do ato-programa, de modo que o mesmo problema possa atingir outros interessados, a correção da programação é indispensável, devendo ser feita o quanto antes.

${ }^{1386}$ Em sentido contrário, pela impossibilidade de impugnação autônoma do software, devendo o questionamento dirigir-se ao ato eletrônico final, cf. GIURDANELLA, Carmelo, GuARNACCIA, Elio, op. cit., p. 79.

${ }^{1387}$ Cf. JACQUE, Jean Paul, op. cit., p. 109.

${ }^{1388}$ Entendendo que somente poderia impugnar diretamente o ato-programa aquele que estivesse em condição de ser destinatário de um ato automatizado, cf. FANTIGROSSI, Umberto, op. cit., p. 123.
} 
se trata de um recurso, mas de um requerimento fundado no direito de petição, por meio do qual é impugnada a legalidade da programação. Cabe à Administração apreciar tal requerimento, demonstrando a compatibilidade da programação com o ordenamento jurídico ou declarando sua invalidade, hipótese em que será necessário proceder à adequação do sistema informático.

Por fim, é preciso ressaltar que o processo administrativo eletrônico não deve enfraquecer ou obstar o controle judicial ${ }^{1389}$, inclusive nas atividades automatizadas ${ }^{1390}$. Como ocorre em relação ao processo em papel, qualquer ilegalidade pode ser levada ao conhecimento dos tribunais. Para exercer de modo apropriado suas funções, o órgão judicial deve ter acesso às informações do processo ${ }^{1391}$, o que se espera possa ser feito, em futuro não muito distante, por meio de um adequado nível de interoperabilidade entre os sistemas da Administração Pública e do Poder Judiciário. Sendo necessária a apreciação de questões relacionadas à tecnologia, o juiz deve solicitar o auxílio de peritos ${ }^{1392}$. Também no caso das discussões travadas em juízo, a Administração deve, em regra, demonstrar o adequado funcionamento de seus sistemas informáticos, não cabendo transferir tais ônus para o administrado.

\footnotetext{
${ }^{1389}$ Cf. Asís RoIG, Agustín de, op. cit., p. 185.

1390 A respeito do controle judicial das atividades vinculadas executadas por meio de sistemas informáticos, cf. BRAIBANT, Guy, Introduction, cit., p. 11.

${ }^{1391}$ Cf. PAlOMAR OlmedA, Alberto, Administración electrónica y actuación jurisdiccional, cit., p. 86 e PALOMAR OlmedA, Alberto, Procedimientos administrativos y régimen documental en la actuación de la Agencia Española de Protección de Datos, cit., p. 94.

${ }^{1392}$ Cf. SAITTA, Fabio, op. cit., p. 27.
} 


\section{CONCLUSÕES}

São frequentes as alusões - não raro na forma de crítica - ao caráter conservador do direito. Há algo de verdadeiro nessa afirmativa, pois as estruturas jurídicas muitas vezes têm o propósito de garantir a estabilidade das relações entre os seres humanos, oferecendo mecanismos contra os abusos de poder. Todavia, esse propósito garantista não pode ser um motivo para o distanciamento da realidade. $\mathrm{O}$ direito deve estar atento às transformações dos fatos, para antecipar ou acompanhar as novas tendências.

O mesmo ocorre com a ciência do direito. É natural algum atraso no reconhecimento das mudanças e até uma revolução pode demorar a ser percebida pelos juristas, sendo assim negada por muitos deles. Há várias razões para isso, incluindo tanto o justo envolvimento com antigas e produtivas linhas de pesquisa quanto o comodismo proporcionado por certos conhecimentos consolidados em relação a um mundo supostamente estático. Afora tais aspectos, de ordem subjetiva, é preciso reconhecer que uma realidade em intensa mutação traz riscos e desafios para a ciência. Os antigos postulados deixam de ser seguros, aumentando os riscos de conclusões equivocadas. Exatamente por isso, as novas questões precisam ser enfrentadas pela ciência do direito, pois, se os próprios juristas se tornam mais expostos a falhas, não será sua omissão que trará melhores resultados.

Com o impulso proporcionado por essas inquietações, o presente estudo procurou enfrentar alguns temas suscitados pelo uso das novas tecnologias no âmbito da Administração Pública, no contexto da revolução tecnológica responsável pelo advento da chamada sociedade da informação. Para tanto, não se optou por uma investigação cautelosa, preocupada em evitar polêmicas. De fato, uma perspectiva conservadora em relação à matéria não seria apropriada e uma visão apenas genérica poderia ser inútil. Ademais, um trabalho científico desta espécie exige alguma ousadia, ainda que acompanhada do risco de expor falhas ou deficiências no pensamento do autor, destacadas ainda mais diante de um tema tão complexo. 
No curso desta tese, foram investigadas as três hipóteses lançadas em sua introdução: 1) o governo eletrônico é uma realidade jurídica, que pode ser compreendida também sob a perspectiva do direito administrativo; 2) na condição de realidade jurídica, o governo eletrônico está sujeito a um conjunto de fundamentos, decorrentes do ordenamento vigente, em especial de seus preceitos constitucionais; 3) a utilização de meios eletrônicos provoca consequências substanciais em relação a institutos clássicos do direito administrativo, tornando necessário que estes e suas respectivas bases sejam reavaliados pela ciência do direito a partir da realidade tecnológica atual e dos fundamentos jurídicos sistemáticos referidos na hipótese anterior.

A primeira hipótese foi demonstrada por meio da apresentação de alguns aspectos relacionados ao governo eletrônico, tendo por referência pontos fundamentais do direito constitucional e administrativo, o que permitiu verificar a relevância de seu tratamento jurídico. Os inúmeros problemas e questões apresentadas neste estudo mostram a possibilidade - e mesmo a necessidade - de observar o governo eletrônico também sob a perspectiva do direito. O desenvolvimento de uma visão jurídica a respeito da incorporação das novas tecnologias no âmbito da Administração Pública é fundamental para que o direito não tenha uma posição marginal em relação ao tema, assumindo uma posição de liderança, essencial no âmbito de um Estado de Direito.

Na investigação da segunda hipótese, foi possível apurar que o governo eletrônico, como tema jurídico, é passível de um enquadramento sistemático. Ele é regido por um conjunto de bases jurídicas, identificado a partir da aplicação de regras fundamentais do ordenamento brasileiro em relação à realidade tecnológica. Foram apresentados, assim, os seguintes princípios do governo eletrônico: a) a equivalência de suportes, responsável por lastrear a validade do documento eletrônico; b) a eficiência administrativa, a qual impõe a constante atualização tecnológica por parte da Administração; c) a equivalência de garantias, cuja missão é projetar sobre o governo eletrônico toda a proteção jurídica reconhecida ao administrado nas formas tradicionais de atuação; d) a interoperabilidade, incumbida de viabilizar o relacionamento entre sistemas informáticos públicos, em benefício da eficiência administrativa e, por consequência, do administrado. 
A existência de um conjunto de bases jurídicas é essencial para servir como referência para o enfrentamento das novas questões que surgem a cada dia. O presente trabalho procurou avaliar algumas dessas questões, agrupadas em torno de dois temas fundamentais, relacionados a toda a atividade administrativa e influenciados diretamente pelos efeitos das novas tecnologias: o ato e o processo administrativo. Tal análise proporcionou a demonstração da terceira hipótese lançada, identificando a necessidade de que esses institutos clássicos sejam revistos segundo o contexto tecnológico atual, observadas as bases jurídicas do governo eletrônico.

Na exposição sobre o ato administrativo eletrônico, foi apontada a viabilidade jurídica de duas novidades trazidas pelo uso da informática na Administração Pública: a utilização do suporte eletrônico para o registro das decisões, em substituição ao papel, e a expedição de atos administrativos de modo automatizado, sem interferência humana diante do caso concreto. $\mathrm{O}$ ato administrativo em forma digital pode ser considerado uma decorrência da viabilidade do documento público eletrônico. Já o ato automatizado deve ser tido como o resultado da atuação de um equipamento informático, programado pela autoridade segundo regras compatíveis com a ordem jurídica, destinado a maximizar os resultados das decisões humanas nas quais está baseada tal programação.

Por fim, o estudo apontou algumas transformações contemporâneas relativas ao processo administrativo, sobretudo aquelas provocadas pelo uso da tecnologia, que permitem compreendê-lo como mecanismo abrangente de troca e produção de informações. Na esteira da admissibilidade do documento público em suporte digital, apresentouse o conceito de processo administrativo eletrônico. Foram também expostas as implicações do emprego das tecnologias da informação e da comunicação em relação às diversas fases e atos do processo, mostrando as repercussões da digitalização das informações, dos meios telemáticos de relacionamento e da automatização de tarefas. Tais técnicas, compatíveis com nosso sistema jurídico, constituem os eixos de transformação para propiciar o adequado aproveitamento das tecnologias no âmbito do processo administrativo, respeitadas as garantias constitucionais pertinentes.

Demonstradas, assim, as hipóteses propostas no início deste trabalho, parece possível concluí-lo. A praxe poderia recomendar um relato mais minucioso dos 
vários pontos apresentados em cada item deste estudo. Todavia, a retomada sintética das hipóteses lançadas parece mais apropriada, por uma razão de conteúdo e por um motivo simbólico. Quanto ao conteúdo, uma eventual apresentação dos diversos pontos tratados só levaria a oferecer, de maneira resumida e por certo com perda de conteúdo, diversos temas que só podem ser compreendidos de modo adequado no contexto em que foram expostos. Sua síntese, em breves páginas, representaria um empobrecimento da exposição, sem uma utilidade verdadeira para o leitor. Quanto ao lado simbólico, apresentar respostas finais minuciosas a respeito de cada questão pontual analisada pelo texto não parece adequado a uma tese sobre tema tão dinâmico, cujo propósito é também servir de convite ao aprofundamento das ideias nela lançadas.

Espera-se que a presente tese tenha trazido uma contribuição original para a ciência jurídica brasileira, abrindo caminhos para outros estudos que possam continuar a desenvolver os temas aqui apresentados. A evolução da pesquisa jurídica relativa ao governo eletrônico é fundamental para harmonizar os resultados positivos almejados com o uso das novas tecnologias e as exigências próprias do Estado de Direito.

A compreensão das relações entre governo eletrônico e direito administrativo deve ter a consistência dogmática necessária para afastar o simples medo da inovação digital e evitar a invocação vazia do princípio da eficiência como legitimador de qualquer iniciativa de modernização administrativa, equívoco muitas vezes decorrente de um simplório deslumbramento provocado pela tecnologia. A utilização dos meios eletrônicos na Administração Pública envolve uma problemática jurídica complexa, a ser explorada de modo aprofundado à luz das bases do ordenamento, envolvendo uma rediscussão e atualização dos institutos do direito administrativo de acordo com a realidade tecnológica contemporânea. Somente com base em uma compreensão adequada de tais temas será possível construir soluções aptas a realizar a eficiência administrativa não apenas em benefício do Poder Público, mas em proveito dos direitos de pessoas físicas e jurídicas em seu relacionamento com a Administração. 


\section{GLOSSÁRIO}

(Os números se referem às notas de rodapé do texto associadas ao conceito)

Algoritmo: sucessão ordenada de operações predeterminadas que formalizam um processo de raciocínio (1010).

Base de dados (ou banco de dados): coleção organizada de fatos e informações, logicamente relacionados entre si (5).

Conhecimento: consciência e entendimento de um conjunto de informações, de maneira a torná-las úteis para a realização de uma tarefa específica ou para a tomada de uma decisão (8).

Dado: diferença observável na realidade, representada de modo formalizado (2). Também usado no texto como sinônimo de informação registrada em base de dados (5).

Digital: adjetivo empregado para qualificar as diversas realidades que se utilizam das novas tecnologias. Usado no texto com o mesmo significado de eletrônico e informático (13 e 195).

Eletrônico: adjetivo empregado para qualificar as diversas realidades que se utilizam das novas tecnologias. Usado no texto com o mesmo significado de digital e informático (13 e 195).

Informação: dado organizado de modo a ter valor adicional, ou seja, apresentado de maneira compreensível e útil para o ser humano (7).

Informática: técnica de memorização artificial dos dados, por meio de impulsos eletromagnéticos, que permite o confronto, a análise e a agregação dos dados assim registrados, bem como sua decifração e comunicação visual impressa ou sobre uma tela (12). 
Informático: adjetivo empregado para qualificar as diversas realidades que se utilizam das novas tecnologias. Usado no texto com o mesmo significado de eletrônico e digital (13 e 195).

Internet: conjunto de redes, os meios de transmissão e comutação, roteadores, equipamentos e protocolos necessários à comunicação entre computadores, bem como o software e os dados contidos nestes computadores (20).

Novas tecnologias: conjunto de técnicas que compreende a informática e a telemática (16).

Portal: espécie de sítio na internet que serve como ponto central de acesso para outros sítios (250).

Programa de computador: o mesmo que software.

Sítio: página da internet presente em um servidor, acessível de modo unívoco por meio de um endereço (250).

Sociedade da informação: sociedade caracterizada pelo crescimento exponencial das novas formas de comunicação e a necessidade de troca de informação entre os cidadãos, os operadores econômicos e o Estado (36).

Software: conjunto de instruções dadas aos equipamentos informáticos para o processamento de informações (941).

Suporte: base física na qual são registrados dados ou informações (12).

Tecnologia da informação: a área de conhecimento voltada ao estudo da informática e da telemática (103).

Telemática: técnica de comunicação a distância entre equipamentos informáticos, por meio da transmissão de dados entre eles (16). 


\section{BIBLIOGRAFIA}

AgirReaZKuenaga, Iñaki, Chinchilla, Carmen, El uso de medios electrónicos, informáticos y telemáticos en el ámbito de las Administraciones Públicas, in Revista Española de Derecho Administrativo, n. 109, Madrid, Civitas, jan.-mar. 2001, pp. 35-59.

AIBAR PUENTES, Eduard, Gobernanza electrónica: innovación tecnológica y cambio organizativo en las burocracias públicas, in FABRA VALLs, Modesto, BLASCo DíAZ, José Luis (org.), La administración electrónica en España: experiencias y perspectivas de futuro, Castelló de la Plana, Universitat Jaume I, 2007, pp. 17-42.

Alamillo Domingo, Ignacio, Urios Aparisi, F. Xavier, La actuación administrativa automatizada en el ámbito de las administraciones públicas, Barcelona, Escola d'Aministració Pública de Catalunya, 2011.

Alamillo Domingo, Ignacio; Urios APARISI, Xavier; HeNao Hoyos, Erika; La identidad y la firma electrónica en la participación electrónica, in SÁNCHEZ SÁNCHEZ, Zulima (coord.), Nuevas Tecnologías, Administración y Participación Ciudadana, Granada, Comares, 2010, pp. 76-94.

ÁlAmo GonZÁlEZ, Nayra, La utilización de las nuevas tecnologías en las relaciones entre las Administraciones Públicas y los ciudadanos, in Revista Española de Derecho Administrativo, n. 133, Madrid, Civitas, jan-mar. 2007, pp. 89-128.

Alli Aranguren, Juan-Cruz, Marco social y legal de referencia, in Aldi Aranguren, Juan-Cruz, ENÉRIZ OlAECHEA, Francisco Javier (org.), La administración eletrónica en la Administración de la Comunidad Foral de Navarra. Comentarios a la Lei Foral 11/2007, de 4 de abril, Pamplona, Gobierno de Navarra, 2008, pp. 31-126.

AlmeIDA, André de, Aspectos jurídicos do e-government no Brasil, in FERRER, Florencia, SANTOS, Paula, E-government: o governo eletrônico no Brasil, São Paulo, Saraiva, 2004, pp. 50-54.

AlMEIDA, Fernando Dias Menezes de, Atos administrativos normativos: algumas questões, in MedauAR, Odete, Schirato, Vitor Rhein, Os caminhos do ato administrativo, São Paulo, RT, 2011, pp. 219-236.

Amaral, Antônio Carlos Cintra do, O princípio da eficiência do direito administrativo, in Licitações e contratos administrativos: uma visão atual à luz dos Tribunais de Contas, 1 . $^{\text {a }}$ ed., 5. ${ }^{a}$ reimpressão, Curitiba, Juruá, 2010, pp. 213-219.

, Teoria do ato administrativo, Belo Horizonte, Fórum, 2008.

ARENA, Gregorio, E-government y nuevos modelos de administración, in Revista de Administración Pública, n. 163, Madrid, Centro de Estudios Políticos y Constitucionales, jan.abr. 2004, pp. 413-430. 
Asís Roig, Agustín de, Documento electrónico en la Administración Pública, in GallarDO ORTIZ, Miguel Ángel (org.), Ámbito Jurídico de las tecnologías de la información, Madrid, Consejo General del Poder Judicial, 1996, pp. 137-189.

BAL, Aminata, Quelques réflexions sur l'administration électronique, in Lex Electronica, vol. 10, n. 1, 2005, disponível em http://www.lex-electronica.org/articles/v10-1/bal.htm, acesso em 19.10.2010.

BAPTISTA, Luiz Olavo, Direito e informática: reflexões sobre novas fronteiras, in Revista de Direito Publico, n. 86, São Paulo, RT, abr.-jun. 1988, pp. 159-163.

BAQUIAST, Jean-Paul, Internet et les administrations: la grande mutation, Paris, BergerLevrault, 1999.

BARNÉS VÁZQUEZ, Javier, El procedimiento administrativo y el gobierno electrónico, in Cuadernos de Derecho Local, n. 22, Madrid, Fundación Democracia y Gobierno Local, fev. 2010, pp. 83-95.

, Procedimientos administrativos y nuevos modelos de gobierno. Algunas consecuencias sobre la transparencia, in GARCíA MACHO, Ricardo, Derecho administrativo de la información y administración transparente, Madrid, Marcial Pons, 2010, pp. 4979.

Reforma e innovación del procedimiento administrativo, in VVAA, La Transformación del Procedimiento Administrativo, Sevilla, Global Law Press - Editorial Derecho Global, 2006, pp. 15-69.

, Sobre el derecho administrativo de la información, in Revista Catalana de Drét Públic, n. 35, Barcelona, Escola de Administració Pública de Catalunya, nov. 2007, pp. 121-160.

, Sobre el procedimiento administrativo: evolución y perspectivas, in VVAA, Innovación y reforma en el Derecho Administrativo, Global Law Press - Editorial Derecho Global, Sevilla, 2006, pp. 263-341.

, Una reflexión introductoria sobre el Derecho Administrativo y la Administración Pública de la Sociedad de la Información y del Conocimiento, in Revista Andaluza de Administración Pública, n. 40, Sevilla, Instituto Andaluz de Administración Pública, out.-dez. 2000, pp. 25-76.

BauzÁ Martorell, Felio José, Procedimiento Administrativo Electrónico, Granada, Comares, 2002.

Régimen jurídico de los registros telemáticos, in Revista Española de Derecho Administrativo, n. 118, Madrid, Civitas, abr-jun. 2003, pp. 181-199.

Beauvais, François, SchnäBele, Philippe, Réforme de l'Etat et téléprocédures, in Actualité juridique - Droit administratif, v. 57, n. 7-8, 2001, pp. 608-616.

Beloulou, Véronique, Les téléprocédures: un enjeu essentiel pour les citoyens et pour l'Etat, in Actualité Juridique - Droit Administratif, n. 7, 2001, pp. 624-627. 
BENYEKHLEF, Karim, L'administration publique en ligne au Canada: précisions terminologiques et état de la réflexion, in Revue française d'administration publique, n. 110, Paris, ENA, 2004, pp. 267-278.

BERNADÍ GIL, Xavier, Derecho Público y Administración Electrónica: una visión panorámica, in Nuevas Políticas Públicas - Anuario multidisciplinar para la modernización de las Administraciones Públicas, Sevilla, Instituto Andaluz de Administración Pública, n. 1, 2005, pp. 211-241.

BIGLIASSI, Renato, Governo eletrônico e teoria dos serviços públicos, in PEREIRA, Cláudia Fernanda de Oliveira, $O$ novo direito administrativo brasileiro: o Estado, as agências e o terceiro setor, Belo Horizonte, Fórum, 2003, pp. 223-248.

BINENBojM, Gustavo, O princípio da publicidade administrativa e a eficácia da divulgação de atos do poder público pela internet, in Revista Brasileira de Direito Público RBDP, n. 13, Belo Horizonte, Fórum, abr.-jun. 2006, pp. 89-111.

BLASCo Díaz, José Luis, Los derechos de los ciudadanos en su relación electrónica con la Administración, in Revista Española de Derecho Administrativo, n. 136, Madrid, Civitas, out-dez. 2007, pp. 791-821.

Bombardelli, Marco, Informatica pubblica, e-government e sviluppo sostenible, in Rivista italiana di diritto pubblico comunitario, Milano, Giuffrè, 2002, pp. 991-1028.

Borruso, Renato, Prefazione, in Contaldo, Alfonso, Gorga, Michele, E-law - Le professioni legali, la digitalizzazione delle informazioni giuridiche e il processo telematico, Soveria Mannelli, Rubbettino, 2006, pp. 5-9.

Bovens, Mark, ZouRIDIS, Stavros, From Street-Level to System-Level Bureaucracies: How Information and Communication Technology is Transforming Administrative Discretion and Constitutional Control, in Public Administration Review, v. 62, n. 2, mar.-abr. 2002, pp. 174-184.

Braibant, Guy, Données personnelles et société de l'information: rapport au Premier ministre sur la transposition en droit français de la directive numéro 95-46, Paris, La Documentation française, 1998, disponível em: http://lesrapports.ladocumentationfrancaise.fr/cgibin/brp/telestats.cgi?brp_ref=984000836\&brp_file=0000.pdf, acesso em 30.12.2010.

BRAIBANT, Guy, Introduction, in VVAA, L'informatique dans l'administration, Paris, Cujas, 1969, pp. 5-14.

BRASIL, Guia Livre. Referência de Migração para Software Livre do Governo Federal, Brasília, 2005, disponível em www.governoeletronico.gov.br/anexos/E15 469GuiaLivre v099.pdf, acesso em 17.01.2011.

, Projetos do Programa de Governo Eletrônico Brasileiro, disponível em http://www.governoeletronico.gov.br/acoes-e-projetos, acesso em 10.05.2011.

Brousseau, Eric, Les trois défis de l'administration électronique, in CHATILlON, Georges, MARAIS, Bertrand du (org.), L'administration électronique au service des citoyens, Bruxelles, Bruylant, 2003, pp. 247-259.

BuOnOMO, Giovanni, Il nuovo processo telematico, Milano, Giuffrè, 2009. 
CAMARgo, Guilherme Bueno de, Governança Republicana como vetor para a interpretação das normas de direito financeiro, São Paulo, USP, 2010.

CAmmarata, Manlio, E-content e accesso: le libertà fondamentali nel Codice dell'amministrazione digitale, in Informatica e diritto, n. 1/2, Napoli, Edizioni Scientifiche Italiane, 2005, pp. 99-110.

CAMmarota, Giuseppe, L'erogazione on line di servizi pubblici burocratici, in Informatica e diritto, n. 2, Napoli, Edizioni Scientifiche Italiane, 2002, pp. 45-84.

, Servizi pubblici in rete e applicabilità dei principi classici del servizio pubblico, in Informatica e diritto, n. 1/2, Napoli, Edizioni Scientifiche Italiane, 2005, pp. 183196.

CANTERO, Anne, Des actes unilatéraux des comune dans le contexte électronique -Vers la dématérialisation des actes administratifs?, Aix-En-Provence, PUAM, 2002.

CARCEnac, Thierry, Pour une administration électronique citoyenne: contributions au débat, Paris, La Documentation française, 2001, disponível em: http://lesrapports.ladocumentationfrancaise.fr/cgi-

bin/brp/telestats.cgi?brp_ref=014000291\&brp_file=0000.pdf, acesso em 31.12.2010.

CARIDI, Gianfranco, Informatica giuridica e procedimenti amministrativi, Milano, Franco Angeli, 1983.

CARLONI, Enrico, I servizi in rete delle pubbliche amministrazioni, in MERLONI, Francesco, Introduzione all'e-government, Torino, G. Giappichelli, 2005, pp. 191-207.

Le difficoltà per una visione organica dell'e-government: il pluralismo amministrativo, in MERLONI, Francesco, Introduzione all'e-government, Torino, G. Giappichelli, 2005, pp. 35-55.

Carvalho Filho, José dos Santos, Manual de Direito Administrativo, 22a . ed., Rio de Janeiro, Lumen Juris, 2009.

CASTElls ARTeche, José Manuel, Aproximación a la problemática de la informática y administración pública, in Jornadas Internacionales sobre Informática y Administración Pública, Oñati, Instituto Vasco de Administración Pública, 1986, pp. 25-53.

La limitación informática, in MARTín RETORTILlo, Sebastián (org.), Estudios sobre la Constitución Española - Homenaje al Profesor Eduardo García de Enterría, Tomo II: De los Derechos y Deberes Fundamentales, Madrid, Civitas, 1991, pp. 907-941.

CAstells, Manuel, La sociedad red, trad. castellana de Carmen Martínez Gimeno y Jesús Alborés, $2^{a}$ ed., Madrid, Alianza Editorial, 2001.

Cavalcanti, Themístocles Brandão, Teoria dos atos administrativos, São Paulo, RT, 1973.

, Tratado de Direito Administrativo, vol. IV, São Paulo, Freitas Bastos, 1961.

Cerrillo i Martínez, Agustí, Administración electrónica, in Peguera Poch, Miquel (coord.), Derecho y nuevas tecnologías, Barcelona, UOC, 2005, pp. 231-286. 
, E-información: hacia una nueva regulación del acceso a la información, in IDP - Revista de Internet, Derecho y Política, n. 1, 2005, pp. 1-16, disponível em http://www.ouc.edu/idp/1/dt/esp/cerrillo.pdf, acesso em 27.08.10.

, La difusión de información pública en internet, in CERRILLO I MARTíNEZ, Agustí e oo., La administración y la información, Madrid, Marcial Pons, 2007, pp. 11-39.

, La información del sector público: del acceso a la reutilización, in CERRILlo i MARTínez, Agustí, Galán Galán, Alfredo (org.), La reutilización de la información del sector público, Granada, Comares, 2006, pp. 1-24.

La interoperabilidad y la protección de datos. La interconexión de los registros de protección de datos, in VVAA, La protección de datos en la Administración Electrónica, Pamplona, Aranzadi, 2009, pp. 23-58.

Cervantes SÁnchez-Rodrigo, Carlos Javier et al., Guía de la Ley General Tributaria, Valencia, Cisspraxis, 2004.

CHAHIN, Ali et al., e-gov.br: a próxima revolução brasileira: eficiência, qualidade e democracia: o governo eletrônico no Brasil e no mundo, São Paulo, Prentice Hall, 2004.

Chatillon, Georges, Administration électronique et services publics, in Actualité juridique - Droit administratif, n. 20, jul.-ago 2001, pp. 617-623.

, L'administration électronique, in Revue internationale de droit comparé, $\mathrm{n}$. 2, abr.-jun. 2006, pp. 673-725.

, in Chatillon, Georges, MARAis, Bertrand du (org.), L'administration électronique au service des citoyens, Bruxelles, Bruylant, 2003, pp. 7-10.

Chevallier, Jacques, L'État post-moderne, 2008, trad. port. de Marçal Justen Filho, $O$ Estado Pós-Moderno, Belo Horizonte, Fórum, 2009.

, La mise en ouvre de l'administration électronique, in CHATILlon, Georges, MARAIS, Bertrand du (org.), L'administration électronique au service des citoyens, Bruxelles, Bruylant, 2003, pp. 385-392.

Chissick, Michael, Harrington, Justin, E-Government: a Practical Guide to the Legal Issues, London, Sweet \& Maxwell, 2004.

CiAMPI, Isabella D'Elia, L'informatica e le banche dati, in CASSESE, Sabino (org.), Diritto amministrativo speciale, $t$. II, 2. $^{a}$ ed., Milano, Giuffrè, 2003, pp. 1625-1701.

Coelho, Fábio Ulhoa, Títulos de crédito eletrônicos, in Revista do Advogado, n. 96, São Paulo, AASP, mar. 2008, pp. 41-47.

COMEAU, Paul. A., Les enjeux socio-politiques de la mise en place de l'autoroute de l'information, in Revue française d'administration publique, n. 81, Paris, ENA, jan.-mar. 1997, pp. 71-75.

Contaldo, Alfonso, Gorga, Michele, E-law - Le professioni legali, la digitalizzazione delle informazioni giuridiche e il processo telematico, Soveria Mannelli, Rubbettino, 2006. 
CORRÊA, Davi Beltrão de Rossiter, Processo administrativo eletrônico, in Jus Navigandi, Teresina, ano 16, n.2850, 21.abr. 2011, disponível em http://jus.uol.com.br/revista/texto/18959, acesso em 03.05.2011.

Cotino Hueso, Lorenzo, Derechos del ciudadano administrado e igualdad ante la implantación de la Administración electrónica, in Revista Vasca de Administración Pública, Oñati, Instituto Vasco de Administración Pública, n. 68, jan-abr. 2004, pp. 125-154.

, Derechos del ciudadano, in GAMERo CASADO, Eduardo, VALERo TORRIJOS, Julián (coord.), Comentarios a la Ley de Administración electrónica - Ley 11/2007, de 22 de junio, de acceso electrónico de los ciudadanos a los servicios públicos, 1. a ed., 2. imp., Cizur Menor (Navarra), Thomson-Civitas, 2009, pp. 117-233.

CRESPO RodríGuez, Miguel, Firma Electrónica y Administración Electrónica, in MATEU DE Ros, Rafael, LóPEZ-Monís GALLEGo, Mónima, Derecho de Internet: La Ley de Servicios de la Sociedad de la Información y de Comercio Electrónico, Cizur Menor, Aranzadi, 2003, pp. 703-726.

Culbertson, Stuart, Building E-government: Organisational and Cultural Change in Public Administration, in OLIVER, E. Lynn, SANDERS, Larry (ed.), E-Government Reconsidered: Renewal of Governance for the Knowledge Age, Regina, Canadian Plains Research Center, 2004, pp. 59-75.

Curtin, Gregory G., SOMmer, Michael H., VIS-SOMmER, Veronika, The world of egovernment, New York, Haworth Press, 2003.

Dallari, Adilson Abreu, Ferraz, Sérgio, Processo administrativo, 1. ${ }^{\mathrm{a}}$ ed., 3. ${ }^{\mathrm{a}}$ tir., São Paulo, Malheiros, 2003.

DAVARA RodríGUEZ, Miguel Ángel, El documento electrónico en la vigente ley de régimen jurídico de las administraciones públicas y del procedimiento administrativo común, in Revista de Administración Pública, n. 131, Madrid, Centro de Estudios Políticos y Constitucionales, mai.-ago. 1993, pp. 455-491.

DE LUCA, Flavio, Informatica e pubblica amministrazione (sputi di indagine), in Il diritto delle radiodiffusioni e delle telecomunicazioni, n. 2, Roma, RAI, mai.-ago. 1980, pp. 295 316, disponível em http://www.flaviodeluca.net/dettarticolo.php?idx=15\&dt=1827\&stqry $=0 \& a n=1980$, acesso em 15.12.2010.

De Roy, David, De Terwangne, Cécile, Poullet, Yves, La Convention européenne des droits de l'homme en filigrane de l'administration électronique, in Entre ombres et lumières: cinquante ans d'application de la Convention Européenne des Droits de l'Homme en belgique, Bruyllant, Bruxelles, 2008, pp. 283-357.

De Terwangne, Cécile, Lobet-Maris, Claire, Poullet, Yves, L'e-gouvernement: aux armes, citoyens?, in Revue Louvain, n. 166, dez. 2006 - jan. 2007, pp. 22-24. 
Delgado García, Ana Maria, Oliver Cuello, Rafael, La actuación administrativa automatizada. Algunas experiencias en el ámbito tributario, in Revista Catalana de Drét Públic, n. 35, Barcelona, Escola de Administració Pública de Catalunya, nov. 2007, disponível

em

http://www10.gencat.net/eapc_revistadret/recursos_interes/Notes/NOTA_35_DelgadoOliver.pdf acesso em 12.10.2010.

DelPiAzzo, Carlos E., Las nuevas telecomunicaciones y el tránsito de la administración prestacional a la administración electrónica, in Anuario da Facultade de Dereito da Universidade de A Coruña, n. 11, A Coruña, Universidade da Coruña, 2007, pp. 177-200.

DENTE, Bruno, Informatica e pubblica amministrazione, in Amministrare, n. 38, Milano, Giuffrè, 1972, pp. 83-105.

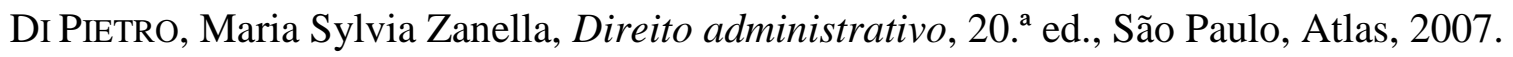

DieTrich, Daniel et al., The Open Data Manual, Cambridge, Open Knowledge Foundation, 2010, trad. e adapt. brasileira de Comunidade Transparência Hacker, Manual dos dados abertos: governo, São Paulo, W3C - Escritório Brasil, disponível em http://www.w3c.br/pub/Materiais/PublicacoesW3C/Manual_Dados_Abertos_WEB.pdf, acesso em 20.07.2011.

DomíngueZ LuIS, José Antonio, El derecho de información administrativa: información documentada y transparencia administrativa, in Revista Española de Derecho Administrativo, n. 88, Madrid, Civitas, out.-dez. 1995, pp. 537-563.

, La explosión informática, el Derecho y la Administración, in Revista de la Facultad de Derecho de la Universidad Complutense, n. 86, Madrid, Universidad Complutense, 1996, pp. 115-176.

Donati, Daniele, Digital divide e promozione della diffusione delle ICT, in MERLONI, Francesco, Introduzione all'e-government, Torino, G. Giappichelli, 2005, pp. 209-235.

DUNI, Giovanni, Ancora sul procedimento amministrativo telematico: le ultime ricerche, in Quaderni del DAE - Rivista di Diritto Amministrativo Elettronico, jul. 2004, disponível em http://www.cesda.it/quadernidae/pdf/Duni_DAE2004.pdf, acesso em 08.12.2010.

, I "viaggi telematici" dell'atto informatico. Note sul procedimento informatico., in Quaderni del DAE - Rivista di Diritto Amministrativo Elettronico, jul. 2003, disponível em http://www.cesda.it/quadernidae/index.php, acesso em 08.12.2010.

, La teleamministrazione come terza fase dell'informatica amministrativa, in DUNI, Giovanni (org.), Dall'informatica amministrativa alla teleamministrazione, Roma, Istituto Poligrafico dello Stato, 1992, disponível em http://spol.unica.it/teleamm/italiano/pubblicazioni/dallin-sezione1.htm\#duni, acesso em 08.12.2010.

, L'amministrazione digitale - il diritto amministrativo nella evoluzione telematica, Milano, Giuffrè, 2007. 
L'utilizzabilità delle tecniche elettroniche nell'emanazione degli atti e nei procedimenti amministrativi. Spunto per una teoria dell'atto amministrativo emanato nella forma elettronica, in Rivista Amministrativa della Repubblica Italiana, Vol. CXXIX, fasc. 6, jun. 1978, Di Castello, Tappini, 1978, disponível em http://spol.unica.it/teleamm/italiano/1978/luti.htm, acesso em 25.10.2010.

, Teleamministrazione, in Enciclopedia Giuridica Treccani, Roma, Istituto

della Enciclopedia Italiana, 1993, disponível em http://spol.unica.it/teleamm/italiano/pubblicazioni/telea.htm, acesso em 07.12.2010.

, Verso un'amministrazione integrata dei procedimenti amministrativi, in Informatica e diritto, n. 1/2, Napoli, Edizioni Scientifiche Italiane, 2005, pp. 43-47.

ESPANHA, Lei 11/2007 - Exposición de motivos, in Boletin Oficial del Estado, 23.07.2007, pp. 27150-27166, disponível em http://www.boe.es/boe/dias/2007/06/23/pdfs/A2715027166.pdf, acesso em 20.05.2011.

EzZ, Inas E., E-government Emerging Trends: Organization Challenges, in ANTTIROIKO, Ari-Veikko, Electronic government: concepts, methodologies, tools and applications, Hershey/New York, Information Science Reference, 2008, pp. 3721-3737.

FABRA VALls, Modesto, Blasco Díaz, José Luis, Introducción, in FABRA VALLS, Modesto, BLASCO DÍAZ, José Luis (org.), La administración electrónica en España: experiencias y perspectivas de futuro, Castelló de la Plana, Universitat Jaume I, 2007, pp. 13-15.

FANTIGROSSI, Umberto, Automazione e pubblica amministrazione: profili Giuridici, Bologna, Il Mulino, 1993.

FARIA, Edimur Ferreira de, Curso de Direito Administrativo Positivo, $6^{\mathrm{a}}$ ed., Belo Horizonte, Del Rey, 2007.

Fernandes, Ciro Campos Christo, Governo eletrônico e transformação da administração pública, in CHAHIN, Ali et al., e-gov.br: a próxima revolução brasileira: eficiência, qualidade e democracia: o governo eletrônico no Brasil e no mundo, São Paulo, Prentice Hall, 2004, pp. 102-108.

FERNÁNDEZ SALMERÓN, Manuel, El acceso a los registros y archivos administrativos: perspectiva telemática de un Derecho contemporáneo, in DAVARA RODRÍGUEZ, Miguel Ángel (coord.), Quince años de encuentros sobre informática y derecho (1987-2002), tomo II, Madrid, Universidad Pontificia Comillas, 2002, pp. 613-625.

, La protección de los datos personales en las administraciones públicas, Madrid, Thomson-Civitas, 2003.

Fernández Salmerón, Manuel, Parra SÁez, Samuel, Valero TorriJos, Julián, Crónica del año 2009, in Revista Española de Protección de Datos, n. 6, Madrid, Agencia de Protección de Datos de la Comunidad de Madrid - Civitas, jan.-jun./2009, p. 139-178. 
Fernández SAlmerón, Manuel, VAlero TORRIJOS, Julián, La difusión de información administrativa en Internet y la protección de los datos personales: análisis de un proceso de armonización jurídica, in Nuevas Políticas Públicas: Anuario multidisciplinar para la modernización de las Administraciones Públicas, n. 1, Sevilla, Instituto Andaluz de Administración Pública, 2005, pp. 307-342, disponível em http://www.juntadeandalucia.es/institutodeadministracionpublica/servlet/descarga?up=165 $\underline{14}$, acesso em 24.10.2010.

La publicidad de la información administrativa en internet: implicaciones para el derecho a la protección de los datos personales, in Revista Aragonesa de Administración Pública, n. 26, Zaragoza, Instituto Aragonés de Administración Pública, jun. 2005, pp. 77-125.

, Protección de datos personales y Administración electrónica, in Revista Española de Protección de Datos, n. 1, Madrid, Agencia de Protección de Datos de la Comunidad de Madrid - Civitas, jul.-dez./2006, p. 115-141.

FERraZ Júnior, Tercio Sampaio, MARAnhão, Juliano de Souza Albuquerque, Software livre: a Administração Pública e a comunhão do conhecimento informático, in Revista de Direito Público da Economia - RDPE, n. 11, pp. 173-208.

FERrer, Florência, SANTOS, Paula, Introdução, in FERRER, Florência, SANTOS, Paula (org.), E-government: o governo eletrônico no Brasil (São Paulo, Saraiva, 2004, pp. XII-XIX.

Figueiredo, Lúcia Valle, Curso de Direito Administrativo, 9a. ed., São Paulo, Malheiros, 2007.

FILGUEIRAS JÚNIOR, Marcus Vinicius, A informática como opção jurídica vinculada da Administração Pública, in Boletim de Direito Administrativo, v. 21, n. 2, São Paulo, NDJ, fev. 2005, pp. 191-7.

, Ato administrativo eletrônico e teleadministração. Perspectivas de investigação, in Revista de Direito Administrativo, n. 237, jul. /set. 2004,

, L'atto amministrativo elettronico in Brasile, in Quaderni del DAE - Rivista

di Diritto Amministrativo Elettronico, jul. 2004, disponível em http://www.cesda.it/quadernidae/index.php, acesso em 15.12.2010.

FINOCCHIARO, Giusella, Informatica e pubblica amministrazione, Bologna, CLUEB, 1991.

FORSTHOFF, Ernst, Rechtsfragen der leistenden Verwaltung, 1959, Der Staat als Auftraggeber, 1963, trad. esp. de Celestino Fernández de la Vega, Sociedad industrial y Administración Pública, Madrid, Escuela Nacional de Administración Pública, 1967.

FouILLEUL, Nicolas, Le contrat administratif electronique - L'exemple des marchés publics, Aix-En-Provence, PUAM, 2007.

FountAIN, Jane E., Building the virtual state: information technology and institutional change, Washington, Brookings, 2001.

FrosinI, Vittorio, Cibernetica diritto e società, $3^{\mathrm{a}}$. ed., Milano, Edizioni di Comunità, 1977. 
Informática y Administración Pública, in Revista de Administración Pública, n. 105, Madrid, Centro de Estudios Políticos y Constitucionales, set.-dez. 1984, pp. 447-458.

, Telematica e informatica giuridica, in Enciclopedia del Diritto, XLIV, Milano, Giuffrè, 1992, pp. 60-81.

GAMERO CASADO, Eduardo, El derecho administrativo ante la era de la información, in GAmero CASAdo, Eduardo, VAlero TORRIJOS, Julián (coord.), Comentarios a la Ley de Administración electrónica - Ley 11/2007, de 22 de junio, de acceso electrónico de los ciudadanos a los servicios públicos, 1. ${ }^{\mathrm{a}}$ ed., 2. ${ }^{\mathrm{a}}$ imp., Cizur Menor (Navarra), ThomsonCivitas, 2009, pp. 29-56.

Interoperabilidad y administración electrónica: conéctense, por favor, in Revista de Administración Pública, n. 179, Madrid, Centro de Estudios Políticos y Constitucionales, mai.-ago. 2009, pp. 291-332.

, Objeto, ámbito de aplicación y principios generales de la ley de administración electrónica; su posición en el sistema de fuentes, in GAMERO CASADO, Eduardo, VALERO TORRIJOS, Julián (coord.), Comentarios a la Ley de Administración electrónica Ley 11/2007, de 22 de junio, de acceso electrónico de los ciudadanos a los servicios públi$\cos , 1$. $^{\mathrm{a}}$ ed., 2. ${ }^{\mathrm{a}}$ imp., Cizur Menor (Navarra), Thomson-Civitas, 2009, pp. 57-115.

, Objeto y ámbito de aplicación de la Lei 11/07, in VVAA, La protección de datos en la Administración Electrónica, Pamplona, Aranzadi, 2009, pp. 109-145.

GARCÍA DE ENTERRÍA, Eduardo, Constitucionalización definitiva de las medidas cautelares contencioso-administrativas y ampliación de su campo de aplicación (medidas positivas), $y$ "jurisdicción plenaria" de los Tribunales contencioso-administrativos, no limitada al efecto revisor de actos previos. Dos sentencias constitucionales, in Revista Española de Derecho Administrativo, n. 109, Madrid, Civitas, jul.-set. 1993, pp. 475-490.

García MaChO, Ricardo, Procedimiento Administrativo y sociedad de la información y del conocimiento, in VVAA, La Transformación del Procedimiento Administrativo, Sevi1la, Global Law Press - Editorial Derecho Global, 2006, pp. 183-229.

GARCÍA MARCO, Francisco Javier, Administración electrónica: el acceso electrónico de los ciudadanos a los servicios públicos, in GALINDO AYUDA, Fernando, Rover, Aires José (coord.), Derecho, gobernanza y tecnologías de la información en la sociedad del conocimiento, Zaragoza, Prensas Universitarias de Zaragoza, 2009, pp. 167-191.

, Ontologías y documentación electrónica en las actividades públicas, in GALINDO AYUDA, Fernando (org.), Gobierno, derecho y tecnología: las actividades de los poderes públicos, Cizur Menor (Navarra), Thomson-Civitas, 2006, pp. 174-225.

GARCíA MeXíA, Pablo, El Derecho de Internet y sus implicaciones para la Administración, in Documentación Administrativa, n. 265-266, Madrid, Escuela Nacional de Administración Pública, jan-ago. 2003, pp. 85-114.

García-Poggio, Paz, Hacia una nueva Administración pública en la sociedad de la información, in Actualidad Informática Aranzadi, n. 32, Navarra, Aranzadi, 1999, pp. 8-12. 
GARDINI, Gianluca, Le regole dell'informazione: principi giuridici, strumenti, casi, Milano, Bruno Mondadori, 2005.

GAROT, Marie José, De la administración electrónica a uma democracia digital, in Revista Direito GV, v. 2, n. 1, São Paulo, FGV, jan-jun. 2006, pp. 89-110.

GaSPARINI, Diógenes, Direito administrativo, 5. a ed., São Paulo, Saraiva, 2000.

GIANESI, Irineu G. N., CORRÊA, Henrique Luiz, Administração estratégica de serviços, São Paulo, Atlas, 1994.

GIBBINS, Roger, Federalism and the Challenge of Electronic Portals, in OLIVER, E. Lynn, SANDERS, Larry (ed.), E-Government Reconsidered: Renewal of Governance for the Knowledge Age, Regina, Canadian Plains Research Center, 2004, pp. 33-42.

GILLI, Jean-Paul, Informatique et administration, in VVAA, L'informatique dans l'administration, Paris, Cujas, 1969, pp. 99-109.

GiURdanella, Carmelo, GuARnACCIA, Elio, Elementi di diritto amministrativo elettronico, Matelica, Halley, 2005.

GóMEZ PUENTE, Marcos, La administración electrónica, in VVAA, La autorización administrativa. La administración electrónica. La enseñanza del derecho administrativo hoy. Actas del I Congreso de la Asociación Española de Profesores de Derecho Administrativo, Pamplona, Aranzadi, 2007, pp. 93-191.

GonzÁlez Bustos, María de los Ángeles, Derecho a la información del ciudadano y las nuevas tecnologías, in SÁNCHEZ SÁNCHEZ, Zulima (coord.), Nuevas Tecnologías, Administración y Participación Ciudadana, Granada, Comares, 2010, pp. 9-29.

González Navarro, Francisco, Cincuenta años de procedimiento administrativo en un mundo cambiante, Madrid, Iustel, 2009.

Gordillo, Agustín, Tratado de Derecho Administrativo, t. 4, 8ª ed., Buenos Aires, Fundación de Derecho Administrativo, 2004.

GRISTI, Éric, La réforme de l'État, Paris, Vuibert, 2007.

Gross, Thomas, E-Government: Influences on Procedure and Organisation of Public Administration, in Flogaitis, S., KARPEN, U., MASUCCI, A. (eds.), E-Government and EDemocracy, London, Esperia, 2006, pp. 65-79.

GUARNACCIA, Elio, Evoluzione del ruolo della firma digitale nel dialogo tra cittadino e P.A., in Quaderni del DAE - Rivista di Diritto Amministrativo Elettronico, jul. 2004, disponível em http://www.cesda.it/quadernidae/index.php, acesso em 15.12.2010.

GUERrA, Maria Paola, Archivi delle pubbliche amministrazioni e gestione informatica dei documenti, in ARENA, Gregorio et al., La documentazione amministrativa: Certezze, semplificazione e informatizzazione nel d. P.R. 28 dicembre 2000, n. 445, Rimini, Maggioli, 2001, pp. 231-303. 
, Circolazione dell'informazione e sistema informativo pubblico. Profili giuridici dell'accesso interamministrativo telematico, in Diritto Pubblico, n. 2, 2005, pp. 525572.

GuILlÉN CARAMÉs, Javier, La administración electrónica, in GARCíA MeXíA, Pablo, Principios de derecho de internet, $2^{\mathrm{a}}$. ed., Valencia, Tirant lo Blanch, 2005, pp. 247-291.

GuILlou, Yves-René, Le régime juridique de la dématérialisation, in LAJOIE, Thierry, HISLAIRE, Loïc, Les marches publics dématérialisés, Paris, Moniteur, 2004, pp. 39-60.

Heredero Higueras, Manuel, Problemas Jurídicos de la mecanización administrativa, in Documentación Administrativa, n. 124, Madrid, Escuela Nacional de Administración Pública, jul.-ago. 1968, pp. 71-84.

HISLAIRE, Loïc, Le contexte de la dématérialisation, in LAJOIE, Thierry, HISLAIRE, Loïc, Les marches publics dématérialisés, Paris, Moniteur, 2004, pp. 23-38.

HoEsCHL, Hugo César, O que é governo eletrônico?, in KAMINSKI, Omar (org.), Internet legal: O direito na tecnologia da informação, Curitiba, Juruá, 2003, pp. 199-201.

Holmes, Douglas, E-gov, an E-business plan for government, London, Nicholas Brealey, 2001.

IASELLI, Michele, La pubblica amministrazione digitale, Napoli, Simone, 2009.

JACQUE, Jean Paul, Droit administratif et informatique, in VVAA, L'emergence du droit de l'informatique - Université de Paris X Nanterre, Paris, Ed. des Parques, 1983.

JINESTA LOBO, Ernesto, Administraciones públicas electrónicas: retos y desafíos para su regulación, in Ivstitia, n. 261-262, São José, Vip Tax, set.-out. 2008, pp. 4-16, disponível em www.ernestojinesta.com/ADMINISTRACIONES_PUBLICAS.pdf, acesso em 22.10.2010.

Joly-PASSANT, Elisabeth, L'écrit confronte aux nouvelles technologies, Paris, LGDJ, 2006.

Justen FILHo, Marçal, Curso de direito administrativo, $7^{\mathrm{a}}$. ed., Belo Horizonte, Fórum, 2011.

Pregão: comentários à legislação do pregão comum e eletrônico, 5. ${ }^{\mathrm{a}} \mathrm{ed}$., São Paulo, Dialética, 2009.

KLUTH, Winfried, NUCKET, Jana, La legislación de procedimiento administrativo y la generación de conocimiento en el ámbito de la administración pública, in VVAA, La Transformación del Procedimiento Administrativo, Sevilla, Global Law Press - Editorial Derecho Global, 2006, pp. 183-229.

La Coste, Pierre de, BenARd, Vincent, L'Hyper-République: bâtir l'administration en réseau autour du citoyen, Paris, Ministère de la fonction publique, de la réforme de l'Etat et de l'aménagement du territoire, 2003, disponível em: http://lesrapports.ladocumentationfrancaise.fr/cgibin/brp/telestats.cgi?brp_ref $=034000010 \&$ brp_file $=0000$.pdf 
LAUDON, Kenneth C., LAUDON, Jane P., Essentials of management information systems, 5 a $^{\mathrm{a}}$ ed., 2004, trad. port. de Arlete Simille Marques, revisão técnica de Érico Veras Marques e Belmiro João, Sistemas de informação gerenciais: administrando a empresa digital, 3. ${ }^{\text {a }}$ reimpressão, São Paulo, Pearson Prentice Hall, 2006.

LEMAITRE, Marie-Françoise, Téléprocédure administrative: le pari de la confiance, in Actualité juridique - Droit administratif, n.20, jul.-ago. 2001, pp. 628-633.

LENK, Klaus, TRAUnMÜLlER, Roland, Broadening the Concept of Electronic Government, in PRINS, J.E.J. (ed.), Designing e-Government: On the Crossroads of Technological Innovation and Institutional Change, The Hague, Kluwer Law International, 2001, pp. 63-74.

LIMBERGER, Têmis, Transparência administrativa e novas tecnologias: o dever de publicidade, o direito a ser informado e o princípio democrático, in Revista de Direito Administrativo, Rio de Janeiro, FGV-Atlas, jan. abr. 2007, pp. 248-263.

LiNARES GIL, Maximino Ignacio, Identificación y autenticación de las administraciones públicas, in GAMERO CASAdO, Eduardo, VALERO TORRIJOS, Julián (coord.), Comentarios a la Ley de Administración electrónica - Ley 11/2007, de 22 de junio, de acceso electrónico de los ciudadanos a los servicios públicos, 1. ${ }^{\mathrm{a}}$ ed., 2. ${ }^{\mathrm{a}}$ imp., Cizur Menor (Navarra), Thomson-Civitas, 2009, pp. 281-316.

, Modificaciones del Régimen Jurídico Administrativo derivadas del empleo masivo de nuevas tecnologías. En particular el caso de la Agencia Estatal de Administración Tributaria, in MATEu De Ros, Rafael, LóPEZ-Monís Gallego, Mónima, Derecho de Internet: La Ley de Servicios de la Sociedad de la Información y de Comercio Electrónico, Cizur Menor, Aranzadi, 2003, pp. 727-745.

LoSANO, Mario G., Informática Jurídica, São Paulo, Saraiva-EDUSP, 1976.

MaCHADO, Robson, Certificado Digital ICP Brasil: os caminhos do documento eletrônico no Brasil, Niterói, Impetus, 2010.

MagÁn Perales, José María Aristóteles, La nueva administración pública electrónica, las relaciones electrónicas entre la administración y el ciudadano. Especial referencia a la firma electrónica, in PUNZÓN MORALEDA, Jesús (coord.), Administraciones Públicas y nuevas tecnologías, Valladolid, Lex Nova, 2005, pp. 75-123.

MAISL, Herbert, De l'administration cloisonnée a l'administration en réseau : fin de la vie privée et/ou satisfaction de l'usager, in CHATILlON, Georges, MARAIS, Bertrand du (org.), L'administration électronique au service des citoyens, Bruxelles, Bruylant, 2003, pp. 349359.

Le citoyen «internaute», entre liberté d'accès aux documents administratifs et protection des données personnelles, in Revue française d'administration publique, $\mathrm{n}$. 81, Paris, ENA, jan.-mar. 1997, pp. 77-85.

Mandolfo, Giovanni, L'atto amministrativo elettronico, in CASSANO, Giuseppe, Diritto delle nuove tecnologie informatiche e dell'internet, Milano, Ipsoa, 2002, pp. 1299-1316.

MARANhão, Mauriti, MACIEIRA, Maria Elisa Bastos, O processo nosso de cada dia: modelagem de processos de trabalho, Rio de Janeiro, Qualitymark, 2004. 
MarCaCinI, Augusto Tavares Rosa, Certificação eletrônica, sem mitos nem mistérios, in Revista do Advogado, n. 69, São Paulo, AASP, mai. 2003.

MARCOU, Gérard, Le régime de l'acte administratif face à l'électronique, in CHATILLON, Georges, MARAIS, Bertrand du (org.), L'administration électronique au service des citoyens, Bruxelles, Bruylant, 2003, pp. 79-96.

MARONE, Umberto, L'informatica nella pubblica amministrazione, Napoli, EsselibriSimone, 1998.

MARONGIU, Daniele, Gli atti amministrativi ad elaborazione elettronica: la compilazione di un "pre-sofware in lingua italiana, in Quaderni del DAE - Rivista di Diritto Amministrativo Elettronico, jul. 2003, disponível em http://www.cesda.it/quadernidae/index.php, acesso em 08.12.2010.

, Il governo dell'informatica pubblica - Tra Stato, regioni ed enti locali, Napoli, Edizioni Scientifiche Italiane, 2007.

MARTín Delgado, Isaac, Identificación y autenticación de los ciudadanos, in GAMERO CASAdo, Eduardo, VAlero Torrijos, Julián (coord.), Comentarios a la Ley de Administración electrónica - Ley 11/2007, de 22 de junio, de acceso electrónico de los ciudadanos a los servicios públicos, 1. ${ }^{\mathrm{a}}$ ed., 2. ${ }^{\mathrm{a}}$ imp., Cizur Menor (Navarra), Thomson-Civitas, 2009, pp. 317-368.

La administración electrónica como problema actual para la investigación y la docencia en el derecho administrativo, in Revista Aragonesa de Administración Pública, Monográfico XI, Zaragoza, Instituto Aragonés de Administración Pública, 2009, pp. 355-375.

La administración electrónica como reto del derecho administrativo en el siglo XXI, in García Costa, Francisco Manuel, PARdo LóPEZ, María Magnolia, Retos del Derecho en el Siglo XXI, Valencia, Tirant lo Blanch, 2009, pp. 309-338.

La gestión electrónica del procedimiento administrativo, in Cuadernos de Derecho Local, n. 22, Madrid, Fundación Democracia y Gobierno Local, out. 2009, pp. 84-101.

, Los derechos de los ciudadanos ante la administración electrónica, in VVAA, La protección de datos en la Administración Electrónica, Pamplona, Aranzadi, 2009, pp. 147-175.

, Naturaleza, Concepto y Régimen Jurídico de la Actuación Administrativa Automatizada, in Revista de Administración Pública, n. 180, Madrid, Centro de Estudios Políticos y Constitucionales, set.-dez. 2009, pp. 353-386.

MARTínez DíEz, Roberto, El proceso de informatización de la Administración Pública Española, in Documentación Administrativa, n. 200, Madrid, Escuela Nacional de Administración Pública, jan.-mar. 1984, pp. 133-162.

Martínez Gutiérrez, Rubén, Administración Pública Electrónica, Cizur Menor (Navarra), Civitas Thomson Reuters, 2009. 
Instrumentos para el acceso de los ciudadanos a la administración electrónica, in GALINDO AYUdA, Fernando, Rover, Aires José (coord.), Derecho, gobernanza y tecnologías de la información en la sociedad del conocimiento, Zaragoza, Prensas Universitarias de Zaragoza, 2009, pp. 193-220.

, Nuevos derechos y nuevos retos del modelo de Administración electrónica, in Actualidad Jurídica Aranzadi, Navarra, Aranzadi, n. 786, 19.11.2009, pp. 1-6.

MARTINI, Renato, Tecnologia e cidadania digital: ensaio sobre tecnologia, sociedade e segurança, Rio de Janeiro, Brasport, 2008.

MARTINS, Ricardo Marcondes, Efeitos dos vícios do ato administrativo, São Paulo, Malheiros, 2008.

MARTOS GARCÍA, Juan Jesús, DNI electrónico: obligaciones jurídicas para el titular y límites constitucionales en el derecho fundamental a la intimidad y a la protección de datos, in Revista Aranzadi de Derecho y Nuevas Tecnologías, n. 9, Cizur Menor (Navarra), Aranzadi, set.-dez. 2003, pp. 91-107.

MASUCCI, Alfonso, Erogazione on line dei servizi pubblici e teleprocedure amministrative - disciplina giuridica e riflessi sull'azione amministrativa, in Diritto Pubblico, n. 3, Bologna, Il Mulino, 2003, pp. 991-1011.

, Il documento amministrativo informatico, Rimini, Maggioli, 2000.

, L'atto amministrativo informatico, Napoli, Jovene, 1993.

, Procedimento amministrativo e nuove tecnologie, Torino, G. Giappichelli,

2011.

Medauar, Odete, A Processualidade no Direito Administrativo, 2a . ed., São Paulo, RT, 2008.

, Administração Pública: do ato ao processo, in ARAGão, Alexandre Santos de, Marques Neto, Floriano de Azevedo (coord.), Direito administrativo e seus novos paradigmas, Belo Horizonte, Fórum, pp. 405-409.

, Ato administrativo: origem, concepções, abrangência, in MEDAUAR, Odete, SCHIRATO, Vitor Rhein, Os caminhos do ato administrativo, São Paulo, RT, 2011, pp. 1136.

, Direito administrativo moderno, 12a . ed., São Paulo, RT, 2008.

, O direito administrativo em evolução, 2. ${ }^{\text {a }}$ ed., São Paulo, RT, 1992.

MeIRELlES, Hely Lopes, Direito administrativo brasileiro, 22. a ed., São Paulo, Malheiros, 1997.

Mello, Celso Antonio Bandeira de, Ato administrativo e direitos dos administrados, São Paulo, RT, 1981.

, Curso de Direito Administrativo, 26ª ed., São Paulo, Malheiros, 2009. 
Mello, Oswaldo Aranha Bandeira de, Princípios gerais de direito administrativo, Vol. I: Introdução, $3^{\mathrm{a}}$. ed., São Paulo, Malheiros, 2007.

Menegale, J. Guimarães, Direito administrativo e ciência da administração, v. 2, Rio de Janeiro, Borsoi, 1950.

MENICHETTI, Enrico, Accesso alle informazioni pubbliche e trasparenza amministrativa, in Merloni, Francesco, Introduzione all'e-government, Torino, G. Giappichelli, 2005, pp. 127-151.

MERINO, Muriel, L'obligation d'informer dans l'action administrative, Aix-en-Provence, PUAM, 2006.

MERLONI, Francesco, La documentazione amministrativa digitalizzata. Aspetti giuridici, in MERLONI, Francesco, Introduzione all'e-government, Torino, G. Giappichelli, 2005, pp. 85-104.

, Le difficoltà per una visione organica dell'e-government: la dispersione normativa, in MERLONI, Francesco, Introduzione all'e-government, Torino, G. Giappichelli, 2005, pp. 17-33.

, Sviluppo dell'e-government e riforma delle amministrazioni, in MERLONI, Francesco, Introduzione all'e-government, Torino, G. Giappichelli, 2005, pp. 3-15.

Mestre Delgado, Juan Francisco, Nuevas tecnologías y Administración Pública, in Documentación Administrativa, n. 265-266, Madrid, Escuela Nacional de Administración Pública, jan.-ago. 2003, pp. 117-135.

Minerva, Massimiliano, L'atto amministrativo in forma elettronica e la sicurezza dei sistemi informativi pubblici, in Diritto dell'informazione e dell'informatica, n. 4-5, Milano, Giuffrè, 1999, pp. 939-954.

MistiCHELLI, Sara, L'informazione e la comunicazione pubblica, in MERLONI, Francesco, Introduzione all'e-government, Torino, G. Giappichelli, 2005, pp. 173-190.

Mitchinson, Tom, Ratner, Mark, Promoting Transparency Through the Electronic Dissemination of Information, in OLIVER, E. Lynn, SANDERS, Larry (ed.), E-Government Reconsidered: Renewal of Governance for the Knowledge Age, Regina, Canadian Plains Research Center, 2004, pp. 89-105.

Moreira Neto, Diogo de Figueiredo, Curso de Direito Administrativo, 15 a . ed., Rio de Janeiro, Forense, 2009.

MoreIRA, Egon Bockmann, Processo administrativo: princípios constitucionais e a Lei 9.784/1999, 2a . ed., São Paulo, Malheiros, 2003.

NATALini, Alessandro, La semplificazione e l'amministrazione digitale, in Giornale di diritto amministrativo, n.1, Milano, Ipsoa, 2008, p. 105-111.

NorA, Simon, Minc, Alain, L’informatisation de la societé, 1978, trad. port. de Luísa Ribeiro, A informatização da sociedade, Rio de Janeiro, FGV, 1980. 
Notarmuzi, Carlo, Il Codice dell'amministrazione digitale, disponível em http://www.astrid-online.it/E-governme/Codice-del/NOTARMUZI-Codice-Amm-Digitale.pdf, acesso em 07.12.2010.

O'BRIEN, James A., Introduction to information systems, 11. a ed., 2003, trad. port. de Célio Knipel Moreira e Cid Kneipel Moreira, Sistemas de informação e as decisões gerenciais na era da internet, 2. ${ }^{\text {a }}$ ed., São Paulo, Saraiva, 2004.

OBERDORFF, Henri, L'administration électronique ou l'e-administration, in Recherches et Prévisions, n. 86, Paris, CNAF, dez. 2006, pp. 9-18, disponível em: http://www.caf.fr/web/WebCnaf.nsf/090ba6646193ccc8c125684f005898f3/6d586507f49d d316c12572a300364de9/\$FILE/RP86-HOberdorff.pdf, acesso em 31.12.2010.

OCDE, E-government for better government, 2005, trad. esp. de Teodoro Sacristián, Egobierno para un major gobierno, Madrid, INAP, 2008.

OCHOA Monzó, Josep, Hacia la ciberadministración y el ciberprocedimiento?, in SosA WAGNER, Francisco, El derecho administrativo en el umbral del siglo XXI - Homenaje al Profesor Dr. D. Ramón Martín Mateo, Valencia, Tirant lo Blanch, 2000, pp. 151-171.

OchoA Monzó, Josep, MARTínez GutiéRrez, Rubén, La permeabilidad de la actividad administrativa al uso de tecnologías de la información y de la comunicación: hacia la administración electrónica y el procedimiento administrativo electrónico, FABRA VALLS, Modesto, BLASCO DíAZ, José Luis, La administración electrónica en España: experiencias y perspectivas de futuro, Castelló de la Plana, Universitat Jaume I, 2007, pp. 71-121.

Oliver, E. Lynn, SANDers, Larry, Introduction, in Oliver, E. Lynn, SANDERS, Larry (ed.), E-Government Reconsidered: Renewal of Governance for the Knowledge Age, Regina, Canadian Plains Research Center, 2004, pp. xii-xiv.

, The Regina Declaration - E-Government for the 21st Century, in Optimum

Online, v. 33, n. 2, jun.-2003, disponível em http://www.optimumonline.ca/archives.phtml?volume=33\&, acesso em 27.01.2011.

Olivo, Luis Carlos Cancellier de, Controle social em rede da Administração Pública virtual, in Rover, Aires José, Direito e Informática, Barueri, Manole, 2004, p. 155-189.

UFSC, 2000.

, Desafios do direito administrativo diante do Estado em rede, Florianópolis,

Oller RUBERT, Marta, La administración electrónica en Europa, FABRA VALLS, Modesto, Blasco DíAZ, José Luis, La administración electrónica en España: experiencias y perspectivas de futuro, Castelló de la Plana, Universitat Jaume I, 2007, pp. 43-70.

OrOFINO, Angelo Giuseppe, Forme elettroniche e procedimenti amministrativi, Bari, Cacucci, 2008.

Telematica ed azione amministrativa, in Quaderni del DAE - Rivista di Diritto Amministrativo Elettronico, jul. 2004, disponível em http://www.cesda.it/quadernidae/index.php, acesso em 15.12.2010. 
Ortega Álvarez, Luis, Nuevas Tecnologías y procedimiento administrativo, in Revista Jurídica de Castilla - La Mancha, n. 18, Toledo, Junta de Comunidades de Castilla-La Mancha, ago. 1993, pp. 211-217.

Palmirani, Monica, Prefazione, in Palmirani, Monica, Martoni, Michele, Il cittadino elettronico e l'identità digitale nell'e-governance, Bologna, Gedit, 2006, pp. 7-9.

Palomar Olmeda, Alberto, Administración electrónica y actuación jurisdiccional, in VVAA, La administración electrónica y el servicio a los ciudadanos: el Ministerio de Economía y Hacienda ante los retos de la Ley 11/2007, de Acceso Electrónico de los Ciudadanos a los Servicios Públicos, Madrid, Ministerio de Economía y Hacienda, Centro de Publicaciones, Fábrica Nacional de Moneda y Timbre-Real Casa de la Moneda, 2009, pp. 77-92.

, El acto administrativo dictado sobre bases tecnológicas, in Revista de Derecho y Nuevas Tecnologias, n. 7, Cizur Menor (Navarra), Thomson-Aranzadi, pp. 75-97.

, Gestión Electrónica de los procedimientos, in GAMERO CASADO, Eduardo, VALERO TORRIJOS, Julián (coord.), Comentarios a la Ley de Administración electrónica Ley 11/2007, de 22 de junio, de acceso electrónico de los ciudadanos a los servicios públi-

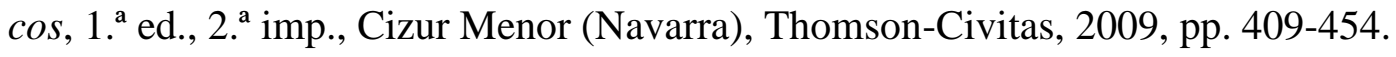

La utilización de las nuevas tecnologías en la actuación administrativa, in Revista Española de Derecho Administrativo, n. 87, Madrid, Civitas, jul.-set. 1995, pp. 361-384.

, Procedimientos administrativos y régimen documental en la actuación de la Agencia Española de Protección de Datos, in VVAA, La protección de datos en la Administración Electrónica. Pamplona, Aranzadi, 2009, pp. 59-107.

, Un paso más en la aplicación de la tecnología en el procedimiento administrativo: hacia un procedimiento administrativo común de base tecnológica, in Revista Aranzadi de Derecho y Nuevas Tecnologías, n. 3, Cizur Menor (Navarra), Aranzadi, set.dez. 2003, pp. 91-107.

PEREIRA JÚNIOR, Jessé Torres, DotTI, Marinês Restelatto, A licitação no formato eletrônico e o compromisso com a eficiência: Projeto de Lei $n^{\circ} 7.709$, de 2007, in Revista do Tribunal de Contas da União, v.38, n.109, Brasília, TCU, mai.-ago. 2007, pp. 49-60.

, As licitações e contratações públicas no cenário da governança eletrônica, in Interesse Público, n. 50, Belo Horizonte, Fórum, 2008, pp. 44-68.

PÉREZ GÁlvez, Juan Francisco, Incidencia de las nuevas tecnologías en el procedimiento administrativo español, in AlENZA GARCÍA, José Francisco, RAZQUIN LIZARRAGA, José Antonio, Organización y Procedimientos Administrativos, Navarra, Arazandi - Instituto Navarro de Administración Pública, 2007, pp. 565-587.

PÉREZ LuÑo, Antonio-Enrique, Manual de informática y derecho, Barcelona, Ariel, 1996. 
PetRAuSKas, Rimantas, KISKIS, Mindaugas, Teaching on E-government: aspects of legal environment, in GALINDO, Fernando, TRAUNMÜLLER, Roland (ed.), E-Government: Legal, Technical and Pedagogical Aspects, Zaragoza, Seminario de Informatica y Derecho, 2003, pp. 339-348.

Pietrangelo, Marina, Il diritto all'uso delle tecnologie nei rapporti con la pubblica amministrazione: luci de ombre, in Informatica e diritto, n. 1/2, Napoli, Edizioni Scientifiche Italiane, 2005, pp. 73-87.

PinHEIRO, Patrícia Peck, Direito digital, 4ª . ed., São Paulo, Saraiva, 2010, pp. 25-29.

PIÑAR MAÑAS, José Luis, Revolução tecnológica, derecho administrativo y administración pública. Notas provisionales para una reflexión, in VVAA, La autorización administrativa. La administración electrónica. La enseñanza del derecho administrativo hoy. Actas del I Congreso de la Asociación Española de Profesores de Derecho Administrativo, Pamplona, Aranzadi, 2007, pp. 51-92.

PIPERATA, Giuseppe, Lo sportello unico, in Rivista trimestrale di diritto pubblico, vol. 52, n.1, 2002, pp. 41-81.

PIRAS, Paola, Organizzazione, tecnologie e nuovi diritti, in Informatica e diritto, n. 1/2, Napoli, Edizioni Scientifiche Italiane, 2005, pp. 89-98.

PIRES, Adriana Tavares Pereira, Leilão administrativo: eletrônico ou presencial, in Fórum de Contratação e Gestão Pública - FCGP, n. 69, Belo Horizonte, Fórum, set. 2007, pp. $23-48$

PITSCHAS, Raines, El derecho administrativo de la información. La regulación de la autodeterminación informativa y el gobierno electrónico, in VVAA, Innovación y reforma en el Derecho Administrativo, Sevilla, Derecho Global, 2006, pp. 203-262.

Plantey, Alain, Prospective de L'État, Paris, Centre National de la Recherche Scientifique, 1975.

PONTI, Benedetto, L'informatica nelle pubbliche amministrazioni, in MERLONI, Francesco, Introduzione all'e-government, Torino, G. Giappichelli, 2005, pp. 59-83.

PorTa, Marcos de Lima, Direito Administrativo e influxos do Direito Eletrônico, in Consultor Jurídico, 03.06.2003, disponível em http://www.conjur.com.br/2003-jun03/direito_administrativo_influxos_direito_eletronico, acesso em 17.05.2011.

Poullet, Yves, Informatisation et secteur public: de la protection des libertés à la transparence administrative, in Actes du colloque "Informatique et vie privée", Namur, 1 out. 1988, pp. 41-43.

, La technologie et le droit: du défi à l'alliance, in VVAA, Mélanges G. Horsmans, Bruxelles, Bruylant, 2004, pp. 943-967.

PRINS, J.E.J. (ed.) et al., E-Government and its Implications for Administrative Law: Regulatory Initiatives in France, Germany, Norway and the United States, The Hague, TMC Asser, 2002. 
Punzón MoRAledA, Jesús, El documento tecnológico en el ámbito jurídico administrativo, in Punzón Moraleda, Jesús (coord.), Administraciones Públicas y nuevas tecnologias, Valladolid, Lex Nova, 2005, pp. 53-74.

Introducción, in PUNZÓN MORALEDA, Jesús (coord.), Administraciones Públicas y nuevas tecnologías, Valladolid, Lex Nova, 2005, pp. 9-11.

QUADROS, Jaqueline Maria, Governo eletrônico e direito administrativo, in Rover, Aires José, Direito e Informática, Barueri, Manole, 2004, p. 233-246.

RABBITO, Chiara, Il percorso di attuazione dell'e-government nella pubblica amministrazione italiana, in PALMIRANI, Monica, MARTONI, Michele, Il cittadino elettronico e l'identità digitale nell'e-governance, Bologna, Gedit, 2006, pp. 11-55.

, L'informatica al servizio della pubblica amministrazione e del citadino, Bologna, Gedit, 2007.

RAMOS JÚNIOR, Hélio Santiago, Democracia e direitos fundamentais na sociedade da informação: Desafios para o governo eletrônico, in Atuação - Revista Jurídica do Ministério Público Catarinense, vol. 5. n. 13, Florianópolis, PGJ/ACMP, set.-dez. 2007, pp. 63-74, disponível

em http://www.mp.sc.gov.br/portal/site/conteudo/cao/ceaf/revista_juridica/revista13internet.pd f, acesso em 17.05.2011.

RAMOS JÚNIOR, Hélio Santiago, Rover, Aires José, $O$ ato administrativo eletrônico sob a ótica do princípio da eficiência, in Anais da II Conferência Sul-Americana de Ciência e Tecnologia Aplicada ao Governo Eletrônico - CONEGOV 2005, Florianópolis, Ijuris, 2005, pp. 33-40, disponível em http://www.infojur.ufsc.br/aires/arquivos/ato\%20administrativo\%20eletronico\%20helioAir es.pdf, acesso em 17.05.2011.

RIVERO ORTEGA, Ricardo, Archivo y expediente electrónico: dos herramientas claves del derecho administrativo de la sociedad de la información y el conocimiento, in SÁNCHEZ SÁNCHEZ, Zulima (coord.), Nuevas Tecnologías, Administración y Participación Ciudadana, Granada, Comares, 2010, pp. 31-40.

, El expediente administrativo - de los legajos a los soportes electrónicos, Navarra, Arazandi, 2007.

RONDEAU, Jean-Claude, Vers une redéfinition des relations entre l'administration, les citoyens et les entreprises, in Revue française d'administration publique, n. 81, Paris, ENA, jan.-mar. 1997, pp. 9-15.

RUSSO, Vincenzo, Introduzione agli atti amministrativi elettronici: tra discrezionalità $e$ vincolatività, in CARBONI, Sandro, RuSSO, Vincenzo (org.), Diritto e Nuove Tecnologie saggi di informatica giuridica avanzata, Sgurgola, D-lex, 2008, pp. 85-99, disponível em http://www.nuovetecnologie.itisavogadro.org/sito/materiale_informativo/diritto_nuove tec nologie.pdf, acesso em 08.12.2010.

SAITTA, Fabio, Le patologie dell'atto amministrativo elettronico e il sindacato del giudice amministrativo, in Quaderni del DAE - Rivista di Diritto Amministrativo Elettronico, jul. 2003, disponível em http://www.cesda.it/quadernidae/index.php, acesso em 15.12.2010. 
Salon, Serge, Savignac, Jean-Charles, Le citoyen et l'administration, Paris, BergerLevrault, 2006.

SÁNCHEZ RODRÍGUEZ, Francisco, Las nuevas tecnologías de la información y la comunicación en la Administración Pública como paradigmas de un servicio público eficaz y eficiente prestado a los ciudadanos, in PUNZÓn MORALEDA, Jesús (coord.), Administraciones Públicas y nuevas tecnologías, Valladolid, Lex Nova, 2005, pp. 23-47.

SANTOLIM, Cesar, Aspectos jurídicos do governo eletrônico: as tecnologias da informação na Administração Pública, in Revista de Direito de Informática e Telecomunicações RDIT, Belo Horizonte, Fórum, n. 2, p. 85-97, jan.-jun. 2007,

SANTOS, Rogério Santana dos, Manifesto por um governo eletrônico democrático e socialmente includente, in FERRER, Florencia, SANTOS, Paula, E-government: o governo eletrônico no Brasil, São Paulo, Saraiva, 2004, pp. 73-77.

SANZ LARRUGa, Francisco Javier, Documentos y archivos electrónicos, in GAMERo CASADO, Eduardo, VALERo TORRIJOS, Julián (coord.), Comentarios a la Ley de Administración electrónica - Ley 11/2007, de 22 de junio, de acceso electrónico de los ciudadanos a los servicios públicos, 1. ${ }^{\mathrm{a}}$ ed., 2. ${ }^{\mathrm{a}}$ imp., Cizur Menor (Navarra), Thomson-Civitas, 2009, pp. 455-493.

, Las bases jurídicas de la 'administración electrónica' en España: el uso de las técnicas informáticas, electrónicas y telemáticas en las Administraciones públicas, in Anuario da Facultade de Dereito da Universidade da Coruña, A Coruña, Universidade da Coruña, n. 6, 2002 , pp. 713-760.

SAUNIER, Sébastien, Recherche sur la notion de formalisme en droit administratif français, Aix-en-Provence, PUAM, 2007.

SAURET, Jacques, Efficacité de l'administration et service à l'administré: les enjeux de l'administration électronique, in Revue française d'administration publique, n. 110, Paris, ENA, 2004, pp. 279-296.

SCHMIDT-AsSMANN, Eberhard, Pluralidad de estructuras y funciones de los procedimientos administrativos en el Derecho alemán, europeo e internacional, in VVAA, La Transformación del Procedimiento Administrativo, Sevilla, Global Law Press - Editorial Derecho Global, 2006, pp. 71-112.

SCORZA, Guido, Il cittadino digitale tra vecchi e nuovi diritti e libertà, in Quaderni del DAE - Rivista di Diritto Amministrativo Elettronico, jul. 2004, disponível em http://www.cesda.it/quadernidae/index.php, acesso em 15.12.2010.

Silva, José Afonso da, Comentário contextual à Constituição, São Paulo, Malheiros, 2005.

2011. , Curso de direito constitucional positivo, $34^{\mathrm{a}}$ ed., São Paulo, Malheiros, 
Smith, Peter Jay, New Information Technologies and Empowerment: The Implications for Politics and Governance, in OLIVER, E. Lynn, SANDERS, Larry (ed.), E-Government Reconsidered: Renewal of Governance for the Knowledge Age, Regina, Canadian Plains Research Center, 2004, pp. 135-149.

Souto, Marcos Juruena Villela Souto, Licitações e controle de eficiência: repensando o princípio do procedimento formal à luz do "placar eletrônico"!, in ARAGÃO, Alexandre Santos de, MARQues Neto, Floriano de Azevedo (coord.), Direito administrativo e seus novos paradigmas, Belo Horizonte, Fórum, pp. 553-569.

StAIR, Ralph M., REYNOLDS, George W., Principles of information systems: a managerial approach, $6^{\mathrm{a}}$ ed., trad. port. de Flávio Soares Corrêa da Silva (coord.), Giuliano Mega, Igor Ribeiro Sucupira, Princípios de sistemas de informação: uma abordagem gerencial, São Paulo, Pioneira Thomson Learning, 2006.

SundFELD, Carlos Ari, A importância do procedimento administrativo, in Revista de Direito Público, n. 84, São Paulo, RT, 1987, p. 64-74.

, Processo e procedimento administrativo no Brasil, in As leis de processo administrativo, São Paulo, Malheiros, 2000, pp. 17-36.

TIBIRIÇÁ, Beatriz, Telecentros de São Paulo: tecnlogia de informação no combate à pobreza, in FERRER, Florencia, SANTOS, Paula, E-government: o governo eletrônico no Brasil, São Paulo, Saraiva, 2004, pp. 132-136.

TINTÓ GIMBERnAt, Montserrat, Actividad administrativa formalizada y medios telemáticos: requisitos legales y técnicos del procedimiento administrativo electrónico, in Revista de Estudios Locales - Cunal, n. extraordinário 1, Madrid, Cosital, 2004, pp. 59-70.

Administración electrónica y ciberprocedimiento, Barcelona, Observatorio de la Evolución de las Instituciones, Universitat Pompeu Fabra, 2006.

TORRES LóPEZ, Maria Asunción, El documento electrónico en las relaciones jurídicoadministrativas: especial referencia a los actos de comunicación, in Revista Vasca de Administración Pública, Oñati, Instituto Vasco de Administración Pública, n. 55, set.-dez. 1999, pp. 253-283.

Truche Pierre, FAugere, Jean-Paul, Flichy, Patrice, Administration électronique et protection des données personnelles - Livre blanc, Paris, La Documentation française, 2002, disponível em: $\quad$ http://lesrapports.ladocumentationfrancaise.fr/cgibin/brp/telestats.cgi?brp_ref=024000100\&brp_file=0000.pdf, acesso em 30.12.2010.

TRUDEL, Pierre, Améliorer la protection de la vie privée dans l'administration électronique: pistes afin d'ajuster le droit aux réalités de l'État en réseau, Montréal, Ministère des Relations avec les citoyens et de l'Immigration, Montréal, mar. 2003, disponível em: http://www.institutions-democratiques.gouv.qc.ca/acces-

information/documents/Rapport_Me_Pierre_Trudel.pdf, acesso em 30.12.2010.

Uncitral, Model Law on Electronic Signatures with Guide to Enactment, New York, United Nations, 2002, disponível em http://www.uncitral.org/pdf/english/texts/electcom/mlelecsig-e.pdf, acesso em 29.12.2010. 
UsAi, Alessandro, Le elaborazioni possibili delle informazioni. I limiti alla decisioni amministrative automatiche, in DUNI, Giovanni (org.), Dall'informatica amministrativa alla teleamministrazione, Roma, Istituto Poligrafico dello Stato, 1992, disponível em http://spol.unica.it/teleamm/italiano/pubblicazioni/dallin-sezione1.htm\#alessandrousai, acesso em 08.12.2010.

VAlERo TORRIJOS, Julián, Acceso a los servicios y difusión de la información por medios electrónicos, in GAMERO CASADO, Eduardo, VAlERO TORRIJOS, Julián (coord.), Comentarios a la Ley de Administración electrónica - Ley 11/2007, de 22 de junio, de acceso electrónico de los ciudadanos a los servicios públicos, 1. ${ }^{\mathrm{a}}$ ed., 2. ${ }^{\mathrm{a}}$ imp., Cizur Menor (Navarra), Thomson-Civitas, 2009, pp. 235-280.

, Administración pública, ciudadanos y nuevas tecnologías, in SosA WAGNER, Francisco, El derecho administrativo en el umbral del siglo XXI - Homenaje al Profesor Dr. D. Ramón Martín Mateo, Valencia, Tirant lo Blanch, 2000, pp. 2943-2966.

, Administrative Law and eGovernment, in EUROPEAN COMMISSION, DG INFORMATION SOCIETY, EGOVERNMENT UNIT, Breaking Barriers to eGovernment - Overcoming obstacles to improving European public services, 2006, pp. 41-53, disponível em http://www.egovbarriers.org/downloads/deliverables/Deliverable_1b_Aug_16_2006.pdf, acesso em 30.01.2011.

, El acceso telemático a la información administrativa: un presuposto inexcusable para la e-Administración (Análisis desde la perspectiva del Derecho español), in Derecho y Tecnología, n. 6-7, San Cristóbal, Universidad Católica del Táchira, jan.-dez. 2005, pp. 27-51.

2007.

,El régimen jurídico de la e-Administración, 2. ${ }^{\text {a }}$ ed., Granada, Comares,

, El uso de cookies por las administraciones públicas: ¿una vulneración de la normativa sobre protección de los datos personales, in Revista Aranzadi de Derecho y Nuevas Tecnologías, n. 3, Cizur Menor (Navarra), Aranzadi, set.-dez. 2003, pp. 173-179.

, Implicaciones de la protección de datos de carácter personal para la Administración electrónica, in VVAA, La protección de datos en la Administración Electrónica. Pamplona, Aranzadi, 2009, pp. 177-198.

La e-Administración Pública, in FERnández SAlMerón, M., SiERrA RODRÍGUEZ, J., VALERO TORRIJOS, J. (coord.) Nuevos retos en el horizonte de las Administraciones Públicas, Murcia, Universidad de Murcia - Facultad de Derecho, 2003, pp. 95105.

La gestión y conservación del documento administrativo electrónico, in $\mathrm{El}$ documento electrónico: aspectos jurídicos, tecnológicos y archivísticos, Castelló de la Plana, Universitat Jaume I, 2008, pp. 23-71.

, La nueva regulación legal del uso de las tecnologías de la información y las comunicaciones en el ámbito administrativo: ¿el viaje hacia un nuevo modelo de Administración, electrónica?, in Revista Catalana de Drét Públic, n. 35, Barcelona, Escola de Administració Pública de Catalunya, nov. 2007, pp. 209-235. 
, Las garantías jurídicas en la Administración electrónica ¿avance o retroceso?, in Cuenta con IGAE, Madrid, IGAE, n. 22, 2009, pp. 19-28.

, Las relaciones con la Administración Pública mediante sistemas electrónicos, informáticos y telemáticos, in DAVARA RoDRÍGUEZ, Miguel Ángel (coord.), JIS'2000, III Jornadas sobre informática y sociedad, Madrid, Universidad Pontificia Comillas, 2001, pp. 259-270.

, Protecção de datos personales y administración electrónica, in CERRILLO I MARTíneZ, Agustí e oo., La administración y la información, Madrid, Marcial Pons, 2007, pp. 41-53.

VAlero ToRrijos, Julián, LóPEz Pellicer, José Antonio, Algunas consideraciones sobre el derecho a la protección de los datos personales en la actividad administrativa, in Revista Vasca de Administración Pública, Oñati, Instituto Vasco de Administración Pública, n. 59, jan.- abr. 2001, pp. 255-286.

VAlero TorriJos, Julián, SANZ LARrUga, Francisco Javier, E-administración, identificación del ciudadano y protección de datos personales en la Unión Europea: ¿una ecuación posible?, disponível em http://www.apdcat.net/media/191.pdf, acesso em 27.08.10.

VARCÁRCEL FERNÁNDEZ, Patricia, Documentos y archivos electrónicos, in PIÑAR MAÑAS, José Luis (dir.), Administración electrónica y ciudadanos, Cizur Menor (Navarra), Aranzadi, 2011, pp. 531-631.

VELASCO Rico, Clara, Archivo y conservación de los documentos administrativos electrónicos. Especial referencia la Ley 11/2007, de acceso electrónico de los ciudadanos a las administraciones públicas, in Cotino HuESO, Lorenzo, VALERO TORRIJOS, Julián, Administración Electrónica - La Ley 11/2007, de 22 de junio, de acceso electrónico de los ciudadanos a los Servicios Públicos y los retos jurídicos del e-gobierno en España, Valencia, Tirant lo Blanc, 2010, pp. 603-622.

VILlar Palasí, José Luis, Aspectos jurídicos y políticos de la telemática, in Revista Española de Derecho Administrativo, n. 19, Madrid, Civitas, out.-dez. 1978, pp. 501-515.

VILlORIA MENDIETA, Manuel, La modernización de la administración como instrumento al servicio de la democracia, Madrid, INAP, 1996.

WEBER, Max, Wirtschaft und Gesellschaft: Grundriss der verstehenden Soziologie, 1972, trad. port. de Regis Barbosa e Elsabe Barbosa, Economia e sociedade: fundamentos da

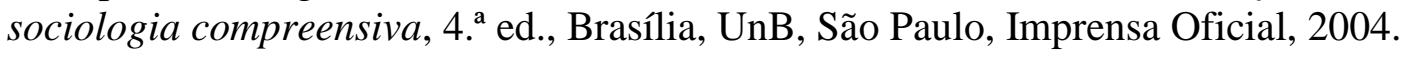

WORLD BANK, Definition of e-government, disponível em http://go.worldbank.org/M1JHE0Z280, acesso em 10.02.2011.

ZEIDLER, Karl, Über die Technisierung der Verwaltung (Eine Einführung in die juristische Beurteilung der modernen verwaltung), 1959, trad. esp. de Manuel Heredero Higueras, Implicaciones jurídicas de la mecanización administrativa, Madrid, Centro de Formación y Perfeccionamiento de Funcionarios, 1963.

Zugman, Fábio, Governo eletrônico, São Paulo, Livro Pronto, 2006. 